\title{
ESTUDIO DE LA EMISIÓN DE COMPUESTOS DE FLÚOR DURANTE LA COCCIÓN DE BALDOSAS CERÁMICAS
}

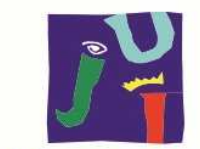

UNIVERSITAT JAUME•I

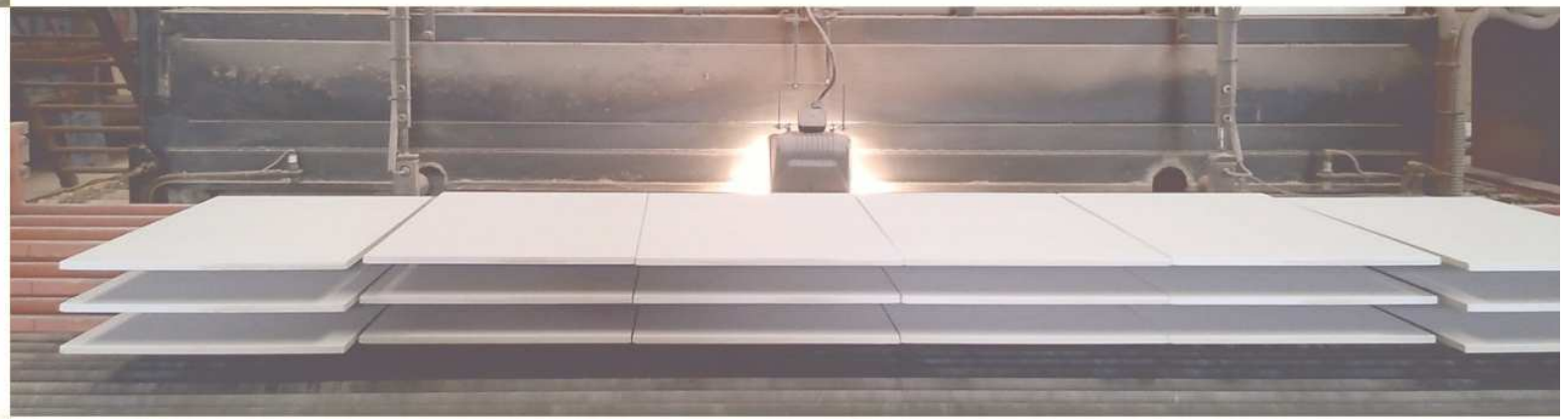

\section{TESIS DOCTORAL}

\section{SALVADOR GOMAR PEIRÓ}

ESCUELA SUPERIOR DE TECNOLOGÍA $Y$ CIENCIAS EXPERIMENTALES

Departamento de Ingeniería Química

Castellón, enero 2016
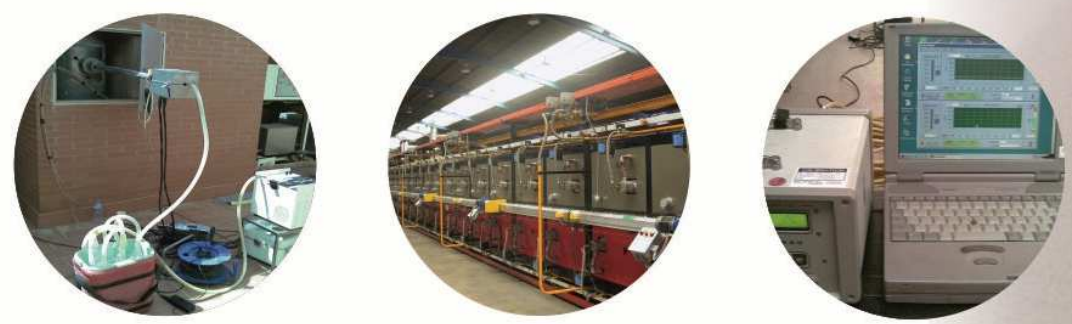





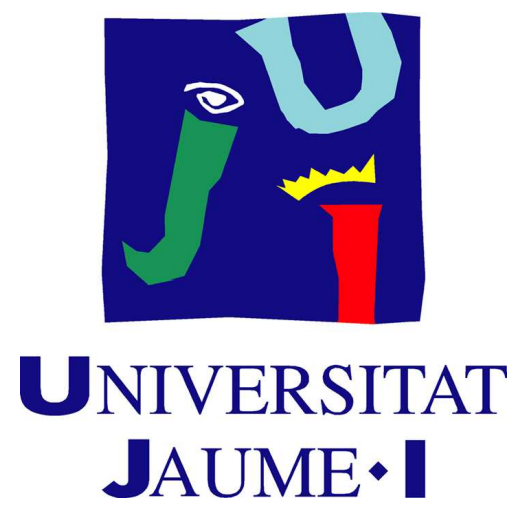

UNIVERSITAT JAUME I DE CASTELLÓ

ESCUELA SUPERIOR DE TECNOLOGÍA Y CIENCIAS EXPERIMENTALES

Departamento de Ingeniería Química

\title{
EMISIÓN DE COMPUESTOS DE FLÚOR DURANTE LA COCCIÓN DE BALDOSAS CERÁMICAS
}

\author{
MEMORIA \\ que para optar al grado de \\ Doctor en Ingeniería Química presenta \\ SALVADOR GOMAR PEIRÓ
}

Castellón, 2016 

ELISEO MONFORT GIMENO, CATEDRÁTICO DE INGENIERÍA QUíMICA DE LA UNIVERSITAT JAUME I DE CASTELlÓ y FRANCISCO JAVIER GARCÍA-TEN, DOCTOR EN CIENCIAS QUÍMICAS

CERTIFICAN: Que D. Salvador Gomar Peiró ha realizado bajo su dirección, en los laboratorios del Instituto de Tecnología Cerámica, dentro del programa de doctorado del Departamento de Ingeniería Química de la Universitat Jaume I de Castellón, el trabajo que bajo el título "EMISIÓN DE COMPUESTOS DE FLÚOR DURANTE LA COCCIÓN DE BALDOSAS CERÁMICAS" presenta en esta memoria y que constituye su tesis para optar al grado de Doctor en Ingeniería Química.

Y, para que conste a los efectos oportunos, firman el presente certificado en Castellón, a 13 de enero de 2016.

Eliseo Monfort Gimeno

Catedrático de Ingeniería Química
Francisco Javier García-Ten

Doctor en Ciencias Químicas 

A mi madre María, a mi padre Salvador. 



\section{Agradecimientos}

La realización de este trabajo ha sido posible gracias a la colaboración de un gran número de fabricantes de gránulo atomizado y de baldosas situadas, todas ellas, en la provincia de Castellón, a la financiación de diferentes organismos públicos y privados y al esfuerzo de los compañeros del Instituto de Tecnología Cerámica en general y de la Unidad de Medio Ambiente en particular. Por ello, quiero dar las gracias a todas aquellas personas y entidades que han colaborado en la realización del mismo.

En especial quiero expresar mi agradecimiento a los directores de la Tesis, Eliseo y Javier, por vuestras ganas de enseñar y también de aprender, por vuestro esfuerzo y dedicación.

Como emigrante y masover quiero también acordarme de mi familia, amigos y compañeros de Castellón, Vila-real, Oliva y Gandia, aunque prefiero no llegar a nombraros a ninguno ;). 



\section{Resumen}

La emisión de compuestos ácidos durante la fabricación de baldosas cerámicas está fuertemente asociada a la presencia de precursores en las materias primas y/o combustibles utilizados, con algunas excepciones como el $\mathrm{NO}_{x}$ térmico. Por tanto, estos compuestos se pueden generar en aquellas etapas donde tienen lugar procesos de combustión y/o donde los materiales procesados alcanzan elevadas temperaturas. De acuerdo con estas premisas y la información previa disponible, las etapas susceptibles de presentar emisiones significativas de estos compuestos son: el secado de suspensiones por atomización y la cocción.

Por ello, en la primera parte de este trabajo se ha realizado una caracterización de los niveles de emisión de los contaminantes ácidos en dichas etapas para los principales tipos de baldosas cerámicas fabricadas en la actualidad: azulejo de coloración en cocido roja y blanca (en adelante azulejo rojo y azulejo blanco), gres esmaltado y gres porcelánico.

De acuerdo con los resultados obtenidos, los valores de emisión de los compuestos ácidos en la etapa de secado de suspensiones por atomización se encuentran muy por debajo de los niveles de emisión asociados a las mejores técnicas disponibles (NEA - MTD).

Por el contrario, los resultados obtenidos en la etapa de cocción indican que la emisión de $\mathrm{HCl}$ y, particularmente, de HF, es significativa, superando en muchos casos los NEA - MTD propuestos actualmente. Por tanto, de acuerdo con estos resultados, una gran parte de las empresas deben introducir medidas preventivas y/o correctivas, para reducir las emisiones de HF en los hornos de cocción de baldosas. Por el contrario, las emisiones de $\mathrm{SO}_{2}$ y de $\mathrm{NO}_{x}$ son en todos los casos estudiados muy inferiores a los NEA - MTD en la etapa de cocción.

Los menores niveles de emisión de HF se han observado en las emisiones de la cocción de baldosas de azulejo blanco, en las que, en algunos casos, podría incluso no ser necesario adoptar medidas correctivas para cumplir con los niveles objetivo. Por ello se ha buscado una justificación a dicho comportamiento y se ha llegado a la conclusión de que es debido al menor contenido de compuestos de flúor en las materias primas, junto con el menor peso específico y temperatura máxima de cocción de las composiciones de azulejo blanco.

Dado que las emisiones de HF en la etapa de cocción de baldosas cerámicas pueden considerarse como las más críticas desde el punto de vista normativo, los documentos BREF y la bibliografía inciden reiteradamente en la conveniencia de implantar medidas primarias 0 de prevención (source reduction), destinadas a reducir la emisión basándose en favorecer la formación de $\mathrm{CaF}_{2}$. En este sentido, cabe destacar dos de ellas: i) incrementar el contenido de calcio, mediante la adición de $\mathrm{CaCO}_{3}$ en las composiciones de materias primas, y ii) favorecer el contacto entre gases y piezas en la fase de precalentamiento durante la cocción. Sin embargo, los resultados del estudio de caracterización previo (con composiciones con diferentes contenidos de $\mathrm{CaCO}_{3}$ ) y la experiencia industrial en el sector de baldosas 
cerámicas, revela que la eficacia de estas medidas en hornos industriales es ciertamente muy limitada.

Por ello, una parte importante de los esfuerzos en el desarrollo de esta tesis doctoral se han centrado en el estudio en detalle de las emisiones de HF en diferentes tipos de hornos y, en particular, en profundizar en los mecanismos de emisión, así como en las interacciones de este contaminante con el material procesado.

En este sentido, se han examinado los fenómenos de adsorción y emisión de compuestos de flúor que tienen lugar en la cocción de baldosas cerámicas, procesadas tanto en hornos discontinuos eléctricos de laboratorio como en hornos continuos de combustión industriales. Se ha comprobado que en la zona de precalentamiento de los hornos continuos industriales se produce una adsorción neta de flúor sobre el material cerámico procesado, a pesar de ser sometido a ciclos de cocción relativamente rápidos. Ahora bien, prácticamente la totalidad del flúor adsorbido se emite posteriormente cuando las piezas alcanzan la zona de máxima temperatura de cocción ( $>1100^{\circ} \mathrm{C}$ ). Ello se debe a que las especies cristalinas que retienen el flúor - fluorita $\left(\mathrm{CaF}_{2}\right)$ y cuspidina $\left(\mathrm{Ca}_{4} \mathrm{Si}_{2} \mathrm{O}_{7} \mathrm{~F}_{2}\right)$ - no son termodinámicamente estables en el seno de una matriz cerámica a temperaturas superiores a $1050^{\circ} \mathrm{C}$, a diferencia de lo que ocurre en los materiales sometidos a una menor temperatura máxima, como los productos de cerámica estructural $(850-1000 \stackrel{\circ}{\circ}$ ), donde el flúor adsorbido queda retenido de forma estable en el producto procesado.

El uso de un equipo de seguimiento en continuo de HF, adaptado a las características de la industria cerámica, se ha mostrado como una herramienta muy valiosa, que ha permitido determinar que, si los hornos operan en régimen estacionario, dichas emisiones son continuas y constantes en el tiempo, y cuyo valor depende, principalmente, del flujo másico y de la tipología de producto procesado. Asimismo, el seguimiento en continuo de la emisión de HF al introducir modificaciones en las condiciones de operación en hornos industriales, ha permitido corroborar los fenómenos de emisión y adsorción de HF en el proceso de cocción industrial.

Igualmente, se ha comprobado que la introducción de modificaciones realistas en las condiciones de fabricación a nivel industrial, como pueden ser en el tratamiento térmico y en la densidad aparente en seco de las piezas producidas, no permite alcanzar una reducción significativa de la emisión de HF.

Finalmente, el trabajo presentado ha permitido conocer que la aplicación de esmalte sobre la baldosa, realizada con la finalidad de conferir unas propiedades superficiales determinadas, reduce de forma efectiva la emisión de HF. Las causas más probables para justificar este comportamiento son la formación de un recubrimiento impermeable sobre la pieza debido a la fusión de los componentes del esmalte cuando alcanza su temperatura de sellado, y/o la disolución de parte del flúor en la fase líquida formada a alta temperatura. 


\section{Resum}

L'emissió de compostos àcids durant la fabricació de taulells ceràmics està fortament associada a la presència de precursors en les matèries primeres i/o combustibles utilitzats, amb algunes excepcions com ara el $\mathrm{NO}_{\mathrm{x}}$ tèrmic. Per tant, aquests compostos es poden generar en les etapes en les quals tenen lloc processos de combustió i/o en les quals els materials processats arriben a temperatures elevades. D'acord amb aquestes premisses i la informació prèvia disponible, les etapes susceptibles de presentar emissions significatives d'aquests compostos són: l'assecat de suspensions per atomització i la cocció.

Per això, en la primera part d'aquest treball s'ha realitzat una caracterització dels nivells d'emissió dels contaminants àcids en aquestes etapes per als principals tipus de taulells ceràmics fabricats en l'actualitat: taulells de coloració en cuit roig i blanc (en endavant taulell roig i taulell blanc), gres esmaltat i gres porcellànic.

D'acord amb els resultats obtinguts, els valors d'emissió dels compostos àcids en l'etapa d'assecat de suspensions per atomització es troben molt per sota dels nivells d'emissió associats a les millors tècniques disponibles (NEA - MTD).

Per contra, els resultats obtinguts en l'etapa de cocció indiquen que l'emissió de $\mathrm{HCl}$ i, particularment, de HF, és significativa, i supera en molts casos els NEA - MTD proposats actualment. Per tant, d'acord amb aquests resultats, una gran part de les empreses han d'introduir mesures preventives i/o correctives per reduir les emissions de HF en els forns de cocció de taulells. Per contra, les emissions de $\mathrm{SO}_{2}$ i de $\mathrm{NO}_{\mathrm{X}}$ són en tots els casos estudiats molt inferiors als NEA - MTD en l'etapa de cocció.

Els menors nivells d'emissió de HF s'han observat en les emissions de la cocció de taulells de coloració en cuit blanc en les quals, en alguns casos, podria fins i tot no ser necessari adoptar mesures correctives per complir amb els nivells objectiu. Per això s'ha buscat una justificació a aquest comportament i s'ha arribat a la conclusió que és a causa del menor contingut de compostos de fluor en les matèries primeres, juntament amb el menor pes específic i temperatura màxima de cocció de les composicions de taulell de coloració en cuit blanc.

Atès que les emissions de HF en l'etapa de cocció de taulells ceràmics poden ser considerades com les més crítiques des del punt de vista normatiu, els documents BREF i la bibliografia incideixen reiteradament en la conveniència d'implantar mesures primàries 0 de prevenció (source reduction), destinades a reduir l'emissió en base a l'afavoriment de la formació de $\mathrm{CaF}_{2}$. En aquest sentit, cal destacar-ne dues: i) incrementar el contingut de calci, mitjançant l'addició de $\mathrm{CaCO}_{3}$ en les composicions de matèries primeres, i ii) afavorir el contacte entre gasos i peces en la fase de preescalfament durant la cocció. No obstant això, els resultats de l'estudi de caracterització previ (amb composicions amb diferents continguts de $\mathrm{CaCO}_{3}$ ) i l'experiència industrial en el sector de taulells ceràmics, revela que l'eficàcia d'aquestes mesures en forns industrials és certament molt limitada. 
Per això, una part important dels esforços en el desenvolupament d'aquesta tesi doctoral s'han centrat en l'estudi en detall de les emissions de HF en diferents tipus de forns i, en particular, en aprofundir en els mecanismes d'emissió, així com en les interaccions d'aquest contaminant amb el material processat.

En aquest sentit, s'han examinat els fenòmens d'adsorció i emissió de compostos de fluor que tenen lloc en la cocció de taulells ceràmics, processats tant en forns discontinus elèctrics de laboratori com en forns continus de combustió industrials. S'ha comprovat que a la zona de preescalfament dels forns continus industrials es produeix una adsorció neta de fluor sobre el material ceràmic processat, tot i ser sotmès a cicles de cocció relativament ràpids. Ara bé, pràcticament la totalitat del fluor adsorbit s'emet posteriorment quan les peces arriben a la zona de màxima temperatura de cocció (> $\left.1100^{\circ} \mathrm{C}\right)$. Això és així perquè les espècies cristal-lines que retenen el fluor -fluorita $\left(\mathrm{CaF}_{2}\right)$ i cuspidina $\left(\mathrm{Ca}_{4} \mathrm{Si}_{2} \mathrm{O}_{7} \mathrm{~F}_{2}\right)-$ no són termodinàmicament estables en el si d'una matriu ceràmica a temperatures superiors $\mathrm{a}$ $1050^{\circ} \mathrm{C}$, a diferència del que passa en els materials sotmesos a una menor temperatura màxima, com els productes de ceràmica estructural $\left(850-1000^{\circ} \mathrm{C}\right)$, on el fluor adsorbit queda retingut de forma estable en el producte processat.

L'ús d'un equip de seguiment en continu de HF, adaptat a les característiques de la indústria ceràmica, ha resultat ser una eina molt valuosa, que ha permès determinar que si els forns operen en règim estacionari aquestes emissions són contínues i constants en el temps i el valor depèn, principalment, del flux màssic i de la tipologia de producte processat. Així mateix, el seguiment en continu de l'emissió de HF en introduir modificacions en les condicions d'operació en forns industrials ha permès corroborar els fenòmens d'emissió i adsorció de HF en el procés de cocció industrial.

Igualment, s'ha comprovat que la introducció de modificacions realistes en les condicions de fabricació industrial, com poden ser en el tractament tèrmic i en la densitat aparent en sec de les peces produïdes, no permet assolir una reducció significativa de l'emissió de HF.

Finalment, el treball presentat ha permès conèixer que l'aplicació d'esmalt sobre el taulell, realitzat amb la finalitat de conferir unes propietats superficials determinades, redueix de forma efectiva l'emissió de HF. Les causes més probables per justificar aquest comportament són la formació d'un recobriment impermeable sobre la peça a causa de la fusió dels components de l'esmalt quan aconsegueix la seua temperatura de segellat, i/o la dissolució de part del fluor en la fase líquida formada a alta temperatura. 


\section{Summary}

The emission of acid compounds during the manufacture of ceramic tiles is strongly related to the presence of precursors in the raw materials and/or fuels used, with some exceptions such as thermal $\mathrm{NO}_{x}$. Therefore, these compounds can be generated in the stages where combustion processes take place and/or where the processed materials reach high temperatures. Consequently, and in view of the preliminary information available, the stages that could have significant emissions of these compounds are the suspension spray drying and tile firing stages.

In the first part of this study, the emission levels of acid pollutants in these stages for the main types of ceramic tiles being made today were therefore characterised: earthenware tile (redand white-firing body), glazed stoneware tile and porcelain stoneware tile.

The results show that acid compound emissions in spray dryers are far below the emission limit values associated with the best available techniques (ELV - BAT).

In contrast, the results obtained in firing indicate that the $\mathrm{HCl}$, and particularly $\mathrm{HF}$, emissions are the most significant, in many cases exceeding the currently proposed ELV - BAT. Therefore, according to these results, many companies need to introduce preventive and/or corrective measures to reduce HF emissions in the kilns. In contrast, in all cases studied, the $\mathrm{SO}_{2}$ and $\mathrm{NO}_{x}$ emissions lie below the ELV-BAT in firing.

The lowest emission levels were observed in HF emissions from firing white-body earthenware tile, which in some cases might not even require corrective actions to meet the target levels. An explanation for such behaviour was therefore sought and it was concluded that this was due to the lower fluorine compound content in the raw materials, coupled with lower specific weight and the peak firing temperature of the white-body earthenware tile compositions.

Since HF emissions in ceramic tile firing kilns may be deemed the most critical from a regulatory point of view, the BREF documents and the literature repeatedly highlight the desirability of implementing source reduction techniques based on favouring $\mathrm{CaF}_{2}$ formation. In this regard, two techniques may be noted: i) increasing the calcium content by adding $\mathrm{CaCO}_{3}$ in the raw materials compositions, and ii) promoting contact between gases and tiles in the preheating stage during firing. However, the findings of the preliminary characterization (with compositions having different $\mathrm{CaCO}_{3}$ contents) and industrial experience in the field of ceramic tiles indicate that the effectiveness of these measures in industrial kilns is certainly very limited.

Therefore, an important part of the efforts in the development of this $\mathrm{PhD}$ thesis has focused on the detailed study of HF emissions in different types of kilns and, in particular, on in-depth study of the emission mechanisms and of HF interactions with the processed material.

In this sense, the study examined the fluorine compound emission and adsorption phenomena in ceramic tile firing, both in laboratory electric batch kilns and in industrial continuous kilns. It 
was found that, in the preheating zone of industrial continuous kilns, there was a net adsorption of fluorine on the processed ceramic material, despite the relatively rapid firing cycles used. However, virtually all the adsorbed fluorine was subsequently released when the tiles reached the peak firing temperature zone $\left(>1100{ }^{\circ} \mathrm{C}\right)$. This is because the fluoride-retaining crystalline species - fluorite $\left(\mathrm{CaF}_{2}\right)$ and cuspidine $\left(\mathrm{Ca}_{4} \mathrm{Si}_{2} \mathrm{O}_{7} \mathrm{~F}_{2}\right)$ - are not thermodynamically stable within a ceramic matrix at temperatures above $1050^{\circ} \mathrm{C}$, unlike what happens in materials subjected to a lower maximum temperature such as structural ceramics $\left(850-1000{ }^{\circ} \mathrm{C}\right)$, where the adsorbed fluorine is retained stably in the processed product.

Using a continuous HF monitoring device adapted to the characteristics of the ceramic industry has proven to be a valuable tool. It has shown that, if the kilns are running in a steady state, these emissions are continuous and constant in time, their value depending mainly on the mass flow and the type of product being processed. Moreover, when the operating conditions in industrial kilns were changed, continuously monitoring the HF emission enabled the HF adsorption and emission phenomena in the industrial firing process to be corroborated.

It has also been found that the introduction of modifications in realistic industrial manufacturing conditions, such as in heat treatment and in the dry bulk density of the tiles produced, does not significantly reduce HF emissions.

Finally, the study shows that tile glazing, performed in order to provide certain surface properties, effectively reduces HF emissions. The most likely explanation of this behaviour is the formation of an impermeable coating on the substrate due to the fusion of the glaze components when the glaze reaches its sealing temperature, and/or dissolution of the fluoride in the liquid phase formed at high temperature. 


\section{Índice}

Capítulo 1. Introducción.

1.1. Compuestos de flúor como contaminantes atmosféricos

1.2. Baldosas cerámicas y proceso de fabricación ........................................55

1.3. Instrumentos normativos aplicables a las emisiones atmosféricas de la fabricación de baldosas cerámicas.

Capítulo 2. Estado del arte en la emisión de compuestos de flúor durante la cocción de materiales cerámicos.

2.1. Introducción

2.2. El flúor en las materias primas de la industria cerámica 108

2.3. Emisión de flúor durante el tratamiento térmico. 110

2.4. Minimización de las emisiones de flúor mediante la aplicación de medidas primarias

2.5. Técnicas de medida de los compuestos de interés en matrices gaseosas y sólidas

2.6. Motivaciones para realizar el presente estudio..... 124

Capítulo 3. Objetivos y alcance.

3.1. Objetivos 129

3.2. Alcance 130

3.3. Estructura de la tesis 131 
4.1. Materiales

4.2. Metodología utilizada en los ensayos realizados en horno eléctrico de laboratorio

4.3. Metodología utilizada en los ensayos realizados en horno industrial de combustión.

Capítulo 5. Resultados y discusión.

5.1. Introducción a los resultados 159

5.2. Caracterización de las emisiones de contaminantes ácidos en la fabricación de baldosas cerámicas (Artículo ํo 1)

5.3. Influencia del contenido de calcita sobre las emisiones de compuestos de flúor durante la cocción de baldosas cerámicas (Artículo no 2)

5.4. Evolución de la emisión de compuestos de flúor durante el tratamiento térmico (Artículo no 3)

5.5. Monitorización y posible reducción de HF en la corriente de gases procedente de la cocción de baldosas cerámicas (Artículo ํㅜ 4)

Capítulo 6. Conclusiones y futuras líneas de investigación

6.1. Conclusiones 219

6.2. Futuras líneas de investigación 225

Capítulo 7. Artículos publicados.

Capítulo 8. Glosario. 
Capítulo 9. Anexos.

9.1. Anexo I. Ejercicio de cálculo teórico de la humedad presente en un horno continuo de combustión.......

9.2. Anexo II. Concentración y emisión de flúor en determinadas materias primas utilizadas en composiciones cerámicas .......................................... 284

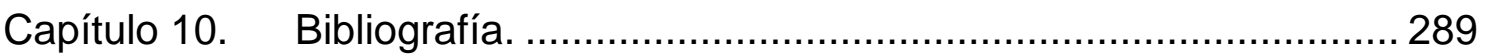



Capítulo 1. Introducción. 



\subsection{Compuestos de flúor como contaminantes atmosféricos}

\subsubsection{Aspectos generales}

La química ambiental es compleja, dado que debe tener en cuenta las interacciones que se dan entre las cinco esferas del medio ambiente. Estas cinco esferas son: hidrosfera (agua), atmósfera (aire), geosfera (tierra), biosfera (vida) y, por último, la antroposfera. La antroposfera incluye las actividades desarrolladas por los humanos que entran a formar parte integrante del ambiente, de modo que su comportamiento puede mejorar o empeorar el estado del ambiente.

La atmósfera se puede definir como la envoltura de gases que rodea la Tierra. Las funciones de la atmósfera son diversas: proporciona oxígeno, dióxido de carbono y nitrógeno a los organismos vivos para su desarrollo; protege de la radiación ultravioleta mediante la capa de ozono estratosférico; y regula la temperatura del planeta mediante la absorción de la radiación infrarroja que se emite tras absorber la energía proveniente del sol. También sirve de sustrato para distribuir la energía solar desde el ecuador hacia otras partes del planeta. La atmósfera constituye el primer paso del ciclo hidrogeológico mediante el transporte del vapor de agua procedente de los océanos hasta la masa de tierra para precipitarse, posteriormente, en forma de lluvia, granizo o nieve.

La atmósfera está muy involucrada en los procesos de transporte y destino de las sustancias químicas ambientales. Para entender estos procesos es necesario considerar las fuentes, el transporte, la dispersión y los flujos de los contaminantes aerotransportados. El movimiento y el destino de los contaminantes ambientales son aspectos clave en la determinación de sus impactos. Ambos aspectos están controlados por el transporte físico, por el movimiento sin sufrir reacciones con otras fases, y por su reactividad, promoviendo la aparición de reacciones químicas, bioquímicas o físicas con otras fases.

Por su parte, la antroposfera desarrolla fuertes interacciones con el resto de las esferas ambientales como consecuencia de las actividades humanas: cultivos de grandes extensiones que modifican la geosfera y la biosfera, modificación del flujo natural del agua que puede, incluso, contaminar alterando la hidrosfera, la emisión de dióxido de carbono que puede favorecer el calentamiento global, etc. En definitiva, la antroposfera altera varios de los ciclos biogeoquímicos.

Un contaminante se define como una sustancia presente en una concentración mayor a la natural como resultado de la actividad humana, que tiene un efecto perjudicial neto en el medio ambiente o sobre algo de valor en ese ambiente (Manahan, 2007).

Según la Ley 34/2007, de calidad del aire y protección de la atmósfera, se define contaminación atmosférica como la presencia en la atmósfera de materias, sustancias o 
formas de energía que impliquen molestia grave, riesgo o daño para la seguridad o la salud de las personas, el medio ambiente y demás bienes de cualquier naturaleza.

La contaminación atmosférica es considerada actualmente como uno de los tipos más importantes de contaminación ambiental. El impacto asociado a la misma puede ser considerado en diferentes escalas espaciales y ordenarse de la siguiente forma:

- Global: cuando el impacto involucra a todo el planeta Tierra. Dos de los fenómenos de contaminación atmosférica más importantes a escala global son:

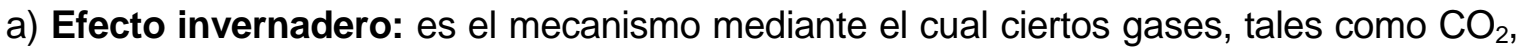
$\mathrm{SiF}_{4}$, algunos compuestos clorofluorocarbonados (CFC) y $\mathrm{CH}_{4}$ absorben radiación infrarroja terrestre por las moléculas constitutivas de esos gases, produciendo una alteración del flujo de energía radiante en la atmósfera (forzamiento radiativo directo) y consecuentemente altera significativamente el balance de energía en la superficie de la Tierra, también denominado forzamiento climático (IPCC, 2014).

b) Destrucción de la capa protectora de $\mathrm{O}_{3}$ : es el mecanismo químico por el cual disminuye la concentración de $\mathrm{O}_{3}$ estratosférico (en el ámbito científico se define como la disminución del espesor o concentración de la capa de $\mathrm{O}_{3}$ ). La emisión de CFC ayuda a la destrucción de dicha capa.

- Regional: Cuando el impacto se puede producir en una zona cercana a la de emisión (de decenas a centenares de $\mathrm{km}$ ) o el efecto del mismo se puede observar a grandes distancias de la fuente generadora (incluso a miles de $\mathrm{km}$ ). Un ejemplo de contaminación a escala regional es la lluvia ácida, impacto que puede llegar a ser de carácter transfronterizo (traspasa las fronteras de los países generadores, dependiendo de la localización de focos, condiciones climáticas y orografía de la zona). Los principales daños de este fenómeno se producen sobre los ecosistemas acuáticos y terrestres.

- Local: referida al impacto de la contaminación sobre la salud humana y al efecto sobre el medio ambiente en un entorno inmediato a la emisión.

Independientemente de la escala del impacto, todas las sustancias o compuestos que se encuentran presentes en la atmósfera pueden tener diferentes orígenes y clasificaciones.

\subsubsection{Clasificación de los contaminantes atmosféricos}

Los contaminantes atmosféricos pueden clasificarse en función de diferentes parámetros, como por ejemplo: el origen, el proceso de emisión y su naturaleza. 


\section{Clasificación según su origen}

Un determinado contaminante atmosférico se puede clasificar en función de su origen en natural o antropogénico.

Contaminantes de origen natural (biogénico y geogénico): provienen fundamentalmente de: volcanes, incendios forestales y descomposición de la materia orgánica en el suelo y en los océanos, la resuspensión natural de los suelos áridos o zonas desérticas, de las olas marinas, así como de emisiones biogénicas forestales. Algunos ejemplos de este tipo de contaminantes se detallan en la Tabla 1.1.

Tabla 1.1. Contaminantes de origen natural.

\begin{tabular}{|c|c|}
\hline Fuente & Contaminante \\
\hline Volcanes & Óxidos de azufre, partículas \\
\hline Fuegos forestales & $\begin{array}{l}\text { Monóxido de carbono, dióxido de carbono, óxidos } \\
\text { de nitrógeno, partículas }\end{array}$ \\
\hline Vientos elevados & Partículas \\
\hline Plantas (vivas) & Hidrocarburos, polen \\
\hline Plantas (en descomposición) & Metano, sulfuro de hidrógeno \\
\hline Suelo & Virus, partículas \\
\hline Mar & Aerosol marino \\
\hline Emisiones biogénicas forestales & Isoprenos y terpenos \\
\hline
\end{tabular}

Un claro ejemplo de contaminación atmosférica por presencia de contaminantes de origen natural, y que entre otras afecta a la zona donde se ubica el sector cerámico de Castellón, es la intrusión de masas de aire sahariano, las cuales conllevan una elevada carga de material particulado mineral. Dicho fenómeno presenta una gran influencia en los niveles de $\mathrm{PM}_{10}$ y $\mathrm{PM}_{2,5}$ en la Península Ibérica, Baleares y Canarias, y constituye una fuente muy importante de emisiones de material particulado crustal, que es transportado a largas distancias y es causa de superaciones de los valores límite diarios de $\mathrm{PM}_{10}$ en calidad de aire (Querol et al., 2009).

Otro ejemplo de contaminación atmosférica de origen natural es la emisión de compuestos gaseosos, tales como $\mathrm{SO}_{2}, \mathrm{CO}_{2}, \mathrm{CO}, \mathrm{H}_{2} \mathrm{~S}, \mathrm{HF}$ y $\mathrm{SiF}_{4}$, desde los volcanes (Sawyer y Oppenheimer, 2006).

Contaminantes de origen antropogénico: se originan como resultado de la actividad humana. Aunque a escala planetaria, la cantidad generada es mucho menor en comparación con los contaminantes de origen natural, se considera que presentan una amenaza más significativa a largo plazo para la biosfera. Estos contaminantes pueden proceder de focos fijos (industria, instalaciones de calefacción), móviles (automóviles, aeronaves, buques) o compuestos (aglomeraciones urbanas, polígonos industriales). 
La industria cerámica y la del vidrio son fuentes de emisiones de origen antropogénico, fundamentalmente de material particulado y de algunos gases ácidos $\left(\mathrm{HF}, \mathrm{HCl}, \mathrm{NO}_{x}, \mathrm{CO}, \mathrm{CO}_{2}\right.$, $\mathrm{SO}_{2}$ ). Debido al elevado grado de concentración de la citada industria en la provincia de Castellón, la contribución de dichas fuentes es muy significativa.

La presente tesis se ha centrado en las emisiones de compuestos ácidos, con especial interés en los compuestos de flúor, emitidos durante la fabricación de baldosas cerámicas.

\section{Clasificación según el proceso de emisión}

La agrupación de los contaminantes, en función del proceso de emisión, es la siguiente:

Contaminantes primarios: aquellos que proceden directamente de la fuente de emisión como por ejemplo las cenizas de carbón procedentes de una central térmica.

Contaminantes secundarios: aquellos originados en la atmósfera a partir de precursores primarios como por ejemplo el $\mathrm{O}_{3}$ producido en la atmósfera a partir de $\mathrm{COV}$ y NOx.

\section{Clasificación según su naturaleza}

La clasificación de los contaminantes, en función de su naturaleza química, es la siguiente:

\section{Material particulado o aerosoles}

En el campo de la contaminación atmosférica, el término aerosoles designa aquellas sustancias en estado sólido o líquido, dispersas en un gas. La vida media de los aerosoles en la atmósfera varía desde unos pocos segundos hasta más de un año en algunos casos. El término aerosol incluye las partículas (sólidas y/o líquidas) y el gas sobre el que éstas se encuentran suspendidas (Mészáros, 1999).

Las características del material particulado que más definen los posibles impactos de la contaminación atmosférica sobre el medio son: el tamaño de sus partículas, la morfología y la composición química (Hinds, 1999; McKenna et al., 2008; Baron et al., 2011).

El tamaño de partícula es considerado el parámetro más importante para caracterizar el comportamiento de las partículas, así como su afección sobre la salud humana y sobre el medio ambiente.

En el caso de estudios de calidad de aire y de emisiones industriales, las fracciones granulométricas consideradas son PST, $\mathrm{PM}_{10}$ y $\mathrm{PM}_{2,5}$. El término PST se refiere a partículas en suspensión totales, mientras que los términos $\mathrm{PM}_{10}$ y $\mathrm{PM}_{2,5}$ corresponde al material particulado en suspensión que atraviesa un cabezal de tamaño selectivo para un diámetro aerodinámico de 10 ó 2,5 $\mu \mathrm{m}$ con una eficiencia de corte del 50\%. Las siglas PM vienen del inglés particulate matter (material particulado o materia particulada). 
El diámetro aerodinámico es el diámetro de una partícula ficticia esférica de densidad $1 \mathrm{~g} / \mathrm{cm}^{3}$, que tiene el mismo comportamiento aerodinámico que la partícula real (misma velocidad terminal en régimen estacionario en el aire).

La morfología de las partículas incluye la forma, porosidad o rugosidad de la partícula y las características de su superficie.

Por su parte, la composición química de las partículas es una materia de estudio de enorme interés de cara a conocer el impacto de las mismas sobre el medio y los seres vivos.

Dependiendo de su origen, la composición química varía de unas partículas a otras. Así, las partículas de polvo procedentes del suelo contienen principalmente compuestos de calcio, aluminio y silicio.

En el caso de las partículas procedentes de focos industriales, la composición dependerá del proceso productivo, de su naturaleza y del flujo de materias primas y combustibles, de las condiciones de operación y de la presencia de otros contaminantes.

\section{Contaminantes gaseosos}

Los contaminantes gaseosos pueden clasificarse en función de su naturaleza en compuestos inorgánicos y compuestos orgánicos. Una segunda clasificación, habitualmente utilizada, es referente al elemento principal que lo compone. Así, se puede hablar de compuestos de azufre, de nitrógeno, de carbono y halógenos.

Existe una interconexión entre las distintas categorías planteadas, dado que puede haber una amplia diversidad de compuestos que pertenecen a dos o más familias simultáneamente, como en el caso de los compuestos de carbono orgánico halogenados.

Los gases de interés en la presente tesis son los denominados gases ácidos. Estos gases incluyen compuestos como el $\mathrm{SO}_{2}$, el $\mathrm{NO}_{x}$ y gases halogenados de carácter inorgánico, como el $\mathrm{HF}$ y el $\mathrm{HCl}$. Estos contaminantes además de proceder de fuentes naturales (como las erupciones volcánicas), también se generan en actividades industriales como: fundiciones de aluminio, de vidrio, industrias cerámicas, fábricas de fosfato, etc.

Los gases ácidos, y en concreto los compuestos de flúor, son contaminantes del aire que se caracterizan por ser tóxicos en general para las plantas, animales y seres humanos.

A modo de resumen del presente apartado de aspectos generales de contaminación atmosférica se ha confeccionado la Figura 1.1. En la misma se han representado, de forma esquemática, las diferentes clasificaciones que se le confieren a los contaminantes del aire, con las alternativas de flujo del proceso de contaminación según la fuente, tipo, naturaleza y origen del contaminante. 


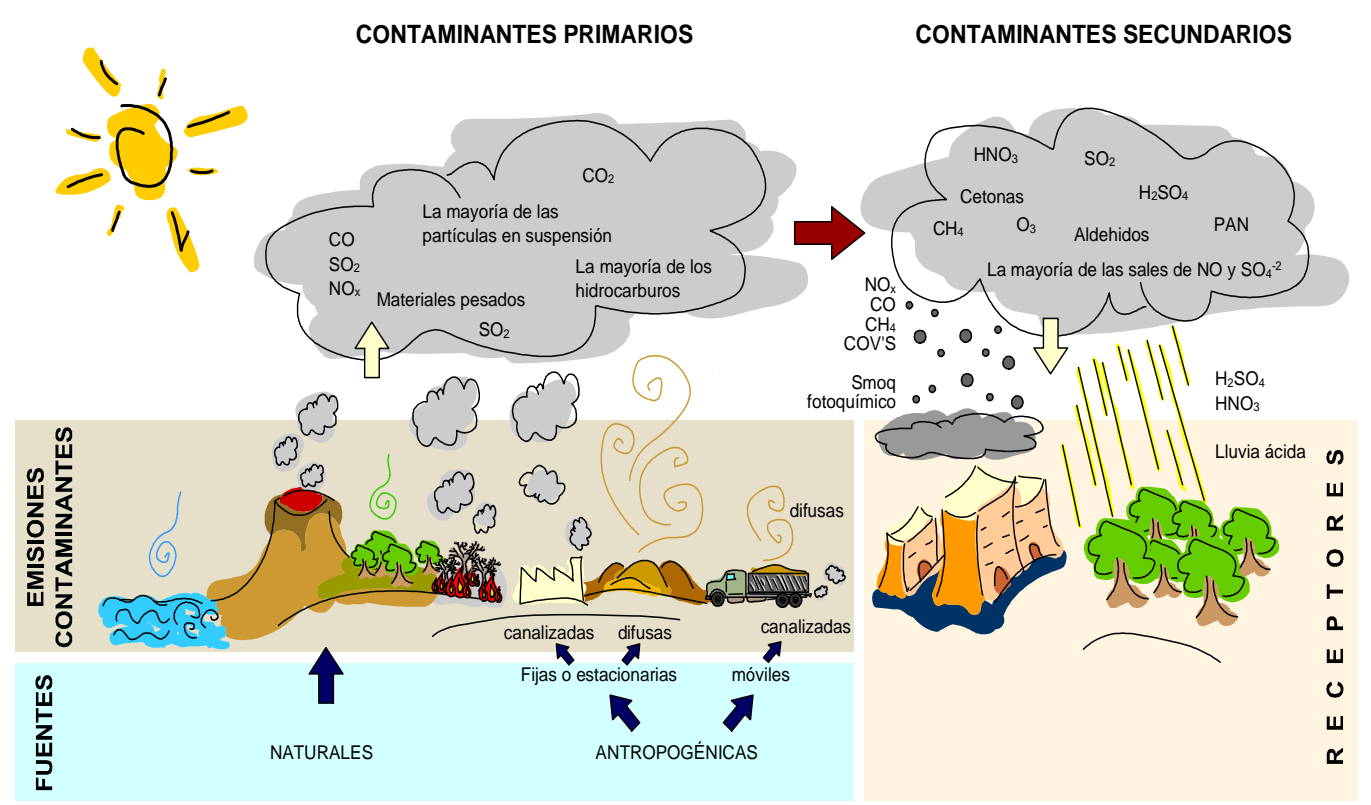

Figura 1.1. Ciclo completo de la contaminación atmosférica.

Los objetivos generales de la presente tesis incluyen el estudio de la emisión de compuestos ácidos y, en especial, de los compuestos de flúor. Por este motivo las siguientes secciones describen las principales características de dichos compuestos.

\subsubsection{El elemento flúor y el ácido fluorhídrico (HF) como contaminante}

El flúor como contaminante y sus efectos sobre el ambiente y la salud de las personas han sido extensamente tratados por la literatura científica, a través de artículos y monografías especializadas. Incluso existe una revista científica, Fluoride, sobre el flúor, publicada por la International Society for Fluoride Research. Por lo tanto, el intento de resumir el estado del arte concerniente al flúor y a sus implicaciones ambientales y sobre la salud está limitado necesariamente a un resumen general como el que se muestra a continuación y que incluye los hechos más importantes relacionados con el ambiente y la salud ambiental en humanos, plantas y animales. Dadas estas limitaciones, el principal propósito del presente capítulo es el de presentar un marco conceptual que sirva de base para conocer las implicaciones de este elemento y sus compuestos. Para ello se ha tomado como base la información contenida en las siguientes referencias: Weinstein y Davison, 2004; Tressaud, 2006 y Ozsvath, 2009. No obstante, cuando se ha considerado necesario, se ha ampliado el contenido de las mismas mediante la adición de determinadas fuentes convenientemente citadas a lo largo del texto. 


\subsubsection{Introducción}

El flúor es el elemento más reactivo y más electronegativo de la tabla periódica. Como consecuencia del reducido tamaño del enlace que forma y de su elevada carga nuclear efectiva dispone de un fuerte poder de atracción de electrones que le hace capaz de reaccionar con el resto de elementos, de modo que son conocidos enlaces con todos los elementos a excepción del neón y del helio. Por este motivo el flúor no se encuentra en estado libre en la naturaleza y puede formar enlaces iónicos y covalentes con otros elementos. Su electronegatividad extrema hace que los enlaces covalentes sean fuertemente polares. El reducido tamaño del enlace covalente del átomo de flúor y su alta electronegatividad permite sustituir a los enlaces de hidrógeno.

El flúor también forma enlaces fuertes con el carbono que lo hacen resistente al ataque químico y biológico. Esta característica es muy apreciada a nivel médico, a nivel industrial y a nivel ambiental.

Los átomos de flúor pueden sustituir a átomos de hidrógeno e iones hidroxilo en moléculas. Por ejemplo, puede sustituir a la mayoría de los átomos de hidrógeno de los hidrocarburos y formar compuestos organofluorados. También puede formar huesos más duros y resistentes al ataque ácido cuando sustituye a los iones hidroxilo en el fosfato cálcico que forma la base de los huesos.

El reducido tamaño del átomo de flúor y su electronegatividad hace que este elemento y sus compuestos tengan propiedades diferenciadas respecto al resto de halógenos, como por ejemplo mayores puntos de fusión y de evaporación.

El flúor se presenta principalmente en forma de ${ }^{19} \mathrm{~F}$, aunque pueden existir isótopos por reacciones nucleares como el ${ }^{18} \mathrm{~F}$, que tiene una vida media corta $(1,87 \mathrm{~h})$ que le permite ser utilizado en investigaciones médicas y biológicas (Weinstein y Davison, 2004).

Los compuestos fluorados contenidos en la atmósfera incluyen gases inorgánicos $\left(\mathrm{HF}, \mathrm{SiF}_{6}\right.$, $\mathrm{SiF}_{4}, \mathrm{~F}_{2}, \mathrm{H}_{2} \mathrm{SiF}_{4}$ ), compuestos orgánicos (fluorocarbonos, perfluorocarbonos, ácido trifluoro acético) y minerales $\left(\mathrm{CaF}_{2}, \mathrm{NaF}, \mathrm{Na}_{2} \mathrm{SiF}_{6}, \mathrm{NaAlF}_{4}\right)$. Se ha estimado que la presencia de gases fluorados orgánicos en la troposfera es de $1 \mathrm{ppb}$ de media, mientras que los gases fluorados inorgánicos alcanzan entre 0,1-0,4 ppb. Algunos compuestos fluorados gaseosos tienen unos tiempos de vida media en la atmósfera muy largos y son transportados a la estratosfera donde destruyen la capa de $\mathrm{O}_{3}$. Sin embargo, las fases particuladas que contienen flúor no están tan bien caracterizadas en términos de niveles de fondo, distribución global y fuentes (Jayarathne et al., 2014).

Mención especial merece el fluoruro de hidrógeno o ácido fluorhídrico (HF) por ser el principal compuesto de flúor emitido durante la cocción de baldosas cerámicas. Este compuesto es ampliamente utilizado por la industria química especialmente como producto intermedio en la fabricación de productos que contienen flúor. Es un gas incoloro o un líquido humeante fuertemente irritante y muy corrosivo. El límite de detección odorífera se sitúa alrededor de 
$30-130 \mu \mathrm{g} / \mathrm{m}^{3}$. Industrialmente se fabrica a partir de la fluorita $\left(\mathrm{CaF}_{2}\right)$. Los humanos son razonablemente tolerantes al HF gaseoso, aunque se puede decir que es uno de los compuestos más tóxicos de todos los contaminantes del aire si nos centramos en su efecto sobre plantas y sobre ciertos animales (Weinstein y Davison, 2004).

Algunos fluoruros no son inertes. La elevada estabilidad termodinámica de la molécula de HF a menudo hace que los fluoruros sean inestables con respecto a la hidrólisis y, que si el elemento que está unido al flúor está en un estado de oxidación alto, el HF puede estar acompañado de $\mathrm{O}_{2}, \mathrm{O}_{3}$ u otros productos de oxidación. La hidrólisis del HF provoca la sustitución de los grupos $\mathrm{OH}$ por $\mathrm{F}$ (Tressaud, 2006).

\subsubsection{Distribución y presencia de fluoruros en el medio ambiente}

La presencia de fluoruros en el medio ambiente es amplia en cualquiera de sus esferas, hasta el punto que es posible hablar de una esfera específica para el flúor o fluoroesfera (Figura 1.2). La representación esquemática de los reservorios y flujos de compuestos fluorados naturales y antropogénicos, que existen a nuestro alrededor, puede ayudar a entender los efectos de la actividad humana en el ambiente (Tavener et al., 2006).

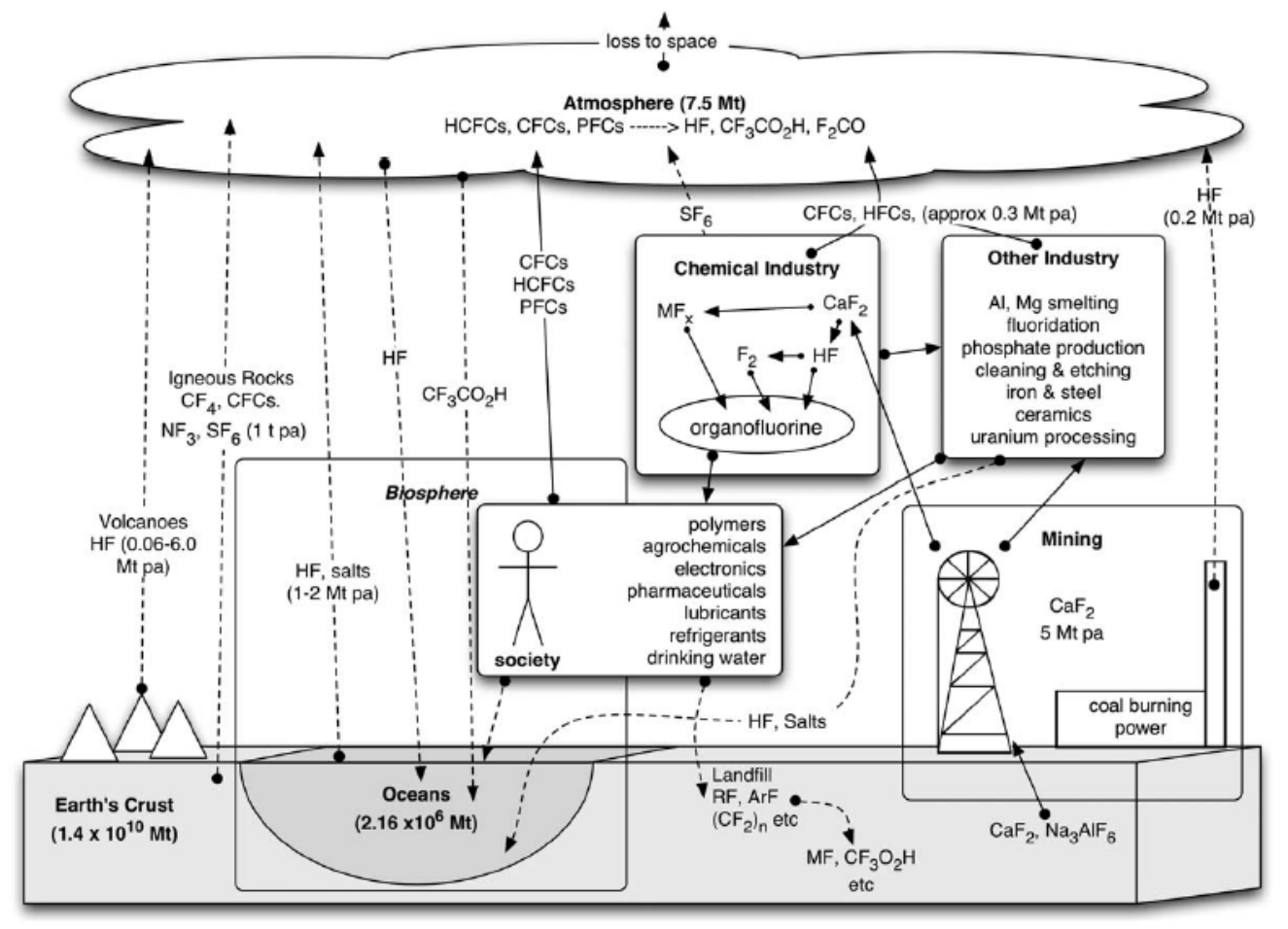

Figura 1.2. La fluoroesfera. Representación esquemática de los reservorios de flúor y del flujo en la

Tierra, con volúmenes aproximados. Las flechas continuas indican la manipulación deliberada de productos y minerales que contienen flúor. Las flechas de puntos indican subproductos de los procesos productivos, emisiones al medio ambiente y los procesos naturales (Tavener et al., 2005). 
A continuación, en este apartado, se describen las fuentes de los compuestos fluorados más importantes.

\section{Fuentes de emisión atmosféricas}

Los volcanes, sus fumarolas y los sistemas hidrotermales que existen a su alrededor son una fuente natural de fluoruros atmosféricos. La quema de madera en los incendios forestales junto con el flúor originado en la superficie de los océanos también puede contribuir como fuente natural de flúor. Sin embargo, los más de 600 volcanes conocidos y activos son la fuente que provee la mayor parte del flúor presente como fondo en el aire. El magma que alcanza la superficie se desgasifica en forma de burbujas y es lanzado a la atmósfera al producirse un descenso de la presión. La emisión global de HF desde los volcanes se ha estimado en 7000 - 8600 kt. Sin embargo, la concentración disminuye rápidamente con la distancia al punto de emisión, por lo que los efectos ambientales están restringidos a las proximidades de la fuente y en periodos inmediatamente posteriores a los sucesos más importantes. En distancias superiores a los pocos kilómetros de la fuente natural, la concentración natural en la atmósfera es muy similar a la concentración de fondo. Algunos datos citados por la Organización Mundial de la Salud (OMS) indican que el valor de fondo habitual de flúor inorgánico atmosférico total, suma del gaseoso y del particulado, es inferior a $0,1 \mu \mathrm{g} / \mathrm{m}^{3}$ y en la mayor parte de casos inferior a $0,05 \mu \mathrm{g} / \mathrm{m}^{3}$ (Weinstein y Davison, 2004).

En consecuencia, las intrusiones naturales de fluoruro en el medio ambiente de la atmósfera, no han sido directamente vinculadas a los problemas de salud humana en la literatura científica. Sin embargo, existen casos de fluorosis aguda y crónica sufrida por animales que pastaban en pastizales cubiertos por cenizas y otras partículas procedentes de erupciones volcánicas recientes o por el polvo derivado de rocas fosfáticas.

La forma principal en la que el flúor es emitido a la atmósfera es el HF aunque también se emite en forma de fluoruro de amonio $\left(\mathrm{NH}_{4} \mathrm{~F}\right)$, tetrafluoruro de silicio $\left(\mathrm{SiF}_{4}\right)$, fluorosilicato de amonio $\left(\left(\mathrm{NH}_{4}\right)_{2} \mathrm{SiF}_{6}\right)$, fluorosilicato de sodio $\left(\mathrm{Na}_{2} \mathrm{SiF}_{6}\right)$ y de potasio $\left(\mathrm{K}_{2} \mathrm{SiF}_{6}\right)$ y, fluoroborato de potasio $\left(\mathrm{KBF}_{4}\right)$. También es posible la presencia de fluoruro de sodio (NaF), fluoruro de potasio $(\mathrm{KF})$, fluoruro de magnesio $\left(\mathrm{MgF}_{2}\right)$ y fluoruro de calcio $\left(\mathrm{CaF}_{2}\right)$. Los volcanes también son una fuente importante de compuestos organofluorados, incluyendo algunos CFC.

Las fuentes antropogénicas de flúor emitido a la atmósfera, tanto de compuestos gaseosos como particulados, proceden de diversos tipos de actividades industriales. Las principales operaciones básicas asociadas a dichas emisiones son: calcinación de minerales 0 pigmentos, reacciones con ácidos, reducción electroquímica de metales que utilizan electrolitos con presencia de flúor, cocción de materiales cerámicos, fundido de materias primas en procesos de fabricación de vidrio, uso de agentes químicos de limpieza que contienen flúor, galvanización y grabado en varios procesos industriales. 
Además de los procesos anteriores, la combustión de carbón es la mayor fuente de emisión potencial de flúor dado que es un constituyente habitual del mismo y es emitido a la atmósfera en forma de HF durante el proceso de combustión. También es de importancia la introducción de flúor en las aguas y otros productos tales como: pasta de dientes, fibras, fármacos, protectores de madera y productos agroquímicos que dispensan compuestos de flúor al ambiente.

En la Tabla 1.2 se recogen siete de las actividades industriales más importantes que emiten flúor a la atmósfera y que ocasionan problemas ambientales (Weinstein y Davison, 2004).

Tabla 1.2. Actividades industriales que emiten flúor.

\begin{tabular}{ll}
\hline \multicolumn{2}{c}{ Actividades industriales que emiten flúor } \\
\hline Fertilizantes fosfóricos y fósforo elemental & Fabricación de vidrio y fibra de vidrio \\
Fundiciones de aluminio & Fabricación de hierro y acero \\
$\begin{array}{l}\text { Alquilación con HF durante el proceso de } \\
\text { refino del petróleo }\end{array}$ & $\begin{array}{l}\text { Fabricación de ladrillos, azulejos, cerámica } \\
\text { doméstica y cemento }\end{array}$ \\
& Combustión de carbón \\
\hline
\end{tabular}

Por otro lado, existe una gran cantidad de industrias que utilizan el HF en sus procesos: limpieza de metales y eliminación de óxidos en el galvanizado, grabado químico húmedo de semiconductores en placas solares de la industria electrónica, fundente corrosivo en procesos de soldadura, producción de compuestos organofluorados, como los CFC y como reactivo para convertir el uranio en hexafluoruro de uranio en el proceso de enriquecimiento de este elemento, además de como derivado químico en otros procesos de fabricación.

Estas fuentes de contaminación emiten flúor al medio ambiente, tanto en forma gaseosa (por ejemplo, $\mathrm{HF}, \mathrm{SiF}_{4}, \mathrm{~F}_{2}$ y $\mathrm{H}_{2} \mathrm{SiF}_{6}$ ) como en forma particulada (por ejemplo $\mathrm{CaF}_{2}$, $\mathrm{NaF}$, y $\mathrm{Na}_{2} \mathrm{SiF}_{6}$ ). Los CFC presentes en el ambiente también contribuyen a la fluorización de la lluvia, pero su concentración $(0,001 \mathrm{mg} / \mathrm{l})$ es insignificante en comparación con los niveles naturales de fondo (Ozsvath, 2009).

La lluvia contaminada por las emisiones de la industria puede contener concentraciones de flúor que son un orden de magnitud mayor que el nivel de fondo, incluso superiores a $1 \mathrm{mg} / \mathrm{l}$. Además, estas concentraciones pueden darse hasta a $2 \mathrm{~km}$ de distancia de la fuente.

Existen casos documentados de fluorosis en animales de granjas cercanas a fábricas de ladrillo del Reino Unido, así como en huesos y astas de ciervos que viven en países industrializados de regiones de la Europa continental. Por lo tanto, aunque las agencias reguladoras gubernamentales sostienen que las normas actuales de calidad del aire son de protección de la salud humana, los grupos de defensa del medio ambiente argumentan que las personas que viven cerca de una fuente industrial que emite flúor se enfrentan a riesgos significativos para la salud. 
En China existen zonas con presencia de fluorosis endémica de origen natural asociado a la utilización de agua potable con elevados contenidos en flúor (Zhang et al., 2003). También es el único país donde se ha informado de la existencia de fluorosis endémica atribuida a la utilización de carbón como combustible doméstico (Dai et al., 2007). Como consecuencia, la contaminación atmosférica debida al fluoruro es considerada en este país como uno de los principales problemas ambientales (Xie et al., 2003). Algunas investigaciones atribuyen los problemas de salud al flúor liberado durante la combustión de carbón con elevado contenido en flúor, en lugar de al agua potable, o al consumo de maíz y chiles (Zheng y Huang, 1989; Zhang y Cao, 1996; An et al., 1995; Zheng et al., 1999). Sin embargo, los estudios realizados por Finkelman et al. (1999), Dai et al. (2004), DaiShe et al. (2004) y Wu (2004) confirman que la fluorosis endémica es debida principalmente a la combustión del carbón que contiene arcilla utilizada como aglutinante (Dai et al., 2007).

Los compuestos organofluorados merecen una mención especial. Estos compuestos, al igual que el resto de compuestos fluorados, pueden tener un origen natural o antropogénico. Así, durante la década de los 90 se encontraron más de una treintena de estos compuestos que poseen, en su mayoría, un origen geológico y por lo tanto natural. Sin embargo, las técnicas de cuantificación y extracción todavía no están lo suficientemente desarrolladas por lo que la investigación en este campo es relativamente pequeña por el momento.

Los compuestos organofluorados más importantes son los CFC. Algunos compuestos son gaseosos y producen efecto invernadero y son destructores de la capa de ozono estratosférico. Sin embargo, cuando quedan atrapados en la estructura de un mineral no presentan una preocupación ambiental inmediata. Estos compuestos son: $\mathrm{CF}_{4}, \mathrm{CF}_{3} \mathrm{Cl}, \mathrm{CF}_{2} \mathrm{Cl}_{2}$, $\mathrm{CFCl}_{3}$, y $\mathrm{CHF}_{3}$.

Aunque es necesario ampliar los estudios referentes a los compuestos organofluorados de origen natural, se sabe que el único CFC detectado en erupciones volcánicas es el $\mathrm{CFCl}_{3}$, y que no se emite en cantidades suficientes como para contribuir significativamente al cambio climático. En el caso del $\mathrm{CF}_{4}$, se cree que la mitad del mismo procede de la desgasificación de las fuentes naturales de la litosfera, mientras que el resto proviene de los procesos de fabricación de aluminio.

Algunas plantas contienen fluoroacetato y otros compuestos organofluorados que las convierten en plantas muy venenosas. En número son más importantes las familias de las Fabaceae y Dichapetalaceae, aunque existen algunas otras. En la Tabla 1.3 se muestran ejemplos de compuestos orgánicos de flúor naturales (Gribble, 2002).

Con respecto a los compuestos organofluorados de origen antropogénico, cabe señalar que son ampliamente utilizados en la industria, el comercio y en el hogar. Los compuestos organofluorados más comunes se utilizan en forma de fármacos, pesticidas, herbicidas, surfactantes, agentes extintores de fuego, propelentes, refrigerantes, adhesivos, revestimiento superficial para papel y tejidos, fibras, membranas, materiales aislantes y lubricantes. 
Tabla 1.3. Ejemplos de compuestos orgánicos de flúor naturales (Gribble, 2002). Se ha mantenido la nomenclatura en inglés ex profeso.

\begin{tabular}{|c|c|c|}
\hline Compuestos (nombre común) & Origen & Autores, comentarios \\
\hline $\begin{array}{l}\text { Perfluoromethane, CF } \\
\text { (CFC-14) }\end{array}$ & $\begin{array}{l}\text { Geological: fluorites, } \\
\text { granites, aimosphere? }\end{array}$ & $\begin{array}{c}\text { Harnisch etal. (1996, 2000); Harnisch and } \\
\text { Eisenhauer (1998) }\end{array}$ \\
\hline $\begin{array}{l}\text { Trifluorochloromethane, } \mathrm{CF}_{3} \mathrm{Cl} \\
\text { (CFC-13, Freon 13) }\end{array}$ & $\begin{array}{l}\text { Geological: fluorite from } \\
\text { Wölsendorf, Germany }\end{array}$ & Harnisch et al. (2000) \\
\hline $\begin{array}{l}\text { Difluorodichloromethane, } \mathrm{CF}_{z} \mathrm{Cl}_{z} \\
\text { (CFC-12, Freon 12) }\end{array}$ & $\begin{array}{l}\text { Geological: fluorites, } \\
\text { granites, volcanites, } \\
\text { metarhyolite, gneiss }\end{array}$ & Harnisch et al. (2000) \\
\hline $\begin{array}{l}\text { Trichlorofluoromethane, } \mathrm{CFCl}_{3} \\
\text { (CFC-11) }\end{array}$ & $\begin{array}{l}\text { Geological fluorites, } \\
\text { granites, volcanites, } \\
\text { metarhyolite, gneiss, } \\
\text { volcanoes? }\end{array}$ & $\begin{array}{l}\text { Isidorov et al. (1993a,b); Harnisch et al. } \\
\text { (2000); Jordan et al.(2000) }\end{array}$ \\
\hline $\begin{array}{l}\text { Trifluoromethane, } \mathrm{CHF}_{3} \\
\text { (HFC-23, fluoroform) }\end{array}$ & $\begin{array}{l}\text { Geological: fluorite from } \\
\text { Wölsendorf, Germany }\end{array}$ & Harnisch et al (2000) \\
\hline $\begin{array}{l}\text { Monofluoroacetic acid, } \mathrm{CH}_{2} \mathrm{FCO}_{2} \mathrm{H} \\
\text { (occurring as the acetate, sodium } \\
\text { salt known as compound 1080) }\end{array}$ & $\begin{array}{c}\text { Biological: Streptomyces } \\
\text { cattleya Biological: Acacia } \\
\text { georginae, some } \\
\text { Dichapetalum spp. sensu } \\
\text { lato }\end{array}$ & $\begin{array}{l}\text { Sanada et al. (1986) Summarized In Gribble } \\
\text { (2002); see also Twigg et al. (1996a) }\end{array}$ \\
\hline $\begin{array}{l}\text { Trífluoroacetic acid, } \mathrm{CF}_{3} \mathrm{CO}_{2} \mathrm{H} \\
\text { (occurring as the acetate) }\end{array}$ & Biological and/or geclogical & $\begin{array}{l}\text { Jordan and Frank (1999); Ellis et al. (2001b, } \\
\text { 2002) }\end{array}$ \\
\hline $\begin{array}{l}\text { Fluoroacetone? } \mathrm{C}_{3} \mathrm{H}_{5} \mathrm{FO} \\
\text { Fluoroacetaldehyde? } \mathrm{C}_{2} \mathrm{H}_{3} \mathrm{FO}\end{array}$ & $\begin{array}{c}\text { Biological: Acacia } \\
\text { georginae, Streptomyces } \\
\text { cattleya }\end{array}$ & $\begin{array}{c}\text { Peters and Shorthouse (1967), but } \\
\text { fluoroacetone doubtful; fluoroacetaldehyde } \\
\text { postulated, see O'Hagan and Harper (1999); } \\
\text { Moss et al. (2000) }\end{array}$ \\
\hline$\omega$-Substituted fluoro fatty acids & $\begin{array}{l}\text { Biological: several isolated } \\
\text { from Dichapetalum } \\
\text { toxicarium, e.g. w-fluoro- } \\
\text { oleic acid }\end{array}$ & $\begin{array}{l}\text { Peters ef al. (1960); Ward et al. (1964); } \\
\text { Harper et al. (1990); Hamilton and Harper } \\
\text { (1997); Gribble (2002) }\end{array}$ \\
\hline 4-Fluorothreonine & $\begin{array}{l}\text { Biological: Streptomyces } \\
\text { cattleya }\end{array}$ & $\begin{array}{c}\text { Sanada et al. (1986); see also O'Hagan and } \\
\text { Harper (1999) }\end{array}$ \\
\hline $\begin{array}{l}\text { Nucleocidin, 4'-fluoro-5'-0- } \\
\text { sulphamoyladenosine }\end{array}$ & $\begin{array}{l}\text { Biological: Streptomyces } \\
\text { calvus }\end{array}$ & Morton et al. (1969) \\
\hline
\end{tabular}

La afección ambiental de estos compuestos es altamente dependiente del tipo de compuesto considerado, de la dispersión y dilución que sufren, de su metabolismo y de las alteraciones químicas que pueden sufrir. En general, las posibles afecciones no han sido determinadas de forma completa. 


\section{Fuentes minerales}

Con una concentración media de $625 \mathrm{mg} / \mathrm{kg}$, el flúor es uno de los elementos traza más abundantes en el la corteza terrestre; sin embargo, su presencia varía mucho de un tipo de roca a otro. Normalmente, el contenido en flúor oscila entre $100 \mathrm{mg} / \mathrm{kg}$ en rocas ultramáficas y algunas calizas, a los $1000 \mathrm{mg} / \mathrm{kg}$ en rocas ígneas alcalinas y $1300 \mathrm{mg} / \mathrm{kg}$ en lutitas marinas, aunque se han medido valores más elevados como $2000 \mathrm{mg} / \mathrm{kg}$ en rocas volcánicas producidas en una zona límite de subducción. Las razones de un reparto diferenciado dentro de la corteza terrestre son importantes para comprender cómo se encuentran distribuidos los fluoruros en el medio ambiente (Ozsvath, 2009).

Los minerales que contienen flúor más comunes en el entorno natural son: fluorita $\left(\mathrm{CaF}_{2}\right)$, fluorapatito $\left(\mathrm{Ca}_{5}\left(\mathrm{PO}_{4}\right)_{3} \mathrm{~F}\right)$, micas y anfíboles (donde el $\mathrm{F}^{-}$sustituye a grupos $\mathrm{OH}^{-}$dentro de la estructura mineral), criolita $\left(\mathrm{Na}_{3} \mathrm{AlF} \mathrm{F}_{6}\right)$, villiaumita $(\mathrm{NaF})$, topacio $\left(\mathrm{Al}_{2}(\mathrm{SiO})_{4} \mathrm{~F}_{2}\right)$, así como en los principales minerales arcillosos (illita, caolinita y clorita) presentes en las arcillas utilizadas en la industria de baldosas cerámicas, tal y como se comenta con mayor detalle en el Capítulo 2. Estos minerales se encuentran principalmente en determinadas rocas ígneas y metamórficas y, en menor medida, en depósitos sedimentarios derivados de tales rocas. Sin embargo, las formaciones sedimentarias pueden contener arcillas enriquecidas en flúor y fluorapatito que precipita a partir de aguas enriquecidas en fosfato.

Muchas regiones del mundo con anomalía geoquímica de flúor tienen como sustrato geológico rocas ígneas cristalinas y metamórficas (por ejemplo, partes de la India, Sri Lanka, Senegal, Ghana, Sudáfrica y Escandinavia) o presentan zonas volcánicas y actividad hidrotermal asociada. La explicación a este comportamiento está relacionada con la geoquímica del flúor en el magma, debido a que el flúor tiene una afinidad mayor por los fundidos de silicato que por las fases sólidas. Así, se enriquece progresivamente en los magmas y las soluciones hidrotermales a través del tiempo, teniendo lugar una diferenciación magmática. Como resultado, los depósitos filonianos hidrotermales y rocas que cristalizan a partir de magmas evolucionados contienen, frecuentemente, fluorita, fluorapatito y micas enriquecidas en fluoruros y/o anfíboles. La criolita, la villiaumita, y/o el topacio también pueden disponer de fluoruros dependiendo de la presencia de sílice y calcio en el magma.

En zonas con sustratos geológicos compuestos de rocas ígneas y metamórficas las anomalías geológicas de flúor están asociados con sienitas, granitos, cuarzo, monzonitas, granodioritas, félsicos y biotita gneis y rocas volcánicas alcalinas, aunque estos tipos de roca pueden contener una amplia variedad de minerales secundarios enriquecidos en flúor.

La mayoría del resto de lugares con elevado contenido de flúor en el suelo están asociados a acuíferos sedimentarios, especialmente en las zonas áridas y ambientes semiáridos. Algunos ejemplos importantes incluyen la provincia de La Pampa del centro de Argentina, la región del Sahara del norte de África, y partes del norte de China. Las fuentes de flúor en los sedimentos 
y rocas sedimentarias incluyen minerales fluorados portadores de derivados de la roca madre, ceniza volcánica, arcillas ricas en fluoruros (sobre todo en los sedimentos marinos y lutitas), y fluorapatito (en algunas rocas carbonatadas, yacimientos de fosfato y depósitos arcillosos).

Dentro de las fuentes minerales merece ser destacada la fuente geotermal. Algunas de las más altas concentraciones de flúor disuelto se encuentran en la corteza terrestre cerca de áreas afectadas por actividad geotérmica, como el Valle del Rift al en el este de África, Nueva Zelanda, Francia, Islandia, China, y partes del oeste de los EE.UU. Los magmas evolucionados y sus soluciones hidrotermales asociadas son especialmente ricos en flúor. Cuando las aguas de escorrentía se ponen en contacto con este tipo de magma o sus soluciones, se puede enriquecer notablemente en fluoruro hasta alcanzar el límite de solubilidad del flúor. Con frecuencia las aguas termales de origen geotérmico, con valor medicinal debido a su exposición prolongada, contienen concentraciones de fluoruro superiores a $1 \mathrm{mg} / \mathrm{l}$.

En el Valle del Rift en el África Oriental, donde la incidencia de fluorosis dental y esquelética es muy alta, la existencia de rocas volcánicas hiperalcalinas y la actividad geotérmica se combinan para producir concentraciones de flúor que a veces pueden exceder de $1000 \mathrm{mg} / \mathrm{l}$ en lagos alcalinos de cuencas cerradas. La exposición de la roca a las condiciones ambientales y el influjo de aguas geotérmicas producen lagos que se caracterizan por una alta concentración de sodio y bicarbonato, casi neutras a valores de $\mathrm{pH}$ alcalino, y de baja saturación con respecto a la fluorita. Estas condiciones son propicias para una alta concentración de flúor en solución, que se incrementa aún más a través de la evaporación.

Las aguas geotérmicas ácidas también pueden contener una alta concentración de fluoruro, pero por una razón diferente. En condiciones de bajo $\mathrm{pH}$, la solubilidad de los fluoruros se ve

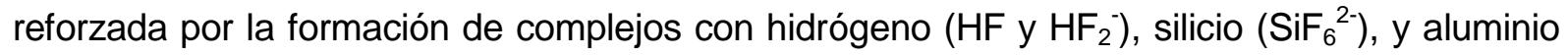
$\left(\mathrm{AlF}_{\mathrm{X}}{ }^{3-x}\right)$, que previenen la formación de fluorita. Los valores bajos de $\mathrm{pH}$ (especialmente los menores de 4) también inhiben la precipitación de silicato sinterizado cuando las aguas geotérmicas llegan a la superficie de la tierra. Es por ello que aumenta la probabilidad de que el fluoruro permanezca en solución, ya que se libera a la superficie del ambiente. Aunque la salud humana no está afectada en muchos casos por estos tipos de aguas, Heikens et al., (2005) documentó un caso de fluorosis dental endémica en Indonesia, como resultado de la ingestión de fluoruros provenientes de un lago volcánico hiperácido (Ozsvath, 2009).

\subsubsection{Movilidad de los fluoruros inorgánicos en la biosfera}

El transporte y la acumulación de los fluoruros inorgánicos en la biosfera puede ser la base científica para interpretar la inmensa variación existente en el contenido de flúor del aire, del suelo, del agua, así como en plantas y animales. En este punto se pretende esquematizar la dispersión de los fluoruros en dichos ambientes, a excepción del agua. 


\section{Flúor en el aire}

Todas las partículas y gases emitidos a la atmósfera desde un foco fijo, como puede ser un volcán o una chimenea, son diluidos y transportados por el viento y mezclados por turbulencia. El modo de dispersión y los gradientes de concentración al nivel del suelo dependen de diferentes factores: concentración en el efluente, altura de la emisión, temperatura del gas, dirección y velocidad del viento, grado de turbulencia, topografía y características de la vegetación. En general, las emisiones de fuentes puntuales fijas, por ejemplo una chimenea de una instalación industrial, muestran patrones similares a los recogidos en la Figura 1.3. Cuando la temperatura del penacho es superior a la del aire que le rodea, aquel es menos denso, y se eleva verticalmente aumentando la altura efectiva de la chimenea. Una vez fuera de la chimenea, el penacho se dispersa por la acción del viento y es diluido por difusión y por mezcla turbulenta. Posteriormente, se expande y en ocasiones alcanza el nivel del suelo. Normalmente, las concentraciones de contaminante a nivel del suelo cerca de la fuente son bajas, mientras que son máximas a sotavento cuando la línea central del penacho alcanza el suelo.

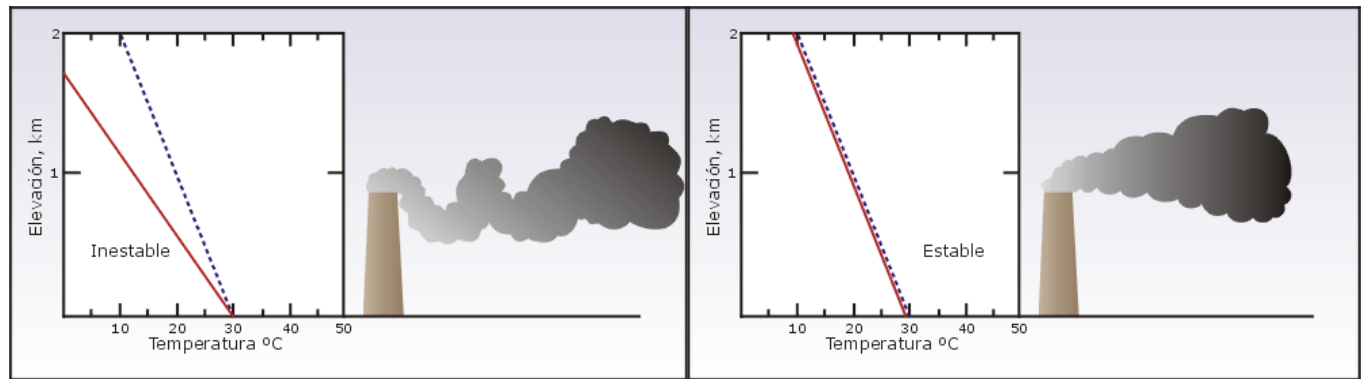

a)

b)

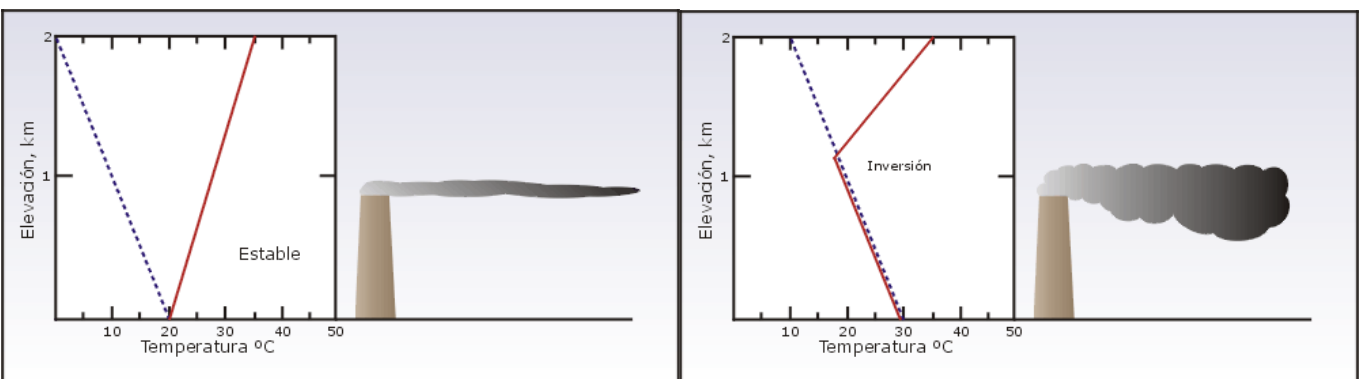

c)

d)

Figura 1.3. Ejemplos de patrones de dispersión del penacho de una chimenea bajo diferentes condiciones del perfil de temperatura: a) espiral, b) cono, c) tubular y d) fumigante (Weinstein y Davison, 2004).

Generalmente, cuando mayor es la altura que alcanza el penacho y la velocidad del viento, más lejos se traslada y más se diluye dicho penacho antes de alcanzar el suelo. En la Figura 1.3 se presentan algunos ejemplos de patrones de dispersión existentes. En cada ejemplo se 
incluye una representación del perfil de temperatura con la altura, en rojo, y el perfil adiabático de temperatura en azul.

En condiciones de sol y con bajas velocidades de viento, cuando la atmósfera es inestable, el perfil de temperatura se sitúa por debajo del perfil adiabático. En este caso, el penacho puede tener diferentes trayectorias y ser transportado en forma de grandes remolinos con forma de espiral a), dirigiéndose a los receptores que pueden estar expuestos a concentraciones mayores de contaminante en periodos cortos de tiempo. El siguiente ejemplo tiene lugar cuando se dan condiciones de estabilidad neutra, es decir, cuando el perfil de temperatura y el adiabático coinciden, con un viento más o menos intenso, el penacho toma una forma de cono b). Cuando la capa límite es estable, el perfil de temperatura se sitúa por encima del perfil adiabático. Esta situación se da normalmente cuando se pone el sol y la tierra se enfría más rápidamente que el aire y da lugar a condiciones de estratificación estable donde el penacho es tubular c). Con frecuencia las condiciones anteriores son precursoras de la inversión térmica, donde se modifica el descenso habitual de la temperatura con la altura y el penacho, denominado fumigante, no se eleva dado que es más denso que el aire de alrededor d). De esta forma, los contaminantes quedan atrapados bajo la capa de inversión térmica aumentando su concentración mientras continua dicha inversión.

Si el terreno se eleva en la dirección de sotavento, la concentración máxima puede ser mayor en dicha elevación que en terreno llano. El efecto es contrario si el terreno desciende. Sin embargo, los efectos de la topografía son más evidentes cuando las fuentes de contaminación se encuentran en valles estrechos. El aire se mueve a lo largo del valle, obstaculizado por la ladera, manteniendo una elevada concentración de contaminante durante largas distancias (Weinstein y Davison, 2004).

El seguimiento de la concentración de contaminantes fluorados en el aire, cerca de las fuentes de emisión, no ha sido adecuado en el pasado, debido a que las técnicas analíticas existentes no han sido capaces de detectar concentraciones bajas de contaminantes típicas de entornos ambientales. Esta circunstancia se ha revertido con la aparición de detectores remotos capaces de medir cantidades traza de compuestos tales como el HF, haciendo uso de diodos láser en el rango del infrarrojo. Esta tecnología permite medir por debajo de las 10 ppb (Grigoriev et al., 2010).

No obstante, es bien conocido que la concentración de compuestos de flúor en el ambiente disminuye con la distancia de forma no lineal (Franzaring et al., 2006). Incluso cuando los intervalos de emisión son relativamente constantes, debido a factores como el viento y demás parámetros meteorológicos, la concentración de contaminantes es considerablemente fluctuante a nivel del suelo.

Es importante conocer la concentración de los compuestos de flúor particulados y gaseosos debido a que pueden presentar diferencias en cuanto a toxicidad. Sin embargo, existe un reducido número de estudios que recogen información relativa a los compuestos particulados 
y aún es menor el número de los que especifican características tales como el tamaño y la naturaleza química de los mismos.

Al mismo tiempo que se dan fenómenos de difusión y turbulencia en el penacho que disminuyen la concentración de contaminante en el mismo con la distancia a la fuente, se pueden dar fenómenos de deposición de contaminantes desde la atmósfera. Es posible distinguir dos tipos de deposición: seca y húmeda. La deposición húmeda es la eliminación del contaminante por efecto de la lluvia, la niebla o la nieve. Esta eliminación es muy efectiva y reduce significativamente la contaminación atmosférica en periodos de precipitación. Por su parte, la deposición seca se produce cuando el contaminante impacta en una superficie o, en el caso de las plantas, es transportado hasta las hojas a través de sus poros o sus estomas. Así pues, no debe sorprender que la capacidad de adsorción de compuestos gaseosos y particulados de flúor sea considerablemente diferente si se trata de la superficie de la cutícula de una hoja, del suelo o de un lago. En general, la deposición en superficies húmedas es mayor que la deposición en superficies secas, lo que significa que las deposiciones en seco son mayores en hojas humedecidas de lluvia o rocío. De todos modos, la medida de la deposición húmeda o seca de los compuestos de flúor es complicada y no incluye una discriminación adecuada para todas las posibilidades de deposición.

\section{Movilidad en el suelo}

La movilidad de los fluoruros en el suelo depende fundamentalmente de la capacidad de adsorción de este. Dicha capacidad varía con el pH, con los tipos de adsorbentes presentes y con la salinidad del suelo (Ozsvath, 2009). En general, los suelos de granulometría fina, que disponen de elevados contenidos de arcillas e hidróxidos, retienen más flúor que los suelos arenosos. Un estudio muestra que hasta la mitad de los fluoruros disueltos pueden atravesar suelos de granulometría gruesa si contienen un poco de arcilla, hierro o aluminio (Pickering, 1985). La menor movilidad de fluoruros tiene lugar en suelos de granulometría fina a pH entre 6 y 6,5. Cuando el pH se sitúa por encima de este rango, las superficies coloidales eliminan el $\mathrm{F}^{-}$que es desplazado por un aumento de la concentración de $\mathrm{OH}^{-}$. A pH inferiores a 6 , la formación de cationes complejos $\mathrm{AlF}^{2+}$ y $\mathrm{AlF}_{2}{ }^{+}$inhibe la adsorción. La alta salinidad (fuerza iónica) afecta a la movilidad de los fluoruros aumentando la posibilidad de que se formen compuestos fluorados y que aumente el número de iones que compiten por la adsorción del mismo en el suelo.

El contenido natural de flúor en el suelo puede ser alterado por diversas fuentes de contaminación. La principal fuente es la deposición atmosférica. A esta fuente se le pueden unir otras tales como: la contaminación debida a pesticidas inorgánicos, fertilizantes fosfatados, escoria de yeso o el yeso recuperado (Weinstein y Davison, 2004). 
El efecto del flúor sobre el suelo es superficial cuando el suelo no ha sido labrado y llega a alcanzar elevadas concentraciones, mientras que puede llegar a los $50 \mathrm{~cm}$ en caso de haber sido cultivado, aunque su concentración se diluye hasta seis veces por dicho motivo.

El aumento significativo de la concentración de flúor cerca de las fuentes de emisión es un hecho constatado, aunque es muy variable, dependiendo del tipo de actividad y de las características del suelo (densidad de la materia orgánica o mineral). Así, los suelos que han sido fertilizados durante largos periodos de tiempo aumentan significativamente la cantidad de flúor en sus capas superficiales. En estas capas se da una fuerte retención de flúor que evita su acumulación en las aguas de drenaje aunque aumenta el riesgo de fluorosis del ganado al permanecer en los pastos.

La forma de adsorción del flúor contenido en el suelo es muy variable. No existe una correlación entre el flúor libre y el flúor encontrado en las plantas, debido a que no todo el flúor presente en el suelo es desorbido, ni llega a las trayectorias de adsorción de las diferentes tipologías de plantas existentes. Este fenómeno está influido por las propias características del suelo, por la proporción de flúor en el suelo y en disolución, por el tiempo de equilibrio, por el $\mathrm{pH}$ y por la forma en la que se encuentra el flúor.

\section{Flúor en las plantas}

La concentración de flúor en las plantas es muy variable y viene condicionada por diferentes factores que controlan la adsorción, tanto desde el suelo como desde el aire.

El factor más importante en la adsorción desde el suelo es la baja solubilidad del flúor en el mismo. Las investigaciones revelan que un aumento de la cantidad de flúor hace aumentar la concentración en las hojas y en la raíz con el tiempo, disminuyendo progresivamente en las hojas más jóvenes y más alejadas de la raíz. Además, las concentraciones varían entre diferentes especies.

El flúor se acumula en las raíces, preferentemente en las paredes celulares y los espacios intercelulares, antes que en la membrana celular o en la endodermis, dado que se promueve la fijación de los iones cargados negativamente $\left(\mathrm{F}^{-}\right)$disminuyendo la cantidad disponible para sobrepasar la barrera endodérmica. Otra posible vía de entrada del flúor en las plantas se produce cuando existen pasos preferentes de agua en algunas especies, que hacen aumentar la cantidad de flúor en sus hojas.

Algunas especies contienen mayor cantidad de flúor que otras, incluso si son cultivadas en suelos con niveles normales de flúor. Estas especies denominadas acumuladoras son, por ejemplo, teáceas, caryas y cornejo florido. También es conocida la relación existente entre los complejos formados por aluminio y flúor en relación al aumento de la adsorción de este elemento por las plantas. Stevens et al. (2000) lograron cuantificar el fluoruro total en disolución en función del $\mathrm{pH}$ y del contenido en flúor de los brotes, identificando un mayor contenido en los brotes que se desarrollan a pH inferiores a 6 . Así, en suelos con pH neutro, el 
riesgo asociado al flúor es relativamente pequeño en comparación con suelos ácidos o alcalinos.

Los brotes y las hojas de las especies forrajeras aumentan el contenido en flúor debido a la adhesión del polvo contenido en las salpicaduras de lluvia, el humus y en los cascos del ganado, especialmente en hierbas de tamaño corto. Este flúor no es peligroso para las plantas aunque si que lo es para el ganado.

La especiación del flúor en las hojas cobra importancia cuando se dan reacciones con calcio, magnesio, aluminio y algunas otras especies químicas, que determinan la toxicidad del mismo. La mayor parte de flúor se encuentra en forma inorgánica, en forma de anión libre o asociado a los elementos anteriores.

La adsorción de flúor atmosférico por parte de las hojas está condicionada por diferentes factores: la concentración de flúor en la atmósfera, la capa límite, la naturaleza de la superficie y la apertura de los estomas. Si el movimiento de aire que tiene lugar alrededor de una hoja se realiza a velocidad reducida tiene lugar, fundamentalmente, por difusión molecular. Los gases y partículas depositados en la superficie de las hojas pueden ser retenidos o eliminados con el paso del tiempo. Las cutículas de las hojas están diseñadas para tener una baja permeabilidad al agua y a otras moléculas, aunque puede ocurrir que algunas moléculas de bajo peso molecular permeen a través de los poros hidrofílicos, como por ejemplo el HF que se forma en la superficie cuando existe una fina capa de agua ácida en la misma. Esta permeabilidad es muy baja en comparación con la encontrada en los casos donde existen daños o desgaste en las hojas debido a insectos.

En la Figura 1.4 se puede observar la sección transversal de una hoja que muestra el camino de adsorción de fluoruros gaseosos (Weinstein y Davison, 2004).

El gas es transportado por turbulencia hasta la hoja y una vez allí, se difunde a través de la capa límite y de los estomas hasta los espacios intercelulares. Quedan afectadas las paredes celulares y es transportado por las corrientes de transpiración hasta los lugares de máxima evaporación/transpiración, los márgenes y las puntas.

En el caso concreto del HF, su adsorción a través de las hojas está relacionada con su concentración, con el tiempo de exposición y con el coeficiente de acumulación. Este coeficiente depende de la especie y, aunque se han desarrollado diferentes modelos que tratan de dar una explicación a este fenómeno, ninguno de ellos es capaz de dar una respuesta adecuada a la gran cantidad de variables relacionadas con este movimiento. En general, el proceso de adsorción del HF en las hojas comienza con su difusión a través de la capa límite y a través de los estomas. Dicha adsorción está condicionada por el movimiento diurno de los mismos, dado que habitualmente permanecen cerrados por la noche. En los márgenes y en el ápice de las hojas existe una gran pérdida de agua y es en estas zonas 
donde se suele acumular el flúor disuelto con mayor frecuencia. Una vez depositado, reacciona en parte con el calcio y, en parte, es difundido a través de la membrana celular.

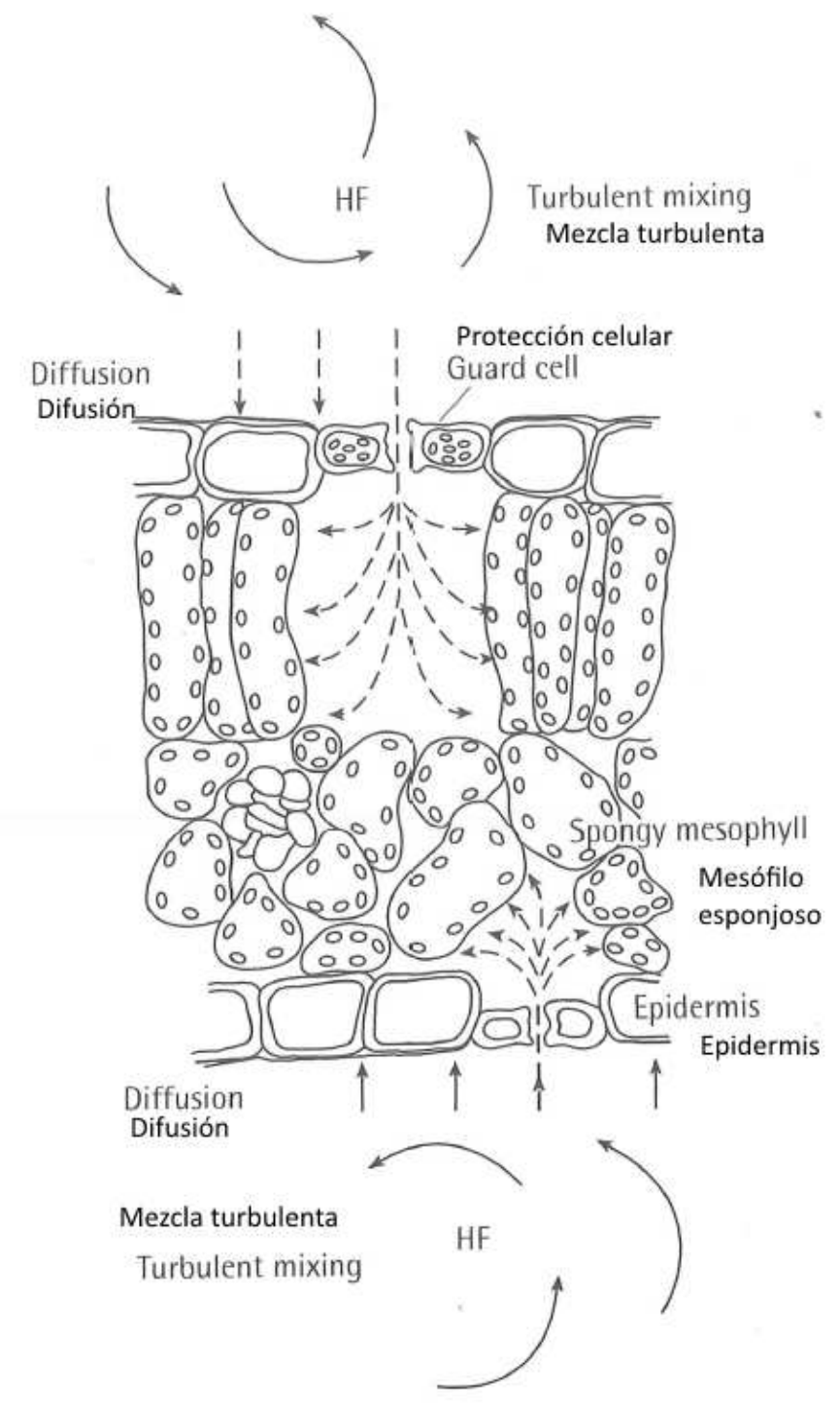

Figura 1.4. Sección transversal de una hoja que muestra el camino de adsorción de fluoruros gaseosos (Weinstein y Davison, 2004).

El proceso de adsorción del HF atmosférico en una planta es un proceso que alcanza las decenas de minutos, por lo que este fenómeno no está afectado por los cambios de concentración en periodos cortos. En la actualidad, los procesos de transporte en las plantas son considerados poco importantes desde el punto de vista ambiental. 
Otro aspecto a tener en cuenta es la acción de la lluvia dado que, por una parte, es capaz de añadir flúor mediante deposición húmeda, y por otra parte, puede tener un efecto de limpieza sobre la hierba. Cabe recordar que la deposición seca aumenta en los pastos humedecidos por acción de la lluvia.

Respecto a las partículas, los ratios de acumulación son bajos en partículas pequeñas, aunque es considerable en partículas de radio superior $(>5 \mu \mathrm{m})$. Este efecto cobra importancia solamente en los alrededores de las fuentes de emisión donde pueden depositarse dichas partículas. Otro factor a considerar es el peso específico de las hojas, dado que para el mismo ratio de deposición de flúor, la afección por acumulación disminuye al aumentar su peso específico.

\section{Flúor en los animales}

El contenido de flúor en animales está relacionado con cinco factores: los niveles de exposición de flúor, la ruta de adsorción, la presencia de agentes complejantes en la dieta, el $\mathrm{pH}$ del sistema digestivo, y la presencia de tejidos calcificados en el cuerpo. Las rutas de adsorción son: la inhalación, la deposición en superficies externas y la ingesta. La presencia de agentes complejantes y el $\mathrm{pH}$ en el sistema digestivo determinan la especiación del flúor y por tanto su biodisponibilidad. El flúor tiene una fuerte afinidad por el calcio y se acumula en los tejidos calcificados, como pueden ser los huesos humanos, las conchas de los cangrejos o las glándulas cálcicas de las lombrices de tierra.

La inhalación no está considerada como una ruta de adsorción importante en vertebrados, dado que la cantidad retenida en términos absolutos durante la respiración es pequeña en comparación con otras rutas, del orden de 7000 veces menor. Incluso en ambientes contaminados, la inhalación es poco importante comparada con la alimentación.

El ratio de deposición a través de superficies externas no ha sido tan estudiado como el contenido en tejidos de animales. En ciertos niveles tróficos la importancia de esta adsorción puede ser alta cuando los depredadores pueden ingerir el flúor depositado en sus presas. Otros ejemplos se dan cuando las aves se arreglan las plumas con el pico o cuando los humanos trasfieren el flúor de la piel a la boca en ambientes industriales.

La ingestión de comida y bebida es la principal fuente de adsorción de flúor en los animales. Los estudios en humanos son extensos y cabe destacar que es muy variable en función de la edad, la dieta y su contendido de flúor. En muchas circunstancias, el flúor contenido en el agua es más de la mitad del flúor ingerido diariamente. Así, incluso en zonas con presencia de emisiones industriales, la cantidad de flúor no es mayor que en zonas no industrializadas. 


\subsubsection{Efecto de los fluoruros inorgánicos sobre el medio ambiente y la salud de las personas}

Como se ha comentado anteriormente, los efectos de los fluoruros sobre el ambiente y la salud de las personas han sido extensamente tratados por la literatura científica, a través de artículos y monografías especializadas. A continuación se presenta un resumen que incluye los hechos más importantes relacionados con la salud ambiental en humanos, animales y plantas (Weinstein y Davison, 2004; Tressaud, 2006; Ozsvath, 2009).

\subsubsection{Afecciones sobre los humanos}

La influencia de los compuestos de flúor y, en especial del fluoruro, sobre la salud humana ha sido ampliamente estudiada. Sin embargo, las conclusiones extraídas de dichas investigaciones mantienen cierta controversia. Aunque la presencia de niveles traza de fluoruros en la dieta está claramente relacionada con una menor afección de la caries dental y con la formación de huesos fuertes, existe un gran número de problemas de salud crónica y aguda asociado con la ingesta de fluoruros en grandes dosis. La controversia se centra en la cuantificación de un valor límite que separa una dosis segura de una dosis no segura, y si los beneficios de la ingesta superan los potenciales efectos adversos sobre la salud.

Aunque las fuentes de emisión de flúor a la atmósfera de origen antropogénico han sido ocasionalmente la causa de problemas en la salud humana, la inmensa mayoría de los problemas de salud asociados con el flúor son consecuencia de la ingesta de flúor procedente de fuentes naturales.

La exposición aguda al HF en forma gaseosa en humanos ha sido estudiada por Lund et al., (1997). En dicho estudio se comprobó que existe una fuerte relación entre el HF inhalado y la concentración de flúor en el plasma sanguíneo, y que aparecían síntomas en el tracto superior respiratorio y en los ojos una hora después de la exposición, incluso con niveles inferiores a los valores recomendados en salud laboral. Los síntomas del tracto respiratorio inferior consisten en tos y expectoración. La totalidad de los síntomas desaparecen cuatro horas después de la exposición.

Las fuentes de flúor asociadas a la salud humana son variadas: agua, alimentos, productos de higiene dental, etc. Sin embargo, el desarrollo de estudios relacionados con la exposición crónica al flúor, debido a factores ambientales, son complicados de llevar a cabo en la sociedad moderna, debido a la dificultad de encontrar poblaciones con una exposición definida al ion fluoruro. Por este motivo se ha planteado el desarrollo de estudios en naciones en vías de desarrollo donde la población se mantiene en un único lugar a lo largo de su vida con la ingesta de comida y agua de fuentes locales. 


\section{Biodisponibilidad y absorción}

El consumo de agua es la principal fuente de fluoruro en humanos, siendo las principales contribuciones el ion fluoruro presente en algunas aguas potables, del orden del $95 \%$ del flúor total, y el complejo flúor - magnesio $\left(\mathrm{MgF}^{+}\right)$. Otros aportes pueden ser los fluoruros en forma de complejos con otros metales, que a $\mathrm{pH}$ inferiores a 5 se disocian para formar $\mathrm{HF}$ e iones $\mathrm{F}^{-}$.

En el estómago, los ácidos gástricos de bajo $\mathrm{pH}$ favorecen la formación del complejo HF, que es la especie predominante a $\mathrm{pH} 2$, con cerca del $90 \%$. El HF es absorbido con facilidad tanto por el estómago como por el intestino delgado mediante un proceso de difusión simple, una vez se encuentra en la mucosa, de carácter menos ácido, se descompone dando lugar a fluoruro. Prácticamente la mitad de los fluoruros absorbidos son rápidamente incorporados a los huesos y a los dientes en formación, mientras que el resto es eliminado a través de la orina.

La absorción sistemática de fluoruros procedentes de aguas de consumo no varía por la calidad del agua debido a que la absorción de fluoruros solubles inorgánicos está controlada principalmente por la acidez del estómago. Sin embargo, la absorción de fluoruros inorgánicos y orgánicos menos solubles es más complicada, pudiendo aumentar o disminuir la cantidad adsorbida por diferentes factores asociados a la dieta.

No se puede obviar la cantidad de fluoruros que pueden formar parte de la dieta, además del agua de consumo, ya que el contenido de fluoruro en la comida y la bebida puede ser elevado. A modo de ejemplo, se puede nombrar el marisco, ciertos tipos de tés y vinos, fórmulas infantiles, zumos y bebidas gaseosas fabricadas con agua con un elevado contenido en fluoruros, pescados provenientes de lagos con elevadas concentraciones de fluoruros y vegetales cultivados en suelos ricos en fluoruros.

\section{Efectos beneficiosos}

Existe un elevado número de evidencias que indican que los niveles moderados de ingesta de fluoruros pueden reducir la incidencia de caries dental y, bajo ciertas circunstancias, promover el desarrollo de huesos mecánicamente más fuertes. El hidroxiapatito $\left(\mathrm{Ca}_{10}\left(\mathrm{PO}_{4}\right)_{6}(\mathrm{OH})_{2}\right)$ es el mineral que se deposita alrededor de las fibras de colágeno de los tejidos esqueléticos para formar los huesos. En presencia de fluoruros, se sustituyen los grupos hidroxilo en la estructura del hidroxiapatito para formar fluoroapatito $\left(\mathrm{Ca}_{10}\left(\mathrm{PO}_{4}\right)_{6} \mathrm{~F}_{2} \mathrm{O}\left(\mathrm{Ca}_{10}\left(\mathrm{PO}_{4}\right)_{6}(\mathrm{OH}) \mathrm{F}\right)\right)$. Esta sustitución conlleva una reducción del volumen del cristal, un incremento de la estabilidad estructural y un descenso de la solubilidad del mineral. La presencia de iones fluoruro libres en fase líquida puede servir para aumentar la fuerza impulsora del crecimiento del mineral de apatito. La cantidad de fluoruro en el agua de consumo, para reducir la caries dental, parece encontrase en el intervalo 0,7 y $1,2 \mathrm{mg} / \mathrm{l}$. 
Las investigaciones clínicas y los estudios epidemiológicos, han mostrado que la ingesta de fluoruros acompañada de una dosis apropiada de calcio y vitamina $D$, puede mejorar la mineralización de los huesos pero no necesariamente reducir la incidencia del número de fracturas. Así pues, aunque el fluoruro puede ayudar en el tratamiento de la osteoporosis, queda mucho por aprender acerca de los niveles óptimos para maximizar los beneficios y minimizar los riesgos.

\section{Efectos adversos}

Los efectos de una toxicidad aguda de fluoruro debida a una sobredosis accidental, la ingestión de pesticidas sódico - fluorados o productos dentales están bien documentados e incluyen: vómito, hemoptisis, calambres en los brazos y las piernas, broncoespasmo, paro cardiaco, fibrilación ventricular, pupilas fijas y dilatadas, hiperpotasemia, hipocalcemia y, a veces, incluso la muerte. La lista de enfermedades que se atribuye a la ingestión crónica de fluoruro es aún más larga, pero en algunos casos (como por ejemplo mutaciones genéticas, defectos al nacer, reacciones de hipersensibilidad, enfermedades alérgicas, lesión ósea repetitiva, y la enfermedad de Alzheimer), los datos científicos no son concluyentes actualmente. A continuación se describen aquellos problemas de salud mejor estudiados, con especial énfasis en los efectos de la ingestión crónica de los seres humanos sobre los resultados de los estudios en animales de laboratorio.

\section{Efectos en los dientes}

Durante el periodo de formación del esmalte dental se puede producir fluorosis dental, si hay un aumento de la mineralización dentro del desarrollo del diente acompañado por una pérdida de proteínas de la matriz. La exposición a fluoruros durante este proceso causa una disrupción en la mineralización que provoca huecos anormalmente grandes en su estructura cristalina, retención excesiva de proteínas y aumento de la porosidad del tejido mineralizado y, subyacentemente, del esmalte del diente. Algunos investigadores han sugerido que la exposición crónica al fluoruro puede facilitar la rotura de los dientes envejecidos, pero esta posibilidad aún no ha sido confirmada.

\section{Efectos en el esqueleto}

La fluorosis ósea se caracteriza por un aumento de la masa y densidad de los huesos, acompañada por una amplia variedad de síntomas esqueléticos y de las articulaciones. Los mecanismos que dan lugar a la fluorosis son poco conocidos. Sin embargo sus etapas han sido ampliamente documentadas. Así, en las primeras etapas los síntomas incluyen dolor y rigidez en la columna vertebral, de la cadera y de las articulaciones, acompañada de un aumento de la densidad ósea (osteosclerosis). La rigidez aumenta de manera constante hasta que toda la columna vertebral se convierte en un hueso continuo. 
La enfermedad progresa y varios ligamentos de la columna también pueden calcificarse y osidificarse. En sus etapas más avanzadas, la fluorosis produce defectos neurológicos, pérdida de masa muscular, parálisis, deformidades incapacitantes de la columna vertebral y de las principales articulaciones y, por último, la compresión de la médula espinal.

\section{Efectos en la reproducción}

La mayor parte de estudios realizados en esta materia se ha llevado a cabo sobre animales por lo que sus conclusiones no son directamente aplicables a los humanos. Los estudios realizados en humanos han obtenido resultados destacables aunque parece necesario profundizar en este campo.

Posiblemente, el estudio más concluyente sea el de Freni (1994). Los resultados de este trabajo muestran una asociación entre el aumento de la concentración de fluoruros y la disminución de los índices de natalidad. Las razones de esta relación no están claras, pero se cree que están relacionadas con los efectos de la ingestión de fluoruro por parte de los hombres y la movilidad y morfología del esperma o los niveles de testosterona.

\section{Efectos en el desarrollo}

Numerosos investigadores han encontrado una relación entre la concentración de fluoruros medida en el plasma sanguíneo del cordón umbilical y el materno, que sugiere que en la placenta se permite una difusión pasiva de los fluoruros desde la madre al feto. Los estudios realizados en laboratorio con animales indican que es posible obtener resultados adversos en el desarrollo con ratios de ingestión muy elevados. Sin embargo, en la población humana, la evaluación de los efectos sobre el desarrollo no es concluyente, principalmente debido a la reducida calidad de los estudios realizados. En este sentido, una de las líneas de investigación estudia la conexión entre la ingesta de fluoruros y la prevalencia del síndrome de Down, especialmente para los recién nacidos de madres de edad inferior a 30 años. También existen estudios, llevados a cabo en la India, que indican que existe una probabilidad anormalmente alta de sufrir espina bífida oculta en regiones susceptibles de sufrir fluorosis. 


\section{Efectos renales}

El sistema renal es el responsable de excretar la mayor parte de los fluoruros que se encuentran en exceso en el cuerpo humano, por lo que está expuesto a concentraciones de flúor superiores respecto a las encontradas en otros órganos. Este hecho permite pensar que podría tener un elevado riesgo de toxicidad. Sin embargo, en la actualidad, solamente existen dos estudios que sugieren que la ingesta crónica de fluoruros puede tener efectos no cancerígenos sobre el riñón. Ambos estudios están relacionados con las piedras de riñón, si bien las conclusiones no son demasiado convincentes.

\section{Efectos neurológicos}

Numerosos estudios desarrollados en China indican que la ingestión de fluoruros en la dieta tiene efectos sobre la inteligencia de los niños, de modo que los niños que ingieren elevadas cantidades de fluoruros, obtienen peores puntuaciones en los test de inteligencia que aquellos que ingieren menores cantidades de dicho elemento.

Por otro lado, se ha encontrado una relación inversa, estadísticamente significativa, entre el cociente intelectual y los niveles de fluoruros en la orina de los niños en edad escolar.

También ha sido estudiada la relación existente entre el uso de fluorosilicatos, para aumentar el contenido de fluoruros del agua de consumo, y las elevadas concentraciones de plomo en sangre de niños. Sin embargo, los estudios más recientes no son concluyentes con respecto a esta apreciación.

\section{Efectos endocrinos}

Los fluoruros pueden afectar la respuesta y función normal del sistema endocrino. Los efectos primarios se resumen en la disminución de la función tiroidea, aumento de la actividad de la calcitonina, aumento de la actividad paratiroidea, hiperparatiroidismo secundario y una intolerancia a la glucosa (diabetes tipo II). Sin embargo, estos efectos varían en grado y forma para diferentes individuos, y muchos pueden ser clasificados como subclínicos, lo que significa que no pueden ser considerados como efectos adversos sobre la salud.

\section{Efectos gastrointestinales}

Se han estudiado una gran variedad de efectos gastrointestinales debido a la toxicidad aguda de los fluoruros: náuseas, vómitos, diarrea y dolor abdominal. Los estudios realizados en animales revelan que los fluoruros pueden estimular la secreción de ácidos estomacales, reduciendo el flujo sanguíneo lejos del revestimiento del estómago, e incluso causar la muerte de las células epiteliales del tracto gastrointestinal. Cuando la exposición a los fluoruros es 
leve o moderada, menos del $1 \%$ de la población experimenta síntomas gastrointestinales en forma de hipersensibilidad gastrointestinal.

\section{Efectos cancerígenos}

Los estudios epidemiológicos diseñados para identificar el potencial carcinogénico de la exposición crónica a los fluoruros afrontan complicados desafíos. Uno de los mayores problemas es que el diagnóstico de cáncer normalmente se da después de años, o quizás décadas, de exposición a los factores causales, tiempo durante el cual los individuos migran tanto dentro como fuera del área de estudio. En muchos casos este hecho conduce a una estimación incorrecta de la exposición del grupo de estudio. Otra dificultad es la gran diversidad de tipos de cáncer y factores causales potenciales, que requiere que cada tipo de cáncer sea evaluado por separado. Por lo tanto, parece que los esfuerzos para encontrar una correlación entre el agua fluorada y las tasas generales de cáncer no han sido fructíferos. No obstante, a continuación se muestran algunos ejemplos:

- Cáncer de huesos. Algunos estudios de laboratorio sobre animales han mostrado evidencia de aumento de osteosarcoma (cáncer de hueso) y osteoma (tumores óseos no cancerosos), aunque existe cierta indecisión en la aplicación de estos hallazgos sobre los seres humanos. Los estudios realizados sobre humanos han obtenido resultados dispares y no concluyentes.

- Cáncer de vejiga y riñón basados en la formación de HF en la orina. Los estudios realizados por Grandjean et al. (1990, 1992 y 2004) examinaron los efectos de la exposición crónica ocupacional a material particulado compuesto por fluoruros en los trabajadores de una planta de procesamiento de criolita. Se encontró que la inhalación de polvo de criolita puede provocar fluorosis en el esqueleto y se asocia también con mayores tasas de cáncer de vejiga. Sin embargo, debido a que los trabajadores que manipulaban criolita fueron expuestos a elevados contenidos de fluoruro, no está claro cómo dichos resultados pueden aplicarse a niveles moderados de dicho contaminante.

Varios estudios han encontrado evidencias de la existencia de una relación entre la exposición a los fluoruros y algunos tipos específicos de cánceres para los cuales no existe un mecanismo conocido de causa biológica. También existen asociaciones entre el fluoruro presente en el agua potable y la prevalencia de cáncer de útero y cáncer de colon.

Los estudios llevados a cabo en las plantas de fabricación de aluminio, donde se utiliza criolita como un electrolito para facilitar la reducción del óxido de aluminio, han hallado que los trabajadores expuestos tanto a fluoruros gaseosos (HF) como a material particulado compuesto de flúor, experimentan tasas superiores de bronquitis crónica, enfisema y asma, aunque los mecanismos causales subyacentes no han sido establecidos.

En la Tabla 1.4 se han recogido los efectos de los compuestos de flúor sobre la salud humana a modo de resumen. 
Tabla 1.4. Resumen de los efectos de los compuestos de flúor sobre la salud humana (Ozsvath, 2009).

\begin{tabular}{|c|c|c|}
\hline Tipo de efectos & Categoría & Ejemplos \\
\hline \multirow[t]{2}{*}{ Beneficiosos } & -- & Disminución de la caries dental \\
\hline & -- & Desarrollo de los huesos \\
\hline \multirow[t]{9}{*}{ Adversos } & Sobre los dientes & Fluorosis en los dientes \\
\hline & Sobre los huesos & $\begin{array}{l}\text { Fluorosis ósea, osteosclerosis y } \\
\text { efectos neurológicos }\end{array}$ \\
\hline & Sobre la reproducción & Disminución de los índices de natalidad \\
\hline & Sobre el desarrollo & $\begin{array}{l}\text { Desarrollo adverso en fetos } \\
\text { Prevalencia del síndrome de Down } \\
\text { Espina bífida }\end{array}$ \\
\hline & Sobre el sistema renal & Desarrollo de piedras en el riñón \\
\hline & Neurológicos & $\begin{array}{l}\text { Posibles efectos en la inteligencia de los } \\
\text { niños }\end{array}$ \\
\hline & Endocrinos & Disminución de la función tiroidea \\
\hline & Gastrointestinales & $\begin{array}{l}\text { Vómitos, diarrea, dolor abdominal } \\
\text { Hipersensibilidad intestinal }\end{array}$ \\
\hline & Carcinogénicos & $\begin{array}{l}\text { Cáncer sobre los huesos, la vejiga, } \\
\text { el colon y el útero }\end{array}$ \\
\hline
\end{tabular}

\subsubsection{Afecciones sobre los animales}

Además de las afecciones sobre los humanos, los compuestos de flúor tienen efectos sobre los animales. Sin embargo, los principales problemas son similares a los descritos para el caso de los humanos. Por ejemplo, el ganado y los mamíferos salvajes tienen una posibilidad muy reducida de sufrir episodios de toxicidad aguda y, en caso de producirse, está asociada normalmente a periodos de erupciones volcánicas o emisiones accidentales. En el caso de toxicidad crónica se han descrito episodios de fluorosis como: lesiones dentales, osteosclerosis, exostosis, rigidez de articulaciones y cojera. En otros vertebrados no se han documentado lesiones en huesos, ni afecciones sobre la población en general. Aunque históricamente se han utilizado compuestos de flúor como pesticidas, debido a su poder tóxico para algunos invertebrados, el riesgo de envenenamiento se ha reducido al disminuir el uso generalizado de dichos compuestos para este fin.

En el caso de invertebrados, la presencia de flúor no se ha podido relacionar, de forma directa, con la afección de sus poblaciones debido a la presencia simultánea de otros contaminantes tales como: $\mathrm{SO}_{2}, \mathrm{NO}_{\mathrm{X}}, \mathrm{O}_{3} \mathrm{O}$ metales pesados. Otros estudios documentan efectos nulos relacionados con la presencia de flúor en invertebrados o incluso efectos positivos. 
Los experimentos llevados a cabo en condiciones controladas con exposiciones extremadamente altas de flúor han determinado la toxicidad directa y los efectos mutagénicos de dicho contaminante, no obstante, las conclusiones alcanzadas no son relevantes en la vida real dado que es altamente improbable encontrar atmósferas tan contaminadas de flúor.

Los estudios realizados en invertebrados acuáticos revelan que la diversidad de los organismos marinos aumenta con la distancia a las fuentes de emisión, aunque la concentración de flúor no es la única causa posible, dado que en niveles de concentración de fondo normales, la diversidad no es tan alta como cabría esperar.

Algunos estudios realizados con muy bajas concentraciones de flúor demuestran que el flúor debe ser esencial para determinados organismos, estimulando su crecimiento en dichas circunstancias.

\subsubsection{Afecciones sobre las plantas}

Los fluoruros inorgánicos son tóxicos para las plantas y otros organismos (líquenes, hongos, etc.). Afectan a la actividad enzimática, la fotosíntesis y la respiración. Tiene síntomas visibles, en especial la necrosis, afecta al crecimiento y a la producción de semillas e interacciona con el ambiente biótico y abiótico.

La literatura científica sobre este aspecto es antigua y ha utilizado técnicas que hacen que estos no sean comparables entre sí. Los mecanismos responsables de la concentración y acumulación de flúor en las células y en las hojas de las plantas son la transpiración y los niveles bajos de $\mathrm{pH}$. La corriente de transpiración de las plantas vasculares causa un enorme gradiente de concertación en las hojas y, a pocos milímetros de la punta o de los márgenes, puede acumularse mayor cantidad de flúor en comparación con el resto de la hoja. Cuando existen pH bajos, los fluoruros se convierten en HF que es acumulado por las células de hongos y líquenes. Esto ocurre después de periodos de lluvias sobre las hojas de las plantas donde viven estos organismos.

Los efectos en los procesos metabólicos pueden ser explicados por las interacciones entre los fluoruros con el calcio y el magnesio. Así, la mayor parte de las plantas con reservas de calcio están expuestas al flúor que es transportado en las corrientes de transpiración. Esta interacción provoca numerosos problemas en la fisiología de las plantas. La interacción con el magnesio se da en el citosol o en los cloroplastos.

Los estudios relativos a las afecciones del flúor sobre las plantas no consideran a este contaminante como un contaminante atmosférico ya que la mayoría de los estudios se han realizado con concentraciones muy elevadas de gas o en forma de sales de flúor. Los resultados de los pocos estudios realizados al respecto pueden considerarse como una colección de datos muy confusos que no permiten conocer paso a paso qué ocurre cuando una planta se expone a valores ambientalmente realistas de flúor. Con las consideraciones realizadas, es posible mostrar algunos resultados generales. 
La presencia de flúor afecta a la actividad enzimática de las plantas inhibiendo su funcionamiento. Lo mismo ocurre con la fotosíntesis, aunque este último punto no es compartido por todos los estudios y algunos de ellos sugieren que, en concentraciones de $2-3 \mu \mathrm{g} / \mathrm{m}^{3}$, los efectos no son apreciables con el paso del tiempo. Por el contrario, está aceptado el hecho de que los efectos sobre la fotosíntesis están relacionados con la aparición de síntomas visibles, aunque existen estudios que no subrayan estos resultados e incluso plantean la posibilidad de que se recuperen tras la exposición.

La mayoría de estudios publicados destacan el aumento de la respiración de las plantas al ser tratadas con flúor. También las bajas concentraciones de flúor o las exposiciones cortas favorecen la adsorción de $\mathrm{O}_{2}$, mientras que la exposición se vuelve inhibitoria según se incrementan las concentraciones o los periodos de exposición.

También cabe destacar los efectos del flúor sobre el funcionamiento de las membranas de plasma, dado que es uno de los primeros lugares en ser afectados.

Los efectos del flúor son reconocibles en diferentes taxones y han sido recogidos en numerosos trabajos científicos. Algunos de los taxones estudiados contemplan: líquenes, briofitas, peteridofitas, gimnospermas, angiospermas (monocotiledóneas y dicotiledóneas), así como olivos (Tsiros et al., 1998).

Diagnosticar la causa de un daño presente en una hoja o en una planta no siempre es fácil o posible, incluso en el caso de que exista una sola fuente de flúor. Concurren un elevado número de factores que pueden afectar: la especie, la presencia de otros contaminantes $\left(\mathrm{SO}_{2}\right.$, $\mathrm{O}_{3}$ y $\mathrm{Cl}$ ), los síntomas similares debidos a otros factores, etc. Desde un punto de vista general, se puede decir que los síntomas son similares para diferentes contaminantes cuando se dan concentraciones elevadas pero se tornan más específicos cuando las concentraciones son menores. Por lo tanto, para investigar la sensibilidad y resistencia a los contaminantes atmosféricos de las diferentes tipologías de plantas es necesario realizar análisis microscópicos junto con estudios histológicos y bioquímicos.

En el caso del flúor los cambios histológicos y los efectos en la ultraestructura se restringen a los tejidos en los cuales los síntomas son visibles y están desarrollados. Los efectos reseñados del HF son numerosos, muy variados y afectan a ribosomas, membranas vacuolares, cloroplastos, mitocondrias, etc.

A modo de resumen se ha elaborado la Tabla 1.5, donde se recopilan los informes histológicos y ultraestructurales sobre efectos de los fluoruros o compuestos de flúor sobre las plantas. 
Tabla 1.5. Resumen de los informes histológicos y ultraestructurales sobre efectos de los fluoruros 0 compuestos de flúor en las plantas. Se ha mantenido la nomenclatura en inglés ex profeso. (Weinstein y Davison, 2004).

\begin{tabular}{|c|c|c|}
\hline Especie & Comentario & Autores \\
\hline \multicolumn{3}{|l|}{ Angiosperms } \\
\hline Glycine (soybean) & $\begin{array}{c}\text { Changes in endoplasmic reticulum; disrupíion of vacuolar } \\
\text { membrane; detachment of ribosomes; changes in chloroplast } \\
\text { shape; cellular collapse }\end{array}$ & $\begin{array}{l}\text { Wei and Miller, } \\
1972\end{array}$ \\
\hline Gossypium (cotton) & $\begin{array}{l}\text { Within } 0,5 \mathrm{~mm} \text { of necrotic lesions: various stages of } \\
\text { plasmolysis; less chlorophyll; chloroplasts and mitochondria } \\
\text { swollen; eventually degradation of membranes and cellular } \\
\text { collapse }\end{array}$ & Timmerman, 1967 \\
\hline Zea (maize) & $\begin{array}{l}\text { In subnecrotic zones shrinkage of chloroplasts; fewer } \\
\text { chloroplast lamellae }\end{array}$ & $\begin{array}{l}\text { Lhoste and } \\
\text { Garrec, } 1975\end{array}$ \\
\hline Saccharum (sugarcane) & $\begin{array}{l}\text { In chlorotic areas: decrease in size of chloroplasts, number of } \\
\text { grana; increase in osmiophilic globules; swelling of middle } \\
\text { lamellae. In red-brown areas destruction of chlorophyll and } \\
\text { increase in other pigments }\end{array}$ & $\begin{array}{l}\text { Englebrecht and } \\
\text { Louw, } 1973\end{array}$ \\
\hline Oiea (olive) & $\begin{array}{l}\text { Progressive changes over months including: large starch } \\
\text { grains; increased plastoglobuli in chloroplasts, changes in } \\
\text { shape of chloroplasts and mitochondria; dilatation of } \\
\text { thylakoids; electron-dense granules in vacuoles }\end{array}$ & $\begin{array}{l}\text { Eleffheriou and } \\
\text { Tsekos, } 1991\end{array}$ \\
\hline \multicolumn{3}{|l|}{ Gymnosperms } \\
\hline $\begin{array}{l}\text { Several species including } \\
\text { Phaseolus (bean), Malos } \\
\text { (apele), Prunus (apricoi) }\end{array}$ & $\begin{array}{l}\text { Before complete collapse of cells, disintegration of } \\
\text { chloroplasts occurred. Thls could be seen macroscopically as } \\
\text { pale areas in the normally dark Breen leaves }\end{array}$ & $\begin{array}{l}\text { Solberg and } \\
\text { Adams, } 1956\end{array}$ \\
\hline Prunus (prune, apricot) & Effects similar to above in area Within $2 \mathrm{~mm}$ of necrotic tissue & Treshow, 1957 \\
\hline Pinus ponderosa & $\begin{array}{l}\text { Transitional zone adjacent to necrosis: enlargement of xylem } \\
\text { and phloem parenchyma; transfusion parenchyma cells } \\
\text { swollenlcollapsed. Resin canal epithelial cells hypertrophied, } \\
\text { plasmolysed; epithelial the resin canal until they completely } \\
\text { occluded the openings cells enlarged withín }\end{array}$ & Solberg et al, 1955 \\
\hline Pinus & $\begin{array}{l}\text { Hypertrophy of phloem and transfusion parenchyma cells; } \\
\text { granulosis of chloroplasts; occlusion of resin canals }\end{array}$ & $\begin{array}{l}\text { Carlson and } \\
\text { Dewey, } 1971\end{array}$ \\
\hline Pinus (various species) & $\begin{array}{l}\text { Detailed comparison of effects of several pollutants and } \\
\text { abiotic stresses. All produced similar effects, including } \\
\text { changes in the phloem and occlusion of resin canals }\end{array}$ & $\begin{array}{l}\text { Stewart et al., } \\
1973\end{array}$ \\
\hline Pinus & $\begin{array}{l}\text { Abundant starch granules, dilaíation of thylakoids, increase in } \\
\text { endoplasmic reticulum and cell vacuolization }\end{array}$ & $\begin{array}{l}\text { Soikkeli and } \\
\text { Tcuvinen, 1979; } \\
\text { Soikkeli, } 1981\end{array}$ \\
\hline Abies (fir) & $\begin{array}{l}\text { Young peedles emerging from bud: chloroplasts smaller, } \\
\text { thylakoids dilated; delayed formation of epicuticular waxes }\end{array}$ & $\begin{array}{l}\text { Bligny et al., } \\
1973 a\end{array}$ \\
\hline Pinos strobus & $\begin{array}{l}\text { Membrane integrity affected; plasma membranes among first } \\
\text { sites affected }\end{array}$ & $\begin{array}{l}\text { Rakowski and } \\
\text { Zwiazek, } 1992\end{array}$ \\
\hline
\end{tabular}


El flúor afecta al crecimiento de las plantas vasculares, también llamadas tracheobionta (que es el nombre del taxón de plantas que abarca a las traqueófitas). En este caso, los estudios realizados han demostrado que durante el crecimiento de algunas plantas, como la uva y el trigo, las semillas no contienen flúor aunque las plantas estén sometidas a su presencia. Tampoco existe un daño visible en las mismas. En el caso de las habas, la presencia de HF no altera el crecimiento vegetativo ni afecta, de forma visible, a la planta aunque disminuye de forma significativa el número y la masa de vainas. En el caso del sorgo, los estudios han comprobado la reducción de la producción en presencia de HF pero han puesto de manifiesto que la relación entre la dosis y la respuesta de la planta, en cuanto a producción, es muy compleja, especialmente en condiciones de campo que incluyen un elevado número de variables.

Otra de las afecciones del flúor es la relacionada con la fertilización y la producción de semillas y frutos. En este caso, el papel del calcio en la fertilización es clave y se ve alterado por la presencia de flúor. Las plantas con menor contenido de flúor también muestran mayores lesiones. A modo de ejemplo, los melocotones en presencia de flúor sufren una maduración prematura y, en ocasiones, un aumento de las malformaciones de los frutos. La fresa también sufre deformaciones en presencia de HF. Se cree que este efecto está provocado por la inhibición de la fertilización y/o el desarrollo embrionario provocado por el HF.

Por su parte, los estudios realizados sobre los anillos de crecimiento de los árboles suministran información de los efectos de la exposición prolongada durante varios años. Así se han constatado menores crecimientos en pinos y abetos situados en las inmediaciones de las fundiciones de aluminio. Por otro lado, se sabe que existe una relación entre el contenido de flúor de la pinocha y la reducción de la tasa de crecimiento, aunque no ha sido cuantificada, además de que estos hallazgos pueden estar afectados por la presencia de otros contaminantes. Algunos estudios muestran que una concentración pequeña de flúor puede, en algunos casos, favorecer el crecimiento, sin embargo, no se conoce la causa de este efecto.

Cualquier factor ambiental, biótico o abiótico que pueda alterar la adsorción o el movimiento del flúor en las hojas, la concentración de ciertos elementos clave, como el calcio, o el ratio de desarrollo durante el crecimiento o la distribución de recursos disponible, puede afectar potencialmente sobre la respuesta de la planta al flúor. Algunos de estos factores son: la luz, la temperatura, la humedad, la presencia de otros contaminantes, los nutrientes minerales, el agua, los pesticidas y ciertas dolencias.

La afección de las emisiones de HF desde las instalaciones de fabricación de la industria cerámica se ha descrito en diferentes publicaciones. En el distrito de Castellón, Aucejo et al. (1997), encontraron afecciones en los huertos de naranjos situados alrededor de las zonas industriales, debido al exceso de flúor procedente del aire contaminado y del alto contenido de boro que se encuentra en el suelo y en las hojas de dichos árboles frutales. 
En la Comunitat Valenciana se han descrito afecciones de diferentes tipologías de plantas debidas al HF procedente de la industria cerámica por parte de los investigadores del Centro de Estudios Ambientales del Mediterráneo, dentro del programa de Efectos de los Contaminantes (Fundación CEAM, Valencia). Sin embargo, estos trabajos no se han llegado a publicar en revistas científicas.

A modo de ejemplo, la Figura 1.5 muestra la afección del HF sobre la vid - Vitis vinifera. Se observa la necrosis producida por este contaminante y su evolución posterior.
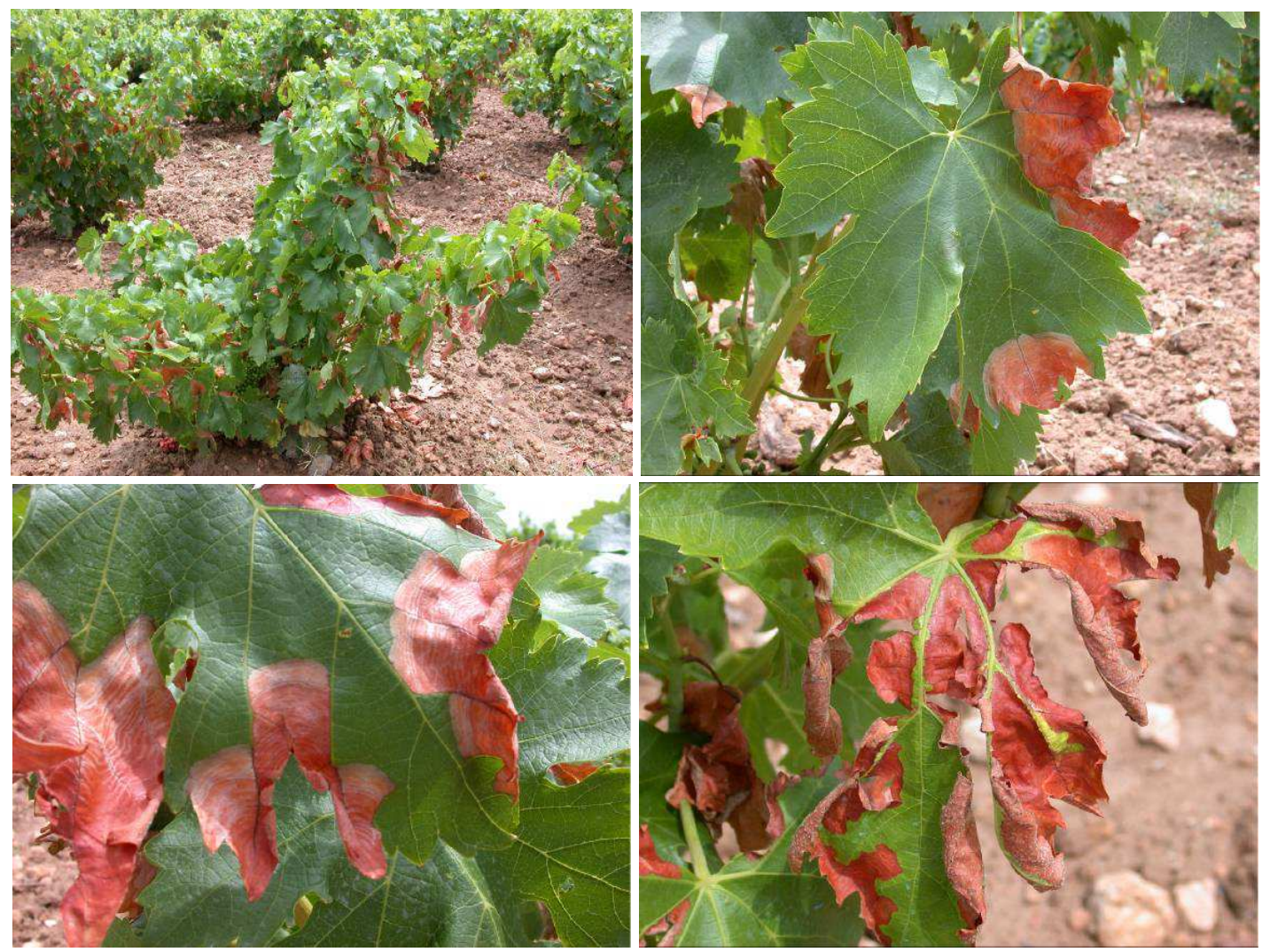

Figura 1.5. Síntomas de HF en vid: Necrosis marrón rojizas marginales y su evolución hasta desprendimiento (Villar del Arzobispo 2003 en las inmediaciones de una fábrica de sanitarios. Fotografías gentileza de MJ Sanz, CEAM).

Aunque en la bibliografía los daños por HF se describen como una necrosis delimitada en bandas, con lesiones de marrón claro a marrón rojizo (incluso parcialmente negras), éstas comienzan con una clorosis en casi todos los casos. La clorosis comienza en los márgenes de las hojas y progresa hacia el nervio. Cuando se producen concentraciones elevadas en exposiciones cortas aparece una necrosis sin clorosis, mientras que, a concentraciones bajas y periodos más largos de exposición, puede ocurrir lo contrario. 
Otro fenómeno que puede observarse es la malformación de las hojas, debido al menor crecimiento de las células marginales de las hojas, donde la concentración de flúor es mayor, respecto a las del centro de la hoja, que crecen con normalidad. Las hojas pueden retorcerse o presentar un aspecto cóncavo.

Los centros de producción asiáticos también han sido objeto de estudio. Por una parte Tong, (1988) y Fu et al., (1993) presentan estudios sobre la afección en la salud de los humanos relacionadas con este tipo de industria. Mientras los estudios de Wen et al. (2006) y de Ahmad et al. (2012) describen afecciones severas sobre diferentes tipos de plantas y árboles frutales tales como el ciruelo, el mango y el albaricoquero debidas a exposiciones largas a contaminantes atmosféricos procedentes de centros de producción cerámica con una elevada concentración de industrias. 


\subsection{Baldosas cerámicas y proceso de fabricación}

\subsubsection{La industria de baldosas cerámicas}

La fabricación de baldosas cerámicas es uno de los sectores industriales más dinámicos y competitivos del estado español. El tejido industrial directamente asociado a la fabricación de baldosas cerámicas presenta multitud de actividades: extracción de materias primas, fabricación de materias primas semielaboradas (granulado atomizado, fritas, esmaltes y pigmentos cerámicos), fabricación de piezas y decoraciones especiales (denominadas en el lenguaje industrial fábricas de tercer fuego).

Además del tejido industrial directamente relacionado con la fabricación de baldosas cerámicas, existe otro tipo de actividades asociadas a dicho sector de forma indirecta (talleres, ingenierías, empresas de servicios, proveedores de materias primas minoritarias, entre otras). Este conjunto de actividades forman en la provincia de Castellón, lo que en términos económicos se denomina un cluster industrial, debido al elevado grado de concentración existente de estas actividades, en especial en el área delimitada al Norte por l' Alcora y Vall d'Alba, al Oeste por Onda, al Sur por Nules y Xilxes y al Este por Castellón de la Plana. En la Figura 1.6 se muestra la situación geográfica del cluster industrial de la provincia de Castellón.

En 2013, la industria de baldosas cerámicas contaba a nivel nacional con 167 empresas, de las que 136 se encuentran localizadas en la provincia de Castellón. Las empresas fabricantes de baldosas cerámicas ascienden a 128, las empresas dedicadas a la atomización de arcillas son 11, mientras que el número de empresas dedicadas a la fabricación de soporte es de 5 (en el cómputo no se incluyen las pequeñas empresas o talleres dedicados a la fabricación artesanal) y aproximadamente 20 empresas dedicadas a la fabricación de fritas, esmaltes y pigmentos cerámicos (ASCER, 2014; ANFFECC, 2014). La Figura 1.7 muestra la distribución de las industrias más relevantes en el cluster industrial de Castellón.

Debido a la crisis económica mundial, y especialmente en la UE y en España en particular, desde el año 2006 se registra un paulatino descenso del número de fabricantes de baldosas, tanto por fusión o adquisición como por el cierre de algunas de ellas (ASCER, 2014).

Generalmente, las empresas de fabricación de baldosas cerámicas no incluyen en su ciclo productivo la obtención de fritas, esmaltes y pigmentos cerámicos. Las empresas dedicadas a la fabricación de estas materias primas semielaboradas disponen de una importancia elevada tanto a nivel económico como a nivel ambiental. En concreto, tanto en la fabricación de fritas como en la fabricación de pigmentos se realizan tratamientos térmicos a elevadas temperaturas (del orden de los $1500^{\circ} \mathrm{C}$ en el primer caso y en torno a $1000^{\circ} \mathrm{C}$ en el segundo) en los que pueden existir emisiones de compuestos ácidos. Estos compuestos pueden provenir tanto de las impurezas presentes en las materias primas, como de la utilización de 
materias primas y aditivos fluorados (normalmente en forma de fluorita o criolita). El estudio de las emisiones ácidas generadas en estos procesos requiere de un estudio amplio y específico que incluya las posibles fuentes de compuestos de flúor. La realización de dicho estudio queda fuera del alcance del presente trabajo aunque no se descarta que nuestro grupo de investigación aborde dicho estudio en un futuro.

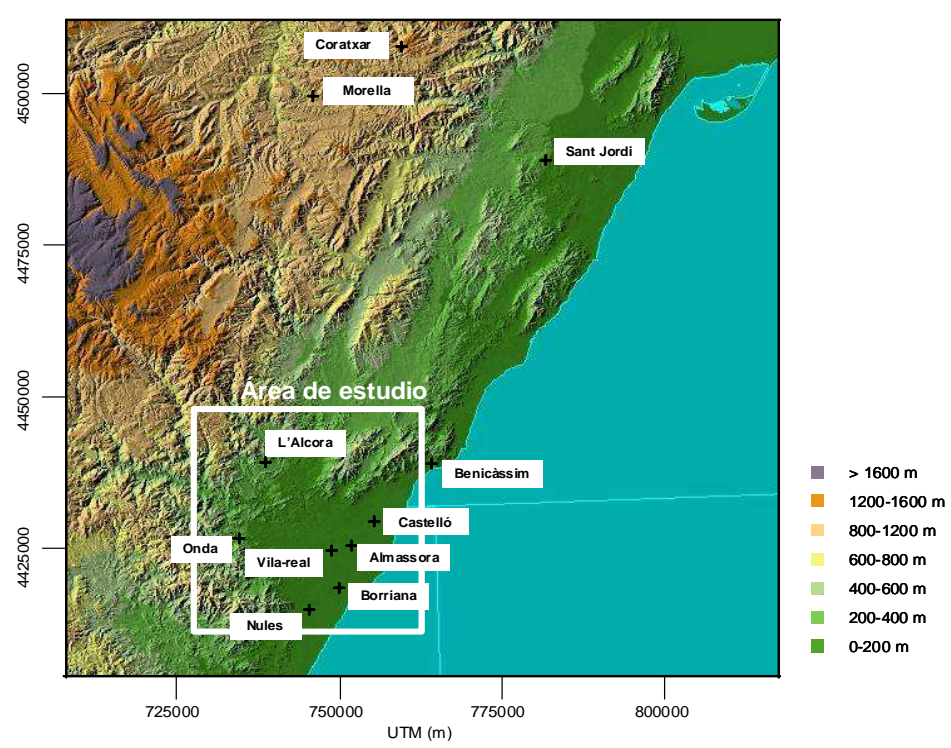

Figura 1.6. Cluster industrial de la provincia de Castellón (Minguillón, 2007).

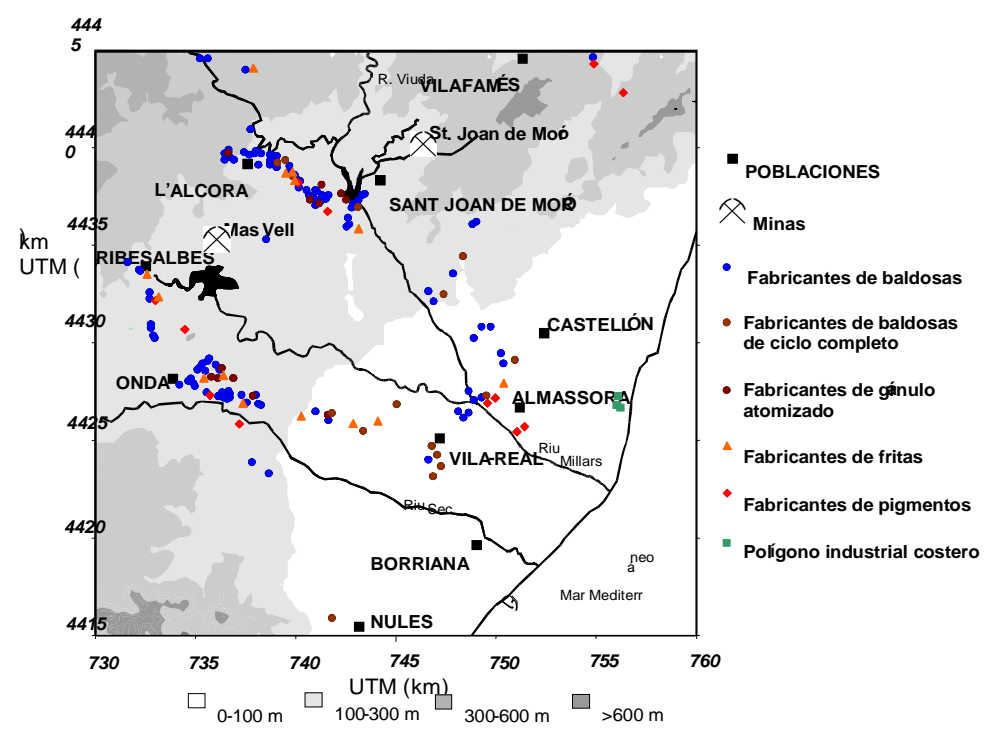

Figura 1.7. Mapa del cluster con indicación de las industrias más relevantes (Minguillón, 2007). 


\subsubsection{Baldosas cerámicas}

Según la norma EN 14411, las baldosas cerámicas son piezas planas de poco espesor fabricadas con arcillas, sílice, fundentes, colorantes y otras materias primas. Generalmente se utilizan como revestimientos de suelos, paredes y fachadas.

Las baldosas cerámicas pueden ser esmaltadas (GL), no esmaltadas (UGL) o engobadas, y son incombustibles e inalterables a la luz.

El esmalte aporta diferentes propiedades técnicas y estéticas. Este recubrimiento se aplica sobre el soporte cerámico, tal y como se muestra en la Figura 1.8. En dicha figura se muestra una fotografía de una pieza esmaltada y dos secciones transversales de baldosas cerámicas acabadas en las que pueden observarse las diferentes capas aplicadas sobre el soporte cerámico. La coloración del soporte es una característica de uso común para clasificar las baldosas cerámicas en productos de coloración en cocido roja y blanca.
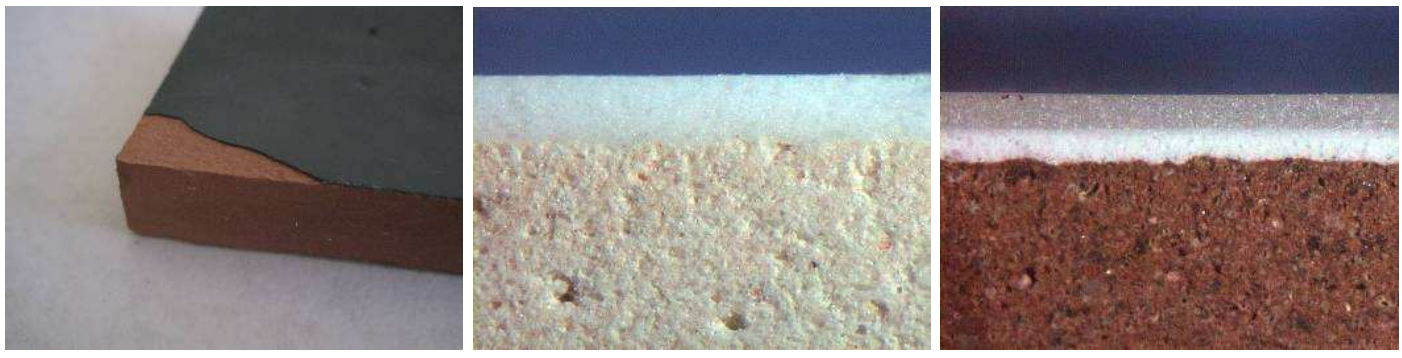

Figura 1.8. Ejemplos de soportes de coloración roja y blanca (izquierda y centro) y de decoraciones, sin y con engobe (centro y derecha).

La extensa gama de productos cerámicos existente en el mercado actual está condicionada por las variadas utilidades de este material de construcción. En función de su aplicación existen diferentes tipologías de producto y características.

La norma UNE EN 14411 clasifica a las baldosas cerámicas en función del método utilizado para su moldeo (prensado, extrusión o colado) y de la absorción de agua, que evalúa la porosidad abierta del soporte del producto acabado. La existencia o no de un recubrimiento superficial (esmaltadas o no esmaltadas) da lugar a una posterior clasificación. En la Tabla 1.6 se muestran los grupos normalizados de baldosas cerámicas. 
Tabla 1.6. Grupos normalizados de baldosas cerámicas.

\begin{tabular}{|c|c|c|c|c|}
\hline $\begin{array}{l}\text { Tipo de } \\
\text { moldeo }\end{array}$ & $\begin{array}{l}\text { Grupo I } \\
E \leq 3 \%\end{array}$ & $\begin{array}{c}\text { Grupo Ila } \\
3 \%<E \leq 6 \%\end{array}$ & $\begin{array}{c}\text { Grupo Ilb } \\
6 \%<E \leq 10 \%\end{array}$ & $\begin{array}{l}\text { Grupo III } \\
E>10 \%\end{array}$ \\
\hline $\begin{array}{l}\text { A } \\
\text { Baldosas } \\
\text { extrudidas }\end{array}$ & $\begin{array}{l}\text { Grupo } \mathrm{Al} \\
\text { Absorción de } \\
\text { agua baja } \\
(\mathrm{E} \leq 3 \%)\end{array}$ & $\begin{array}{l}\text { Grupo Alla } \\
\text { Absorción de } \\
\text { agua media-baja }\end{array}$ & $\begin{array}{l}\text { Grupo Allb } \\
\text { Absorción de } \\
\text { agua media-alta }\end{array}$ & $\begin{array}{l}\text { Grupo Alll } \\
\text { Absorción de } \\
\text { agua alta }\end{array}$ \\
\hline $\begin{array}{l}\text { Baldosas } \\
\text { prensadas }\end{array}$ & $\begin{array}{l}\text { Grupo Bla } \\
\text { Absorción de } \\
\text { agua muy baja } \\
(\mathrm{E} \leq 0,5 \%) \\
\text { Grupo Blb } \\
\text { Absorción de } \\
\text { agua baja } \\
(0,5<E \leq 3 \%)\end{array}$ & $\begin{array}{l}\text { Grupo Blla } \\
\text { Absorción de } \\
\text { agua media-baja }\end{array}$ & $\begin{array}{l}\text { Grupo Bllb } \\
\text { Absorción de } \\
\text { agua media-alta }\end{array}$ & $\begin{array}{l}\text { Grupo BIII } \\
\text { Absorción de } \\
\text { agua alta }\end{array}$ \\
\hline $\mathrm{E}=$ Absorció & le agua $(\%)$ & & & \\
\hline
\end{tabular}

Estos grupos no disponen de denominaciones normalizadas. Sin embargo, se ha considerado adecuado describir los diferentes tipos de baldosas cerámicas, con información sobre sus características, usos más frecuentes y aspecto, utilizado para ello las denominaciones más extendidas, aunque se debe tener presente que estas denominaciones no son aceptadas 0 entendidas por igual en todas partes (IVE, 2011).

- Azulejo: es la denominación tradicional de las baldosas cerámicas con soporte de porosidad alta (absorción de agua entre el 10\% y el 15\%), conformadas por prensado unidireccional, esmaltadas y fabricadas por bicocción o monococción. Sus características las hacen particularmente adecuadas para revestir paredes interiores en locales residenciales o comerciales. Los azulejos, junto con el gres esmaltado, representan el grueso de la producción española de baldosas cerámicas.

- Gres esmaltado: es la denominación más frecuente de las baldosas cerámicas con soporte de porosidad baja o media - baja (absorción de agua entre el 0,5 \% y el $6 \%$ ), conformadas por prensado unidireccional, esmaltadas y fabricadas generalmente por monococción, conocidas también como pavimento gresificado, pavimento cerámico esmaltado o simplemente pavimento cerámico. Son adecuadas para suelos interiores en locales residenciales o comerciales. Las que reúnen las características pertinentes (resistencia a la helada y a la abrasión) pueden utilizarse también para revestimiento de fachadas y de suelos exteriores.

- Gres porcelánico: es el nombre generalizado de las baldosas cerámicas con muy baja absorción de agua (absorción de agua inferior al 0,5\%), conformadas por prensado unidireccional, extrudidas en algunas ocasiones, esmaltadas o sin esmaltar, y sometidas a una única cocción. Se utilizan para suelos interiores en edificación residencial, comercial e 
incluso industrial, para suelos exteriores y fachadas, y para revestimientos de paredes interiores, en este caso preferentemente con acabado pulido. La cara vista puede tener relieves similares a los de las piedras naturales, con fines decorativos, o en forma de puntas de diamante, estrías, ángulos, con fines antideslizantes, para uso en suelos exteriores o de locales industriales.

- Gres rústico: es el nombre dado a las baldosas cerámicas con porosidad baja (absorción de agua inferior al 3\%) o media - baja (absorción de agua entre el $3 \%$ y el $6 \%$ ), conformadas por extrusión, esmaltadas o no esmaltadas. Dentro de una producción relativamente pequeña, hay una gran variedad de tipos, cuyas características particulares las hacen especialmente adecuadas para revestimiento de fachadas, solados exteriores, incluso de espacios públicos, suelos de locales públicos, suelos industriales, etc. Las irregularidades de color, superficie y aristas les dan posibilidades decorativas particulares.

- Baldosín catalán: es el nombre tradicional de baldosas con absorción de agua desde media - alta a alta o incluso muy alta, extrudidas, generalmente no esmaltadas y, por tanto, sometidas a una única cocción. La producción y el consumo son estables o con suave tendencia a la baja, y como su nombre indica, están concentradas en Cataluña, así como en Valencia. El baldosín no esmaltado se utiliza para solado de terrazas, balcones y porches, con frecuencia en combinación con olambrillas (pequeñas piezas cuadradas de gres blanco con decoración azul, o de loza esmaltada con decoración en relieve o multicolor).

- Barro cocido: es la denominación más comúnmente aplicada a gran variedad de baldosas con características muy diferentes, coincidentes solo en la apariencia rústica y en la alta absorción de agua. La producción es limitada, discontinua y muy dispersa y, generalmente, se fabrican en pequeñas unidades productivas y con medios artesanales. Sus características las hacen especiales y casi exclusivamente adecuadas para edificación o locales de buscada rusticidad.

En la Tabla 1.7 se muestra la correspondencia de las denominaciones de los productos anteriormente descritos con el grupo al que pertenecen, según la norma UNE EN 14411. También se incluye información acerca de las características y proceso empleado en su fabricación.

Además de esta clasificación, las baldosas también se dividen en dos grandes grupos, en función del color que presenta el soporte tras la cocción:

- Baldosa de coloración roja en cocido o, simplemente, baldosa roja (p. ej. Gres rojo)

- Baldosa de coloración blanca en cocido o baldosa blanca (p. ej. Azulejo blanco)

Esta clasificación, que no se encuentra normalizada, no implica una diferenciación en las características técnicas ni en la calidad de las baldosas. La fabricación de uno u otro tipo posee una enorme influencia en la tipología de materias primas que se utilizan para 
confeccionar los soportes. Como excepción deben citarse aquellos productos en los que el soporte desempeña, además de funciones técnicas, un papel estético importante que condiciona que la coloración de éste presente unas determinadas características. Algunos de estos productos, casi siempre no esmaltados, son el gres porcelánico y el gres rústico.

Tabla 1.7. Tipos de baldosas cerámicas usuales en España.

\begin{tabular}{llccc}
\hline Tipo de baldosa & Moldeo & Soporte & Esmaltado & $\begin{array}{c}\text { Grupo norma } \\
\text { según UNE EN } \\
\mathbf{1 4 4 1 1}\end{array}$ \\
\hline Azulejo & Prensado & Poroso & Sí & BIII \\
Gres esmaltado & Prensado & No poroso & Sí & Blb/Blla \\
Gres porcelánico & Prensado & No poroso & No/Sí & Bla \\
& Extrudido & & & Al \\
Baldosín catalán & Extrudido & Poroso & No & Allb - Alll \\
Gres rústico & Extrudido & No poroso & No/Sí & Al - Alla \\
Barro cocido & Extrudido & Poroso & No & Allb - Alll \\
\hline
\end{tabular}

\subsubsection{Proceso de fabricación}

En Europa el proceso más utilizado actualmente, en la fabricación de las baldosas cerámicas, tanto en el caso de azulejos como en el de gres esmaltado y gres porcelánico, es el proceso denominado vía húmeda y monococción. Este proceso consiste en preparar la mezcla de materias primas del soporte por molienda vía húmeda, secando por atomización la suspensión resultante hasta obtener un producto granulado con valores de 0,05-0,06 kg de agua/kg sólido seco, adecuado para el posterior conformado de las piezas por prensado unidireccional. A continuación se realiza el secado de las piezas, la aplicación del esmalte y de las decoraciones para, finalmente, llevar a cabo una cocción simultánea del soporte y de la decoración aplicada sobre éste en crudo (monococción). Aunque es el proceso más extendido, en otros países o zonas se continúa utilizando la molienda vía seca y los procesos de doble cocción, sobre todo en Brasil.

Por tanto, el proceso de fabricación de las baldosas cerámicas por monococción comprende las siguientes etapas:

- Preparación de la composición de materias primas para el soporte

- Prensado

- Secado

- Preparación de la composición de materias primas para el esmalte 
- Esmaltado y decoración

- Cocción

- Tratamientos mecánicos (rectificado, pulido, etc.)

- Selección o clasificación

A continuación se describe brevemente cada una de estas etapas.

\section{Preparación de la composición del soporte}

Los objetivos de esta fase son confeccionar una mezcla íntima y homogénea de los distintos componentes, con un tamaño de partícula determinado, y acondicionar dicha mezcla para el adecuado prensado de la pieza.

El proceso comienza con el almacenamiento de los distintos tipos de materias primas en graneros o silos. La mezcla, que se dosifica gravimétricamente, se introduce en molinos de bolas tipo Alsing, que operan en discontinuo o en continuo, junto con el agua y los desfloculantes en proporción adecuada. El contenido en sólidos de esta suspensión varía normalmente entre el 60 y el $70 \%$ en peso, dependiendo de las características de las materias primas utilizadas (Blasco et al., 1992). Estas suspensiones son denominadas barbotinas en el lenguaje industrial.

El secado por atomización convierte a la suspensión, obtenida tras la molienda, en aglomerados esféricos huecos de partículas (gránulos) con una humedad controlada, muy adecuados para el prensado (Masters, 1991).

El material recién atomizado se almacena en silos con objeto de que se uniformice, en la medida de lo posible, la humedad en el interior de cada gránulo y entre los gránulos de distinto tamaño. El tiempo de permanencia del atomizado en los silos no suele ser superior a 2 días.

\section{Prensado}

El moldeado de las piezas, debido a su forma sencilla (rectangular, cuadrada, etc.), y a la pequeña relación espesor/superficie, se realiza por prensado unidireccional con una humedad de prensado de $0,05-0,06 \mathrm{~kg}$ de agua/kg sólido seco, en prensas hidráulicas de efecto simple. La sencillez de este método facilita su automatización y permite alcanzar producciones más elevadas que con los otros tipos de prensado (isostático, doble efecto, etc.) y de moldeo (extrusión, colado, etc.). 


\section{Secado}

Las piezas recién moldeadas, o conformadas, se introducen en un secadero continuo para reducir su humedad de prensado hasta valores inferiores a $0,005 \mathrm{~kg}$ de agua $/ \mathrm{kg}$ sólido seco, incrementando de esta forma su resistencia mecánica en un valor 2 ó 3 veces superior al que tenía recién prensada, lo que permite su procesado posterior (Jarque, 2001).

\section{Esmaltado y decoración}

Las piezas recién salidas del secadero, a una temperatura entre 80 y $110^{\circ} \mathrm{C}$, se recubren con una o varias capas de esmalte en la línea de esmaltado.

La operación se realiza aplicando sucesivamente en los distintos elementos de la línea de esmaltado las suspensiones o polvo de esmalte adecuados. En determinadas ocasiones, las piezas se decoran automáticamente mediante distintos sistemas de impresión serigráfica, huecograbado, chorro de tinta, etc. (Moreno, 2000), aunque la decoración mediante sistemas de chorro de tinta ha tenido una rápida penetración y está sustituyendo al resto de sistemas de decoración en los últimos años.

\section{Cocción}

Durante esta etapa se producen las transformaciones físico - químicas más importantes que conducen a la microestructura definitiva de la pieza cocida y que definen, por tanto, las propiedades del producto final.

La cocción de las piezas esmaltadas se realiza actualmente en hornos continuos de combustión monoestrato. En estos hornos el material se cuece en una sola capa y se transporta normalmente apoyado directamente sobre rodillos cerámicos accionados convenientemente. Como consecuencia de ello, el ciclo de cocción que se consigue en estos hornos suele oscilar entre 35 y 70 minutos, dependiendo del tipo de producto y de la geometría de las piezas.

Las curvas de cocción que se emplean en la fabricación de baldosas cerámicas por monococción varían de una factoría a otra en función de las composiciones del soporte y del esmalte, del desarrollo de las etapas anteriores a la cocción y de las características del producto acabado que se desea obtener (absorción de agua, etc.). Cualitativamente, la forma de la curva es, en todos los casos, similar a la representada en la Figura 1.9 (Ferrer et al., 2015). 


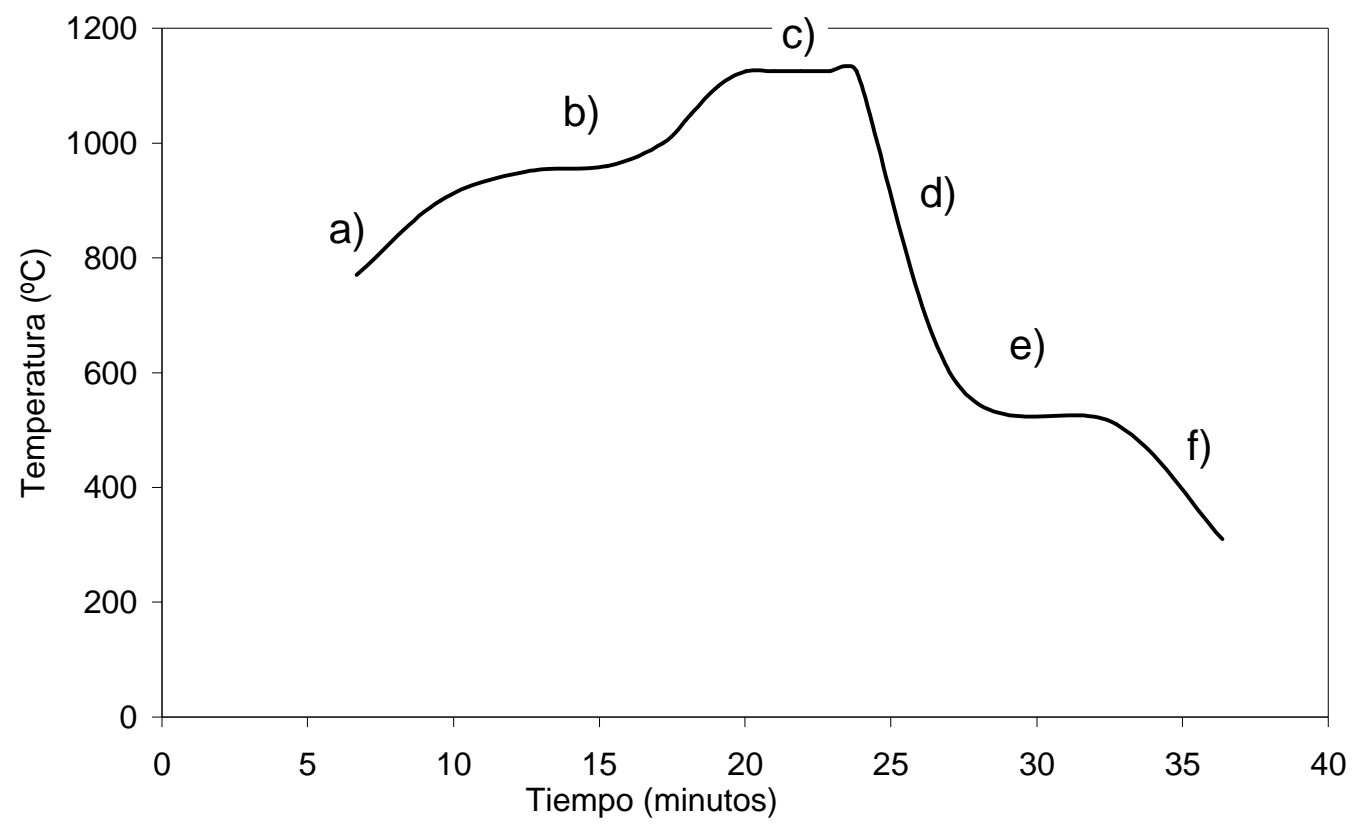

Figura 1.9. Curva de cocción (Ferrer et al., 2015).

Los aspectos que se deben considerar a la hora de diseñar las curvas de cocción son los siguientes:

- Etapa inicial de calentamiento (Figura 1.9. a). La explosión de piezas, motivada por una eliminación violenta de un exceso de humedad residual en forma de vapor, es el factor que puede limitar la velocidad de calentamiento en esta primera fase de la cocción (Amorós et al., 1982). Esta humedad procede de la adsorción de humedad del ambiente por las piezas durante su almacenamiento y del agua que se aplica en el esmaltado (Blasco et al., 1987).

- Periodo de descomposición y oxidación (Figura 1.9. b). En monococción, las reacciones de descomposición y oxidación con desprendimientos gaseosos deben completarse antes de que el esmalte impermeabilice la superficie donde se aplicó, o de lo contrario la superficie esmaltada del producto acabado resultará deteriorada por la presencia de pinchados, provocados por desprendimiento de los productos gaseosos de dichas reacciones (Amorós et al., 1986; Enrique et al., 1998).

Para evitar la aparición de estos defectos en el producto acabado, es imprescindible que este periodo se desarrolle a la temperatura apropiada y que sea lo suficientemente largo para que las reacciones de oxidación y descomposición se completen, antes de que se produzca la fusión del esmalte. 
- Periodo de máxima temperatura (Figura 1.9. c). La etapa de cocción propiamente dicha se realiza a una temperatura comprendida entre $1120-1220{ }^{\circ} \mathrm{C}$, dependiendo de las características del producto acabado, de las variables de proceso anteriores a la cocción y de la composición del vidriado y del soporte. En monococción, es deseable que la temperatura de maduración del esmalte coincida con la temperatura a la que el soporte alcanza las características requeridas (contracción lineal, absorción de agua, resistencia mecánica, etc.).

- El enfriamiento de las piezas se realiza en tres etapas: enfriamiento forzado a alta temperatura (Figura 1.9. d), donde la gran resistencia al choque térmico de las piezas a temperaturas superiores a $600 \stackrel{\circ}{\circ}$ permite que estas puedan enfriarse rápidamente sin que se produzcan roturas. Enfriamiento natural (Figura 1.9. e), cuando la temperatura de la pieza está cercana a los $573^{\circ} \mathrm{C}$, a la que se produce la transformación alotrópica del cuarzo. La baja resistencia al choque térmico que adquiere el material obliga a que la velocidad de enfriamiento se reduzca considerablemente, por lo que el enfriamiento se realiza por convección natural. Por último se da el enfriamiento forzado a baja temperatura (Figura 1.9. f) donde, una vez superado el punto crítico del cambio alotrópico del cuarzo, el material se hace de nuevo resistente al choque térmico, por lo que el enfriamiento final de las piezas se puede realizar otra vez por convección forzada (Amorós et al., 1982; Funk, 1982).

\section{Tratamientos mecánicos, selección o clasificación}

Una vez cocida la pieza es posible realizar sobre la misma tratamientos mecánicos de pulido, lapado, biselado y/o rectificado. Estos tratamientos se introdujeron inicialmente para los productos de gres porcelánico no esmaltado, pero poco a poco se han extendido a una parte de los productos esmaltados.

Por último, después de la etapa de cocción o de los tratamientos mecánicos citados, se realiza una clasificación del producto final, de forma manual o automática, antes del proceso de embalado.

Para finalizar este apartado, y a título orientativo, en la Tabla 1.8 se muestran valores típicos de las variables de proceso más importantes para cada uno de los productos cerámicos considerados. 
Tabla 1.8. Valores típicos de las variables de proceso más importantes.

\begin{tabular}{|c|c|c|c|c|}
\hline Etapa & Variable & Azulejo & $\begin{array}{c}\text { Gres } \\
\text { esmaltado }\end{array}$ & $\begin{array}{c}\text { Gres } \\
\text { porcelánico }\end{array}$ \\
\hline Preparación & Contenido en sólidos (\%) & $65-68$ & $66-70$ & $63-66$ \\
\hline composición & Viscosidad (cP) & $700-1000$ & $700-1000$ & $700-1000$ \\
\hline \multirow[t]{2}{*}{ Prensado } & Presión (kg/cm²) & $230-250$ & $250-300$ & $300-400$ \\
\hline & $\begin{array}{c}\text { Humedad } \\
\text { (kg agua/kg sólido seco) }\end{array}$ & $0,053-0,056$ & $0,055-0,060$ & $0,050-0,060$ \\
\hline \multirow[t]{2}{*}{ Cocción } & Temperatura máxima $\left({ }^{\circ} \mathrm{C}\right)$ & $1120-1160$ & $1130-1160$ & $1180-1220$ \\
\hline & Ciclo (min) & $30-90$ & $35-55$ & $45-90$ \\
\hline
\end{tabular}

En las Figura 1.10 y Figura 1.11 se muestran el esquema de producción correspondiente al proceso de fabricación de azulejos y gres esmaltado, y gres porcelánico, respectivamente. 


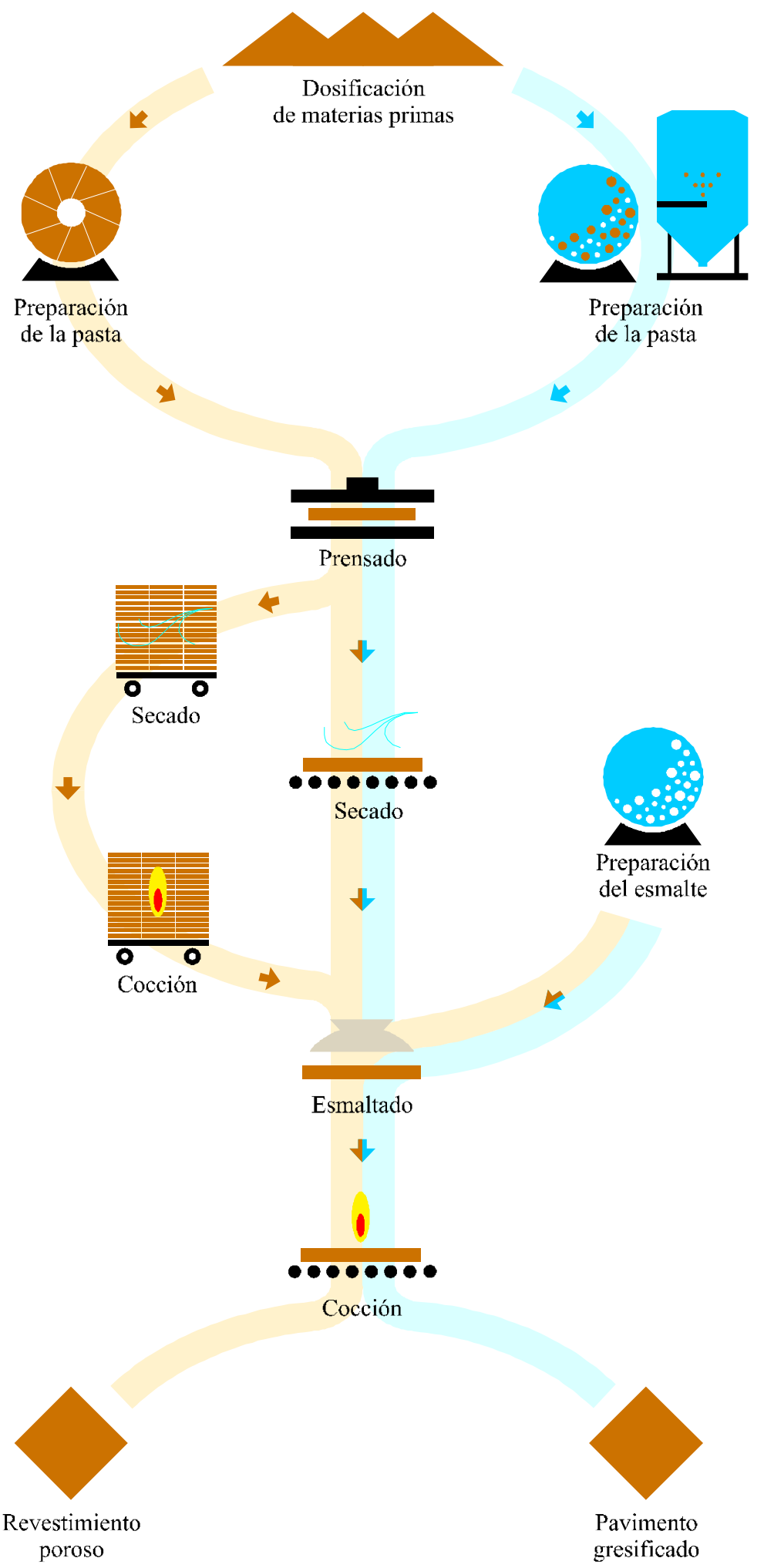

Figura 1.10. Esquema de fabricación de los azulejos y gres esmaltado. 


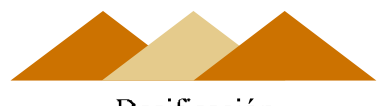

Dosificación

de materias primas y aditivos

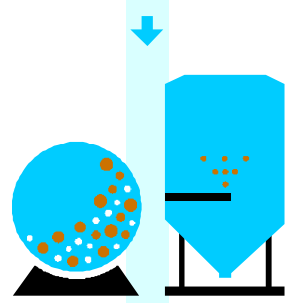

Preparación

de la pasta

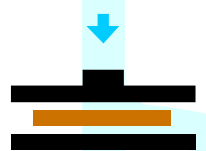

Prensado

$\checkmark$

$\bullet \bullet \bullet \bullet \bullet \bullet \bullet \bullet$

Secado/

Preparación

del esmalte

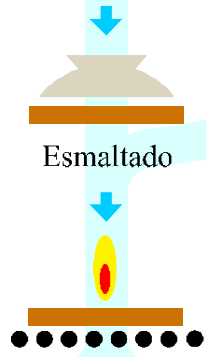

Cocción

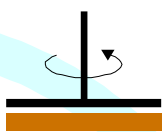

Pulido

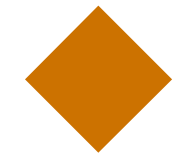

Gres procelánico no pulido

Gres porcelánico pulido

Figura 1.11. Esquema de fabricación del gres porcelánico. 


\subsubsection{Composiciones empleadas para fabricar los soportes de las baldosas cerámicas}

Las baldosas cerámicas se utilizan mayoritariamente para revestir paredes y pavimentar suelos. En líneas generales, las composiciones utilizadas para fabricar los soportes de las baldosas cerámicas son diferentes en función de las propiedades exigidas para cada uso. Se diferencian tres tipos principales de productos: azulejo, gres esmaltado y gres porcelánico.

\section{$\underline{\text { Azulejo }}$}

Las composiciones utilizadas como revestimiento, o azulejos, han de exhibir una alta estabilidad dimensional, la cual se obtiene mediante el uso de composiciones con una baja contracción de cocción. La baja contracción de cocción va unida a una alta porosidad, lo que supone una mayor facilidad en su colocación con materiales tradicionales (Sánchez et al., 1990).

La elevada porosidad de la pieza facilita el acceso de agua hacia su interior, lo que puede hidratar las fases amorfas y vítreas presentes. Este hecho conduce a un aumento del tamaño del soporte cocido, denominado expansión por humedad, que puede llegar a producir curvaturas en las piezas e incluso cuarteos y grietas en la capa de vidriado. Debido a ello es necesario que las piezas cocidas presenten una elevada proporción de fases cristalinas estables con una mínima presencia de fases amorfas y vítreas (Smith, 1955).

La estabilidad dimensional, la alta porosidad y la formación de fases cristalinas se consiguen, normalmente, mediante el empleo de materias primas que aporten óxido de calcio a la composición. Este óxido reacciona con la sílice y alúmina provenientes de la deshidroxilación de los minerales arcillosos para formar silicatos y silicoaluminatos cálcicos estables frente a la acción de la humedad: wollastonita, gelenita, anortita, etc. (Amorós et al., 1993).

Las composiciones utilizadas para la fabricación de azulejos de soporte poroso son muy distintas en función de su coloración, realizándose una división entre composiciones rojas y blancas.

En las composiciones rojas se utiliza normalmente una mezcla de arcillas de alto contenido en hierro. Estas arcillas presentan proporciones variables de cuarzo y de carbonato cálcico, siendo este último mineral el que aporta los óxidos alcalinotérreos (Sánchez et al., 1996). En ocasiones se adicionan pequeñas proporciones de cuarzo, borras y residuos de piezas cocidas (tiesto) para reducir la contracción de cocción.

En cambio, en las composiciones blancas se utiliza una mezcla de arcillas no calcáreas de bajo contenido en óxido de hierro, junto a un conjunto de materias primas desgrasantes entre las que destacan la calcita, que aporta los óxidos alcalinotérreos, y el cuarzo, que mejora la compacidad y aumenta el coeficiente de dilatación (Beltrán et al., 1996). En general, este tipo 
de composiciones requiere un alto grado de blancura, por lo que en ocasiones se introducen distintas proporciones de caolín.

El caolín desde el punto de vista geológico es una arcilla blanca. No obstante en este trabajo es considerada como una materia prima diferenciada del resto de arcillas blancas, como suele ser habitual en los tratados de tecnología cerámica, debido a sus propiedades y funciones específicas.

\section{Gres esmaltado y gres porcelánico}

Las composiciones utilizadas para fabricar gres esmaltado y gres porcelánico se caracterizan por proporcionar a las piezas una alta resistencia mecánica y, en algunos casos, un buen comportamiento frente a la helada. Estas propiedades se consiguen reduciendo la porosidad inicial de las piezas mediante la formación de fase líquida durante la cocción, lo que produce su sinterización. Para ello se utilizan materias primas que aportan óxidos alcalinos como las arcillas illíticas y los feldespatos sódicos, potásicos y mixtos (Sánchez et al., 1990). Algunas veces se introducen pequeñas proporciones de talco, con el propósito de reducir la temperatura de gresificación, dado que este mineral forma mezclas eutécticas de baja temperatura de fusión con los feldespatos alcalinos (Beltrán et al., 1996).

En las composiciones de gres esmaltado los requerimientos de blancura no son tan elevados como en el gres porcelánico, siendo necesario obtener la máxima compacidad posible en crudo con el fin de minimizar la contracción de cocción. Por tanto, es conveniente emplear arcillas con una adecuada distribución de tamaño de partícula y una baja pérdida por calcinación, pero no excesivamente arenosas para no elevar demasiado la temperatura de cocción. Este tipo de composiciones se formulan con arcillas nacionales, más o menos silíceas, aunque es habitual adicionar pequeñas proporciones de arcillas de importación para mejorar la resistencia mecánica en seco.

Las composiciones de gres porcelánico son similares a las de gres esmaltado, pero adecuadas a un proceso que permite obtener piezas con una porosidad, tanto abierta (normalmente inferior al $0,5 \%$ de absorción de agua) como cerrada, lo más baja posible. Para la consecución de estos objetivos la molienda debe ser muy enérgica, originando distribuciones de tamaño de partícula poco favorables para la obtención de una elevada densidad aparente en seco. Por lo tanto, en este tipo de productos, la elección de arcillas y desgrasantes que den lugar a una alta compacidad en las piezas crudas es de enorme importancia, mayor si cabe que en el caso del gres esmaltado, si se pretende reducir la contracción de cocción.

En las formulaciones de gres porcelánico deben utilizarse arcillas y desgrasantes de elevado grado de blancura en cocido, ya que el desarrollo del color está relacionado con la proporción de impurezas colorantes $\left(\mathrm{Fe}_{2} \mathrm{O}_{3}\right.$ y $\mathrm{TiO}_{2}$ principalmente) presentes en la composición. 
Por otro lado, dado que el producto se caracteriza por una mínima porosidad por lo general, son necesarios feldespatos de elevada fundencia y mínimo contenido en impurezas.

A continuación, en la Tabla 1.9, se detallan los intervalos de composición (en \% en peso) de las mezclas de materias primas empleadas en la fabricación de soportes de baldosas rojas y blancas.

Tabla 1.9. Composición de las materias primas empleadas en la fabricación de los soportes de baldosas cerámicas rojas y blancas (en \% en peso).

\begin{tabular}{ccccc}
\hline $\begin{array}{c}\text { Tipo de } \\
\text { baldosa }\end{array}$ & Composición roja & \multicolumn{2}{c}{ Composición blanca } \\
\hline Azulejo & Arcillas no calcáreas & $40-55$ & Arcillas & $50-65$ \\
& Arcillas calcáreas & $45-60$ & Calcita & $12-15$ \\
& & & Feldespato & $0-15$ \\
& & & Cuarzo & $15-30$ \\
& & & Caolín & $0-10$ \\
\hline Gres & Arcillas no calcáreas & 100 & Arcillas & $50-65$ \\
esmaltado & & & Feldespato & $30-40$ \\
& & & Talco & $0-10$ \\
\hline Gres & Arcillas no calcáreas & 100 & Arcillas & $35-50$ \\
porcelánico & & & Feldespato & $40-50$ \\
& & & Arena feldespática & $5-15$ \\
& & & Caolín & $0-10$ \\
\hline
\end{tabular}

\subsubsection{Transformaciones físico - químicas que se producen durante la cocción}

Cuando una composición cerámica se calienta a temperaturas superiores a los $1000{ }^{\circ} \mathrm{C}$ experimenta una serie de transformaciones físico - químicas que provocan un cambio permanente e irreversible en su estructura y composición química y mineralógica.

En la Figura 1.12 se muestra la curva de ATD, mientras que en la Figura 1.13 se muestra la curva TG y DTG de una composición empleada habitualmente en la fabricación de azulejos. Asimismo, en la Figura 1.14 se ha representado el diagrama de expansión - contracción.

Los principales cambios que experimentan estas composiciones, en términos generales, se detallan a continuación:

a) En las primeras etapas del calentamiento se elimina el agua adsorbida físicamente sobre la superficie de la arcilla. El pico endotérmico que se observa en la curva del ATD a $100{ }^{\circ} \mathrm{C}$ aproximadamente corresponde a la desorción de dicha agua, etapa que se completa sobre los $200^{\circ} \mathrm{C}$. La extensión del pico depende del tipo de mineral arcilloso (caolinita, illita o 
montmorillonita), del tamaño de partícula, y del tratamiento previo recibido por la muestra (Mckenzie, 1957; Funk, 1982).

b) A temperaturas comprendidas entre los 300 y $500{ }^{\circ} \mathrm{C}$ tienen lugar las reacciones de oxidación de la materia orgánica, hecho que puede visualizarse claramente en la moderada pero continua pérdida en peso que experimenta la muestra hasta los $400{ }^{\circ} \mathrm{C}$ (curva TG). La materia orgánica se descompone en atmósfera oxidante proporcionando un efecto exotérmico gradual entre $300-500^{\circ} \mathrm{C}$, intervalo de temperaturas muy cercano a la zona donde se producen los cambios energéticos característicos de los minerales arcillosos. La oxidación de la materia orgánica desprende calor y la extensión de este efecto es proporcional a la cantidad presente en la arcilla (Brindley y Nakahira, 1957).

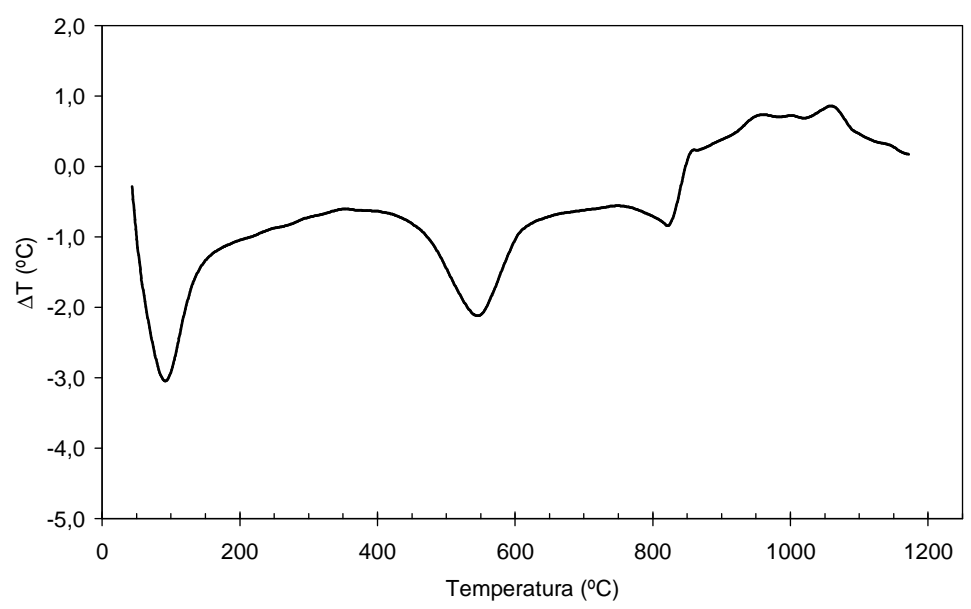

Figura 1.12. Análisis térmico diferencial de una composición de azulejo.

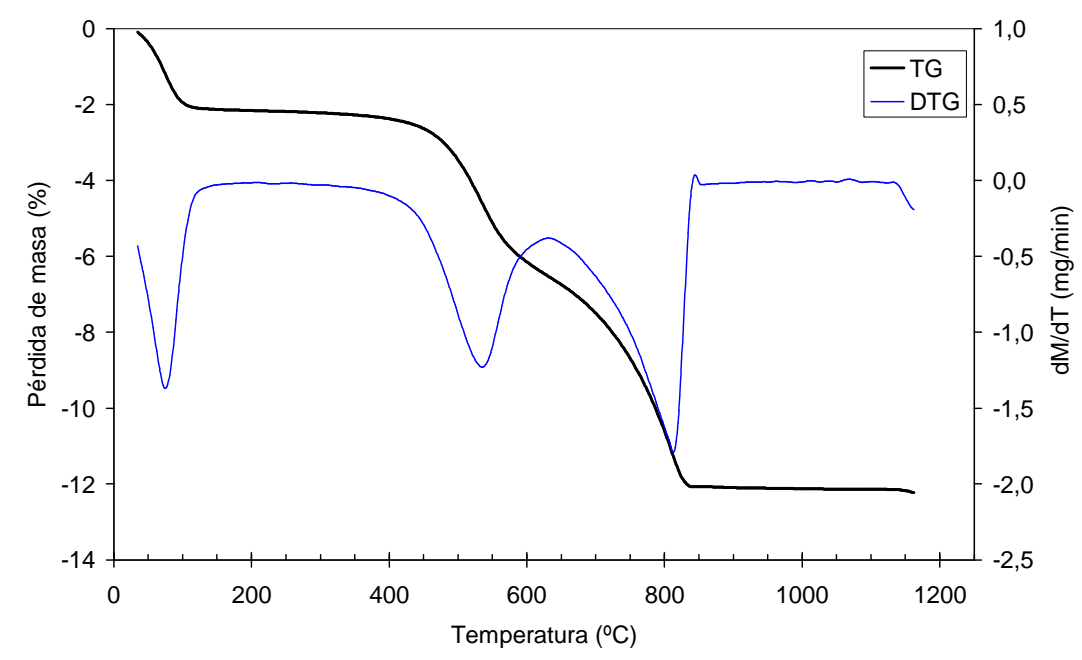

Figura 1.13. Análisis termogravimétrico de una composición de azulejo. 


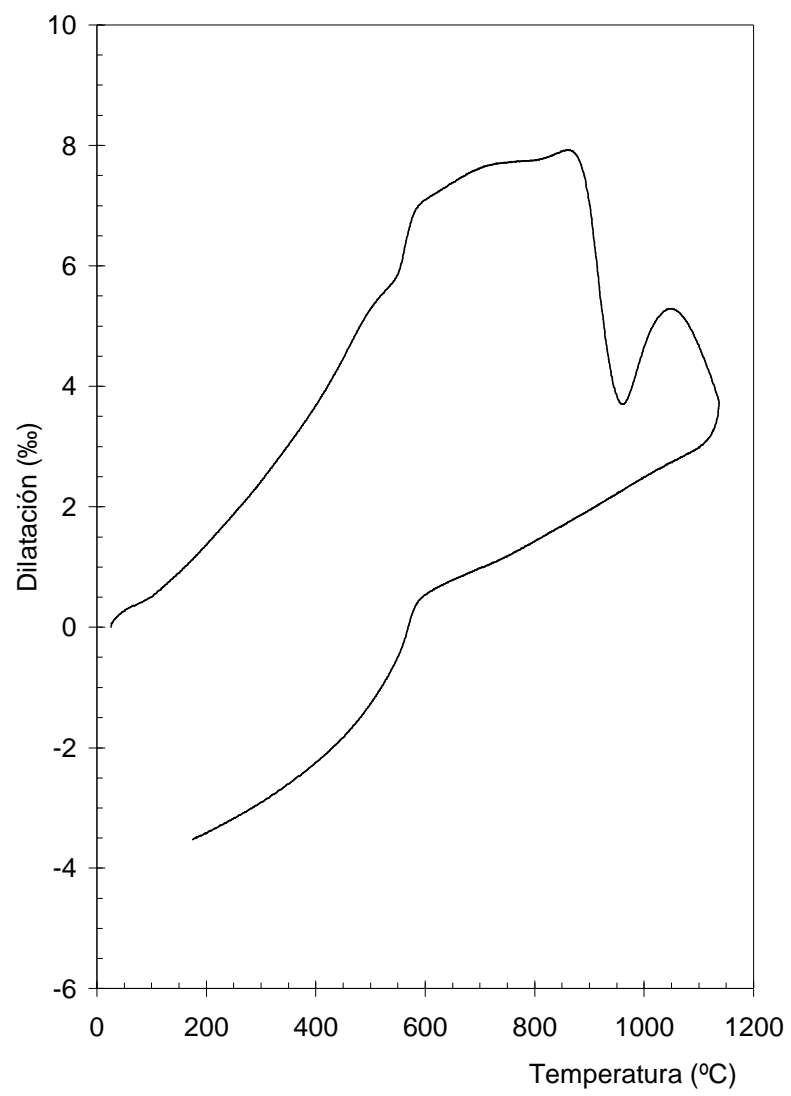

Figura 1.14. Curva de expansión - contracción de una composición de azulejo.

c) Entre los $450-650^{\circ} \mathrm{C}$ se produce la deshidroxilación de los minerales arcillosos (Grim y Bradley, 1940). Esta reacción corresponde al pico endotérmico del ATD situado a $530{ }^{\circ} \mathrm{C}$. Cuando la caolinita es calentada no experimenta ningún cambio hasta alcanzar aproximadamente los $470{ }^{\circ} \mathrm{C}$, momento en el que los iones $\mathrm{OH}$ de la estructura cristalina comienzan a ser eliminados en forma de vapor de agua: $\mathrm{OH}+\mathrm{OH}^{-} \rightarrow \mathrm{H}_{2} \mathrm{O}+\mathrm{O}^{2-}$. Durante esta transformación se produce una pérdida de peso y una destrucción parcial de la estructura cristalina debido al reordenamiento de los átomos, formándose una fase amorfa y metaestable denominada metacaolín. La estructura de la caolinita, por tanto, persiste en el metacaolín con algunas modificaciones, pero el colapso de las hojas destruye su periodicidad normal (Brindley y Nakahira, 1957). Por otra parte, entre los 400 y $550{ }^{\circ} \mathrm{C}$ la mayor parte del agua estructural de las illitas es eliminada. Sin embargo, dicha agua es eliminada de forma gradual hasta que se inicia la fusión. Al contrario que en la caolinita, el análisis de rayos $X$ muestra que la cristalinidad no se pierde como resultado de esta deshidroxilación, aunque la superficie específica del material si que se incrementa (Grim y Bradley, 1940). 
d) A $573^{\circ} \mathrm{C}$ se produce el cambio alotrópico $\alpha \rightarrow \beta$ del cuarzo. Esta transformación produce un cambio brusco en la pendiente de la curva de expansión - contracción y un pequeño efecto endotérmico en la curva de ATD (Warshaw y Seider, 1967).

e) En las composiciones de azulejo, a partir de los $600^{\circ} \mathrm{C}$, tiene lugar la descomposición del $\mathrm{CaCO}_{3}$ con liberación de $\mathrm{CO}_{2}$, la cual está asociada con el efecto endotérmico situado a $790^{\circ} \mathrm{C}$ (Todor, 1976). Esta transformación, al igual que las reacciones de oxidación de la materia orgánica e inversión del cuarzo, conduce a una expansión progresiva de la muestra. La reacción que se produce puede representarse por el esquema:

$$
\mathrm{CaCO}_{3}(\mathrm{~s}) \rightarrow \mathrm{CaO}(\mathrm{s})+\mathrm{CO}_{2}(\mathrm{~g}) .
$$

Poco después de la pérdida de $\mathrm{CO}_{2}$ hay una reorganización de los átomos para formar núcleos de $\mathrm{CaO}$. Al prolongar el calentamiento, dichos núcleos crecen. La velocidad de crecimiento es grande al principio, pero disminuye con el tiempo.

Coincidiendo prácticamente con la finalización de la etapa de descomposición se produce una sinterización rápida de la muestra entre los 825 - $950{ }^{\circ} \mathrm{C}$, que se manifiesta en una brusca contracción de la pieza y en una reducción paralela de su porosidad y superficie específica. La velocidad a la que se desarrolla esta sinterización alcanza un máximo sobre los $850^{\circ} \mathrm{C}$, temperatura que coincide prácticamente con un punto de inflexión en la curva ATD. Este punto de inflexión puede asociarse a la formación de fases cristalinas, y su máximo aparece a $890^{\circ} \mathrm{C}$. En consecuencia, la contracción se debe a una sinterización de las fases amorfas procedentes de la descomposición de los minerales arcillosos y del CaO procedente del $\mathrm{CaCO}_{3}$.

Al seguir calentando se produce una nueva expansión debido a la progresiva formación de gelenita y, sobre todo, de pseudowollastonita y anortita; simultáneamente, el tamaño de los poros va creciendo sin que se modifique prácticamente la porosidad de la muestra.

f) Finalmente, a temperaturas superiores a $1100{ }^{\circ} \mathrm{C}$ comienza la fusión progresiva de las fases cristalinas y la sinterización de la pieza debido a la fase líquida desarrollada, rica en calcio.

g) En las composiciones de gres y gres porcelánico los cambios más importantes que experimentan a alta temperatura se deben a la sinterización de la muestra a temperaturas superiores a $800^{\circ} \mathrm{C}$, cuando comienza a desarrollarse fase líquida a partir de las arcillas illíticas y de los feldespatos. Con el aumento de temperatura aumenta la proporción de fase líquida y disminuye su viscosidad, lo que acelera el proceso de sinterización. La illita va desapareciendo paulatinamente hasta los $950{ }^{\circ} \mathrm{C}$ y la hematita permanece hasta $1150^{\circ} \mathrm{C}$, temperatura a partir de la cual se descomponen liberando oxígeno. El cuarzo permanece estable hasta los $950^{\circ} \mathrm{C}$ y a continuación comienza a disolverse de forma progresiva en la abundante fase líquida formada. Todos estos cambios conducen a una 
disminución de la porosidad de las piezas, a un aumento de su contracción lineal y de su deformación piroplástica.

\subsubsection{Características de las emisiones atmosféricas existentes en el proceso de fabricación de baldosas cerámicas}

Las emisiones atmosféricas generadas a lo largo del proceso productivo de las baldosas cerámicas tienen unas características definidas dependiendo de la etapa de la que se trate, tal y como se recoge en la Tabla 1.10 (Celades, 2013). En dicha tabla, los tipos de emisiones se dividen en canalizadas y difusas, y en función de la temperatura de la corriente. Se entiende por emisión canalizada la emisión a través de una conducción o chimenea; por emisión difusa, la emisión que llega a la atmósfera sin haber sido canalizada a través de una conducción; se entiende por emisión fría aquella corriente de gases que está a temperatura ambiente o similar; por emisión caliente, los gases de combustión a temperatura superior a $60{ }^{\circ} \mathrm{C}$. En cuanto al tipo de contaminante emitido, en la Tabla 1.10 se ha distinguido entre partículas (con independencia de su composición química) y metales pesados (cuando su presencia en forma de partículas o gases puede ser crítica); mientras que los gases se han clasificado en dos grupos: gases de combustión $\left(\mathrm{CO}\right.$ y $\left.\mathrm{CO}_{2}\right)$ y gases ácidos $\left(\mathrm{SO}_{x}, \mathrm{NO}_{x}, \mathrm{HF}\right.$ y $\left.\mathrm{HCl}\right)$.

Tabla 1.10. Caracterización de las emisiones de la industria de baldosas cerámicas.

\begin{tabular}{|c|c|c|c|c|}
\hline Etapa de proceso & $\begin{array}{l}\text { Nivel de } \\
\text { emisión }\end{array}$ & $\begin{array}{l}\text { Caudal de } \\
\text { emisión }\end{array}$ & Tipo & Contaminante emitido \\
\hline $\begin{array}{l}\text { Almacenamiento y } \\
\text { manipulación de } \\
\text { materias primas }\end{array}$ & Variable & Continuo & Difusa fría & Partículas \\
\hline Molienda en seco & Variable & $\begin{array}{l}\text { Continuo/ } \\
\text { discontinuo }\end{array}$ & $\begin{array}{l}\text { Canalizada } \\
\text { fría }\end{array}$ & Partículas \\
\hline Molienda en húmedo & Variable & $\begin{array}{l}\text { Continuo/ } \\
\text { discontinuo }\end{array}$ & $\begin{array}{c}\text { Canalizada } \\
\text { fría }\end{array}$ & Partículas \\
\hline $\begin{array}{l}\text { Secado por } \\
\text { atomización }\end{array}$ & Constante & Continuo & $\begin{array}{l}\text { Canalizada } \\
\text { caliente }\end{array}$ & $\begin{array}{l}\text { Partículas y gases de } \\
\text { combustión }\end{array}$ \\
\hline Conformado & Variable & Continuo & $\begin{array}{c}\text { Canalizada } \\
\text { fría }\end{array}$ & Partículas \\
\hline Secado & Constante & Continuo & $\begin{array}{c}\text { Canalizada } \\
\text { caliente }\end{array}$ & $\begin{array}{l}\text { Partículas y gases de } \\
\text { combustión }\end{array}$ \\
\hline $\begin{array}{l}\text { Preparación de } \\
\text { esmaltes }\end{array}$ & Variable & Discontinuo & $\begin{array}{l}\text { Canalizada } \\
\text { fría }\end{array}$ & Partículas \\
\hline Esmaltado & Variable & Continuo & $\begin{array}{c}\text { Canalizada } \\
\text { fría }\end{array}$ & Partículas \\
\hline Cocción & Constante & Continuo & $\begin{array}{l}\text { Canalizada } \\
\text { caliente }\end{array}$ & $\begin{array}{l}\text { Partículas, metales, gases } \\
\text { ácidos y de combustión }\end{array}$ \\
\hline
\end{tabular}


La fabricación de fritas y pigmentos cerámicos queda fuera del alcance del presente trabajo de investigación por lo que no se ha incluido en la tabla anterior.

\subsubsection{Emisiones de material particulado}

La emisión de partículas procedentes de la industria cerámica está considerada como uno de los impactos ambientales más significativos del proceso de fabricación de materiales cerámicos, ya que se trata de un tipo de actividad industrial que procesa materiales de naturaleza pulverulenta.

Este material particulado se emite a partir de focos canalizados o difusos. En el caso de la fabricación de productos cerámicos tradicionales, como las baldosas cerámicas, la naturaleza o composición del material particulado emitido por chimenea de forma canalizada, está relacionada con la composición y/o naturaleza de las materias primas procesadas.

Por su parte, las emisiones difusas de materiales pulverulentos suponen un aspecto medioambiental poco valorado desde el punto de vista legislativo, pero con un impacto significativo que, dependiendo de las instalaciones, puede ser de tanta o más importancia que el debido a las emisiones canalizadas, y que afecta tanto al medio ambiente como a la salud humana (Mallol et al., 2001).

\subsubsection{Emisiones de contaminantes gaseosos}

Este tipo de contaminantes son característicos de actividades o procesos industriales de alta temperatura y/o donde tienen lugar procesos de combustión. En el caso de la fabricación de baldosas cerámicas estas etapas son tres: secado de suspensiones por atomización, secado y cocción de las baldosas conformadas. Los principales contaminantes gaseosos se pueden agrupar de la siguiente forma:

- Gases generados en los procesos de combustión, como: $\mathrm{CO}_{2}, \mathrm{CO}, \mathrm{NO}_{\mathrm{x}}, \mathrm{SO}_{\mathrm{x}}$, entre otros, generados en el caso del secado por atomización, secado de piezas conformadas y cocción.

- Gases producidos por descomposición de materias primas, como: $\mathrm{CO}_{2}$ de carbonatos, $\mathrm{NO}_{x}$ de nitratos, $\mathrm{HF}$ de silicatos, $\mathrm{HCl}$ de impurezas minerales, $\mathrm{SO}_{x}$ de sulfatos y/o sulfuros, entre otros. Estos contaminantes son característicos de procesos a alta temperatura, en el que se producen transformaciones físico - químicas importantes en los materiales procesados, como puede ser la etapa de cocción de baldosas cerámicas.

También es posible realizar una agrupación de los contaminantes gaseosos atendiendo a su naturaleza. Así, se puede hablar de contaminantes ácidos que son característicos de la fabricación de baldosas cerámicas y sobre los que se ha realizado el grueso del trabajo desarrollado en la presente memoria. Seguidamente se realiza una breve descripción de cada uno de ellos desde un punto de vista ambiental. 


\section{Compuestos de flúor (mayoritariamente HF)}

Los compuestos de flúor se encuentran presentes en las emisiones de la etapa de cocción de productos cerámicos fundamentalmente en forma de compuestos gaseosos. En general, el flúor en los hornos de cocción se genera como consecuencia de la descomposición de los minerales presentes en las materias primas. Estos minerales contienen impurezas de flúor en su estructura y pueden emitirse a partir de temperaturas del orden de $400-600^{\circ} \mathrm{C}$. El compuesto mayoritario que se forma y se emite es el HF y, en menor medida, el tetrafluoruro de silicio $\left(\mathrm{SiF}_{4}\right)$ y los fluoruros alcalinos en forma de partículas, aunque pueden considerarse prácticamente despreciables en la etapa de cocción (Semrau, 1957; Mazzali, 1989; Gazulla et al., 1996; Mallol et al., 2001; Moro et al., 2008).

\section{Compuestos de azufre (SO $\underline{x})$}

$\mathrm{El} \mathrm{SO}$ xe genera principalmente por la oxidación del azufre contenido en los combustibles fósiles (carbón y petróleo) durante el proceso de combustión. En el caso concreto del sector de baldosas cerámicas español cabe destacar una clara tendencia a disminuir la utilización de dichos combustibles fósiles y ser sustituidos por gas natural. Este gas está considerado dentro del grupo de los denominados combustibles limpios, ya que la presencia de azufre e impurezas en su composición es prácticamente despreciable.

No obstante, se debe tener en cuenta que en la fabricación de productos cerámicos se utilizan, en algunos casos, materias primas (fundamentalmente arcillas) que introducen azufre en la composición a través de impurezas; básicamente pirita $\left(\mathrm{FeS}_{2}\right)$ y yeso $\left(\mathrm{CaSO}_{4} \cdot 2 \mathrm{H}_{2} \mathrm{O}\right)$, que provocan emisiones de compuestos de azufre $\left(\mathrm{SO}_{\mathrm{x}}\right)$, particularmente $\mathrm{SO}_{2}-\mathrm{SO}_{3}$, durante la etapa de cocción (Kolkmeier, 1991; Monfort et al., 2010a).

La emisión de azufre en el proceso de cocción de materiales cerámicos se produce en dos periodos: una primera emisión se detecta alrededor de los $450 \stackrel{\circ}{\mathrm{C}}$ y es atribuida a la oxidación de pirita $\left(\mathrm{FeS}_{2}\right)$ y a la emisión de azufre asociado a materia orgánica. La segunda emisión tiene lugar por encima de los $750 \stackrel{\circ}{C}$ hasta el final del ciclo de cocción. En este caso la emisión se debe a la descomposición de los sulfatos (anhidrita $\left(\mathrm{CaSO}_{4}\right)$ o forma anhidra del sulfato cálcico), estando limitada por el proceso de vitrificación de la pieza (sinterización), donde tiene lugar un cerramiento de poros. Si estos sulfatos no son completamente eliminados durante el proceso de cocción pueden dar lugar a la presencia de eflorescencias en el producto final (Kolkmeier, 1991; Monfort et al., 2010a). 


\section{Compuestos de cloro $(\mathrm{HCl})$}

La emisión de compuestos de cloro, fundamentalmente $\mathrm{HCl}$, en el proceso de fabricación de baldosas cerámicas tiene su origen, especialmente, en las etapas de secado por atomización y cocción de baldosas cerámicas (Mallol et al., 2001).

El origen de dichas emisiones viene asociado, principalmente, a la presencia del ion cloro en el agua utilizada como materia prima. Los niveles de cloro en dichas aguas pueden verse incrementados cuando el agua utilizada es agua industrial tratada, ya que es habitual el uso del cloro como desinfectante en su tratamiento. Por otra parte, la gran mayoría de arcillas y aditivos utilizados contienen niveles traza de cloro. Sin embargo, aunque esté en niveles traza, el procesado de grandes cantidades de estos materiales da lugar a niveles de emisión elevados.

El cloro presente en el producto conformado y esmaltado se encuentra, fundamentalmente, en forma de compuestos inorgánicos (sales); aunque puede haber una cierta cantidad de compuestos orgánicos.

La emisión de compuestos de cloro se produce principalmente durante la etapa de cocción donde la mayor parte del cloro se volatiliza cuando se alcanzan temperaturas superiores a $850^{\circ} \mathrm{C}$, debido a la descomposición de las sales minerales que contienen cloro. También la descomposición de compuestos orgánicos que contienen cloro provoca la emisión de $\mathrm{HCl}$ en el intervalo de 450 y $550 \stackrel{\circ}{\circ}$ (IPTS, 2007).

\section{Óxidos de nitrógeno (NOX)}

Se denomina $\mathrm{NO}_{x}$ al conjunto de óxidos de nitrógeno presentes en una corriente gaseosa, compuesta básicamente por $\mathrm{NO}$ y $\mathrm{NO}_{2}$. Generalmente, la proporción de estos compuestos en las emisiones industriales de fabricantes de productos cerámicos se encuentra en un $90 \%$ de $\mathrm{NO}$ y un $10 \%$ de $\mathrm{NO}_{2}$ (ITC, 2009). Sin embargo, la oxidación de $\mathrm{NO}$ a $\mathrm{NO}_{2}$ es bastante rápida en aire ambiente.

El $\mathrm{NO}_{x}$ presente en las emisiones puede proceder de:

- La reacción entre el nitrógeno $\left(\mathrm{N}_{2}\right)$ y el oxígeno $\left(\mathrm{O}_{2}\right)$ del aire a elevada temperatura, es el denominado $\mathrm{NO}_{\mathrm{x}}$ térmico.

- La oxidación de moléculas de nitrógeno presentes en el combustible. Normalmente, a estos óxidos nitrosos se les denomina $\mathrm{NO}_{x}$ del combustible y la cantidad generada es baja si el combustible utilizado es gas natural.

- La descomposición de nitratos presentes en las materias primas. 
El origen más importante en los procesos de combustión es el $\mathrm{NO}_{x}$ térmico, la formación del mismo se ve favorecida por los siguientes factores:

- Elevada temperatura de llama (>1400 ํㅡ).

- Alta concentración de oxígeno y nitrógeno en la zona de la llama de mayor temperatura.

- Elevado tiempo de residencia de los reactivos a temperaturas elevadas (>1400 $\stackrel{\circ}{C})$.

- Aumento de la presión absoluta en la zona de alta temperatura.

En las emisiones de la industria cerámica la presencia de este contaminante se asocia a las etapas en las que existen procesos de combustión, en concreto: secado por atomización y cocción de baldosas (Mallol et al., 2001). 


\subsection{Instrumentos normativos aplicables a las emisiones atmosféricas de la fabricación de baldosas cerámicas}

\subsubsection{Marco normativo general en la Unión Europea}

El ámbito de actuación de los instrumentos normativos, recogidos en el presente punto, se enmarca en la Unión Europea (UE). La UE es una asociación económica y política singular de 28 países europeos que abarcan juntos gran parte del continente. Entre los Estados miembros se encuentran España e Italia, principales países productores de baldosas cerámicas a nivel europeo y entre los mayores a nivel mundial.

A nivel ambiental, el fundamento jurídico se recoge en el Tratado de Funcionamiento de la Unión Europea (TFUE), donde se dice que la UE es competente para actuar en todos los ámbitos de la política de medio ambiente, como la contaminación del aire y el agua, la gestión de residuos y el cambio climático. Su ámbito de actuación se ve limitado por el principio de subsidiariedad y por el requisito de unanimidad en el Consejo en los ámbitos de asuntos fiscales, ordenación territorial, utilización del suelo, gestión cuantitativa de los recursos hídricos, elección de fuentes de energía y estructura del abastecimiento energético.

La política europea en materia de medio ambiente tiene el objetivo de preservar la calidad del medio ambiente, proteger la salud humana y garantizar un uso racional de los recursos naturales.

Para conseguir dicho objetivo, la UE ha integrado la protección medioambiental en todas sus políticas sectoriales, en sus estrategias horizontales y se tiene en cuenta en las negociaciones internacionales en materia de medio ambiente, con el fin último de promover el desarrollo sostenible. En los últimos años, la integración de la política medioambiental ha alcanzado, por ejemplo, avances significativos en el ámbito de la política energética, tal como se refleja en el desarrollo paralelo del paquete de la UE sobre el clima y la energía o en la Hoja de ruta hacia una economía hipocarbónica competitiva en 2050, en la que se estudian maneras rentables de hacer que la economía europea sea más respetuosa con el clima y consuma menos energía. Esto obligará a los sectores responsables de las emisiones en Europa (generación de energía, industria, transporte, edificios y construcción, así como la agricultura) a contribuir a la transición a una economía hipocarbónica en las próximas décadas.

\section{Principios básicos de la política ambiental de la Unión Europea}

La política medioambiental de la UE se basa en los principios de cautela, prevención, corrección de la contaminación en su fuente y «quien contamina paga». Estos principios generales afectan a los ciudadanos de la UE y a sus actividades. 
El principio de «quien contamina paga» se aplica por medio de la Directiva 2004/35/CE, sobre responsabilidad medioambiental (DRM), cuyo objetivo es prevenir o poner remedio a los daños medioambientales causados a especies protegidas y hábitats naturales, el agua y el suelo. En dicha directiva se especifica que los operadores que realizan determinadas actividades profesionales, como las incluidas en ámbito de aplicación de la Directiva 2010/75/EU sobre emisiones industriales, deben tomar medidas preventivas en caso de amenaza inminente para el medio ambiente. De haberse producido ya el daño, están obligados a tomar las medidas adecuadas para remediarlo y a pagar los costes derivados.

\section{Marco básico}

El marco básico de la legislación ambiental en el ámbito de la Unión Europea se fundamenta en diferentes puntos, tal y como se recoge a continuación:

\section{A. Programas de acción en materia de medio ambiente}

Estos programas fijan las futuras propuestas legislativas y los objetivos para la política medioambiental de la UE; las medidas concretas se adoptan a continuación por separado. El Sexto Programa de Acción en Materia de Medio Ambiente, que determinó la política ambiental a lo largo de la década 2002 - 2012, se centró en cuatro prioridades: el cambio climático, la biodiversidad, el medio ambiente y la salud, y los recursos naturales y los residuos. Las medidas relativas a estas prioridades se detallaron en siete «estrategias temáticas», centradas en temas medioambientales horizontales, más que en contaminantes o en actividades económicas específicas.

En 2013, se adoptó el Séptimo Programa de Acción en Materia de Medio Ambiente hasta 2020 con el título «Vivir bien, respetando los límites de nuestro planeta». Partiendo de un conjunto de iniciativas estratégicas recientes (la Hoja de ruta sobre la gestión eficiente de los recursos, la Estrategia sobre biodiversidad para 2020 y la Hoja de ruta hacia una economía hipocarbónica competitiva en 2050), establece nueve objetivos prioritarios, entre ellos la protección de la naturaleza, una mayor resistencia ecológica, el crecimiento sostenible, eficiente en el uso de los recursos e hipocarbónico y la lucha contra las amenazas para la salud relacionadas con el medio ambiente. El programa también subraya la necesidad de una mejor aplicación de la legislación de la UE en materia de medio ambiente, la ciencia más avanzada, la inversión y la integración de los aspectos medioambientales en otras políticas.

En diciembre de 2013 la Comisión Europea adoptó el Programa «Aire Puro» para Europa. Con este programa se actualiza la legislación existente y se promueve la reducción de las emisiones perjudiciales desde la industria, el tráfico, las instalaciones energéticas y la agricultura, con la intención de reducir su impacto sobre la salud humana y el ambiente. El contenido de este programa destaca que la calidad del aire en Europa ha mejorado notablemente en las últimas décadas, pero también que la contaminación atmosférica se mantiene como el principal factor ambiental asociado a las enfermedades evitables y a la 
mortalidad prematura en la UE, y sigue teniendo efectos negativos en gran parte del medio natural europeo. Así, según la OCDE, la contaminación del aire en las ciudades se convertirá, de aquí a 2050, en la principal causa ambiental de mortalidad en todo el mundo, por delante de las aguas contaminadas y la falta de infraestructuras sanitarias.

\section{B. Estrategias horizontales}

Las estrategias horizontales permiten a la UE definir prioridades en un ámbito amplio. Sirva como ejemplo la Estrategia Europa 2020 que es la estrategia de crecimiento de la Unión. En esta estrategia se establece, entre otros, un objetivo principal para el clima y la energía, con el fin de aspirar a un «crecimiento inteligente, sostenible e integrador». También propone siete iniciativas emblemáticas, entre la que se encuentra la iniciativa «Una Europa que utilice eficazmente los recursos", donde se señala el camino hacia un crecimiento sostenible y se respalda el avance hacia una economía hipocarbónica y eficiente en el uso de los recursos.

\section{Evaluación de impacto ambiental y participación pública}

Aquellos proyectos, planes y programas públicos que vayan a tener probablemente repercusiones significativas sobre el medio ambiente se han de someter a una «evaluación de impacto ambiental» (EIA) o a una «evaluación estratégica medioambiental» (EEA). En ambos casos, la consulta al público es un aspecto central de la evaluación. Esta forma de actuación se remonta al Convenio de Aarhus, donde la «participación del público en la toma de decisiones» supone uno de los tres derechos garantizados al público en materia de medio ambiente. Los otros dos derechos son: el derecho de acceso a la información medioambiental en poder de las autoridades públicas (por ejemplo, sobre el estado del medio ambiente o la salud humana, de haber resultado afectada por el primero) y, el derecho de acceso a la justicia en caso de no haberse tenido en cuenta los otros dos derechos.

\section{Cooperación internacional en materia de medio ambiente}

\section{E. Aplicación, cumplimiento y seguimiento}

La legislación de la UE viene desarrollándose desde la década de 1970. En este ámbito están actualmente en vigor cientos de directivas, reglamentos y decisiones. Sin embargo, la eficacia de la política medioambiental de la UE depende en gran medida de su aplicación a escala nacional, regional y local. La aplicación y ejecución deficiente sigue siendo, con todo, una cuestión importante. También el seguimiento es esencial, tanto por lo que se refiere al estado del medio ambiente, como al nivel de aplicación de la legislación medioambiental de la UE.

A nivel industrial, la Directiva 2010/75/EU sobre emisiones industriales (DEI), trata de contrarrestar la gran divergencia en el nivel de aplicación entre los Estados miembros, y establece la necesidad de realizar inspecciones medioambientales de forma planificada. A fin de mejorar el cumplimiento de la legislación medioambiental europea, la Directiva 2008/99/CE relativa a la protección del medio ambiente mediante el Derecho Penal obliga a los Estados miembros a prever sanciones penales efectivas, proporcionadas y disuasorias 
para los delitos medioambientales de mayor gravedad, como por ejemplo, la emisión o vertido ilegal de sustancias a la atmósfera, el agua o el suelo, el comercio ilegal de especies silvestres, el comercio ilegal de sustancias que agotan la capa de ozono y el traslado o vertido ilegal de residuos.

Por su parte, se ha creado un importante instrumento de seguimiento de la actividad industrial mediante el Registro europeo de emisiones y transferencias de contaminantes integrado (PRTR europeo), que recoge información referente a los contaminantes emitidos a la atmósfera, el agua y el suelo, así como a las transferencias de residuos fuera del emplazamiento y de contaminantes en aguas residuales, facilitando datos medioambientales clave procedentes de más de 30000 instalaciones industriales de la UE, así como de Islandia, Liechtenstein, Noruega, Serbia y Suiza. El registro está disponible al público de forma gratuita en Internet.

\subsubsection{Legislación ambiental en materia de protección del medio ambiente atmosférico}

La protección del ambiente atmosférico se ha desarrollado en función de dos objetivos: i) mantener una calidad de aire adecuada $y$, ii) eliminar o reducir las emisiones de contaminantes atmosféricos, desde las diferentes fuentes, mediante la identificación e implementación de las medidas de reducción más efectivas a nivel local, nacional o comunitario. De esta forma, la legislación comunitaria está dividida en dos grandes bloques: calidad de aire y control de emisiones.

La legislación relativa a la calidad de aire viene definida en la Directiva 2008/50/CE, relativa a la calidad del aire ambiente y a una atmósfera más limpia en Europa, donde se definen los límites aceptables (estándares) de las concentraciones ambientales de determinados contaminantes atmosféricos. Esta directiva unifica los criterios de calidad de aire utilizados con anterioridad y los actualiza tomando en consideración la investigación científica más reciente y la experiencia de los Estados miembros.

Los parámetros regulados a nivel europeo son: $\mathrm{PM}_{10}, \mathrm{PM}_{2,5}, \mathrm{O}_{3}, \mathrm{C}_{6} \mathrm{H}_{6}, \mathrm{~Pb}, \mathrm{As}, \mathrm{Cd}, \mathrm{Hg}, \mathrm{Ni}$, $\mathrm{PAHs}, \mathrm{SO}_{2}, \mathrm{NO}_{2}, \mathrm{CO}$ y los $\mathrm{NO}_{x}$. Además, es de obligado cumplimiento para los estados miembros realizar un seguimiento en las áreas rurales de la composición química del $\mathrm{PM}_{2,5}$, para los siguientes elementos: $\mathrm{NO}_{3}{ }^{-}, \mathrm{SO}_{4}{ }^{2-}, \mathrm{Cl}^{-}, \mathrm{NH}_{4}{ }^{+}, \mathrm{Na}^{+}, \mathrm{K}^{+}, \mathrm{Mg}^{2+}, \mathrm{Ca}^{2+}$, carbono orgánico y carbono elemental.

En cuanto al control de emisiones, la legislación europea incluye la Directiva 2001/81/CE sobre techos nacionales de emisión (NEC), que impone límites de emisión a los Estados miembros sobre cuatro contaminantes atmosféricos clave que dañan la salud humana y el medio ambiente $\left(\mathrm{NO}_{x}, \mathrm{SO}_{2}, \mathrm{COV}\right.$ excepto $\mathrm{CH}_{4}$ y $\left.\mathrm{NH}_{3}\right)$. 
También existe legislación dirigida a reducir las emisiones de contaminantes atmosféricos procedentes de fuentes específicas. Las emisiones procedentes del tráfico regulan los siguientes contaminantes: $\mathrm{NO}_{x}$, hidrocarburos totales (THC), hidrocarburos no metanos (NMHC), CO y partículas para la mayoría de los tipos de vehículos.

En el caso de las pinturas y renovación del acabado de vehículos, se ha publicado la Directiva 2004/42/CE, también conocida como la Directiva de pinturas, dedicada a la limitación de la emisión de COV en dichos productos.

Probablemente, la fuente de emisión específica más importante sea la relacionada con las actividades industriales. Es indudable el papel que dichas actividades juegan en la economía y en el crecimiento sostenible de Europa. Sin embargo, también tienen un impacto significativo sobre el ambiente. Las instalaciones industriales más grandes representan una considerable aportación del total de las emisiones de los contaminantes atmosféricos principales junto con otros impactos ambientales. También incluye una gran variedad de contaminantes diferentes que dependen, fundamentalmente, del tipo de instalación, de la tecnología utilizada en el proceso de fabricación, y de las materias primas.

Precisamente las emisiones procedentes de instalaciones industriales han sido objeto de legislación europea desde hace algún tiempo y en la actualidad se basan, principalmente, en los siguientes instrumentos: Directiva 2010/75/EU sobre emisiones industriales, que incluye los requisitos de permiso y control de las instalaciones industriales y supone el marco normativo más importante en materia de emisiones industriales, la Directiva 1994/63/EU y la Directiva 2009/126/EU sobre distribución y almacenamiento de gasolina y el Reglamento 166/2006, que establece la obligación, para los Estados miembros, de informar a la Comisión Europea de las principales emisiones contaminantes a la atmósfera y al agua producidas en su país que hayan superado determinados valores límite umbrales. Con dicha información se elabora un Inventario Europeo de Emisiones Contaminantes (PRTR, del inglés Pollutant Release and Transfer Register). Dicho inventario permite el acceso público a información detallada de las emisiones y de otras transferencias de contaminantes y residuos de alrededor de 30000 instalaciones industriales.

\subsubsection{Directiva de emisiones industriales}

El objetivo de la Directiva 2010/75/EU, sobre emisiones industriales (DEI), es garantizar un nivel elevado de protección del medio ambiente considerado en su conjunto. Para su consecución utiliza los siguientes conceptos: enfoque integrado, mejores técnicas disponibles, flexibilidad, inspección y participación ciudadana.

El enfoque integrado significa que los permisos que las instalaciones deben solicitar para desarrollar su actividad deben tener en cuenta todo el desempeño ambiental de la planta, y que cubra por ejemplo: las emisiones a la atmósfera, el agua y el suelo, la generación de residuos, el uso de materias primas, la eficiencia energética, el ruido, la prevención de accidentes y la restauración del lugar una vez producido el cierre. 
Las condiciones de los permisos, incluidos los valores límite de emisión (VLE), deben basarse en el contenido de las conclusiones sobre las mejores técnicas disponibles (MTD). Dichas conclusiones se recogen en documentos que contienen información sobre los niveles de emisión asociados a las mejores técnicas disponibles. Para ayudar a las autoridades competentes en la concesión de licencias y a las empresas a determinar las MTD, la Comisión Europea organiza un intercambio de información entre expertos de los Estados miembros de la UE, la industria y organizaciones ambientales. Este trabajo está coordinado por la Oficina Europea de IPPC del Instituto de Prospectiva Tecnológica (Institute for Prospective Technological Studies, IPTS) del Centro de Investigación Común de la UE (Joint Research Centre, JRC), situado en Sevilla (España). Este proceso se traduce posteriormente en la adopción y publicación por parte la Comisión de las conclusiones sobre las MTD y los documentos de referencia, los denominados BREF, cuyas siglas provienen del inglés $B A T$ Reference Documents.

La DEI contiene ciertos elementos de flexibilidad que permiten que las autoridades competentes en la concesión de licencias establezcan valores límite de emisión menos estrictos en determinados casos. Dichas medidas sólo son aplicables cuando una evaluación muestra que sólo es posible alcanzar los niveles de emisión asociados a las mejores técnicas, descritas en las conclusiones sobre las MTD, generando costes desproporcionadamente altos en comparación con los beneficios ambientales, debido a:

a) la ubicación geográfica o las condiciones ambientales locales 0

b) las características técnicas de la instalación

La autoridad competente siempre debe documentar las razones de la aplicación de las medidas de flexibilidad en el permiso, incluido el resultado de la evaluación coste - beneficio.

La DEI también contiene requisitos obligatorios sobre las inspecciones medioambientales. Los Estados miembros deben establecer sistemas de inspección medioambientales o planes sobre todas las instalaciones afectadas. Estos planes son revisados y actualizados periódicamente.

Sobre la base de los planes de inspección se elaboran programas de inspección medioambiental prefijados que incluyen la frecuencia de las visitas a los distintos tipos de instalaciones. El periodo entre dos visitas in situ se basa en una evaluación sistemática de los riesgos medioambientales de las instalaciones correspondientes y no debe exceder de un año para las instalaciones que planteen los riesgos más altos y tres años para las instalaciones que planteen riesgos menores.

De igual modo, la Directiva asegura que el público tiene derecho a participar en el proceso de toma de decisiones, y de ser informado de sus consecuencias, teniendo acceso a:

- las solicitudes de permisos con el fin de dar opiniones

- los permisos 
- los resultados de la vigilancia de las emisiones

- el Inventario Europeo de Emisiones Contaminantes (PRTR). En el PRTR, los datos de las emisiones notificados por los Estados miembros se hacen accesibles en un registro público, que tiene por objeto proporcionar información ambiental sobre las principales actividades industriales

La DEI es de aplicación a las actividades industriales con un importante potencial de contaminación, como se define en el anexo I de la misma (las industrias de energía, producción y transformación de metales, la industria minera, la industria química, gestión de residuos, la cría de animales, etc.). Asimismo, contiene disposiciones especiales para las siguientes instalaciones: instalaciones de combustión ( $\geq 50 \mathrm{MW}$ ); de incineración o coincineración de residuos; ciertas instalaciones y actividades que utilizan disolventes orgánicos e instalaciones que producen dióxido de titanio.

La DEI no es de aplicación en las actividades de investigación, actividades de desarrollo o experimentación de nuevos productos y procesos.

\section{$\underline{\text { Requisitos ambientales }}$}

Según la Directiva, cualquier instalación industrial donde se lleven a cabo las actividades enumeradas en el anexo I de la misma debe cumplir con ciertas obligaciones básicas:

- implementar medidas preventivas contra la contaminación

- aplicar las mejores técnicas disponibles (MTD)

- no causar ningún tipo de contaminación significativo

- reducir los residuos, reciclarlos o eliminarlos de la manera que generen menor contaminación

- maximizar la eficiencia energética

- prevenir posibles accidentes y limitar su impacto

- rehabilitar los lugares cuando las actividades llegan a su fin

\section{Aplicación de las mejores técnicas disponibles}

La DEI indica que las instalaciones industriales deben utilizar las mejores técnicas disponibles según se definen en las conclusiones sobre las MTD correspondientes a su sector de actividad. Estas conclusiones contienen los niveles de emisión asociados a las MTD, NEA - MTD, y sirven como referencia para la elaboración de las condiciones de los permisos. 


\section{Condiciones del permiso}

Las disposiciones de la DEI indican que el permiso deberá prever las medidas necesarias para garantizar el cumplimiento de las obligaciones básicas del operador y las normas de calidad ambiental. Estas medidas deberán incluir, entre otra información relevante: los valores límite de emisión de sustancias contaminantes; las reglas para garantizar la protección del suelo, agua y aire; requisitos relativos a la metodología de medición de las emisiones, la frecuencia y el procedimiento de evaluación; las medidas relativas a las circunstancias excepcionales (fugas, fallos de funcionamiento, paradas momentáneas o definitivas, etc.); disposiciones relativas a la minimización de la contaminación de larga distancia o la contaminación transfronteriza y las condiciones para evaluar el cumplimiento de los valores límite de emisión.

\subsubsection{Aplicación en España de la Directiva de emisiones industriales}

A nivel estatal, el proceso de transposición de la Directiva 2010/75/UE ha consistido en la publicación de Ley $5 / 2013$, de 11 de junio, sobre emisiones industriales que modifica la Ley 16/2002, de 1 de julio, de prevención y control integrados de la contaminación, y del Real Decreto 815/2013, de 18 de octubre, por el que se aprueba el Reglamento de emisiones industriales que desarrolla la citada Ley 16/2002.

Además de la legislación aplicable a las instalaciones con elevado poder de contaminación existe legislación de carácter general en materia de contaminación atmosférica a nivel estatal. En concreto, la Ley 34/2007 es una normativa que aborda aspectos relativos a la protección del ambiente atmosférico entre los que se destacan la evaluación y gestión de la calidad del aire, la prevención y control de emisiones, los instrumentos de fomento de protección de la atmósfera y su planificación y los mecanismos de control, inspección y seguimiento de las emisiones, así como el régimen sancionador.

La Ley promulga dos tipos de medidas principales para la prevención y el control de emisiones: establece unos valores límite de emisión para los distintos contaminantes y actividades y fija las obligaciones específicas respecto a los distintos procesos que afectan a productos que pueden generar contaminación.

En relación al control, inspección y seguimiento de las emisiones a la atmósfera, la ley atribuye a las comunidades autónomas la responsabilidad de la adopción de las medidas de inspección necesarias, y a los funcionarios que las lleven a cabo el carácter de agentes de la autoridad.

\section{Fabricación de baldosas cerámicas}

Las empresas cerámicas afectadas por la DEI que han obtenido recientemente el permiso administrativo en forma Autorización Ambiental Integrada (AAI) tienen fijados los límites de emisión de sustancias contaminantes que se detallan en la Tabla 1.11. 
Tabla 1.11. Límites de emisión fijados en AAI concedidas a empresas cerámicas en la Comunitat Valenciana.

\begin{tabular}{|c|c|c|}
\hline Contaminante & Condiciones & Límite de emisión \\
\hline \multirow[t]{2}{*}{ Partículas sólidas (PST) } & Genérico & $30 \mathrm{mg} / \mathrm{Nm}^{3}$ \\
\hline & $\begin{array}{c}\text { Secaderos por atomización existentes, } \\
\text { con sistema de depuración } \\
\text { (hasta 2015) }\end{array}$ & $50 \mathrm{mg} / \mathrm{Nm}^{3}$ \\
\hline \multirow{2}{*}{$\begin{array}{c}\mathrm{NO}_{\mathrm{x}} \\
\text { (expresado como } \mathrm{NO}_{2} \text { ) }\end{array}$} & Gases de proceso & $250 \mathrm{mg} / \mathrm{Nm}^{3}$ \\
\hline & Cogeneración & $800 \mathrm{mg} / \mathrm{Nm}^{3}$ \\
\hline $\mathrm{SO}_{2}$ & Genérico & $200 \mathrm{mg} / \mathrm{Nm}^{3}$ \\
\hline \multirow{2}{*}{$\begin{array}{c}\text { Fluoruros } \\
\text { (expresados como HF) }\end{array}$} & Genérico & $10 \mathrm{mg} / \mathrm{Nm}^{3}$ \\
\hline & $\begin{array}{c}\text { Hornos de cocción } \\
\mathrm{Qv}<3000 \mathrm{Nm}^{3} / \mathrm{h} ; \mathrm{Qm}<0,1 \mathrm{~kg} / \mathrm{h}\end{array}$ & $30 \mathrm{mg} / \mathrm{Nm}^{3}$ \\
\hline
\end{tabular}

Cabe señalar que los niveles de emisión fijados en las AAI basados en NEA - MTD según el BREF de cerámica son considerablemente inferiores a los establecidos por la normativa anterior.

En el caso de las emisiones difusas de partículas, originadas como consecuencia del transporte, manipulación y almacenamiento al aire libre de materiales de naturaleza pulverulenta, la legislación a nivel nacional no concreta límites de emisión, pero sí establece la necesidad de adoptar medidas preventivas. Así, el artículo 51 del Decreto 833/1975 especifica que:

"En los parques de almacenamiento al aire libre de materiales a granel se tomarán las medidas adecuadas para evitar que la acción del viento pueda levantar el polvo. A tal fin, se aplicarán las medidas correctoras oportunas, como mantener el material constantemente humedecido, cubrirlo con fundas de lona, plástico o de cualquier otro tipo o se protegerá mediante la colocación de pantallas cortavientos...".

Este tipo de emisiones viene recogido en el BREF horizontal denominado: Emissions from storage, donde se contemplan las posibles MTD aplicables para disminuir las emisiones difusas de partículas (IPTS, 2006). 


\subsubsection{Legislación ambiental en materia de calidad de aire para compuestos de flúor}

Según las recomendaciones de la Organización Mundial de la Salud (WHO, 2002), en las áreas expuestas a compuestos de flúor procedentes de fuentes antropogénicas, los cambios en los niveles de dichos contaminantes deben ser supervisados mediante la utilización de los bioindicadores adecuados. En España, el Real Decreto 102/2011, relativo a la mejora de la calidad del aire, transpone al ordenamiento jurídico nacional los objetivos de calidad del aire establecidos por las directivas europeas, para los contaminantes con más incidencia en la salud de las personas y en el medio ambiente. Además, en su disposición transitoria única, establece objetivos de calidad para otros contaminantes, los cuales derivan del Decreto 833/1975, de 6 de febrero, por el que se desarrolla la Ley 38/1972, de protección del ambiente atmosférico. Entre estos contaminantes se encuentran los compuestos de flúor $y$, específicamente como compuesto independiente, el HF.

En concreto, la disposición transitoria única del Real Decreto 102/2011, establece objetivos de calidad del aire para cada contaminante como concentración media en veinticuatro horas y concentración media en treinta minutos. Estos objetivos, que se muestran en la Tabla 1.12, no deben superarse y serán de aplicación en tanto no se revisen según lo especificado en el artículo 9 de la Ley 34/2007.

Tabla 1.12. Objetivos de calidad de aire. Niveles de concentración media en veinticuatro horas y de concentración media en treinta minutos, que no deben superarse.

\begin{tabular}{ccc}
\hline Contaminante & $\begin{array}{c}\text { Concentración media en } \\
\text { treinta minutos, que no } \\
\text { debe superarse }\end{array}$ & $\begin{array}{c}\text { Concentración media en } \\
\text { veinticuatro horas, que no } \\
\text { debe superarse }\end{array}$ \\
\hline Compuestos de flúor & $60 \mu \mathrm{g} / \mathrm{m}^{3}$ & $20 \mu \mathrm{g} / \mathrm{m}^{3}$ \\
Fluoruro de hidrógeno & $30 \mu \mathrm{g} / \mathrm{m}^{3}$ & $10 \mu \mathrm{g} / \mathrm{m}^{3}$ \\
Cloro molecular & $300 \mu \mathrm{\mu} / \mathrm{m}^{3}$ & $50 \mu \mathrm{g} / \mathrm{m}^{3}$ \\
Cloruro de hidrógeno & $300 \mu \mathrm{\mu g} / \mathrm{m}^{3}$ & $50 \mu \mathrm{g} / \mathrm{m}^{3}$ \\
Sulfuro de hidrógeno & $100 \mu \mathrm{\mu g} / \mathrm{m}^{3}$ & $40 \mu \mathrm{g} / \mathrm{m}^{3}$ \\
Sulfuro de carbono & $30 \mu \mathrm{g} / \mathrm{m}^{3}$ & $10 \mu \mathrm{g} / \mathrm{m}^{3}$ \\
\hline
\end{tabular}

La metodología de medida de los objetivos de calidad de aire establecidos viene descrita en el anexo 2 de la Orden de 10 de agosto de 1976, y está basada en la toma de muestras gaseosas mediante la captación de un pequeño volumen de gas que atraviesa un borboteador con una disolución captadora adecuada.

En España, la información disponible sobre la concentración ambiental de HF y de compuestos de flúor es muy limitada, debido a la falta de estaciones de medida, a pesar de la existencia de objetivos de calidad de aire específicos para estos contaminantes. 
A modo de ejemplo, los estudios realizados en el distrito de Castellón por Escrig et al. (2009), muestran que los valores de concentración de fluoruros son fuertemente dependientes de la zona de muestreo, tal y como se aprecia en la Tabla 1.13. En todo caso los valores medidos son muy inferiores a los niveles de referencia detallados en la Tabla 1.12. No obstante, cabe considerar que los valores incluidos en la Tabla 1.13 corresponden únicamente a los fluoruros presentes en la parte soluble en agua a $60 \stackrel{\circ}{ } \mathrm{C}$ del material particulado $\mathrm{PM}_{10}$ recogido mediante captadores de alto volumen en periodos de 24 horas.

Tabla 1.13. Concentración media anual de material particulado $\mathrm{PM}_{10}$ y su contenido de cloruros y fluoruros solubles medidos en el distrito cerámico de Castellón $\left(\mu \mathrm{g} / \mathrm{m}^{3}\right)$ (Escrig et al., 2009).

\begin{tabular}{c|ccccc|cc|ccc}
\hline \multirow{2}{*}{$\boldsymbol{\mu g} / \mathbf{m}^{\mathbf{3}}$} & \multicolumn{4}{|c|}{ L'Alcora } & \multicolumn{3}{c|}{ Onda } & \multicolumn{3}{c}{ Borriana } \\
\cline { 2 - 12 } & $\mathbf{2 0 0 3}$ & $\mathbf{2 0 0 4}$ & $\mathbf{2 0 0 5}$ & $\mathbf{2 0 0 6}$ & $\mathbf{2 0 0 7}$ & $\mathbf{2 0 0 6}$ & $\mathbf{2 0 0 7}$ & $\mathbf{2 0 0 5}$ & $\mathbf{2 0 0 6}$ & $\mathbf{2 0 0 7}$ \\
\hline $\mathrm{PM}_{10}$ & 34 & 34 & 34 & 31 & 31 & 25 & 26 & 37 & 36 & 35 \\
$\mathrm{Cl}^{-}$ & 0,46 & 0,15 & 0,11 & 0,02 & 0,09 & 0,04 & 0,09 & 0,22 & 0,09 & 0,24 \\
$\mathrm{~F}$ & 0,24 & 0,20 & 0,20 & 0,17 & 0,19 & 0,02 & 0,03 & 0,09 & 0,07 & 0,08 \\
№ Muestras & 24 & 27 & 27 & 25 & 31 & 23 & 29 & 28 & 22 & 28 \\
\hline
\end{tabular}

La falta de información de niveles ambientales de estos contaminantes también se da en otros países vecinos, como por ejemplo el Reino Unido, donde se dispone de datos de concentraciones ambientales para un pequeño número de localizaciones rurales en concentraciones medias mensuales. Sin embargo, no se dispone de información relativa a exposiciones cortas (una hora o media, como exige la legislación) de este contaminante que permitan conocer la exposición de la población. No obstante, se recomienda que la concentración de HF, en forma de gas o aerosol, no supere los 0,2 ppm (160 $\left.\mu \mathrm{g} / \mathrm{m}^{3}\right)$ durante un período promedio de 1 hora, con el fin de proteger contra los efectos irritantes e inflamatorios a la piel, los ojos y las vías respiratorias (EPAQS, 2006).

\subsubsection{Legislación ambiental voluntaria aplicable a baldosas cerámicas}

Además de la legislación ambiental de obligado cumplimiento, existe legislación de carácter voluntario que puede ser de aplicación a las baldosas cerámicas. Un ejemplo de este tipo de normativa lo constituye la etiqueta ecológica comunitaria, definida en el Reglamento (CE) no 66/2010 de la UE, conocida como la EU - ECOLABEL. Se trata de una herramienta voluntaria en materia de gestión medioambiental que permite identificar aquellos productos 0 categorías de productos que presentan un mejor comportamiento ambiental, mediante el establecimiento de una serie de criterios ecológicos que debe cumplir para ostentar dicho distintivo.

Las baldosas cerámicas pueden optar a la concesión de la etiqueta ecológica europea al estar incluidas dentro de la categoría de producto denominada revestimientos rígidos. Los requisitos 
ambientales a cumplir para esta categoría de producto se recogen en la Decisión 2009/607/CE. En la misma se incluyen, entre otros, requisitos relativos a la emisión de contaminantes a la atmósfera. En concreto se exige que dichas emisiones no superen los valores recogidos en la Tabla 1.14 durante la fase de cocción.

Tabla 1.14. Valores límite de emisión exigidos para la concesión de la etiqueta ecológica de baldosas cerámicas en la etapa de cocción.

\begin{tabular}{lcc}
\hline \multicolumn{1}{c}{ Parámetro } & Valor límite $\left(\mathbf{m g} / \mathbf{m}^{2}\right)$ & $\begin{array}{c}\text { Método de } \\
\text { ensayo }\end{array}$ \\
\hline $\begin{array}{l}\text { Fluoruro, expresado como HF } \\
\text { Óxidos de nitrógeno ( } \mathrm{NO} \text { ), expresado como } \mathrm{NO}_{2}\end{array}$ & 200 & ISO 15713 \\
$\begin{array}{l}\mathrm{SO} \text {, expresado como } \mathrm{SO}_{2} \text {. Contenido de azufre en la } \\
\text { materia prima } \leq 0,25 \%\end{array}$ & 1500 & EN 14792 \\
$\begin{array}{l}\text { SOx considerado como } \mathrm{SO}_{2} \text {. Contenido de azufre en } \\
\text { la materia prima }>0,25 \%\end{array}$ & 5000 & EN 14791 \\
\hline
\end{tabular}

\subsubsection{Documento de referencia MTD de fabricación de cerámica (CER)}

La fabricación cerámica (CER) dispone de su documento BREF desde el año 2007 (IPTS, 2007), dado que dentro de las actividades industriales especificadas en la sección 3.5 del anexo I de la Directiva 2010/75/EU, aparecen las siguientes:

«3.5. Instalaciones para la fabricación de productos cerámicos mediante horneado, en particular de tejas, ladrillos, ladrillos refractarios, azulejos, gres cerámico o porcelanas, con una capacidad de producción superior a 75 toneladas por día, y/o una capacidad de horneado de más de $4 \mathrm{~m}^{3}$ y de más de $300 \mathrm{~kg} / \mathrm{m}^{3}$ de densidad de carga por horno».

Las actividades industriales contempladas en esta descripción se denominan industria cerámica. Los principales sectores de esta industria son los siguientes:

- pavimentos y revestimientos (baldosas cerámicas)

- ladrillos y tejas

- cerámica de mesa y de decoración (cerámica doméstica)

- productos refractarios
- cerámica sanitaria

- cerámica técnica

- tuberías de gres vitrificado

- agregados de arcilla expandida

- abrasivos aglomerados inorgánicos

Además de las actividades básicas de fabricación, este documento abarca todas las actividades directamente relacionadas que podrían tener un impacto en las emisiones o en la contaminación. Por lo tanto, incluye procesos desde la preparación de materias primas hasta 
la expedición de productos acabados. Quedan excluidas determinadas actividades como la extracción de materias primas y la fabricación de fritas y esmaltes, ya que no se consideran directamente relacionadas con la actividad primaria.

Cabe destacar que los valores de concentración de las emisiones gaseosas incluidos en el documento BREF se encuentran en unidades de $\mathrm{mg} / \mathrm{m}^{3}$ y se refieren a gases secos en condiciones normales (temperatura de $273 \mathrm{~K}$ y presión de $1013 \mathrm{hPa}$ ) con un contenido de oxígeno del $18 \%$ volumétrico.

En los siguientes apartados se ha extraído aquella información relativa a las MTD aplicables a la emisión de los compuestos gaseosos ácidos que se encuentra incluida en el BREF de fabricación cerámica, con especial atención a los compuestos de flúor. En concreto se ha incluido la información relativa a las medidas primarias aplicables a la emisión de compuestos de flúor y las medidas secundarias aplicables al conjunto de contaminantes ácidos.

La aplicación de algunas de las tecnologías incluidas en dicho documento BREF es discutible, principalmente las referentes al caso del HF en forma de medida primaria, al menos para el sector de baldosas cerámicas, tal y como se pone de manifiesto en los resultados obtenidos durante el presente trabajo de investigación.

\subsubsection{MTD aplicables a la emisión de compuestos gaseosos de la industria cerámica}

El documento BREF identifica diferentes tipos de MTD aplicables a la emisión de gases ácidos y establece dos niveles para ellas. El primer nivel incluye las MTD denominadas genéricas, es decir, aquellas aplicables en general al conjunto de sectores de la industria cerámica. El segundo nivel incluye las MTD más específicas, es decir, aquellas aplicables solamente a alguno de los sectores cerámicos incluidos en este documento. En el caso de las emisiones de compuestos gaseosos, los sectores que incluyen algún tipo de medida sectorial son cinco, en concreto: pavimentos y revestimientos (baldosas cerámicas), ladrillos y tejas, cerámica doméstica, cerámica sanitaria y cerámica técnica. A continuación se describen cada una de las MTD aplicables.

\section{a) MTD genéricas}

Medidas/técnicas primarias:

EI BREF indica que es posible reducir las emisiones de compuestos gaseosos tales como HF, $\mathrm{HCl}$ y $\mathrm{SO}_{x}$, procedentes de los gases de combustión de los procesos de cocción en los hornos mediante la aplicación de una o varias de las siguientes técnicas:

- Minimización del uso de precursores de estos contaminantes en las materias primas

- Optimización de la curva de cocción 
Medidas/técnicas secundarias en combinación con medidas/técnicas primarias:

En este apartado el documento establece que la aplicación de una o varias de las técnicas primarias y una o varias de las siguientes técnicas secundarias puede reducir la emisión de compuestos gaseosos:

- Adsorbentes de lecho fijo de tipo cascada

- Limpieza de gases con un filtro vía seca con adición de reactivo

\section{b) MTD sectoriales}

Esta sección incluye las conclusiones sobre las MTD específicas utilizadas en el tratamiento de las emisiones de gases inorgánicos para aquellos sectores donde dicha emisión es significativa.

Medidas/técnicas primarias:

\section{Ladrillos y tejas:}

Para este sector se propone reducir las emisiones de compuestos gaseosos (es decir, $\mathrm{HF}, \mathrm{HCl}$ y $\mathrm{SO}_{\mathrm{x}}$ ) procedentes de los gases de escape de los procesos de cocción en los hornos mediante la utilización de aditivos ricos en calcio.

Medidas/técnicas secundarias:

Pavimentos y revestimientos, cerámica doméstica, cerámica sanitaria y cerámica técnica:

Para los sectores indicados, el BREF muestra que se puede reducir las emisiones de los compuestos inorgánicos gaseosos procedentes de los gases de combustión de los procesos de cocción en los hornos mediante adsorbentes modulares, especialmente en los casos en los que el caudal de efluentes gaseosos no es muy elevado (por debajo de $18000 \mathrm{~m}^{3} / \mathrm{h}$ ) y las concentraciones de polvo y de compuestos inorgánicos distintos de $\mathrm{HF}\left(\mathrm{SO}_{x}\right.$ y $\left.\mathrm{HCl}\right)$ son bajas.

\section{Pavimentos y revestimientos:}

Para el sector de baldosas cerámicas propone, además, medidas para la reducción de las emisiones de HF procedentes de los gases de combustión de los procesos de cocción en los hornos a $1-5 \mathrm{mg} / \mathrm{m}^{3}$, como valor medio diario, mediante, por ejemplo, la depuración en seco de los gases de escape con un filtro de mangas con adición de reactivos químicos adecuados.

\subsubsection{Medidas primarias propuestas para el HF}

Este apartado recoge aquellas medidas de carácter primario incluidas en el documento BREF de fabricación de cerámica que son de aplicación para el caso del HF, dado que se ha centrado gran parte del presente trabajo de investigación en los compuestos de flúor al ser considerados como los contaminantes característicos de este tipo de industria. 
Para cada una de las medidas propuestas, se ha incluido una revisión crítica sobre su aplicación en la fabricación de baldosas cerámicas, con ciclos rápidos y elevadas temperaturas de cocción, con respecto a otros productos cerámicos como son las tejas y ladrillos.

\section{a) Minimización del uso de precursores de HF en las materias primas}

Según se recoge en el BREF, existen dos posibilidades de actuación mediante:

- El uso de materias primas y aditivos bajos en flúor que puede reducir significativamente las emisiones de flúor.

- En el caso de materias primas ricas en flúor, la adición de aditivos bajos en flúor (p. ej. arena) o de arcilla de bajo contenido en flúor que reducen las emisiones de flúor por un efecto de dilución.

La aplicación de estas medidas primarias seria una solución óptima dado que resolvería el problema en origen, pero la realidad industrial es diferente, ya que su aplicación real es limitada, aunque aplicable en principio a cualquiera de los sectores cerámicos.

También se establece que la eliminación de ciertas materias primas puede conllevar la aparición de problemas de calidad en las piezas (pérdida de resistencia mecánica o a la helada), por lo que se ha de realizar un completo estudio de laboratorio antes de implementar este tipo de soluciones.

De igual forma se indica que el contenido de contaminantes en las materias primas es un parámetro significativo, aunque no siempre determinante, en las emisiones de contaminantes durante la cocción, ya que dichas emisiones dependen de otras variables, como por ejemplo, los parámetros operativos del proceso de cocción y la permeabilidad de la pieza cerámica a alta temperatura. Por lo tanto, una reducción del 50 \% del contenido de contaminantes en las materias primas no siempre implica una reducción equivalente en la emisión de los mismos.

\section{Comentario crítico en su aplicación a la fabricación de baldosas cerámicas}

En un principio, esta medida debería de ser aplicable de forma eficaz a cualquier producto cerámico. Sin embargo, según nuestra experiencia, la sustitución de las materias primas actuales por otras de menor contenido de flúor es poco viable a nivel industrial en el distrito de Castellón debido a la escasez de determinadas tipologías de materias primas, como arcillas, con muy bajo contenido de flúor, como ha quedado demostrado en los trabajos previos realizados por el ITC (Gazulla et al., 1996) y se puede observar en los datos de contenido en flúor en materias primas incluidos en el anexo II del apartado 9.2. 


\section{b) Adición de aditivos ricos en calcio}

El BREF dedica un comentario importante a esta medida estableciendo que la adición de carbonato cálcico a los soportes cerámicos tiene un efecto de dilución, pero además también reaccionan a temperaturas relativamente bajas, entre los 700 y $850{ }^{\circ} \mathrm{C}$, con las materias primas que contengan fluoruro y cloruro, y con óxidos de azufre emitidos durante la cocción de materias primas que contengan azufre, reteniendo de esta forma el flúor, el cloro y el azufre en el interior del soporte cocido.

Esta reacción química sirve para fijar el flúor mediante la formación de fluoruro de calcio estable, y puede reducir significativamente la emisión de HF.

$$
\begin{gathered}
\mathrm{CaCO}_{3} \rightarrow \mathrm{CaO}+\mathrm{CO}_{2} \\
\mathrm{CaO}+2 \mathrm{HF} \rightarrow \mathrm{CaF}_{2}+\mathrm{H}_{2} \mathrm{O}
\end{gathered}
$$

Mediante reacciones similares se puede fijar también el azufre y el cloro al soporte cerámico durante la cocción.

Sin embargo la concentración de $\mathrm{HF}, \mathrm{HCl}$ y $\mathrm{SO}_{x}$ en la corriente de gases no está necesariamente relacionada con la cantidad de $\mathrm{CaO}$ presente en la materia prima, porque según algunos experimentos la presencia de carbonatos finos o de $\mathrm{CaO}$ en la composición del soporte durante la cocción, puede tener un efecto mínimo o nulo en los niveles de emisión de dichos contaminantes.

No obstante según se indica en el BREF, es posible que los aditivos ricos en calcio induzcan una reducción de la emisión de flúor comprendida entre un 10 y un $75 \%$ dependiendo de las materias primas utilizadas y de la temperatura máxima de cocción, pero dicha adición puede afectar a la calidad del producto final, por lo que esta medida no se puede aplicar de forma ilimitada en la práctica.

El principal sector de aplicación es la industria ladrillera, donde es posible mantener las propiedades técnicas del producto final con la adición de este compuesto, aunque se pueden alterar algunos aspectos de calidad como por ejemplo: color, resistencia a la compresión, contracción lineal, absorción de agua y aparición de eflorescencias.

\section{Comentario crítico en su aplicación a la fabricación de baldosas cerámicas}

Los resultados obtenidos en este trabajo, artículo $\mathrm{n}^{0}$ 1, indican que la emisión de flúor durante la etapa de cocción de baldosas cerámicas no presenta una clara dependencia con el contenido de $\mathrm{CaCO}_{3}$ presente en la composición del soporte, a pesar de que en el tipo de composiciones estudiadas varia entre el 0 y el $15 \%$. Por lo que, obviamente, en este tipo de productos la adición de $\mathrm{CaCO}_{3}$ como medida primaria parece, a priori, que no es efectiva, dado que todos ellos presentan emisiones de HF apreciables independientemente de su contenido en calcio. Precisamente uno de los objetivos del presente trabajo es profundizar en 
las causas que hacen que esta medida primaria no sea efectiva en la fabricación de baldosas cerámicas.

\section{c) Optimización de la curva de cocción y reducción de vapor de agua en los gases del horno}

Según se indica en el BREF, la optimización de la curva de cocción puede afectar a la emisión de HF, tal y como se describe a continuación:

a) La reducción de la velocidad de calentamiento en la escala más baja de temperatura (hasta $400^{\circ} \mathrm{C}$ ) ayuda a la readsorción de HF en la formación de $\mathrm{CaF}_{2}$, lo cual redunda en un descenso de las emisiones de HF. Un efecto similar puede aplicarse a las emisiones de $\mathrm{SO}_{\mathrm{x}}$. Suelen formarse a partir de la oxidación de la pirita y/o la disociación del sulfato de calcio presente en el soporte cerámico.

b) El aumento de la velocidad de calentamiento en la escala de temperatura que va de los $400{ }^{\circ} \mathrm{C}$ a la temperatura de cocción. La temperatura de sinterizado se alcanza con mayor rapidez y, por lo tanto, la menor difusión limita la liberación de emisiones, con lo que se reducen las emisiones.

c) La temperatura de cocción afecta a la descomposición de los sulfatos. Cuanto menor es la temperatura de cocción, menor descomposición se produce y, por lo tanto, más se reducen las emisiones de $\mathrm{SO}_{\mathrm{x}}$. La reducción de la temperatura de cocción se puede conseguir añadiendo fundentes a la mezcla de la materia prima.

d) Por regla general, cuanto más rápido es el ciclo de cocción, menor es la emisión específica de compuestos de flúor. Las características de la materia prima afectan a la liberación de estos compuestos, pero, para cualquier producto cerámico, resulta decisivo el tiempo de cocción a una temperatura superior a los $800^{\circ} \mathrm{C}$.

La optimización del control del proceso/curva de calentamiento puede aplicarse en todos los sectores de la industria cerámica, pero conviene destacar que, en la práctica, las curvas de calentamiento en la industria cerámica se optimizan teniendo en cuenta la calidad del producto y el consumo de energía. Por lo tanto, las curvas de calentamiento sólo pueden cambiarse si las propiedades técnicas del producto final lo permiten, y hay que tener en cuenta los costes adicionales al alterar las curvas de calentamiento debido a las emisiones.

La reducción de los niveles de vapor de agua en los gases del horno suele conllevar menores índices de emisión de fluoruro, ya que el mecanismo básico de liberación de fluoruro de los minerales arcillosos es la pirohidrólisis (Semrau, 1957). Esta reacción se produce a temperaturas de $800 \stackrel{\circ}{\mathrm{C}}$ y superiores.

En la práctica, la reducción del contenido de agua en la atmósfera del horno sería difícil de conseguir desde el punto de vista técnico, dado que el agua se produce durante la combustión de los combustibles fósiles empleados para calentar el horno. Esta producción de agua únicamente puede evitarse calentando el horno bien indirectamente, por ejemplo con 
quemadores de tubo radiante alimentados por gas, bien con electricidad, aunque esta última opción obligaría a introducir cambios importantes en el diseño del horno y supondría un consumo de energía más elevado.

Existen algunos ejemplos de utilización de hornos específicos que reducen el contenido de vapor de agua. Sin embargo, el uso de estas técnicas se define como emergente en el BREF. Se han documentado ejemplos para pequeñas producciones en hornos eléctricos en cerámicas técnicas y con quemadores de tubo radiante en hornos de rodillos.

\section{Comentario crítico en su aplicación a la fabricación de baldosas cerámicas}

Como indica el BREF, el margen de maniobra sobre las condiciones de cocción de un horno industrial de baldosas cerámicas es estrecho debido a su influencia sobre las propiedades finales de las baldosas cerámicas. No obstante, en el presente trabajo se han realizado maniobras en hornos industriales para ver la posibilidad de reducir los niveles de emisión mediante la aplicación de esta medida primaria (artículos ํㅡ 3 y no 4).

\subsubsection{Medidas secundarias propuestas para emisiones ácidas}

En muchos procesos de cocción de materiales cerámicos la adopción exclusiva de medidas primarias no es suficiente para cumplir con los límites de emisión por lo que la solución a las emisiones ácidas precisa de la adopción de medidas secundarias. Los sistemas de depuración de contaminantes en fase gaseosa más habituales se agrupan según el mecanismo de funcionamiento, en tres grandes grupos (Mallol et al., 2001; IPTS, 2007):

- Sistemas vía húmeda

- Sistemas semi - húmedos o semi - secos

- Sistemas vía seca

Las corrientes provenientes de los hornos de cocción utilizan, principalmente, los sistemas basados en la depuración vía seca. Estos sistemas funcionan en dos etapas. La primera etapa es una etapa química, donde se ponen en contacto los gases con un reactivo capaz de retener los contaminantes gaseosos mediante su transformación en un producto sólido. La segunda etapa es un proceso físico y consiste en la separación sólido - gas del producto sólido formado.

En la etapa química de la depuración tienen lugar reacciones de neutralización ácido - base. Los reactivos utilizados con mayor frecuencia son: carbonato cálcico $\left(\mathrm{CaCO}_{3}\right)$, hidróxido cálcico o cal apagada $\left(\mathrm{Ca}(\mathrm{OH})_{2}\right)$, bicarbonato sódico $\left(\mathrm{NaHCO}_{3}\right)$, carbonato sódico $\left(\mathrm{Na}_{2} \mathrm{CO}_{3}\right) \mathrm{O}$ mezclas de estos reactivos (Monfort et al., 2002).

Los reactivos pueden utilizarse en forma granulada o micronizada, en función del sistema de separación utilizado. 
El rendimiento de la depuración en los sistemas vía seca depende del contaminante a eliminar, del sistema utilizado, de la temperatura, de la presencia de otros contaminantes, del tipo de reactivo, etc. (Mallol et al., 2001).

A continuación se describen brevemente algunos de los sistemas utilizados para la depuración de compuestos gaseosos ácidos. También se aporta un resumen del rendimiento alcanzado por alguno de los sistemas más implantados en la industria.

\section{Adsorbedores}

En función de su configuración, estos sistemas se pueden dividir en adsorbedores de lecho tipo cascada, donde el reactivo es transportado en el interior del reactor, y adsorbedores de módulo, donde la corriente a depurar atraviesa un lecho de reactivo fijo.

\section{Adsorbedores de lecho tipo cascada}

En este sistema, la reacción entre el reactivo adsorbente, generalmente $\mathrm{CaCO}_{3}$, y los contaminantes presentes en la corriente gaseosa tienen lugar en una cámara, por donde circulan los gases y donde el adsorbente cae por gravedad. Para aumentar el tiempo de reacción y la superficie de contacto se colocan una serie de tabiques en dicha cámara, los cuales aseguran una circulación y distribución efectiva de la corriente gaseosa. El reactivo consumido se recoge en la parte inferior de la instalación. Estos adsorbedores pueden soportar temperaturas de los gases superiores a $500^{\circ} \mathrm{C}$ sin necesidad de tener que enfriarlos previamente, siendo eficientes para la depuración simultánea de $\mathrm{HF}, \mathrm{SO}_{x}$ y $\mathrm{HCl}$ en las emisiones provenientes de hornos.

\section{Adsorbedores de módulos}

Este sistema se utiliza principalmente para la depuración de HF. Se trata de una adsorción seca, en la cual se utilizan módulos conocidos como honeycomb, generalmente de hidróxido cálcico. En este proceso, la corriente gaseosa pasa a través de un reactor de acero en cuyo interior se depositan dichos módulos. Se produce la reacción del HF presente en la corriente gaseosa con los módulos de reactivo, formándose una sal fluorada (generalmente $\mathrm{CaF}_{2}$ ). El tiempo de vida de los módulos depende del tiempo de operación de la planta, del caudal de gases y de la concentración de flúor en la corriente gaseosa. Una vez agotados, los módulos saturados son remplazados por otros nuevos.

\section{Filtros de mangas}

En este caso, los gases a depurar son tratados mediante la adición de un reactivo, que es pulverizado en la propia conducción por un sistema neumático, antes del filtro de mangas. De esta forma, se permite un buen contacto entre el adsorbente y los contaminantes gaseosos a depurar. 
Durante el diseño de un filtro de mangas se debe tener en cuenta la elevada temperatura de los gases a tratar provenientes del horno de cocción. En caso necesario, los gases a tratar deben enfriarse por dilución con aire a temperatura ambiente o con un intercambiador de calor aire - aire. Esta variable condiciona el modo de operación del filtro y el tipo de manga a emplear. Las mangas filtrantes pueden ser de diferentes materiales aunque en esta aplicación es normal el uso del Nomex o del Nomex teflonado.

El material con el que están construidos los filtros de mangas debe ser resistente a condiciones alcalinas y ácidas.

En la Figura 1.15, se presenta el esquema de una instalación que utiliza un filtro de mangas como sistema de separación sólido - gas.

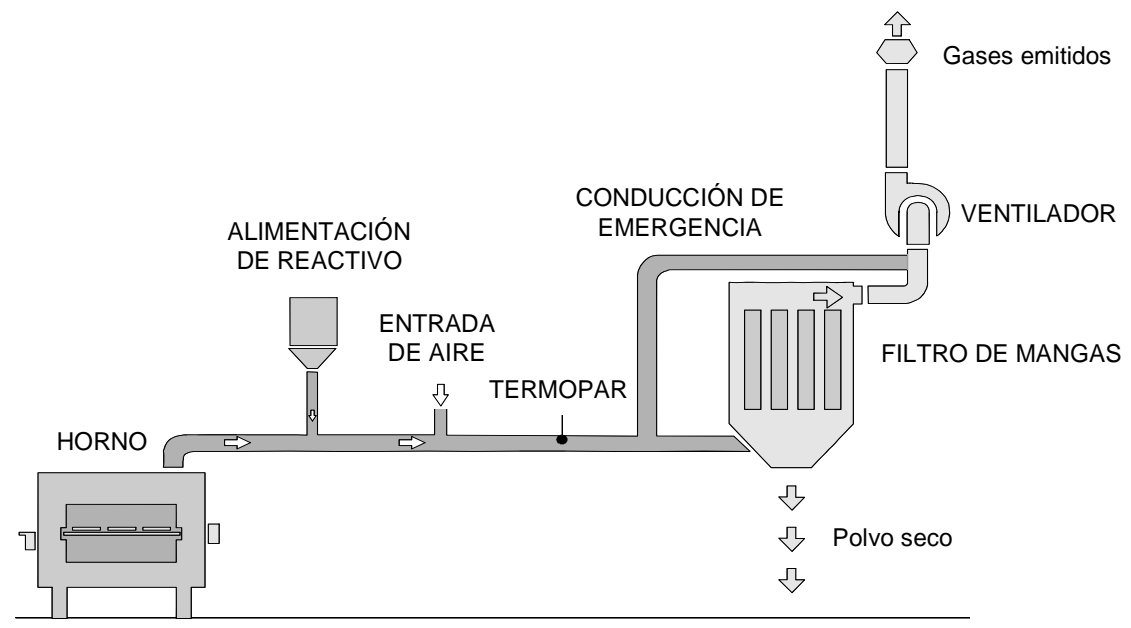

Figura 1.15. Depuración de ácidos mediante un sistema de adición de reactivos y filtro de mangas en un horno de combustión industrial de cocción de baldosas (Mallol et al., 2001).

\section{Precipitadores electrostáticos}

Los precipitadores electrostáticos pueden utilizarse en lugar de los filtros de mangas, utilizando el mismo sistema de inyección de reactivo. Este sistema ofrece la ventaja de poder operar a temperaturas superiores de la corriente de gases a depurar (superior a $400{ }^{\circ} \mathrm{C}$ ) sin necesidad de enfriar la corriente gaseosa antes de introducirla en el sistema de depuración. Además, posibilita su aprovechamiento energético en otras etapas del proceso de producción. Sin embargo, el contacto entre el adsorbente y el contaminante no es tan bueno como en el caso de utilizar filtros de mangas (Mallol et al., 2001).

La separación de las partículas del gas se realiza en tres etapas consecutivas. En primer lugar las partículas sólidas se cargan eléctricamente para, posteriormente, ser recogidas sobre los electrodos colectores. Por último, el polvo acumulado se descarga por vibración o por percusión de los electrodos y se recoge en la tolva de extracción. 


\section{Sistemas semi - húmedos o semi-secos}

Esta variante difiere de los sistemas en seco porque utiliza una pequeña cantidad de agua, lo que aumenta la reactividad del adsorbente y la eficiencia de la limpieza. Además, el consumo de adsorbente es menor, disminuyendo la generación de residuos. Las desventajas de esta técnica son los problemas de corrosión debido a la elevada humedad de la corriente y la complejidad de las operaciones de control. Por otro lado, la inversión inicial es muy elevada.

\section{$\underline{\text { Resumen de rendimiento de algunos sistemas de depuración por vía seca }}$}

El rendimiento alcanzable mediante la aplicación de sistemas de depuración vía seca sobre los efluentes típicos de la industria cerámica, puede llegar a ser muy elevado, tal y como se deduce de la Tabla 1.15 (Blasco et al., 1992; Busani et al., 1995; Mallol et al., 2001; ITC, 2001; IPTS, 2007).

Tabla 1.15. Comparativa de los rendimientos de depuración de los diferentes sistemas aplicables a las emisiones ácidas procedentes de la etapa de cocción de baldosas cerámicas.

\begin{tabular}{|c|c|c|c|c|c|}
\hline \multicolumn{2}{|c|}{ Equipo } & \multicolumn{2}{|c|}{$\begin{array}{l}\text { Adsorbedor de lecho tipo } \\
\text { cascada }\end{array}$} & \multirow{2}{*}{$\begin{array}{c}\begin{array}{c}\text { Filtro de } \\
\text { mangas }\end{array} \\
\begin{array}{c}\mathrm{Ca}(\mathrm{OH})_{2} \\
\text { micronizado }\end{array}\end{array}$} & \multirow{2}{*}{$\begin{array}{c}\begin{array}{c}\text { Filtro de mangas/ } \\
\text { Precipitador } \\
\text { eletrostático }\end{array} \\
\begin{array}{c}\mathrm{NaHCO}_{3} \\
\text { micronizado }\end{array}\end{array}$} \\
\hline Adso & nte & $\mathrm{CaCO}_{3}$ granulado & $\begin{array}{c}\mathrm{CaCO}_{3} \\
\text { modificado } \\
\text { granulado }\end{array}$ & & \\
\hline \multirow{5}{*}{$\begin{array}{c}\text { Rendimiento } \\
(\%)\end{array}$} & HF & $>99$ & $>99$ & $>99$ & $>99$ \\
\hline & $\mathrm{SO}_{2}$ & $>20$ & $>85$ & $>80$ & $>99$ \\
\hline & $\mathrm{SO}_{3}$ & $>80$ & $>85$ & $>90$ & $>99$ \\
\hline & $\mathrm{HCl}$ & $>50$ & $>50$ & $>85$ & $>89$ \\
\hline & Partículas & $>99$ & $>99$ & $>99$ & $>99$ \\
\hline \multicolumn{2}{|c|}{ Ratio estequiométrico } & 2,5 & 2,5 & 2,0 & 1,2 \\
\hline \multicolumn{2}{|c|}{$\begin{array}{l}\text { Coste adsorbente }(€ / t) \text { en } \\
2008\end{array}$} & $30-60$ & 100 & $60-100$ & 500 \\
\hline
\end{tabular}




\subsubsection{Niveles de emisión de compuestos gaseosos asociados a las MTD}

El documento BREF de fabricación cerámica recoge también los niveles de emisión asociados a las MTD (NEA - MTD) para compuestos inorgánicos gaseosos procedentes de la etapa de cocción, tal y como se muestra en la Tabla 1.16.

Tabla 1.16. Niveles de emisión asociados a las MTD para compuestos gaseosos ácidos.

\begin{tabular}{|c|c|c|}
\hline Parámetro & $\begin{array}{l}\text { Unidad, expresada } \\
\text { como valor medio } \\
\text { diario }\end{array}$ & NEA - MTD ${ }^{1)}$ \\
\hline Fluoruro, expresado como HF & $\mathrm{mg} / \mathrm{m}^{3}$ & $1-10^{2)}$ \\
\hline Cloruro, expresado como $\mathrm{HCl}$ & $\mathrm{mg} / \mathrm{m}^{3}$ & $1-30^{3)}$ \\
\hline $\mathrm{NO}$, expresado como $\mathrm{NO}_{2}$. Temperatura de gases $<1300 \stackrel{\circ}{\mathrm{C}}$ & $\mathrm{mg} / \mathrm{m}^{3}$ & $<250$ \\
\hline $\mathrm{NO} x$, expresado como $\mathrm{NO}_{2}$. Temperatura de gases $>1300 \stackrel{\circ}{\mathrm{C}}$ & $\mathrm{mg} / \mathrm{m}^{3}$ & $<500$ \\
\hline $\begin{array}{l}\mathrm{SO}_{x} \text {, expresado como } \mathrm{SO}_{2} \text {. Contenido de azufre en la } \\
\text { materia prima } \leq 0,25 \%\end{array}$ & $\mathrm{mg} / \mathrm{m}^{3}$ & $<500$ \\
\hline $\begin{array}{l}\mathrm{SO} \times \text { considerado como } \mathrm{SO}_{2} \text {. Contenido de azufre en la } \\
\text { materia prima }>0,25 \%\end{array}$ & $\mathrm{mg} / \mathrm{m}^{3}$ & $500-2000^{4)}$ \\
\hline \multicolumn{3}{|c|}{$\begin{array}{l}\text { 1) Las gamas dependen del contenido de contaminante (precursor) en las materias primas: en los procesos de cocción de } \\
\text { productos cerámicos con bajo contenido de contaminante (precursor) en las materias primas, los niveles inferiores dentro de } \\
\text { la gama constituyen NEA - MTD; en los procesos de cocción de productos cerámicos con alto contenido de contaminante } \\
\text { (precursor) en las materias primas, los niveles más elevados dentro de la gama se consideran NEA - MTD. }\end{array}$} \\
\hline \multicolumn{3}{|c|}{$\begin{array}{l}\text { 2) El nivel MTD superior puede ser menos elevado en función de las características de la materia prima. El NEA-MTD para el } \\
\text { sector de baldosas cerámicas es de } 5 \mathrm{mg} / \mathrm{m}^{3} \text {. }\end{array}$} \\
\hline \multicolumn{3}{|c|}{$\begin{array}{l}\text { 3) EI nivel MTD superior puede ser menos elevado en función de las características de la materia prima. Asimismo, el NEA - } \\
\text { MTD superior no debe impedir la reutilización de las aguas residuales. }\end{array}$} \\
\hline 4) El nivel MTD superior se aplica únicamente a las materias primas con & contenido de azufre suma & \\
\hline
\end{tabular}




Capítulo 2. Estado del arte en la emisión de compuestos de flúor durante la cocción de materiales cerámicos. 



\subsection{Introducción}

Desde la segunda mitad del siglo veinte, la comunidad científica ha mantenido un interés especial por conocer, con un mayor grado de detalle, la importancia de los contaminantes gaseosos de carácter ácido emitidos durante la cocción de materiales cerámicos. Este interés es debido a la afección que dichas emisiones pueden provocar sobre los seres vivos.

Los principales compuestos ácidos emitidos durante la cocción de materiales cerámicos son $\mathrm{HF}, \mathrm{HCl}, \mathrm{SO}_{x}$ y $\mathrm{NO}_{x}$. Aunque desde un punto de vista cuantitativo la emisión de compuestos de flúor no suele ser la más importante, desde un punto de vista legal es la más problemática puesto que la legislación europea establece, para estos compuestos, unos valores límite de emisión muy estrictos por sus potenciales afecciones al medio ambiente (como se ha descrito en el apartado 1.1.3). Por su parte, la emisión de $\mathrm{HCl}, \mathrm{SO}_{x}$ y $\mathrm{NO}_{x}$ está presente en numerosos procesos industriales, los dos últimos asociados, fundamentalmente, a procesos de combustión. El origen de cada uno de estos contaminantes ha sido descrito en el apartado 1.2.5.2 de la introducción.

Los compuestos de flúor son, probablemente, los contaminantes ácidos más característicos de la industria cerámica y, en especial, de la fabricación de baldosas cerámicas. Por este motivo, el resumen bibliográfico que se presenta a continuación recopila los resultados de los principales estudios relativos al origen, evolución y control de la emisión de dichos compuestos mediante la aplicación de medidas primarias de prevención durante la cocción de materiales cerámicos. Este resumen ha servido como base para la preparación del trabajo de investigación llevado a cabo en esta tesis.

Los primeros trabajos sobre emisiones de compuestos fluorados de especial significancia se desarrollaron en Alemania durante los años 80. En este país la industria de fabricación de tejas y ladrillos ha tenido una presencia significativa. Los trabajos se realizaron, en un primer momento en hornos de laboratorio y posteriormente en hornos túnel industriales de ciclos térmicos lentos (de hasta 24 horas) y con temperaturas máximas de cocción sobre los $1000 \stackrel{\circ}{\circ}$, en su mayoría. Estas investigaciones han sido objeto de revisión por diferentes autores (Strohmenger, 1983; Kolkmeier, 1986). Se han repasado igualmente trabajos realizados sobre este mismo tipo de producto y modo de producción en otras zonas geográficas, como las llevadas a cabo por estadounidenses (Brosnan, 1992; Brosnan y Sanders, 1998).

En el caso de las baldosas cerámicas, la emisión de compuestos de flúor durante su fabricación ha sido estudiada en Italia, uno de los principales países productores europeos. Estos trabajos fueron desarrollados en hornos industriales de combustión provistos de rodillos, con ciclos térmicos lentos (de hasta 8 horas) y rápidos (inferiores a 1,5 horas) y con temperaturas máximas de cocción de $1200^{\circ} \mathrm{C}$. Los resultados de estas investigaciones han sido revisados por diferentes autores (Fabbri, 1992; Palmonari y Timellini, 1992; Bonvicini et 
al., 2006). También han sido objeto de revisión otras investigaciones realizadas por autores turcos relacionadas con la fabricación de baldosas en hornos industriales de rodillos y en hornos túnel (Dogeroglu y Kara, 2002a, 2002b y 2004). Asimismo, en esta recopilación se han incluido trabajos de autores holandeses (Reymer y Jong, 1993; Denissen y Vries, 1998).

Las principales características de los trabajos de investigación revisados se han recopilado, en forma de tablas, en función del tipo de producto fabricado: tejas y ladrillos en la Tabla 2.1 y baldosas cerámicas en Tabla 2.2. La totalidad de las referencias mostradas han sido incluidas en el presente apartado.

\section{Estudios previos del Instituto de Tecnología Cerámica}

El Instituto de Tecnología Cerámica (ITC) ha centrado sus trabajos relativos a la emisión de compuestos ácidos en diferentes líneas desde mediados de los años 90. En concreto, estas líneas han sido:

- Caracterización de emisiones industriales procedentes de la fabricación de baldosas cerámicas, con especial atención a la determinación del contenido de compuestos ácidos en corrientes gaseosas. En el caso del flúor se han utilizado procedimientos de medida discontinuos y continuos, basados en métodos químicos y en tecnología láser, respectivamente.

- Determinación del contenido de compuestos de flúor en materias primas cerámicas.

- Estudio de aplicación de medidas de prevención y de corrección de la emisión de los compuestos ácidos generados durante la cocción de baldosas cerámicas.

El trabajo de caracterización de las emisiones procedentes de la fabricación de baldosas cerámicas y el estudio de la aplicación de medidas primarias conforman la base del trabajo presentado en esta tesis. 
Tabla 2.1. Investigaciones realizadas sobre ladrillos y tejas.

\begin{tabular}{|c|c|c|c|c|c|}
\hline Autores & Horno & $\begin{array}{l}\text { Tiempo de } \\
\text { ciclo }(h)\end{array}$ & $\mathrm{T}_{\text {máx }}\left({ }^{\circ} \mathrm{C}\right)$ & $\begin{array}{c}\text { Análisis de F } \\
\text { en gas }\end{array}$ & $\begin{array}{c}\text { Análisis de } F \\
\text { en pieza }\end{array}$ \\
\hline $\begin{array}{c}\text { Kother y Pauls, } \\
1982\end{array}$ & $\begin{array}{l}\text { Laboratorio e } \\
\text { industrial túnel }\end{array}$ & 24 & 1050 & ISE & ISE \\
\hline $\begin{array}{c}\text { Hauck y Hilker, } \\
1986\end{array}$ & Laboratorio & $6-9$ & 1050 & Continuo ND & -- \\
\hline Dehne, 1987 & $\begin{array}{c}\text { Laboratorio sin } \\
\mathrm{H}_{2} \mathrm{O}\end{array}$ & -- & $>1000$ & -- & Valoración \\
\hline Hill, 1995 & Laboratorio & -- & 1150 & FTIR & -- \\
\hline $\begin{array}{l}\text { Denissen y } \\
\text { Vries, } 1998\end{array}$ & $\begin{array}{l}\text { Laboratorio e } \\
\text { industrial túnel }\end{array}$ & 10 & 1100 & ISE & -- \\
\hline $\begin{array}{c}\text { Chipera y Bish, } \\
2002\end{array}$ & Laboratorio & 16 & $>1000$ & -- & XRD, TGA, IC \\
\hline
\end{tabular}

Tabla 2.2. Investigaciones realizadas sobre baldosas cerámicas.

\begin{tabular}{|c|c|c|c|c|c|c|}
\hline Autores & Producto & Horno & $\begin{array}{l}\text { Tiempo } \\
\text { ciclo (h) }\end{array}$ & $\begin{array}{l}T_{\text {máx }} \\
\left({ }^{\circ} \mathrm{C}\right)\end{array}$ & $\begin{array}{c}\text { Análisis de F } \\
\text { en gas }\end{array}$ & $\begin{array}{c}\text { Análisis de } F \\
\text { en pieza }\end{array}$ \\
\hline $\begin{array}{c}\text { Mazzali et al., } \\
1980\end{array}$ & -- & Laboratorio & $4 \mathrm{~h}$ & 1200 & ISE & ISE \\
\hline $\begin{array}{c}\text { Tunker y } \\
\text { Schmidt, } 1981\end{array}$ & $\begin{array}{c}\text { Gres } \\
\text { porcelánico }\end{array}$ & Laboratorio & $16 \mathrm{~h}$ & 1200 & -- & ISE \\
\hline $\begin{array}{c}\text { Reymer y Jong } \\
1993\end{array}$ & $\begin{array}{l}\text { Azulejo y } \\
\text { gres }\end{array}$ & Laboratorio & $80 \min$ & $\begin{array}{l}1100 \\
1200\end{array}$ & ISE & -- \\
\hline $\begin{array}{c}\text { Reymer y } \\
\text { Denissen, } 2001\end{array}$ & $\begin{array}{l}\text { Azulejo y } \\
\text { gres }\end{array}$ & $\begin{array}{l}\text { Laboratorio e } \\
\text { industrial rodillos }\end{array}$ & $45 \min$ & -- & -- & -- \\
\hline $\begin{array}{l}\text { Dogeroglu y } \\
\text { Kara, 2002a }\end{array}$ & -- & $\begin{array}{c}\text { Industrial rodillos } \\
\text { y túnel }\end{array}$ & $\begin{array}{c}30 \min a \\
48 \mathrm{~h}\end{array}$ & $\begin{array}{l}1050 \\
1175\end{array}$ & ISE & ISE \\
\hline $\begin{array}{l}\text { Dogeroglu y } \\
\text { Kara, } 2004\end{array}$ & $\begin{array}{l}\text { Azulejo y } \\
\text { gres }\end{array}$ & $\begin{array}{c}\text { Industrial rodillos } \\
\text { y túnel }\end{array}$ & -- & 1180 & ISE & $\begin{array}{c}\text { ISE; } \\
\text { Colorimetría }\end{array}$ \\
\hline
\end{tabular}




\subsection{El flúor en las materias primas de la industria cerámica}

El origen de los compuestos ácidos emitidos durante la fabricación de productos cerámicos está asociado fundamentalmente al uso de materias primas y combustibles que los pueden contener. En los hornos industriales de combustión, utilizados en la fabricación de baldosas cerámicas, el uso de gas natural como combustible es generalizado, y su contenido en flúor despreciable. Así, la principal fuente de ion flúor se encuentra asociada a la presencia del mismo en las materias primas utilizadas en la composición de materiales cerámicos.

Desde un punto de vista general, se puede afirmar que las materias primas tienen una concentración de flúor comprendida entre $500-1000 \mathrm{mg} / \mathrm{kg}$, con valores extremos entre 200 y $20000 \mathrm{mg} / \mathrm{kg}$ (Fabbri, 1992).

Las arcillas pueden contener pequeñas cantidades de minerales de flúor, siendo el más frecuente la fluorita $\left(\mathrm{CaF}_{2}\right)$, aunque con contenidos reducidos, inferiores a un $0,5 \%$ (Fabbri, 1992). El flúor también se presenta en proporciones elevadas, cercanas al $80-90 \%$ del contenido total de una arcilla, en minerales micáceos, como por ejemplo la biotita, la moscovita y la illita y, en proporciones menores, en minerales caoliníticos. Esto se confirma haciendo una separación de las distintas fracciones granulométricas y observando que, para distribuciones granulométricas con tamaños de partícula mayores, típicas de la caolinita, la cantidad de flúor disminuye (Dehne, 1987).

El flúor contenido en las arcillas se encuentra, generalmente, en la estructura cristalina de las mismas ocupando los huecos que dejan los oxidrilos $\left(\mathrm{OH}^{-}\right)$en la estructura del propio mineral arcilloso. Este fenómeno se conoce como sustitución iónica y es posible debido a la similitud dimensional existente entre el ion $\mathrm{F}^{-}$y el ion $\mathrm{OH}^{-}$(Fabbri, 1992).

En concreto, los grupos oxidrilos que son sustituidos por el flúor son los grupos $\mathrm{OH}^{-}$saturados y coordinados en el interior del retículo cristalino y, en segundo lugar, en la posición de los iones $\mathrm{OH}^{-}$intercambiables dispuestos en las diferentes posiciones superficiales activas de los silicatos laminares (filosilicatos). De todos modos, el contenido de flúor en un mismo depósito arcilloso puede variar como consecuencia de las eventuales modificaciones del material, tanto en dirección vertical como horizontal (Fabbri, 1992).

En el caso de las materias primas utilizadas en las composiciones de ladrillos, el contenido en flúor es directamente proporcional a la abundancia de filosilicatos del tipo 2:1 (Chipera y Bish, 2002).

En los trabajos realizados en el ITC se ha analizado el contenido de flúor en muestras de arcilla roja. Estas arcillas son utilizadas en el distrito de Castellón para la fabricación de baldosas cerámicas. Los resultados obtenidos permiten conocer que existe una estrecha variación en la concentración de flúor que puede ir desde los 500 a los $800 \mathrm{mg} / \mathrm{kg}$ de arcilla, tal y como se muestra en la Tabla 2.3 (Gazulla et al., 1996). 
Tabla 2.3. Flúor en las principales arcillas rojas utilizadas en Castellón (Gazulla et al., 1996).

\begin{tabular}{cc}
\hline Muestra & $\mathbf{F}(\mathbf{m g} / \mathbf{k g})$ \\
\hline Arcilla de Moró & 543 \\
Arcilla de Mas Vell & 631 \\
Arcilla de Galve & 645 \\
Arcilla de Chulilla & 787 \\
Arcilla de Villar & 773 \\
Arcilla de Higueruelas & 537 \\
\hline
\end{tabular}

Los minerales arcillosos como la illita y la caolinita contienen flúor. Este elemento también está presente en otros minerales tales como el talco, la pirofilita, la montmorillonita y la biotita. Cuando las arcillas poseen mayor contenido de calcio, magnesio, alúmina y elementos alcalinos, el contenido de flúor normalmente también aumenta (Brosnan, 1992).

Bonvicini et al., 2006 recopilaron el contenido de flúor de algunas materias primas utilizadas habitualmente en composiciones cerámicas. Dicha recopilación se muestra en la Tabla 2.4.

Tabla 2.4. Flúor en las materias primas principales de materiales cerámicos (Bonvicini et al., 2006).

\begin{tabular}{|c|c|c|}
\hline Materias primas & Tipología & $F(\mathbf{m g} / \mathbf{k g})$ \\
\hline \multirow[t]{4}{*}{ Arcillas } & Composición de ladrillos & $500-660$ \\
\hline & Utilizadas en Italia & $500-1250$ \\
\hline & Utilizadas en el distrito cerámico de Italia & $500-1700$ \\
\hline & Utilizadas en Alemania & $400-700$ \\
\hline \multirow[t]{2}{*}{ Caolines } & Caolín & 260 \\
\hline & Materias primas caoliníticas & $200-500$ \\
\hline \multirow{3}{*}{$\begin{array}{l}\text { Otras materias } \\
\text { primas }\end{array}$} & Apatito & 5800 \\
\hline & Talco & 2500 \\
\hline & Cuarzo y feldespatos & $2-420$ \\
\hline \multirow{3}{*}{$\begin{array}{l}\text { Minerales } \\
\text { micáceos }\end{array}$} & Flogopita & 16000 \\
\hline & Biotita & $3400(19000-23000)$ \\
\hline & Moscovita & $0-4000$ \\
\hline
\end{tabular}

Basándose en los datos de contenido en flúor se podría establecer una estrategia de selección y utilización de materias primas o aditivos con bajo contenido en dicho elemento para permitir la disminución de la emisión de dichos compuestos. El propio documento BREF establece que si se disminuye la cantidad de flúor presente en las materias primas o si ésta se purifica, se pueden conseguir disminuciones en la cantidad de contaminante emitido (IPTS, 2007), tal y 
como se ha revisado en el capítulo de introducción, apartados 1.3.5.1 y 1.3.5.2. Esta afirmación parece acertada a priori, dado que en la literatura científica se han encontrado correlaciones significativas entre los valores de flúor en las materias primas y su emisión, sin embargo, no todos los autores han sido tan categóricos en sus conclusiones (Dogeroglu y Kara, 2004).

En el caso de las arcillas rojas, atendiendo a los resultados mostrados en la Tabla 2.3, se deduce que la capacidad de utilizar materias primas con un menor contenido de flúor como medida primaria posee una aplicabilidad limitada dado que parece que dicho contenido se encuentra en un margen estrecho de concentración y no existen, al menos para los casos estudiados, grandes diferencias entre unas materias primas y otras.

\subsection{Emisión de flúor durante el tratamiento térmico}

La emisión de flúor más importante durante el proceso de fabricación cerámica tiene lugar en la etapa de cocción debido a las elevadas temperaturas alcanzadas $\left(>500^{\circ} \mathrm{C}\right)$ que modifican la estructura mineral de las arcillas. Por el contrario, en otras etapas del proceso productivo como, por ejemplo, durante la etapa de secado de piezas conformadas, debido a las bajas temperaturas alcanzadas la emisión de compuestos de flúor gaseosos es improbable, excepto si se utilizan gases calientes, procedentes de la zona de enfriamiento de la etapa de cocción. Cuando la extracción de dichos gases no se realiza de forma adecuada se produce un arrastre de parte de los gases desde la zona de máxima temperatura del horno donde la presencia de flúor es mayor (Busani et al., 1995; Mallol et al., 2001).

Durante la etapa de cocción, el flúor presente en las arcillas se libera en un intervalo de temperatura que va desde los $300^{\circ} \mathrm{C}$ hasta pasados los $1200^{\circ} \mathrm{C}$. Durante el transcurso de esta liberación se forman compuestos como el HF, $\mathrm{H}_{2} \mathrm{SiF}_{6}$ y $\mathrm{SiF}_{4}$ (Mazzali et al., 1980).

El mecanismo de emisión del flúor presente en un material cerámico sometido a un tratamiento térmico en una atmósfera con presencia de vapor de agua, se presenta en forma de esquema en la Figura 2.1. Sobre dicha figura se explican, de forma detallada, las diferentes reacciones en las que está implicado dicho flúor. En este caso, el mecanismo de emisión propuesto se ha obtenido a partir de los resultados de los experimentos realizados en laboratorio y confirmados, posteriormente, con medidas industriales en hornos túnel de cerámica estructural con ciclos térmicos de varias horas de duración (Denissen y Vries, 1998). 


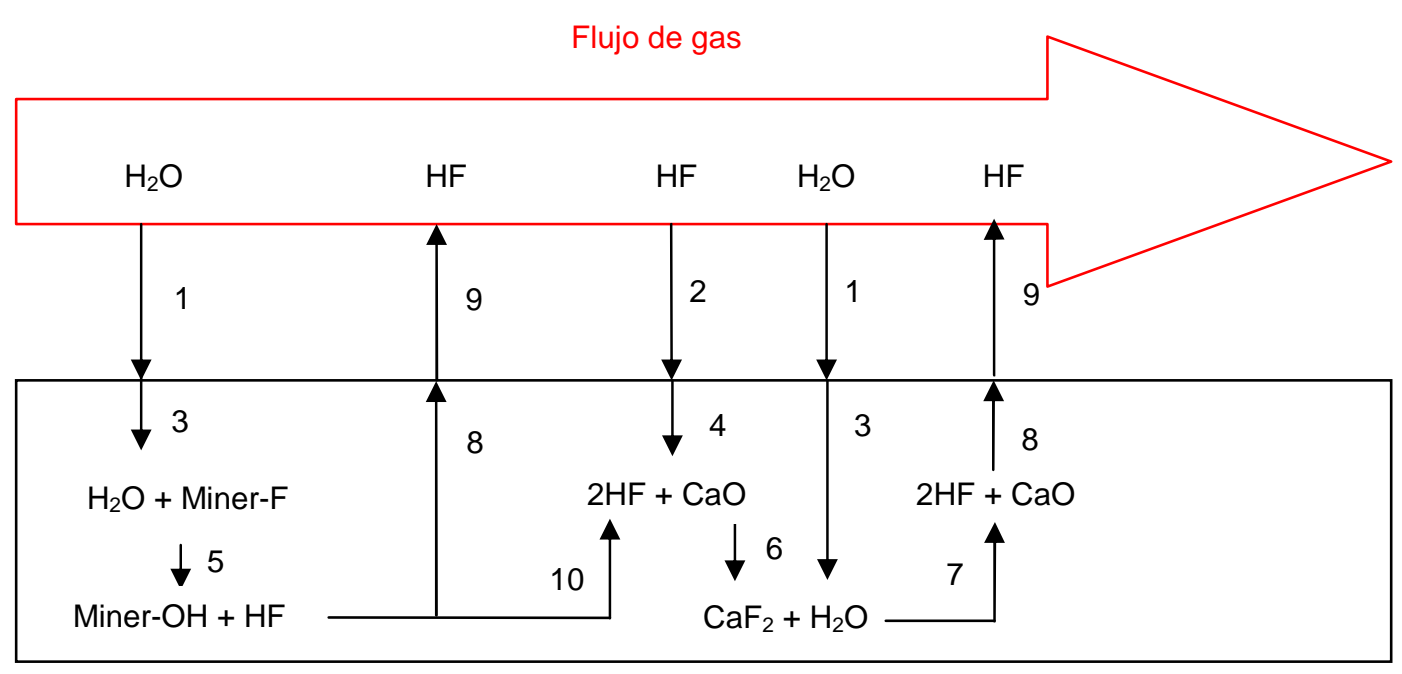

Soporte cerámico

1. Transporte de agua desde el gas a la pieza

2. Transporte de HF desde el gas a la pieza

3. Difusión del agua en el material

4. Difusión del HF en el material

5. Formación de HF en el mineral arcilloso

6. Reacción entre $\mathrm{HF}$ y $\mathrm{CaO} / \mathrm{CaCO}_{3}$ en la pieza
7. Formación de $\mathrm{HF}$ por reacción entre $\mathrm{CaF}_{2} \mathrm{y}$ $\mathrm{H}_{2} \mathrm{O}$

8. Difusión de HF desde el material

9. Transporte de HF desde la pieza a la corriente gaseosa

10. Reacción del HF durante la difusión

Figura 2.1. Esquema del mecanismo de emisión (Denissen y Vries, 1998).

Cuando se realiza el seguimiento de la emisión de HF en función de la temperatura en la atmósfera de un horno de cocción que presenta una cantidad apreciable de vapor de agua, superior al $4 \%$, se observa que la concentración de la emisión de HF evoluciona en dos etapas diferenciadas, tal y como se muestra en la Figura 2.2 (Hill, 1995). La primera etapa tiene lugar en el intervalo de temperatura de $450-750^{\circ} \mathrm{C}$, mientras que la segunda etapa se produce alrededor de los $900 \stackrel{\circ}{\circ}$. Este estudio se ha llevado a cabo sobre ladrillos cerámicos tratados térmicamente en un horno de laboratorio a cuya atmósfera se ha añadido vapor de agua de forma artificial. 


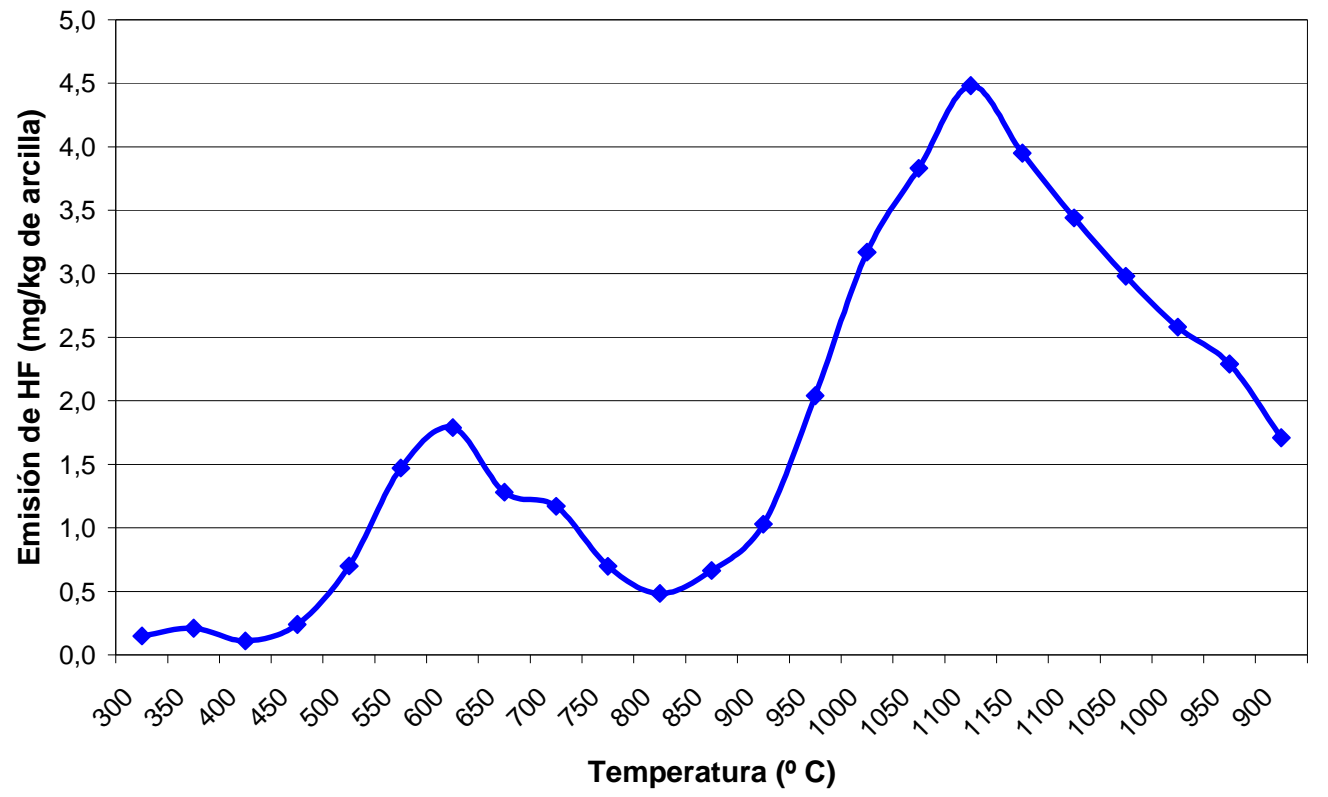

Figura 2.2. Evolución de HF en una atmósfera con presencia de vapor de agua (Hill, 1995).

El primer intervalo de emisión de HF que se observa en la Figura 2.2 se debe a la deshidroxilación de la materia prima que provoca la liberación de flúor en forma de HF. Este compuesto es la única especie estable de flúor presente en un proceso de combustión. A partir de este momento la emisión de flúor comienza a aumentar, de forma más apreciable a partir de los $800{ }^{\circ} \mathrm{C}$, y disminuye cuando empieza la sinterización (1100 $\left.{ }^{\circ} \mathrm{C}\right)$. En el transcurso de esta investigación también se observó que el tiempo de permanencia a temperaturas superiores a $800 \stackrel{\circ}{\circ}$ tiene influencia en la cantidad de HF liberada, siendo mayor la emisión cuando aumenta dicho tiempo.

El segundo periodo de emisión de HF se debe a la descomposición de los compuestos de flúor formados temporalmente sobre la superficie de las partículas, durante y después de la deshidroxilación. De hecho, existe un equilibrio entre las partículas de arcilla y los gases que contienen flúor, debido a la elevada presión parcial del flúor durante la deshidroxilación, que favorece la formación de compuestos de arcilla - flúor, que no se descomponen hasta intervalos de temperaturas más elevados, durante el precalentamiento o por la permanencia, durante un tiempo dado, a una temperatura determinada (Brosnan y Sanders, 1998).

Por su parte, en la Figura 2.2 también se observa la existencia de una emisión de HF durante el periodo de enfriamiento. Esta emisión es debida a que la pieza se encuentra a su temperatura máxima. Este periodo de enfriamiento desempeña un importante papel en el control de las emisiones de flúor puesto que la emisión presenta un máximo en esa fase de la cocción. Así, el punto donde se inicia el enfriamiento y la velocidad a la que éste se lleva a 
cabo es un factor crítico de cara a controlar la cantidad total de flúor emitido (Reymer y Jong, 1993).

A nivel industrial se constata que el tipo de tratamiento térmico aplicado a los materiales cerámicos influye en la emisión del flúor contenido en los mismos. Por este motivo, el proceso productivo utilizado por una determinada instalación industrial para la cocción de materiales cerámicos tiene asociado una emisión de flúor diferente. En la Tabla 2.3 se ha comparado la emisión generada en diferentes procesos de cocción para el caso de las baldosas rojas. Los diferentes productos estudiados se clasificaron en función de su porosidad determinada por la absorción de agua: $\mathrm{BI}<3 \%$, Blla $3-6 \%$, Bllb $6-10 \%$ y BlII >10 \%.

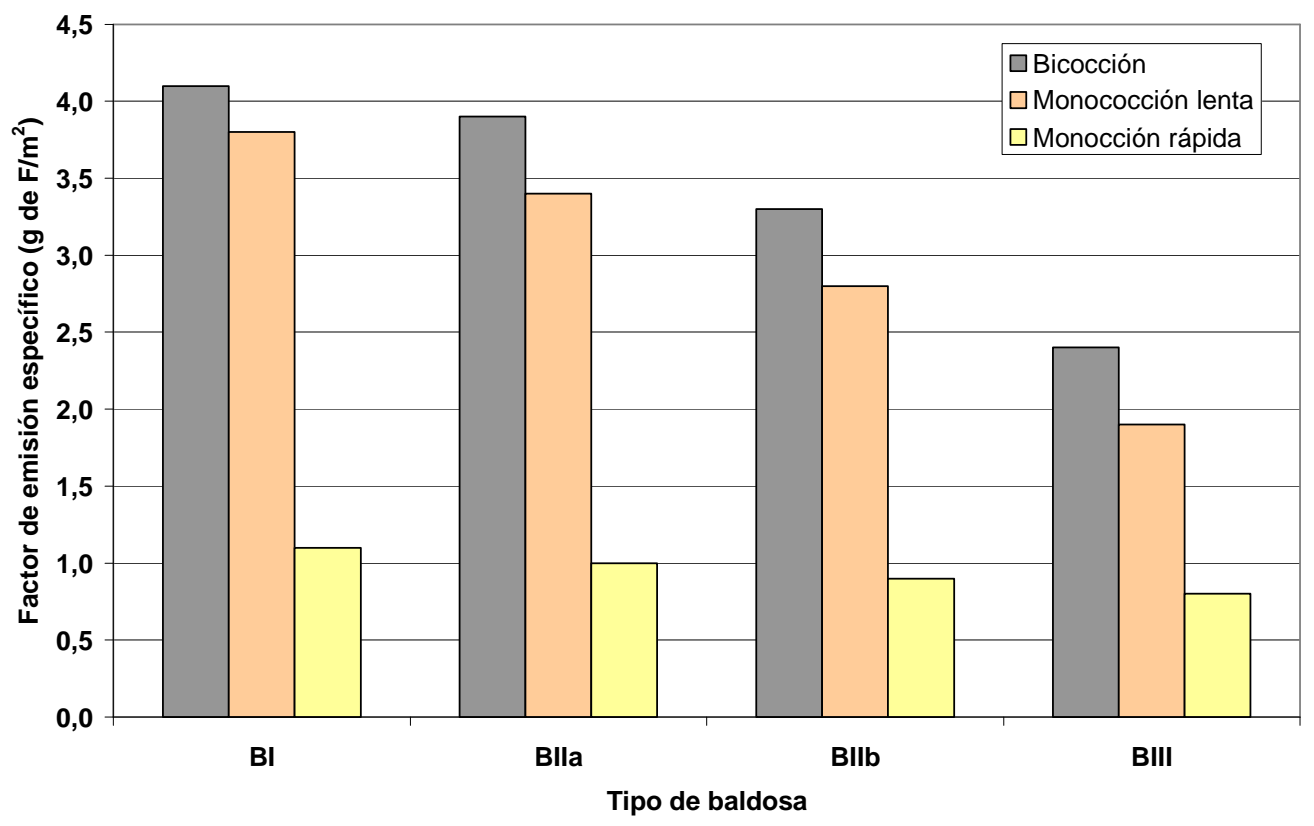

Figura 2.3. Comparación de emisiones de flúor en función de la tipología de producto y de la tecnología de cocción utilizada (Palmonari y Timellini, 1992).

El proceso de fabricación mediante monococción rápida en hornos de combustión continuos, que utilizan como combustible gas natural, es el sistema productivo que presenta menores emisiones. Cabe destacar que en la actualidad, este sistema supone la forma de producción más ampliamente implantada en la industria de fabricación de baldosas cerámicas (Mallol et al., 2001).

A partir de los datos de la Figura 2.3 también se deduce que, para un mismo tipo de tecnología de cocción, el factor de emisión de flúor tiende a disminuir cuando aumenta la adsorción de agua. Este hecho está relacionado no tanto con la composición de las materias primas sino con la temperatura de cocción de dichos productos que varía entre 1200 y $1250 \stackrel{\circ}{\mathrm{C}}$ para el caso del grupo BI y entre 1000 y $1050 \stackrel{\circ}{\circ}$ para el caso del grupo BIII. Así, al aumentar la temperatura máxima de cocción aumenta la emisión a la atmósfera de los compuestos de flúor 
(Palmonari y Timellini, 1992). En soportes de gres (BII) y gres porcelánico (BI) la sinterización del material disminuye la permeabilidad de la pieza a elevada temperatura, dificultando la salida de HF. Sin embargo, el efecto global observado es que la emisión de dicho compuesto aumenta al aumentar la temperatura de cocción o el tiempo de permanencia a elevada temperatura.

En resumen, numerosos autores (Routschka y Majdic, 1978; Kother y Pauls, 1982; Dehne, 1987; Palmonari y Timellini, 1992) sugieren que es posible conseguir disminuciones del nivel de emisión de flúor mediante la reducción del tiempo de permanencia del soporte cerámico en la zona de mayor temperatura del horno y la disminución de la temperatura máxima de cocción.

Otro factor a tener en consideración en un horno industrial respecto a la emisión de flúor es el sentido de circulación de los gases en su interior. Cuando esta circulación es en contracorriente, el HF puede reaccionar con el soporte cerámico a temperaturas comprendidas entre $700-300{ }^{\circ} \mathrm{C}$, aumentando el contenido en HF del soporte y reduciendo así la emisión de este compuesto. De la misma forma, se ha comprobado la existencia de fenómenos de desorción de HF en la zona de máxima temperatura. Este comportamiento ha dado pie a considerar la existencia de un ciclo de flúor en el interior de los hornos de cocción (Hauck y Hilker, 1986; Brosnan, 1992; Denissen y Vries, 1998).

Un aumento de la turbulencia en la zona de precalentamiento que permita un mejor contacto entre los gases y los soportes cerámicos a lo largo del horno favorece la adsorción del HF en la pieza en dicha zona. Del mismo modo, la reutilización del flujo de gases en la zona de precalentamiento o en el secadero puede mejorar la adsorción del flúor.

Por otra parte, la cantidad de aire de combustión o la existencia de infiltraciones de aire en la zona de adsorción puede disminuir la concentración de HF en la atmósfera del horno y, por tanto, perjudicar la adsorción del mismo obteniendo como consecuencia un aumentando de la emisión de flúor (Strohmenger, 1983).

Por último, cabe remarcar que el contenido de flúor del material cerámico no es emitido en su totalidad durante el tratamiento térmico ya que parte del flúor es retenido en la pieza cocida y puede ser emitido, en cantidades variables, en sucesivos tratamientos térmicos (Döğeroğlu y Kara, 2002a).

\subsubsection{Efecto del contenido de vapor de agua en la emisión de flúor}

El vapor de agua presente en el horno de cocción, tanto en la atmósfera como en la propia baldosa, contribuye a la formación de $\mathrm{HF}$ y a la descomposición del $\mathrm{CaF}_{2}$ presente en la pieza (Reymer y Jong, 1993). Cuando se lleva a cabo el seguimiento de la emisión de HF en función de la temperatura en una atmósfera exenta de vapor de agua, el comportamiento difiere del mostrado en la Figura 2.2, dado que no tiene lugar el primer periodo de emisión. Sin embargo, 
se ha comprobado que existe una fuerte correlación entre la emisión de flúor y la cantidad de agua cristalina contenida en el material tratado térmicamente (Reymer y Jong, 1993; Denissen y Vries, 1998; Wei-hong et al., 2001).

En el caso de que la atmósfera del horno disponga de una cantidad reducida de vapor de agua, menor del $3 \%$, los gases emitidos contienen $\mathrm{SiF}_{4}$ además del HF, formado a elevada temperatura como consecuencia de las reacciones del HF con la sílice. Cuando los gases se enfrían hasta temperaturas inferiores a la del punto de rocío del agua, el $\mathrm{SiF}_{4}$ puede formar $\mathrm{H}_{2} \mathrm{SiF}_{6}$ (Hill, 1995).

Se ha comprobado de forma experimental que la emisión de flúor es mínima durante la cocción de baldosas cerámicas en atmósferas secas, con un contenido de agua cero. También se ha comprobado, en el caso de la fase de enfriamiento, que si se reduce el contenido de vapor de agua, el nivel de HF emitido disminuye drásticamente (Reymer y Jong, 1993).

El vapor de agua presente en la atmósfera en un horno de combustión industrial monoestrato, como los utilizados habitualmente en la fabricación de baldosas cerámicas, tiene diferentes orígenes. En el anexo I, incluido en el apartado 9.1, se ha desarrollado un ejercicio de cálculo para determinar dichos orígenes, de forma aproximada, para un escenario habitual en un horno industrial utilizando los valores medios de los materiales incluidos en el Capítulo 4. Los resultados obtenidos se han recogido en la Tabla 2.5. A partir de los mismos, se deduce que la cantidad de agua más significativa, aportada al proceso de cocción de baldosas cerámicas, se realiza durante la combustión de gas natural en el interior del horno.

Tabla 2.5. Resumen de la cantidad de vapor de agua presente en el interior de un horno de cocción.

\begin{tabular}{ccc}
\hline Situación del agua & Cantidad (kg agua/h) & \% del total \\
\hline Humedad de la pieza (suponiendo un 0,5\%) & 21 & 3 \\
Agua estructural de la materia prima & 138 & 21 \\
Vapor de agua generado en la combustión & 452 & 69 \\
Agua introducida en el aire de combustión & 48 & 7 \\
\hline
\end{tabular}

Las posibilidades de disminución de la cantidad de vapor de agua presente en el horno con el fin de minimizar la emisión de flúor pasan por aplicar alguna de las siguientes alternativas:

- Calentamiento indirecto mediante muflas o calentamiento eléctrico.

- Utilización de combustibles con menor contenido en hidrógeno, que minimicen la formación de agua en el interior del horno.

- Utilización de quemadores estequiométricos, que utilicen la mínima cantidad de aire posible (Denissen y Vries, 1998). Estrictamente, esta alternativa no reduce el contenido de vapor de agua en el interior del horno aunque puede servir para controlarlo. 
En este sentido existen algunos ejemplos, incluidos en la literatura científica, como son los desarrollos tecnológicos llevados a cabo en el Institute of Applied Physics del TNO y por la empresa SACMI, uno de los principales constructores de hornos de cocción para materiales cerámicos a nivel mundial. Estos desarrollos utilizan quemadores radiantes que permiten controlar la temperatura y la composición de la atmósfera del horno en la zona de máxima temperatura y minimizar la cantidad de vapor de agua en la misma (Reymer y Denissen, 2001; SACMI, 2015).

\subsubsection{Efecto de la presencia de carbonato cálcico en la emisión de flúor}

Como se ha descrito en el apartado 1.3.5.2. c), uno de los compuestos que forma parte de las piezas cerámicas es la calcita. Este compuesto puede reaccionar con el HF para formar fluoruro cálcico $\left(\mathrm{CaF}_{2}\right)$, como se muestra en la reacción 6 de la Figura 2.1. Favorecer esta reacción es una posible estrategia para retener el flúor en la composición arcillosa. De hecho, según la bibliografía los materiales con poca calcita desprenden HF a $600{ }^{\circ} \mathrm{C}$ y prácticamente pierden todo el flúor a los $900^{\circ} \mathrm{C}$. Por su parte, los materiales que tienen un contenido elevado de calcita emiten a $800 \stackrel{\circ}{ } \mathrm{C}$ pero mantienen todavía una buena parte del mismo a los $900{ }^{\circ} \mathrm{C}$ (Mazzali et al., 1980; Fabbri, 1992). Estos datos se han obtenido a partir de estudios de laboratorio realizados sobre la reacción que tiene lugar entre el fluoruro de sodio y el carbonato de calcio:

$$
2 \mathrm{NaF}+\mathrm{CaCO}_{3} \rightarrow \mathrm{CaF}_{2}+\mathrm{Na}_{2} \mathrm{CO}_{3}
$$

Las reacciones comienzan a $300{ }^{\circ} \mathrm{C}$ y obtienen su máximo desarrollo a $500{ }^{\circ} \mathrm{C}$. A $600{ }^{\circ} \mathrm{C}$ se detecta la desaparición de $\mathrm{CaF}_{2}$ y la disminución de $\mathrm{SiO}_{2}$ formándose cuspidina $\left(\mathrm{Ca}_{4} \mathrm{~F}_{2} \mathrm{Si}_{2} \mathrm{O}_{7}\right)$. No se observan variaciones significativas hasta superar los $800 \stackrel{\circ}{ } \mathrm{C}$, aunque a temperaturas más elevadas se forman otros fluorosilicatos cálcicos $\left(\mathrm{Ca}_{10} \mathrm{Si}_{3} \mathrm{O}_{15} \mathrm{~F}_{2}\right)$. A partir de aquí se inicia la fusión que se completa a los $900 \stackrel{\circ}{ } \mathrm{C}$ como se recoge en la Tabla 2.6 (Dehne, 1987).

Los ensayos de laboratorio realizados con pequeñas adiciones de calcio muestran que es posible disminuir la emisión de HF, siempre que dicha adición sea suficiente para neutralizar todo el flúor presente. Sin embargo, si se adiciona en exceso puede aumentar la emisión de dicho compuesto, debido al aumento de la porosidad de la pieza, como en el caso de las composiciones de azulejo (Dehne, 1987).

Otro de los efectos a considerar es el grado de cristalización en el que se encuentra el fluoruro cálcico, dado que influye en su posible emisión. Así, si este compuesto presenta un bajo nivel de cristalización es expulsado en mayor cantidad que si se encuentra bien cristalizado (Strohmenger, 1983).

La permeabilidad del material es otra de las características que interviene en la emisión de flúor. Cuando se reduce dicha permeabilidad se mejora la retención del flúor en el interior de la pieza cerámica al aumentar el tiempo de reacción del HF con la calcita (Brosnan, 1992). La 
formación de fase vítrea durante la sinterización también disminuye la permeabilidad y, por tanto, la emisión de flúor. Existen aditivos que favorecen la formación de fase vítrea al aumentar la sinterización de la baldosa (Tunker y Schmidt, 1981).

Tabla 2.6. Análisis de flúor en una arcilla mezclada con un $10 \%$ de $\mathrm{CaCO}_{3}$ y tratada térmicamente en un horno eléctrico de laboratorio (Dehne, 1987).

\begin{tabular}{|c|c|c|}
\hline \multirow{2}{*}{ Temperatura ( $\left({ }^{\circ} \mathrm{C}\right)$} & \multicolumn{2}{|c|}{ Contenido de $\mathrm{F}^{-}(\mathrm{mg} / \mathrm{kg})$} \\
\hline & Arcilla & Arcilla $+10 \%$ de $\mathrm{CaCO}_{3}$ \\
\hline Inicial & 530 & 530 \\
\hline 400 & 506 & 598 \\
\hline 500 & 496 & 571 \\
\hline 600 & 506 & 568 \\
\hline 700 & 471 & 561 \\
\hline 800 & 442 & 516 \\
\hline 850 & 303 & 494 \\
\hline 900 & 32 & 427 \\
\hline 950 & 0 & 222 \\
\hline 1000 & 0 & 0 \\
\hline
\end{tabular}

La captación de flúor por parte de la calcita puede ser interferida por el desprendimiento de vapores de azufre $\left(\mathrm{SO}_{\mathrm{x}}\right)$, de modo que cuando la cantidad de óxidos de azufre en la composición de la materia prima aumenta, también lo hacen las emisiones de flúor. Así, la presencia de piritas $\left(\mathrm{FeS}_{2}\right)$ promueve la emisión de flúor dado que la calcita consume el $\mathrm{SO}_{2}$ para formar anhidrita $\left(\mathrm{CaSO}_{4}\right)$ y así reducir la formación de fluorita. De igual forma, la existencia de una mayor cantidad de azufre en la atmósfera del horno, en presencia de vapor de agua, aumenta la emisión de flúor. Este factor depende principalmente del contenido de azufre en la arcilla, y no tanto del azufre proveniente del combustible (Strohmenger, 1983).

Por otro lado, a elevadas temperaturas se puede producir la reacción 7 de la Figura 2.1, de modo que el $\mathrm{CaF}_{2}$ se hidroliza en presencia de vapor de agua a $1200^{\circ} \mathrm{C}$, obteniéndose como resultado de la reacción HF. Para las mezclas de $\mathrm{CaF}_{2}$ y arcilla, esta hidrólisis, con posterior desprendimiento de HF, se produce a $1060 \stackrel{\circ}{ }$ (Brosnan, 1992).

Como ha quedado patente, la modificación de las variables de composición mediante la introducción de aditivos a la materia prima permite fijar el flúor en el interior de la pieza y evitar así su emisión. En general, los materiales que se pueden utilizar como aditivos a las materias primas deben cumplir algunas características, especialmente:

- No afectar negativamente a las propiedades del producto.

- Ser de fácil introducción en el proceso productivo. 
- Tener un bajo coste.

Los procesos de adición estudiados en la literatura científica han sido numerosos, y además del carbonato de calcio se han estudiado otros compuestos cálcicos que también son capaces de retener flúor en la composición arcillosa, como por ejemplo el $\mathrm{Ca}_{3}\left(\mathrm{PO}_{4}\right)_{2}$. Sin embargo, los resultados obtenidos en estos estudios fueron menos significativos que los alcanzados en el caso del $\mathrm{CaCO}_{3}$ (Wei - hong et al., 2001).

Además de los compuestos cálcicos, otros compuestos estudiados han sido los hidróxidos metálicos procedentes de la industria metalmecánica. Estos compuestos han conseguido inhibir la emisión de HF en composiciones de ladrillos. También se han estudiado compuestos fundentes que disminuyen la temperatura de vitrificación y aumentan el intervalo de dicha vitrificación en la pieza. Estos compuestos han obtenido buenos resultados en la fabricación por monococción de ciclo rápido donde se dan bajas emisiones de flúor (Kolkmeier, 1986).

Además de los compuestos nombrados, existen otros aditivos con potencial para reducir las emisiones de flúor, según el TNO (Junge y Hauck, 2000) y el CERAM Research, aunque en estos estudios no se profundiza en los mecanismos de actuación de los mismos. En concreto, dichos aditivos son: escoria de alto horno, lodo cerámico, pulverizado de ceniza de combustible y viruta de vidrio (DETR, 1999).

\subsection{Minimización de las emisiones de flúor mediante la aplicación de medidas primarias}

La literatura científica recoge diferentes formas de actuación encaminadas a conseguir una disminución en las emisiones de compuestos de flúor a la atmósfera. En general, la estrategia de minimización de este tipo de emisiones se divide en tratamientos de prevención y tratamientos de corrección. La aplicación de estos tratamientos prioriza las acciones preventivas dado que consiguen disminuir la emisión en la fuente y, cuando no es posible alcanzar los niveles aceptables de emisión es cuando se aplican los sistemas de depuración con anterioridad a la evacuación de los gases de escape a la atmósfera.

Tal y como se ha visto, la contaminación debida al flúor viene fuertemente influenciada por la presencia de este elemento en las materias primas, por la estabilidad térmica y la evolución de las especies mineralógicas en que se encuentra y por el tratamiento térmico aplicado. De este modo, las soluciones preventivas aplicables para alcanzar disminuciones en la emisión de flúor se clasifican de la siguiente forma:

- Minimización del uso de precursores de HF, mediante la selección y utilización de materias primas o aditivos con bajo contenido en flúor, que permite la disminución de la emisión de dichos compuestos. 
- Modificaciones en el proceso productivo que comporten la disminución de la emisión de HF, mediante la modificación de variables de proceso como la optimización de la curva de cocción y la reducción de vapor de agua en el horno.

- Modificación de las variables de composición que permitan retener en el interior de la pieza conformada los iones flúor, mediante la adición de algún compuesto que evite su salida bien por métodos de fijación o bien por métodos de barrera.

Las medidas primarias han sido utilizadas con éxito en los sectores de fabricación de productos cerámicos como tejas y ladrillos. Sin embargo, su aplicación en la fabricación de baldosas cerámicas ha sido escasa.

En la Tabla 2.7 se ha recogido, a modo de resumen, la cuantificación máxima de la disminución de la emisión de HF alcanzada mediante la aplicación de diferentes técnicas de reducción sobre el proceso productivo de fabricación de ladrillos (DETR, 1999).

Tabla 2.7. Posibilidades de optimización del proceso de fabricación de ladrillos (DETR, 1999).

\begin{tabular}{|c|c|c|}
\hline Técnica de reducción & Ejemplo & $\begin{array}{l}\text { Máxima reducción } \\
\text { alcanzable en la } \\
\text { emisión de HF (\%) }\end{array}$ \\
\hline Modificar el ciclo de cocción & $\begin{array}{l}\text { Reducir el tiempo a máxima } \\
\text { temperatura }\end{array}$ & 10 \\
\hline Reducir el caudal de aire del horno & Disminuir la velocidad de flujo & 63 \\
\hline $\begin{array}{c}\text { Aumentar la turbulencia en la zona } \\
\text { de precalentamiento }\end{array}$ & $\begin{array}{l}\text { Implantar quemadores de alta } \\
\text { velocidad en el precalentamiento }\end{array}$ & 86 \\
\hline $\begin{array}{l}\text { Aumento de la interacción entre el } \\
\text { producto y la atmósfera del horno }\end{array}$ & $\begin{array}{c}\text { Mejorar el contacto entre los gases } \\
\text { y las piezas }\end{array}$ & 53 \\
\hline Reutilizar el flujo de gases & $\begin{array}{c}\text { Reutilizar el gas en el } \\
\text { precalentamiento o en los } \\
\text { secaderos }\end{array}$ & 94 \\
\hline Adición de reactivos & $\begin{array}{c}\text { Añadir un } 2 \% \text { de } \mathrm{CaCO}_{3} \text { en la } \\
\text { composición }\end{array}$ & 75 \\
\hline
\end{tabular}




\subsection{Técnicas de medida de los compuestos de interés en matrices gaseosas y sólidas}

Los métodos de determinación de la emisión de compuestos ácidos y, en concreto, del flúor, son uno de los aspectos clave dentro de la literatura científica. Dichos métodos incluyen procedimientos para la caracterización de flúor tanto sobre material sólido como sobre la propia corriente de gases emitida.

\subsubsection{Determinación del contenido de compuestos de flúor en arcillas}

Existen diferentes métodos para la determinación de los compuestos de flúor en muestras sólidas. En el caso de materiales cerámicos, algunas de las técnicas utilizadas han sido el electrodo selectivo, la colorimetría y la eriocromo - cianina R. Estas técnicas presentan resultados diferenciados y no pueden ser consideradas como equivalentes (Dogeroglu y Kara, 2004). Aun así, la técnica más aplicada en el análisis de materias primas es el electrodo selectivo donde la muestra es sometida a un proceso de fusión seguido de una destilación (Weinstein y Davison, 2004).

En concreto, este procedimiento consiste en someter a la muestra sólida a una fusión alcalina con $\mathrm{Na}_{2} \mathrm{CO}_{3}$ durante 30 minutos en un horno eléctrico de laboratorio a una temperatura de $900 \stackrel{\circ}{ } \mathrm{C}$ en un crisol de platino que, posteriormente, se disuelve con agua destilada.

En la disolución, el ion fluoruro se determina potenciométricamente usando un electrodo selectivo. Para conseguir la lectura correcta en la medida del ion fluoruro, es necesario eliminar las posibles interferencias, como por ejemplo:

- Valores de $\mathrm{pH}$ extremos

- Existencia de cationes polivalentes, como el $\mathrm{Fe}^{3+}$ y el $\mathrm{Al}^{3+}$, que pueden formar complejos con el ion fluoruro

Para evitar dichos inconvenientes, previamente al análisis, se añade un tampón a la disolución con el fin de ajustar la fuerza iónica total del mismo. La disolución acondicionadora utilizada es el denominado TISAB III que contiene un reactivo CDTA que actúa como agente complejante y un tampón que ajusta la fuerza iónica del medio, con el fin de asegurar que la fuerza iónica sea alta, que el ion fluoruro no esté complejado y que se ajuste el pH de la solución (Gazulla et al., 1996).

La utilización del método de electrodo selectivo, comparada con otros métodos, tiene la ventaja de ser rápido, preciso, económico y con un bajo límite de detección. Además, no requiere de instrumentación sofisticada (Gazulla et al., 2003).

Aparte del método de electrodo selectivo, la comunidad científica ha empezado a utilizar un amplio abanico de técnicas instrumentales para la determinación de flúor. Estas técnicas están 
basadas en la emisión de radiación electromagnética desde los niveles electrónicos interiores de los átomos característicos de cada elemento. En este sentido, cabe citar las siguientes técnicas a modo de ejemplo: microsonda electrónica de barrido (electron probe microanalyzer, EPMA), fluorescencia de rayos $X(X R F)$, espectroscopia de fotoelectrones emitidos por rayos $X$ (XPS) y emisión de rayos $X$ inducida por partículas (PIXE) (Bonvicini et al., 2006), además de métodos mas convencionales como por ejemplo la espectroscopia por transformada de Fourier (FTIR).

Destaca que el método potenciométrico para la determinación de flúor presenta una incertidumbre muy inferior al método por fluorescencia de rayos $X$ (XRF). No obstante, se puede usar también este método cuando la concentración de flúor en la muestra no es inferior a $80 \mathrm{mg} / \mathrm{kg}$. En la determinación de flúor mediante XRF, la muestra se debe preparar en forma de pastillas ya que el flúor es un elemento volátil a la temperatura de preparación de las perlas utilizadas habitualmente y por lo tanto no es posible preparar la muestra por fusión. (Gazulla et al., 2003; Gazulla et al., 2005, Gazulla et al., 2015).

Otra técnica utilizada para la identificación de fluoruros minerales es la difracción de rayos $X$ (XRD). Esta técnica es no destructiva y se realiza directamente sobre la muestra en polvo (Bonvicini et al., 2006). Este método no facilita el contenido en flúor pero identifica alguna de las especies que lo contienen y es capaz de detectar cambios muy pequeños en la estructura cristalina o en la composición de la fase, aunque llegar a relacionar los cambios estructurales con los químicos requiere un análisis cuidadoso y el uso de técnicas complementarias (Roche y Stanton, 2014).

Por otro lado, también se han desarrollado técnicas instrumentales de laboratorio para el análisis de emisiones gaseosas (EGA) en materias primas arcillosas y composiciones cerámicas utilizadas en la fabricación de baldosas cerámicas, mediante técnicas acopladas de análisis térmico (TG - DSC - QMS - FTIR). Esta técnica es capaz de facilitar información sobre las concentraciones de diferentes contaminantes $\left(\mathrm{CO}_{2}, \mathrm{CO}, \mathrm{NO}, \mathrm{HF}, \mathrm{SO}\right)$ en emisiones procedentes de un ciclo térmico hasta una temperatura máxima de $1200{ }^{\circ} \mathrm{C}$. Igualmente, esta metodología permite la identificación del origen mineralógico de los elementos presentes en los gases desprendidos. Sin embargo, la cuantificación de compuestos de flúor mediante esta técnica continúa en proceso de desarrollo a día de hoy, dado que encuentra dificultades de análisis en la zona de baja temperatura donde tiene lugar la deshidroxilación de la arcilla (Gómez et al., 2007). 


\subsubsection{Determinación de gases en emisiones atmosféricas}

La determinación de la emisión de contaminantes gaseosos, incluidos los contaminantes ácidos, se puede realizar mediante el muestreo de la matriz gaseosa de interés utilizando métodos manuales o sistemas automáticos de medida.

Los métodos manuales son métodos discontinuos en los que se realiza una toma de muestra extractiva en la chimenea y, posteriormente, se lleva a cabo el análisis de la misma en un laboratorio. En concreto, la toma de muestra se basa en la extracción isocinética o no isocinética y mediante una sonda adecuada, de un volumen conocido de gases que se hacen pasar por un sistema de absorción que capta dichos compuestos; posteriormente se lleva a cabo la determinación del contaminante de interés, presente en la disolución captadora, y se calcula la concentración del mismo en la corriente gaseosa.

Los métodos de medición manuales se recogen en normas de ensayo en función del contaminante a determinar y del ámbito geográfico abarcado por dichas normas. Los métodos normalizados incluyen una secuencia lógica de operaciones, descritas de forma genérica para ser usadas en la realización de mediciones. Se pueden encontrar métodos de medición normalizados de ámbito internacional (ISO), europeo (EN) o nacionales (p. ej. EPA, UNE, UNICHIM) o desarrollados por entidades de contrastado prestigio como por ejemplo la American Society for Testing and Materials International (ASTM). En algunos casos también es posible el desarrollo de métodos de medida específicos por parte de los propios laboratorios de ensayo, como por ejemplo cuando no existen normas de ensayo, o estas normas aún no se han publicado.

Por su parte, los métodos automáticos de medida permiten realizar un seguimiento en continuo de la variación de los niveles de emisión del contaminante de interés. En este caso, el muestreo y el análisis se realizan de forma consecutiva. La medida puede realizarse en la propia chimenea, medida in situ, o mediante un muestreo extractivo y posterior análisis instrumental cerca de la propia chimenea.

Los sistemas in situ se pueden dividir en medidores puntuales, cuando solamente comprenden parte del paso de la corriente de gases a caracterizar, o medidores de paso abierto, que incluyen la totalidad del diámetro de la chimenea que está siendo monitorizada.

Los muestreos extractivos se pueden realizar mediante sistemas de dilución o mediante sistemas que mantienen el nivel de concentración de la fuente hasta el instrumento de medida (DTI, 2004). En la Tabla 2.8 se han recogido las tecnologías disponibles en la actualidad para medir emisiones atmosféricas de gases ácidos.

Se han marcado en azul aquellos métodos aconsejados por la Agencia Ambiental del Reino Unido para su utilización como métodos de medida para monitorización regulada, dado que dispone de uno de los esquemas de certificación más importantes aplicables a equipamiento, 
personal y organizaciones dedicadas a la monitorización ambiental (conocido por sus siglas en inglés, MCERTS Monitoring Certification Scheme).

Tabla 2.8. Tecnologías disponibles en la actualidad para medir contaminantes gaseosos emitidos a la atmósfera (DTI, 2004). Se ha mantenido la nomenclatura en inglés por ser de uso habitual.

\begin{tabular}{|c|c|c|c|c|}
\hline \multirow{2}{*}{ Técnica de análisis } & \multicolumn{4}{|c|}{ Contaminante } \\
\hline & HF & $\mathrm{HCl}$ & $\mathrm{SO}_{2}$ & NOx \\
\hline \multicolumn{5}{|l|}{ Sistemas extractivos } \\
\hline Simple non - dispersive infrared (NDIR) & $\checkmark$ & $\checkmark$ & $\checkmark$ & $\checkmark$ \\
\hline Luft detector NDIR & & & $\checkmark$ & $\checkmark$ \\
\hline Photoacoustic detector & & & $\checkmark$ & $\checkmark$ \\
\hline Gas filter correlation (GFC) NDIR & $\checkmark$ & $\checkmark$ & $\checkmark$ & $\checkmark$ \\
\hline Differential optical absorption spectroscopy (DOAS) & $\checkmark$ & $\checkmark$ & $\checkmark$ & $\checkmark$ \\
\hline Fourier transform infrared spectroscopy (FTIR) & $\checkmark$ & $\checkmark$ & $\checkmark$ & $\checkmark$ \\
\hline Non - dispersive ultraviolet (NDUV) & & & $\checkmark$ & $\checkmark$ \\
\hline Ultraviolet fluorescence & & & $\checkmark$ & \\
\hline Electrochemical cells & & & $\checkmark$ & $\checkmark$ \\
\hline Flame photometric & & & $\checkmark$ & \\
\hline Conductivity (conductometric) analyser & & $\checkmark$ & $\checkmark$ & \\
\hline Chemiluminescence analysers & & & & $\checkmark$ \\
\hline Ion - mobility spectrometry (IMS) & $\checkmark$ & $\checkmark$ & & \\
\hline Potentiometric analysis & $\checkmark$ & $\checkmark$ & & \\
\hline Tuneable diode laser absorption spectroscopy (TDLAS) & $\checkmark$ & $\checkmark$ & $\checkmark$ & $\checkmark$ \\
\hline \multicolumn{5}{|l|}{ Sistemas in situ } \\
\hline Differential optical absorption spectroscopy (DOAS) & $\checkmark$ & $\checkmark$ & $\checkmark$ & $\checkmark$ \\
\hline Derivative spectroscopy & $\checkmark$ & $\checkmark$ & $\checkmark$ & $\checkmark$ \\
\hline Gas filter correlation (GFC) NDIR & $\checkmark$ & $\checkmark$ & $\checkmark$ & $\checkmark$ \\
\hline Non - dispersive ultraviolet (NDUV) & & & $\checkmark$ & $\checkmark$ \\
\hline High temperature electrochemical cells & & & $\checkmark$ & $\checkmark$ \\
\hline Tuneable diode laser absorption spectroscopy (TDLAS) & $\checkmark$ & $\checkmark$ & $\checkmark$ & $\checkmark$ \\
\hline
\end{tabular}




\subsection{Motivaciones para realizar el presente estudio}

La revisión de la literatura científica relativa a la emisión de compuestos de flúor y de otros compuestos ácidos mostró una serie de cuestiones aún no resueltas y a las cuales se pretendió dar respuesta mediante el desarrollo del presente estudio. Estas cuestiones se han clasificado desde diferentes puntos de vista.

\section{Materiales estudiados}

Existía una carencia de información relativa a la emisión de compuestos ácidos durante la fabricación de baldosas en el distrito cerámico de Castellón que estuviera desglosada según diferentes parámetros de interés, tales como: niveles y factores de emisión, tipología de producto (azulejo, gres y gres porcelánico) y coloración en cocido del soporte (rojo y blanco).

Esta información, recogida en condiciones reales de emisión, puede ser utilizada por la industria para dar respuesta a exigencias legales presentes y futuras relacionadas con las emisiones industriales, como puede ser el Inventario Europeo de Emisiones Contaminantes (PRTR).

\section{Metodología utilizada}

En la revisión bibliográfica se observó que los estudios realizados hasta el momento utilizan metodologías diferentes, lo que no permite comparar fácilmente los resultados obtenidos, al menos desde un punto de vista cuantitativo. En este sentido, la utilización, durante la realización del presente trabajo de investigación, de una metodología manual especialmente adaptada a las condiciones de emisión de este tipo de industria, ha permitido disponer de datos de emisión homogéneos, fiables y comparables, en función del tipo de baldosa fabricado y de las condiciones de operación utilizadas.

El desarrollo de principios de medida de emisiones en continuo para gases como el HF, basados en tecnología láser, ha permitido el seguimiento en continuo de dichas emisiones y el estudio de su comportamiento en función del tipo de material fabricado y bajo diferentes condiciones de operación a nivel industrial. En la bibliografía revisada no se han encontrado estudios previos que utilicen metodologías en continuo aplicadas a nivel industrial durante la fabricación de materiales cerámicos.

\section{Procesos}

El conocimiento de los mecanismos de emisión de los compuestos de flúor en condiciones reales de fabricación y procedentes de hornos industriales de combustión con ciclo rápido era muy escaso, en comparación con la información disponible para hornos eléctricos de laboratorio, con o sin adición de vapor de agua. Los escasos estudios industriales existentes 
se han realizado sobre hornos túnel y a temperaturas máximas inferiores a $1000{ }^{\circ} \mathrm{C}$, principalmente.

De igual modo, existía escasez de información relativa a la emisión de HF y a los fenómenos de emisión y adsorción asociados en hornos industriales de combustión de ciclo rápido. Por otra parte, el efecto de la aplicación de medidas primarias en la fabricación de baldosas cerámicas no se había estudiado en profundidad en este tipo de instalaciones.

Un aspecto de gran interés era conocer las causas de la falta de efectividad de la utilización de $\mathrm{CaCO}_{3}$ para la minimización de las emisiones de $\mathrm{HF}$ en la fabricación de baldosas cerámicas en hornos industriales de combustión, cuando en otros productos, como pueden ser ladrillos y tejas, son numerosas las referencias que describen su utilización debido a capacidad de retención de HF que presenta este compuesto. 

Capítulo 3. Objetivos y alcance. 



\subsection{Objetivos}

En base a las motivaciones expuestas anteriormente, la presente tesis doctoral se ha orientado a cubrir algunos aspectos concretos que pueden resumirse brevemente en forma de objetivos generales y objetivos específicos.

\subsubsection{Objetivos generales}

- Estudiar la emisión a la atmósfera de compuestos ácidos durante la fabricación de baldosas cerámicas en hornos industriales de combustión de ciclo rápido y en secaderos por atomización.

- Estudiar con detalle la emisión de compuestos de flúor durante la cocción de baldosas cerámicas, puesto que es el contaminante crítico desde el punto de vista legislativo.

- Valorar la posibilidad de aplicar medidas primarias para la reducción de la emisión de compuestos de flúor durante la etapa de cocción de baldosas cerámicas.

\subsubsection{Objetivos específicos}

\section{Contaminantes ácidos}

- Identificar los contaminantes atmosféricos gaseosos de naturaleza ácida que se emiten de forma significativa.

- Caracterizar las emisiones atmosféricas ácidas en función de la etapa de proceso y del tipo de producto fabricado.

- Determinar la concentración de los mismos y, si es posible, obtener factores de emisión específicos de la industria cerámica del distrito de Castellón.

\section{Compuestos de flúor}

- Determinar la estabilidad térmica de compuestos de flúor, tanto puros como introducidos en una matriz cerámica, con el fin de conocer si es posible disminuir la emisión de HF mediante la formación de estos compuestos durante la etapa de cocción.

- Conocer las causas que provocan que la adición de $\mathrm{CaCO}_{3}$ a las composiciones de baldosas cerámicas no resulte eficaz para disminuir las emisiones de compuestos de flúor de estos productos durante la etapa de cocción. 
- Estudiar la evolución de la emisión de compuestos de flúor durante el tratamiento térmico de las baldosas cerámicas, tanto a escala de laboratorio utilizando un horno eléctrico como a escala industrial, utilizando un horno de combustión de gas natural de ciclo rápido.

- Estudiar con detalle los procesos de emisión y adsorción durante el tratamiento térmico y en particular, comprobar si existe adsorción de flúor en el precalentamiento y determinar los mecanismos que la gobiernan y conocer la eficacia de esta acción para disminuir las emisiones.

- Monitorizar en continuo los niveles de concentración de HF contenidos en la corriente gaseosa procedente de la etapa de cocción de baldosas cerámicas, en hornos industriales de combustión, bajo condiciones habituales de operación y después de introducir cambios en las condiciones de producción del horno.

- Estudiar posibles alternativas de prevención que logren alcanzar reducciones de la emisión de HF en la corriente de evacuación de gases procedentes de la etapa de cocción, mediante la modificación de las variables de proceso.

\subsection{Alcance}

El alcance del presente trabajo se ha dividido en función de la tipología de las composiciones de soporte de baldosas cerámicas estudiadas, de los hornos empleados en el tratamiento térmico de la etapa de cocción, y de los métodos de medida utilizados para la caracterización de las emisiones ácidas producidas, con especial atención a los compuestos de flúor.

\section{Composición de los soportes de baldosas cerámicas}

El trabajo presentado comprende el estudio de tres tipos de baldosas cerámicas: azulejo, gres y gres porcelánico. A nivel industrial estos productos suponen actualmente más del $95 \%$ de la producción de baldosas cerámicas. La composición utilizada en la fabricación de cada tipo de baldosa ha incluido materias primas rojas y blancas, excepto en el gres porcelánico, dado que en función de la coloración del soporte en cocido se utilizan distintas materias primas.

\section{Hornos de cocción}

Durante la presente investigación se han utilizado hornos de cocción de diferente naturaleza para el tratamiento térmico de las piezas conformadas. Por un lado, se han utilizado hornos eléctricos discontinuos de laboratorio en algunas fases del estudio. La principal característica de este tipo de hornos, además de la fuente de energía utilizada, es que disponen de una atmósfera de aire prácticamente exenta de vapor de agua. 
Por otro lado, se han empleado hornos industriales continuos de combustión que utilizan como combustible gas natural. El proceso de fabricación empleado es la monococción rápida. En la actualidad este tipo de proceso es el más ampliamente implantado en la industria de fabricación de baldosas cerámicas.

Es precisamente sobre estos hornos industriales donde se ha centrado gran parte del trabajo de investigación dado que es donde se han identificado las mayores lagunas de conocimiento en los trabajos previos.

Los estudios precedentes indican que la presencia de compuestos ácidos en los esmaltes no es significativa. Por ello, el estudio de las emisiones de compuestos ácidos potencialmente emitidas desde el esmalte aplicado sobre las baldosas no se han considerado en el presente trabajo de investigación.

\section{Métodos de medida}

En el plan de trabajo desarrollado en esta investigación se ha incluido el uso de metodologías de medida adaptadas a los diferentes contaminantes atmosféricos de naturaleza ácida que han sido objeto de estudio. Así, se han utilizado métodos de medida manuales y automáticos en función del tipo de contaminante y de la resolución temporal del análisis necesario para cada uno.

En el caso concreto de los compuestos de flúor, que son los compuestos sobre los que se ha centrado el estudio con mayor énfasis debido a su importancia ambiental, se han utilizado sistemas discontinuos basados en la absorción química de dichos compuestos y su posterior análisis en el laboratorio, así como métodos de medida continuos basados en tecnología láser.

\subsection{Estructura de la tesis}

La memoria de la tesis se presenta con la siguiente estructura:

- El primer capítulo presenta una amplia introducción sobre los compuestos ácidos y, en especial, sobre los compuestos de flúor, como contaminantes atmosféricos, la problemática ambiental asociada a los mismos y su relación con la fabricación de baldosas cerámicas.

- El segundo capítulo muestra la revisión realizada sobre la emisión de compuestos de flúor y de otros compuestos ácidos en los procesos de fabricación de productos cerámicos tradicionales, incluyendo tejas, ladrillos y baldosas.

- En el tercer capítulo se recogen los objetivos de la investigación, el alcance y, finalmente, la estructura del presente documento.

- En el cuarto capítulo se presentan los materiales y la metodología utilizados. 
- En el quinto capítulo se presenta un extenso resumen de los resultados alcanzados. Dichos resultados se han dividido en cuatro bloques diferenciados que se corresponden con cada uno de los artículos publicados y que describen el presente trabajo de investigación. En algunos puntos también se exponen resultados adicionales no incluidos en dichas publicaciones.

- En el sexto capítulo se muestran las conclusiones obtenidas en la tesis, así como las futuras líneas de investigación propuestas.

- En el séptimo capítulo se han incluido los artículos que recogen la investigación desarrollada durante la presente tesis doctoral. En total se han escrito cuatro artículos que han sido objeto de publicación en diferentes revistas de carácter científico. A continuación se enumeran las referencias bibliográficas correspondientes a cada uno de ellos:

Artículo no 1. MONFORT, E.; CELADES, I.; GOMAR, S.; RUEDA, F.; MARTÍNEZ, J. Characterisation of acid pollutant emissions in ceramic tile manufacture. Bol. Soc. Esp. Ceram. Vidr., 50(4), 179-184, 2011.

Artículo no 2. GARCÍA-TEN, J.; MONFORT, E.; GÓMEZ, M.P.; GOMAR, S. Influence of calcite content on fluorine compound emissions during ceramic tile firing. J. ceram. proc. res., 7(1), 75-82, 2006.

Artículo no 3. MONFORT, E.; GARCÍA-TEN, J.; CELADES, I.; GAZULLA, M.F.; GOMAR, S. Evolution of fluorine emissions during the fast firing of ceramic tile. Appl. clay sci., 38, 250-258, 2008.

Artículo no 4. MONFORT, E.; GARCÍA-TEN, J.; CELADES, I.; GOMAR, S. Monitoring and possible reduction of HF in stack flue gases from ceramic tiles. J. Fluorine Chem., 131, 6-12, 2010.

- Se ha creído conveniente añadir dos capítulos adicionales con el fin de simplificar la lectura de la memoria de la tesis, dedicados a glosario de términos y a anexos, respectivamente.

- Finalmente, en el décimo capítulo se recoge la bibliografía utilizada en el desarrollo de la presente tesis doctoral. 


Capítulo 4. Metodología. 



\subsection{Materiales}

\subsubsection{Composiciones cerámicas}

Para realizar el estudio se han seleccionado tres granulados empleados industrialmente en la fabricación de los principales tipos de soportes de baldosas cerámicas producidas en el distrito cerámico de Castellón: azulejo, gres esmaltado y gres porcelánico. Con el fin de facilitar la comprensión del texto, la nomenclatura utilizada para denominar a cada uno de los materiales utilizados se ha simplificado al máximo y se ha basado en la propia composición, siendo: azulejo $(A)$, gres esmaltado $(G)$ y gres porcelánico $(P)$. Cuando ha sido necesario, se ha añadido una segunda letra que corresponde al color de la propia composición en cocido: rojo (R) y blanco (B). Cuando no se especifica el color de la composición en cocido para los productos de $A$ y $G$, se entiende que los valores corresponden a composiciones de color rojo en cocido. Esta distinción es debida a que las materias primas empleadas en cada una de las composiciones son diferentes. Este aspecto ha sido tratado con anterioridad en el capítulo de introducción (apartado 1.2.3). En la Tabla 4.1 y en la Tabla 4.2 se resumen las características de interés de las diferentes composiciones utilizadas en el presente trabajo. En la primera tabla se ha destacado el contenido de flúor y de calcio y se ha incluido la incertidumbre asociada a dichas determinaciones debido a la importancia de estos parámetros.

Tabla 4.1. Composición química del soporte crudo de los granulados estudiados.

\begin{tabular}{lcccccc}
\hline \multicolumn{1}{c}{ Parámetro } & $\begin{array}{c}\text { Azulejo } \\
\text { rojo (AR) }\end{array}$ & $\begin{array}{c}\text { Azulejo } \\
\text { blanco } \\
\text { (AB) }\end{array}$ & $\begin{array}{c}\text { Gres rojo } \\
\text { (GR) }\end{array}$ & $\begin{array}{c}\text { Gres } \\
\text { blanco } \\
\text { (GB) }\end{array}$ & $\begin{array}{c}\text { Gres } \\
\text { porcelánico } \\
\text { (P) }\end{array}$ \\
\hline $\begin{array}{l}\text { Composición } \\
\text { química } \\
\text { (\% en peso) }\end{array}$ & $\mathrm{SiO}_{2}$ & 57,5 & 62,8 & 64,0 & 65,1 & 65,8 \\
& $\mathrm{Al}_{2} \mathrm{O}_{3}$ & 15,6 & 14,6 & 17,5 & 18,7 & 20,6 \\
& $\mathrm{Fe}_{2} \mathrm{O}_{3}$ & 5,26 & 1,32 & 6,01 & 1,58 & 0,66 \\
& $\mathbf{C a O}$ & $\mathbf{6 , 2 5} \mathbf{0 , 1 0}$ & $\mathbf{7 , 9 0 \pm \mathbf { 0 , 1 0 }}$ & $\mathbf{1 , 2 1} \pm \mathbf{0 , 1 0}$ & $\mathbf{1 , 0 5} \pm \mathbf{0 , 1 0}$ & $\mathbf{0 , 7 2} \pm \mathbf{0 , 1 0}$ \\
& $\mathrm{MgO}$ & 1,78 & 0,24 & 0,85 & 2,01 & 1,34 \\
& $\mathrm{Na}_{2} \mathrm{O}$ & 0,41 & 0,31 & 0,47 & 3,51 & 4,48 \\
\hline $\begin{array}{l}\text { Pérdidas por } \\
\text { calcinación (\%) }\end{array}$ & 3,23 & 1,45 & 3,34 & 1,51 & 1,60 \\
\hline $\begin{array}{l}\text { Contenido de flúor } \\
\text { (mg/kg) }\end{array}$ & $\mathbf{6 5 0}$ & & 10,7 & 5,93 & 4,78 & 3,91 \\
\hline
\end{tabular}


Tabla 4.2. Composición mineralógica del soporte crudo de los granulados estudiados deducida mediante XRD.

\begin{tabular}{llccccc}
\hline \multicolumn{1}{c}{ Parámetro } & $\begin{array}{c}\text { Azulejo } \\
\text { rojo } \\
\text { (AR) }\end{array}$ & $\begin{array}{c}\text { Azulejo } \\
\text { blanco } \\
\text { (AB) }\end{array}$ & $\begin{array}{c}\text { Gres } \\
\text { rojo } \\
\text { (GR) }\end{array}$ & $\begin{array}{c}\text { Gres } \\
\text { blanco } \\
\text { (GB) }\end{array}$ & $\begin{array}{c}\text { Gres } \\
\text { porcelánico } \\
\text { (P) }\end{array}$ \\
\hline $\begin{array}{l}\text { Composición } \\
\text { mineralógica } \\
\text { (\% en peso) }\end{array}$ & Illita & 18 & 3 & 19 & 15 & 14 \\
& Caolinita & 18 & 30 & 22 & 20 & 18 \\
& Clorita & 2 & - & - & 2 & 5 \\
& Cuarzo & 36 & 42 & 39 & 28 & 24 \\
& Albita & - & 3 & - & 30 & 38 \\
& Microclina & 6 & 6 & 6 & - & - \\
& Calcita & 10 & 13 & 3 & 2 & - \\
& Dolomita & 2 & 1 & 2 & 1 & \\
& Hematita & 5 & 1 & 6 & 1 & 0,5 \\
\hline
\end{tabular}

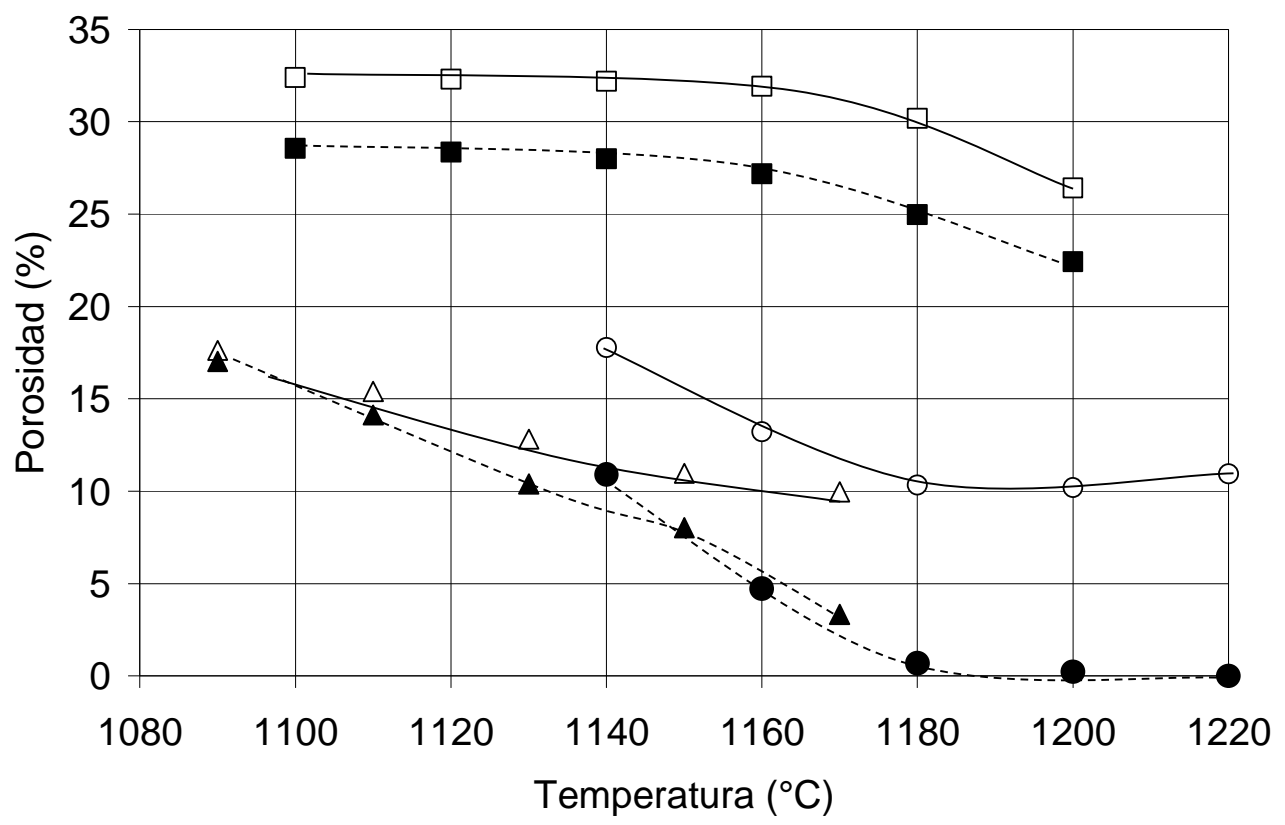

Figura 4.1. Evolución de la porosidad total (línea continua) y porosidad aparente o abierta (línea discontinua) con la temperatura de las composiciones (correspondiendo los cuadrados a la composición

A, los triángulos a la composición $\mathrm{G}$ y los círculos a la composición $\mathrm{P}$ ) utilizados en este estudio.

El comportamiento de las composiciones empleadas durante el proceso de cocción es diferente en función de las propiedades finales deseadas (porosidad, resistencia mecánica, etc.). En la Figura 4.1 se muestra la evolución de la porosidad total y aparente de las tres 
composiciones en función de la temperatura. Las composiciones de gres y de gres porcelánico presentan un comportamiento muy similar. Estos dos tipos de composiciones forman una fase líquida por encima de los $900^{\circ} \mathrm{C}$ (Orts et al., 1993), la cual conduce a una progresiva reducción de la porosidad con el aumento de la temperatura. Por el contrario, la composición de azulejo muestra una porosidad alta y estable en el intervalo de temperaturas estudiado debido a la cristalización de los silicatos y los aluminosilicatos cálcicos (gelenita, anortita y wollastonita) por la reacción de $\mathrm{CaO}$ procedente de la descomposición de la calcita con $\mathrm{Al}_{2} \mathrm{O}_{3}$ y $\mathrm{SiO}_{2}$ generada en la deshidroxilación del mineral arcilloso (Amorós et al., 1993).

\subsubsection{Gas natural}

El gas natural es el combustible más extendido en la fabricación de baldosas cerámicas en el distrito de Castellón. La sustitución de combustibles sólidos por combustibles gaseosos de baja emisión es considerada como una MTD por el documento BREF de cerámica (Mallol et al., 2001; IPTS, 2007).

El gas natural se obtiene de la naturaleza en los campos petrolíferos y está formado por hidrocarburos gaseosos, principalmente metano, etano, propano y butano. La composición y las características medias aproximadas del gas natural distribuido en el año 2000 en la zona de Castellón se indican en la Tabla 4.3.

Tabla 4.3. Características medias del gas natural en Castellón en el año 2000 (Mallol et al., 2001).

\begin{tabular}{llc}
\hline \multicolumn{1}{c}{ Característica } & \multicolumn{1}{c}{ Parámetro } & Valor \\
\hline Composición media & Metano & $90,0 \%$ \\
& Etano & $7,5 \%$ \\
& Propano & $1,5 \%$ \\
& Butano & $0,4 \%$ \\
& Nitrógeno & $0,6 \%$ \\
& Azufre en el odorizante & $6,0 \mathrm{mg} / \mathrm{Nm}^{3}$ \\
\hline Densidad & Real & $0,7955 \mathrm{~kg} / \mathrm{Nm}^{3}$ \\
& Relativa al aire & 0,6153 \\
\hline Poder calorífico & Superior & $12,00 \mathrm{kWh} / \mathrm{Nm}^{3}$ \\
& Inferior & $10,83 \mathrm{kWh} / \mathrm{Nm}^{3}$ \\
\hline Combustión estequiométrica & Aire & 10,4 \\
(Nm ${ }^{3} / \mathrm{Nm}^{3}$ gas) & Humos secos & 9,3 \\
& Humos húmedos & 11,4 \\
\hline Factores de emisión & $\mathrm{CO}_{2}$ & 182 \\
referidos al poder calorífico \\
inferior (g/kWh)
\end{tabular}




\subsection{Metodología utilizada en los ensayos realizados en horno eléctrico de laboratorio}

Los tratamientos térmicos en horno de laboratorio se han realizado sobre probetas cilíndricas, de $40 \mathrm{~mm}$ de diámetro y $6 \mathrm{~mm}$ de espesor, conformadas por prensado unidireccional en una prensa de laboratorio. Las variables de prensado utilizadas fueron similares a las que se emplean en la industria para conformar los soportes de las baldosas cerámicas. En concreto, una humedad del granulados de 0,055 kg agua $/ \mathrm{kg}$ sólido seco y una presión de prensado de $25 \mathrm{MPa}$. La densidad aparente en seco media de las probetas ha sido de 2,000 $\pm 0,005 \mathrm{~g} / \mathrm{cm}^{3}$.

Las probetas obtenidas se han secado en estufa eléctrica a $110{ }^{\circ} \mathrm{C}$, y posteriormente se han tratado térmicamente a distintas temperaturas máximas en un horno eléctrico de laboratorio, con atmósfera estática de aire que simulaba los ciclos de cocción industriales. En concreto, el ciclo de cocción empleado ha sido el siguiente:

- Fase de calentamiento: velocidad de calentamiento $25^{\circ} \mathrm{C} / \mathrm{min}$.

- Temperaturas máximas: 400, 600, 800, 1000 y 1125, 1150 y $1200 \stackrel{\circ}{\circ}$ en función del tipo de producto (azulejo, gres ó gres porcelánico). El tiempo de permanencia a cada una de las temperaturas ha sido de 30 minutos.

- Fase de enfriamiento: se ha realizado por convección forzada, excepto en el intervalo entre 600 y $500 \stackrel{\circ}{\mathrm{C}}$ en el que se ha realizado por convección natural.

\subsubsection{Determinación de la emisión de flúor a partir del análisis de la matriz sólida}

Los compuestos de flúor han sido los contaminantes de interés en la parte experimental del trabajo de investigación realizada en hornos de laboratorio. Estos compuestos han sido estudiados sobre la matriz sólida donde se ha determinado el contenido y la estructura mineralógica en la que se encuentran.

\subsubsection{Análisis químico}

En el presente trabajo de investigación, el análisis del contenido de compuestos de flúor en las muestras sólidas se ha realizado mediante electrodo selectivo (Gazulla et al., 1996).

Para evaluar la emisión de flúor durante la etapa de cocción se han determinado los contenidos de flúor en las piezas antes y después del tratamiento térmico.

Con el fin de obtener resultados comparables entre las piezas crudas y las que han sido sometidas a tratamiento térmico, se ha realizado una corrección teniendo en cuenta las pérdidas por calcinación de las piezas cocidas a la temperatura correspondiente a cada ensayo mediante la ecuación [4.1]. 


$$
C_{c}=C_{o} \cdot \frac{[100-P P C(\%)]}{100}
$$

siendo:

$\mathrm{C}_{\mathrm{c}}$ : concentración de flúor corregida $(\mathrm{mg} / \mathrm{kg})$

$\mathrm{C}_{0}$ : concentración de flúor medida experimentalmente $(\mathrm{mg} / \mathrm{kg})$

PPC: pérdidas por calcinación (\% en peso)

Finalmente, con los valores corregidos obtenidos se ha calculado la emisión de flúor durante el tratamiento térmico por diferencia entre el contenido de flúor inicial (probeta cruda) y final (probeta tratada a la temperatura correspondiente) (Gazulla et al., 1996; García-Ten et al., 2003).

\subsubsection{Análisis mineralógico}

La determinación mineralógica de fluoruros se ha realizado mediante XRD. Esta técnica ha sido utilizada en el presente trabajo para estudiar la estabilidad térmica de diferentes fluoruros $\left(\mathrm{CaF}_{2}, \mathrm{BaF}_{2}\right.$ y $\left.\mathrm{SrF}_{2}\right)$ en el seno de una matriz cerámica. Los resultados de este estudio se presentan en el apartado 5.3 correspondiente al artículo $\mathrm{n}-2$.

Para realizar esta parte del trabajo se han preparado probetas de laboratorio a partir de materiales compuestos de una mezcla de los diferentes fluoruros sintéticos $\mathrm{CaF}_{2}, \mathrm{BaF}_{2}$ y $\mathrm{SrF}_{2}$ de calidad analítica PRS (purísimo > 99\%) con la composición cerámica de gres rojo que tiene un contenido del 1,1\% de $\mathrm{CaO}$ como impureza de las arcillas rojas en forma de carbonato. La preparación ha sido efectuada en un molino de anillos de carburo de wolframio. Con estos materiales se han preparado probetas, que posteriormente se han sometido a tratamiento térmico en un horno de laboratorio, utilizando para ello la misma metodología descrita anteriormente.

La identificación de las diferentes fases cristalinas en muestras sólidas se ha realizado por XRD de la muestra en polvo utilizando un difractómetro PHILIPS PW 1840. Las condiciones de ensayo se detallan en la Tabla 4.4.

Tabla 4.4. Determinación de las fases cristalinas. Condiciones de ensayo.

Condiciones de ensayo en el análisis de XRD

\begin{tabular}{cc}
\hline \multicolumn{2}{c}{ Condiciones de ensayo en el análisis de XRD } \\
\hline Tubo de $\mathrm{Cu}$ & Tiempo de adquisición: 1 segundo \\
Tamaño de paso: $0,01(2 \theta)$ & $40 \mathrm{kV}, 40 \mathrm{~mA}$ \\
Uso de monocromador & Rendija: $0,2 \mathrm{~mm}$ \\
\hline
\end{tabular}




\subsubsection{Análisis térmico diferencial y análisis termogravimétrico}

El análisis mineralógico de los diferentes materiales se ha complementado con el estudio de la estabilidad térmica de aquellos materiales que contienen flúor. Para ello se han realizado análisis térmicos simultáneos (ATD y TG) a dos velocidades de calentamiento, $10 \stackrel{\circ}{\circ} \mathrm{C} / \mathrm{min}$ y 50 ○C/min. La temperatura máxima de ensayo ha variado en función de la naturaleza de los compuestos de flúor estudiados entre $1200^{\circ} \mathrm{C}$ y $1300 \stackrel{\circ}{\circ}$.

Los ensayos se han efectuado en atmósfera de aire dinámica y con crisoles de alúmina.

\subsection{Metodología utilizada en los ensayos realizados en horno industrial de combustión}

Las cocciones a escala industrial se han realizado en tres hornos industriales de combustión, uno para cada tipo de producto estudiado, que operan en continuo, como el mostrado en la Figura 4.2. Estos hornos emplean gas natural como combustible, y son los que se utilizan habitualmente en la fabricación de baldosas cerámicas.

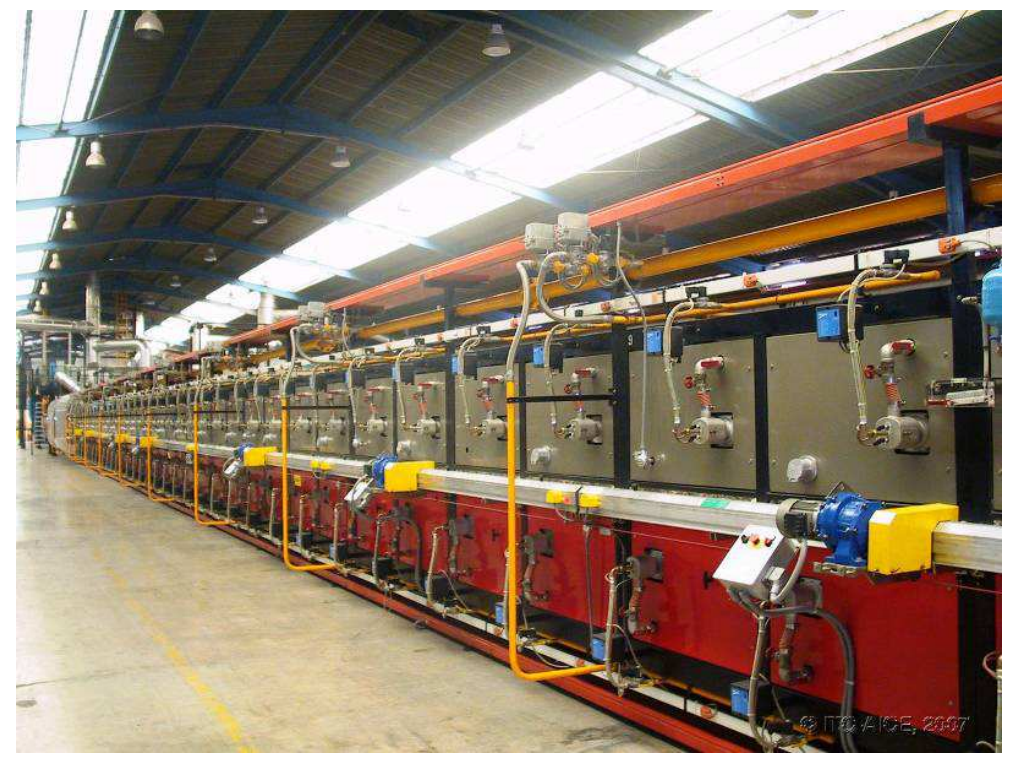

Figura 4.2. Horno industrial de cocción de baldosas cerámicas

En general, durante el trabajo desarrollado en los hornos de combustión, se han utilizado piezas industriales. Aunque las condiciones específicas de utilización de dichas piezas se indica en cada apartado, se puede decir que la densidad aparente en seco de las mismas ha sido de $1,95 \pm 0,03 \mathrm{~g} / \mathrm{cm}^{3}$ para el gres porcelánico, y de $2,00 \pm 0,02 \mathrm{~g} / \mathrm{cm}^{3}$ para las composiciones de azulejo y gres.

Las piezas se han sometido a los ciclos térmicos habituales utilizados en las empresas en las que se han desarrollado los ensayos, con tiempos totales de cocción (frío - frío) comprendidos entre los 40 y los 55 minutos, y temperaturas máximas sobre 1125, 1150 y $1200 \stackrel{\circ}{C}$ en función 
del tipo de producto fabricado, $\mathrm{A}, \mathrm{G}$ y $\mathrm{P}$, respectivamente. Las curvas de temperatura - tiempo completas se muestran en la Figura 4.3.

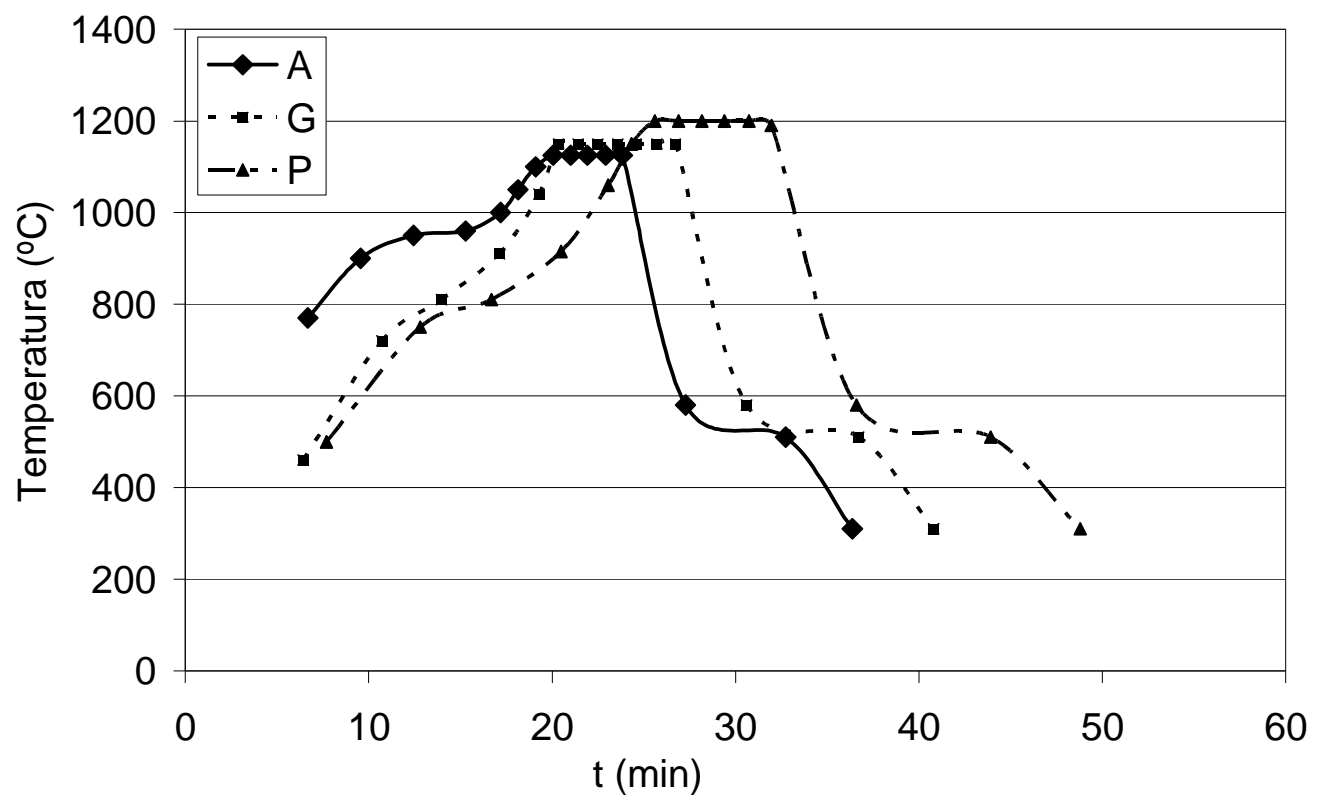

Figura 4.3. Curvas de temperatura - tiempo en los hornos industriales para las tres composiciones estudiadas.

Por su parte, en la Figura 4.4 se muestra, de forma esquemática, uno de estos hornos. La diferencia más significativa en relación con la concentración de HF de este tipo de horno respecto al horno de laboratorio es, aparte del combustible utilizado, el movimiento de los gases de combustión en el interior de los mismos, dado que circulan en contracorriente respecto a las piezas en las zonas de precalentamiento y cocción de acuerdo con la curva de presión estática del mismo. 


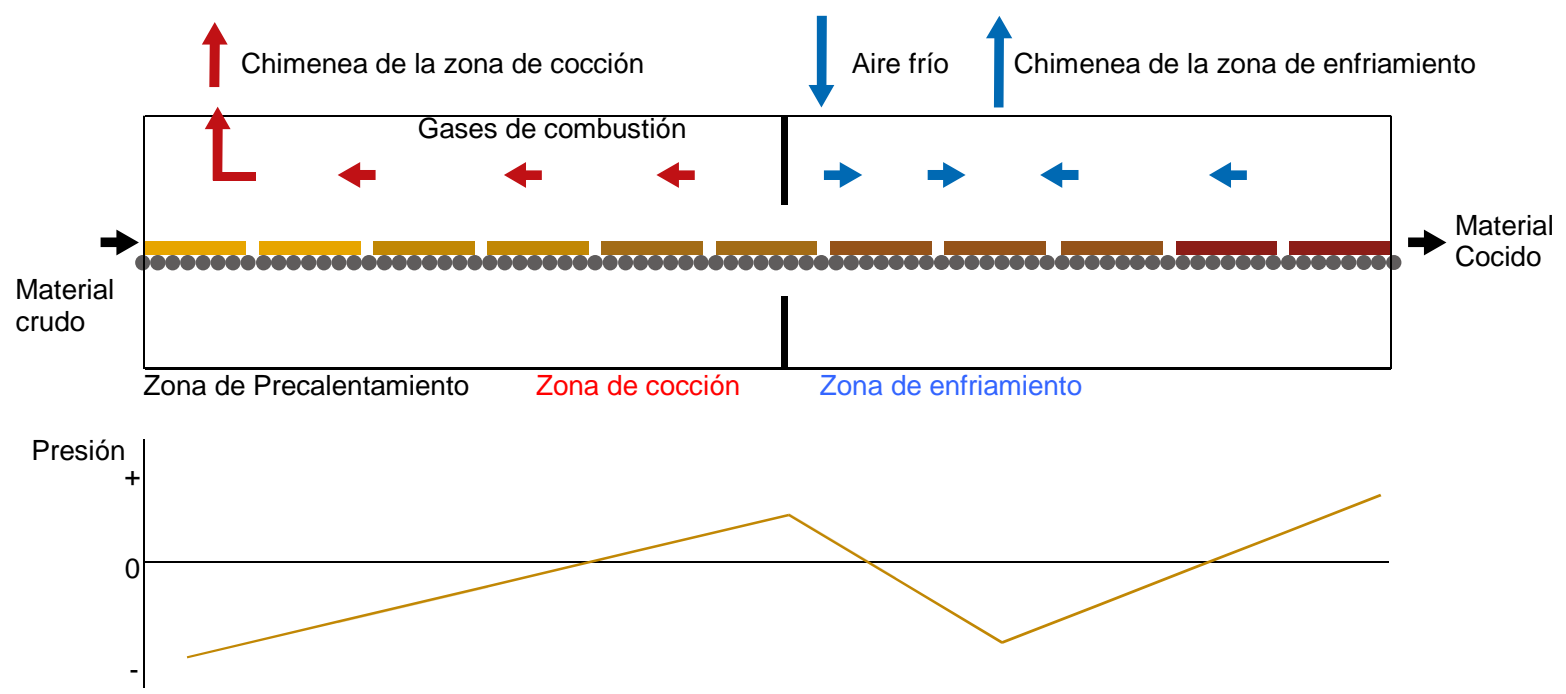

Figura 4.4. Esquema del horno de rodillos indicando el sentido de circulación de los gases y la curva de presión estática.

\subsubsection{Determinación de la emisión de flúor a partir del análisis de la matriz sólida}

En los hornos industriales también se ha determinado el contenido de flúor mediante el método de electrodo selectivo, siguiendo el mismo procedimiento utilizado en el caso de las probetas de laboratorio. Para ello, se ha tomado un número significativo de piezas de producción (no esmaltadas), tanto crudas como tratadas térmicamente en distintas fases de la cocción. Las piezas cocidas han sido tomadas en diferentes puntos a lo largo del horno industrial. Para la extracción de estas piezas ha sido necesario retirar algunos rodillos en la zona de interés, al objeto de que las piezas caigan a la solera del mismo, de donde se han recogido manualmente y se han enfriado rápidamente con el fin de detener el proceso de emisión. Conociendo el punto en el cual se recoge la pieza y el ciclo de cocción, ha sido posible determinar la temperatura máxima de la atmósfera a la que ha sido sometida cada una de las piezas.

\subsubsection{Determinación de la emisión a partir del análisis de las corrientes gaseosas}

El contenido de los compuestos ácidos presentes en la corriente de gases ha sido determinado en la chimenea de evacuación de los gases de combustión y, para el caso de compuestos de flúor, en la propia atmósfera del horno. En este último caso se ha procedido a la extracción de muestras en diferentes puntos longitudinales de los hornos industriales, a través de las aberturas para el control de quemadores o mirillas (Figura 4.5). En la toma de muestra se ha tenido en cuenta algunas precauciones básicas, como por ejemplo: evitar la 
entrada de aire exterior en los puntos del horno en depresión, el uso de sondas de alúmina y, en zonas de alta temperatura $\left(\mathrm{T}>1000^{\circ} \mathrm{C}\right)$, utilizar sondas refrigeradas.

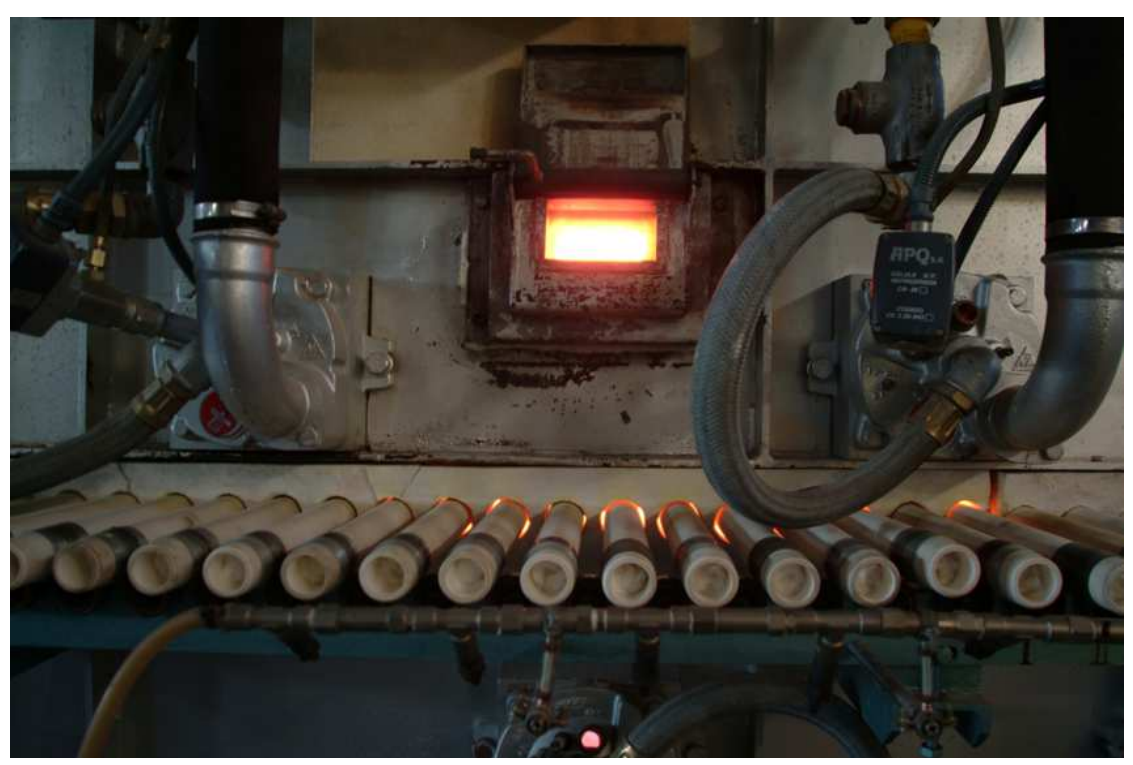

Figura 4.5. Mirilla en la zona de quemadores de un horno industrial.

El muestreo de gases se puede realizar mediante métodos de medición manuales o métodos automáticos. En el presente trabajo se han utilizado métodos manuales para la determinación de $\mathrm{HF}, \mathrm{HCl}$ y $\mathrm{SO}_{2}$, mientras que se han utilizado métodos automáticos para la determinación de $\mathrm{HF}$ y $\mathrm{NO}_{x}$.

En el siguiente apartado se describe de forma resumida cada uno de los métodos de medición empleados en función de la tipología del método y del contaminante de interés.

\subsubsection{Métodos manuales}

\section{Fluoruros gaseosos, HF}

Este método de medida fue puesto a punto en el ITC para la determinación de compuestos de flúor gaseosos en la industria cerámica en 2002 (Monfort et al., 2003). Con posterioridad al desarrollo de dicho método específico, en el año 2006 se publicó la norma ISO de ámbito internacional, para el muestreo y determinación del contenido de fluoruros gaseosos, ISO 15713.

En la Tabla 4.5 se recogen las principales características a tener en cuenta en la determinación de este componente.

El método desarrollado en el ITC recubre el paso de gas con teflón, para evitar reacciones del flúor con el metal de la sonda y los elementos de vidrio del tren de muestreo. La sonda no se calefacta, y el muestreo se realiza en condiciones no isocinéticas, puesto que los compuestos de flúor se encuentran en fase gaseosa. 
Tabla 4.5. Detalle de los principales requisitos de las normas para la determinación de fluoruro gaseoso procedente de emisiones canalizadas.

\begin{tabular}{|c|c|c|c|c|c|c|c|}
\hline \multirow{2}{*}{$\begin{array}{l}\text { Método de } \\
\text { referencia }\end{array}$} & \multicolumn{4}{|c|}{ Tren de absorción (borboteadores) } & \multirow{2}{*}{$\underset{(\mathrm{I} / \mathrm{min})}{\mathbf{Q}}$} & \multirow{2}{*}{$\stackrel{t}{t}$} & \multirow{2}{*}{$\begin{array}{l}\text { Método de } \\
\text { análisis }\end{array}$} \\
\hline & 1B & 2B & 3B & 4B & & & \\
\hline ITC & $\begin{array}{c}\mathrm{NaOH} \\
0,1 \mathrm{~mol} / \mathrm{l}\end{array}$ & $\begin{array}{c}\mathrm{NaOH} \\
0,1 \mathrm{~mol} / \mathrm{l}\end{array}$ & Vacío & $\begin{array}{c}\text { Gel } \\
\text { sílice }\end{array}$ & 5 & 45 & \multirow{4}{*}{$\begin{array}{l}\text { Electrodo } \\
\text { selectivo }\end{array}$} \\
\hline ISO 15713 & $\begin{array}{c}\mathrm{NaOH} \\
0,1 \mathrm{~mol} / \mathrm{l}\end{array}$ & $\begin{array}{c}\mathrm{NaOH} \\
0,1 \mathrm{~mol} / \mathrm{l}\end{array}$ & Vacío & $\begin{array}{c}\text { Gel } \\
\text { sílice }\end{array}$ & $2-6$ & 30 & \\
\hline $\begin{array}{c}\text { UNICHIM } \\
10787\end{array}$ & $\mathrm{KOH} 0,05 \mathrm{~N}$ & $\begin{array}{c}\mathrm{KOH} \\
0,05 \mathrm{~N}\end{array}$ & $\begin{array}{c}\text { Gel } \\
\text { sílice }\end{array}$ & - & 2 & 50 & \\
\hline $\begin{array}{c}\text { EPA Met. } \\
\text { 13B }\end{array}$ & $\begin{array}{c}\text { Agua } \\
\text { destilada }\end{array}$ & $\begin{array}{c}\text { Agua } \\
\text { destilada }\end{array}$ & Vacío & $\begin{array}{c}\text { Gel } \\
\text { sílice }\end{array}$ & 2 & 60 & \\
\hline
\end{tabular}

\section{Cloruros gaseosos, $\mathrm{HCl}$}

En el caso de los cloruros gaseosos, el método manual utilizado se puso en marcha en 2005. En la Tabla 4.6 se recogen las principales características a tener en cuenta en la determinación de este componente.

El ensayo desarrollado en el ITC se realiza de forma simultánea con la determinación de HF, por lo que comparte materiales y características con dicho ensayo.

Tabla 4.6. Detalle de los principales requisitos de las normas para la determinación cloruro gaseoso procedente de emisiones canalizadas.

\begin{tabular}{|c|c|c|c|c|c|c|c|c|c|}
\hline \multirow{2}{*}{$\begin{array}{l}\text { Método de } \\
\text { referencia }\end{array}$} & \multicolumn{6}{|c|}{ Tren de absorción (borboteadores) } & \multirow{2}{*}{$\underset{(\mathrm{I} / \mathrm{min})}{\mathbf{Q}}$} & \multirow{2}{*}{$\underset{(\min )}{t}$} & \multirow{2}{*}{ Método de análisis } \\
\hline & 1B & 2B & 3B & 4B & 5B & 6B & & & \\
\hline ITC & $\begin{array}{c}\mathrm{NaOH} \\
0,1 \mathrm{~mol} / \mathrm{l}\end{array}$ & $\begin{array}{c}\mathrm{NaOH} \\
0,1 \mathrm{~mol} / \mathrm{l}\end{array}$ & Vacío & $\begin{array}{l}\text { Gel } \\
\text { sílice }\end{array}$ & - & - & 5 & 45 & $\begin{array}{c}\text { Titulación } \\
\text { volumétrica }\end{array}$ \\
\hline $\begin{array}{l}\text { EN } 1911 \\
\text { UNE } \\
77-041\end{array}$ & $\begin{array}{c}\text { Agua } \\
\text { destilada }\end{array}$ & $\begin{array}{c}\text { Agua } \\
\text { destilada }\end{array}$ & Vacío & $\begin{array}{l}\text { Gel } \\
\text { sílice }\end{array}$ & - & - & $1,5-3,5$ & $30-60$ & $\begin{array}{c}\text { Titulación } \\
\text { volumétrica, } \\
\text { Espectrofotometría, } \\
\text { Cromatoarafía iónica }\end{array}$ \\
\hline $\begin{array}{c}\text { EPA } \\
\text { Met. } 26\end{array}$ & Vacío & $\begin{array}{c}\mathrm{H}_{2} \mathrm{SO}_{4} \\
0,1 \mathrm{~N}\end{array}$ & $\begin{array}{c}\mathrm{H}_{2} \mathrm{SO}_{4} \\
0,1 \mathrm{~N}\end{array}$ & $\begin{array}{c}\mathrm{NaOH} \\
0,1 \mathrm{~N}\end{array}$ & $\begin{array}{c}\mathrm{NaOH} \\
0,1 \mathrm{~N}\end{array}$ & $\begin{array}{l}\text { Gel } \\
\text { sílice }\end{array}$ & 2 & 60 & Cromatografía iónica \\
\hline
\end{tabular}




\section{Dióxido de azufre, $\mathrm{SO}_{2}$}

En este caso, el método manual utilizado también se puso en marcha en 2005. En la Tabla 4.7 se recogen las principales características a tener en cuenta en la determinación del $\mathrm{SO}_{2}$.

Tabla 4.7. Detalle de los principales requisitos de las normas para la determinación de $\mathrm{SO}_{2}$ procedente de emisiones canalizadas.

\begin{tabular}{|c|c|c|c|c|c|c|c|}
\hline \multirow{2}{*}{$\begin{array}{l}\text { Método de } \\
\text { referencia }\end{array}$} & \multicolumn{4}{|c|}{ Tren de absorción (borboteadores) } & \multirow{2}{*}{$\underset{(1 / \min )}{Q}$} & \multirow{2}{*}{$\stackrel{t}{t}$} & \multirow{2}{*}{$\begin{array}{l}\text { Método de } \\
\text { análisis }\end{array}$} \\
\hline & 1B & 2B & 3B & 4B & & & \\
\hline ITC & $\begin{array}{c}\mathrm{H}_{2} \mathrm{O}_{2} \\
3 \% \mathrm{v} / \mathrm{v}\end{array}$ & $\begin{array}{c}\mathrm{H}_{2} \mathrm{O}_{2} \\
3 \% \mathrm{v} / \mathrm{v}\end{array}$ & Vacío & $\begin{array}{c}\text { Gel } \\
\text { sílice }\end{array}$ & 5 & 45 & $\begin{array}{c}\text { Cromatografía } \\
\text { iónica }\end{array}$ \\
\hline $\begin{array}{c}\text { EN } \\
14791\end{array}$ & $\begin{array}{c}\mathrm{H}_{2} \mathrm{O}_{2} \\
0,3 \text { ó 3\% v/v }\end{array}$ & $\begin{array}{c}\mathrm{H}_{2} \mathrm{O}_{2} \\
0,3 \text { ó } \\
3 \% \mathrm{v} / \mathrm{v}\end{array}$ & Vacío & $\begin{array}{l}\text { Gel } \\
\text { sílice }\end{array}$ & 3,5 & 30 & $\begin{array}{c}\text { Cromatografía } \\
\text { iónica. Método } \\
\text { de la torina }\end{array}$ \\
\hline $\begin{array}{c}\text { UNE } \\
77-216\end{array}$ & $\mathrm{H}_{2} \mathrm{O}_{2}$ & $\mathrm{H}_{2} \mathrm{O}_{2}$ & Vacío & $\begin{array}{l}\text { Gel } \\
\text { sílice }\end{array}$ & 1 & 30 & $\begin{array}{l}\text { Método de la } \\
\text { torina }\end{array}$ \\
\hline VDI 2462 & Isopropanol & $\mathrm{H}_{2} \mathrm{O}_{2}$ & Vacío & $\begin{array}{l}\text { Gel } \\
\text { sílice }\end{array}$ & 1 & 60 & $\begin{array}{l}\text { Método de la } \\
\text { torina }\end{array}$ \\
\hline $\begin{array}{c}\text { EPA } \\
\text { Met. } 6\end{array}$ & $\begin{array}{c}\text { Isopropanol } \\
80 \% \mathrm{v} / \mathrm{v}\end{array}$ & $\begin{array}{c}\mathrm{H}_{2} \mathrm{O}_{2} \\
3 \% \mathrm{v} / \mathrm{v}\end{array}$ & $\begin{array}{c}\mathrm{H}_{2} \mathrm{O}_{2} \\
3 \% \mathrm{v} / \mathrm{v}\end{array}$ & $\begin{array}{c}\text { Gel } \\
\text { sílice }\end{array}$ & 1 & 20 & $\begin{array}{l}\text { Método de la } \\
\text { torina }\end{array}$ \\
\hline
\end{tabular}

\section{Estimación de la incertidumbre de medida de $\mathrm{HF}, \mathrm{HCl}$ y $\mathrm{SO}_{2}$}

EI ITC ha estado acreditado por la Entidad Nacional de Acreditación (ENAC) como laboratorio de ensayo, conforme a los criterios recogidos en la norma ISO 17025, para la realización de ensayos de emisiones atmosféricas de fuentes estacionarias de concentración de partículas (2002), HF (2002), $\mathrm{HCl}$ (2005) y SO 2 (2005). El número de acreditación del laboratorio era el no 2/LE565 y se ha mantenido vigente hasta el año 2011, cuando por razones estratégicas se decidió no renovar la acreditación.

Debido a la condición de laboratorio de ensayo los métodos utilizados han sido validados y se ha estimado la incertidumbre asociada a los mismos. Los resultados del trabajo de validación y de estimación de la incertidumbre de los ensayos se recogen en la Tabla 4.8. A la vista de los mismos, se comprueba que la incertidumbre asociada a cada parámetro es del mismo orden que las incertidumbres demandadas en los métodos de referencia patrón (MRP), cuando dichos métodos están disponibles. 
Tabla 4.8. Incertidumbre expandida para la determinación de HF, $\mathrm{HCl}$ y $\mathrm{SO}_{2}$.

\begin{tabular}{ccccc}
\hline Parámetro & Unidades & $\mathrm{HF}$ & $\mathrm{HCl}$ & $\mathrm{SO}_{2}$ \\
\hline Intervalo de medida & $\mathrm{mg} / \mathrm{Nm}^{3}$ & $3-1000$ & $15-1000$ & $15-1700$ \\
Incertidumbre expandida & $\mathrm{mg} / \mathrm{Nm}^{3}$ & 3 & 10 & 17 \\
$\mathrm{NEA}-\mathrm{MTD}$ (BREF) & $\mathrm{mg} / \mathrm{Nm}^{3}$ & 5 & 30 & 500 \\
$\begin{array}{c}\text { Incertidumbre expandida } \\
\text { relativa en el VLE }\end{array}$ & $\%$ & 60 & 33 & 4 \\
$\begin{array}{c}\text { Incertidumbre global del MRP } \\
\text { en el VLE }\end{array}$ & $\%$ & $\mathrm{ND}$ & 30 & 20 \\
$\begin{array}{c}\text { Intervalo de confianza de } \\
\text { reproducibilidad. IC } \mathrm{R} \text { INERIS }\end{array}$ & $\%$ & 44 & 73 & 22,6 \\
\hline
\end{tabular}

\subsubsection{Métodos automáticos de medida}

\section{Determinación de HF}

La técnica de detección de HF utilizada en el trabajo de investigación es una técnica óptica de absorción denominada espectroscopia de absorción láser de diodo sintonizable (tuneable diode laser absorption spectroscopy, TDLAS), o, simplemente TDL (Bogue, 2015).

En esta técnica la emisión de un láser cuya longitud de onda es sintonizada para una de las líneas de absorción del gas se transmite a través de una muestra que contiene el gas objetivo y posteriormente, se determina la concentración del gas de interés mediante la medida de la absorción óptica.

Las técnicas basadas en la absorción son conceptualmente simples y se basan en la conocida ley de absorción de Lambert - Beer:

$$
\mathrm{I}=\mathrm{I}_{0} \cdot \exp (-\alpha \mathrm{L})
$$

donde I es la intensidad de la emisión láser que llega al sensor, $I_{0}$ es la intensidad incidente, $\alpha$ es el coeficiente de absorción del gas, como producto de la concentración de gas y su absorbicidad específica, y $\mathrm{L}$ es la longitud del paso óptico, que está relacionado con la sensibilidad del detector (Bogue, 2015).

Los sistemas TDLAS operan en el espectro del infrarrojo cercano. Los coeficientes de absorción en esta región de longitud de onda son varios órdenes de magnitud más débiles que en la región fundamental del espectro infrarrojo medio. Sin embargo, en la actualidad, la 
calidad de los láseres permite el uso de una modulación de muy alta frecuencia para mejorar la sensibilidad de la medida (Schiff et al., 1996).

La especificidad de esta técnica es alta dado que es posible sintonizar con precisión la longitud de onda para una línea de absorción determinada, mediante el control específico de la temperatura del láser y la corriente de accionamiento. Esta forma de actuación permite seleccionar la absorción sin interferentes de otros compuestos. Los sistemas TDLAS utilizan un láser de realimentación distribuida (DFB) que permite detectar la mayoría de los gases con bandas de absorción en el infrarrojo cercano, como por ejemplo: $\mathrm{CO}, \mathrm{CO}_{2}, \mathrm{NO}, \mathrm{HCl}, \mathrm{NH}_{3}$ y $\mathrm{HF}$.

En el caso de los compuestos de flúor este tipo de equipamiento es capaz de distinguir entre una molécula de HF y otros compuestos fluorados, como por ejemplo el $F_{2}$, al disponer de bandas de absorción específicas.

Estos sistemas pueden ser configurados con tres modos diferentes de paso de luz: extractivo, donde el gas es bombeado hasta una célula de medición, incluyendo células Herriot multifase que proporcionan un camino de gran longitud en un pequeño volumen y, por lo tanto, presentan una sensibilidad mejorada; paso abierto (open path), donde el haz láser viaja en el espacio libre y utiliza un catadióptrico; y stand-off, donde la reflectancia pasiva del haz de láser desde estructuras sólidas permite la medición de la trayectoria integrada de concentraciones en distancias de hasta unas pocas decenas de metros (Bogue, 2015).

Como principales características de los equipos láser cabe destacar las siguientes:

- Alta resolución: mínimas interferencias con otros gases, así como una respuesta lineal en un amplio rango de concentraciones.

- Elevada intensidad de radiación: esta característica permite obtener respuestas rápidas del sistema, normalmente $1-2$ segundos, y una elevada sensibilidad, por lo que son capaces de medir concentraciones a nivel de partes por millón (ppm) e incluso, con una configuración adecuada, partes por billón (ppb).

- Equipos robustos: esto les confiere un pequeño tamaño y la capacidad de soportar condiciones ambientales variables (laboratorio e industriales).

- Análisis de un solo componente: como desventaja principal de estos equipos hay que señalar que, dado que se selecciona una banda de absorción específica del espectro, sólo son capaces de realizar la determinación del compuesto elegido.

En concreto, el equipo de análisis tipo láser utilizado en este trabajo ha sido el GasFinderFC suministrado por la firma Boreal Laser Inc. (Canadá) y que se muestra en la Figura 4.6. Este equipo ha sido diseñado en la configuración stand-off para ser utilizado en la propia chimenea como equipo in situ. El diseño original se ha adaptado para la medida de HF procedente de la etapa de cocción de baldosas cerámicas, y ha sido validado convenientemente frente al método manual de determinación de HF (Monfort et al., 2004; Monfort et al., 2005). 


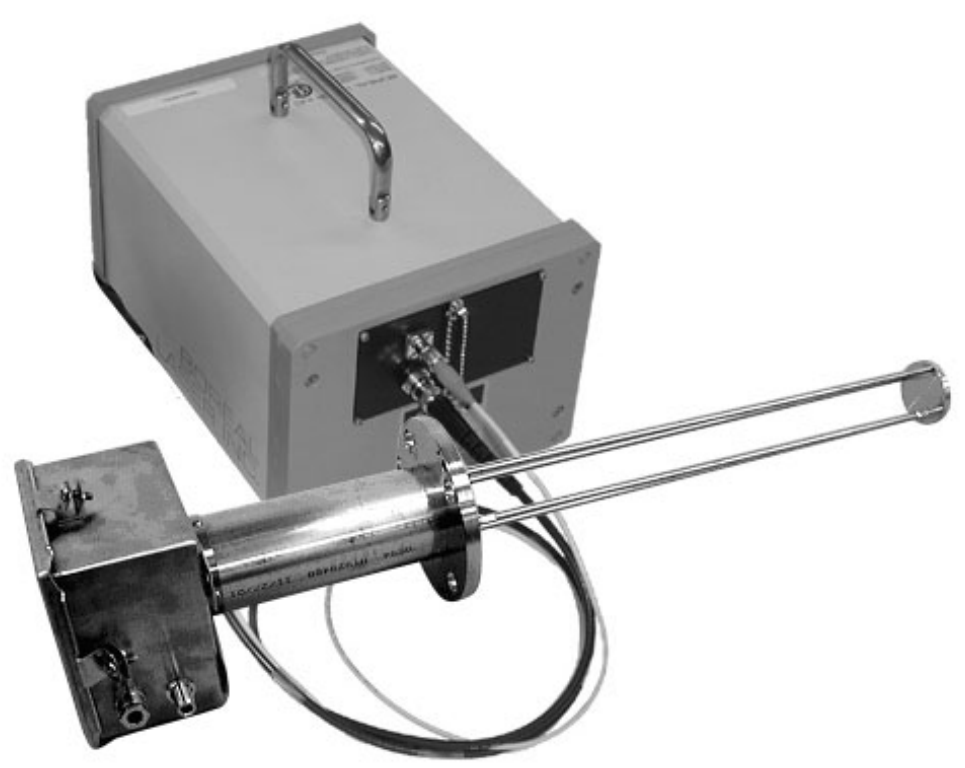

Figura 4.6. Medidor de HF GasFinderFC suministrado por la firma Boreal Laser Inc.

El esquema de funcionamiento del equipo y de la sonda diseñada para el muestreo en chimenea se detalla en la Figura 4.7.

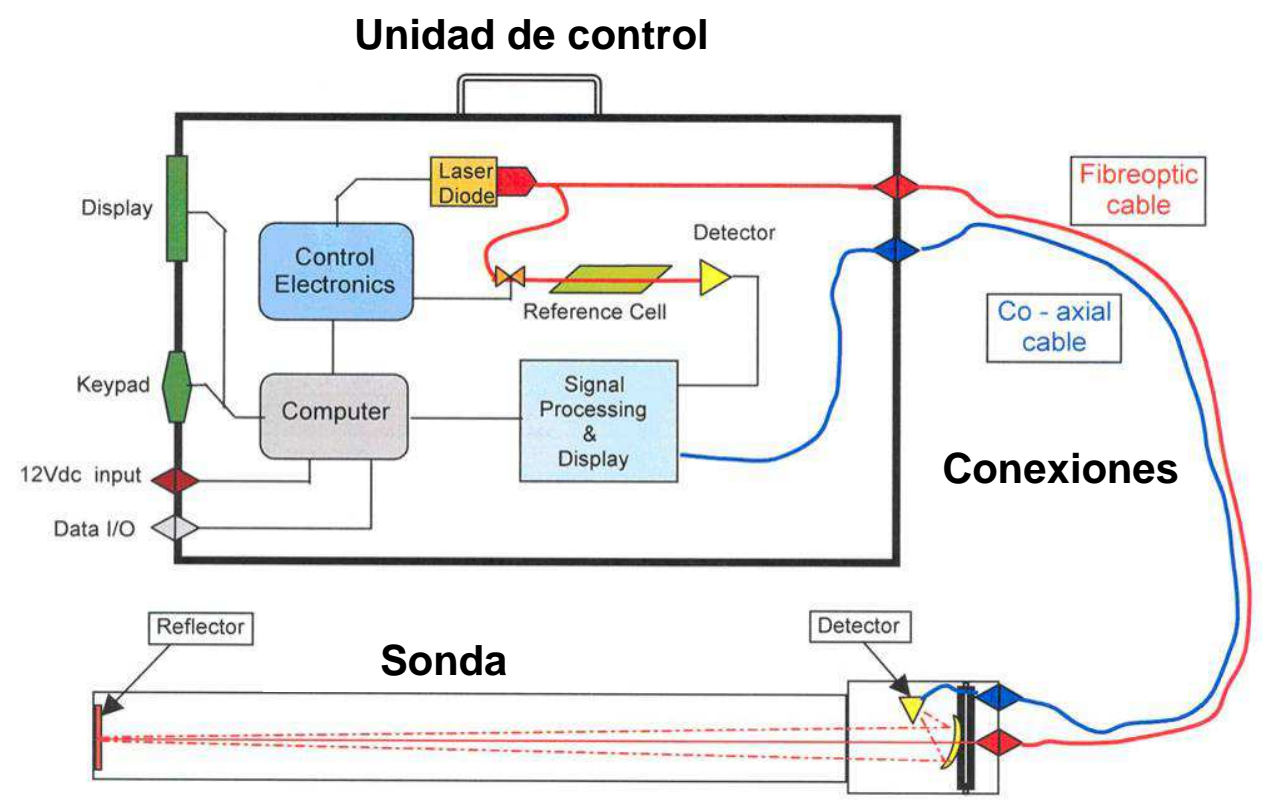

Figura 4.7. Esquema del equipo utilizado y diseño de la sonda de medida en chimenea (Monfort et al., 2004).

Una de las características principales de este equipo es que dispone de un sistema de calibrado en continuo, que se basa en que una fracción de la radiación láser generada pasa a través de una célula de referencia con un contenido en HF conocido. Esto permite comparar 
las señales de medida y de referencia para determinar si los picos de absorción coinciden (Figura 4.8. Muestra A; izquierda) o no coinciden (Figura 4.8. Muestra B; derecha), lo cual se cuantifica mediante un coeficiente de correlación $\left(R^{2}\right)$ que indica la similitud en la banda emitida por la muestra y por la celda de referencia. Para llevar a cabo medidas con fiabilidad, los valores de $R^{2}$ deben ser próximos a uno (Tulip, 2000).
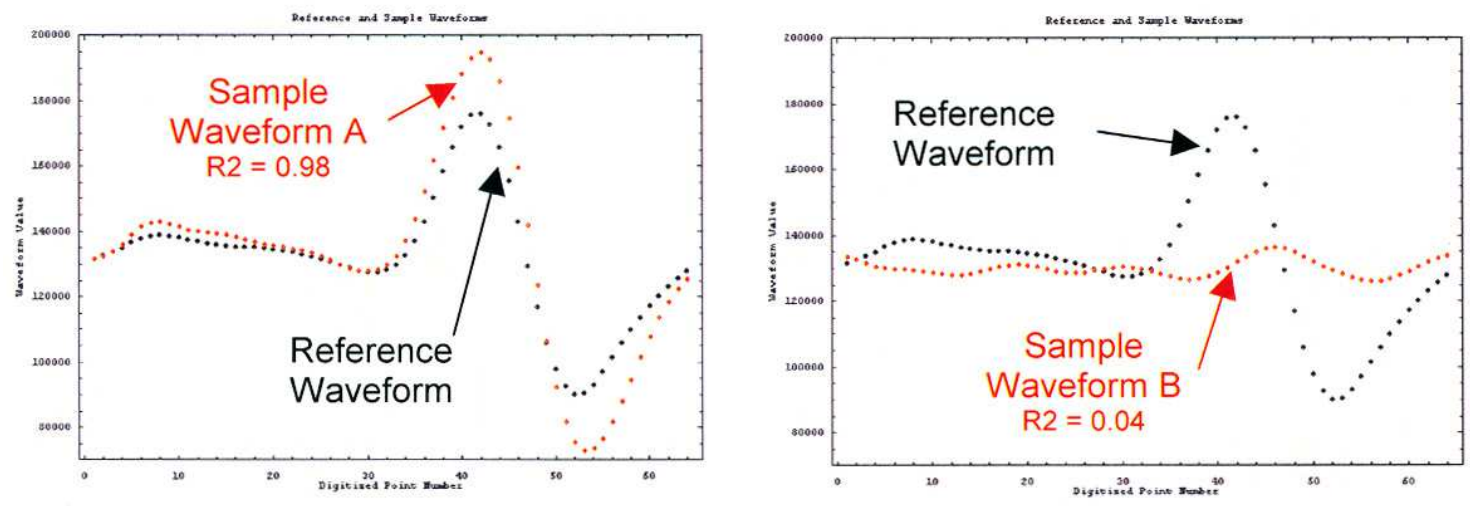

Figura 4.8. Comparativa de las señales de la célula de referencia y de la muestra A (izq.) y B (dcha.) (Monfort et al., 2004).

Además, utilizando la señal de la célula de referencia el equipo dispone de un algoritmo que permite realizar continuamente un ajuste del cero. Desde el punto de vista práctico, el hecho de que el analizador disponga de un sistema de autocalibración es de enorme importancia, dado que no requiere el uso de gases patrón, lo que simplifica en gran medida el trabajo de campo.

\section{Determinación de $N O_{X}$}

La técnica de detección de $\mathrm{NO}_{x}$ utilizada en el trabajo de investigación es una técnica de extracción basada en células electroquímicas. Esta técnica ha sido implantada en equipos de medida portátiles, que han presentado un importante desarrollo en los últimos años, convirtiendo este tipo de equipos en equipos económicos, simples y robustos. Los sensores electroquímicos están basados en la medida de la diferencia de potencial que se crea en dos celdas que contienen especies químicas que presentan diferentes concentraciones y que se encuentran separadas por un conductor iónico denominado electrolito. Dependiendo del tipo de electrolito, los sensores se clasifican en sensores de electrolito sólido y sensores de electrolito líquido. Los sensores líquidos están rellenos con un electrolito acuoso, específico para cada contaminante de interés, en el que están dispuestos dos o tres electrodos, igualmente combinados específicamente, entre los que hay un campo eléctrico. Los sensores están sellados del exterior mediante membranas permeables al gas de interés. La corriente generada en la célula es proporcional a la concentración de contaminante existente alrededor de la misma. 
Tanto el diseño como el funcionamiento de los sensores difieren en función del componente del gas a medir. En el caso del $\mathrm{NO}_{x}, \mathrm{CO}$ y $\mathrm{SO}_{x}$ se utiliza un diseño basado en tres electrodos. Este diseño incluye un electrodo de medida, un contraelectrodo y un electrodo de referencia. El contraelectrodo está localizado en el interior de la celda de forma que la difusión de los gases atmosféricos hasta el mismo está muy restringida. El electrodo de medida está situado de forma que los gases externos tienen fácil acceso al mismo. Además de los electrodos, existen otros elementos presentes en las células electroquímicas:

- El electrolito acuoso de conducción iónica concentrado (por ejemplo ácido sulfúrico, soluciones alcalinas,...).

- El circuito externo de baja impedancia que conecta los electrodos y proporciona una tensión a través de una resistencia para medir la corriente de salida de la celda.

- La barrera de difusión que controla la difusión de los gases reactivos hacia el eléctrodo de medida, previniendo una reacción inversa en el contraelectrodo y haciendo que la reacción en el electrodo de medida y la corriente resultante estén limitadas solamente por la velocidad de difusión a través de la barrera. Con la inclusión de la barrera, la concentración del gas reactivo se aproxima a cero en el eléctrodo de medida.

El flujo de gas $(\Phi)$ reactivo a través de la barrera de difusión es proporcional al gradiente de concentración a través de la misma:

$$
\Phi=\alpha C_{1}-C_{2}
$$

donde $\mathrm{C}_{1}$ y $\mathrm{C}_{2}$ son las concentraciones del gas en el ambiente y en la celda respectivamente. Como $\mathrm{C}_{2}$ tiende a cero en la condición de corriente limitada, se tiene que:

$$
\Phi=\alpha C_{1}
$$

Por la ley de Fick, la corriente límite de la celda es directamente proporcional al flujo de gas:

$$
\Phi(\mathrm{mol} / \mathrm{s})=\mathrm{i}_{\mathrm{L}} / \mathrm{nF}=\mathrm{K} \cdot \mathrm{C}_{1}
$$

donde $i_{L}$ es la densidad de corriente límite, $n$ es el número de electrones transferidos por mol, $F$ es la constante de Faraday, y $K$ es la difusibilidad de la barrera. Por tanto, la corriente límite del sensor es proporcional a la concentración del gas en el ambiente.

Este principio se puede aplicar para medir cualquier sustancia gaseosa que pueda reaccionar con el eléctrodo apropiado (Kane y Larrabee, 2013).

En una célula electroquímica diseñada para la medida de $\mathrm{NO}_{\mathrm{x}}$, las moléculas de $\mathrm{NO}$ y de $\mathrm{NO}_{2}$ pasan, a través de la membrana permeable al gas, al electrodo de trabajo donde se forman iones $\mathrm{H}^{+}$como consecuencia de una reacción química de oxidación. Estos iones migran como consecuencia del campo eléctrico existente hasta el contraelectrodo, donde se genera un flujo de corriente en el circuito externo mediante otra reacción química desencadenada por el 
oxígeno $\left(\mathrm{O}_{2}\right)$ del aire puro, también aportado. En la Tabla 4.9 se recogen las ecuaciones de reacción de la oxidación electroquímica para la detección de $\mathrm{NO}_{\mathrm{x}}$.

Tabla 4.9. Ecuaciones de reacción de la oxidación electroquímica para la detección de $\mathrm{NO}_{x}$ (India T, 2012).

\begin{tabular}{ll}
\hline & Ecuaciones de reacción \\
\hline Ánodo: & $\mathrm{NO}+2 \mathrm{H}_{2} \mathrm{O} \rightarrow \mathrm{HNO}_{3}+3 \mathrm{H}^{+}+3 \mathrm{e}^{-}$ \\
& $\mathrm{NO}_{2}+2 \mathrm{H}^{+}+2 \mathrm{e}^{-} \rightarrow \mathrm{NO}+\mathrm{H}_{2} \mathrm{O}$ \\
& $1 / 2 \mathrm{O}_{2}+2 \mathrm{H}^{+}+2 \mathrm{e}^{-} \rightarrow \mathrm{H}_{2} \mathrm{O}$ \\
\hline
\end{tabular}

Los sistemas basados en células electroquímicas presentan sensibilidades cruzadas con otros componentes, por lo que la corriente debe ser filtrada, enfriada y secada antes de realizar la medida. Este tipo de sistemas presentan una respuesta lenta y una vida útil de la célula limitada. No obstante, debido a las características que presentan estos equipos, son ampliamente utilizados en mediciones periódicas.

La norma de ensayo ASTM 6522 presenta una metodología de medida estandarizada para la determinación de diferentes contaminantes presentes en los gases de combustión de diversas fuentes estacionarias, mediante la utilización de la tecnología de células electroquímicas.

El equipo de medida utilizado en este caso ha sido un analizador de gases portátil denominado Testo 350, suministrado por la empresa Testo AG (Alemania). Este equipo dispone de certificación MCERTS.

En la Figura 4.9 se muestra el esquema de funcionamiento de un sensor electroquímico de tres electrodos válido para la detección de $\mathrm{CO}, \mathrm{SO}_{\mathrm{x}}$ y $\mathrm{NO}_{\mathrm{x}}$ aportado por el propio fabricante Testo (India T, 2012).

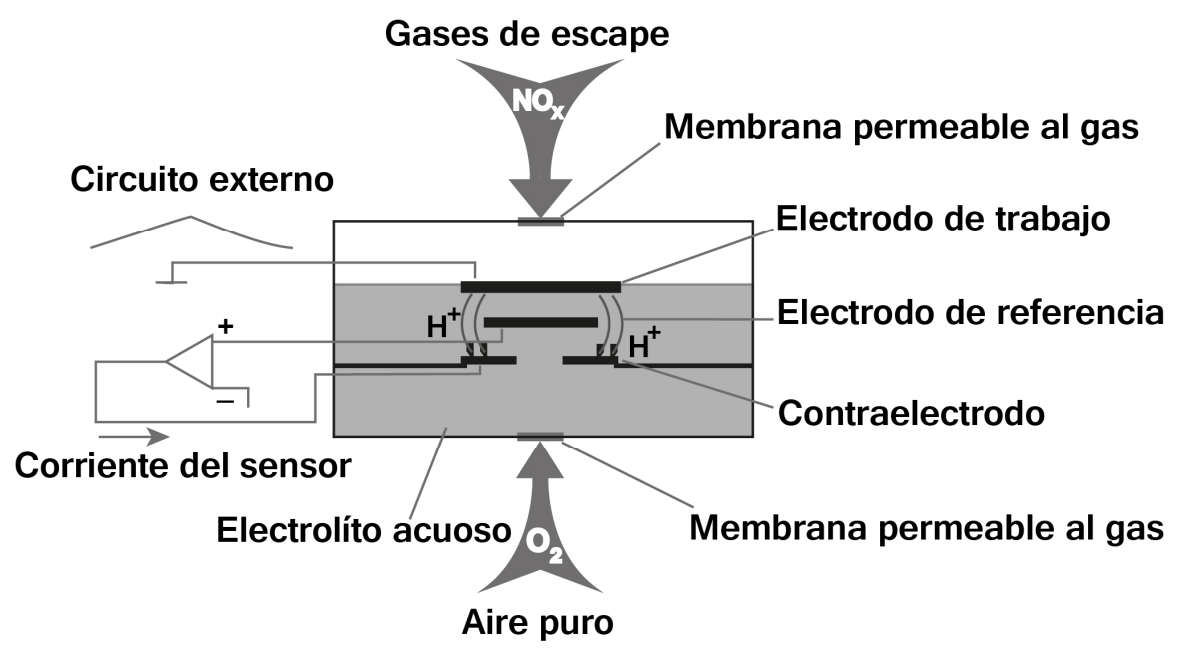

Figura 4.9. Esquema de funcionamiento de un sensor electroquímico de tres electrodos, válido para la detección de $\mathrm{CO}, \mathrm{SO}_{x}$ y NOx (India T, 2012). 


\section{Estimación de la incertidumbre de medida de $H F$ y $N O_{X}$}

La incertidumbre asociada a la medida de HF con el equipo láser se puede estimar mediante la comparación de sus resultados con los obtenidos utilizando el método manual. Cabe recordar que, para este contaminante, no se ha publicado un método de referencia patrón, por lo que se ha utilizado el método de ensayo desarrollado en el ITC. En los trabajos de validación llevados a cabo se ha determinado que la incertidumbre expandida en todo el rango de medida es de $5 \mathrm{mg} / \mathrm{Nm}^{3}$ (Monfort et al., 2004; Monfort et al., 2005). Esta incertidumbre supone que el equipo de medida muestra un intervalo de confianza del $100 \%$ en el valor límite de emisión prescrito en las autorizaciones administrativas.

En el caso de la medida de $\mathrm{NO}_{x}$ no se ha realizado la comparación pertinente con el método de referencia patrón para dicho contaminante, que es el método de quimioluminiscencia descrito en la norma EN 14792. Sin embargo, la estimación de la incertidumbre realizada por el propio fabricante para la medida de este parámetro se sitúa en el $5 \%$ del valor medido. Por tanto, en el valor límite de emisión para este contaminante $\left(500 \mathrm{mg} / \mathrm{Nm}^{3}\right)$, la incertidumbre de medida se estima en $25 \mathrm{mg} / \mathrm{Nm}^{3}$. 


Capítulo 5. Resultados y discusión. 



\subsection{Introducción a los resultados}

El trabajo de investigación desarrollado pretende profundizar en el conocimiento científico relativo a la emisión de contaminantes ácidos de naturaleza gaseosa que tiene lugar durante el tratamiento térmico de baldosas cerámicas. Se ha prestado especial atención a los compuestos de flúor por sus implicaciones ambientales y porque son considerados como los contaminantes característicos de la industria cerámica. Una parte muy importante del trabajo desarrollado se ha llevado a cabo a nivel industrial sobre hornos continuos de cocción rápida, monoestrato, y que utilizan como combustible gas natural.

La emisión de compuestos ácidos está asociada, fundamentalmente, al uso de materias primas y combustibles que los pueden contener. Se generan en aquellas etapas de producción donde tienen lugar procesos de combustión o donde los materiales procesados alcanzan elevadas temperaturas. Durante la producción de baldosas cerámicas se generan emisiones calientes en la etapa de secado por atomización de suspensiones, en la etapa de secado de piezas conformadas y en la etapa de cocción de baldosas cerámicas. En el caso de la etapa de secado de piezas, si se han utilizado combustibles libres de azufre, la emisión de contaminantes gaseosos ácidos generados por el material cerámico procesado puede considerarse despreciable, dado que se opera con una temperatura de la atmósfera del secadero inferior a $250{ }^{\circ} \mathrm{C}$, donde el material cerámico apenas supera los $125^{\circ} \mathrm{C}$. El contaminante relevante en esta etapa del proceso es el $\mathrm{PM}_{10}$ (Blasco et al., 1992; Busani et al., 1995).

En la primera parte del estudio se han caracterizado las emisiones de los contaminantes ácidos generadas durante la fabricación de baldosas cerámicas. El trabajo desarrollado, junto con los resultados obtenidos en el mismo, se han recogido para su difusión en forma de publicación científica en el artículo ํo 1.

Los resultados obtenidos en esta parte del trabajo muestran que las emisiones de compuestos ácidos asociadas a la etapa de secado por atomización de suspensiones son poco significativas, en comparación con los NEA - MTD establecidos en el documento BREF. Además, se ha comprobado que los valores de emisión en esta etapa de proceso no presentan diferencias significativas entre los diferentes tipos de producto estudiados: azulejo, gres esmaltado y gres porcelánico.

En el caso de la etapa de cocción, la emisión de compuestos ácidos se puede considerar significativa a tenor de los niveles alcanzados en la misma. Así, cuando se comparan dichos niveles con los diferentes NEA - MTD establecidos en la actualidad, se deduce que la emisión de $\mathrm{HF}$ y HCl es la más relevante para este grupo de contaminantes, y que existe la necesidad mayoritaria de ser corregidas, mediante la adopción de medidas primarias y/o sistemas de depuración adecuados, antes de su emisión a la atmósfera. Por su parte, la emisión de $\mathrm{SO}_{2}$ y 
de $\mathrm{NO}_{x}$ se sitúa muy por debajo de los límites de emisión por lo que no requieren ningún tipo de corrección.

Los resultados referentes a la emisión de compuestos ácidos son aplicables a los diferentes tipos de producto considerados: azulejo, gres esmaltado y gres porcelánico. En el caso del azulejo blanco existe una salvedad, dado que la menor concentración de HF asociada a este producto conlleva que puede no ser necesaria la adopción de medidas correctoras previamente a su emisión a la atmósfera. Sin embargo, los niveles asociados al resto de productos presentan un valor de emisión muy similar con independencia de la composición en calcio del mismo.

Esta parte de la investigación ha determinado la importancia de la emisión de los compuestos de cloro y de flúor durante la etapa de cocción de baldosas cerámicas dentro de la familia de contaminantes ácidos. Esta situación es aplicable a otros materiales cerámicos tradicionales (tejas y ladrillos), y supone considerar los compuestos de flúor y cloro como los más significativos de este tipo de industria. En concreto, la emisión de compuestos de flúor es considerada como uno de los impactos ambientales más característicos de la industria de baldosas cerámicas (Mallol et al., 2001).

Los elevados niveles de emisión de flúor generados en los hornos industriales de cocción obligan a su corrección antes de ser vertidos a la atmósfera. Esta necesidad ha promovido una especial dedicación al estudio de los sistemas de prevención y corrección de este tipo de emisiones, al menos en la UE. También ha favorecido el estudio del origen de las emisiones de compuestos de flúor y de los mecanismos asociados a las mismas (Mazzali et al., 1980; Strohmenger, 1983; Dehne, 1987; Hauck et al., 1992; Reymer y Jong, 1993; Denisen y Vries, 1998; Galán et al., 2002; González et al., 2002; González et al., 2006; IPTS, 2007).

Los sistemas primarios o de prevención (source reduction) actúan sobre las materias primas o sobre el proceso. El nivel de emisión de compuestos de flúor depende de la concentración de fluoruro en las materias primas y de la estabilidad térmica de la especie mineralógica en que se encuentre. En base a ello y según la revisión de la bibliografía realizada en secciones anteriores de esta tesis, se establece una clasificación de las soluciones preventivas en función de las siguientes acciones:

- Minimización del uso de precursores de HF, mediante la selección y utilización de materias primas o aditivos con bajo contenido en flúor, que permite la disminución de la emisión de dichos compuestos.

- Modificaciones en el proceso productivo que conlleven la disminución de la emisión de $\mathrm{HF}$, mediante la modificación de variables de proceso como la optimización de la curva de cocción y la reducción de vapor de agua en el horno. 
- Modificación de las variables de composición que permitan retener en el interior de la pieza conformada los iones flúor, mediante la adición de algún compuesto que evite su salida, bien por métodos de fijación, o bien por métodos de barrera.

Por su parte, los sistemas secundarios o de corrección (end-of-pipe) se basan en la neutralización del HF en la corriente de gases residual, predominando claramente los sistemas basados en procesos vía seca que utilizan como reactivo $\mathrm{CaCO}_{3}, \mathrm{Ca}(\mathrm{OH})_{2}, \mathrm{NaHCO}_{3}$ ó $\mathrm{Na}_{2} \mathrm{CO}_{3}$. Estos sistemas permiten alcanzar rendimientos de eliminación muy elevados (hasta el $99 \%$ ), pero con el inconveniente de necesitar la instalación de un sistema de depuración adicional y de la gestión adecuada de los residuos generados.

Estos sistemas son considerados como una tecnología madura en la industria cerámica europea debido a su gran implantación. Este hecho ha motivado que el presente trabajo de investigación se haya centrado en estudiar la aplicabilidad de medidas primarias en la fabricación de baldosas cerámicas, cuando se utilizan hornos industriales de combustión.

Según se deduce de la revisión bibliográfica de secciones anteriores de la tesis y en los artículos $n^{\circ} 2$ y $n^{\circ}=3$, la presencia de compuestos de flúor está asociada a algunas materias primas cerámicas, donde el ion flúor se encuentra como impureza sustituyendo a los grupos $\mathrm{OH}^{-}$en la estructura cristalina de la mica y de muchos minerales arcillosos (montmorillonita, illita, caolinita, entre otros) por lo que el inicio de la emisión de los compuestos de flúor suele coincidir con la deshidroxilación de estos minerales a temperaturas del orden de los $500-700{ }^{\circ} \mathrm{C}$ (Fabbri, 1992; Reymer y Jong, 1993; Chipera y Bish, 2002).

La emisión de los compuestos de flúor tiene lugar, mayoritariamente, en forma de HF en fase gas, cuando la cocción se desarrolla en hornos industriales de combustión y, por tanto, en presencia de vapor de agua. El HF formado se emite parcialmente a la atmósfera junto con los gases de combustión (Hill, 1995).

El trabajo recogido en el artículo no 2 ha permitido explicar porque la adición de $\mathrm{CaCO}_{3}$ no resulta eficaz para disminuir las emisiones de compuestos de flúor durante la etapa de cocción de las baldosas cerámicas. La investigación llevada a cabo en este caso ha consistido en determinar la influencia del contenido en $\mathrm{CaCO}_{3}$ sobre la evolución del contenido en fases cristalinas con la temperatura en una composición de baldosa cerámica de gres, con un bajo contenido en $\mathrm{CaCO}_{3}$, sobre la que se ha realizado adiciones de $\mathrm{CaF}_{2}$. Además, también se ha adicionado $\mathrm{BaF}_{2}$ y $\mathrm{SrF}_{2}$ a la citada composición para determinar su estabilidad térmica.

Se ha comprobado que en la zona de precalentamiento de los hornos industriales se produce una adsorción neta de flúor sobre el material cerámico procesado, a pesar de ser sometido a ciclos de cocción relativamente rápidos. Ahora bien, prácticamente la totalidad del flúor adsorbido se emite posteriormente cuando las piezas alcanzan la zona de máxima temperatura de cocción ( $\left.\mathrm{T}>1100^{\circ} \mathrm{C}\right)$. Ello se debe a que las especies cristalinas que retienen el flúor - fluorita $\left(\mathrm{CaF}_{2}\right)$ y cuspidina $\left(\mathrm{Ca}_{4} \mathrm{Si}_{2} \mathrm{O}_{7} \mathrm{~F}_{2}\right)$ - no son termodinámicamente estables en el seno de una matriz cerámica a temperaturas superiores a $1050^{\circ} \mathrm{C}$, a diferencia de lo que 
ocurre en los materiales procesados a menor temperatura, en los que el flúor adsorbido queda retenido de forma estable en el producto procesado.

Así pues, las medidas primarias de reducción de la emisión de flúor que se basan en favorecer la formación de $\mathrm{CaF}_{2}$ no son de aplicación en la fabricación de baldosas cerámicas que emplean ciclos de cocción rápida con elevadas temperaturas de trabajo en los hornos de combustión.

En la siguiente etapa de la investigación se han examinado los fenómenos de adsorción y emisión de compuestos de flúor que tienen lugar durante la cocción de baldosas cerámicas. Esta parte del trabajo se ha publicado en el artículo no 3. En concreto, se han estudiado composiciones de soporte de azulejo, gres esmaltado y gres porcelánico por sus diferentes contenidos de flúor y de calcio. Estos materiales han sido procesados con ciclos rápidos en hornos eléctricos discontinuos de laboratorio y en hornos continuos industriales de combustión.

Se ha comprobado que la emisión de flúor durante la etapa de cocción en una atmósfera de aire de un horno de eléctrico de laboratorio empieza a temperaturas superiores a $800 \stackrel{\circ}{\circ}$ y aumenta progresivamente hasta alcanzar la temperatura máxima de cocción. Sin embargo, en los hornos continuos industriales la emisión empieza a temperaturas menores y decrece en ciertas zonas del mismo. Esta disminución indica que existen algunas zonas en este tipo de hornos donde el flúor es adsorbido en lugar de ser emitido por el material que está siendo procesado, como en el caso de la zona de precalentamiento, a pesar de ser sometido a ciclos de cocción rápidos. Ahora bien, prácticamente la totalidad del flúor adsorbido durante el precalentamiento se emite posteriormente, cuando las piezas alcanzan la máxima temperatura de cocción (>1100 ํㅡ).

Por otra parte, la extracción de piezas en distintos puntos del horno industrial ha permitido constatar la importancia que poseen los fenómenos de adsorción de HF que tienen lugar sobre la superficie de las piezas procesadas en la zona de precalentamiento del horno.

Los resultados obtenidos en el trabajo demuestran la poca eficacia exhibida por parte de las medidas preventivas señaladas por las referencias bibliográficas (Mazzali et al., 1980; Tunker y Schmidt, 1981; Strohmenger, 1983; Kolkmeier, 1986; Dehne, 1987; Brosnan, 1992; Fabbri, 1992; DETR, 1999; Junge y Hauck, 2000; Wei - hong et al., 2001), encaminadas a favorecer la adsorción de flúor en la zona de precalentamiento, a la hora de reducir las emisiones de flúor durante la cocción de productos cerámicos procesados a temperaturas máximas superiores a $1100^{\circ} \mathrm{C}$, como ocurre en el caso de las baldosas cerámicas.

En la última parte del trabajo, recogida en el artículo $n^{\circ} 4$, se ha realizado el seguimiento en continuo de los niveles de HF contenidos en la corriente gaseosa procedente de la etapa de cocción de baldosas cerámicas. Para llevar a cabo este estudio se ha utilizado un equipo de medida de la emisión de HF basado en tecnología láser TDLAS, que se ha instalado en la chimenea de evacuación de gases de los hornos continuos industriales de combustión. La 
utilización de un equipo de medida en continuo presenta la ventaja, respecto a la metodología utilizada en otras partes de la investigación, de generar una respuesta inmediata frente a los cambios repentinos en la emisión de HF. Además, permite conocer la concentración en la propia conducción de salida de gases, tal y como se prescribe en el control legal de este tipo de emisiones.

La realización del seguimiento en continuo ha permitido conocer que la emisión de HF en hornos industriales de combustión, bajo diferentes condiciones habituales de operación, presenta un comportamiento continuo y constante en el tiempo, con pequeñas variaciones alrededor de un valor medio prácticamente estable que depende, principalmente, de las características del producto fabricado - tipología y grosor - y de las variables de operación temperatura máxima, duración de la cocción, entre otros.

Por su parte, cuando se producen algunos cambios importantes en las condiciones de producción en los hornos industriales de combustión se comprueba que la emisión de HF varía de forma apreciable, como por ejemplo cuando se origina una interrupción en la alimentación del horno que provoca un hueco en la entrada de material al mismo. Este tipo de incidencia, habitual en los procesos industriales, provoca, en primer lugar, un incremento de la emisión de HF como consecuencia de la falta de material en la zona de precalentamiento que impide la existencia de fenómenos de adsorción en la misma. En segundo lugar, cuando el hueco formado alcanza la zona de máxima temperatura, la emisión disminuye debido a dos efectos simultáneos: la falta de material que pueda emitir flúor en la zona de máxima temperatura y la presencia de material en la zona de precalentamiento que rebaja la cantidad de flúor albergada en la atmósfera del horno.

Igualmente, se ha comprobado que la introducción de modificaciones realistas en las condiciones de fabricación a nivel industrial, como pueden ser el tratamiento térmico y la densidad aparente en seco de las piezas producidas, no permite alcanzar una reducción significativa de la emisión de HF asociada a este proceso cuando la temperatura de trabajo alcanza los $1100^{\circ} \mathrm{C}$. Así pues, el margen de maniobra es limitado si nos referimos a la modificación de los parámetros de producción como medida de prevención de la emisión de HF. Por otro lado, esta parte de la investigación ha permitido conocer que la aplicación de esmalte en la baldosa es una forma efectiva de reducir la emisión de HF cuando se procesa en hornos continuos industriales, extendiendo a este tipo de productos la solución aportada en la bibliografía y probada en laboratorio (Tunker y Schmidt, 1981). Este fenómeno está causado, probablemente, por la formación de un recubrimiento impermeable sobre la pieza debido a la fusión de los componentes del esmalte cuando alcanza su temperatura de sellado y/o por la disolución de parte del flúor en la fase líquida que se desarrolla en la capa de esmalte a alta temperatura. 


\subsection{Caracterización de las emisiones de contaminantes ácidos en la fabricación de baldosas cerámicas (Artículo nํㅜ)}

El estudio de la emisión de contaminantes ácidos durante la fabricación de baldosas cerámicas pretende, como primer objetivo, identificar los contaminantes atmosféricos gaseosos de naturaleza ácida que se emiten de forma significativa. También pretende determinar la concentración de los mismos y, si es posible, obtener factores de emisión específicos de la industria cerámica del distrito de Castellón.

La finalidad del estudio es disponer de información sectorial actualizada y veraz sobre la emisión de dichos contaminantes que permita alcanzar las siguientes metas:

- Optimizar costes en controles de contaminantes atmosféricos, estableciendo un sistema de control de contaminantes para la industria cerámica que sea realista.

- Mejorar la transparencia informativa y la relación con la administración.

- Establecer factores de emisión que permitan realizar inventarios de emisiones adaptados a la realidad.

El estudio de emisiones se ha realizado en aquellas etapas del proceso de fabricación de baldosas cerámicas donde existen procesos de combustión y se alcanza una temperatura en proceso superior a $500^{\circ} \mathrm{C}$. Las instalaciones involucradas han sido las siguientes:

- Secaderos por atomización, provistos de sistemas de depuración de partículas tales como filtros de mangas o lavadores tipo Venturi.

- Hornos de cocción, sin sistemas de corrección para las emisiones ácidas, o caracterizadas antes de dichos sistemas.

El estudio se ha centrado en la emisión de contaminantes de naturaleza ácida emitidos en dichas etapas, en forma de compuestos de flúor, cloro, azufre y nitrógeno, pertenecientes a las baldosas cerámicas de azulejo, gres y gres porcelánico que aparecen en la Tabla 5.1. En dicha tabla se han unificado bajo la misma denominación los productos de gres blanco y de gres porcelánico, dado que se trata de productos de muy baja porosidad fabricados con materias primas muy similares y, por tanto, sus emisiones son similares.

La etapa de secado de piezas conformadas no se ha considerado en este estudio, dado que opera a temperaturas de gas, normalmente, inferiores a $250^{\circ} \mathrm{C}$, y en las que el material cerámico apenas supera los $125 \stackrel{\circ}{\circ}$, por lo que la emisión de contaminantes puede considerarse despreciable, siempre que se utilicen combustibles exentos de azufre (Blasco et al., 1992; Busani et al., 1995). 
El trabajo publicado se ha complementado con el estudio de la concentración de flúor que presentan las materias primas empleadas en la fabricación de los soportes de baldosas cerámicas, que ha sido incluido como resultados adicionales en el apartado 5.2.3.

Tabla 5.1. Nomenclatura utilizada en función del tipo de baldosa.

\begin{tabular}{c|c|c}
\hline \multicolumn{1}{c}{ Tipo de baldosa } & Coloración del soporte & Referencia en el estudio \\
\hline \multirow{2}{*}{ Azulejo } & Rojo & AR \\
\cline { 2 - 3 } & Blanco & AB \\
\hline \multirow{2}{*}{ Gres esmaltado } & Rojo & GR \\
\cline { 2 - 3 } & Blanco & \multirow{2}{*}{ GB } \\
\hline Gres porcelánico & Blanco & \\
\hline
\end{tabular}

\subsubsection{Secado por atomización}

En la Tabla 5.2 se presenta la distribución de focos pertenecientes a la etapa de secado por atomización medidos durante el desarrollo del estudio. En la tabla, además de indicar el tipo de granulados atomizados fabricados (tipología y color), se especifica si la instalación está conectada a una turbina de cogeneración, dado que el BREF de la industria cerámica distingue estas dos posibilidades. El parámetro caracterizado en esta etapa ha sido la concentración de los diferentes contaminantes ácidos estudiados ( $\mathrm{HF}, \mathrm{HCl}, \mathrm{SO}_{2}$ y NOx ).

Tabla 5.2. Distribución de focos medidos para los secaderos por atomización.

\begin{tabular}{ccc}
\hline Instalación & Tipo de producto & Cogeneración \\
\hline 1 & Granulados de atomizado para azulejo rojo (AR) & Sí \\
2 & Granulados de atomizado para azulejo rojo (AR) & Sí \\
3 & Granulados de atomizado para gres rojo (GR) & Sí \\
4 & Granulados de atomizado para gres porcelánico (GB) & Sí \\
5 & Granulados de atomizado para gres porcelánico (GB) & No \\
\hline
\end{tabular}

Los resultados correspondientes a la emisión de compuestos ácidos en la etapa de atomización se muestran en la Tabla 5.3. Los resultados obtenidos no presentan variaciones significativas en función de la utilización de cogeneración, ni debidas al tipo de producto fabricado, por lo que en la Tabla 5.4 se expresan de forma agrupada junto con los NEA - MTD, de forma que sea posible evaluar fácilmente la situación actual respecto a dichos valores. 
Tabla 5.3. Concentración de contaminantes ácidos durante el secado por atomización ( $\mathrm{mg} / \mathrm{Nm}^{3}$ al $18 \%$ de $\mathrm{O}_{2}$ y gas seco).

\begin{tabular}{cccccc}
\hline Instalación & Tipo de producto & $\mathbf{H F}$ & $\mathbf{H C l}$ & $\mathbf{S O}_{\mathbf{2}}$ & $\mathbf{N O}_{\mathbf{x}}$ \\
\hline 1 & $\mathrm{AR}$ & $<3$ & $<15$ & 46 & 51 \\
2 & $\mathrm{AR}$ & $<3$ & $<15$ & 43 & 26 \\
3 & $\mathrm{GR}$ & $<3$ & 23 & 44 & 99 \\
4 & $\mathrm{~GB}$ & $<3$ & $<15$ & 49 & $<25$ \\
5 & $\mathrm{~GB}$ & $<3$ & $<15$ & 44 & 34 \\
\hline
\end{tabular}

Tabla 5.4. Concentración máxima de contaminantes ácidos durante el secado por atomización $\left(\mathrm{mg} / \mathrm{Nm}^{3}\right.$ al $18 \%$ de $\mathrm{O}_{2}$ y gas seco).

\begin{tabular}{lccc}
\hline Contaminante & № datos & $\begin{array}{c}\text { Concentración } \\
\text { máxima }\end{array}$ & $\begin{array}{c}\text { BREF } \\
\text { (NEA - MTD ) }\end{array}$ \\
\hline $\mathrm{HF}$ & 5 & $<3$ & -- \\
$\mathrm{HCl}$ & 5 & $<25$ & -- \\
$\mathrm{SO}_{2}$ & 5 & $<50$ & -- \\
$\mathrm{NO}_{4}\left(\mathrm{como} \mathrm{NO}_{2}\right)$ & 5 & $<100$ & 500 (cogeneración) \\
\hline
\end{tabular}

A tenor de los resultados presentados en la Tabla 5.4, se deduce que la emisión de contaminantes ácidos en la etapa de atomización es poco significativa, incluso para el caso del $\mathrm{NO}_{\mathrm{x}}$. En este sentido cabe destacar que, en las instalaciones estudiadas, no se han encontrado grandes diferencias en la emisión de compuestos nitrogenados debida al uso de sistemas de cogeneración. Estos sistemas incluyen procesos de combustión a elevada temperatura que pueden elevar el contenido de $\mathrm{NO}_{x}$ del gas emitido.

La elevada homogeneidad de los resultados obtenidos es debida, probablemente, a la baja temperatura que alcanza el granulado atomizado durante el proceso de secado, entre $50 \mathrm{y}$

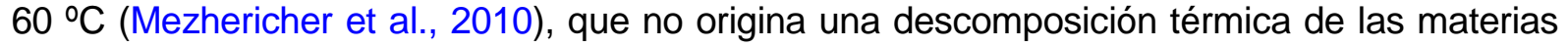
primas, al contrario de lo que ocurre en la etapa de cocción. Por este motivo, la ausencia de datos en focos de granulado para la fabricación de azulejo blanco no se considera significativa. Los resultados obtenidos son consistentes con la información contenida en el documento BREF de fabricación de cerámica (IPTS, 2007).

Desde el punto de vista del control de las emisiones atmosféricas, y siempre que no existan cambios en el proceso productivo que justifiquen su necesidad, se puede afirmar que es posible eliminar o disminuir la frecuencia de los controles periódicos de la emisión de $\mathrm{SO}_{2}$ y de $\mathrm{NO}_{x}$ realizados en la actualidad en virtud del contenido de las $\mathrm{AAl}$, debido a las bajas 
emisiones detectadas en estas instalaciones. El resto de contaminantes ácidos, $\mathrm{HF}$ y $\mathrm{HCl}$, no son objeto de inspección para este tipo de foco.

\subsubsection{Hornos de cocción}

En la Tabla 5.5 se presenta la distribución de focos pertenecientes a la etapa de cocción que han sido medidos durante el desarrollo del estudio. Los parámetros determinados en este caso han sido los siguientes:

- Concentración de contaminante $\left(\mathrm{mg} / \mathrm{Nm}^{3}\right)$, por ser el parámetro que habitualmente se utiliza para establecer el NEA - MTD.

- Factores de emisión, porque se consideran de gran utilidad para realizar registros o inventarios ambientales. Se han distinguido dos tipos de factores de emisión:

- Emisión absoluta $(\mathrm{g} / \mathrm{h})$, utilizada habitualmente para caracterizar la emisión de los procesos con operación en continuo y para la elaboración periódica de informes medioambientales (PRTR). La emisión absoluta depende directamente de la producción másica de los hornos estudiados, por lo que es necesario tener en cuenta esta consideración a la hora de interpretar los datos obtenidos.

- Factor de emisión específico (mg/kg producto cocido), usado para comparar procesos diferentes entre ellos, independientemente de la producción real de cada uno.

De los datos de la Tabla 5.5 se pueden realizar las siguientes matizaciones:

- El número de datos disponible para cada uno de los parámetros estudiados no coincide para los diferentes contaminantes considerados, ya que en algunos casos no se disponía de toda la información necesaria para su obtención como, por ejemplo, valores de caudal de gases o de producción de baldosas.

- Los datos pertenecientes a gres blanco y a gres porcelánico se han tratado de forma conjunta tal y como se ha comentado con anterioridad, dado que se trata de productos de muy baja porosidad fabricados con materias primas muy similares $y$, por tanto, sus emisiones presentan un comportamiento similar. 
Tabla 5.5. Distribución del número de datos considerados para los hornos de cocción.

\begin{tabular}{|c|c|c|c|c|c|c|}
\hline \multirow{2}{*}{\multicolumn{2}{|c|}{$\begin{array}{c}\text { Contaminante y parámetro } \\
\text { estudiado }\end{array}$}} & \multirow{2}{*}{$\begin{array}{l}\text { № total } \\
\text { datos }\end{array}$} & \multicolumn{2}{|c|}{ Azulejo } & \multicolumn{2}{|c|}{ Gres } \\
\hline & & & Rojo (AR) & Blanco (AB) & Rojo (GR) & Blanco (GB) \\
\hline \multirow[t]{3}{*}{$\mathrm{HF}$} & $\begin{array}{l}\text { Concentración } \\
\left(\mathrm{mg} / \mathrm{Nm}^{3} \text { al } 18 \% \text { de } \mathrm{O}_{2}\right)\end{array}$ & 72 & 11 & 7 & 35 & 19 \\
\hline & Emisión absoluta (g/h) & 65 & 11 & 5 & 30 & 19 \\
\hline & $\begin{array}{l}\text { Factor de emisión } \\
\text { específico (mg/kg cocido) }\end{array}$ & 56 & 11 & 6 & 22 & 17 \\
\hline \multirow[t]{3}{*}{$\mathrm{HCl}$} & $\begin{array}{l}\text { Concentración } \\
\left(\mathrm{mg} / \mathrm{Nm}^{3} \text { al } 18 \% \text { de } \mathrm{O}_{2}\right)\end{array}$ & 43 & 7 & 6 & 15 & 15 \\
\hline & Emisión absoluta (g/h) & 43 & 7 & 6 & 15 & 15 \\
\hline & $\begin{array}{l}\text { Factor de emisión } \\
\text { específico (mg/kg cocido) }\end{array}$ & 30 & 5 & 4 & 13 & 8 \\
\hline \multirow[t]{3}{*}{$\mathrm{SO}_{2}$} & $\begin{array}{l}\text { Concentración } \\
\left(\mathrm{mg} / \mathrm{Nm}^{3} \text { al } 18 \% \text { de } \mathrm{O}_{2}\right)\end{array}$ & 18 & 4 & 5 & 3 & 6 \\
\hline & Emisión absoluta (g/h) & 18 & 4 & 5 & 3 & 6 \\
\hline & $\begin{array}{l}\text { Factor de emisión } \\
\text { específico (mg/kg cocido) }\end{array}$ & 18 & 4 & 5 & 3 & 6 \\
\hline \multirow[t]{3}{*}{$\mathrm{NO}_{x}$} & $\begin{array}{l}\text { Concentración } \\
\left(\mathrm{mg} / \mathrm{Nm}^{3} \text { al } 18 \% \text { de } \mathrm{O}_{2}\right)\end{array}$ & 42 & 8 & 6 & 14 & 14 \\
\hline & Emisión absoluta (g/h) & 30 & 6 & 5 & 6 & 13 \\
\hline & $\begin{array}{l}\text { Factor de emisión } \\
\text { específico (mg/kg cocido) }\end{array}$ & 19 & 5 & 4 & 4 & 6 \\
\hline
\end{tabular}

\subsubsection{Concentración}

Los resultados correspondientes a los hornos de cocción, para los diferentes parámetros estudiados, se presentan en la Figura 5.1 en forma de mediana (percentil 50). La mediana es considerada un estimador más robusto que la media aritmética, ya que los valores extremos tienen menos influencia sobre el mismo. De igual modo, en la figura se han representado los NEA - MTD aplicables a esta etapa de proceso.

La Figura 5.1 muestra un orden decreciente en cuanto a niveles de emisión de la siguiente forma: $\mathrm{SO}_{2}, \mathrm{NO}_{x}, \mathrm{HCl}$ y, por último, el HF. Destaca también que la emisión de cada contaminante presenta variaciones apreciables en función del tipo de producto del que se trate. 

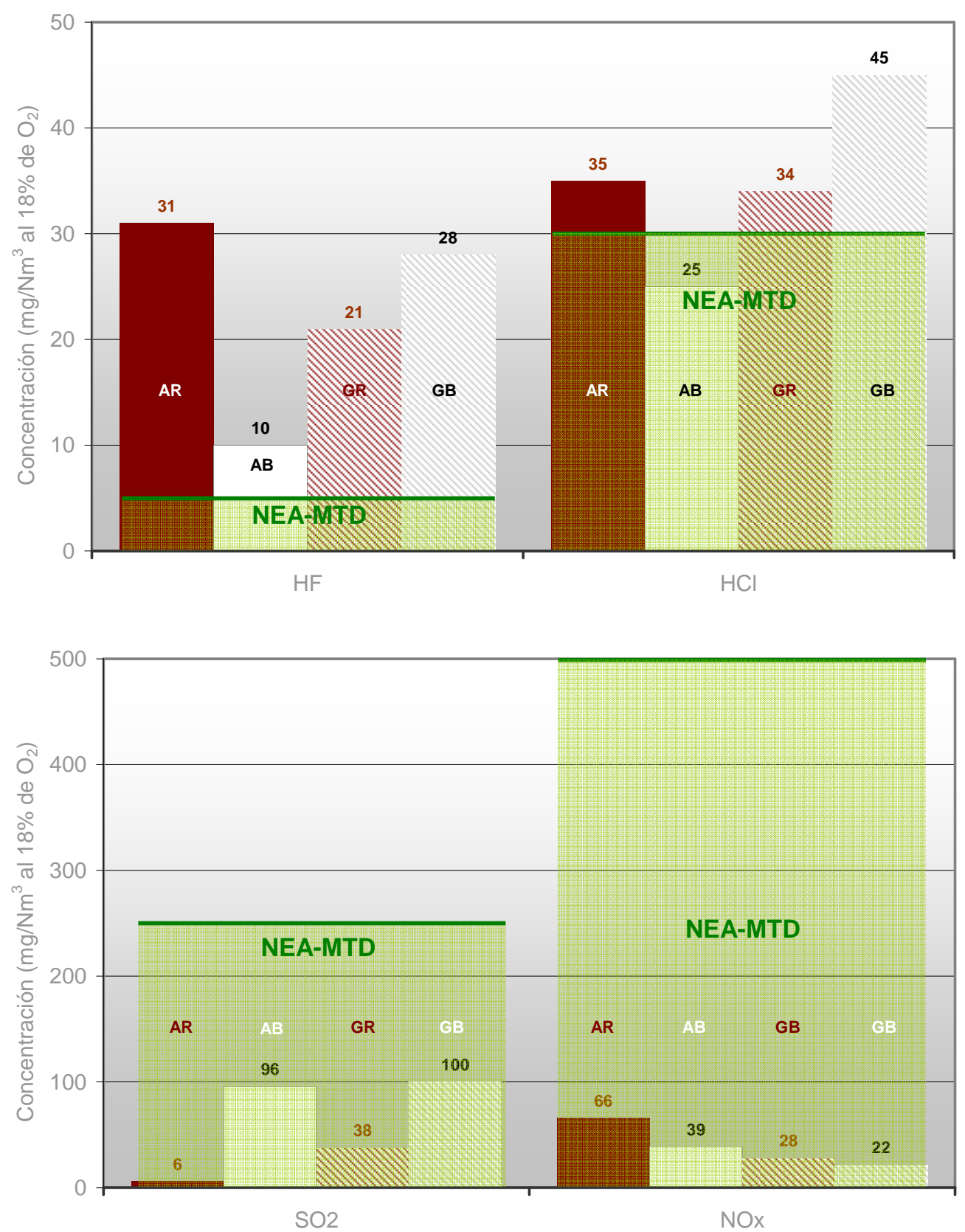

Figura 5.1. Mediana de la concentración de contaminantes ácidos para azulejo y gres $\left(\mathrm{mg} / \mathrm{Nm}^{3}\right.$ al $18 \%$ de $\mathrm{O}_{2}$ y gas seco). Siendo: AR: Azulejo rojo, AB: Azulejo blanco; GR: Gres rojo; GB: Gres blanco.

En el caso del HF se observa que el azulejo blanco presenta un valor de emisión claramente inferior al resto, al contrario que ocurre con el $\mathrm{SO}_{2}$ y el $\mathrm{NO}_{x}$. Por su parte, el azulejo rojo presenta el valor de emisión más elevado seguido muy de cerca por el gres blanco, mientras que por debajo se encuentra el gres rojo. 
El comportamiento diferenciado de la composición de azulejo blanco en cuanto a la emisión de $\mathrm{HF}$, ha sido objeto de un estudio adicional con el fin de poder interpretar dicho resultado. El contenido de dicho estudio, no publicado, se ha incluido como resultados adicionales al artículo ํo 1 en el apartado 5.2.3.

Por su parte, el comportamiento de los valores de emisión de $\mathrm{HCl}$ sigue la misma tendencia que el mostrado en el caso del HF, a excepción del azulejo rojo, cuya emisión es muy parecida a la mostrada por el gres rojo. Cabe recordar que la emisión de compuestos de cloro viene motivada, principalmente, por la presencia del ion cloro en el agua utilizada como materia prima para la fabricación de baldosas cerámicas y a su presencia a nivel de traza en la gran mayoría de arcillas y aditivos utilizados.

Por su parte, la concentración de $\mathrm{SO}_{2}$ presenta una diferencia clara en función de las materias primas del soporte. Así, el azulejo y gres de color blanco disponen de valores de emisión superiores a la de sus homólogos de color rojo.

La emisión de compuestos de azufre es debida al contenido de azufre de las materias primas y del tipo de combustible utilizado. Las arcillas utilizadas en la fabricación de baldosas cerámicas pueden contener sulfuros en forma de pirita o sulfatos de calcio y magnesio, como el yeso, y sulfatos orgánicos.

El uso mayoritario de gas natural y el hecho de que esté, prácticamente, exento de azufre en su composición, minimiza la presencia del mismo debida al combustible, aunque si se utiliza fuelóleo, carbón o coque de petróleo, la emisión de azufre puede ser más elevada (Kolkmeier, 1991; Monfort et al., 2010a).

Por último, la emisión de $\mathrm{NO}_{x}$ es muy baja en comparación con los valores límite de emisión para todos los tipos de baldosas estudiadas, además las diferencias encontradas no pueden considerarse significativas al tomar en consideración los valores de incertidumbre mostrados en el apartado 4.3.2.2. En la cocción de productos cerámicos, el principal origen de los compuestos nitrogenados está asociado a la formación de $\mathrm{NO}_{x}$ térmico (Mallol et al., 2001). Esta reacción está favorecida en procesos desarrollados a alta temperatura, especialmente si la temperatura es superior a $1400^{\circ} \mathrm{C}$. No obstante, la formación de $\mathrm{NO}$ x puede ser significativa incluso a temperaturas de proceso inferiores a $1200^{\circ} \mathrm{C}$, si se opera en los quemadores con elevadas temperaturas de llama. La descomposición y combustión de compuestos nitrogenados presentes en las materias primas, aditivos o combustibles, puede ser también una fuente de $\mathrm{NO}_{x}$ a temperaturas inferiores (IPTS, 2007).

Desde un punto de vista normativo, cuando se comparan los valores de emisión con los NEAMTD aplicables, se deduce que la emisión más significativa dentro de los contaminantes ácidos generados durante la etapa de cocción corresponde al $\mathrm{HF}$ y al $\mathrm{HCl}$, dado que superan dichos niveles, especialmente las de HF. Esta superación indica la necesidad de que dichas emisiones sean corregidas mediante la adopción de sistemas de depuración adecuados antes de su emisión a la atmósfera. Sin embargo, para el caso del azulejo blanco, es necesario 
estudiar esta necesidad de depuración en cada caso en particular, puesto que su emisión es característicamente inferior a la registrada para el resto de productos.

En el caso del $\mathrm{SO}_{2}$ y de $\mathrm{NO}_{x}$, la emisión es claramente inferior a los NEA - MTD aplicables a esta etapa de proceso en todas las empresas estudiadas, por lo que si no existen cambios de combustibles o de materias primas no se requiere ningún tipo de corrección.

\subsubsection{Emisión absoluta}

En la Figura 5.2, se representa la emisión absoluta de cada contaminante (g/h) en función del tipo de producto elaborado. Estos valores dependen directamente de la producción másica de los hornos estudiados y es necesario, por tanto, tener en cuenta esta consideración a la hora de interpretar los resultados obtenidos. En general, durante la cocción de un producto dado, cuando la producción másica aumenta, también lo hace la emisión de contaminante.

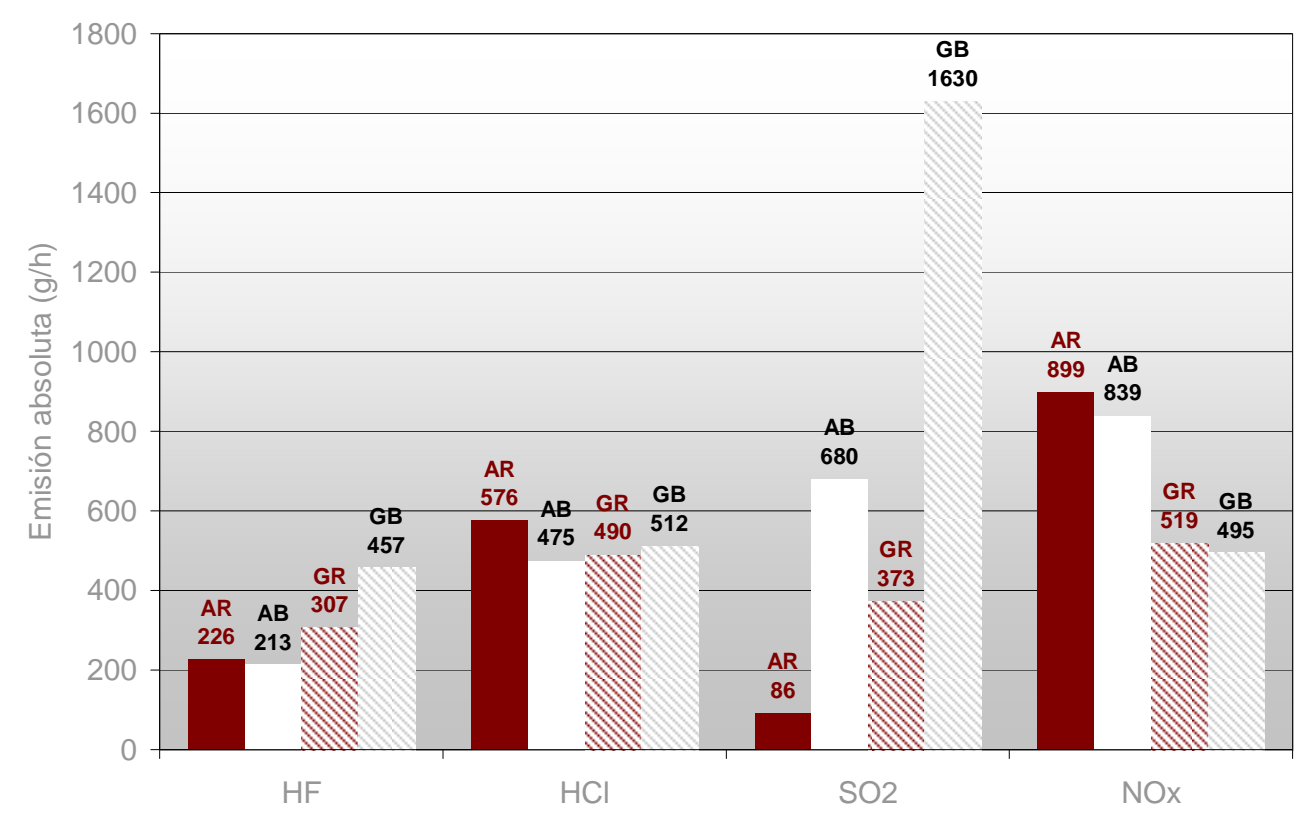

Figura 5.2. Mediana de la emisión absoluta para azulejo y gres $(\mathrm{g} / \mathrm{h})$.

Los resultados muestran que el tipo de producto fabricado es una característica diferenciadora en el caso de la emisión de HF. Se observa que los valores correspondientes al azulejo son inferiores a los registrados cuando se producen baldosas gresificadas. En el caso del $\mathrm{NO}_{\mathrm{x}}$, la tendencia se invierte y son los productos gresificados los que muestran niveles de emisión inferiores al azulejo.

En el caso del $\mathrm{HCl}$ la emisión es homogénea y no presenta grandes variaciones en función del tipo de producto fabricado. Sin embargo, en el caso del $\mathrm{SO}_{2}$, la característica clave pasa a ser las materias primas del soporte cerámico, tal y como ocurría en el caso de presentar los datos en forma de concentración. La emisión de los productos de coloración blanca es superior a la 
correspondiente a los productos de coloración roja, siendo el gres blanco el que presenta, con diferencia, una emisión absoluta más elevada.

\subsubsection{Factor de emisión específico}

La emisión de los contaminantes considerados también se puede representar mediante el factor de emisión específico ( $\mathrm{mg} / \mathrm{kg}$ cocido), tal y como se muestra en la Figura 5.3. En este caso, la emisión está condicionada principalmente por las materias primas del soporte cerámico utilizadas para fabricar productos de diferente coloración. Así, el factor de emisión específico para el caso del $\mathrm{HF}, \mathrm{HCl}$ y $\mathrm{NO}_{x}$ es mayor en el caso de los productos de coloración roja que el correspondiente a los productos de coloración blanca. En el caso concreto de la emisión de $\mathrm{NO}_{x}$ existe una marcada diferencia en función de dicha coloración. El hecho de que los valores mayores se asocien a composiciones de coloración roja, con menor temperatura máxima de cocción, hace pensar que el origen no sea térmico y por tanto podría deberse a la presencia de precursores en la composición. No obstante, no se han encontrado referencias en la bibliografía disponible que justifiquen este comportamiento. Esta tendencia debida a la coloración del soporte se invierte en el caso del $\mathrm{SO}_{2}$, donde los productos blancos presentan valores de emisión superiores a los mostrados por los productos rojos.

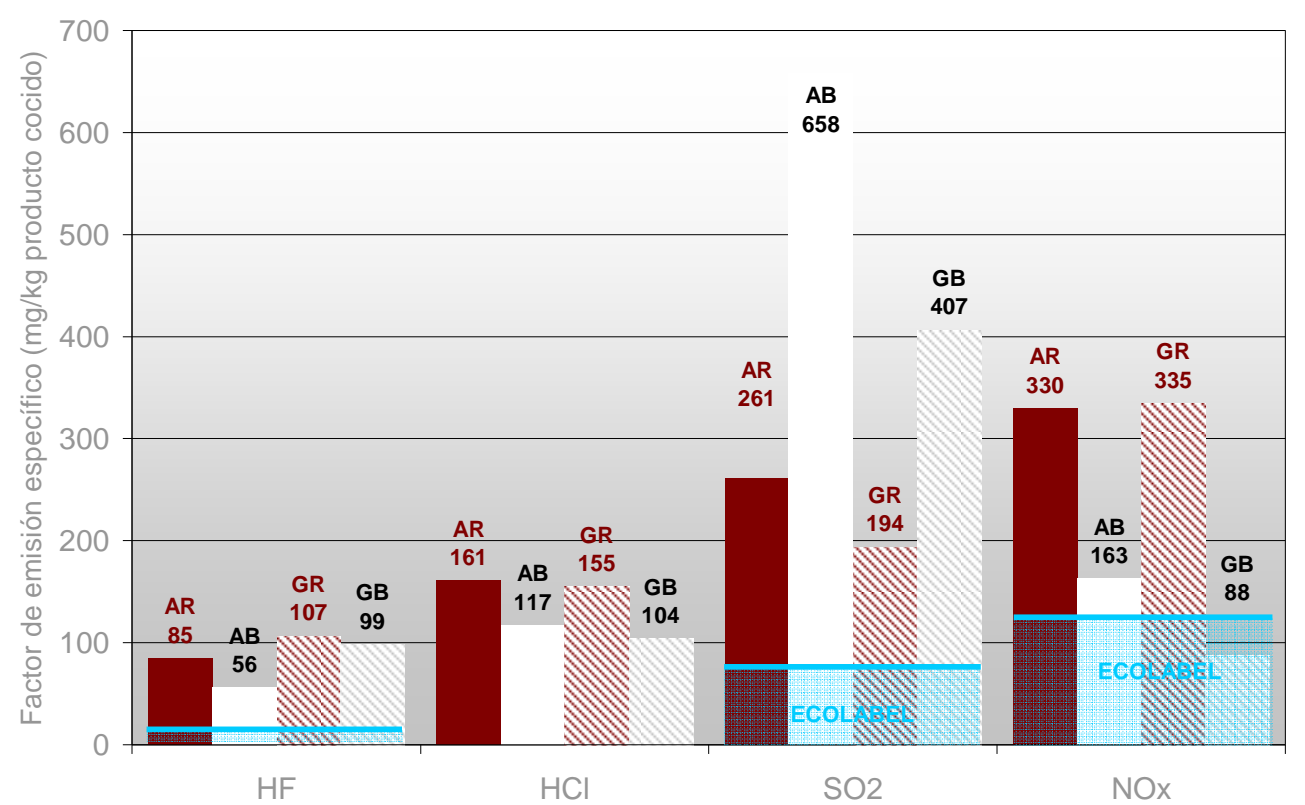

Figura 5.3. Mediana del factor de emisión para azulejo y gres ( $\mathrm{mg} / \mathrm{kg}$ producto cocido).

En la Figura 5.3 también se han incluido los criterios establecidos para la concesión de la etiqueta ecológica de la UE a revestimientos rígidos (baldosas cerámicas). Se aprecia claramente que dichos criterios, en lo referente a las emisiones atmosféricas, son ciertamente restrictivos en comparación con los valores de emisión habituales para este tipo de productos. 
Desde un punto de vista general, se considera que la información obtenida es representativa de la situación actual del sector español de fabricación de baldosas cerámicas y que puede ser utilizada para la elaboración periódica de informes medioambientales, tales como PRTR y para elaborar propuestas de valores límite de emisión en las sucesivas revisiones de los documentos BREF o de la normativa sobre emisiones industriales.

\subsubsection{Resultados adicionales al artículo no 1}

La emisión de HF que presenta el azulejo blanco es netamente inferior al resto de productos estudiados, tanto en valores de concentración como en valores de factor de emisión específico.

Para tratar de entender este comportamiento se ha estudiado la concentración y la emisión de flúor que presentan las materias primas y las composiciones de los productos de interes.

Los resultados individuales de cada uno de los ensayos realizados se han recogido en el anexo II incluido en el apartado 9.2.

\subsubsection{Materias primas de soportes de baldosas cerámicas}

Las materias primas de soportes de baldosas cerámicas consideradas se han dividido en función de su comportamiento con el agua en materias primas plásticas y no plásticas o desgrasantes. Los resultados del análisis de flúor realizado sobre materias primas plásticas en crudo se muestran en la Tabla 5.6. A la vista de los mismos se deduce que el contenido de flúor de las materias primas utilizadas en la composición de productos blancos es claramente inferior a las utilizadas en el caso de productos rojos, con diferencias superiores al $25 \%$.

Tabla 5.6. Concentración en crudo de flúor en las materias primas plásticas empleadas en la fabricación de los soportes de baldosas cerámicas rojas y blancas.

\begin{tabular}{cccccc}
\hline \multirow{2}{*}{ Materia prima } & \multicolumn{3}{c}{ Concentración de flúor crudo $(\mathbf{m g} / \mathbf{k g})$} & \multirow{2}{*}{ № muestras } \\
\cline { 2 - 5 } & Mediana & Mínima & Máxima & \\
\hline \multirow{2}{*}{ Arcillas rojas } & $\begin{array}{c}\text { Bajo contenido de } \\
\text { carbonatos }\end{array}$ & 580 & 470 & 760 & 8 \\
& Calcáreas & 647 & 550 & 744 & 4 \\
& Arcillas blancas & 468 & 289 & 588 & 17 \\
& Caolín & 361 & 170 & 721 & 5 \\
\hline
\end{tabular}

Por su parte, la Tabla 5.7 recoge los resultados obtenidos para las materias primas no plásticas 0 desgrasantes utilizadas en composiciones blancas. En general, las concentraciones en crudo de estas últimas materias primas se encuentran en valores inferiores a los obtenidos por las materias primas plásticas. Destaca la baja concentración de flúor del cuarzo y, también, el elevado contenido de este elemento en el caso del talco. 
Tabla 5.7. Concentración de flúor en crudo en otras materias primas desgrasantes utilizadas en composiciones blancas.

\begin{tabular}{ccccc}
\hline \multirow{2}{*}{ Materia prima } & \multicolumn{2}{c}{ Concentración de flúor crudo $(\mathbf{m g} / \mathbf{k g})$} & \multirow{2}{*}{ № muestras } \\
\cline { 2 - 4 } & Mediana & Mínimo & Máximo & \\
\hline Calcita & 201 & 100 & 246 & 5 \\
Cuarzo & $<50$ & $<50$ & $<50$ & 5 \\
Talco & 3025 & 893 & 5000 & 4 \\
Feldespatos & 240 & $<50$ & 397 & 11 \\
Arena feldespática & 262 & 149 & 701 & 4 \\
\hline
\end{tabular}

También se han recopilado en la Tabla 5.8 los resultados correspondientes a la emisión de flúor, obtenida por diferencia entre el valor crudo y el cocido, tras ser sometido a un tratamiento térmico en un horno eléctrico de laboratorio. Se deduce que la emisión de flúor es del mismo orden para el caso de las arcillas, siendo los feldespatos y el caolín los materiales que presentan una mayor emisión relativa.

Tabla 5.8. Emisión de flúor de las materias primas empleadas en la fabricación de los soportes de baldosas cerámicas rojas y blancas.

\begin{tabular}{ccccc}
\hline \multirow{2}{*}{ Materia prima } & \multicolumn{3}{c}{ Emisión (\%) } & \multirow{2}{*}{ № muestras } \\
\cline { 2 - 4 } & Mediana & Mínima & Máxima & \\
\hline Arcillas rojas de bajo contenido & 33 & 16 & 40 & 5 \\
de carbonatos & 33 & 16 & 25 & 2 \\
Arcillas calcáreas rojas & 32 & 22 & 66 & 12 \\
Arcillas blancas & 53 & 36 & 71 & 5 \\
Caolín & 55 & 42 & 80 & 10 \\
Feldespatos & &
\end{tabular}

\subsubsection{Composiciones de los soportes de baldosas cerámicas}

El contenido de flúor de las composiciones cerámicas se muestra en la Tabla 5.9. En la misma se observa que los valores de las composiciones rojas son superiores a los exhibidos por las composiciones blancas, y alcanzan diferencias del orden del $50 \%$.

También se han calculado las emisiones de las composiciones tras ser sometidas a un tratamiento térmico en un horno eléctrico de laboratorio. Los resultados recogidos en la Tabla 5.10 muestran que los valores se encuentran en un intervalo estrecho entre el 30 y $40 \%$, independientemente del tipo de producto fabricado. Las pequeñas diferencias encontradas en este caso no justifican, por sí mismas, las diferencias encontradas en la corriente de salida de 
humos de la etapa de cocción para el caso del azulejo blanco, al ser determinada en forma de concentración.

Tabla 5.9. Concentración en crudo de flúor en las composiciones de los soportes de baldosas cerámicas rojas y blancas.

\begin{tabular}{ccccc}
\hline \multirow{2}{*}{ Composición } & \multicolumn{2}{c}{ Concentración de flúor crudo $(\mathbf{m g} / \mathbf{k g})$} & \multirow{2}{*}{ № muestras } \\
\cline { 2 - 4 } & Mediana & Mínimo & Máximo & \\
\hline Azulejo rojo (AR) & 624 & 462 & 755 & 8 \\
Azulejo blanco (AB) & 320 & 228 & 551 & 11 \\
Gres rojo (GR) & 607 & 347 & 709 & 13 \\
Gres blanco (GB) & 328 & 181 & 837 & 24 \\
\hline
\end{tabular}

Tabla 5.10. Emisión de las composiciones de los soportes de baldosas cerámicas de rojas y blancas.

\begin{tabular}{ccccc}
\hline \multirow{2}{*}{ Composición } & \multicolumn{3}{c}{ Emisión (\%) } & \multirow{2}{*}{ № muestras } \\
\cline { 2 - 4 } & Mediana & Mínimo & Máximo & 7 \\
\hline Azulejo rojo (AR) & 37 & 32 & 48 & 6 \\
Azulejo blanco (AB) & 38 & 31 & 50 & 10 \\
Gres rojo (GR) & 29 & 11 & 38 & 14 \\
Gres blanco (GB) & 35 & 20 & 49 & \\
\hline
\end{tabular}

Además del contenido neto de flúor, existen otros factores relevantes para justificar la menor emisión de este contaminante asociada al azulejo blanco (Monfort et al., 2010b). En la Tabla 5.11 se muestran los valores correspondientes al peso específico, a la temperatura de cocción y al consumo de energía térmica en la etapa de cocción (referido al PCS).

Tabla 5.11. Peso específico y consumo de energía térmica en la etapa de cocción (referido al PCS).

\begin{tabular}{cccc}
\hline Composición & $\begin{array}{c}\text { Peso específico } \\
\left(\mathbf{k g} / \mathbf{m}^{2}\right)\end{array}$ & $\begin{array}{c}\text { Tmáx } \\
(\mathbf{o} \mathbf{C})\end{array}$ & $\begin{array}{c}\text { Consumo térmico específico en } \\
\text { cocción (kWh/t cocido) }\end{array}$ \\
\hline Azulejo rojo (AR) & $16,4 \pm 0,5$ & $1126 \pm 6$ & $816 \pm 27$ \\
Azulejo blanco (AB) & $18,4 \pm 1,0$ & $1144 \pm 6$ & $885 \pm 51$ \\
Gres rojo (GR) & $19,7 \pm 0,4$ & $1147 \pm 2$ & $754 \pm 18$ \\
Gres blanco (GB) & $21,7 \pm 0,6$ & $1192 \pm 2$ & $802 \pm 20$ \\
\hline
\end{tabular}

Dentro de cada tipo de coloración se observa que las composiciones de azulejo presentan un menor peso específico que los productos de gres correspondiente, lo que supone una menor cantidad de material procesado y, por tanto, una menor emisión de HF. 
La diferencia fundamental entre el azulejo blanco y el rojo es la concentración de flúor en crudo, que parece tener mayor importancia que la diferencia de temperatura máxima de cocción entre estos productos, dado que el azulejo rojo emite por encima del azulejo blanco.

Entre los productos de coloración blanca existe una diferencia importante en la temperatura máxima de cocción entre el gres y el azulejo, que añadido a su menor peso específico puede explicar las diferencias de emisión entre ambos tipos de producto.

Por otro lado, el mayor consumo específico de gas natural durante la cocción es para la composición de azulejo blanco, en comparación con el resto de productos. Un mayor consumo específico provoca la generación de un mayor volumen de humos en el interior del horno, lo que se traduce, a su vez, en una menor concentración de flúor en la corriente de gases.

En resumen, la menor emisión de HF asociada al azulejo blanco en comparación con el resto de productos estudiados se atribuye al menor contenido de flúor que presentan las materias primas y composiciones utilizadas en la elaboración de estos productos en comparación con las utilizadas en el caso de productos rojos. También influyen las condiciones diferenciadas de procesado del azulejo blanco en cuanto al mayor peso específico y temperatura de cocción en comparación con el azulejo rojo y en cuanto a una menor temperatura de cocción y mayor consumo específico en comparación con los productos de gres. 


\subsection{Influencia del contenido de calcita sobre las emisiones de compuestos de flúor durante la cocción de baldosas cerámicas (Artículo n-2)}

El impacto ambiental más característico asociado a la industria cerámica es la emisión de compuestos de flúor y, en especial, de HF, debido a sus implicaciones ambientales y legales. Como se ha descrito en los apartados 1.3 .5 y 2.3.2, estas emisiones pueden reducirse mediante la adición de $\mathrm{CaCO}_{3}$ a la composición de materias primas utilizadas en la fabricación de estos productos. Sin embargo, los datos mostrados en el artículo oㅜ 1 indican que este procedimiento no es eficaz en la fabricación de baldosas cerámicas que utilizan ciclos de cocción rápida, aunque se haya aplicado con éxito en la fabricación de cerámica estructural (tejas y ladrillos).

En esta parte del estudio se ha indagado sobre las causas que hacen que esta medida preventiva no sea aplicable para el caso de las baldosas cerámicas. Para ello, se ha realizado un estudio que ha consistido en determinar la influencia del contenido de $\mathrm{CaCO}_{3}$ en la evolución de las fases cristalinas, en función de la temperatura de cocción, en una composición de gres sobre la que se han realizado adiciones de $\mathrm{CaF}_{2}$. De igual modo, se ha adicionado $\mathrm{BaF}_{2}$ y $\mathrm{SrF}_{2}$ a dicho soporte y se ha estudiado la estabilidad térmica de los tres compuestos.

Aunque en el artículo publicado no se mostraban los resultados relativos al $\mathrm{MgF}_{2}$, éstos sí que se han incluido en el presente trabajo, concretamente en el apartado 5.3.1.1, con el fin de simplificar la discusión de los mismos.

También se ha incluido, como resultados adicionales al artículo ํㅡ 2, el estudio de estabilidad térmica de los fluoruros alcalinos.

\subsubsection{Estabilidad de compuestos de flúor}

Para ver la importancia durante la cocción se ha determinado la estabilidad térmica de los materiales que contienen flúor, en primer lugar se ha estudiado la estabilidad de los compuestos de flúor sencillos por separado. Específicamente se han estudiado los compuestos alcalinos y los compuestos alcalinotérreos. También se ha estudiado la estabilidad de los compuestos alcalinotérreos cuando se incluyen en una composición cerámica de gres.

\subsubsection{Estudio de compuestos de flúor puros}

Para determinar la estabilidad térmica de los diferentes compuestos de flúor se han llevado a cabo tanto análisis térmico diferenciales como análisis termogravimétricos. El primer tipo de análisis registra los procesos endotérmicos y exotérmicos que sufre la muestra durante un 
proceso térmico. El segundo tipo de análisis registra las pérdidas de peso de los materiales analizados durante el citado proceso térmico. En concreto se ha determinado la estabilidad térmica de los siguientes compuestos:

- Fluoruros de cationes alcalinos: LiF, NaF y KF. Los resultados correspondientes a este estudio se han incluido en el apartado 5.3.3, como resultados adicionales al artículo $\mathrm{n}^{\circ} 2$.

- Fluoruros de cationes alcalinotérreos: $\mathrm{CaF}_{2}, \mathrm{MgF}_{2}, \mathrm{BaF}_{2}$ y $\mathrm{SrF}_{2}$.

\section{Estabilidad térmica de fluoruros de cationes alcalinotérreos}

El ensayo de estabilidad de los compuestos alcalinotérreos se ha realizado a una velocidad de calentamiento de $10{ }^{\circ} \mathrm{C} / \mathrm{min}$, y se ha alcanzado una temperatura máxima de $1300{ }^{\circ} \mathrm{C}$, debido al mayor punto de fusión de estos compuestos en comparación con los compuestos alcalinos.

En la Figura 5.4 se muestra el análisis térmico diferencial del $\mathrm{CaF}_{2}, \mathrm{MgF}_{2}, \mathrm{BaF}_{2}$ y $\mathrm{SrF}_{2}$ puros. En la Figura 5.5, se muestra la misma información pero en un rango de temperaturas entre 800 y $1300 \stackrel{\circ}{\mathrm{C}}$.

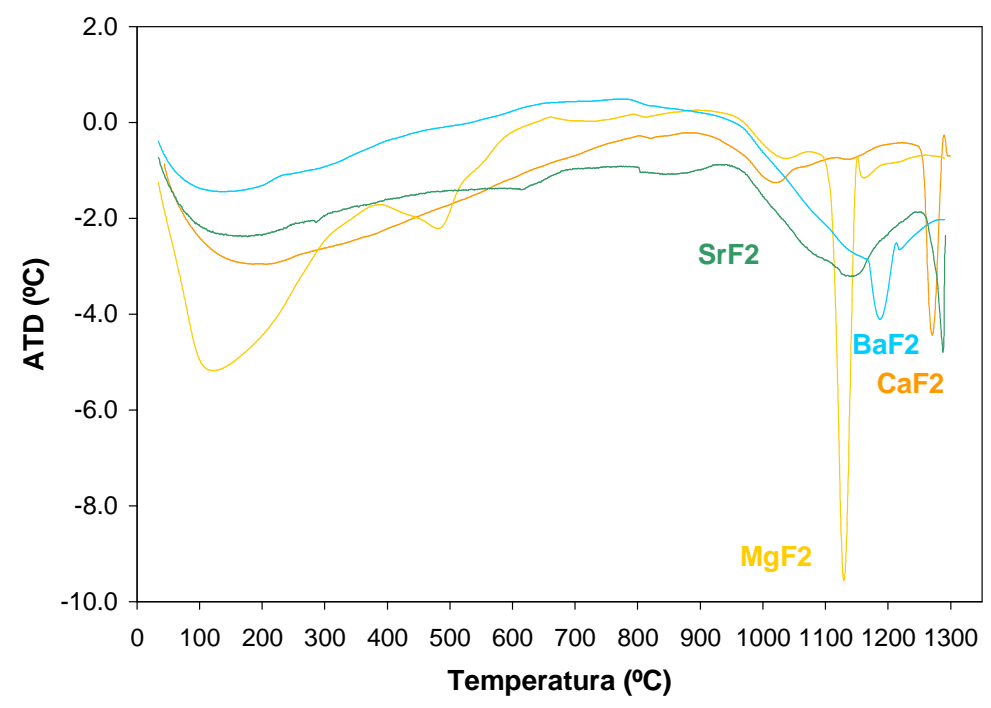

Figura 5.4. Análisis térmico diferencial. Fluoruros de cationes alcalinotérreos.

En estas figuras se observa que el $\mathrm{CaF}_{2}, \mathrm{MgF}_{2}, \mathrm{BaF}_{2}$ y $\mathrm{SrF}_{2}$ son térmicamente estables hasta temperaturas de $910{ }^{\circ} \mathrm{C}$ para el caso del $\mathrm{CaF}_{2}$ y de $960^{\circ} \mathrm{C}$ para el resto de compuestos $\left(\mathrm{MgF}_{2}, \mathrm{BaF}_{2}\right.$ y $\left.\mathrm{SrF}_{2}\right)$. A partir de estas temperaturas se observa una tendencia endotérmica, hasta alcanzar su temperatura de fusión a $1260{ }^{\circ} \mathrm{C}, 1130{ }^{\circ} \mathrm{C}, 1190{ }^{\circ} \mathrm{C}$ y $1290{ }^{\circ} \mathrm{C}$, respectivamente. 


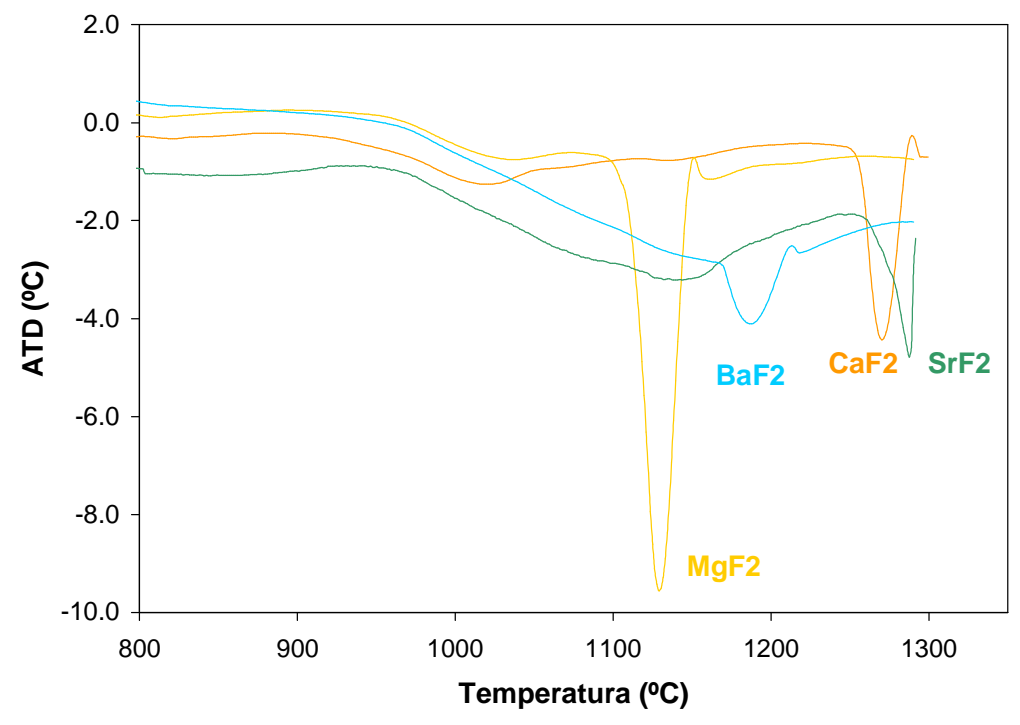

Figura 5.5. Análisis térmico diferencial. Fluoruros de cationes alcalinotérreos (intervalo de temperaturas 800 a $1300^{\circ} \mathrm{C}$ )

Estos resultados muestran que los cambios térmicos significativos son los procesos de fusión de sendos materiales, que se caracterizan por ser procesos marcadamente endotérmicos, aunque el $\mathrm{MgF}_{2}$ presenta un comportamiento diferente. Este compuesto sufre otros procesos endotérmicos en torno a $100^{\circ} \mathrm{C}$, que pueden deberse a la pérdida de humedad y en torno a $500 \stackrel{\circ}{ } \mathrm{C}$, que pueden deberse a una reorganización estructural.

El análisis termogravimétrico se muestra en la Figura 5.6 para todos los fluoruros alcalinotérreos, y en la Figura 5.8 de forma ampliada descartando el $\mathrm{MgF}_{2}$.

Los resultados mostrados del análisis termogravimétrico muestran que los compuestos de flúor de los cationes alcalinotérreos presentan un inicio de pérdida continua de peso a la temperatura de $120{ }^{\circ} \mathrm{C}, 1009{ }^{\circ} \mathrm{C}, 1119{ }^{\circ} \mathrm{C}$ y $790 \stackrel{\circ}{ } \mathrm{C}$ para el $\mathrm{MgF}_{2}, \mathrm{CaF}_{2}, \mathrm{BaF}_{2}$ y $\mathrm{SrF}_{2}$, respectivamente, siendo la pérdida de peso a la temperatura de $1200{ }^{\circ} \mathrm{C}$ del $17 \%, 1 \%, 1 \%$, $2 \%$, respectivamente.

En cuanto a las pérdidas de peso para el $\mathrm{CaF}_{2}, \mathrm{BaF}_{2}, \mathrm{SrF}_{2}$, debe destacarse que se alcanzan valores similares para sus correspondientes temperaturas de fusión, y que las diferencias entre ellos no resultan significativas a las temperaturas habituales de operación. 


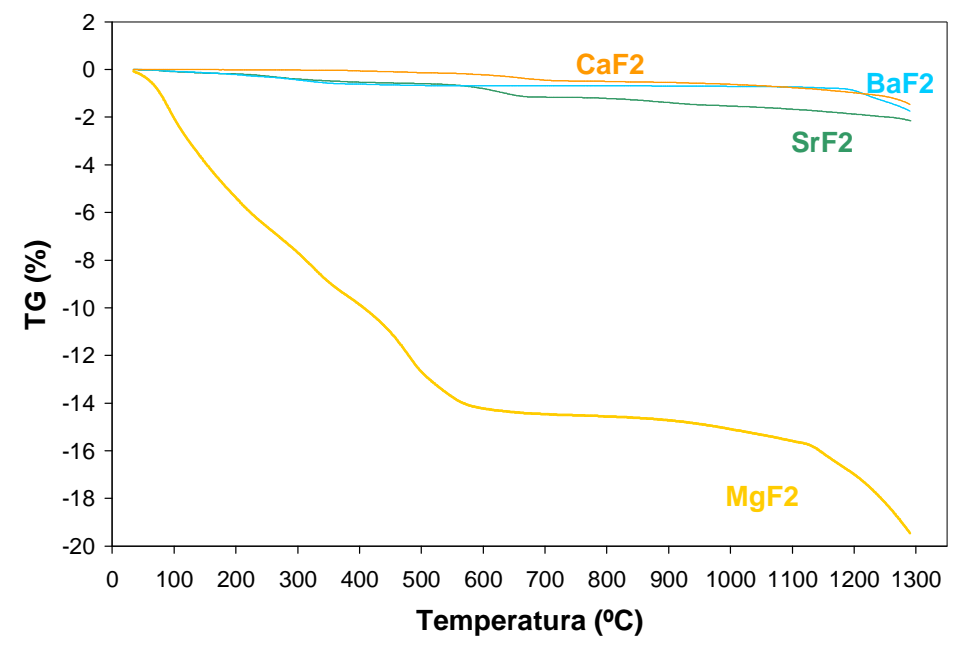

Figura 5.6. Análisis termogravimétrico. Fluoruros de cationes alcalinotérreos.

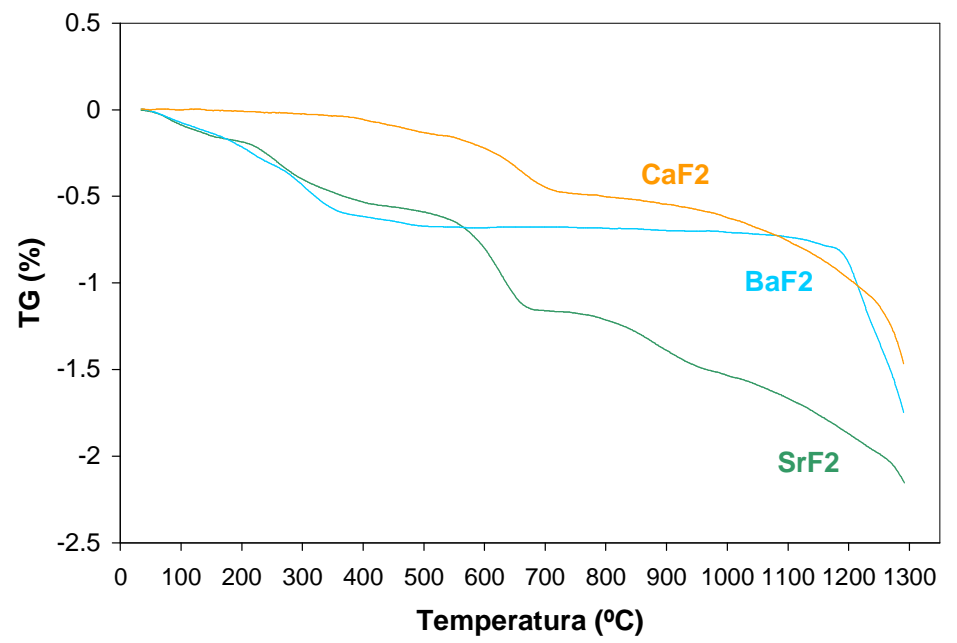

Figura 5.7. Análisis termogravimétrico. Fluoruros de cationes alcalinotérreos a excepción del $\mathrm{MgF}_{2}$.

El comportamiento del $\mathrm{MgF}_{2}$ resulta significativamente diferente al del resto, debido a que se produce una pérdida constante de peso desde los $120^{\circ} \mathrm{C}$ hasta los $600^{\circ} \mathrm{C}$ aproximadamente. Tras un periodo de reorganización estructural el material se estabiliza hasta que se alcanzan temperaturas próximas a la de fusión, donde se produce la volatilización de dicho compuesto.

Si se comparan los resultados del estudio de la estabilidad de los compuestos de flúor alcalinotérreos con los correspondientes a los compuestos de flúor alcalinos, incluidos como resultados adicionales en el apartado 5.3.3, se deduce que los fluoruros puros más estables son los alcalinotérreos. 


\subsubsection{Estabilidad térmica de fluoruros de cationes alcalinotérreos frente a un tratamiento térmico con una velocidad de calentamiento similar a una cocción industrial}

En este apartado se estudia la estabilidad térmica de los fluoruros alcalinotérreos sometidos a un tratamiento térmico similar al de la cocción industrial, llevado a cabo en un horno eléctrico de laboratorio, con el fin de conocer su comportamiento frente al mismo. Las características concretas del tratamiento térmico seguido han sido:

- Temperatura máxima $1200 \stackrel{\circ}{\circ}$

- Velocidad de calentamiento $50 \stackrel{\circ}{\circ} / \mathrm{min}$

- Tiempo de permanencia a 1200: 6 minutos

- Atmósfera dinámica de aire

- Crisol de alúmina

Los resultados obtenidos se detallan en la Figura 5.8. En la misma se observa un comportamiento muy diferente entre el $\mathrm{MgF}_{2}$ y los restantes fluoruros estudiados, al igual que sucede al aplicar un tratamiento térmico con una menor velocidad de calentamiento. El $\mathrm{MgF}_{2}$ presenta unas pérdidas de peso mucho mayores que los restantes compuestos, que además se manifiestan desde temperaturas muy bajas. Por ello, para visualizar mejor los datos obtenidos, se ha incluido la Figura 5.9, en la que se observan con mayor facilidad las diferencias entre los distintos fluoruros, al excluir el $\mathrm{MgF}_{2}$.

El comportamiento del $\mathrm{CaF}_{2}, \mathrm{BaF}_{2}$ y $\mathrm{SrF}_{2}$ sometidos a un tratamiento térmico con una velocidad de calentamiento de $10 \stackrel{\circ}{\circ} / \mathrm{min}$, habitual en los ensayos térmicos de laboratorio, no difiere en gran medida del que presentan frente a una velocidad de calentamiento superior $50 \stackrel{\circ}{C} / \mathrm{min}$, como la que presentan las cocciones industriales, aunque parece que, en este último caso, los fluoruros de calcio y de bario presentan una estabilidad ligeramente superior en el caso de un tratamiento similar al industrial. 


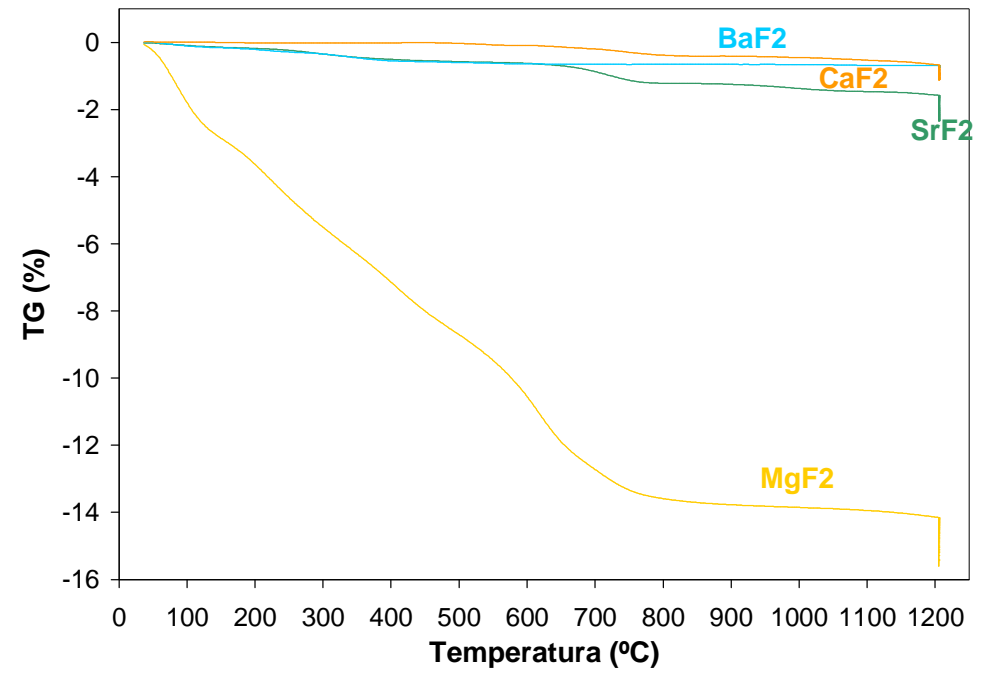

Figura 5.8. Análisis termogravimétricos. Fluoruros de cationes alcalinotérreos sometidos a una velocidad de calentamiento de $50 \stackrel{\circ}{\mathrm{C}} / \mathrm{min}$.

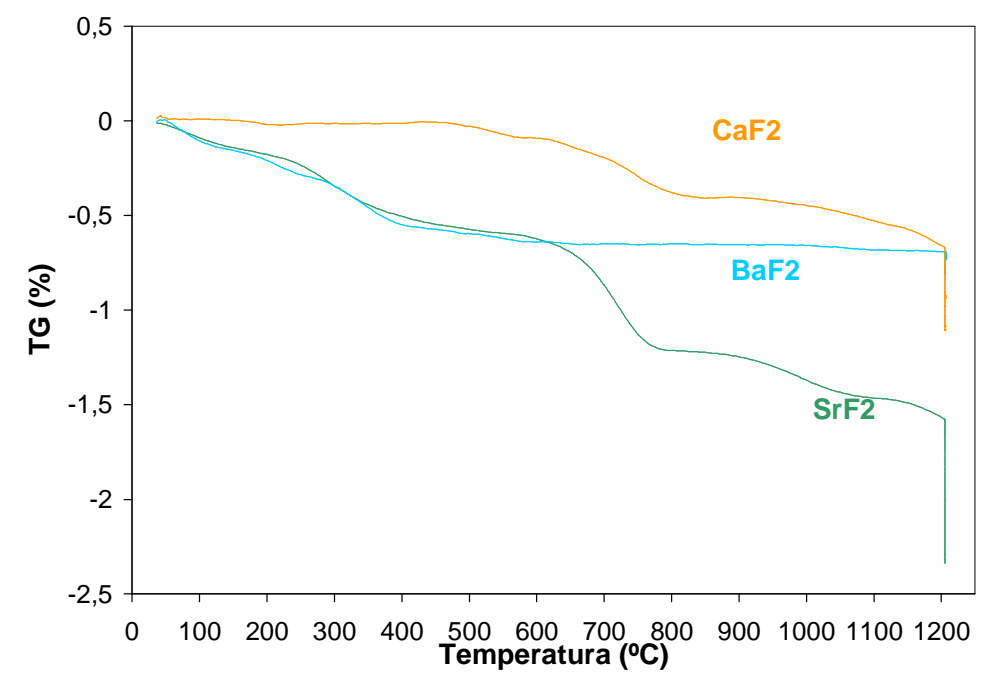

Figura 5.9. Análisis termogravimétricos. Fluoruros de cationes alcalinotérreos sometidos a una velocidad de calentamiento de $50{ }^{\circ} \mathrm{C} / \mathrm{min}$, excluyendo al $\mathrm{MgF}_{2}$.

El estudio del comportamiento de los compuestos puros de flúor frente a tratamientos térmicos con diferentes velocidades de calentamiento, asimilables a las condiciones de trabajo habituales en laboratorio y en la industria, ha mostrado que los compuestos fluorados alcalinotérreos son más estables que los alcalinos, y que el $\mathrm{MgF}_{2}$ es el fluoruro alcalinotérreo menos estable. Por este motivo, el trabajo se continuó con el estudio de la estabilidad de $\mathrm{CaF}_{2}, \mathrm{BaF}_{2}$ y $\mathrm{SrF}_{2}$ al ser introducidos en una matriz cerámica. 


\subsubsection{Estudio de compuestos de flúor en una matriz cerámica}

Para llevar a cabo el estudio de la estabilidad térmica del $\mathrm{CaF}_{2}, \mathrm{BaF}_{2}$ y $\mathrm{SrF}_{2}$ en el seno de una matriz cerámica se han determinado, en primer lugar, el límite de detección (LD) o cantidad mínima detectable y el límite de cuantificación (LC) o cantidad mínima que da una señal capaz de ser cuantificada mediante el cálculo de área de pico mediante XRD para los diferentes fluoruros en la composición $\mathrm{G}$, que corresponde con un gres rojo. Dichos límites se recogen en la Tabla 5.12.

Tabla 5.12. Límites de detección (LD) y cuantificación (LC) mediante XRD para los diferentes fluoruros en la composición de gres $(\mathrm{G})$.

\begin{tabular}{ccc}
\hline Compuesto & LD (\% en peso) & LC (\% en peso) \\
\hline $\mathrm{CaF}_{2}$ & 0,20 & 0,25 \\
$\mathrm{BaF}_{2}$ & 0,25 & 0,50 \\
$\mathrm{SrF}_{2}$ & 0,15 & 0,20 \\
\hline
\end{tabular}

De los resultados obtenidos se puede concluir que el $\mathrm{SrF}_{2}$ puede detectarse y cuantificarse en menores porcentajes, mientras que para el $\mathrm{BaF}_{2}$ es necesaria la presencia de una mayor cantidad en la muestra para su detección y cuantificación. Estos valores justifican el empleo de composiciones sintéticas en este trabajo, dado que la máxima cantidad de los diferentes fluoruros que pueden formarse con el flúor presente en este tipo de composiciones (500 - $700 \mathrm{mg} / \mathrm{kg}$ ) es inferior a los límites de cuantificación.

Posteriormente se ha estudiado la estabilidad del $\mathrm{CaF}_{2}, \mathrm{BaF}_{2}$ y $\mathrm{SrF}_{2}$ inmersos en una matriz cerámica durante la etapa de cocción de las piezas. Para ello se han realizado adiciones del $1 \%$ y del $5 \%$ en peso de los diferentes fluoruros a la composición de gres (G), y se ha seguido el pico de máxima intensidad de cada fluoruro con la temperatura máxima del tratamiento térmico. Estos resultados se han comparado con los obtenidos al ensayar los fluoruros puros. En base a esta información y sabiendo que la temperatura máxima de cocción a escala industrial de la composición $\mathrm{G}$ se sitúa en torno a $1140{ }^{\circ} \mathrm{C}$, se han realizado tratamientos térmicos que simulan los ciclos de cocción industriales a las temperaturas máximas de $950,1000,1100$ y $1150{ }^{\circ} \mathrm{C}$.

La Figura 5.10, Figura 5.11 y la Figura 5.12, muestran los difractogramas correspondientes a la serie de muestras con adición de un $5 \%$ de fluoruro. Para poder determinar la concentración de flúor respectiva de las probetas cocidas, se ha utilizado el área del pico de máxima intensidad de dichas muestras y se ha comparado con los correspondientes de muestras crudas. Estos datos se han recogido en la Tabla 5.13. 


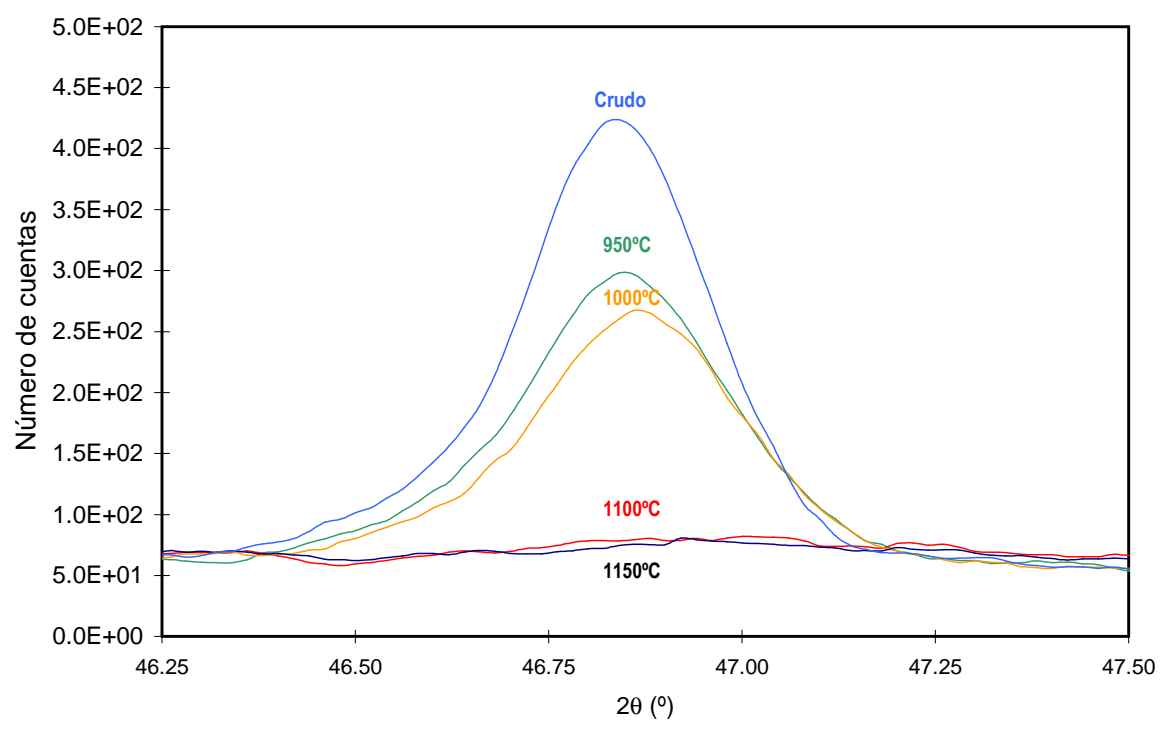

Figura 5.10. Variación de la señal del pico de máxima intensidad del $\mathrm{CaF}_{2}(5 \%)$ con la temperatura.

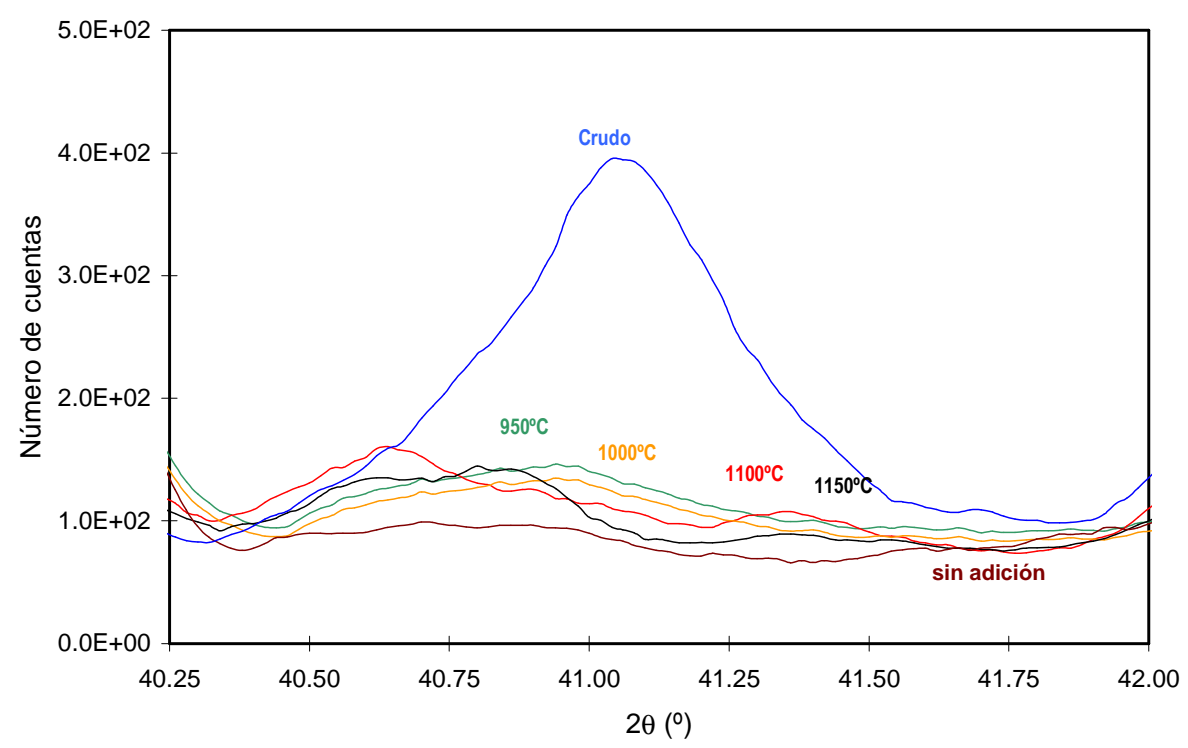

Figura 5.11. Variación de la señal del pico de máxima intensidad del $\mathrm{BaF}_{2}(5 \%)$ con la temperatura. 


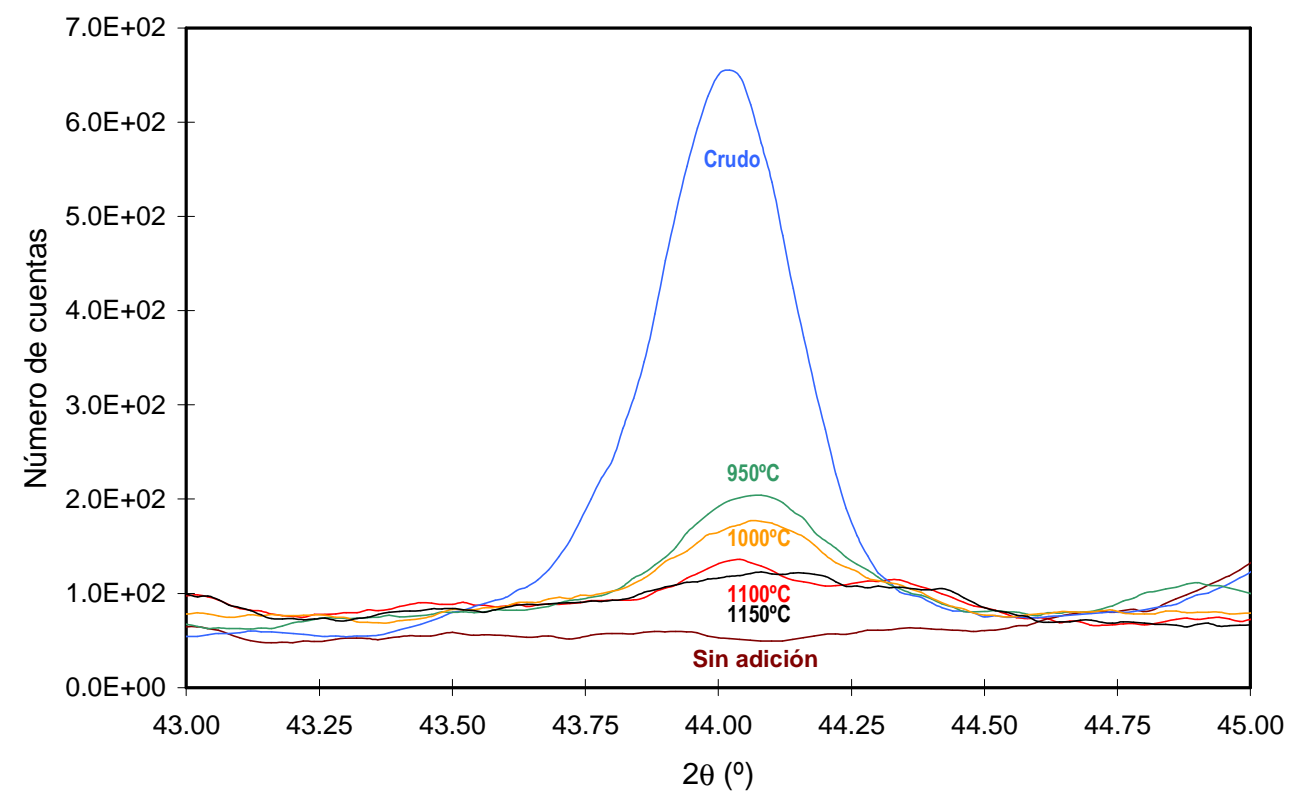

Figura 5.12. Variación de la señal del pico de máxima intensidad del $\mathrm{SrF}_{2}(5 \%)$ con la temperatura.

Tabla 5.13. Contenido de $\mathrm{CaF}_{2}, \mathrm{BaF}_{2}$ y $\mathrm{SrF}_{2}$ que presenta la composición $\mathrm{G}$ tras ser tratada térmicamente a diferentes temperaturas.

\begin{tabular}{|c|c|c|c|c|c|}
\hline \multirow{2}{*}{ Compuesto } & \multirow{2}{*}{$\begin{array}{l}\text { Cantidad } \\
\text { adicionada } \\
\text { (\% en peso) }\end{array}$} & \multicolumn{4}{|c|}{ Contenido de fluoruro (\% en peso) } \\
\hline & & $950 \stackrel{\circ}{C}$ & $1000 \stackrel{\circ}{C}$ & $1100 \stackrel{\circ}{C}$ & $1150 \stackrel{\circ}{C}$ \\
\hline \multirow[t]{2}{*}{$\mathrm{CaF}_{2}$} & 1,0 & 0,5 & $<0,25$ & $<0,25$ & $<0,25$ \\
\hline & 5,0 & 2,5 & 1,9 & 0,25 & $<0,25$ \\
\hline \multirow[t]{2}{*}{$\mathrm{BaF}_{2}$} & 1,0 & $<0,5$ & $<0,5$ & $<0,5$ & $<0,5$ \\
\hline & 5,0 & 1,3 & 1,1 & $<0,5$ & $<0,5$ \\
\hline \multirow[t]{2}{*}{$\mathrm{SrF}_{2}$} & 1,0 & $<0,2$ & $<0,2$ & $<0,2$ & $<0,2$ \\
\hline & 5,0 & 1,5 & 1,1 & 0,5 & $<0,5$ \\
\hline
\end{tabular}

Los resultados obtenidos para el $\mathrm{CaF}_{2}$ en la Tabla 5.13 muestran que, incluso a temperaturas inferiores a $950^{\circ} \mathrm{C}$, se pierde una parte importante del fluoruro cálcico inicialmente añadido, haciéndose inviable el seguimiento mediante difracción de rayos $X$ en las composiciones en las que se realizaron adiciones del $1 \%$. Cuando se adiciona un $5 \%$ se observa una disminución del contenido de $\mathrm{CaF}_{2}$ del $50 \%$ a la temperatura de $950 \stackrel{\circ}{ } \mathrm{C}$. Estos resultados contrastan con los obtenidos para el $\mathrm{CaF}_{2}$ puro que es estable hasta los $910{ }^{\circ} \mathrm{C}$. A temperaturas más elevadas el contenido de $\mathrm{CaF}_{2}$ va disminuyendo progresivamente hasta alcanzar la temperatura de $1100^{\circ} \mathrm{C}$, a la cual la presencia del $\mathrm{CaF}_{2}$ es apenas del $5 \%$ de la cantidad adicionada inicialmente. 
En lo que respecta al $\mathrm{BaF}_{2}$ debe indicarse que, a pesar de que este fluoruro es uno de los más estables térmicamente cuando se encuentra aislado, incluso más que el de calcio, la disminución de su contenido es más acusada que la observada para el $\mathrm{CaF}_{2}$. Este hecho ha imposibilitado el seguimiento de su contenido con la temperatura para la serie en que se ha adicionado un $1 \%$. En la serie en la que la adición es del $5 \%$ se observa que a la temperatura de $950{ }^{\circ} \mathrm{C}$ sólo queda un $25 \%$ del fluoruro de bario inicial, y que no puede ser cuantificado a $1100 \stackrel{\circ}{\circ}$.

Los resultados correspondientes al $\mathrm{SrF}_{2}$ son similares a los obtenidos para el $\mathrm{BaF}_{2}$. Así, no ha sido posible realizar el seguimiento para adiciones del $1 \%$, mientras que para la serie en la que se ha adicionado el $5 \%$, el contenido de $\mathrm{SrF}_{2}$ puro disminuye apreciablemente a la temperatura de $950^{\circ} \mathrm{C}$. Posteriormente, a medida que aumenta la temperatura del tratamiento térmico, desaparece progresivamente hasta alcanzar los $1150{ }^{\circ} \mathrm{C}$, temperatura a la que ya no es posible su cuantificación.

Estos resultados indican que la estabilidad térmica del $\mathrm{CaF}_{2}, \mathrm{BaF}_{2}$ y $\mathrm{SrF}_{2}$ se reduce notablemente cuando se encuentran en una matriz cerámica. Su contenido en la mezcla disminuye progresivamente a partir de temperaturas bajas, $200^{\circ} \mathrm{C}$ para el $\mathrm{CaF}_{2}$, para dejar de detectarse a temperaturas del orden de $1100{ }^{\circ} \mathrm{C}$. El comportamiento diferenciado de estos fluoruros en la composición $\mathrm{G}$ puede deberse a su disolución en la fase líquida que se forma a alta temperatura en dicha composición (Orts, 1991), o a la formación de otros compuestos más estables. Al objeto de conocer si se están formando otras fases cristalinas durante el tratamiento térmico, se han estudiado los difractogramas completos.

El estudio de los difractogramas revela la presencia de anortita $\left(\mathrm{CaAl}_{2} \mathrm{Si}_{2} \mathrm{O}_{8}\right)$ en las series de experimentos en las que se ha introducido un $1 \%$ y un $5 \%$ de $\mathrm{CaF}_{2}$ y de celsiana $\left(\mathrm{BaAl}_{2} \mathrm{Si}_{2} \mathrm{O}_{8}\right)$ en la serie con el $5 \%$ de $\mathrm{BaF}_{2}$. No se ha detectado ninguna nueva especie cristalina en la serie correspondiente a la introducción de $\mathrm{SrF}_{2}$. En la Tabla 5.14 se muestra el contenido de anortita, mientras que en la Tabla 5.15 se muestra el contenido de celsiana detectados en las piezas cocidas.

Tabla 5.14. Contenido de anortita $\left(\mathrm{CaAl}_{2} \mathrm{Si}_{2} \mathrm{O}_{8}\right)$ que presenta la composición tras ser tratada térmicamente a diferentes temperaturas.

\begin{tabular}{|c|c|c|c|c|}
\hline \multirow{2}{*}{$\begin{array}{c}\mathrm{CaF}_{2} \\
\text { adicionado } \\
\text { (\% en peso) }\end{array}$} & \multicolumn{4}{|c|}{ Contenido de anortita (\% en peso) } \\
\hline & $950^{\circ} \mathrm{C}$ & $1000 \stackrel{\circ}{C}$ & $1100 \stackrel{\circ}{C}$ & $1150 \stackrel{\circ}{C}$ \\
\hline $1 \%$ & 5 & 6 & 5 & 3 \\
\hline $5 \%$ & 9 & 10 & 10 & 7 \\
\hline
\end{tabular}


Tabla 5.15. Contenido de celsiana $\left(\mathrm{BaAl}_{2} \mathrm{Si}_{2} \mathrm{O}_{8}\right)$ que presenta la composición tras ser tratada térmicamente a diferentes temperaturas.

\begin{tabular}{ccccc}
\hline $\begin{array}{c}\mathrm{BaF}_{2} \\
\text { adicionado } \\
\text { (\% en peso) }\end{array}$ & $\mathbf{9 5 0 ^ { \circ } \mathrm { C }}$ & $\mathbf{1 0 0 0}{ }^{\circ} \mathrm{C}$ & $\mathbf{1 1 0 0}{ }^{\circ} \mathrm{C}$ & $\mathbf{1 1 5 0}{ }^{\circ} \mathrm{C}$ \\
\hline $5 \%$ & 4 & 4 & 4 & 4 \\
\hline
\end{tabular}

El estudio ha continuado con la elección del óxido de calcio dado que este óxido forma parte, habitualmente, de la mayoría de las composiciones utilizadas en la fabricación de baldosas cerámicas. De esta forma, los resultados obtenidos pueden aplicarse a los procesos y productos industriales existentes en la actualidad.

\subsubsection{Estudio de la influencia del contenido de $\mathrm{CaO}$ en la formación de las fases cristalinas durante el tratamiento térmico}

En el interior de una matriz cerámica se genera $\mathrm{CaF}_{2}$ a partir de la reacción química entre el $\mathrm{CaO}$ presente en la composición y del HF formado en el soporte cerámico, según la literatura científica. La cantidad de $\mathrm{CaF}_{2}$ formada es tan pequeña que no es posible un seguimiento adecuado de la misma mediante difracción de rayos $X$ (XRD), tal y como se ha comentado en el punto anterior. Para eludir este inconveniente se ha procedido de forma similar a la anterior, preparando probetas sintéticas de la composición $\mathrm{G}$ con adiciones del $5 \% \mathrm{CaF}_{2}$. Las composiciones preparadas se indican en la Tabla 5.16. Cabe destacar que los porcentajes de $\mathrm{CaCO}_{3}$ adicionados cubren el intervalo de los contenidos de este mineral presentes en todas las tipologías de baldosas cerámicas, desde aquellas de muy baja porosidad hasta las de porosidad elevada.

Tabla 5.16. Composiciones preparadas para estudiar la influencia del contenido de $\mathrm{CaO}$ sobre la estabilidad térmica del $\mathrm{CaF}_{2}$.

\begin{tabular}{lcccc}
\hline \multicolumn{1}{c}{ Compuesto } & M0 & M5 & M10 & M15 \\
\hline $\mathrm{G}$ & 95 & 90 & 85 & 80 \\
$\mathrm{CaF}_{2}$ & 5 & 5 & 5 & 5 \\
$\mathrm{CaCO}_{3}$ & - & 5 & 10 & 15 \\
\hline
\end{tabular}

Con las mezclas obtenidas se han conformado probetas cilíndricas sobre las que se han realizado tratamientos térmicos a $800,900,950,1000,1050,1100$ y $1150{ }^{\circ} \mathrm{C}$. La composición M0, sin adición de $\mathrm{CaCO}_{3}$, también se ha tratado térmicamente a menores temperaturas al objeto de conocer la estabilidad de la fluorita a baja temperatura. 
En la Figura 5.13 se muestran las fases cristalinas presentes en las piezas tratadas térmicamente para la mezcla M0. A la temperatura de $800^{\circ} \mathrm{C}$ ya no se detecta la presencia de minerales arcillosos ni de calcita. Esta falta de detección indica que los primeros se encuentran deshidroxilados y el segundo se ha descompuesto en su totalidad. Todo ello contribuye a la presencia de $\mathrm{SiO}_{2}, \mathrm{Al}_{2} \mathrm{O}_{3}$ y $\mathrm{CaO}$ en la matriz cerámica. En la figura se observa una disminución progresiva en el contenido de $\mathrm{CaF}_{2}$, a partir de temperaturas bajas $\left(200{ }^{\circ} \mathrm{C}\right)$, que es más acusada entre 600 y $850^{\circ} \mathrm{C}$. A partir de esta temperatura se invierte la tendencia, detectándose un pequeño máximo a $900^{\circ} \mathrm{C}$. La presencia de este pequeño máximo indica que se está formando fluorita, probablemente a partir del flúor que está emitiendo la composición $\mathrm{G}$ y del $\mathrm{CaO}$ procedente de la descomposición del $\mathrm{CaCO}_{3}$ presente como impureza en la composición $\mathrm{G}(1,15 \%)$. A temperaturas superiores disminuye de nuevo el contenido de $\mathrm{CaF}_{2}$ para prácticamente desaparecer a $1100^{\circ} \mathrm{C}$.

La anortita comienza a formarse a partir de $600{ }^{\circ} \mathrm{C}$, aumentando su contenido de forma progresiva hasta los $1050{ }^{\circ} \mathrm{C}$, temperatura a la que se detecta el máximo contenido de anortita. A partir de esta temperatura disminuye su contenido hasta los $1150{ }^{\circ} \mathrm{C}$. Esta disminución se debe a la disolución de los cristales de anortita en la fase líquida que genera la composición $\mathrm{G}$ a elevada temperatura (Orts, 1991).

Comparando estos resultados con los obtenidos al tratar térmicamente el $\mathrm{CaF}_{2}$ puro, se concluye que la estabilidad del $\mathrm{CaF}_{2}$ disminuye notablemente cuando se encuentra rodeado de una matriz cerámica, en particular cuando ésta desarrolla una abundante proporción de fase líquida a temperaturas superiores a los $800-900{ }^{\circ} \mathrm{C}$. Por otra parte, al calcular el $\mathrm{CaO}$ necesario para formar la anortita, se observa que el $\mathrm{CaO}$ presente en la composición $\mathrm{G}$ $(1,21 \%)$ es suficiente para formar únicamente un $5,5 \%$ de anortita. Por consiguiente, la formación de mayores cantidades de anortita requiere que parte del calcio procedente del $\mathrm{CaF}_{2}$ contribuya a la formación de anortita por reacción con la $\mathrm{SiO}_{2}$ y $\mathrm{Al}_{2} \mathrm{O}_{3}$ proveniente de la deshidroxilación de los minerales arcillosos. La formación de anortita a costa del $\mathrm{CaF}_{2}$ se encuentra, además, favorecida termodinámicamente a alta temperatura, a juzgar por los valores de la energía libre de formación a partir de sus elementos $\left(\Delta G_{\mathrm{f}, 1300 \mathrm{~K}}^{\circ}=-3259 \mathrm{~kJ} / \mathrm{mol}\right.$ para la anortita y $\Delta \mathrm{G}_{\mathrm{f}, 1300 \mathrm{~K}}^{\circ}=-1012 \mathrm{~kJ} / \mathrm{mol}$ para el $\mathrm{CaF}_{2}$ ). Es muy probable que el $\mathrm{CaF}_{2}$ se desestabilice en presencia de $\mathrm{SiO}_{2}$ y $\mathrm{Al}_{2} \mathrm{O}_{3}$ para formar anortita a temperaturas superiores a los $800{ }^{\circ} \mathrm{C}$ (Semrau, 1957). Estos resultados podrían justificar la escasa efectividad que presenta la formación de $\mathrm{CaF}_{2}$ a partir del $\mathrm{CaO}$ presente en las composiciones de gres para retener el flúor que se emite durante la etapa de cocción de este producto. 


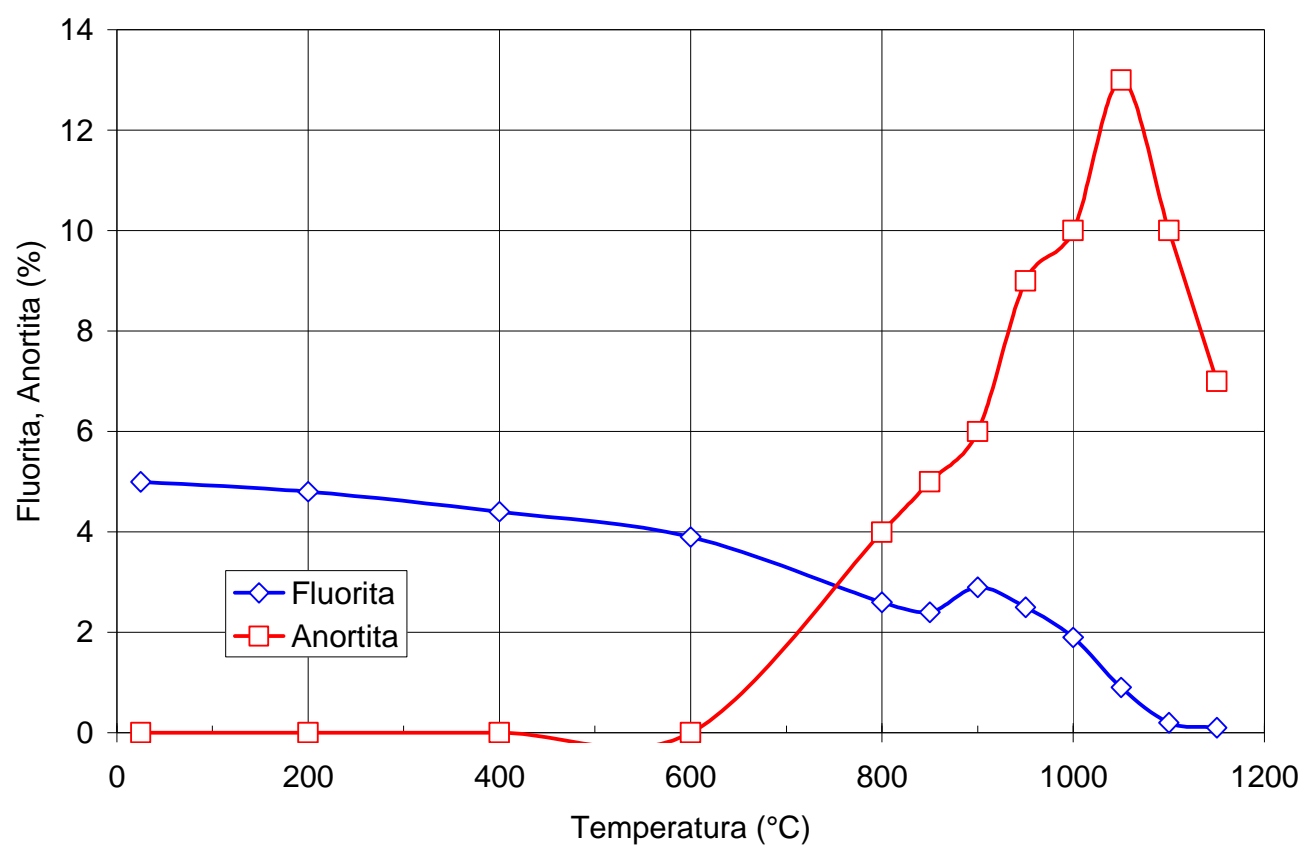

Figura 5.13. Evolución de las fases cristalinas presentes con la temperatura del tratamiento térmico. Mezcla M0.

En la Figura 5.15, Figura 5.16 y Figura 5.17 se muestran los resultados para las mezclas M5, M10 y M15 en el intervalo de temperaturas comprendido entre 800 y $1150^{\circ} \mathrm{C}$. También se muestran, en la Figura 5.14, los resultados para la mezcla M0 en este intervalo de temperatura. Debe indicarse que a $800{ }^{\circ} \mathrm{C}$ no se detectó la presencia de minerales arcillosos ni de $\mathrm{CaCO}_{3}$ en ninguna de las composiciones ensayadas.

La evolución que se observa en el contenido de $\mathrm{CaF}_{2}$ en las mezclas M5, M10 y M15 es muy parecida a la descrita anteriormente para la mezcla M0, y consiste en una disminución progresiva del contenido en $\mathrm{CaF}_{2}$ con el aumento de la temperatura, hasta dejar de detectarse entre 1050 y $1150^{\circ} \mathrm{C}$. Las pequeñas diferencias detectadas en el contenido de $\mathrm{CaF}_{2}$ al modificar la cantidad de $\mathrm{CaCO}_{3}$ no se consideran significativas y deben asociarse a la precisión de la técnica empleada.

En las figuras también se observa la aparición de una nueva especie cristalina con flúor, la cuspidina $\left(\mathrm{Ca}_{4} \mathrm{Si}_{2} \mathrm{O}_{7} \mathrm{~F}_{2}\right)$, que no se ha detectado en la mezcla M0. Esta fase comienza a cristalizar a temperaturas superiores a $850{ }^{\circ} \mathrm{C}$, y su contendido en las piezas depende del porcentaje de $\mathrm{CaCO}_{3}$ adicionado. Así, en la mezcla M5, la cantidad máxima de $\mathrm{Ca}_{4} \mathrm{Si}_{2} \mathrm{O}_{7} \mathrm{~F}_{2}$ se detecta a $900{ }^{\circ} \mathrm{C}$ y es únicamente del $2,5 \%$. Para porcentajes de $\mathrm{CaCO}_{3}$ superiores, la máxima cantidad de $\mathrm{Ca}_{4} \mathrm{Si}_{2} \mathrm{O}_{7} \mathrm{~F}_{2}$ de detecta en torno a $1000{ }^{\circ} \mathrm{C}$ y aumenta hasta valores del 9,5\% (M10) y $15,5 \%$ (M15). 
La aparición de esta especie cristalina en el intervalo de temperaturas en que se produce la disminución del contenido de $\mathrm{CaF}_{2}\left(900-1100^{\circ} \mathrm{C}\right)$ permite la fijación del flúor en la pieza, lo que reduce la emisión de este elemento a la atmósfera en este intervalo de temperaturas. Sin embargo, el contenido de cuspidina disminuye rápidamente a temperaturas mayores de $1000^{\circ} \mathrm{C}$ para desaparecer totalmente a $1100^{\circ} \mathrm{C}$, lo que implica un aumento de la emisión de flúor a la atmósfera a alta temperatura. Este hecho podría justificar la efectividad que presenta la adición de $\mathrm{CaCO}_{3}$ para disminuir la emisión de compuestos de flúor en productos cocidos a temperaturas inferiores a $1000^{\circ} \mathrm{C}$ (tejas y ladrillos), así como su escasa eficacia en productos cocidos a temperaturas superiores (baldosas cerámicas).

En la mezcla M0 se detecta un aumento progresivo del contenido de anortita a medida que aumenta la temperatura del tratamiento térmico hasta alcanzar los $1050{ }^{\circ} \mathrm{C}$, a partir de los cuales disminuye su contenido por disolución en la fase líquida presente en la pieza. Esta tendencia se modifica apreciablemente en las mezclas en las que se adiciona calcita. De este modo, en la mezcla M5 (Figura 5.15) se observa una disminución del contenido de anortita al pasar de 850 a $900{ }^{\circ} \mathrm{C}$ que coincide con la formación de cuspidina, lo que indica que a estas temperaturas se encuentra favorecida termodinámicamente la formación de esta última fase

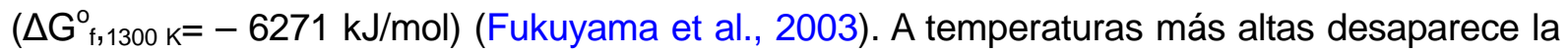
cuspidina y aumenta notablemente el contenido de anortita hasta alcanzar los $1150^{\circ} \mathrm{C}$. Para la mezcla M5 no se aprecia un máximo en el contenido de anortita.

La evolución del contenido de anortita en las mezclas M10 y M15 (Figura 5.16 y Figura 5.17, respectivamente) presenta una tendencia similar a la descrita para la mezcla M5. Así puede apreciarse una disminución del contenido de anortita en el intervalo $900-950{ }^{\circ} \mathrm{C}$ y $950-1000{ }^{\circ} \mathrm{C}$ para contenidos de calcita del $10 \%$ y $15 \%$ respectivamente que coincide con la formación de cuspidina. Posteriormente, se aprecia un importante aumento en el contenido de anortita coincidiendo con la desaparición de la cuspidina. Estos resultados indican que entre 850 y $1000{ }^{\circ} \mathrm{C}$ se encuentra favorecida la formación de cuspidina, mientras que a temperaturas superiores a $1000^{\circ} \mathrm{C}$ se favorece la formación de anortita. 


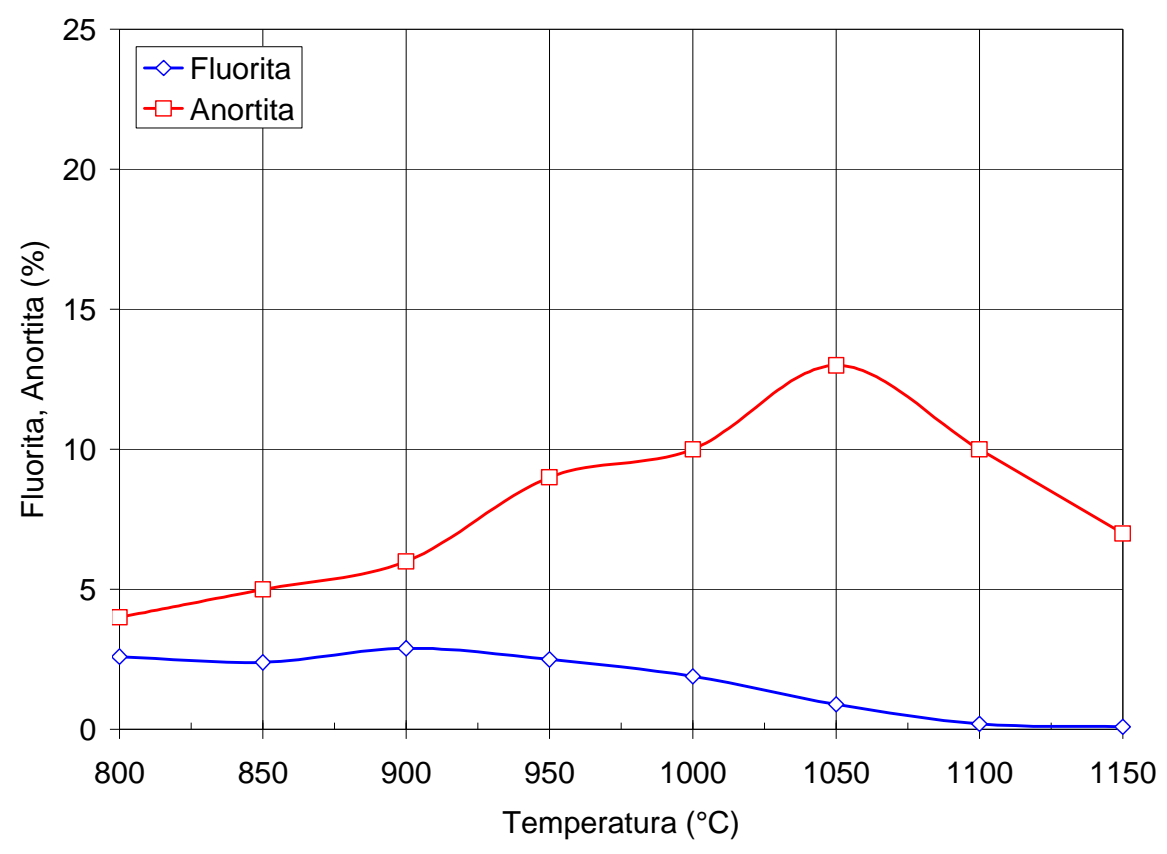

Figura 5.14. Evolución de las fases cristalinas presentes con la temperatura del tratamiento térmico. Mezcla M0.

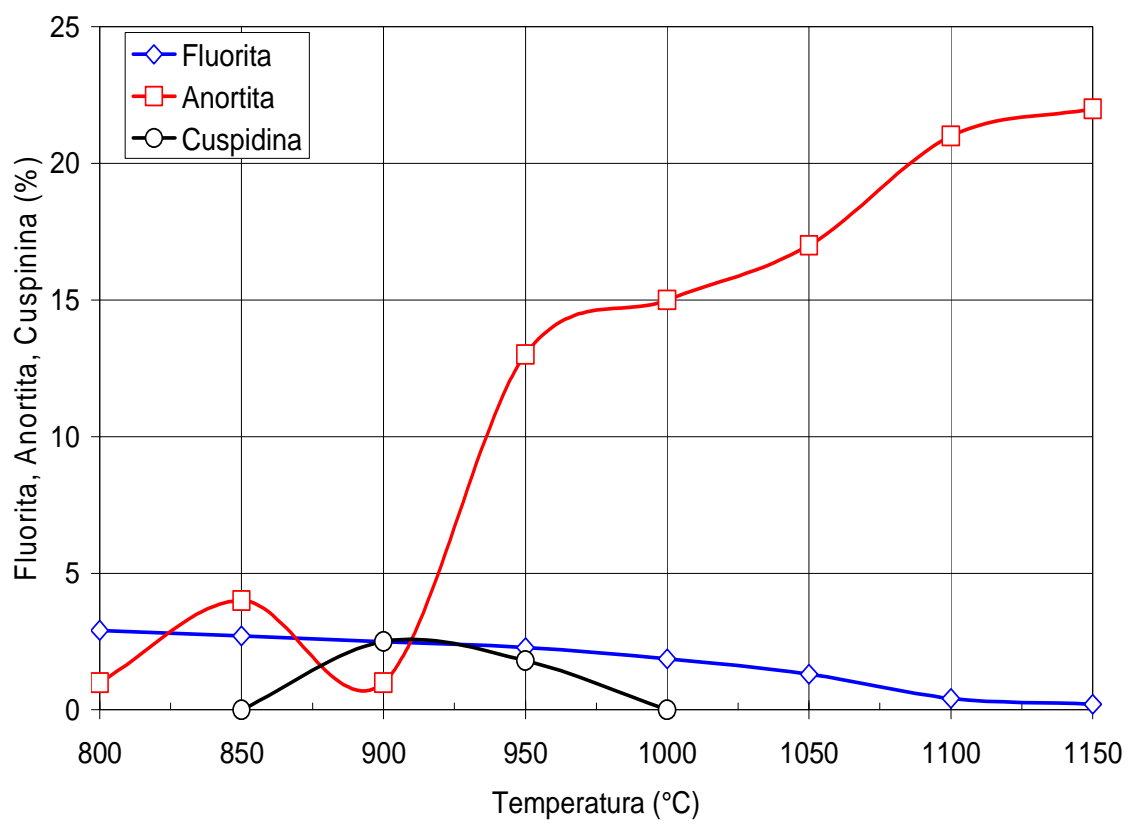

Figura 5.15. Evolución de las fases cristalinas presentes con la temperatura del tratamiento térmico. Mezcla M5. 


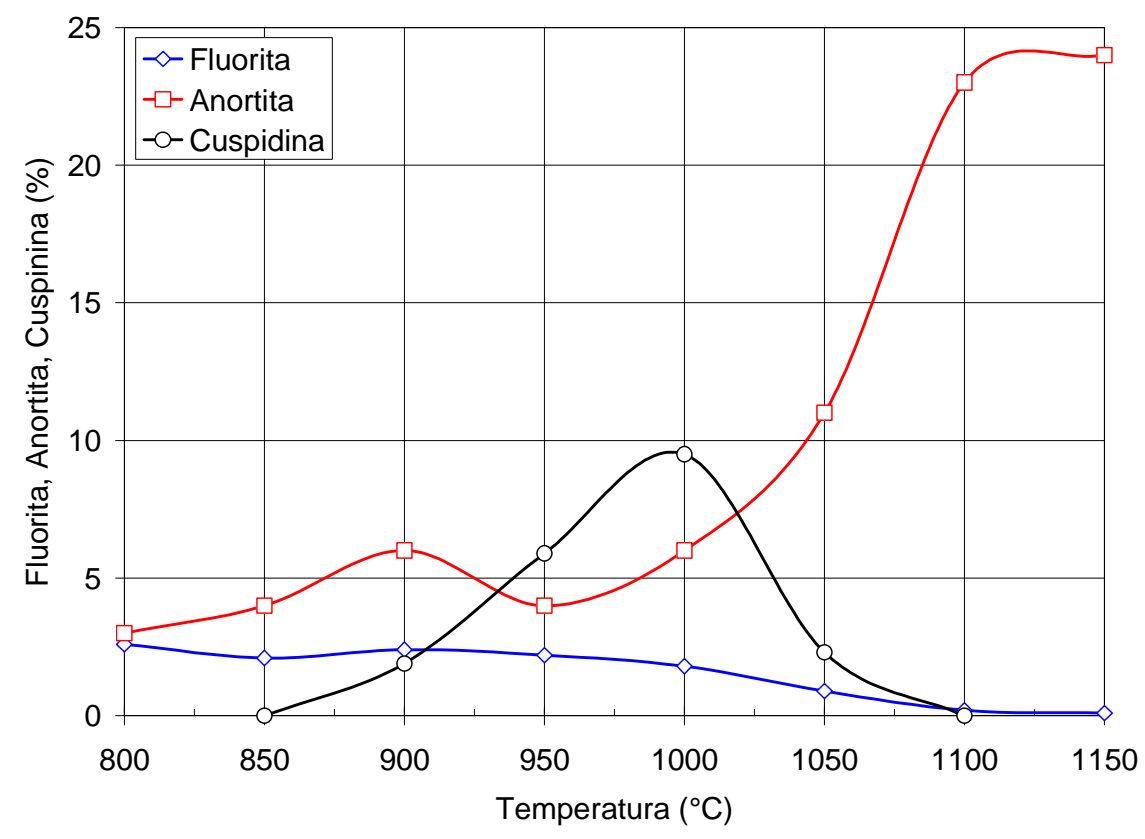

Figura 5.16. Evolución de las fases cristalinas presentes con la temperatura del tratamiento térmico. Mezcla M10.

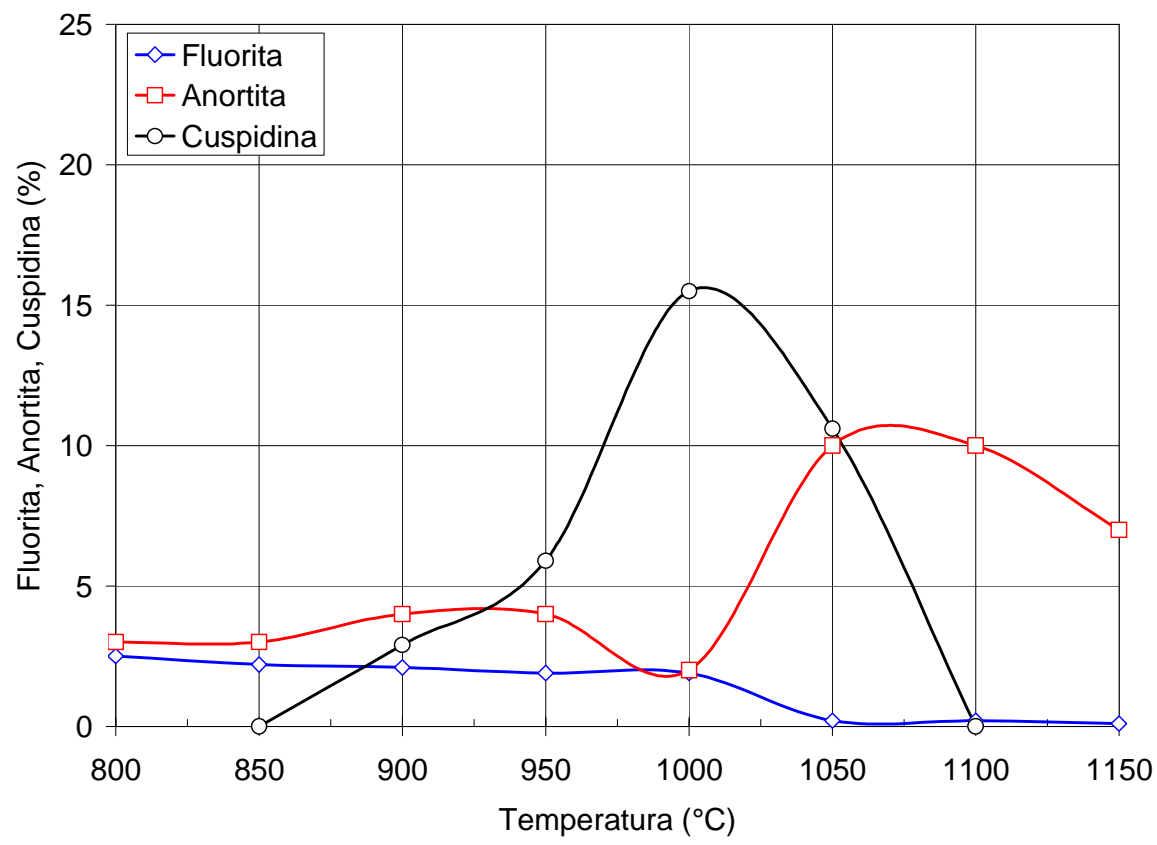

Figura 5.17. Evolución de las fases cristalinas presentes con la temperatura del tratamiento térmico. Mezcla M15. 
Finalmente, se ha calculado la cantidad de flúor retenido en las fases cristalinas fluoradas presentes en las piezas a las diferentes temperaturas ensayadas, que se muestra en la Figura 5.18.

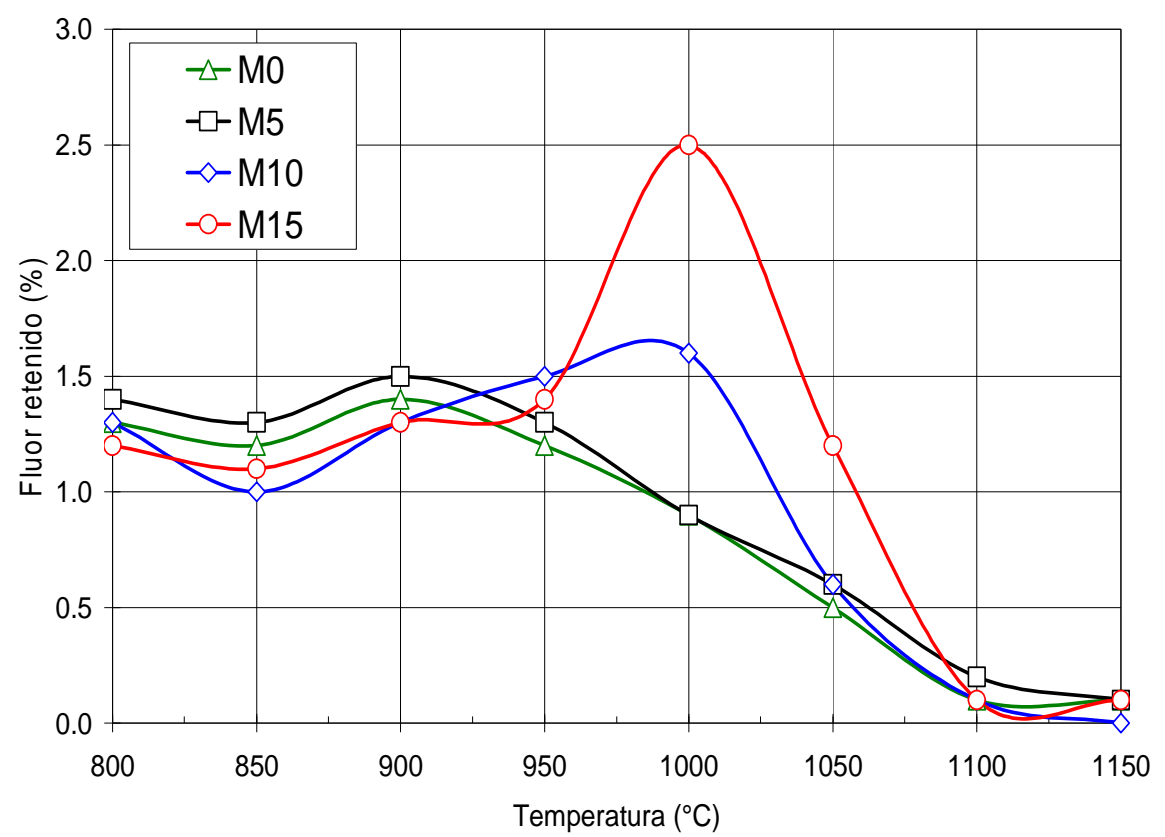

Figura 5.18. Evolución del flúor fijado en las fases cristalinas con la temperatura del tratamiento térmico.

De la observación de esta figura se desprende lo siguiente:

- El flúor retenido en las fases cristalinas disminuye progresivamente hasta los $850 \stackrel{\circ}{ } \mathrm{C}$, debido a la reducción del contenido de $\mathrm{CaF}_{2}$. Por encima de los $850{ }^{\circ} \mathrm{C}$ el contenido de flúor retenido aumenta debido a la formación de $\mathrm{CaF}_{2}$ a partir del flúor del soporte de gres y de la cristalización de la $\mathrm{Ca}_{4} \mathrm{Si}_{2} \mathrm{O}_{7} \mathrm{~F}_{2}$.

- Para las composiciones de menor contenido de $\mathrm{CaCO}_{3}$ (M0 y M5) se observa un máximo en el contenido de flúor retenido a $900^{\circ} \mathrm{C}$. A mayor temperatura disminuye de nuevo la cantidad de flúor retenido como consecuencia de la desaparición de la $\mathrm{CaF}_{2}$ y $\mathrm{Ca}_{4} \mathrm{Si}_{2} \mathrm{O}_{7} \mathrm{~F}_{2}$. Esta tendencia se observa hasta los $1150{ }^{\circ} \mathrm{C}$, en la que la cantidad de flúor retenido es prácticamente nula.

- En las composiciones con mayor contenido de $\mathrm{CaCO}_{3}$ (M10 y M15) también se detecta un valor máximo en el contenido de flúor retenido, aunque a temperaturas mayores $\left(1000{ }^{\circ} \mathrm{C}\right)$. Para estas composiciones la disminución del contenido de flúor retenido debido a la reducción del contenido de $\mathrm{CaF}_{2}$ a partir de los $900{ }^{\circ} \mathrm{C}$ se compensa con la formación de cantidades importantes de $\mathrm{Ca}_{4} \mathrm{Si}_{2} \mathrm{O}_{7} \mathrm{~F}_{2}$, lo que aumenta la cantidad de flúor retenido entre 850 y $1000^{\circ} \mathrm{C}$. 
- A partir de $1000{ }^{\circ} \mathrm{C}$ se detecta una disminución brusca del flúor retenido en las composiciones M10 y M15 debido a la reducción del contenido de fluorita y cuspidina. Esta tendencia se observa hasta los $1150^{\circ} \mathrm{C}$, en la que la cantidad de flúor retenido por las fases cristalinas es prácticamente nula.

En resumen, el flúor retenido en las fases cristalinas presenta uno o dos máximos en función del contenido de $\mathrm{CaO}$ en la composición. Todas las composiciones presentan un máximo de retención sobre $900 \stackrel{\circ}{\circ} \mathrm{C}$ debido a la formación de $\mathrm{CaF}_{2}$ y $\mathrm{Ca}_{4} \mathrm{Si}_{2} \mathrm{O}_{7} \mathrm{~F}_{2}$ (M5, M10 y M15). Además, las composiciones más ricas en calcio (M10 y M15) presentan un segundo máximo de mayor magnitud sobre $1000{ }^{\circ} \mathrm{C}$, debido a la formación de $\mathrm{Ca}_{4} \mathrm{Si}_{2} \mathrm{O}_{7} \mathrm{~F}_{2}$. Independientemente del contenido de $\mathrm{CaCO}_{3}$, todas las composiciones presentan una retención de flúor en fases cristalinas a la máxima temperatura ensayada $\left(1150^{\circ} \mathrm{C}\right)$ prácticamente nula.

\subsubsection{Resultados adicionales al artículo ํo 2}

El estudio de estabilidad térmica de los compuestos de flúor sencillos por separado ha incluido a los compuestos alcalinos ( $\mathrm{LiF}, \mathrm{NaF}$ y $\mathrm{KF}$ ) y los compuestos alcalinotérreos $\left(\mathrm{CaF}_{2}, \mathrm{MgF}_{2}\right.$, $\mathrm{BaF}_{2}$ y $\mathrm{SrF}_{2}$ ). En este apartado se muestran, como resultados adicionales al artículo no 2, los correspondientes a los fluoruros de elementos alcalinos, no incluidos en el contenido original de dicho artículo.

\section{Estabilidad térmica de fluoruros de cationes alcalinos}

En la Figura 5.19 y Figura 5.20, se detallan los resultados de los análisis térmico diferenciales del LiF, NaF y KF. La velocidad de calentamiento utilizada en la realización de estos análisis ha sido de $10^{\circ} \mathrm{C} / \mathrm{min}$. Como puede observarse en ambas figuras, los únicos cambios térmicos significativos son los procesos de fusión de sendos materiales, que se caracterizan por ser procesos fuertemente endotérmicos.

En estas figuras se observa que los diferentes fluoruros son térmicamente estables hasta temperaturas de $847^{\circ} \mathrm{C}, 853^{\circ} \mathrm{C}$ y $997^{\circ} \mathrm{C}$ respectivamente. A partir de esta temperatura se observa una marcada tendencia endotérmica hasta alcanzar su temperatura de fusión a $854 \stackrel{\circ}{\circ}, 864 \stackrel{\circ}{\circ} \mathrm{C}$, y $1001^{\circ} \mathrm{C}$.

El LiF es el fluoruro que empieza a fundir a menor temperatura y no es estable por encima de los $850 \stackrel{\circ}{\circ}$. Todos los fluoruros de cationes alcalinos no son estables por encima de $1000 \stackrel{\circ}{\circ}$ ya que funden y descomponen produciéndose la consecuente volatilización del compuesto.

Los resultados del análisis termogravimétrico muestran que los compuestos de flúor de los cationes alcalinos presentan un inicio de pérdida continua de peso a temperaturas de $879{ }^{\circ} \mathrm{C}$, $880{ }^{\circ} \mathrm{C}$ y $1009{ }^{\circ} \mathrm{C}$ para el LiF, KF y NaF, respectivamente. Si se cuantifica la pérdida de peso a la temperatura de $1200 \stackrel{\circ}{\circ}$ se obtienen los siguientes resultados: $22 \%, 50 \%$ y $26 \%$, respectivamente. 


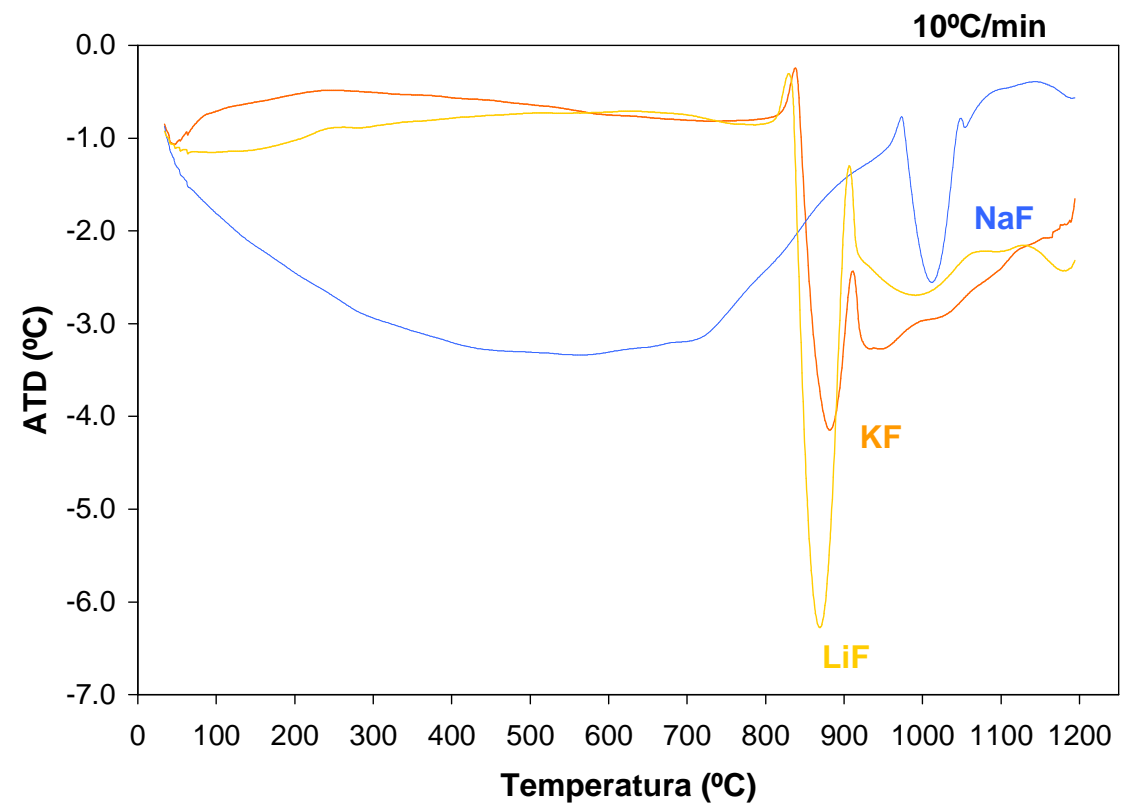

Figura 5.19. Análisis térmico diferencial. Fluoruros de cationes alcalinos.

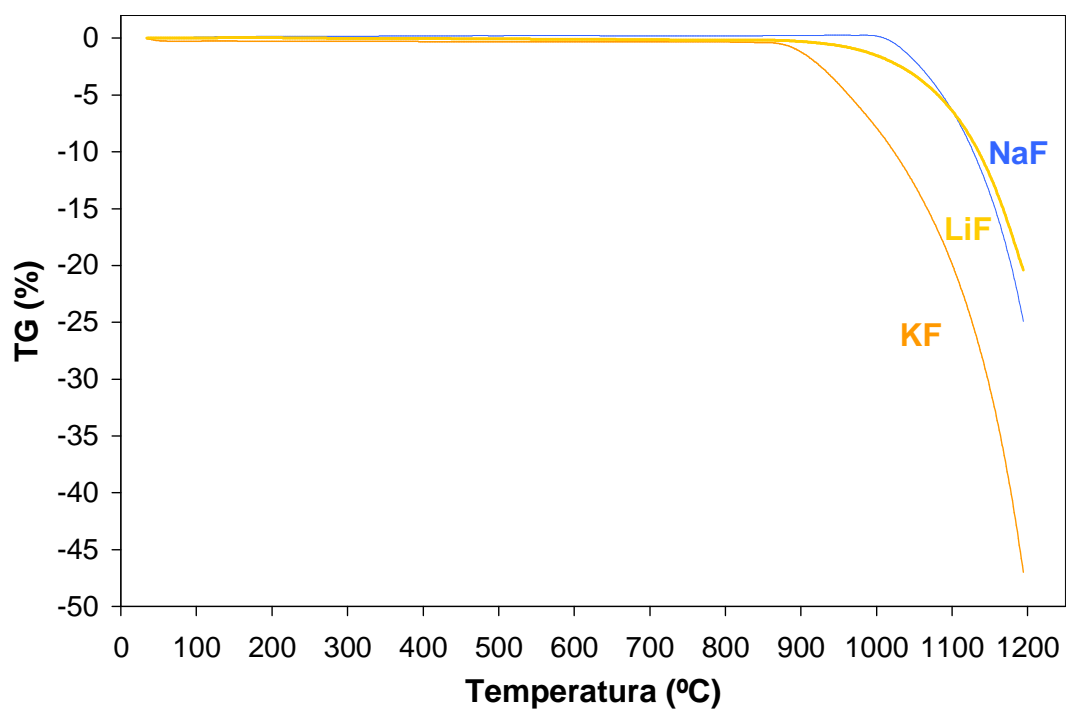

Figura 5.20. Análisis termogravimétrico. Fluoruros de cationes alcalinos. 


\subsection{Evolución de la emisión de compuestos de flúor durante el tratamiento térmico (Artículo no 3)}

En este artículo se han examinado los fenómenos de adsorción y emisión de compuestos de flúor que tienen lugar durante el tratamiento térmico de baldosas cerámicas. Las composiciones estudiadas corresponden a soportes de baldosas cerámicas con diferentes contenidos de flúor y de calcio, procesados con ciclos rápidos en hornos eléctricos discontinuos de laboratorio y en hornos de combustión continuos industriales (hornos de rodillos). Los productos estudiados han sido: azulejo rojo $(A)$, gres rojo $(G)$ y gres porcelánico blanco $(\mathrm{P})$.

\subsubsection{Estudio a escala de laboratorio}

Los resultados obtenidos en el horno eléctrico de laboratorio al estudiar el contenido de flúor en piezas cocidas a diferentes temperaturas se resumen en la Figura 5.21, expresados como la emisión acumulada de flúor a cada temperatura en valor absoluto.

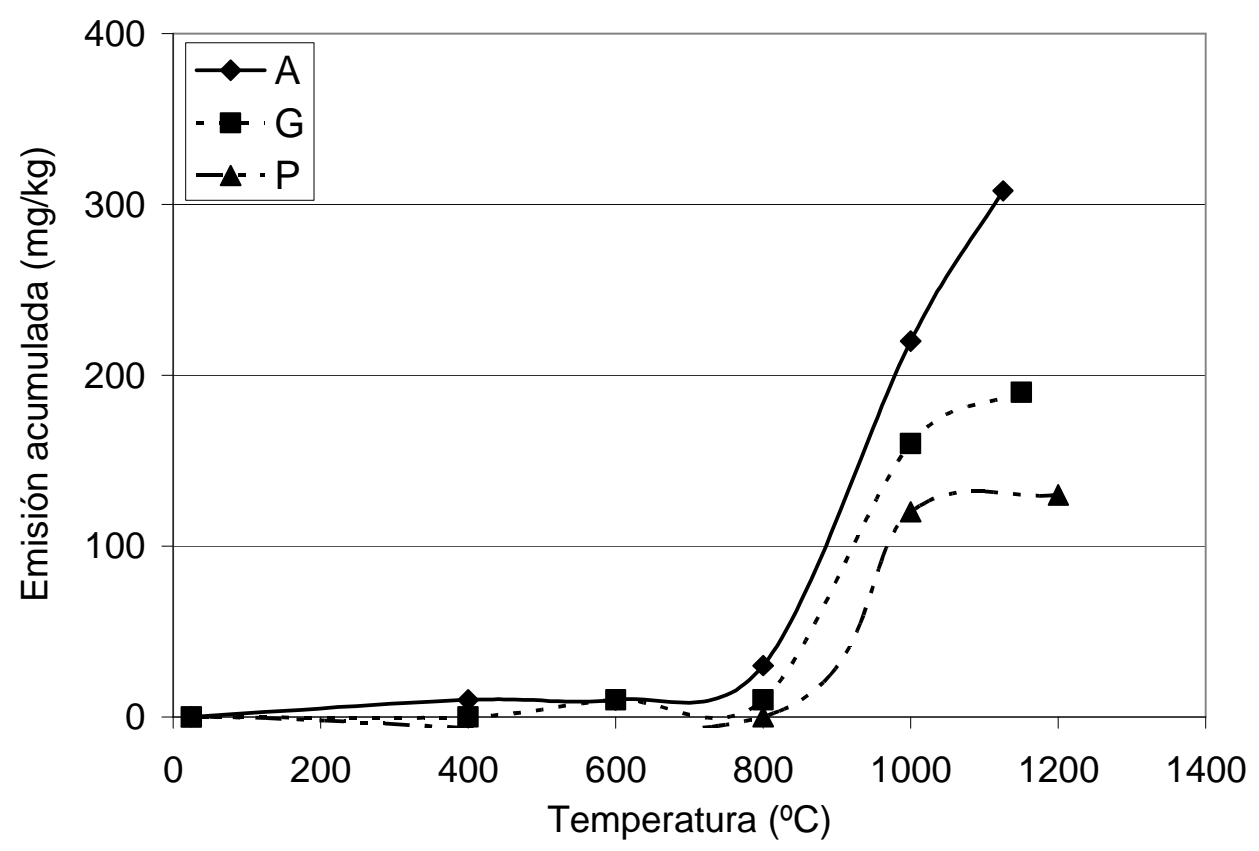

Figura 5.21. Emisión acumulada de flúor en horno eléctrico de laboratorio.

De la observación de la Figura 5.21 se deduce que la emisión de flúor en atmósfera de aire, para los tres productos considerados, no comienza a ser significativa hasta que se alcanzan temperaturas superiores a los $800{ }^{\circ} \mathrm{C}$. A partir de esta temperatura se observa un aumento progresivo de la emisión hasta la temperatura máxima de cocción. No obstante, este aumento 
es distinto en función del tipo de producto. Así, mientras que para el azulejo (A) se aprecia un aumento continuado, para el gres $(G)$ y gres porcelánico $(P)$ se observa una cierta estabilización a partir de los $1000^{\circ} \mathrm{C}$. Este comportamiento diferenciado por tipo de producto podría asociarse a la mayor cantidad de fase liquida que forman las composiciones $G$ y $P$ comparada con la composición $\mathrm{A}$, a elevada temperatura, lo que reduce la permeabilidad de la pieza a los gases dificultando la emisión de flúor.

Aunque existen algunas diferencias en la composición química y mineralógica de las composiciones estudiadas, la más importante, en cuanto a la retención de flúor se refiere, es el alto contenido de calcio de la composición $A$ en comparación con la de las otras composiciones, aunque esta característica no parece tener una especial significancia en la retención de flúor. Una posible explicación se encuentra en los estudios previos recogidos en el artículo $n^{\circ}-2$.

\subsubsection{Estudio a escala industrial}

Los resultados obtenidos durante el estudio de la evolución del contenido de flúor en las piezas durante la cocción industrial se muestran a continuación.

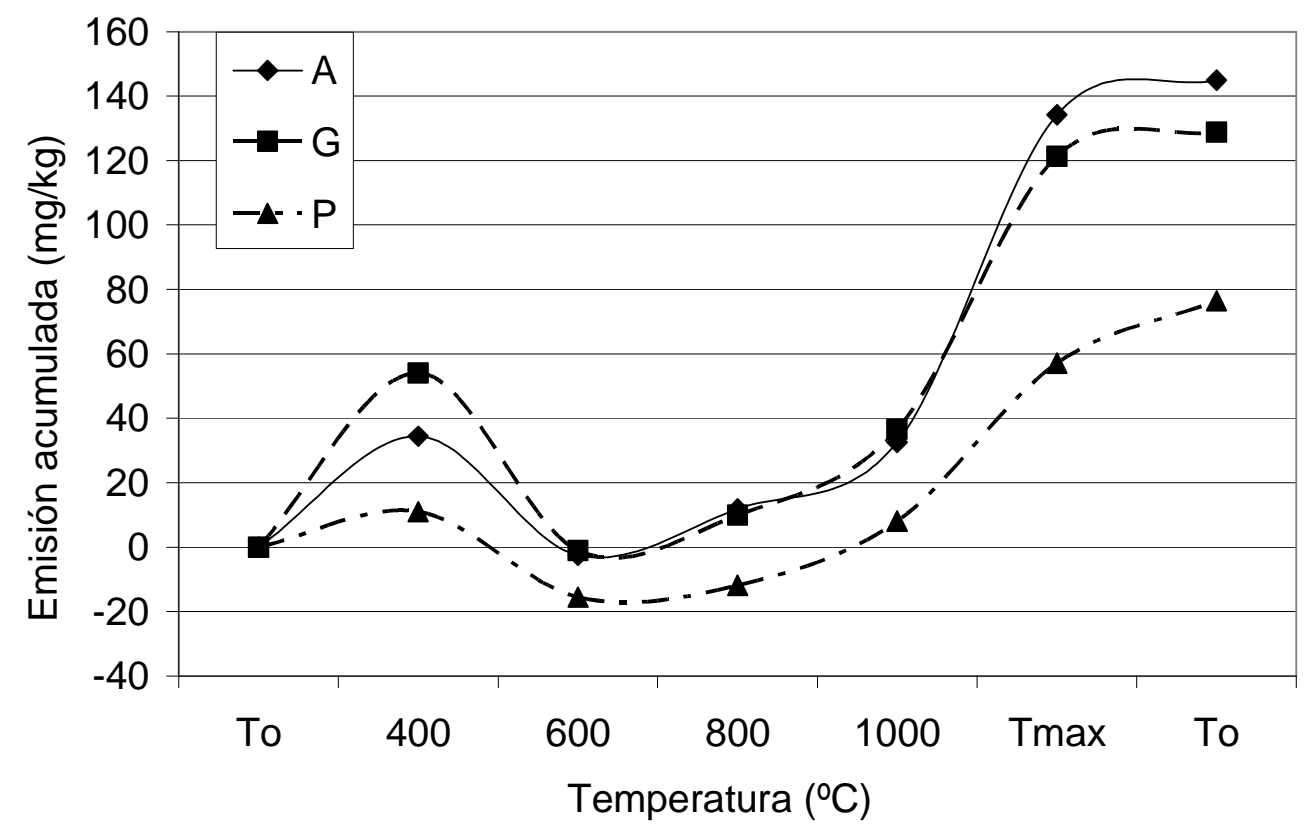

Figura 5.22. Emisión acumulada de flúor en horno industrial de combustión (donde To es la temperatura ambiente).

En la Figura 5.22 se representa la emisión acumulada de flúor (en $\mathrm{mg} / \mathrm{kg}$ ). En primer lugar se observa que la forma de la curva para los tres productos es similar, lo que indica que el mecanismo de emisión también debe serlo. Por otra parte, a diferencia de lo que sucedía en 
los experimentos realizados en atmósfera de aire y en un proceso discontinuo (horno de laboratorio), la emisión de flúor comienza a una temperatura más baja y no se observa un aumento continuado y progresivo de los valores de emisión. Al contrario, incluso en algunas zonas del horno la emisión acumulada disminuye. Este último efecto indica que existen zonas en el horno donde en lugar de producirse emisión de flúor tiene lugar una adsorción de este elemento por parte de las propias baldosas. Además, los valores de emisión en valor absoluto obtenido son notablemente inferiores a los valores registrados en el horno discontinuo de laboratorio (Figura 5.21), siendo este efecto mucho más marcado en la composición A.

En la zona de enfriamiento del horno no existe una emisión significativa de flúor. Únicamente la composición $\mathrm{P}$ muestra una ligera emisión de flúor, que es debida muy probablemente a las altas temperaturas de cocción de este material $\left(120{ }^{\circ} \mathrm{C}\right)$.

Con el fin de poder observar con mayor claridad lo que sucede en cada una de las zonas del horno, en la Figura 5.23 se ha representado la emisión diferencial expresada en $\mathrm{mg}$ de F/kg de muestra, realizando el cálculo respecto al contenido inicial de flúor, mientras que en la Figura 5.24 se ha representado la emisión expresada en porcentaje.

Del análisis de las figuras se deduce que:

- Las temperaturas a las cuales se produce emisión y adsorción coinciden para los tres productos estudiados, aunque la magnitud de estos fenómenos es diferente, debido a las diferencias en composición, en tratamiento térmico y en porosidad.

- Existe una primera emisión de flúor a baja temperatura, entre temperatura ambiente $\left(T_{0}\right)$ y $400{ }^{\circ} \mathrm{C}$. Esta emisión no ha sido detectada en el horno eléctrico con atmósfera de aire, lo que según la bibliografía consultada (Reymer y Jong, 1993; Denissen y Vries, 1998; Wei-hong et al., 2001) se debe a la ausencia de vapor de agua en la atmósfera del horno eléctrico. Este hecho pone de manifiesto la influencia que ejerce la composición química de la atmósfera existente en el horno.

- En el intervalo de temperaturas comprendido entre 400 y $600{ }^{\circ} \mathrm{C}$ existe una adsorción de flúor por parte de las piezas, que incrementan su contenido en flúor en todos los casos. Este flúor adsorbido procede de los gases que circulan en contracorriente con el producto, desde la zona de máxima temperatura hacia la entrada del horno, efecto también descrito en la bibliografía cuando se cuecen tejas y ladrillos en hornos túnel (Hauck y Hilker, 1986; Hauck et al., 1992; Brosnan, 1992; Denissen y Vries, 1998). 


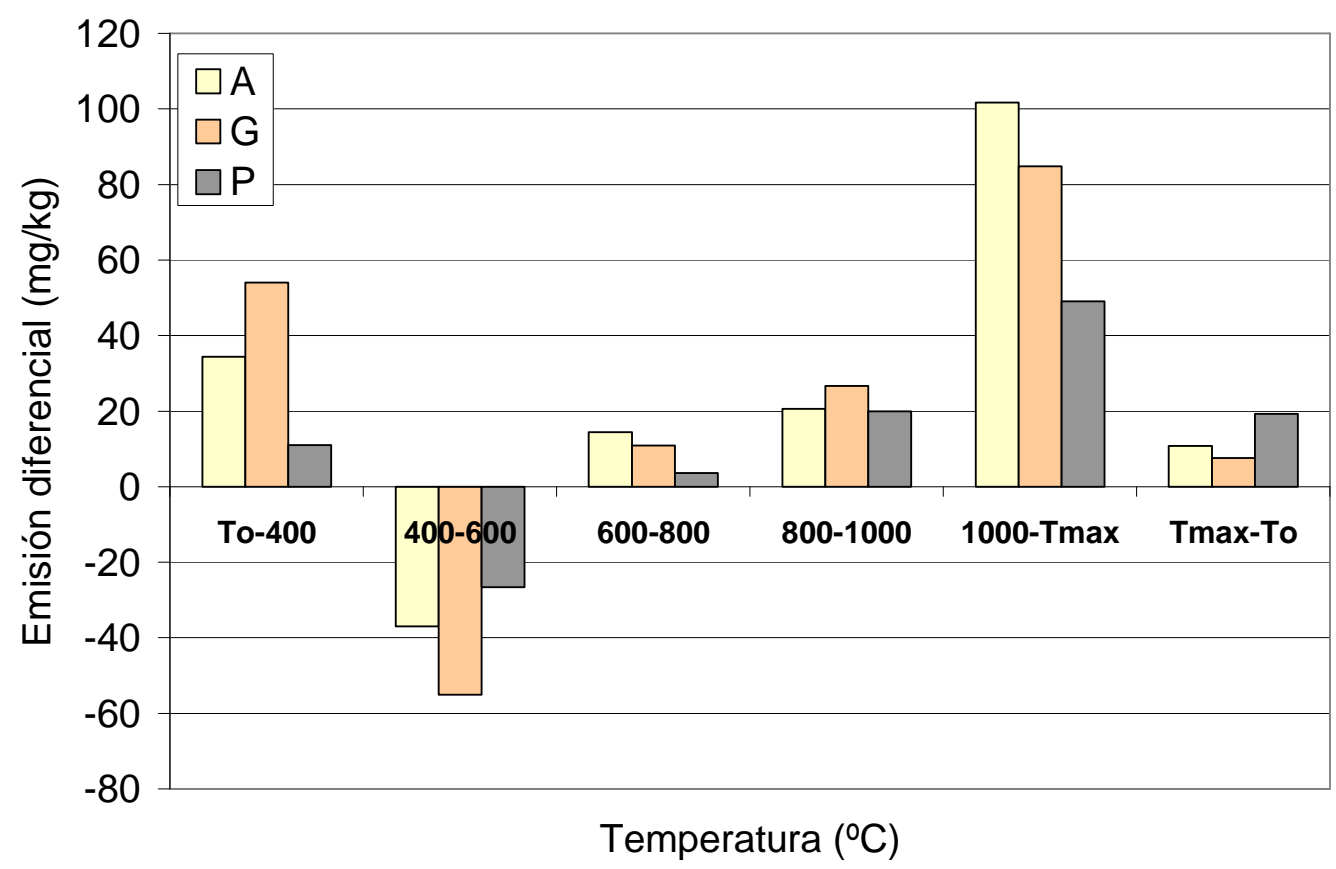

Figura 5.23. Emisión diferencial de flúor $(\mathrm{mg} / \mathrm{kg})$ en hornos industriales de combustión.

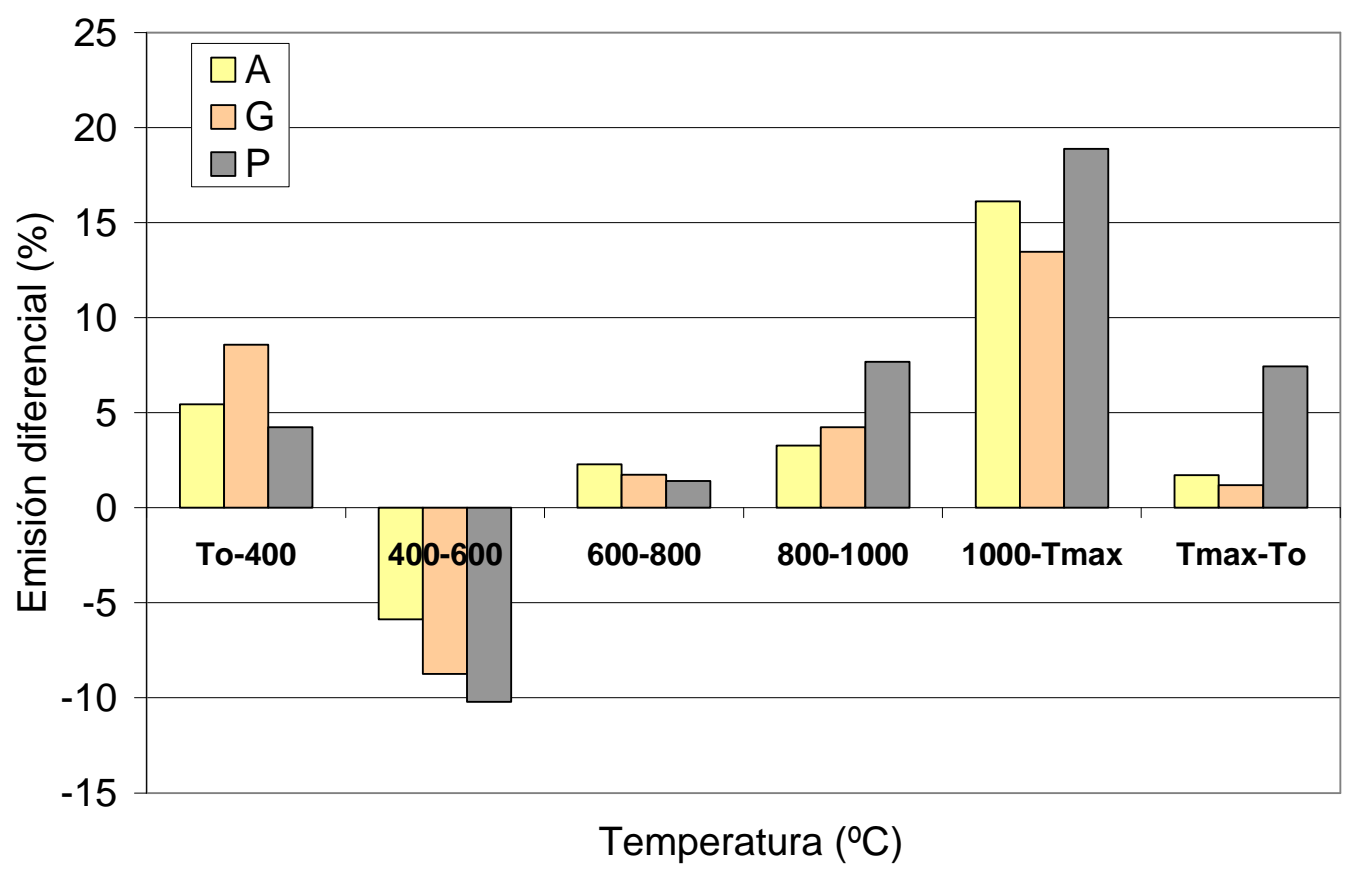

Figura 5.24. Emisión diferencial de flúor (\%) en hornos industriales de combustión. 
- A partir de los $600{ }^{\circ} \mathrm{C}$ existe de nuevo emisión de flúor hasta alcanzar la temperatura máxima de cocción. La emisión en esta zona del horno aumenta notablemente con el aumento de la temperatura, alcanzándose el máximo de emisión en el intervalo comprendido entre los $1000{ }^{\circ} \mathrm{C}$ y la temperatura máxima de cocción. Este comportamiento difiere del observado en el horno de laboratorio para las composiciones $\mathrm{G}$ y $\mathrm{P}$, en las que se detectaba una cierta estabilización de la emisión de flúor a altas temperaturas.

- Tal y como se ha comentado anteriormente, en la emisión acumulada, durante el enfriamiento desde la temperatura máxima ( $T_{\text {máx }}$ ) hasta la temperatura ambiente $\left(T_{0}\right)$, se detecta una ligera emisión de flúor, atribuible a la elevada temperatura que presentan las piezas en la primera zona de enfriamiento, en la que debe producirse esta emisión. Esta emisión es más importante en la composición $\mathrm{P}$, sobre todo en valor relativo, debido probablemente a que se somete a una mayor temperatura durante la cocción $\left(1200^{\circ} \mathrm{C}\right)$.

En líneas generales, los resultados obtenidos en hornos industriales de combustión y ciclos rápidos (30 - 60 minutos), son coherentes con los descritos en la bibliografía consultada para productos cerámicos fabricados en horno túnel de ciclos lentos (30 - 70 horas) y con temperaturas máximas de trabajo inferiores, tales como ladrillos y tejas (Hauck et al., 1992; Denisen y Vries, 1998). Estos trabajos describen la enorme influencia que ejerce la presencia de vapor de agua procedente de la combustión sobre la emisión de flúor a baja temperatura $\left(\mathrm{T}<400^{\circ} \mathrm{C}\right)$, así como la existencia de una adsorción durante el precalentamiento en hornos túnel $\left(400-600^{\circ} \mathrm{C}\right)$.

Por contra, no se observan diferencias importantes debidas al contenido en calcio sobre la emisión global de compuestos de flúor al ser comparadas las composiciones A y G, a diferencia de lo que predicen los trabajos citados anteriormente para otros tipos de productos cocidos a temperaturas máximas inferiores $(800-1000 \stackrel{\circ}{\circ})$.

\subsubsection{Estabilidad térmica del flúor adsorbido en precalentamiento}

En esta fase se ha estudiado, con mayor detenimiento, el fenómeno de captación de flúor por parte de las piezas procesadas en un horno industrial, en el intervalo de temperatura comprendido entre 400 y $600{ }^{\circ} \mathrm{C}$. Para ello, se han mantenido piezas industriales crudas no esmaltadas de las composiciones $A$ y $G$ en el interior del horno en un punto fijo, concretamente en la parte inferior del horno industrial, bajo los rodillos, durante distintos tiempos de permanencia. La zona del horno seleccionada ha sido la de $600 \stackrel{\circ}{\mathrm{C}}$, donde es previsible que se produzca la captación de flúor. Los resultados obtenidos se muestran en la Figura 5.25. 
Dicha figura muestra que el contenido de flúor en la composición A aumenta progresivamente con el tiempo de residencia de las baldosas en el horno industrial. Sin embargo, la composición $\mathrm{G}$ solamente muestra un pequeño aumento del contenido en flúor en periodos cortos mientras que en periodos prolongados, el contenido en flúor se mantiene prácticamente constante en el tiempo.

Los resultados obtenidos ponen de manifiesto la capacidad que presentan las piezas crudas para captar flúor durante la fase de precalentamiento en el horno industrial, en particular las de la composición A. Este comportamiento de la composición A se debe a que presenta un mayor contenido en $\mathrm{CaCO}_{3}$. Este hecho se puede observar en especial si las piezas se someten a ciclos de cocción lentos (hornos túnel), en los que el tiempo de permanencia a esta temperatura es elevado (del orden de horas) (Hauck et al., 1992). Por el contrario, si la cocción se desarrolla en ciclos rápidos (hornos de rodillos), debido a la elevada velocidad de calentamiento, el tiempo de permanencia de las piezas en la zona de adsorción ( $400-600{ }^{\circ} \mathrm{C}$ ) es muy reducido (del orden de $2-4$ minutos), lo que limita la magnitud del proceso de adsorción.

Para estudiar la estabilidad térmica del flúor captado en el precalentamiento, se ha determinado el contenido de flúor de las piezas $A$ y $G$ que habían permanecido en el interior del horno industrial durante distintos periodos de tiempo tras ser tratadas térmicamente a temperaturas máximas de $1150{ }^{\circ} \mathrm{C}$ durante 6 minutos en un horno eléctrico de laboratorio. Este tratamiento térmico pretende simular el tiempo que las piezas permanecen a alta temperatura durante la etapa de cocción industrial (Figura 5.25), y observar la estabilidad térmica de los compuestos de flúor formados durante la adsorción de precalentamiento.

Los resultados obtenidos se muestran en la Figura 5.25. En la misma se observa que el contenido de flúor de las piezas A y $\mathrm{G}$ tratadas a $1150{ }^{\circ} \mathrm{C}$ es prácticamente independiente del tiempo de permanencia de las piezas a $600^{\circ} \mathrm{C}$, lo que indica que la totalidad del flúor captado durante el precalentamiento, para las dos composiciones estudiadas, se emite posteriormente cuando las piezas alcanzan la zona de máxima temperatura del horno industrial.

Los resultados obtenidos para baldosas cerámicas procesadas en hornos industriales ponen de manifiesto que la potenciación de la captación de flúor en precalentamiento como medida para reducir las emisiones de flúor, sugerida por algunos autores a partir de estudios llevados a cabo en hornos eléctricos de laboratorio para la cocción de otros materiales cerámicos cocidos en ciclos lentos y sometidos a temperaturas máximas del orden de $1000 \stackrel{\circ}{\circ}$, no es aplicable a estos productos, incluso en las composiciones más ricas en calcio, dado que estas composiciones se someten a temperaturas máximas de cocción superiores a $1100{ }^{\circ} \mathrm{C}$ (Hauck y Hilker, 1986; Brosnan, 1992; Hauck et al., 1992; Denissen y Vries, 1998) en donde se emite el posible flúor atrapado a temperaturas más bajas. 
Estos resultados pueden ser interpretados en base a la escasa estabilidad térmica de los compuestos cristalinos de flúor que, presumiblemente, se forman en la zona de precalentamiento $\left(\mathrm{CaF}_{2}\right.$ y $\left.\mathrm{Ca}_{4} \mathrm{Si}_{2} \mathrm{O}_{7} \mathrm{~F}_{2}\right)$, tal y como se recoge en el artículo no 2 .

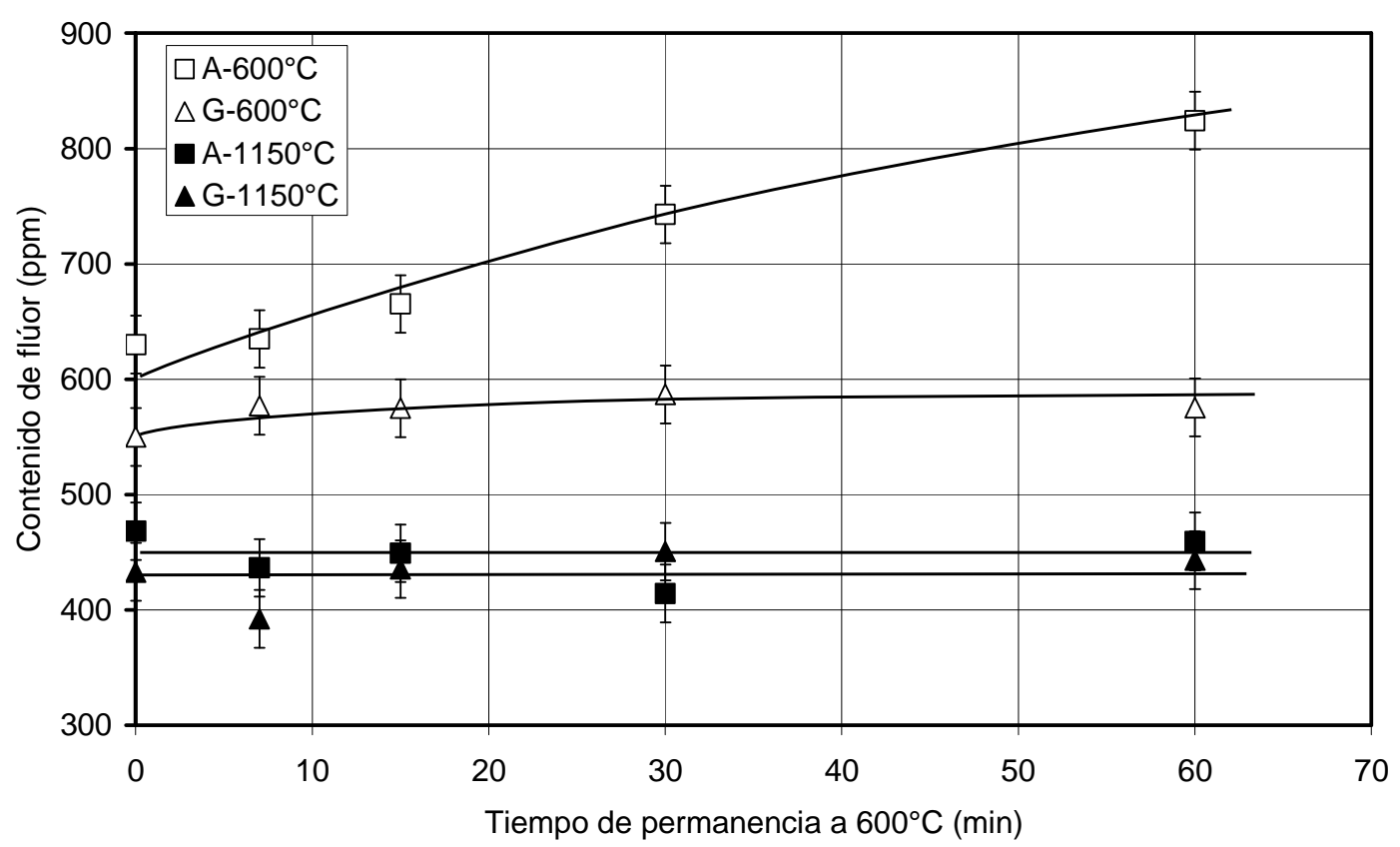

Figura 5.25. Contenido de flúor de los soportes $A$ y $G$ que han permanecido durante tiempos diferentes a $600^{\circ} \mathrm{C}$ y que han sido posteriormente tratados a $1150^{\circ} \mathrm{C}$ durante 6 minutos.

\subsubsection{Emisión de flúor en un segundo tratamiento térmico}

Las baldosas cocidas en ciclos industriales de cocción rápida mantienen cantidades significativas de flúor residual. Este flúor puede ser emitido durante un segundo tratamiento térmico, por ejemplo en un proceso de bicocción, en un proceso de tercer fuego o durante el secado tras una etapa de pulido. Se han realizado diferentes ensayos en un horno eléctrico de laboratorio bajo diferentes condiciones para corroborar dicha hipótesis.

En primer lugar se ha simulado un proceso de bicocción de piezas cocidas de A y de G que han sido sometidas a un ciclo térmico de 6 minutos a temperatura máxima de $1125^{\circ} \mathrm{C}$ para la composición $\mathrm{A}$, caracterizada por tener un elevado contenido en calcio y una elevada porosidad, y de $1150^{\circ} \mathrm{C}$ para la composición $\mathrm{G}$, caracterizadas por un bajo contenido en calcio y porosidad baja en cocción.

En segundo lugar, se ha simulado un proceso de secado tras una etapa de mecanizado (corte, pulido, etc.). En este caso las piezas cocidas de $A$ y $G$ han sido tratadas térmicamente a $300{ }^{\circ} \mathrm{C}$ durante 30 minutos. Los resultados se muestran en la Tabla 5.17. 
Tabla 5.17. Emisión de flúor en un segundo tratamiento térmico adicional a diferentes temperaturas.

\begin{tabular}{llccc}
\hline & \multicolumn{1}{c}{ Muestra } & Contenido de & \multicolumn{2}{c}{ Emisión } \\
\cline { 4 - 5 } & flúor $(\mathbf{m g} / \mathbf{k g})$ & $\mathbf{m g} / \mathbf{k g}$ & $\%$ \\
\hline A & Cocida a $1125^{\circ} \mathrm{C}$ & $500 \pm 20$ & -- & -- \\
& Recocida a $1125^{\circ} \mathrm{C}(6 \mathrm{~min})$ & $360 \pm 20$ & 140 & 28 \\
$\mathrm{G}$ & Recocida a $300^{\circ} \mathrm{C}$ & $490 \pm 20$ & 10 & 2 \\
& Cocida a $1150^{\circ} \mathrm{C}$ & $490 \pm 20$ & -- & -- \\
& Recocida a $1150{ }^{\circ} \mathrm{C}(6 \mathrm{~min})$ & $440 \pm 20$ & 50 & 10 \\
& Recocida a $300^{\circ} \mathrm{C}$ & $500 \pm 20$ & -10 & -2 \\
\hline
\end{tabular}

Considerando las incertidumbres de medida, los resultados indican que los materiales son capaces de emitir compuestos de flúor al someterse a una segunda cocción, en especial la composición A. Al igual que en resultados anteriores, la composición rica en calcio produce las emisiones más altas, probablemente debido a la elevada porosidad y permeabilidad en cocido y a la inestabilidad de las fases que contienen flúor a la temperatura máxima de cocción.

Los resultados obtenidos explican cualitativamente el comportamiento observado en la práctica industrial por otros autores (Palmonari y Timellini, 1982; Dogeroglu y Kara, 2002a) en los que se ha observado que en los procesos de bicocción existe un segundo pico de la emisión de flúor, incluso aunque se utilicen esmaltes libres de flúor.

Por otro lado, estos resultados también son coherentes con el hecho de que en los procesos térmicos de baja temperatura, tales como el secado de las baldosas mecanizadas, a temperaturas de aproximadamente $300^{\circ} \mathrm{C}$, las emisiones de flúor que se observan no sean significativas.

El bajo contenido de flúor y los límites de detección de los compuestos cristalinos de flúor por XRD no han permitido un estudio más detallado de la forma en que los compuestos de flúor son retenidos en las muestras cocidas, ni de sus mecanismos de emisión. 


\subsection{Monitorización y posible reducción de HF en la corriente de gases procedente de la cocción de baldosas cerámicas (Artículo no 4)}

En este artículo se ha utilizado un equipo de medida de la emisión de HF basado en tecnología láser TDLAS, que ha sido instalado en la chimenea de evacuación de gases con el fin de monitorizar su evolución en los hornos continuos industriales de combustión.

El seguimiento en continuo ha permitido conocer cómo es la emisión de HF en dichos hornos, bajo diferentes condiciones habituales de operación, cuando se procesan baldosas de azulejo, gres y gres porcelánico. También ha permitido constatar la importancia que los fenómenos de adsorción de HF que tienen lugar sobre la superficie de las piezas procesadas en la zona de precalentamiento del horno.

De igual modo, se ha evaluado la emisión de HF en los hornos industriales de combustión cuando se producen cambios importantes en las condiciones de producción, como por ejemplo, cuando se interrumpe la alimentación del horno, lo que provoca la existencia de una zona sin piezas (hueco) que se desplaza a lo largo del horno de cocción.

También se han introducido modificaciones realistas en las condiciones de fabricación a nivel industrial, como en el tratamiento térmico y en la densidad aparente en seco de las piezas producidas, para poder conocer si es posible alcanzar reducciones significativas de la emisión de HF asociada a este proceso cuando la temperatura de trabajo alcanza los $1100{ }^{\circ} \mathrm{C}$. Además, en esta parte de la investigación se ha indagado sobre la aplicación de esmalte en la baldosa como acción efectiva para reducir la emisión de HF.

\subsubsection{Concentración de HF en la corriente de gases de salida bajo condiciones de operación habituales}

En este apartado se ha estudiado la evolución de la concentración de HF en la corriente de gases de salida del horno, funcionando de forma estable, para cada uno de los tres tipos de composición de baldosas cerámicas analizados: azulejo, gres y gres porcelánico. El resultado del seguimiento, realizado durante 60 minutos, se muestra en las Figura 5.26, Figura 5.27 y Figura 5.28. En dichas figuras se observa en todos los casos que la variación de la concentración de HF fluctúa en un margen relativamente estrecho alrededor de un valor medio que, a nivel práctico, puede considerarse constante. Los valores de emisión absolutos de HF varían dependiendo de la composición y de las condiciones de cocción (producción y tratamiento térmico).

Estos resultados indican que el procedimiento de muestreo que utiliza periodos relativamente cortos de tiempo (del orden de 30 - 60 minutos), es suficientemente representativo de la emisión a caracterizar y presenta un balance adecuado entre coste, tiempo de ejecución y 
concordancia con el límite de cuantificación de la técnica analítica. Por ello, este procedimiento permite una adecuada determinación de la concentración de HF en un horno que opera en condiciones estables, dado que la concentración de HF en la corriente de gases no presenta variaciones significativas con el tiempo y, por tanto, puede ser adecuadamente caracterizado mediante la concentración media durante dicho periodo, siempre que no ocurran cambios en las condiciones de cocción (producción constante, composición del material fabricado, etc.). De hecho, la norma ISO 15713, de muestreo y determinación del contenido de fluoruros gaseosos, establece una duración mínima de muestreo de 30 minutos si el proceso opera bajo condiciones de estado estables (Monfort et al., 2003).

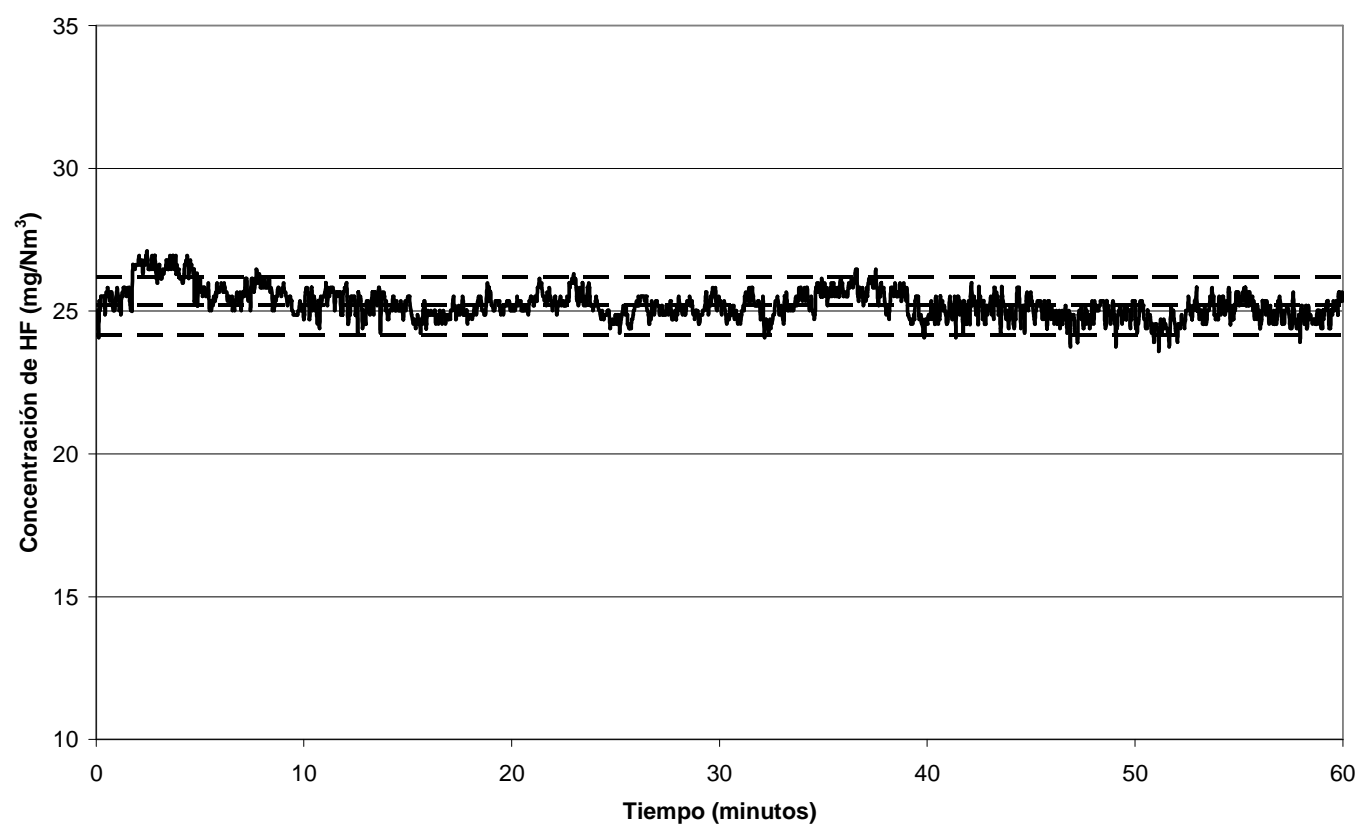

Figura 5.26. Evolución de la concentración de HF en la corriente de salida del horno de cocción bajo condiciones habituales de funcionamiento para composiciones de azulejo $(A)$. 


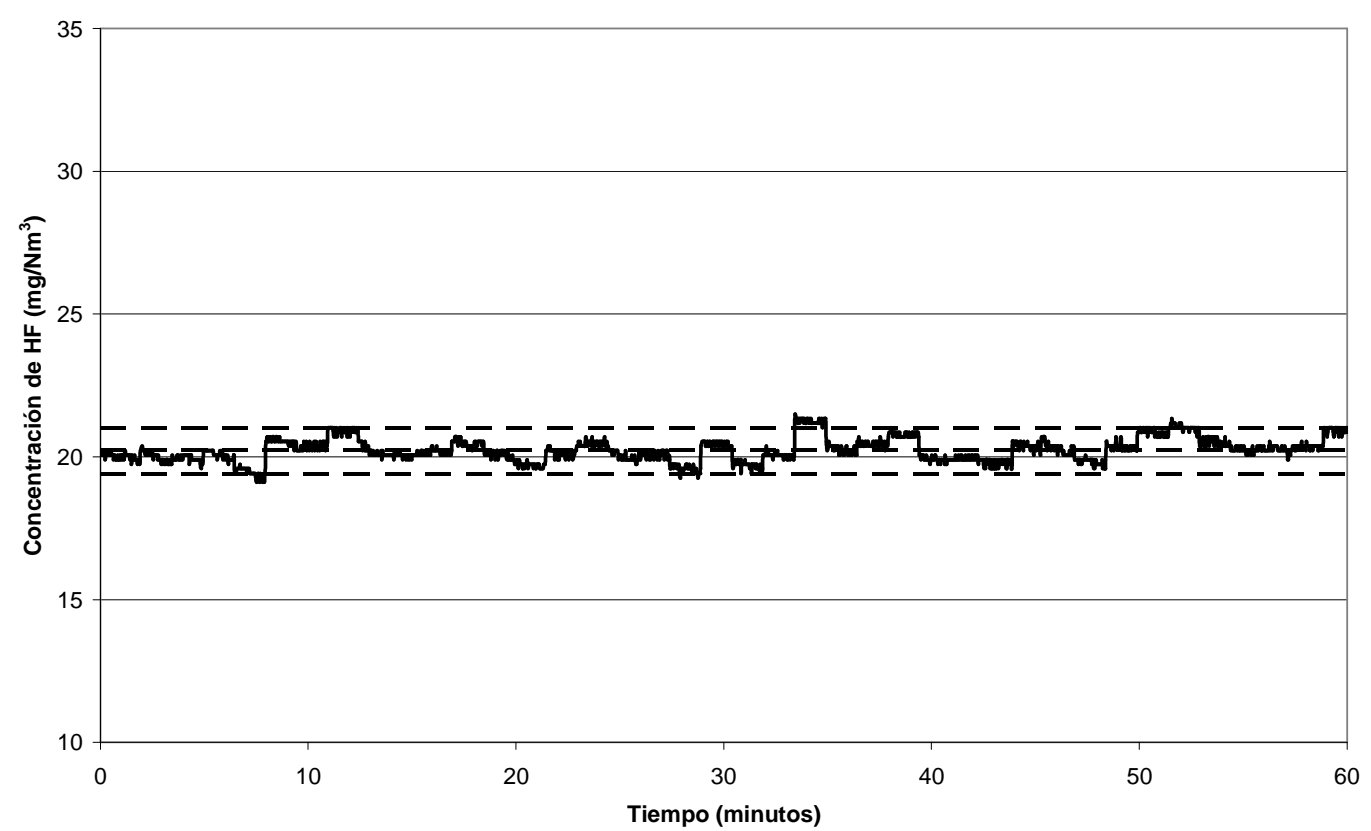

Figura 5.27. Evolución de la concentración de HF en la corriente de salida del horno de cocción bajo condiciones habituales de funcionamiento para composiciones de gres $(\mathrm{G})$.

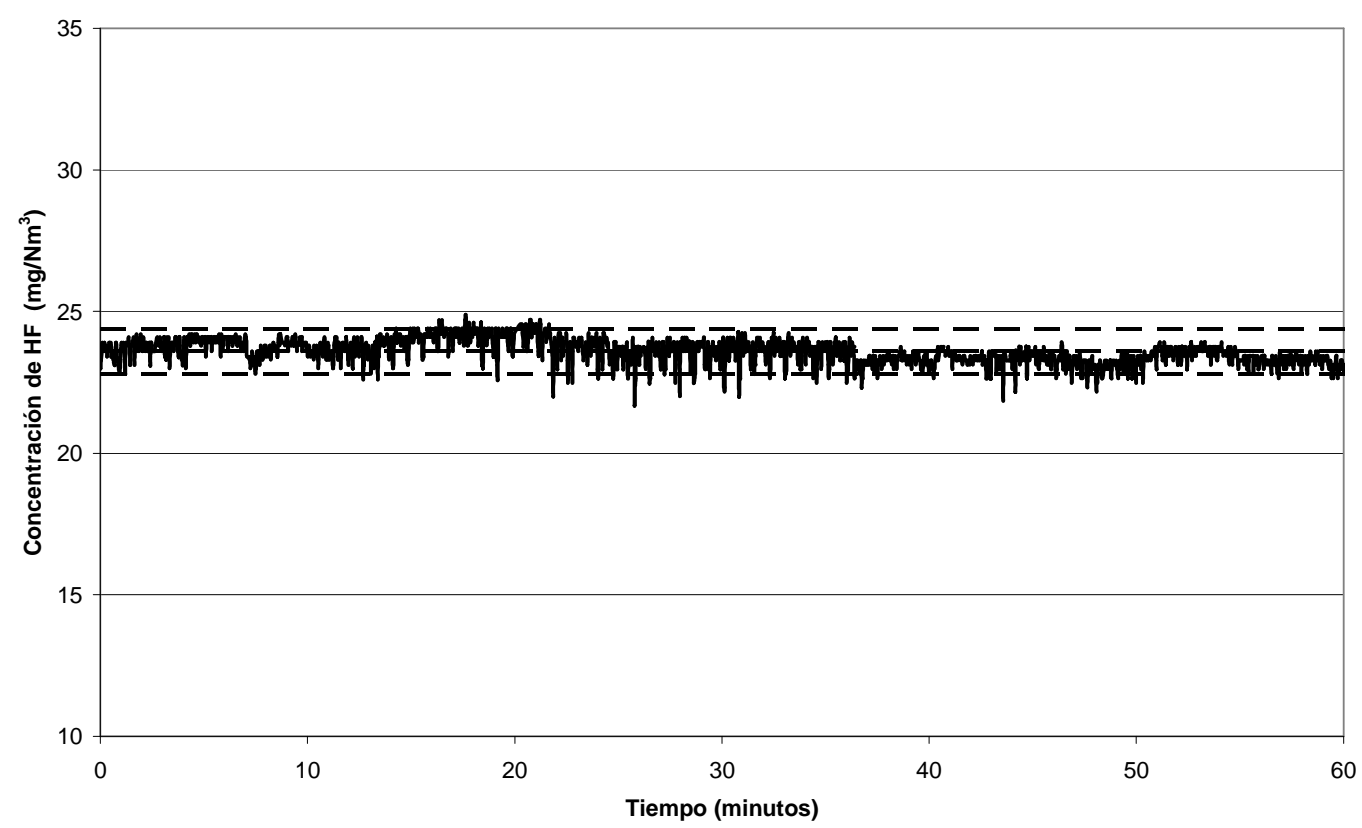

Figura 5.28. Evolución de la concentración de HF en la corriente de salida del horno de cocción bajo condiciones habituales de funcionamiento para composiciones de gres porcelánico $(P)$. 
La Tabla 5.18 muestra la concentración media de la corriente de gases durante el periodo de tiempo analizado, junto con el intervalo de confianza del $95 \%\left(C_{H F} \pm 2 \sigma\right)$. El parámetro $\left(2 \sigma / \mathrm{C}_{\mathrm{HF}}\right)$ presenta un valor de $3-4 \%$ para las diferentes composiciones estudiadas, lo que confirma que las concentraciones de HF permanecen casi constantes en este proceso cuando se realiza en condiciones habituales de operación.

Tabla 5.18. Concentración de HF bajo condiciones habituales de operación.

\begin{tabular}{|c|c|c|c|c|c|}
\hline Ref & $\begin{array}{l}\text { Concentración } \\
\text { media de } \mathrm{HF} \\
\mathrm{C}_{\mathrm{HF}}\left(\mathrm{mg} / \mathrm{Nm}^{3}\right)\end{array}$ & $\begin{array}{l}\text { Desviación } \\
\text { estándar } \\
\sigma\left(\mathrm{mg} / \mathrm{Nm}^{3}\right)\end{array}$ & $\begin{array}{c}2 \sigma \\
\left(\mathrm{mg} / \mathrm{Nm}^{3}\right)\end{array}$ & $\begin{array}{c}\mathrm{C}_{\mathrm{HF}} \pm 2 \sigma \\
\left(\mathrm{mg} / \mathrm{Nm}^{3}\right)\end{array}$ & $\begin{array}{c}(2 \sigma) / \mathrm{C}_{\mathrm{HF}} \\
(\%)\end{array}$ \\
\hline A & 25,2 & 0,5 & 1,0 & $25,2 \pm 1,0$ & 4,0 \\
\hline G & 20,2 & 0,4 & 0,8 & $20,2 \pm 0,8$ & 4,0 \\
\hline P & 23,6 & 0,4 & 0,8 & $23,6 \pm 0,8$ & 3,4 \\
\hline
\end{tabular}

\subsubsection{Concentración de HF en la corriente de gases de salida cuando existen modificaciones en las condiciones de operación}

\subsubsection{Interrupción de la alimentación de material a la entrada del horno}

La alimentación de los hornos de cocción industriales es interrumpida con cierta frecuencia por diferentes razones (mantenimiento, cambios en el modelaje, etc.), apareciendo huecos en la entrada del horno. Para conocer el comportamiento de la concentración de HF en la corriente de gases emitida se ha estudiado la evolución de la concentración de flúor en tres hornos después de provocar periodos de interrupción de la alimentación de 5 y 15 minutos, respectivamente. El resto de condiciones de operación se han mantenido constantes (tipo de material procesado, tratamiento térmico aplicado, etc.).

Los resultados obtenidos, para las diferentes composiciones, son cualitativamente similares. Por simplicidad se muestran los resultados pertenecientes al gres porcelánico en la Figura 5.29. En dicha figura se muestra la evolución de la concentración de HF en la corriente de salida, cuando existen dos periodos de interrupción de la alimentación al horno de 15 minutos. En la misma se aprecia un cambio repentino en la concentración de HF, con un incremento inicial seguido de un periodo de descenso. Este fenómeno puede ser explicado por los procesos de adsorción y emisión que se producen durante el precalentamiento y la cocción, respectivamente, en los hornos industriales de combustión, tal y como se ha recogido en el artículo no 3. El incremento inicial está provocado por la ausencia de baldosas cerámicas en la zona de precalentamiento. Así, el HF transportado hasta dicha zona desde la zona de máxima temperatura no puede ser adsorbido y, en consecuencia, la concentración de HF en la corriente de salida presenta un máximo de emisión, que alcanza valores hasta un $40 \%$ superior a la emisión en condiciones de operación habituales. 
Cuando el hueco provocado por la interrupción en la alimentación alcanza la zona de máxima temperatura, la concentración de HF disminuye drásticamente, llegando a un valor mínimo que es, aproximadamente, un $55 \%$ inferior al valor inicial en condiciones de operación habituales. Este fenómeno es consecuencia de dos efectos simultáneos. Por una parte, cuando el hueco alcanza la zona de temperatura máxima, se minimiza la emisión de HF y, como consecuencia, los gases que llegan a la chimenea, procedentes de dicha área, poseen un bajo contenido de HF. Por otro lado, la presencia de material crudo en la zona de precalentamiento del horno y donde se produce la adsorción retiene HF de la corriente de gases. Como resultado la concentración de HF en la corriente de gases a la salida del horno desciende, incluso en mayor proporción que la provocada por el hueco en la zona de precalentamiento.

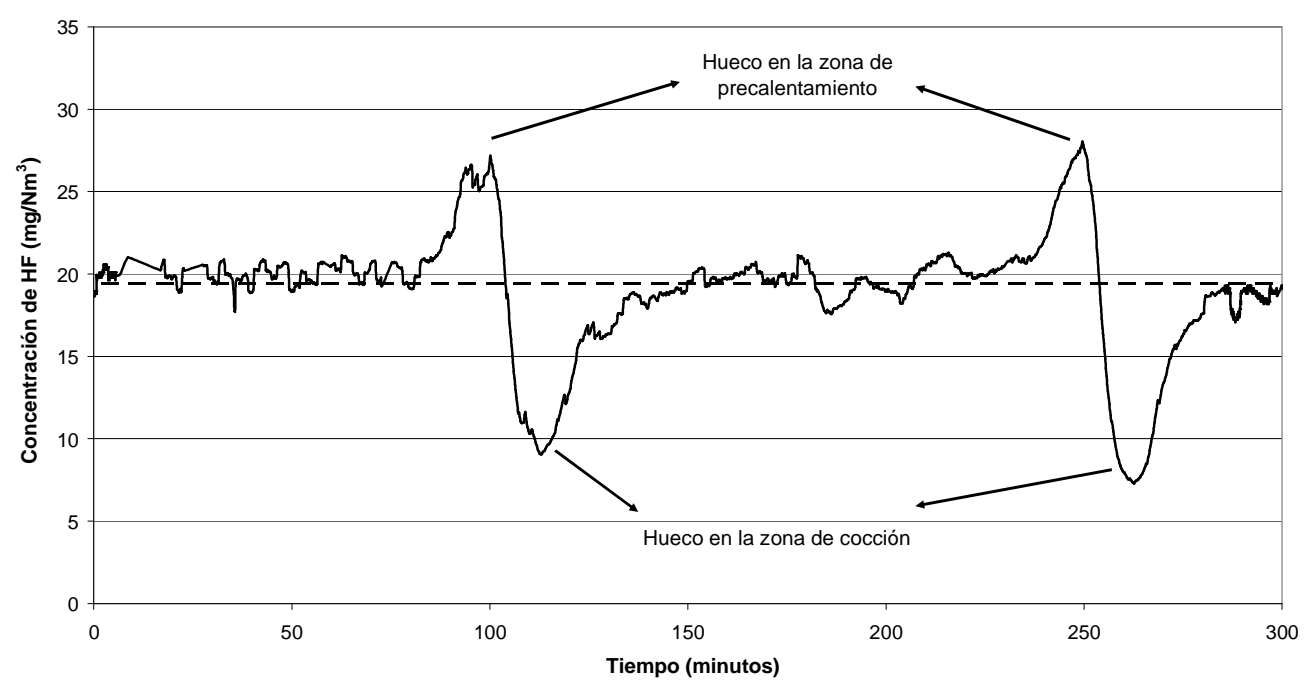

Figura 5.29. Evolución de la concentración de HF cuando existe un periodo de interrupción de la alimentación de 15 minutos (composición P).

Los experimentos se han repetido para las composiciones de azulejo y gres, con resultados similares a los mostrados por la composición de gres porcelánico. La Tabla 5.19 muestra el incremento y el descenso de la concentración de HF, expresado como porcentaje del valor medio, en condiciones habituales de operación, para las tres composiciones estudiadas. En el caso de las composiciones de gres y gres porcelánico, la disminución de la concentración de HF en la corriente da gases de salida es mayor cuando el material alcanza la zona de cocción que el aumento que experimenta cuando alcanza la zona de precalentamiento, tal y como se ha descrito anteriormente. Por el contrario, la composición de azulejo presenta un comportamiento diferente, con un incremento mayor que la correspondiente disminución de la concentración de HF. 
Como ha quedado reflejado con anterioridad en los artículos $n^{\circ} 2$ y $n^{\circ} 3$, las diferencias encontradas pueden deberse al mayor contenido en calcita en la composición de azulejo $(6,25 \% \mathrm{CaO}$ comparado con $1,21 \%$ y $0,72 \%$ de las composiciones de gres y gres porcelánico, respectivamente), que mejora la adsorción del HF en la zona de precalentamiento. Como resultado, cuando el hueco alcanza la zona de precalentamiento, la ausencia de adsorción, que en condiciones normales es elevada, debido al alto contenido de $\mathrm{CaCO}_{3}$ de las piezas, provoca un aumento de la concentración de HF más pronunciado (80 $\%)$ que el causado por las composiciones con menor contenido en $\mathrm{CaCO}_{3}$ (40 y $60 \%$ ).

Tabla 5.19. Aumento y disminución de la emisión de HF cuando se generan huecos en la alimentación del horno.

\begin{tabular}{ccc}
\hline Composición & $\begin{array}{c}\text { Aumento de la } \\
\text { concentración de HF (\%) }\end{array}$ & $\begin{array}{c}\text { Disminución de la } \\
\text { concentración de HF (\%) }\end{array}$ \\
\hline Azulejo (A) & 80 & 50 \\
Gres (G) & 60 & 70 \\
Gres porcelánico (P) & 40 & 55 \\
\hline
\end{tabular}

En general, estos resultados son consistentes con los obtenidos en otras partes del trabajo de investigación, cuando se estudia el contenido de flúor en la propia baldosa y en el gas a lo largo del horno, y pueden ser explicados por fenómenos de emisión y adsorción de HF en la superficie de la baldosa cerámica durante la etapa de precalentamiento y cocción.

\subsubsection{Efecto de la duración del ciclo térmico}

En este caso se ha estudiado la evolución de la emisión de HF en un horno que produce baldosas esmaltadas de gres porcelánico mediante un incrementado del tiempo de cocción del $10 \%$. La maniobra se ha realizado mediante la reducción de la velocidad de entrada del material al horno, esta acción conlleva un aumento del tiempo de ciclo desde los 40 hasta los 44 minutos y una disminución de la producción másica desde 1,25 hasta $1,15 \mathrm{~kg} / \mathrm{s}$, lo que se traduce en una disminución del $8 \%$.

Los resultados obtenidos en la monitorización de la evolución de HF durante este cambio se muestran en la Figura 5.30 y en la Tabla 5.19. Aun cuando no ha sido posible introducir grandes cambios en esta prueba, debido a las limitaciones que imponen los hornos industriales, el gráfico muestra que cuando se reduce la velocidad de calentamiento se dan dos fenómenos contrapuestos, desde el punto de vista de las emisiones: el primero es debido a un aumento del tiempo de residencia en el horno que lleva asociado un aumento de la emisión, el segundo es debido a la disminución de la producción másica, que lleva asociado una disminución de la emisión. El resultado final observado es que la concentración en la corriente de salida aumenta ligeramente, por lo que parece que el primer efecto domina sobre el segundo. Estos resultados están de acuerdo con los obtenidos con anterioridad a nivel de laboratorio, donde ha sido posible realizar cambios de mayor envergadura (Routschka y 
Majdic, 1978; Kother y Pauls, 1982; Dehne, 1987). En los procesos de cocción de ciclo rápido no todo el contenido inicial de HF se emite cuando las piezas alcanzan la temperatura máxima, por lo que un aumento del tiempo de residencia a la temperatura en la que se emite el HF implica un aumento de las emisiones (Mazzali et al., 1980; Bonvicini et al., 2006). Este fenómeno podría asociarse a que a temperaturas superiores a los $1000 \stackrel{\circ}{\mathrm{C}}$ las fases cristalinas en las que podría mantenerse el flúor son inestables, por ejemplo $\mathrm{CaF}_{2}$ y $\mathrm{Ca}_{4} \mathrm{Si}_{2} \mathrm{O}_{7} \mathrm{~F}_{2}$, tal y como se ha observado en los resultados recogidos en el artículo no 2 .

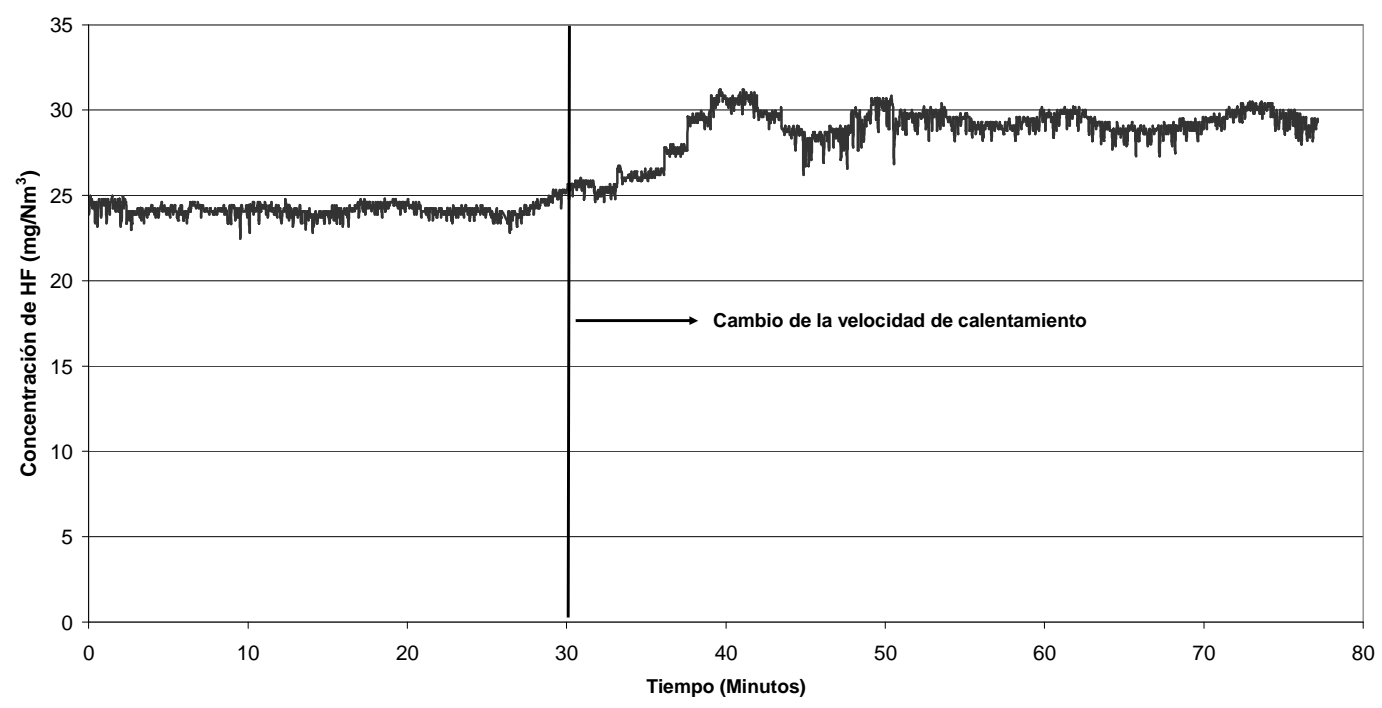

Figura 5.30. Evolución de la emisión de HF durante el cambio de la velocidad de calentamiento (soporte de gres porcelánico $\mathrm{P})$.

Tabla 5.20. Efecto de la velocidad de calentamiento en la concentración de HF. Duración del ciclo de cocción

\begin{tabular}{cccc}
\hline \multirow{2}{*}{ Ciclo de frío a frío $(\mathbf{m i n})$} & \multirow{2}{*}{ Producción $(\mathbf{k g} / \mathbf{s})$} & \multicolumn{2}{c}{ Concentración de $\mathbf{H F}\left(\mathbf{m g} / \mathbf{N m}^{3}\right)$} \\
\cline { 3 - 4 } & & Promedio & $\mathbf{\sigma}$ \\
\hline 40 & 1,25 & 22,2 & 3,4 \\
44 & 1,15 & 24,1 & 2,1 \\
\hline
\end{tabular}

Estos hallazgos están de acuerdo con la experiencia industrial y los resultados aportados por otros autores (Reymer y Jong, 1993, Brosnan, 1994, Dogeroglu y Kara, 2002a) en relación con ciclos de cocción largos, que demuestran que, para las composiciones utilizadas, el factor de emisión resultante decrece cuando se utiliza un ciclo de cocción más rápido. Además, estos resultados justifican que la fabricación de baldosas cerámicas mediante ciclos rápidos dé lugar a menores emisiones de compuestos de flúor que en los procesos de bicocción. 


\subsubsection{Efecto de la densidad aparente en seco}

La densidad aparente en seco es un parámetro relacionado con la porosidad de las baldosas crudas y constituye una variable de proceso importante que puede afectar a la emisión de HF de acuerdo con los estudios a escala de laboratorio (Hauck y Hilker, 1986). Se han desarrollado diferentes experimentos para comprobar estos resultados a escala industrial.

La Figura 5.31 y la Tabla 5.21 muestran los resultados obtenidos en la corriente de salida de un horno que produce gres porcelánico cuando se ha modificado la densidad aparente en seco desde los 2030 hasta los $1945 \mathrm{~kg} / \mathrm{m}^{3}$, lo que supone una disminución de un $4 \%$, mediante la reducción de la presión de conformado. Como en las pruebas anteriores, no se han realizado grandes cambios con el fin de mantener la calidad del producto final constante. Los resultados muestran que la concentración de HF en la corriente de salida aumenta cuando las piezas con menor densidad aparente alcanzan la zona de máxima temperatura de cocción. Por el contrario, no se detectan cambios cuando estas piezas atraviesan la zona de precalentamiento. Este comportamiento está relacionado con el efecto de la presión de conformado sobre la microestructura del material, dado que las presiones de conformado menores aumentan la porosidad de las piezas y el tamaño del poro, mientras que se reduce la tortuosidad del mismo (Escardino et al., 1998). Este efecto permite aumentar la permeabilidad del HF en la pieza, facilitando su movimiento desde dentro de la misma hasta la fase gaseosa del interior del horno. Así pues, a pesar de introducir un ligero cambio en la densidad de la pieza, los resultados permiten deducir que el efecto de disminuir la densidad aparente aumenta la emisión de HF en la etapa de cocción.

Tabla 5.21. Efecto de la densidad aparente en seco en la concentración de HF.

\begin{tabular}{ccc}
\hline \multirow{2}{*}{ Densidad aparente en seco $\left(\mathbf{k g} / \mathbf{m}^{3}\right)$} & \multicolumn{2}{c}{ Concentración de HF $\left(\mathbf{m g} / \mathbf{N m}^{3}\right)$} \\
\cline { 2 - 3 } & Media & $\boldsymbol{\sigma}$ \\
\hline 2030 & 23,8 & 0,7 \\
1945 & 25,3 & 0,6 \\
\hline
\end{tabular}




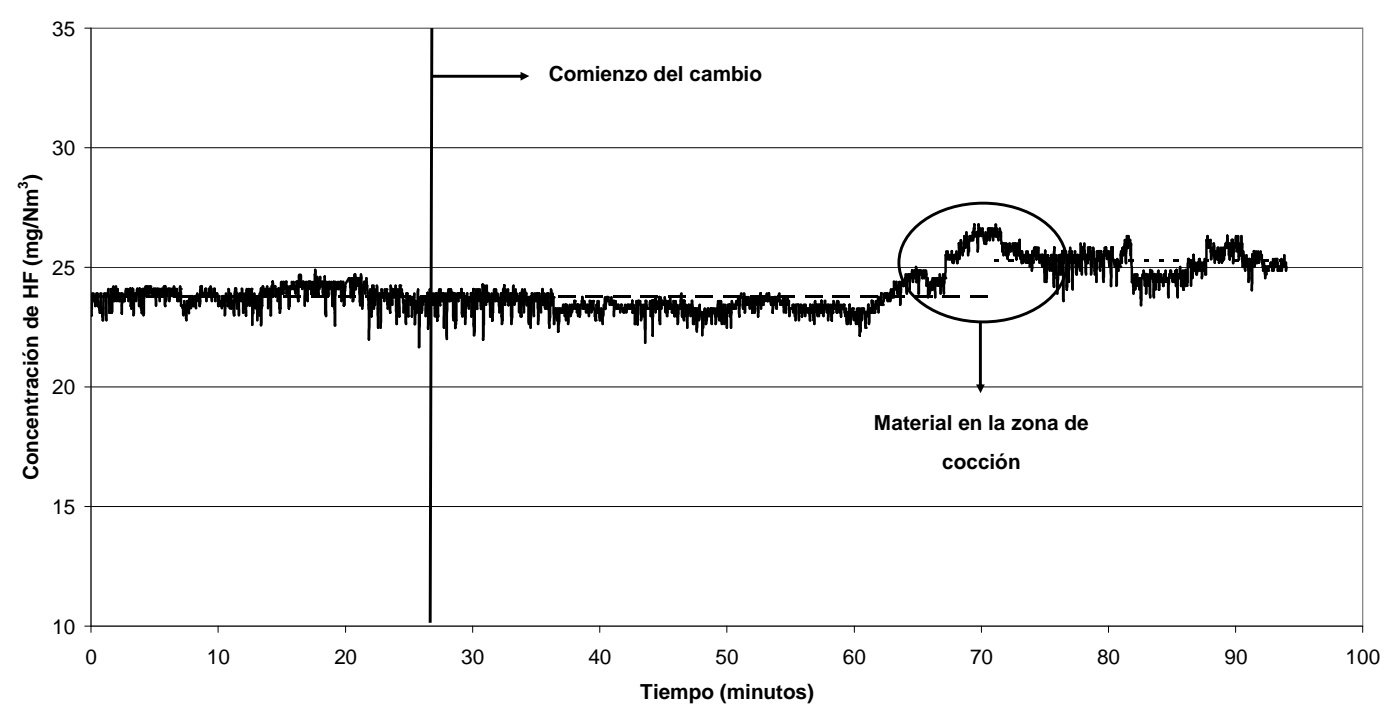

Figura 5.31. Evolución de la emisión de HF durante el cambio de la densidad aparente en seco (soporte de gres porcelánico $\mathrm{P}$ ).

\subsubsection{Efecto de la presencia del esmalte sobre las emisiones}

En este caso las pruebas industriales se han realizado en tres hornos alimentados con piezas decoradas con esmaltes habituales para cada tipología de producto estudiado al que se le han intercalado la misma tipología de piezas pero, en este caso, sin esmaltar. El número de piezas sin esmaltar alimentadas al horno alcanza el $10-15 \%$ de la capacidad productiva del mismo. En cada uno de los hornos estudiados se ha realizado el seguimiento de la emisión de HF emitido junto con la corriente de salida, antes y después de alimentar el horno con las baldosas sin esmaltar.

Los resultados obtenidos son cualitativamente similares, por lo que, en la Figura 5.32 y en la Tabla 5.22 se muestran los correspondientes al azulejo, dado que presenta los valores más significativos. En la Figura 5.32 la línea discontinua representa el valor de emisión de HF correspondiente a las baldosas esmaltadas producidas con las condiciones habituales de operación.

Tabla 5.22. Evolución de la emisión de HF cuando se introducen baldosas no esmaltadas de azulejo (composición A).

\begin{tabular}{cc}
\hline Parámetro & Valor \\
\hline Concentración media de $\mathrm{HF}\left(\mathrm{mg}_{\mathrm{Nm}}{ }^{3}\right)$ & 26,3 \\
Desviación estándar $(\sigma)\left(\mathrm{mg} / \mathrm{Nm}^{3}\right)$ & 0,3 \\
Disminución de la concentración de $\mathrm{HF}(\%)$ & 25 \\
Aumento de la concentración de HF $(\%)$ & 45 \\
\hline
\end{tabular}




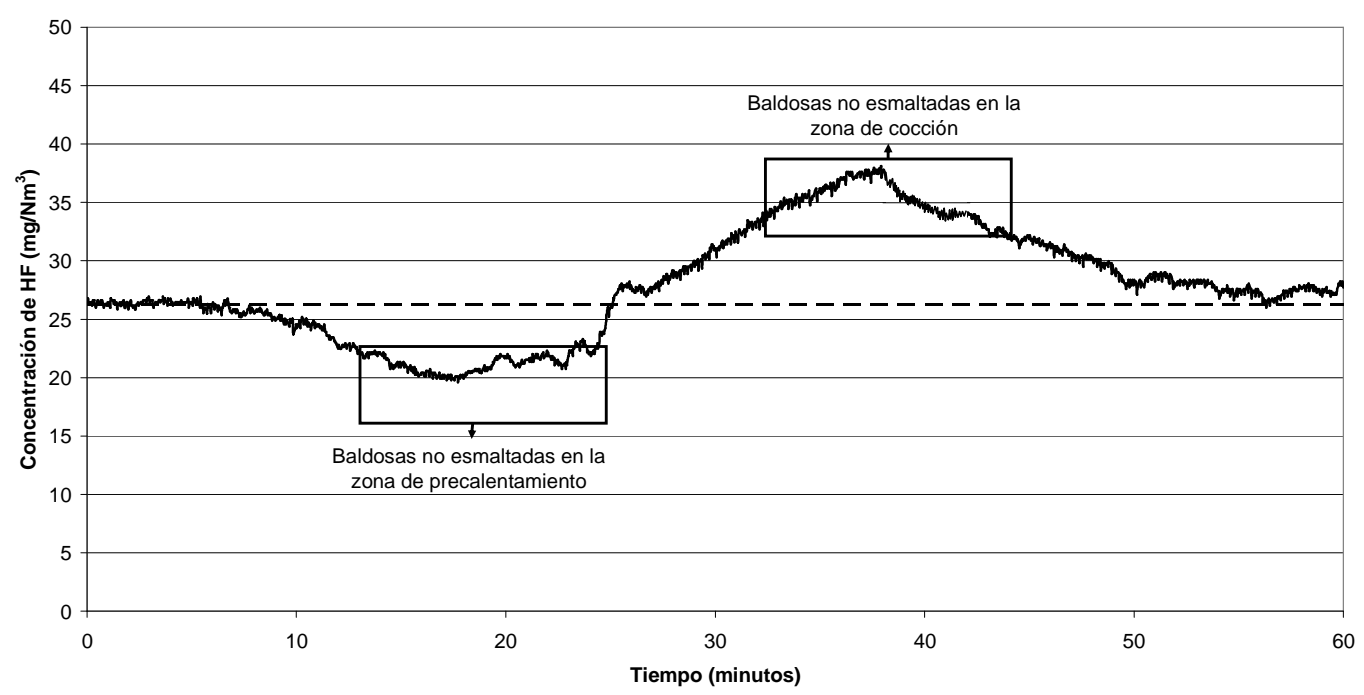

Figura 5.32. Evolución de la emisión de HF cuando se producen baldosas sin esmaltar (composición A).

Observando dicha figura, se deduce que:

- Cuando las baldosas no esmaltadas alcanzan la zona de precalentamiento, la concentración de HF desciende progresivamente. Esta reducción se puede asociar a la ausencia de esmalte en la zona superior de la baldosa, lo que implica un aumento del área de contacto entre el soporte de la propia baldosa y los gases, enriquecidos en $\mathrm{HF}$, que circulan a contracorriente en el interior del horno, desde la zona de máxima temperatura hasta la chimenea de evacuación. En estas condiciones, el proceso de adsorción se ve favorecido y se disminuye el contenido de HF en el gas. Estos resultados también indican que la adsorción de HF por parte de la capa de esmalte puede ser considerada prácticamente despreciable. De hecho, el esmalte no adsorbe flúor debido a que está formado por materias primas cristalinas y vítreas de baja superficie específica.

- Cuando las baldosas no esmaltadas alcanzan la zona de cocción, la concentración de HF es superior a la registrada en el caso de las baldosas esmaltadas. Este hecho puede ser debido a dos efectos. El primer efecto está relacionado con la menor cantidad de HF emitida por parte de las baldosas esmaltadas a alta temperatura, consecuencia, a su vez, de dos mecanismos diferentes. Por un lado la fusión del esmalte que sella el soporte, evitando la emisión de HF por la superficie superior de la baldosa, y/o que parte del HF emitido puede ser disuelto en la fase líquida del esmalte formada a alta temperatura. Por otro, el mayor contenido de flúor de las baldosas no esmaltadas cuando alcanzan la zona de alta temperatura, como consecuencia de una mayor adsorción en la zona de precalentamiento, que produce una mayor emisión de 
HF en la zona de cocción, como resultado de la baja estabilidad térmica de los compuestos cristalinos de flúor formados $\left(\mathrm{CaF}_{2}\right.$ y $\left.\mathrm{Ca}_{4} \mathrm{Si}_{2} \mathrm{O}_{7} \mathrm{~F}_{2}\right)$ (artículo oㅜ 2).

Con el fin de complementar el estudio llevado a cabo se han realizado experimentos variando el tipo de esmalte utilizado. En este caso no se han encontrado diferencias significativas entre las diferentes tipologías de esmalte, debido muy probablemente a la similitud en su temperatura de impermeabilización o sellado. En todo caso, los esmaltes utilizados han sido esmaltes habituales en la producción industrial y que, por tanto, no han sido modificados para aumentar la adsorción de HF sobre los mismos.

Para confirmar el efecto del esmalte en la retención de HF se ha analizado el contenido de flúor en las baldosas esmaltadas y no esmaltadas de azulejo y gres, antes y después del tratamiento térmico. Los resultados obtenidos se muestran en la Tabla 5.23. Los resultados expresan que las baldosas esmaltadas tienen un contenido de flúor superior al contenido correspondiente a las baldosas no esmaltadas. Este hecho corrobora los resultados obtenidos mediante el seguimiento de la emisión en la corriente de gases antes de su evacuación a la atmósfera, es decir, las baldosas esmaltadas emiten una cantidad de HF significativamente menor, aproximadamente un $35 \%$ menor en los experimentos realizados.

Tabla 5.23. Contenido de F $(\mathrm{mg} / \mathrm{kg})$ en las baldosas por efecto del esmalte.

\begin{tabular}{ccccccc}
\hline \multirow{2}{*}{$\begin{array}{c}\text { Tipo de } \\
\text { baldosa }\end{array}$} & \multicolumn{3}{c}{ Baldosa esmaltada } & \multicolumn{3}{c}{ Baldosa no esmaltada } \\
\cline { 2 - 6 } & Cruda & Cocida & Emisión & Cruda & Cocida & Emisión \\
\hline A & 660 & 560 & 100 & 660 & 470 & 160 \\
G & 630 & 530 & 120 & 630 & 440 & 190 \\
\hline
\end{tabular}

Estos resultados sugieren que es necesario realizar investigaciones adicionales para estudiar los mecanismos implicados en este proceso de reducción. 


Capítulo 6. Conclusiones y futuras líneas de investigación 



\subsection{Conclusiones}

Las conclusiones alcanzadas como consecuencia del trabajo de investigación realizado se presentan a continuación:

Caracterización de las emisiones de contaminantes ácidos en la fabricación de baldosas cerámicas (Artículo no 1)

Las conclusiones alcanzadas en la etapa de secado por atomización han sido:

- No se han encontrado diferencias significativas entre las emisiones de compuestos ácidos al tratar las composiciones de diferentes tipos de producto, ni debidas al uso de turbinas de cogeneración.

- La emisión de HF y del resto de contaminantes ácidos $\left(\mathrm{HCl}, \mathrm{SO}_{2}\right.$ y $\left.\mathrm{NO}_{\mathrm{x}}\right)$ en la etapa de secado por atomización, es poco significativa si se comparan con los NEA - MTD establecidos en la actualidad en la UE.

- Por tanto, desde el punto de vista del control de las emisiones atmosféricas, y siempre que no existan cambios en el proceso que justifiquen su necesidad, se puede concluir que la emisión de compuestos ácidos en la etapa de secado por atomización no es crítica y, por tanto, es posible replantearse la frecuencia o, incluso, la necesidad de realizar controles periódicos de la emisión de $\mathrm{SO}_{2}$ y de $\mathrm{NO}_{x}$.

Las conclusiones alcanzadas en la etapa de cocción han sido:

- Las emisiones de HF y HCl son las más significativas entre los contaminantes ácidos estudiados durante la etapa de cocción en comparación con los diferentes NEA - MTD propuestos en el documento BREF de la UE. Los resultados indican la necesidad de que dichas emisiones sean corregidas en su gran mayoría, mediante la adopción de medidas primarias y sistemas de depuración adecuados antes de su emisión a la atmósfera.

- La emisión de $\mathrm{SO}_{2}$ y de $\mathrm{NO}_{x}$ en todas las empresas estudiadas es claramente inferior a los NEA - MTD aplicables a esta etapa de proceso, por lo que no es necesario aplicar ningún tipo de corrección, siempre y cuando no existan cambios de combustibles o de materias primas.

- Se han determinado las emisiones absolutas y los factores de emisión específicos correspondientes a la etapa de cocción para los tipos de baldosas estudiadas, obteniéndose valores que se encuentran dentro de unos márgenes de variación relativamente estrechos para cada tipo de contaminante. La información obtenida se considera representativa de la situación actual del distrito cerámico de Castellón, y puede ser utilizada para la elaboración periódica de informes medioambientales, tales 
como PRTR, así como para elaborar propuestas de valores límite de emisión en las sucesivas revisiones de los documentos BREF y de la normativa sobre emisiones industriales.

- La emisión de HF determinada para el azulejo blanco es claramente inferior a la mostrada por el resto de productos. Una posible explicación a este comportamiento está asociada con la concentración de flúor en crudo de las materias primas que componen los productos blancos, dado que presenta valores netamente inferiores a los mostrados por las materias primas utilizadas para la composición de productos de coloración roja. Sin embargo, existen otros factores que pueden influir en este comportamiento como pueden ser el peso específico, el consumo de gas y la temperatura máxima de cocción.

Influencia del contenido de calcita sobre las emisiones de compuestos de flúor durante la cocción de baldosas cerámicas (Artículo $n^{\circ} 2$ )

- Se ha determinado la estabilidad térmica de compuestos de flúor sencillos, en concreto de los fluoruros de cationes alcalinos y alcalinotérreos. Los resultados muestran que los fluoruros alcalinotérreos son más estables al aumento de la temperatura que los alcalinos. El $\mathrm{MgF}_{2}$ es el compuesto alcalinotérreo que presenta una menor estabilidad térmica.

- La estabilidad térmica del $\mathrm{CaF}_{2}$, del $\mathrm{BaF}_{2}$ y del $\mathrm{SrF}_{2}$ se reduce notablemente cuando se encuentran en una matriz cerámica. Su contenido en la mezcla disminuye progresivamente a partir de temperaturas bajas $\left(200^{\circ} \mathrm{C}\right.$ para el $\left.\mathrm{CaF}_{2}\right)$ para dejar de detectarse a temperaturas del orden de $1100^{\circ} \mathrm{C}$.

- Durante el tratamiento térmico de la composición con $\mathrm{CaF}_{2}$ (sin adición de $\mathrm{CaCO}_{3}$ ), el $\mathrm{CaO}$ presenta una elevada tendencia a formar anortita $\left(\mathrm{CaAl}_{2} \mathrm{Si}_{2} \mathrm{O}_{8}\right)$ a temperaturas superiores a $800{ }^{\circ} \mathrm{C}$. Esta formación se encuentra tan favorecida por la temperatura que incluso provoca la desestabilización del $\mathrm{CaF}_{2}$. Este mismo comportamiento se observa en la mezcla con $\mathrm{BaF}_{2}$, en la que se detectó la formación de celsiana $\left(\mathrm{BaAl}_{2} \mathrm{Si}_{2} \mathrm{O}_{8}\right)$.

- En las mezclas con mayor contenido de $\mathrm{CaCO}_{3}$, la especie cristalina que se encuentra favorecida termodinámicamente entre 850 y $1050{ }^{\circ} \mathrm{C}$ es la cuspidina $\left(\mathrm{Ca}_{4} \mathrm{Si}_{2} \mathrm{O}_{7} \mathrm{~F}_{2}\right)$. Este hecho impide el aumento del contenido de anortita, e incluso produce una apreciable reducción de su contenido en el citado intervalo de temperatura. A partir de $1000{ }^{\circ} \mathrm{C}$ disminuye bruscamente el contenido de $\mathrm{Ca}_{4} \mathrm{Si}_{2} \mathrm{O}_{7} \mathrm{~F}_{2}$ y aumenta el de $\mathrm{CaAl}_{2} \mathrm{Si}_{2} \mathrm{O}_{8}$, hasta alcanzar los $1150{ }^{\circ} \mathrm{C}$.

- La eficacia de la adición de $\mathrm{CaCO}_{3}$ para reducir la emisión de compuestos de flúor en la mayor parte de las composiciones empleadas en la fabricación de productos 
estructurales (tejas y ladrillos) se debe a dos factores: por una parte, la baja temperatura de cocción de estos productos $\left(850-1000{ }^{\circ} \mathrm{C}\right)$ que posibilita que una parte del $\mathrm{CaF}_{2}$ formado durante la cocción permanezca en las piezas; por otra, la presencia de $\mathrm{CaO}$ en estas composiciones favorece la formación de $\mathrm{Ca}_{4} \mathrm{Si}_{2} \mathrm{O}_{7} \mathrm{~F}_{2}$, la cual es estable hasta temperaturas comprendidas entre 1000 y $1050{ }^{\circ} \mathrm{C}$. Ambos factores favorecen la retención del flúor en las piezas, siempre y cuando la temperatura de cocción no sea superior a $1050^{\circ} \mathrm{C}$.

- El motivo por el que la adición de $\mathrm{CaCO}_{3}$ no resulta efectiva en la disminución de la emisión de flúor durante la cocción de baldosas cerámicas se debe a la temperatura máxima a la que se procesan estos productos (1120 - $\left.1220^{\circ} \mathrm{C}\right)$. De este modo se ha observado que las especies cristalinas que contienen flúor $\left(\mathrm{CaF}_{2}\right.$ y $\left.\mathrm{Ca}_{4} \mathrm{Si}_{2} \mathrm{O}_{7} \mathrm{~F}_{2}\right)$ no son estables entre 1100 y $1150{ }^{\circ} \mathrm{C}$, lo que aumenta la emisión de flúor a temperaturas superiores a $1100^{\circ} \mathrm{C}$.

- Estos resultados, obtenidos en un horno eléctrico con atmósfera estática de aire y empleando composiciones sintéticas en las que se han adicionado los diferentes fluoruros, cambian cuando se procesan productos cerámicos a escala industrial. En este sentido, se ha observado que la presencia de vapor de agua en los hornos de combustión industriales favorece la desestabilización del $\mathrm{CaF}_{2}$. Además, el flujo de gases conteniendo HF que circula por el interior del horno en contracorriente con las piezas favorece la formación de $\mathrm{CaF}_{2}$ durante el precalentamiento.

\section{Evolución de la emisión de compuestos de flúor durante el tratamiento térmico (Artículo nㄱ)}

- La emisión de HF de las composiciones estudiadas: azulejo (A), gres esmaltado (G) y gres porcelánico $(P)$, durante la cocción en hornos de laboratorio discontinuos y en atmósfera de aire no comienza a ser significativa hasta que se alcanzan temperaturas superiores a los $800{ }^{\circ} \mathrm{C}$. A partir de esta temperatura se observa un aumento progresivo de la emisión hasta alcanzar la respectiva temperatura máxima de cocción. No obstante, este aumento es diferente, en términos cuantitativos, en función del tipo de composición estudiada.

- La cocción de dichas composiciones en hornos industriales continuos de combustión de ciclo rápido no muestra un aumento continuado y progresivo de los valores de emisión, al contrario, incluso en algunas zonas del horno la emisión acumulada disminuye. Este último efecto indica que existen zonas en el horno en las que en lugar de producirse emisión de flúor tiene lugar una adsorción del mismo en el material que se está procesando. Las temperaturas a las cuales se produce la emisión y la adsorción coinciden para las tres composiciones consideradas, aunque la magnitud de estos fenómenos es diferente. Estos resultados, observados tanto en el análisis de piezas como en el de los gases del horno, coinciden cualitativamente con los descritos 
en la bibliografía consultada para otros tipos de composiciones arcillosas cocidas en hornos túnel.

- Los ensayos realizados muestran que prácticamente todo el flúor adsorbido durante el precalentamiento se emite posteriormente cuando las piezas alcanzan la máxima temperatura de cocción (>1100 ํㅡ). Estos resultados demuestran la poca eficacia exhibida por parte de algunas medidas preventivas, usadas para reducir las emisiones de flúor y encaminadas a potenciar su adsorción en la zona de precalentamiento (aumento del contenido de $\mathrm{CaCO}_{3}$, favorecer la adsorción por contacto entre el gas y la pieza procesada), durante la cocción de productos cerámicos procesados a temperaturas máximas superiores a $1100 \stackrel{\circ}{\circ} \mathrm{C}$. En este trabajo se ha concluido que existe una explicación termodinámica que justifica este comportamiento y que, en consecuencia, impide que este tipo de medidas sean efectivas en la prevención de la emisión de compuestos de flúor bajo estas condiciones. Estos resultados están de acuerdo con la experiencia existente en la industria de baldosas cerámicas.

- El estudio también muestra que las baldosas producidas en ciclos de cocción rápidos son capaces de emitir fluoruros cuando se someten a una segunda cocción a elevada temperatura. En el caso de la composición de azulejo (A) este comportamiento es más acusado debido, probablemente, a la elevada porosidad en cocido que caracteriza a este tipo de material. Este comportamiento explica porque las baldosas fabricadas en ciclos rápidos alcanzan menores emisiones de flúor que las fabricadas en ciclos lentos o mediante bicocción.

Monitorización y posible reducción de HF en la corriente de gases procedente de la cocción de baldosas cerámicas (Artículo nº 4)

- La metodología utilizada en este estudio, basada en la utilización de un analizador de HF en continuo que utiliza tecnología láser, es una valiosa herramienta para estudiar el comportamiento de la emisión de HF en hornos continuos, debido a que permite una medición rápida de este compuesto cuando se implementan diferentes maniobras en el horno.

- La emisión de HF registrada en varios hornos cerámicos industriales, en condiciones habituales de operación, que fabrican diferentes tipos de productos, es constante en el tiempo y, únicamente, presenta ligeras fluctuaciones en torno a un determinado valor medio.

- Desde un punto de vista cualitativo, la variación de la emisión de HF después de modificar las condiciones de cocción habituales es similar para los tres tipos de producto estudiado: azulejo, gres y gres porcelánico. 
- La interrupción de la alimentación de baldosas en un horno de cocción industrial modifica de forma muy diferente la emisión de HF en función de la ubicación del hueco creado en el interior del mismo. Cuando el hueco está en la zona de precalentamiento, se observa un aumento significativo de las emisiones debido a una disminución en la adsorción de HF. Por el contrario, cuando el hueco llega a la zona de cocción se observa una importante disminución de las emisiones de HF debido a la ausencia de baldosas en la zona de alta temperatura del horno.

- El estudio muestra que el ajuste realista de algunas variables de proceso a escala industrial, velocidad de calentamiento y densidad aparente en seco, únicamente permite una reducción restringida de las emisiones de HF.

- Los resultados obtenidos han permitido conocer que la aplicación de esmalte en la baldosa reduce de forma efectiva la emisión de HF. Las causas más probables para justificar este comportamiento son la formación de un recubrimiento impermeable sobre la pieza debido a la fusión de los componentes del esmalte cuando alcanza su temperatura de sellado, y/o la disolución de parte del flúor en la fase líquida a alta temperatura. 



\subsection{Futuras líneas de investigación}

A partir de los resultados obtenidos en el presente trabajo, se pueden plantear una serie de recomendaciones para futuras líneas de investigación que tengan por objeto complementar los resultados obtenidos. Sin pretender realizar una relación exhaustiva, y sólo a modo de ejemplo, se pueden destacar las siguientes:

- Líneas de investigación basadas en considerar que se mantiene la etapa de cocción y el tipo de producto en las condiciones actuales:

- Elaborar composiciones cerámicas con la utilización de materias primas exentas de precursores de contaminantes ácidos, bien de forma natural o bien de forma artificial mediante su purificación previa.

- Diseñar recubrimientos superficiales con capacidad de retención de flúor y demás contaminantes ácidos que eviten su emisión a la atmósfera. En el momento de redactar esta memoria, en el ITC se están desarrollando trabajos centrados en esta línea de investigación.

- Estudiar compuestos que retengan flúor en el interior del soporte cerámico en compuestos estables con el fin de evitar su emisión a la atmósfera.

- Investigar aditivos que puedan ser utilizados en masa que permitan disminuir las temperaturas habituales de cocción por debajo de los $800-1000 \stackrel{\circ}{ } \mathrm{C}$.

- La utilización de medidas primarias para la minimización de las emisiones de compuestos ácidos, en especial de flúor, durante la cocción de baldosas cerámicas a alta temperatura, no ha obtenido, hasta el momento, resultados satisfactorios, por ello se pueden plantear nuevas líneas de investigación basadas en cambios radicales en el proceso de fabricación y/o en el tipo de producto, como por ejemplo:

- Eliminar el proceso de cocción a alta temperatura para obtener las características mecánicas, químicas, etc. deseadas en el producto acabado, mediante el desarrollo de procesos alternativos que requieran temperaturas significativamente menores, como por ejemplo el desarrollo de geopolímeros de elevadas prestaciones. No obstante, la evaluación de estos procesos debe realizarse bajo una perspectiva de análisis de ciclo de vida, y no considerando únicamente las emisiones ácidas.

- Desarrollar baldosas de muy bajo espesor y con materias primas alternativas, que minimicen el consumo de materias primas y las emisiones atmosféricas asociadas. 

Capítulo 7. Artículos publicados. 



\title{
ARTíCULO № 1
}

\author{
MONFORT, E.; CELADES, I.; GOMAR, S.; RUEDA, F.; \\ MARTÍNEZ, J.
}

Characterisation of acid pollutant emissions in ceramic tile manufacture.

Bol. Soc. Esp. Ceram. Vidr., 50(4), 179-184, 2011.

Publicado en: julio - agosto de 2011

Número de citas (fuente: SCOPUS el 30 de junio de 2015): 1

Factor de impacto de la revista (2011): 0,432

Factor de impacto de la revista en cinco años (2011): 0,396 



\title{
Cerámica y Vidrio

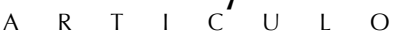

\section{Characterisation of acid pollutant emissions in ceramic tile manufacture}

\author{
E. MONFORT, I. CELADES, S. GOMAR, F. RUEDA, J. MARTÍNEZ (1)
}

IInstituto de Tecnología Cerámica (ITC). Asociación de Investigación de las Industrias Cerámicas (AICE).

Email: emonfort@itc.uji.es.Universitat Jaume I. Castellón. Spain

Este trabajo ha sido presentado como comunicación oral en el XI World Congress on Ceramic Tile Qualicer. (Castellón, España, 2010)

\begin{abstract}
One of the environmental impacts associated with ceramics manufacture is the air emission of acid compounds stem from the presence of impurities in the raw materials and/or fuels.

The present study was undertaken to identify the significant gaseous pollutants of an acid nature, to determine their concentrations, and to obtain the characteristic emission factors in spray dryers and firing kilns.

The results show that, in spray dryers, the emission levels of the different acid pollutants are far below the current emission limit values applied in the European Union (EU). In firing kilns, the most significant acid pollutant emissions, compared with the recommended EU emission limit values (ELV-BAT), correspond to $\mathrm{HF}$ and $\mathrm{HCl}$ emissions, indicating that these emissions need to be corrected by appropriate cleaning systems before such emissions are released into the air. On the other hand, the results indicate that $\mathrm{SO}_{2}$ and $\mathrm{NO}$ emissions in the Castellón industrial ceramic sector lie below the ELV-BAT proposed in the European ceramic industry BREF, owing to the widespread use of natural gas as fuel and of raw materials with reduced sulphur contents.

Keywords: Air emissions, acid pollutants, $\mathrm{HF}, \mathrm{HCl}, \mathrm{SO}_{x^{\prime}} \mathrm{NO}_{x}$

Caracterización de las emisiones de contaminantes ácidos en la fabricación de baldosas cerámicas

Uno de los impactos medioambientales asociado a la fabricación de productos cerámicos es la emisión a la atmósfera de compuestos ácidos debido a la presencia de impurezas en las materias primas y/o combustibles.

Los objetivos del presente estudio son: identificar los contaminantes gaseosos de naturaleza ácida significativos, determinar su concentración y obtener factores de emisión de los secaderos por atomización y los hornos de cocción.

Los resultados obtenidos, en el caso de los secaderos por atomización, muestran que los niveles de emisión de los diferentes contaminantes ácidos se encuentran alejados de los valores límite de emisiones aplicados actualmente en la Unión Europea (UE). En cuanto a los hornos de cocción, la emisión más significativa de contaminantes ácidos, en comparación con los valores límite de emisión (VLE-MTD) recomendados en la UE, corresponde al $\mathrm{HF}$ y al $\mathrm{HCl}$, e indican la necesidad de que dichas emisiones sean corregidas mediante la adopción de sistemas de depuración adecuados antes de su emisión a la atmósfera. Por su parte, los resultados indican que la emisión de $\mathrm{SO}_{2}$ y de $\mathrm{NO}$ en las industrias ubicadas en el sector cerámico de Castellón, es inferior a los VLE-MTD propuestos en el BREF de la industria cerámica europea, debido al uso generalizado de gas natural como combustible y materias primas con reducidos contenidos en azufre.

Palabras clave: Emisiones atmosféricas, contaminantes ácidos, $\mathrm{HF}, \mathrm{HCl}, \mathrm{SO}_{x^{\prime}} \mathrm{NO}_{x}$
\end{abstract}

\section{INTRODUCTION}

Gas emissions into the atmosphere are one of the main environmental impacts in ceramics manufacture. Such emissions may contain particulate matter and gas pollutants of an acid nature, in the form of fluorine, chlorine, sulphur, and nitrogen compounds (1)(2).

Acid compound emissions come from production stages in which combustion processes occur, resulting in hightemperature emissions. During ceramic tile production, hot emissions are generated in the slurry spray-drying stage, in the drying stage of freshly formed tiles, and in the ceramic tile firing stage. In tile drying, however, gas temperatures are usually below $250^{\circ} \mathrm{C}$, and the ceramic material hardly becomes hotter than $100{ }^{\circ} \mathrm{C}$, so that pollutant emissions can be considered negligible (provided sulphur-free fuels are used) (3)(4).

\subsection{Acid compound emissions in the ceramic industry}

The origin of the acid compounds released in ceramic tile manufacture lies, essentially, in the use of raw materials and fuels that could contain them (except $\mathrm{NO}_{x^{\prime}}$ as set out further below).

Fluorine compound emissions during ceramic tile firing are a key type of emission in these processes, fluorine 
compounds therefore being considered the most characteristic ceramic industry pollutants. Their emission stems from the presence of fluorine ions in clays used as raw materials in ceramic tile manufacture.

Fluorine ions replace $\mathrm{OH}^{-}$groups in the crystalline structure of the mica, as well as in that of many other clay minerals (montmorillonite, illite, kaolinite, etc.) (5)(6), which is why fluorine compound emissions usually start with the dehydroxylation of these minerals at temperatures of the order of $500-700{ }^{\circ} \mathrm{C}(7)(8)(9)$. The major compounds that form are hydrofluoric acid, silicon tetrafluoride and, to a lesser extent, alkaline fluorides in particle form, the presence of these alkaline fluorides being practically negligible (10)(11)(12). In the presence of water vapour, a typical situation in industrial combustion kilns, fluorine is mainly emitted as hydrofluoric acid (13)(14)(15).

Chlorine compound emissions stem, mainly, from the presence of chlorine ions in the water used as a raw material in ceramic tile manufacture. Many clays and admixtures contain trace levels of chlorine.

Chlorine compound emissions occur during the firing process at temperatures above $850{ }^{\circ} \mathrm{C}$, from the decomposition of chlorine-containing mineral salts. In addition, the decomposition of organic compounds that contain chlorine leads to $\mathrm{HCl}$ emissions in the $450-550{ }^{\circ} \mathrm{C}$ range (16).

On the other hand, sulphur compound emissions stem from the sulphur content in the raw materials and the type of fuel used. The clays used in ceramic tile manufacture can contain sulphites in the form of pyrite or calcium and magnesium sulphates such as gypsum, and sulphur in organic compounds.

Fossil fuels can also generate sulphur emissions. Natural gas is the most widely used fuel, and contains practically no sulphur in its composition; however, if fuel oil, coal or coke is used, sulphur emissions can be higher (16)(17).

Nitrogen compounds are emitted in the form of nitrogen oxides, and are related to the formation of thermal $\mathrm{NO}_{\mathrm{x}}$ in high-temperature processes when a reaction takes place between nitrogen and oxygen in the combustion air. This reaction is encouraged in processes that unfold at high temperature (particularly at temperatures above $1400{ }^{\circ} \mathrm{C}$ ). However, $\mathrm{NO}_{x}$ formation can even be significant at process temperatures below $1200{ }^{\circ} \mathrm{C}$, when the burners run at high flame temperatures (16).
The decomposition and combustion of nitrogen compounds present in the raw materials, admixtures, or fuels can also be a source of $\mathrm{NO}_{x}$ at lower temperatures.

\subsection{EU legislation on air emissions in the ceramic industry}

In the EU, the application of Directive on integrated pollution prevention and control, known as IPPC (18), obliges companies included in Annex I of the Directive to obtain an Integrated Environmental Authorisation (IEA), which includes emission limit values (ELV) for different atmospheric pollutants. When it comes to fixing the ELV applicable to each installation, authorities take into consideration the existing BREF Documents for those industries affected by the IPPC. BREF documents are EU reference documents that detail the Best Available Techniques for each sector and propose related emission values (ELV-BAT).

In July 2009, the EU criteria were reviewed for the award of the EU eco-label to rigid coverings (ceramic tiles)(19). These requirements are of a voluntary character: as a result, tiles that obtain the eco-label display demonstrable improvements in key ecological issues, such as air emissions.

Table I details the emission values defined for ceramic tile manufacture in the EU. The table presents both the ELVBAT contained in the BREF Document on ceramics and those established in the criteria for the eco-label award.

\section{SCOPE AND OBJECTIVES}

The objectives of the present study on acid pollutant emission during ceramic tile manufacture were as follows:

- Identification of the significant gaseous air pollutants of an acid nature.

- Determination of the concentrations of these pollutants and, if possible, obtainment of specific emission factors for the ceramic industry in the Castellón district.

The purpose of this study has been to obtain updated and truthful sectoral information on the emission of these pollutants in order to be able to achieve the following objectives:

TABLE I. EMISSION VALUES FOR CERAMIC TILE MANUFACTURE IN THE EU.

\begin{tabular}{|c|c|c|c|c|c|c|}
\hline Document & Stage & Units & HF & $\mathrm{HCl}$ & $\mathrm{SO}_{2}$ & $\mathrm{NO}_{x}\left(\right.$ as $\left.\mathrm{NO}_{2}\right)$ \\
\hline \multirow{2}{*}{$\begin{array}{c}\text { BREF } \\
\text { (ELV-BAT) }\end{array}$} & Spray drying & \multirow{2}{*}{$\begin{array}{c}\mathrm{mg} / \mathrm{m}_{0}{ }^{3} \text { at } 18 \% \mathrm{O}_{2} \\
\text { and dry gas }\end{array}$} & -- & -- & -- & 500 (cogeneration) \\
\hline & Firing & & 5 & 30 & 500 & 250 \\
\hline Eco-label $(*)$ & Firing & $\mathrm{mg} / \mathrm{kg}$ fired product & 10 & -- & 75 & 125 \\
\hline
\end{tabular}

$\mathrm{mg} / \mathrm{m}_{0}{ }^{3}$ : concentration in standard conditions: temperature $(273 \mathrm{~K})$ and pressure $(101,3 \mathrm{kPa})$.

* A mean value of $20 \mathrm{~kg} / \mathrm{m}^{2}$ tile has been considered 
- Cost optimisation in air pollutant controls, establishing a realistic pollutant control system for the ceramic industry.

- Greater information transparency and better relationship with the administration.

- The fixing of emission factors that allow emission inventories to be made, in accordance with reality.

The emissions study was conducted in the ceramic tile manufacturing stages in which combustion processes occur and process temperatures above $500{ }^{\circ} \mathrm{C}$ are reached. The facilities involved in these stages are as follows:

- Spray dryers (using bag filters or Venturi- type scrubbers for removing particulate matter)

- $\quad$ Firing kilns (without/ before the acid cleaning systems)

The study addressed pollutants of an acid nature, emitted in the form of fluorine, chlorine, sulphur, and nitrogen compounds at the above emission sources, in relation to the tile types listed in Table II.

\section{MEASUREMENT METHODOLOGY}

The methodology used to determine the gaseous pollutants considered in the present study (fluorine, chlorine, and sulphur) is based on the extraction, by means of an appropriate probe, of a known volume of gases that are put through an absorption system that captures these compounds. The pollutant at issue in the capturing solution is then determined and its concentration in the gas stream is calculated. This methodology is described in various specific test standards, outlined in Table III.

ITC is accredited by the Spanish National Accreditation Body (ENAC) for the determination of fluorine, chlorine, and sulphur concentrations.

Parallel to the determination of acid pollutants, a further series of key gas stream parameters were measured, such as volumetric flow rate, gas humidity, and other gases in these streams $\left(\mathrm{O}_{2}, \mathrm{CO}_{2}\right.$, and $\left.\mathrm{CO}\right)$ : these last gases were determined using automatic batch methods based on electrochemical sensors.

\section{EXPERIMENTAL DEVELOPMENT}

Measurements were performed of the pollutants at issue in the studied process stages: spray drying and firing. The
TABLE III. STANDARDS ON AIR POLLUTANT MEASUREMENT

\begin{tabular}{|c|c|}
\hline Pollutant & Reference standard \\
\hline Fluorides (expressed as HF) & ISO 15713:2007 \\
\hline Chlorides (expressed as HCl) & EN 1911:1998 \\
\hline $\mathrm{SO}_{2}$ & EN 14791:2006 \\
\hline $\mathrm{NOx}$ & ASTM 6522 \\
\hline
\end{tabular}

TABLE IV. Distribution OF THE SOURCES MEASURED IN THE SPRAY DRYINC STAGE.

\begin{tabular}{|c|c|c|}
\hline Installation & Type of product & Cogeneration \\
\hline 1 & $\begin{array}{c}\text { Spray-dried granule for } \\
\text { red earthenware tile (AR) }\end{array}$ & Yes \\
\hline 2 & $\begin{array}{c}\text { Spray-dried granule for } \\
\text { red earthenware tile (AR) }\end{array}$ & Yes \\
\hline 3 & $\begin{array}{c}\text { Spray-dried granule for } \\
\text { red stoneware tile (GR) }\end{array}$ & Yes \\
\hline 4 & $\begin{array}{c}\text { Spray-dried granule for } \\
\text { porcelain tile (GB) }\end{array}$ \\
\hline 5 & $\begin{array}{c}\text { Spray-dried granule for } \\
\text { porcelain tile (GB) }\end{array}$ & No \\
\hline
\end{tabular}

selection of the sources in each studied stage was made as a function of the following parameters:

- $\quad$ Type of product made: earthenware tile (A), stoneware and / or porcelain tile $(G)$

- Colour of the body composition: red (R) or white (B)

\subsection{Spray drying}

Table IV presents the distribution of the sources measured in this study stage. The table also indicates the type of spraydried granule made (type and colour), and indicates whether the spray dryer is connected to a cogeneration turbine, since the BREF also identifies these two possibilities. The parameter characterised in this stage was the concentration of the different studied pollutants.

TABLE II. MOST COMMON TYPES OF CERAMIC TILES IN SPAIN

\begin{tabular}{|c|c|c|c|c|c|c|}
\hline $\begin{array}{l}\text { Reference in the } \\
\text { study }\end{array}$ & Body colour & Type of tile & Forming & Body & Glazed & $\begin{array}{l}\text { Group according to EN } \\
\qquad 14411\end{array}$ \\
\hline AR & Red & \multirow{2}{*}{ Earthenware tile } & \multirow{2}{*}{ Pressing } & \multirow{2}{*}{ Porous } & \multirow{2}{*}{ Yes } & \multirow{2}{*}{ BIII } \\
\hline $\mathrm{AB}$ & White & & & & & \\
\hline GR & Red & \multirow{2}{*}{$\begin{array}{l}\text { Glazed stoneware } \\
\text { tile }\end{array}$} & \multirow{2}{*}{ Pressing } & \multirow{3}{*}{ Non porous } & \multirow{2}{*}{ Yes } & \multirow{2}{*}{$\mathrm{BIb} / \mathrm{BIIa}$} \\
\hline \multirow{2}{*}{ GB } & White & & & & & \\
\hline & White & Porcelain tile & Pressing & & Yes & BIa \\
\hline
\end{tabular}




\subsection{Firing kilns}

The distribution of the sources measured in the firing stage in this study is detailed in Table V. The following parameters were determined in this case:

- Pollutant concentration $\left(\mathrm{mg} / \mathrm{m}_{0}^{3}\right)$, this being the parameter customarily used to establish the ELV-BAT

- Emission factors, because they are considered of great usefulness for setting up environmental registers or inventories. Two types of emission factors are distinguished:

- Emission factor $(\mathrm{g} / \mathrm{h})$, customarily used to characterise the emissions of continuous processes and to draw up regular environmental reports (Pollutant Release and Transfer Register (PRTR)). The emission factor depends directly on the mass production of the studied kilns, which is why it is necessary to take this into account when it comes to interpreting the findings.

- Specific emission factor $(\mathrm{mg} / \mathrm{kg}$ fired product) used to compare different processes, independently of the actual production of each process.

The data set out in Table $\mathrm{V}$ enable the following to be noted:

- The number of data available for each studied parameter does not coincide for the different pollutants considered, since in certain cases not all the necessary information was available such as, for example, the flow rate values of the gases or tile production data.
- The data on white stoneware and porcelain tile have been treated together, since their emissions display very similar behaviour.

\section{RESULTS}

\subsection{Spray drying}

Table VI presents the results corresponding to acid compound emissions in the spray drying stage. Since the results obtained display no significant variations as a function of the use of cogeneration, or of the type of product made, they are shown together with the ELV-BAT, thus enabling the current situation in relation to these values to be readily evaluated.

The results presented in Table VI indicate that the acid pollutant emissions in the spray-drying stage are relatively insignificant, even for $\mathrm{NO}_{x}$. It may be noted in this sense that, in the studied facilities, no great differences were found in nitrogen compound emissions owing to the use of cogeneration systems.

The results obtained display high uniformity, probably because of the low temperature (between 50 and $60{ }^{\circ} \mathrm{C}$ ) reached inside the spray-dried granule during drying, which does not lead to thermal decomposition of the raw materials, as is the case in the firing stage. For this reason, the lack of measurement data on granulate sources for white earthenware tile manufacture $(\mathrm{AB})$ is not considered significant. These findings are consistent with the information in the BREF Document for the ceramic industry (15).

TABLE V. DistRibution OF THE NUMBER OF DATA CONSIDERED IN THE FIRING STAGE.

\begin{tabular}{|c|c|c|c|c|c|c|}
\hline \multirow{2}{*}{ Pollutant } & \multirow{2}{*}{ Studied parameter } & \multirow{2}{*}{$\begin{array}{c}\text { Total no. of } \\
\text { data }\end{array}$} & \multicolumn{2}{|c|}{ Earthenware tile } & \multicolumn{2}{|c|}{ Stoneware tile } \\
\hline & & & $\operatorname{Red}(\mathrm{AR})$ & White (AB) & Red (GR) & White (GB) \\
\hline \multirow{3}{*}{$\mathrm{HF}$} & Concentration $\left(\mathrm{mg} / \mathrm{m}_{0}{ }^{3}\right.$ at $\left.18 \% \mathrm{O}_{2}\right)$ & 72 & 11 & 7 & 35 & 19 \\
\hline & Emission factor $(\mathrm{g} / \mathrm{h})$ & 65 & 11 & 5 & 30 & 19 \\
\hline & $\begin{array}{l}\text { Specific emission factor } \\
\text { (mg/kg fired product) }\end{array}$ & 56 & 11 & 6 & 22 & 17 \\
\hline \multirow{3}{*}{$\mathrm{HCl}$} & Concentration $\left(\mathrm{mg} / \mathrm{m}_{0}{ }^{3}\right.$ at $\left.18 \% \mathrm{O}_{2}\right)$ & 43 & 7 & 6 & 15 & 15 \\
\hline & Emission factor $(\mathrm{g} / \mathrm{h})$ & 43 & 7 & 6 & 15 & 15 \\
\hline & $\begin{array}{l}\text { Specific emission factor } \\
\text { (mg/kg fired product) }\end{array}$ & 30 & 5 & 4 & 13 & 8 \\
\hline \multirow{3}{*}{$\mathrm{SO}_{2}$} & Concentration $\left(\mathrm{mg} / \mathrm{m}_{0}{ }^{3}\right.$ at $\left.18 \% \mathrm{O}_{2}\right)$ & 18 & 4 & 5 & 3 & 6 \\
\hline & Emission factor $(\mathrm{g} / \mathrm{h})$ & 18 & 4 & 5 & 3 & 6 \\
\hline & $\begin{array}{l}\text { Specific emission factor } \\
\text { (mg/kg fired product) }\end{array}$ & 18 & 4 & 5 & 3 & 6 \\
\hline \multirow{3}{*}{$\mathrm{NO}_{x}$} & Concentration $\left(\mathrm{mg} / \mathrm{m}_{0}{ }^{3}\right.$ at $\left.18 \% \mathrm{O}_{2}\right)$ & 42 & 8 & 6 & 14 & 14 \\
\hline & Emission factor $(\mathrm{g} / \mathrm{h})$ & 30 & 6 & 5 & 6 & 13 \\
\hline & $\begin{array}{l}\text { Specific emission factor } \\
\text { (mg/kg fired product) }\end{array}$ & 19 & 5 & 4 & 4 & 6 \\
\hline
\end{tabular}


TABLE VI. ACID POLLUTANT CONCENTRATIONS $\left(\mathrm{mg} / \mathrm{m}_{0}{ }^{3}\right.$ AT $18 \% \mathrm{O}_{2}$ AND DRY GAS) DURING SPRAY DRYING.

\begin{tabular}{|c|c|c|c|}
\hline Pollutant & No. of data & Maximum concentration & BREF (ELV-BAT) \\
\hline $\mathrm{HF}$ & 5 & $<2$ & -- \\
\hline $\mathrm{HCl}$ & 5 & $<25$ & -- \\
\hline $\mathrm{SO}_{2}$ & 5 & $<50$ & -- \\
\hline $\mathrm{NO}_{x}\left(\right.$ as $\left.\mathrm{NO}_{2}\right)$ & 5 & $<100$ & 500 (cogeneration) \\
\hline
\end{tabular}

\subsection{Firing kilns}

\subsubsection{CONCENTRATION}

The results corresponding to firing kilns for the different studied parameters are shown in Figure 1 in the form a median ( $50^{\text {th }}$ percentile). The median is considered a more robust estimator than the arithmetic mean, since the extreme values affect it less. The figure also shows the ELV-BAT applicable to this process stage.

The most significant emissions of the studied acid pollutants in the firing stage correspond to $\mathrm{HF}$ and $\mathrm{HCl}$ compared with the different applicable ELV-BAT, which indicates that these emissions need to be corrected by means of appropriate cleaning systems before such emissions are released into the air. In the case of the white earthenware tile however, it is necessary to study the cleaning need in each
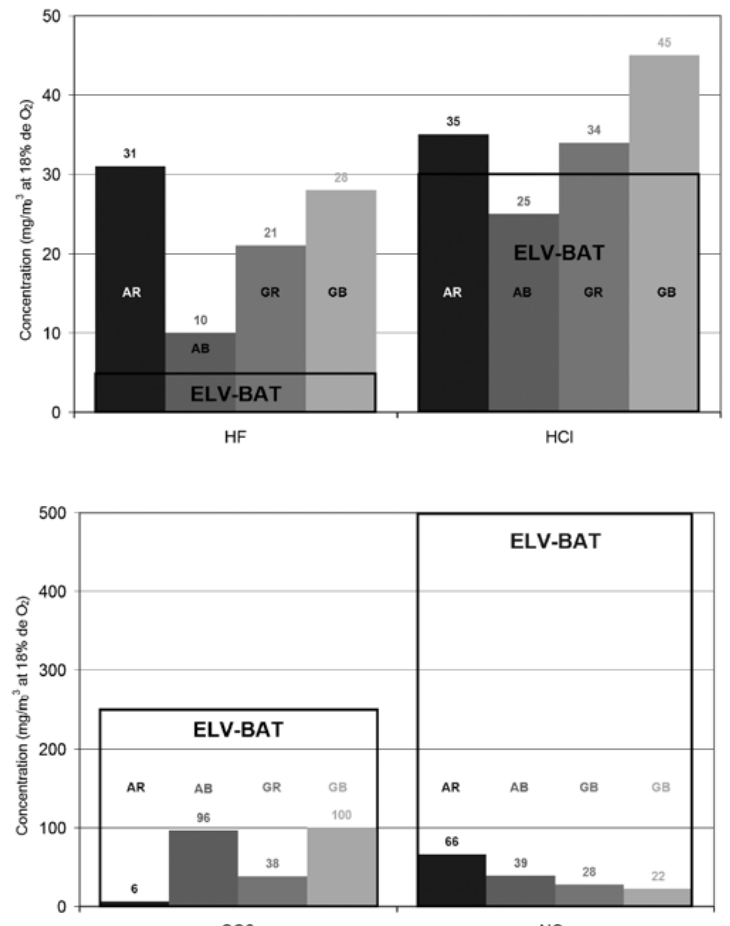

$\mathrm{SO} 2$

NOx

Figure 1 Median acid pollutant concentrations $\left(\mathrm{mg} / \mathrm{m}_{0}{ }^{3}\right.$ at $18 \% \mathrm{O}_{2}$ and dry gas) for earthenware and stoneware tile in the firing stage. particular case, because white earthenware tile emissions (AB) are significantly lower than those recorded for the other products $(20)(21)(22)$

The $\mathrm{SO}_{2}$ and $\mathrm{NO}_{x}$ emissions in the studied ranges are clearly lower than the ELV-BAT proposed for this process stage (16).

\subsubsection{EMISSION FACTORS}

This section summarises the emission factors obtained in the present study for the firing stage. The emission factors $(\mathrm{g} / \mathrm{h})$ are presented in Figure 2 . These values depend directly on the mass production of the studied kilns, this being a factor that must be taken into account when it comes to interpreting the results obtained. The specific emission factors $(\mathrm{mg} / \mathrm{kg}$ fired product) are presented in Figure 3.

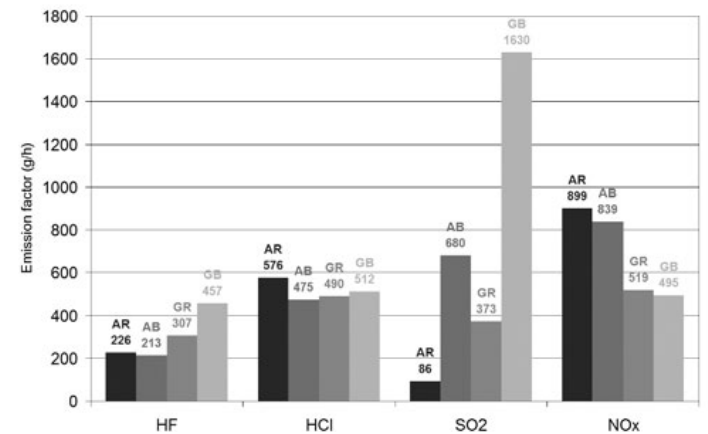

Figure 2 Median emission factors $(\mathrm{g} / \mathrm{h})$ for earthenware and stoneware tile in the firing stage.

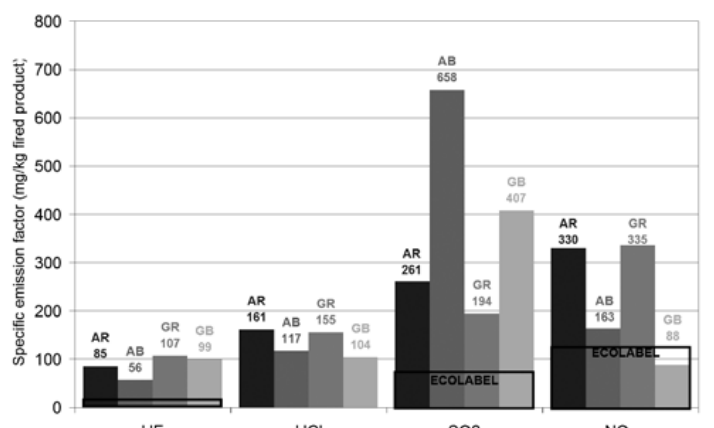

Figure 3 Median specific emission factors ( $\mathrm{mg} / \mathrm{kg}$ fired product) for earthenware and stoneware tile in the firing stage. 
Figure 3 also shows the ecological criteria established for the EU eco-label award for rigid coverings (ceramic tiles). The figure clearly shows that these criteria, in relation to air emissions, are quite restrictive compared with the usual emission values for these types of products.

\section{CONCLUSIONS}

The results of the study allow the following conclusions to be drawn in relation to the studied process stages:

Spray dryers:

- No significant differences were found between the acid compound emissions of the different types of studied products, nor were significant differences found owing to the use of cogeneration turbines.

- The emission of fluorine and of the other acid pollutants in the spray-drying stage is of little significance, compared with the ELV-BAT currently established in the EU.

- From an air emission control standpoint, provided no changes occur in the process that justify the need for such control, it is possible to reconsider the need for regular $\mathrm{SO}_{2}$ and $\mathrm{NO}_{\mathrm{x}}$ emission controls in view of the low emissions detected in these facilities.

Firing kilns:

- $\mathrm{HF}$ and $\mathrm{HCl}$ emissions are the most significant acid pollutant emissions in the firing stage compared with the different ELV-BAT proposed in the EU BREF. The study outcomes indicate the need to correct the great majority of these emissions by adopting appropriate primary measures and cleaning systems before such emissions are released into the air.

- The $\mathrm{SO}_{2}$ and $\mathrm{NO}_{x}$ emissions in all the studied companies are clearly below the ELV-BAT applicable to this process stage, so that if there are no changes in fuels or raw materials, no type of correction is required.

- The emission factors corresponding to the firing stage have been determined with narrow variation ranges for each type of studied pollutant, solely as a function of the type of product made, without any other manufacturing process characteristics being considered. The information obtained is considered to be representative of the current situation in the Spanish ceramic tile manufacturing sector and can be used to draw up regular environmental reports, such as the Pollutant Release and Transfer Register (PRTR), and to prepare limit proposals in future BREF document reviews.

\section{ACKNOWLEDGEMENTS}

This study has been carried out with the collaboration of the Spanish Ceramic Tile Manufacturers' Association (ASCER), through its members and by partial funding of the study through the collaboration agreement made with ITC entitled 'Characterisation of air pollutant emissions in ceramic tile manufacture', in the Competitiveness Plan for Valencian Business, in the period 2005-2007, funded by the Autonomous Government of Valencia through Impiva.

The authors also wish to thank all the companies that participated in the study for their invaluable collaboration during the performance of this study.

\section{REFERENCES}

1. González, I.; Aparicio, P.; Galán, E.; Fabbri, B. A proposal for reducing F and $\mathrm{Cl}$ emission in the brick industry using new formulations. App. Clay Sci., 22, 1-7, 2002

2. Gazulla, M.F.; Gómez, P.; Cabrera, M.J.; Monfort, E. Determinación de flúor en las arcillas utilizadas en la fabricación de baldosas cerámicas. Técnica Cerámica, 243, 298-302, 1996.

3. A. Blasco, A. Escardino, G. Busani, G. Tratamiento de emisiones gaseosa efluentes líquidos y residuos sólidos de la industria cerámica. [S. 1.] Instituto de Tecnología Cerámica; Asociación de Industria Cerámica, 1992.

4. Busani, G.; Palmonari, C. E Timellini, G. Piastrelle ceramiche e ambiente: emissioni gassose, acque, fanghi, rumore. Sassuolo: Edi.Cer, 1995.

5. Fabbri, B. Flúor en las arcillas: contenidos y mecanismos de emisión. Cerám. Inf. (Esp), In: Especial Tecnargilla, 33-36, 1992.

6. Reymer, A.; Jong, J. De. Fluoride emission of ceramic products. In: Third Euro-Ceramics / edited by P. Durán and J.F. Fernández. Castellón: Faenza Editrice Ibérica, v. 2, 1071-1076, 1993.

7. Monfort, E.; García-Ten, J.; Celades, I.; Gazulla, M.F.; Gomar, S. Evolution of fluorine emissions during the fast firing of ceramic tile. Appl. clay sci., 38, 250-258, 2008.

8. García-Ten, J.; Monfort, E.; Gómez, M.P.; Gomar, S. Influence of calcite content on fluorine compound emissions during ceramic tile firing. J. ceram. proc. res., 7(1), 75-82, 2006.

9. Chipera, S.J.; Bish, D.L. Thermal evolution of fluorine from smectite and kaolinite. Clays clay miner, 50 (1), 38-46, 2002

10. Monfort, E.; Celades, I.; Gomar, S.; Gazulla, M.F.; Adams, H.; Tulip, J Application of an on-line measurement system for HF emission control (first part). Industrie Céramique Verrière, 997, 50-56, 2004

11. Monfort, E.; Celades, I.; Gomar, S.; Gazulla, M.F.; Adams, H.; Tulip, J. Application of an on-line measurement system for HF emission control (second part). Industrie Céramique Verrière, 998, 30-36, 2005.

12. Monfort, E.; García-Ten, J.; Celades, I.; Gomar, S. Monitoring and possible reduction of $\mathrm{HF}$ in stack flue gases from ceramic tiles. J. Fluorine Chem., 131, 6-12, 2010.

13. Brosnan, D.A. Monitoring for Hydrogen Fluoride Emissions, Ceram. Ind 143 [1] 38-40, 1994

14. L. Nelms, F. Pretorius, J.Q. Ranney And G.M. Stoffa, Study Rates HF Measurement Methods, Am. Ceram. Soc. Bull., 74 [2] 42-47, 1995

15. Monfort, E.; Gazulla, M.F.; Celades, I.; Gómez, P.; Bigi, M.; Tonelli, M Ceramic kiln fluorine-gas emission measurement. Am. Ceram. Soc. bull. 82(2), 31-35, 2003.

16. Integrated pollution prevention and control (IPPC): Reference document on best available techniques in the ceramic manufacturing industry: Seville: European Commission. European IPPC Bureau, 2007.

17. Monfort, E.; Gomar, S.; Celades, I.; Gómez-Tena, M.P.; Moro, E.; Marquez, E. Reducción de las emisiones de azufre de un horno tunel. Bol. Soc. Esp. Ceram. Vidr., 49(5), 343-350, 2010

18. Directive $2010 / 75$ /EU of the European Parliament and of the council of 24 November 2010 on industrial emissions (integrated pollution prevention and control) (Recast)

19. Commission decision of 9 July 2009, establishing the criteria for the EU eco-label award for rigid coverings

20. Mallol, G.; Monfort, E.; Busani, G.; Lezaun, J. Depuración de los gase de combustión en la Industria Cerámica: guía técnica. $2^{\text {nd }}$ ed. Castellón: Instituto de Tecnología Cerámica, 2001.

21. García-Ten, J.; Monfort, E.; Gómez-Tena, M.P.; Sanz, V. Use of coatings to minimise acid emissions during ceramic tile firing. J. Clean Prod., IN PRESS, 2011.

22. Bono, R.; Llop, H.; De La Hoz, J.M.; Monfort, E.; Celades, I.; Mestre, S Industrial-scale study of $\mathrm{NaHCO} 3$ chemical reactions with $\mathrm{HF}, \mathrm{HCl}$ and $\mathrm{SO} 2$ in kiln flue gases. Key Engineering Materials, 206-213, 855-858, 2002.

Recibido: $17 / 03 / 2011$

Aceptado: $11 / 07 / 2011$ 




\title{
ARTÍCULO № 2
}

GARCÍA-TEN, J.; MONFORT, E.; GÓMEZ, M.P.;

GOMAR, $\mathbf{S}$.

\section{Influence of calcite content on fluorine compound emissions during ceramic tile firing.}

\author{
J. ceram. proc. res., 7(1), 75-82, 2006.
}

Publicado en: 2006

Número de citas (fuente: SCOPUS el 30 de junio de 2015): 10

Factor de impacto de la revista (2006): 0,534

Factor de impacto de la revista en cinco años (2006): ND 



\title{
Influence of calcite content on fluorine compound emissions during ceramic tile firing
}

\author{
J. García-Ten*, E. Monfort, P. Gomez and S. Gomar \\ Instituto de Tecnología Cerámica, Asociación de Investigación de las Industrias Cerámicas, Universitat Jaume I. Castellón, \\ Spain
}

\begin{abstract}
The manufacture of traditional ceramic products (ceramic tiles, roof tiles and bricks) is often associated with the emission of fluorine compounds during the firing stage. According to the literature such emissions can be reduced by adding $\mathrm{CaCO}_{3}$ to the raw materials mixture used in fabricating these products. However, data available to the authors indicate that this procedure, which has been successfully applied in manufacturing structural ceramics (roof tiles and bricks), is ineffective in ceramic tile manufacture. The present study has sought to establish why the $\mathrm{CaCO}_{3}$ addition fails to reduce fluorine compound emissions during the ceramic tile firing stage. The study has thus determined the influence of $\mathrm{CaCO}_{3}$ content on the evolution of the crystalline phases with firing temperature in a typical floor tile composition to which additions of $\mathrm{CaF}_{2}$ were made; additions of $\mathrm{BaF}_{2}$ and $\mathrm{SrF}_{2}$ were also made to this floor tile body, and the thermal stability of these three fluoride compounds was studied. The study shows that the effectiveness of $\mathrm{CaCO}_{3}$ in reducing fluorine compound emissions in roof tile and brick manufacture is due to the relatively low firing temperature $\left(850-100{ }^{\circ} \mathrm{C}\right)$ involved, which enables part of the $\mathrm{CaF}_{2}$ to be retained in the pieces, and to the formation of cuspidine, which is stable up to $1050{ }^{\circ} \mathrm{C}$. At higher temperatures (ceramic tiles are typically fired at temperatures of $1100-1200^{\circ} \mathrm{C}$ ), the fluorine-containing crystalline species (fluorite and cuspidine) are unstable, causing fluorine compound emissions to rise.
\end{abstract}

Key words: tile, fluorine, emission, calcite.

\section{Introduction}

The manufacture of traditional ceramic products (ceramic tiles, roof tiles and bricks) is often associated with the emission of fluorine compounds during the firing stage [1-3]. As set out in the literature, the fluorine ion replaces $\mathrm{OH}^{-}$groups in the crystalline structure of mica and many other clay minerals (montmorillonite, illite, etc.) $[4,5]$, so that fluorine compound emissions usually start when these minerals dehydroxylate at temperatures between 500 and $700{ }^{\circ} \mathrm{C}$ [6-8]. The principal compounds that form are hydrofluoric acid, silicon tetrafluoride and, to a lesser degree, alkaline fluorides in particulate form (whose presence may be considered practically negligible) [9]. In the presence of water vapour - a typical situation in industrial combustion kilns - fluorine is mainly released as hydrofluoric acid [5].

One of the procedures described in the literature for reducing fluorine compound emissions involves adding $\mathrm{CaCO}_{3}$ to the raw materials mixture used in fabricating these ceramic products [3,10-12]. These studies show that when HF (which evolves from the pieces in the high temperature zone) travels towards the preheating zone, it

Corresponding author:

Tel : +34-964-342424

Fax: +34-964-342425

E-mail: jgarcia@itc.uji.es reacts with calcite to form $\mathrm{CaF}_{2}$, which is thermally more stable, causing part of the fluorine to be retained in the pieces. However, data available to the authors indicate that this procedure (successfully applied in the manufacture of structural ceramics, such as roof tiles and bricks) is ineffective in ceramic tile manufacture, where firing is much faster (35-60 minutes as opposed to 35-50 h) and occurs at higher temperatures $\left(1100-1200^{\circ} \mathrm{C}\right.$ as opposed to $850-950{ }^{\circ} \mathrm{C}$ ). The ineffectiveness of $\mathrm{CaCO}_{3}$ in reducing fluorine compound emissions during ceramic tile firing is evidenced by the typical emission values in kilns that process ceramic tiles with different $\mathrm{CaCO}_{3}$ contents. Thus, the usual emission values in roller kilns that fire glazed stoneware (with $\mathrm{CaCO}_{3}$ contents below $4.0 \%$ ) range from 25 to $40 \mathrm{mg} \mathrm{HF} / \mathrm{Nm}^{3}$, which are similar to the values found in kilns that fire wall tiles (with $\mathrm{CaCO}_{3}$ contents of $12-14 \%$ ).

The present study seeks to establish why $\mathrm{CaCO}_{3}$ is so ineffective in diminishing fluorine compound emissions, by examining the thermal stability of $\mathrm{CaF}_{2}$ in a ceramic matrix whose $\mathrm{CaCO}_{3}$ content is modified. The stability of $\mathrm{BaF}_{2}$ and $\mathrm{SrF}_{2}$ in this ceramic composition has also been studied, in order to determine the effectiveness of these three fluorides in fixing fluorine in the fired pieces. 
Table 1. Chemical composition of the GR body

\begin{tabular}{cc}
\hline \hline Oxide & Content (wt $\%)$ \\
\hline $\mathrm{SiO}_{2}$ & 64.0 \\
$\mathrm{Al}_{2} \mathrm{O}_{3}$ & 17.5 \\
$\mathrm{Fe}_{2} \mathrm{O}_{3}$ & 6.0 \\
$\mathrm{CaO}$ & 1.1 \\
$\mathrm{MgO}$ & 0.8 \\
$\mathrm{Na}_{2} \mathrm{O}$ & 0.4 \\
$\mathrm{~K}_{2} \mathrm{O}$ & 3.3 \\
$\mathrm{LOI}$ & 5.9 \\
$\mathrm{~F}$ & $590 \mathrm{ppm}$ \\
\hline
\end{tabular}

\section{Experimental}

Ceramic tile body compositions contain very little fluorine (500-700 ppm) [13, 14]. This prevents using Xray diffraction (XRD) for monitoring the fluoridated crystalline phases that form during the firing stage. Mixtures have therefore been used in this study, obtained by adding $\mathrm{CaF}_{2}, \mathrm{BaF}_{2}$ and $\mathrm{SrF}_{2}$ to a typical ceramic floor tile composition.

\section{Materials}

The study has been conducted using analytical grade ( $>99 \%$ purity) $\mathrm{CaF}_{2}, \mathrm{BaF}_{2}$ and $\mathrm{SrF}_{2}$. The floor tile composition used, referenced GR, is a typical industrial composition for manufacturing red-firing glazed stoneware bodies, and contains $1.1 \% \mathrm{CaO}$ from the impurities (carbonates) in the red-firing clays. The chemical composition of the GR body is set out in Table 1 .

\section{Experimental procedure}

- Test specimen preparation

To conduct the study, the different fluorides were mixed with the GR body in a tungsten carbide ring mill. The resulting mixtures were used to form cylindrical test specimens, $4 \mathrm{~cm}$ in diameter and $7 \mathrm{~mm}$ thick, by uniaxial pressing. The pressing variables applied were similar to those used in industrial practice to form ceramic tile bodies (powder moisture content of $0.055 \mathrm{~kg}$ water $/ \mathrm{kg}$ dry solid and pressing pressure of $25 \mathrm{MPa}$ ). The test specimens obtained were dried in an electric oven at $110{ }^{\circ} \mathrm{C}$ and subsequently thermally treated at different peak temperatures, simulating industrial firing cycles, in an electric laboratory kiln with static air atmosphere. The heating rate was $25^{\circ} \mathrm{C} /$ minute and the dwell time at peak temperature was 6.0 minute. Cooling was by forced air convection.

\section{- Determination of crystalline phases}

The crystalline phases were determined by X-ray diffraction (XRD) of the powder samples, with a PHILIPS PW 1840 diffractometer. The test conditions were as follows:

$$
\begin{array}{ll}
-\mathrm{Cu} \text { tube } & \text { - Step size: } 0.01(2 \theta) \\
\text { - Use of monochromator } & \text { - Acquisition time: } 1 \mathrm{~s} \\
-40 \mathrm{kV}, 40 \mathrm{~mA} & \text { - Slit: } 0.2 \mathrm{~mm}
\end{array}
$$

\section{Results}

$\mathrm{CaF}_{2}, \mathrm{BaF}_{2}$ and $\mathrm{SrF}_{2}$ stability in a ceramic matrix during thermal treatment

A number of tests were conducted first to determine the XRD detection limit (minimum detectable quantity) and quantitation limit (minimum quantity that provides a signal which can be quantified by calculating the peak area) of the test fluorine compounds $\left(\mathrm{CaF}_{2}, \mathrm{BaF}_{2}\right.$ and $\mathrm{SrF}_{2}$ ) in a ceramic matrix.

For this, compositions were prepared by adding $0.5 \%$, $1.0 \%$ and $5.0 \%$ by weight, respectively, of the test fluorides to the GR body. The maximum intensity peak of each fluoride was then recorded, which was not overlapped with reflections of other possible crystalline compounds (quartz, anorthite, hematite, etc.) present in the fired pieces.

The selected measurement angle and crystalline spacing for each compound are detailed in Table 2.

The diffractograms obtained for these compositions exhibit similar trends. As an example, Fig. 1 shows the region of the diffractogram corresponding to the $\mathrm{CaF}_{2}$ maximum intensity peak for the GR composition with the $\mathrm{CaF}_{2}$ additions. The diffractograms of the three test fluorides indicate that very good signals are obtained with $5 \%$ additions. The fluorides of the alkaline-earth cations can also be detected and quantified at considerably lower percentages, since they display quite welldefined peaks without notable interferences.

These results allowed establishing the detection limits (DLs) and quantitation limits (QLs) for the test fluorides in the GR composition (Table 3). Thus, in these compositions, $\mathrm{SrF}_{2}$ can be detected and quantified at lower concentrations, whereas a larger quantity of $\mathrm{BaF}_{2}$ is required for detection and quantitation. In view of these values, since the fluorine present in this type of composition (500-700 ppm) does not allow formation of fluoride concentrations above the QLs, the study was conducted with mixtures obtained by adding $\mathrm{CaF}_{2}, \mathrm{BaF}_{2}$ and $\mathrm{SrF}_{2}$ respectively to the GR body.

After the DLs and QLs had been established, $\mathrm{CaF}_{2}$, $\mathrm{BaF}_{2}$ and $\mathrm{SrF}_{2}$ stability in the ceramic matrix during firing was determined. This was done by adding $1 \%$ and $5 \%$ by weight, respectively, of these fluorides to the GR composition, monitoring the maximum intensity peak of each fluoride (Table 2) with maximum thermal treatment temperature. These results were compared with those obtained when pure fluorides were tested.

Table 2. Measurement angle and crystalline spacing for each test fluoride

\begin{tabular}{ccc}
\hline \hline Compound & $\begin{array}{c}\text { Measurement angle } \\
2 \theta\left({ }^{\circ}\right)\end{array}$ & $\begin{array}{c}\text { Crystalline spacing } \\
\mathrm{d}(\AA)\end{array}$ \\
\hline $\mathrm{CaF}_{2}$ & 47.00 & 1.932 \\
$\mathrm{BaF}_{2}$ & 41.13 & 2.193 \\
$\mathrm{SrF}_{2}$ & 44.12 & 2.051 \\
\hline
\end{tabular}




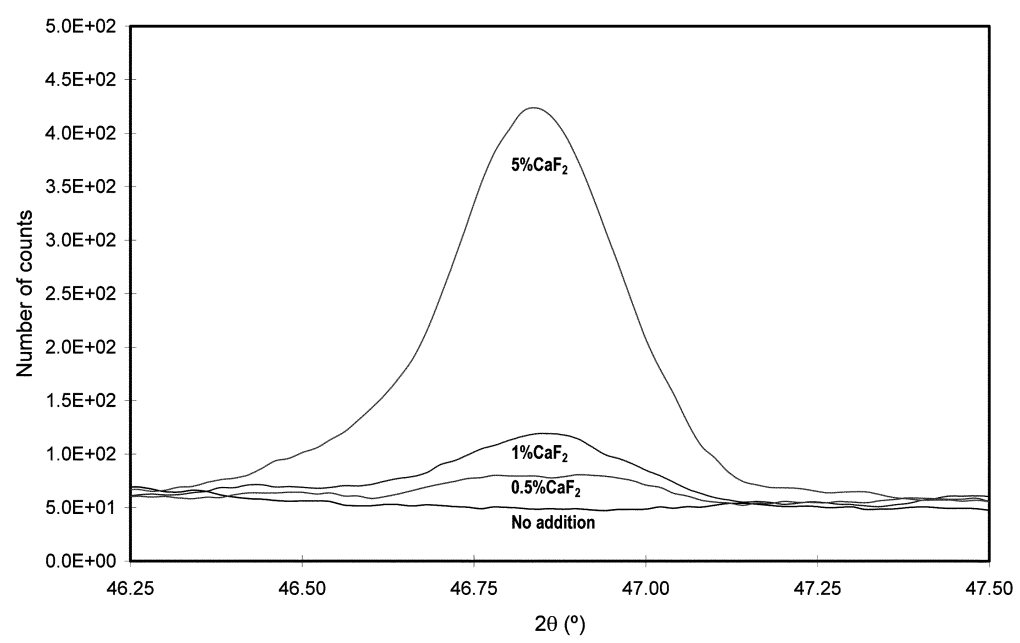

Fig. 1. Signal of the maximum intensity peak of calcium fluoride with increasing additions of $\mathrm{CaF}_{2}$ to the GR body.

Table 3. Detection limits (DLs) and quantitation limits (QLs) of the different fluorides in the GR body

\begin{tabular}{ccc}
\hline \hline Compound & $\begin{array}{c}\mathrm{DL} \\
\text { (\% by weight) }\end{array}$ & $\begin{array}{c}\text { QL } \\
\text { (\% by weight) }\end{array}$ \\
\hline $\mathrm{CaF}_{2}$ & 0.20 & 0.25 \\
$\mathrm{BaF}_{2}$ & 0.25 & 0.50 \\
$\mathrm{SrF}_{2}$ & 0.15 & 0.20 \\
\hline
\end{tabular}

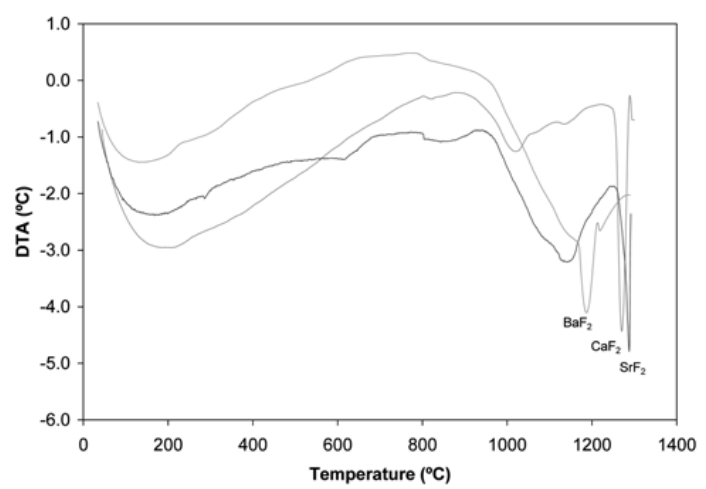

Fig. 2. Differential thermal analysis (DTA) of $\mathrm{CaF}_{2}, \mathrm{BaF}_{2}$ and $\mathrm{SrF}_{2}$.

Figure 2 and 3 show the differential thermal analysis (DTA) and thermogravimetric analysis (TG) of the pure calcium, barium and strontium fluorides. The graphs show that these fluorides are thermally stable up to $910{ }^{\circ} \mathrm{C}, 960{ }^{\circ} \mathrm{C}$ and $960{ }^{\circ} \mathrm{C}$, respectively, after which an endothermal tendency develops until they reach their respective melting temperatures at $1260{ }^{\circ} \mathrm{C}, 1190^{\circ} \mathrm{C}$ and $1290{ }^{\circ} \mathrm{C}$ (Fig. 2). In view of these findings and the fact that the industrial peak firing temperature of the GR body is around $1140^{\circ} \mathrm{C}$, the GR compositions with $1 \%$ and $5 \%$ additions of the fluorides were heat treated at

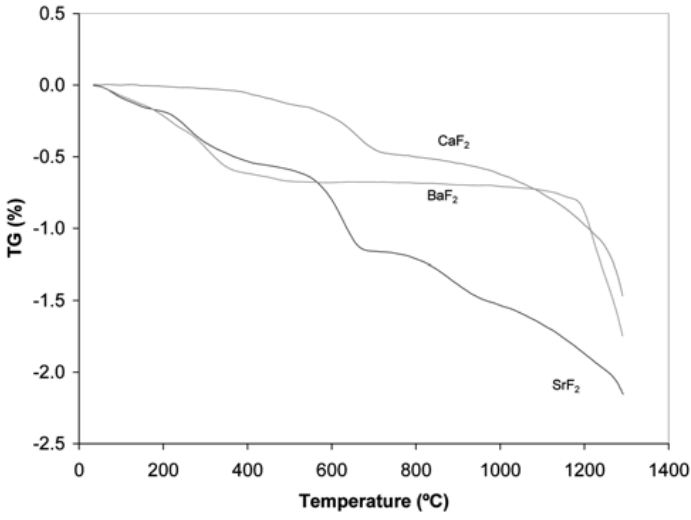

Fig. 3. Thermogravimetric analysis (TG) of $\mathrm{CaF}_{2}, \mathrm{BaF}_{2}$ and $\mathrm{SrF}_{2}$.

peak temperatures of $950{ }^{\circ} \mathrm{C}, 1000^{\circ} \mathrm{C}, 1100{ }^{\circ} \mathrm{C}$ and $1150^{\circ} \mathrm{C}$, simulating the industrial firing cycles.

Figure 4,5 and 6 depict the diffractograms corresponding to the series of tests in which $5 \%$ by weight of each fluoride was added. In order to determine the respective fluoride concentrations in the fired pieces, the area of the maximum intensity peak (Table 2) obtained in each heat-treated sample was compared with the peak area obtained in the green samples. These data are set out in Table 4.

The results obtained for $\mathrm{CaF}_{2}$ indicate that even at temperatures below $950{ }^{\circ} \mathrm{C}$ an important part of the initial $\mathrm{CaF}_{2}$ addition is lost, making monitoring by $\mathrm{XRD}$ unfeasible in the compositions with $1 \% \mathrm{CaF}_{2}$ additions. When $5 \%$ was added, half the $\mathrm{CaF}_{2}$ content had disappeared at $950{ }^{\circ} \mathrm{C}$. These results are in contrast to those obtained for pure $\mathrm{CaF}_{2}$, which is stable up to $910^{\circ} \mathrm{C}$. At higher temperatures the $\mathrm{CaF}_{2}$ content diminishes progressively up to $1100{ }^{\circ} \mathrm{C}$, at which the presence of $\mathrm{CaF}_{2}$ is 


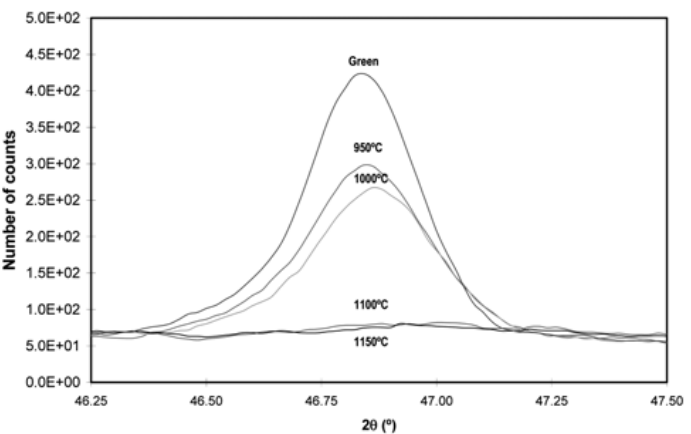

Fig. 4. Variation of the maximum intensity peak signal of $\mathrm{CaF}_{2}$ with temperature.

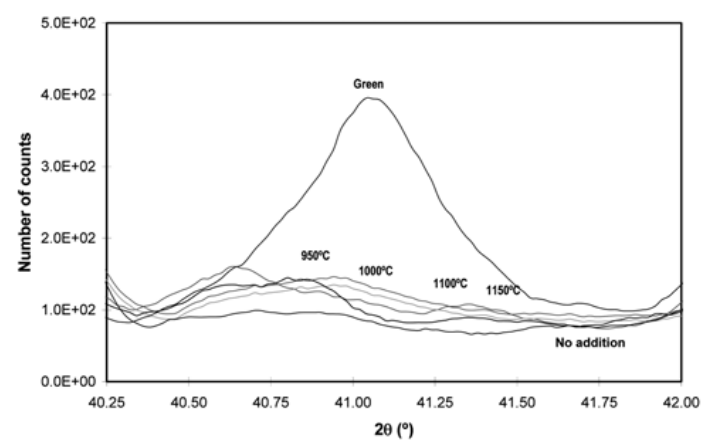

Fig. 5. Variation of the maximum intensity peak signal of $\mathrm{BaF}_{2}$ with temperature.

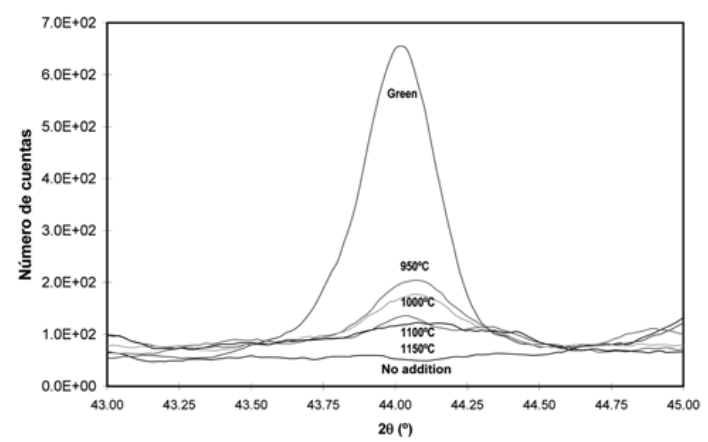

Fig. 6. Variation of the maximum intensity peak signal of $\mathrm{SrF}_{2}$ with temperature.

hardly $5 \%$ of the original addition.

Although $\mathrm{BaF}_{2}$ is one of the thermally most stable fluorides when found in isolation (even more so than $\mathrm{CaF}_{2}$ ), the $\mathrm{BaF}_{2}$ content decreased even further than that of $\mathrm{CaF}_{2}$. The $\mathrm{BaF}_{2}$ content with temperature could, therefore, not be monitored for the $1 \% \mathrm{BaF}_{2}$ addition. In the $5 \% \mathrm{BaF}_{2}$ additions, only $25 \%$ of the initial $\mathrm{BaF}_{2}$ was left at $950{ }^{\circ} \mathrm{C}$, and $\mathrm{BaF}_{2}$ could no longer be quantified at $1100{ }^{\circ} \mathrm{C}$.

The $\mathrm{SrF}_{2}$ results are similar to those of $\mathrm{BaF}_{2}$. Thus, the
Table 4. $\mathrm{CaF}_{2}, \mathrm{BaF}_{2}$ and $\mathrm{SrF}_{2}$ content in the GR body after thermal treatment at different temperatures

\begin{tabular}{cccccc}
\hline \hline \multirow{2}{*}{$\begin{array}{c}\text { Com- } \\
\text { pound }\end{array}$} & $\begin{array}{c}\text { Addition } \\
(\mathrm{wt} \%)\end{array}$ & \multicolumn{5}{c}{ Fluoride content (wt\%) } \\
\cline { 2 - 6 } & $950^{\circ} \mathrm{C}$ & $1000^{\circ} \mathrm{C}$ & $1100^{\circ} \mathrm{C}$ & $1150^{\circ} \mathrm{C}$ \\
\hline \multirow{2}{*}{$\mathrm{CaF}_{2}$} & 1.0 & 0.5 & $<0.25$ & $<0.25$ & $<0.25$ \\
\cline { 2 - 6 } & 5.0 & 2.5 & 1.9 & 0.25 & $<0.25$ \\
\hline \multirow{2}{*}{$\mathrm{BaF}_{2}$} & 1.0 & $<0.5$ & $<0.5$ & $<0.5$ & $<0.5$ \\
\cline { 2 - 6 } & 5.0 & 1.3 & 1.1 & $<0.5$ & $<0.5$ \\
\hline \multirow{2}{*}{$\mathrm{SrF}_{2}$} & 1.0 & $<0.2$ & $<0.2$ & $<0.2$ & $<0.2$ \\
\cline { 2 - 6 } & 5.0 & 1.5 & 1.1 & 0.5 & $<0.5$ \\
\hline
\end{tabular}

$1 \% \mathrm{SrF}_{2}$ additions could not be monitored; in the $5 \%$ additions the $\mathrm{SrF}_{2}$ content diminished appreciably at $950{ }^{\circ} \mathrm{C}$. When the temperature was raised further, $\mathrm{SrF}_{2}$ decreased progressively up to $1150{ }^{\circ} \mathrm{C}$, at which it could no longer be quantified.

These results indicate a pronounced reduction in $\mathrm{CaF}_{2}$, $\mathrm{BaF}_{2}$ and $\mathrm{SrF}_{2}$ thermal stability in a ceramic matrix. The differing behaviour of these fluorides in the GR body could be due to their dissolution in the liquid phase that GR develops at high temperature [15], or to the formation of other, more stable compounds. With a view to establishing whether other crystalline phases evolved during thermal treatment, the complete diffractograms were studied.

The study of these diffractograms revealed the presence of anorthite $\left(\mathrm{CaAl}_{2} \mathrm{Si}_{2} \mathrm{O}_{8}\right)$ in the experiments with $1.0 \%$ and $5 \% \mathrm{CaF}_{2}$ additions, and celsian $\left(\mathrm{BaAl}_{2} \mathrm{Si}_{2} \mathrm{O}_{8}\right)$ in the $5 \% \mathrm{BaF}_{2}$ additions. No new crystalline species was detected in the series of $\mathrm{SrF}_{2}$ additions. The anorthite and celsian contents detected in the above compositions at the different test temperatures are respectively detailed in Tables 5 and 6.

As $\mathrm{CaO}$ is the most widely found oxide in the compositions used for ceramic tile manufacture, it was decided to study the effect of $\mathrm{CaO}$ content in the composition on the crystalline phases formed during firing. Thus, the results could therefore foreseeably be extrapolated to analogous industrial processes and products.

Table 5. Anorthite $\left(\mathrm{CaAl}_{2} \mathrm{Si}_{2} \mathrm{O}_{8}\right)$ content in the GR body with $\mathrm{CaF}_{2}$ additions at different peak heat-treatment temperatures

\begin{tabular}{ccccc}
\hline \hline $\mathrm{CaF}_{2}$ addition & \multicolumn{4}{c}{ Anorthite content (wt\%) } \\
\cline { 2 - 5 }$(\mathrm{wt} \%)$ & $950^{\circ} \mathrm{C}$ & $1000^{\circ} \mathrm{C}$ & $1100^{\circ} \mathrm{C}$ & $1150^{\circ} \mathrm{C}$ \\
\hline $1 \%$ & 5 & 6 & 5 & 3 \\
$5 \%$ & 9 & 10 & 10 & 7 \\
\hline
\end{tabular}

Table 6. Celsian $\left(\mathrm{BaAl}_{2} \mathrm{Si}_{2} \mathrm{O}_{8}\right)$ content in the GR body with $\mathrm{BaF}_{2}$ additions at different peak heat-treatment temperatures

\begin{tabular}{ccccc}
\hline \hline \multirow{3}{*}{$\begin{array}{c}\mathrm{BaF}_{2} \text { addition } \\
(\mathrm{wt} \%)\end{array}$} & \multicolumn{5}{c}{ Celsian content (wt\%) } \\
\cline { 2 - 5 } & $950^{\circ} \mathrm{C}$ & $1000^{\circ} \mathrm{C}$ & $1100^{\circ} \mathrm{C}$ & $1150^{\circ} \mathrm{C}$ \\
\hline $5 \%$ & 4 & 4 & 4 & 4 \\
\hline
\end{tabular}


Table 7. Compositions prepared to study the influence of $\mathrm{CaO}$ content on $\mathrm{CaF}_{2}$ thermal stability

\begin{tabular}{crrrr}
\hline \hline Component & M0 & M5 & M10 & M15 \\
\hline GR & 95 & 90 & 85 & 80 \\
$\mathrm{CaF}_{2}$ & 5 & 5 & 5 & 5 \\
$\mathrm{CaCO}_{3}$ & - & 5 & 10 & 15 \\
\hline
\end{tabular}

\section{Influence of $\mathrm{CaO}$ content on the crystalline phases} formed during firing

To carry out the study, test compositions were prepared of the GR body with $\mathrm{CaF}_{2}$ and $\mathrm{CaCO}_{3}$ additions, as set out in Table 7. The $\mathrm{CaCO}_{3}$ contents in the compositions encompass the range of $\mathrm{CaCO}_{3}$ contents found in ceramic tiles, from very low porosity to highly porous tiles.

The resulting mixtures were used to form cylindrical test specimens, which were fired at $800,900,950,1000$, 1050,1100 and $1150{ }^{\circ} \mathrm{C}$. A composition M0, to which no $\mathrm{CaCO}_{3}$ was added, was also thermally treated at lower temperatures to establish $\mathrm{CaF}_{2}$ stability at low temperatures.

Figure 7 shows the crystalline phases present in the heat-treated $\mathrm{M} 0$ specimens. At $800^{\circ} \mathrm{C}$ clay minerals and calcite are no longer detected. This indicates that the former are dehydroxylated and the latter have fully decomposed, together contributing to the presence of $\mathrm{SiO}_{2}, \mathrm{Al}_{2} \mathrm{O}_{3}$ and $\mathrm{CaO}$ in the ceramic matrix. The figure evidences a progressive reduction in $\mathrm{CaF}_{2}$ content, which starts at low temperatures $\left(200^{\circ} \mathrm{C}\right)$ and becomes more pronounced between 600 and $850^{\circ} \mathrm{C}$. The tendency then reverses and exhibits a small peak at $900{ }^{\circ} \mathrm{C}$. The presence of this small peak indicates that fluorite is forming, probably from the fluorine evolving from the GR body and from the $\mathrm{CaO}$ stemming from the decomposition of $\mathrm{CaCO}_{3}$, present as an impurity in composition $\mathrm{M} 0$. At higher temperatures the $\mathrm{CaF}_{2}$ content again diminishes, and practically disappears at $1100^{\circ} \mathrm{C}$.

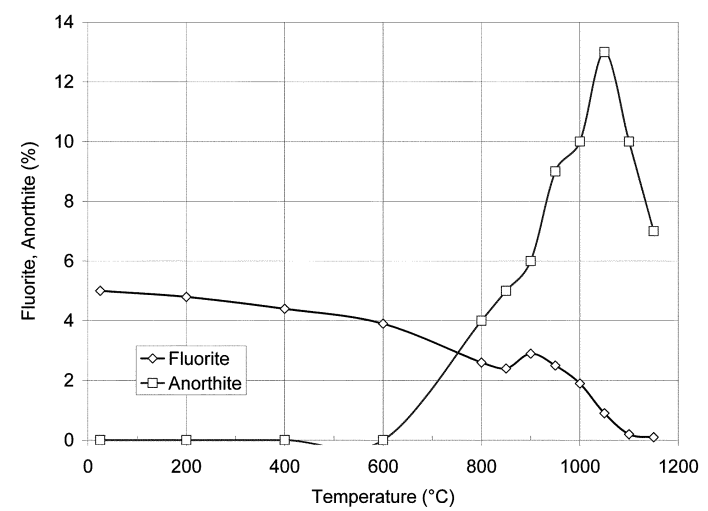

Fig. 7. Evolution of the crystalline phases with thermal treatment temperature. Mixture M0.

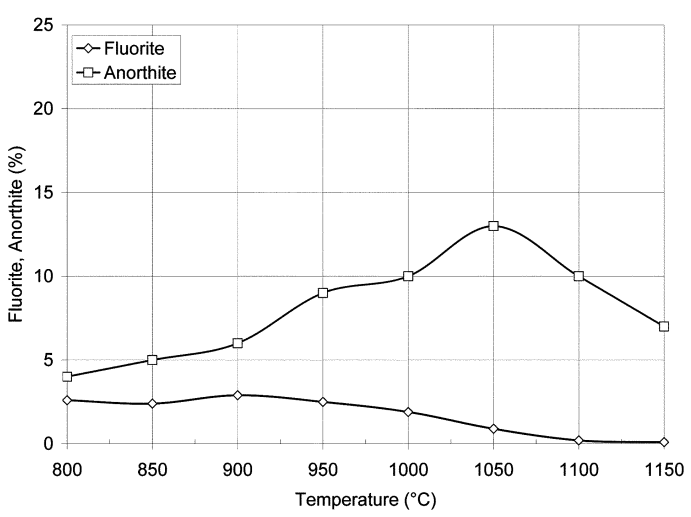

Fig. 8. Evolution of the crystalline phases present with thermal treatment temperature. Mixture M0.

Anorthite starts forming above $600{ }^{\circ} \mathrm{C}$ and increases up to $1050^{\circ} \mathrm{C}$, at which it peaks. The anorthite content then diminishes up to $1150^{\circ} \mathrm{C}$, as a result of anorthite crystal dissolution in the liquid phase generated by GR at high temperature [15].

Comparison of these results with those obtained in the thermal treatment of pure $\mathrm{CaF}_{2}$ indicates that $\mathrm{CaF}_{2}$ stability diminishes notably in a ceramic matrix, particularly when the matrix develops an abundant quantity of liquid phase at temperatures exceeding $800-900^{\circ} \mathrm{C}$. On the other hand, when the $\mathrm{CaO}$ needed to form the anorthite was calculated, it was observed that the $\mathrm{CaO}$ present in the GR body $(1.1 \%)$ only sufficed to form $5.5 \%$ anorthite. Therefore, the formation of larger anorthite contents requires part of the calcium from the $\mathrm{CaF}_{2}$ to contribute to anorthite formation by reacting with $\mathrm{SiO}_{2}$ and $\mathrm{Al}_{2} \mathrm{O}_{3}$ from clay mineral dehydroxylation. Moreover, the formation of anorthite at the expense of fluorite appears to be favoured thermodynamically at high temperature, to judge by the free energies of formation from their elements $\left(\Delta \mathrm{G}_{\mathrm{f}, 1300 \mathrm{~K}}^{\mathrm{o}}=-3259 \mathrm{~kJ} / \mathrm{mol}\right.$ for anorthite and $\Delta \mathrm{G}_{\mathrm{f}, 1300 \mathrm{~K}}^{\mathrm{r}}=-1012 \mathrm{~kJ} / \mathrm{mol}$ for fluorite). Fluorite is, therefore, likely to destabilise in the presence of $\mathrm{SiO}_{2}$ and $\mathrm{Al}_{2} \mathrm{O}_{3}$ and form anorthite at temperatures exceeding $800^{\circ} \mathrm{C}$. These findings could explain the ineffectiveness of the $\mathrm{CaF}_{2}$, which forms from the $\mathrm{CaO}$ present in stoneware compositions, to retain fluorine when these products are fired.

Figure 9 to 11 show the results, respectively, for mixtures M5, M10 and M15 in the range of temperatures from 800 to $1150{ }^{\circ} \mathrm{C}$; the results for mixture M0 in this temperature range are shown in Fig. 8. Note that at $800{ }^{\circ} \mathrm{C}$, clay minerals and calcite are no longer detected in any of the test compositions.

The evolution of $\mathrm{CaF}_{2}$ content in mixtures M5, M10 and M15 closely resembles that observed previously in $\mathrm{M} 0$, and consists of a progressive reduction in $\mathrm{CaF}_{2}$ content with rising temperature, until detection of $\mathrm{CaF}_{2}$ ceases between 1050 and $1150^{\circ} \mathrm{C}$. The small differences 


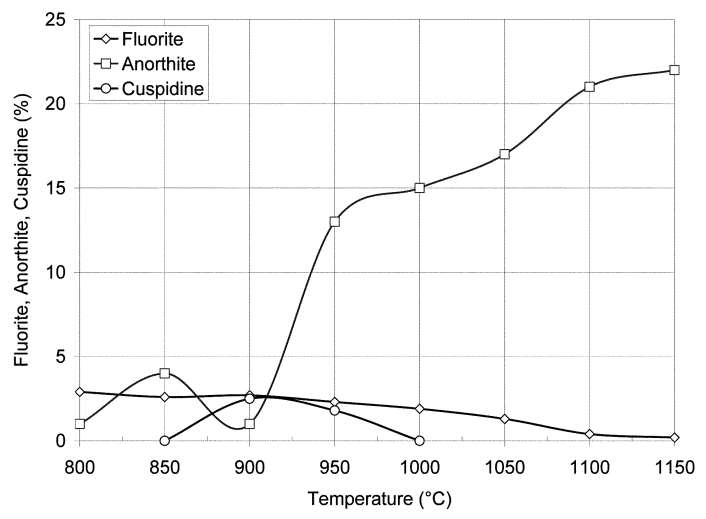

Fig. 9. Evolution of the crystalline phases present with thermal treatment temperature. Mixture M5.

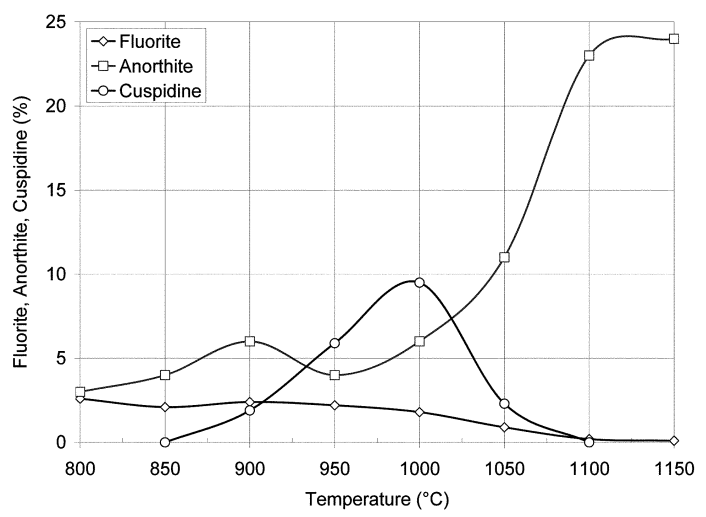

Fig. 10. Evolution of the crystalline phases present with thermal treatment temperature. Mixture M10.

noted in $\mathrm{CaF}_{2}$ content when the $\mathrm{CaCO}_{3}$ addition is modified are not considered significant, and are associated with the accuracy of the technique used.

The figures also evidence the appearance of a new crystalline species, cuspidine $\left(\mathrm{Ca}_{4} \mathrm{Si}_{2} \mathrm{O}_{7} \mathrm{~F}_{2}\right)$, which was not detected in M0. Cuspidine begins to crystallise above $850{ }^{\circ} \mathrm{C}$, and the cuspidine content in the pieces depends on the $\mathrm{CaCO}_{3}$ addition. Thus, in mixture M5 the cuspidine content maximises at $900^{\circ} \mathrm{C}$ and is only $2.5 \%$. In the mixtures with larger $\mathrm{CaCO}_{3}$ additions, the cuspidine content maximises around $1100^{\circ} \mathrm{C}$, and increases to $9.5 \%$ (M10) and $15.5 \%$ (M15).

The appearance of this crystalline species in the temperature range in which the $\mathrm{CaF}_{2}$ content decreases $\left(900-1100{ }^{\circ} \mathrm{C}\right)$ fixes the fluorine in the piece, which reduces fluorine compound emissions into the atmosphere in this range of temperatures. However, the cuspidine content diminishes rapidly above $1000^{\circ} \mathrm{C}$, and disappears completely at $1100^{\circ} \mathrm{C}$, with the ensuing increase in fluorine compound emissions. This could help explain the effectiveness of the $\mathrm{CaCO}_{3}$ addition in reducing such

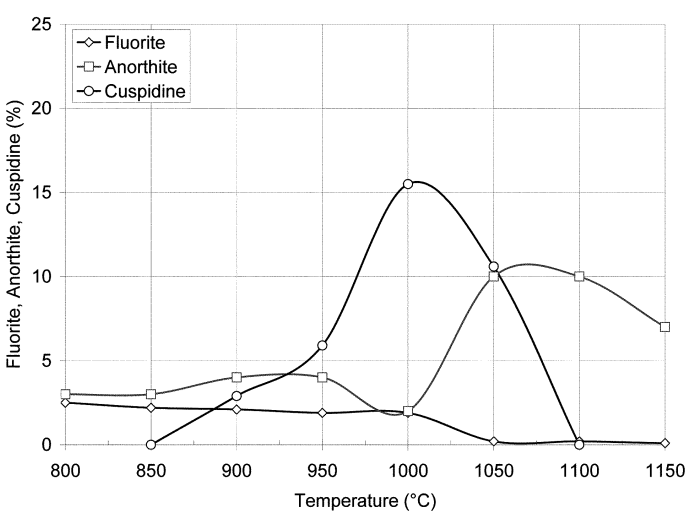

Fig. 11. Evolution of the crystalline phases present with thermal treatment temperature. Mixture M15.

emissions in products fired at temperatures below 1000 ${ }^{\circ} \mathrm{C}$ (roof tiles and bricks), and its ineffectiveness in products fired at higher temperatures (ceramic tiles).

Mixture M0 exhibits a progressive rise in anorthite content with heat-treatment temperature up to $1050^{\circ} \mathrm{C}$. The anorthite content then decreases at higher temperatures, owing to dissolution in the liquid phase in the piece. This tendency changes noticeably in the mixtures with $\mathrm{CaCO}_{3}$ additions. Thus, in M5 (Fig. 9) the anorthite content decreases between 850 and $900{ }^{\circ} \mathrm{C}$, coinciding with cuspidine formation, suggesting that cuspidine formation is thermodynamically favoured $\left(\Delta \mathrm{G}_{\mathrm{f}, 1300 \mathrm{~K}}^{\mathrm{o}}=\right.$ $-6271 \mathrm{~kJ} / \mathrm{mol}$ [16]) at these temperatures. Cuspidine disappears at higher temperatures, while the anorthite content increases notably up to $1150^{\circ} \mathrm{C}$. Mixture M5 displays no peak in anorthite content.

The evolution of anorthite content in mixtures M10 and M15 (Fig. 10 and 11) resembles that in M5. Thus, anorthite content decreases in the temperature ranges $900-950{ }^{\circ} \mathrm{C}$ and $950-1000{ }^{\circ} \mathrm{C}$ for calcite contents of $10 \%$ and $15 \%$, respectively, coinciding with cuspidine formation. After this there is a significant rise in anorthite content, concurrently with the disappearance of cuspidine. These results indicate that cuspidine formation is encouraged between 850 and $1000^{\circ} \mathrm{C}$, whereas anorthite formation is favoured at temperatures above $1000^{\circ} \mathrm{C}$.

Finally, the theoretical fluorine retention in the fluoridated crystalline phases present in the pieces at the different test temperatures has been calculated. The results are plotted in Fig. 12. The figure shows:

- The fluorine retained in the crystalline phases diminishes progressively up to $850^{\circ} \mathrm{C}$, owing to the reduction in $\mathrm{CaF}_{2}$ content. Above $850^{\circ} \mathrm{C}$ the retained fluorine content rises, due to $\mathrm{CaF}_{2}$ formation from the fluorine evolving from the GR body, and to cuspidine crystallisation.

- In the compositions with lower $\mathrm{CaCO}_{3}$ contents (M0 and M5) the retained fluorine content peaks at 900 ${ }^{\circ} \mathrm{C}$. At higher temperatures the quantity of retained 


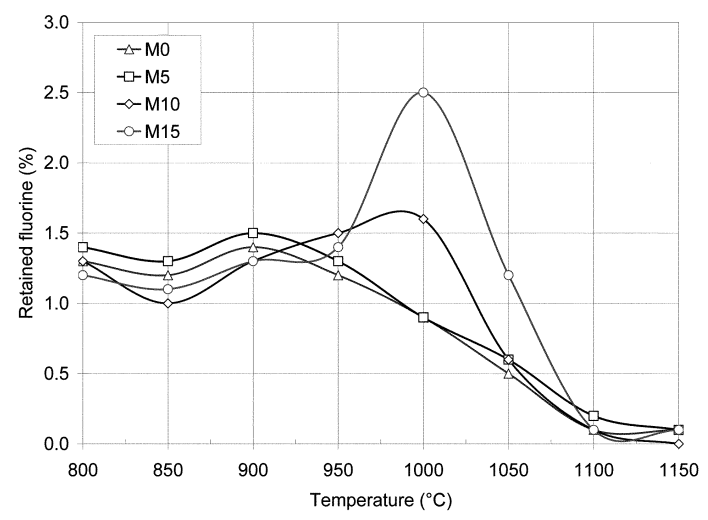

Fig. 12. Evolution of the fluorine retained in the crystalline phases with thermal treatment temperature.

fluorine decreases again, owing to the disappearance of $\mathrm{CaF}_{2}$ and cuspidine. This trend is observed up to $1150^{\circ} \mathrm{C}$, at which practically no fluorine is retained.

- The compositions with larger $\mathrm{CaCO}_{3}$ contents (M10 and $\mathrm{M} 15)$ also display a maximum retained fluorine content, albeit at higher temperatures $\left(1000^{\circ} \mathrm{C}\right)$. In these compositions the decrease in retained fluorine content caused by the reduction in $\mathrm{CaF}_{2}$ content above $900{ }^{\circ} \mathrm{C}$ is offset by the formation of important quantities of cuspidine, causing the retained fluorine content to rise between 850 and $1000{ }^{\circ} \mathrm{C}$.

Above $1000{ }^{\circ} \mathrm{C}$ the retained fluorine content decreases sharply in compositions M10 and M15, owing to the drop in $\mathrm{CaF}_{2}$ and cuspidine content. This trend continues up to $1150{ }^{\circ} \mathrm{C}$, at which practically no fluorine is retained in the crystalline phases.

\section{Conclusions}

The present study has determined the influence of $\mathrm{CaCO}_{3}$ content on the evolution of the crystalline phases with firing temperature in a typical floor tile composition to which additions of $\mathrm{CaF}_{2}$ were made; additions of $\mathrm{BaF}_{2}$ and $\mathrm{SrF}_{2}$ were also made to this floor tile body, and the thermal stability of these three fluoride compounds was studied. The following conclusions can be drawn from the study:

1. The thermal stability of $\mathrm{CaF}_{2}, \mathrm{BaF}_{2}$ and $\mathrm{SrF}_{2}$ decreases notably in a ceramic matrix. Their content in the matrix diminishes progressively, starting at low temperatures $\left(200^{\circ} \mathrm{C}\right.$ for $\left.\mathrm{CaF}_{2}\right)$, and is no longer detected at temperatures around $1100^{\circ} \mathrm{C}$.

2. During thermal treatment of the composition with $\mathrm{CaF}_{2}$ (without any $\mathrm{CaCO}_{3}$ addition), $\mathrm{CaO}$ displays a high tendency to form anorthite at temperatures exceeding $800^{\circ} \mathrm{C}$. This increases as temperatures rise further, even causing $\mathrm{CaF}_{2}$ destabilisation. The same behaviour is observed in the composition with $\mathrm{BaF}_{2}$, in which celsian formation is detected.
3. In the compositions with larger $\mathrm{CaCO}_{3}$ contents, cuspidine formation is favoured between 850 and $1050{ }^{\circ} \mathrm{C}$. This prevents the anorthite content from increasing, even causing it to diminish notably in this temperature range. The cuspidine content decreases sharply above $1000{ }^{\circ} \mathrm{C}$, while the anorthite content rises up to $1150^{\circ} \mathrm{C}$.

4. The effectiveness of the $\mathrm{CaCO}_{3}$ addition in reducing the emission of fluorine compounds in the compositions used in manufacturing structural ceramics (roof tiles and bricks) is due to two factors: the relatively low firing temperature of these products (850-1000 ${ }^{\circ} \mathrm{C}$ ) enables fixing part of the $\mathrm{CaF}_{2}$ that forms during firing in the pieces; and secondly, the presence of $\mathrm{CaO}$ in these compositions encourages the formation of cuspidine, which is stable up to temperatures between 1000 and $1050^{\circ} \mathrm{C}$. Both factors favour fluorine retention in the pieces, provided the firing temperature does not exceed $1050^{\circ} \mathrm{C}$.

5. The reason why the $\mathrm{CaCO}_{3}$ addition is ineffective in reducing fluorine emissions during ceramic tile firing is due to the higher processing temperature required for these products. Thus, the study shows that the crystalline species which contain fluorine (fluorite and cuspidine) are unstable between 1100 and $1150{ }^{\circ} \mathrm{C}$, causing fluorine emissions to rise at temperatures above $1100^{\circ} \mathrm{C}$.

6. These results, obtained in an electric kiln with an static air atmosphere using a standard floor tile body to which the different fluorides were added, could change when ceramic products are processed on an industrial scale. Thus, the presence of water vapour in industrial combustion kilns favours $\mathrm{CaF}_{2}$ destabilisation. In addition, the HF-containing gas stream, which circulates inside the kiln countercurrent to the ceramic tiles, favours $\mathrm{CaF}_{2}$ formation during preheating.

\section{Acknowledgments}

This study has been funded by the Spanish Ministry of Science and Technology in the frame of the National Plan for Scientific Research, Development and Technological Innovation 2000-2003. Reference PPQ200300869.

\section{References}

1. W. Strohmenger, ZI Int. 36 [2] (1983) 67-72.

2. H. Kolkmeier, ZI Int. 44[10] (1991) 544-548.

3. J.A.M. Denissen and A.H. Vries, ZI Int. 51[1-2] (1998) 1926.

4. B. Fabbri, Cerám. Inf. Tecnargilla special issue (1992) 3336.

5. A. Reymer and J. de Jong, in: Third Euro-Ceramics, edited by P. Durán and J.F. Fernández. (Faenza Editrice Ibérica, 1993) p. 1071-1076.

6. D.A. Brosnan, Am. Ceram. Soc. Bull. 71[12] (1992) 1798- 
1802

7. E. Galán, I. González, A. Miras, I. Carretero, and P. Aparicio, in: J. Zapatero, A.J. Ramón and M. Moya "Integración Ciencia-Tecnología de las arcillas en el contexto tecnológico-social del nuevo milenio" (Sociedad Española de Arcillas], 2000) pp. 59-68.

8. S.J. Chipera and D.L. Bish, Clays Clay Miner. 50[1] (2002) 38-46.

9. E. Monfort, I. Celades, S. Gomar, M.F. Gazulla, H. Adams and J. Tulip, in "VIII World congress on ceramic tile quality volume II" (Cámara Oficial de Comercio, Industria y Navegación, 2004) pp. GI401-GI413.

10. H. Kolkmeier, ZI Int. 32[11] (1979) 670-674.
11. D. Hauck, M. Ruppik, and R. Hilker, in "ZI-Jahrbuch 1992", edited by C. Kokot. (Bauverlag, 1992) pp. 47-73.

12. W. Schlandt, CFI/Ber. DKG 63[1-2] (1986) 71-76.

13. M.F. Gazulla, M.P. Gómez, M.J. Cabrera, and E. Monfort, Téc. Cerám. 243 (1996) 298-302.

14. J. García Ten, E. Monfort and M.F. Gazulla, in XLIII Congreso de la Sociedad Española de Cerámica y Vidrio, November 2003 (Sociedad Española de Cerámica y Vidrio, 2003).

15. M.J. Orts Tarí (Universitat de València, 1991) [Tesis Doctoral].

16. H. Fukuyama, H. Tabata, and K. Nagata, Metall. Mater. Trans. B 34[3] (2003) 307-331. 




\section{ARTíCULO № 3}

MONFORT, E.; GARCÍA-TEN, J.; CELADES, I.; GAZULLA, M. F.; GOMAR, S.

\section{Evolution of fluorine emissions during the fast firing of ceramic tile.}

Appl. clay sci., 38, 250-258, 2008.

Publicado en: febrero de 2008

Número de citas (fuente: SCOPUS el 30 de junio de 2015): 14

Factor de impacto de la revista (2008): 2,005

Factor de impacto de la revista en cinco años (2008): ND 



\title{
Evolution of fluorine emissions during the fast firing of ceramic tile
}

\author{
E. Monfort*, J. García-Ten, I. Celades, Mª.F. Gazulla, S. Gomar \\ Instituto de Tecnología Cerámica, Asociación de Investigación de las Industrias Cerámicas, Universitat Jaume I, Castellón, Spain
}

Received 18 October 2006; received in revised form 5 March 2007; accepted 7 March 2007

Available online 12 March 2007

\begin{abstract}
The present paper examines the emission-adsorption phenomena of fluorine compounds in various ceramic tile body compositions with different fluorine and calcium contents, processed by fast firing cycles in an electric laboratory batch kiln and in continuous fast-cycle industrial combustion kilns (roller kilns). In the roller kilns, fluorine emission was monitored by analysing the fluorine content in both solid and gas samples throughout the kilns.

It was found that fluorine emission during firing in air atmosphere in the laboratory batch kiln began at temperatures above $800{ }^{\circ} \mathrm{C}$ and increased progressively up to peak firing temperature. In the roller kilns, however, the emissions started at lower temperatures and decreased in certain kiln zones. This decrease indicates that there are regions in these kilns in which fluorine is adsorbed rather than emitted by the material being processed.

A fluorine adsorption process is thus shown to occur in the preheating stage in the roller kilns, despite the rapid heating rate. However, encouraging this adsorption process in order to foster the formation of crystalline phases is ineffective in abating fluorine emissions when ceramic tiles are fired at peak temperatures exceeding $1100{ }^{\circ} \mathrm{C}$.
\end{abstract}

(C) 2007 Elsevier B.V. All rights reserved.

Keywords: Ceramic tile; Firing; Fluorine; Emission

\section{Introduction}

Fluorine compounds are typically emitted during the heat treatment of clay materials at temperatures above $600{ }^{\circ} \mathrm{C}$ because many clay minerals contain fluorine in their crystalline structure, mainly as $\mathrm{F}^{-}$ions which replace $\mathrm{OH}^{-}$ions. When firing occurs in industrial combustion kilns the most abundant compound emitted is HF (Brosnan, 1994; Nelms et al., 1995; Monfort et al., 2004), which is partly exhausted into the atmosphere together with the combustion gases. In recent years environmental legislation in the more developed countries

\footnotetext{
* Corresponding author. ITC Campus Riu Sec 12006 Castellón, Spain. Tel.: +34 9643424 24; fax: +34 964342425 .

E-mail address: emonfort@itc.uji.es (E. Monfort).
}

(such as the European Union and the United States) has set strict limits on the emission of these compounds into the atmosphere (Brosnan, 1992; IPTS, 2006), the specific emission limit values for ceramic industries being about 5-10 mg HF/ $\mathrm{Nm}^{3}$ at $18 \% \mathrm{O}_{2}$. This has fostered the development of systems for the prevention and abatement of fluorine compound emissions during the firing of ceramic materials, particularly in the EU, and promoted study of emission origins and mechanisms, and of possible emission reduction measures (Mazzali et al., 1980; Strohmenger, 1983; Dehne, 1987; Hauck et al., 1992; Reymer and Jong, 1993; Denisen and Vries, 1998; Galán et al., 2002; Gonzalez et al., 2002; García-Ten et al., 2006; Gonzalez et al., 2006; IPTS, 2006).

Secondary or end-of-pipe systems are based on HF neutralisation in the residual gas stream. These systems 
Table 1

Characteristics of the end products obtained from the studied tile body compositions

\begin{tabular}{llll}
\hline Body reference & A & G & P \\
\hline Type of product & Wall tile & $\begin{array}{l}\text { Glazed } \\
\text { stoneware tile }\end{array}$ & $\begin{array}{l}\text { Porcelain } \\
\text { tile }\end{array}$ \\
$\begin{array}{lll}\text { Fired body colour } \\
\text { Glazed or unglazed }\end{array}$ & Red & Red & $\begin{array}{l}\text { White } \\
\text { Glazed or } \\
\text { unglazed }\end{array}$ \\
$\begin{array}{l}\text { Apparent porosity (\%) } \\
\begin{array}{l}\text { Group according to ISO 13006 } \\
\text { Spanish production in 2005 } \\
\text { (type of product/total \%) }\end{array}\end{array}$ & BIII & BIb-BIIa & BIa \\
& & 35 & 15 \\
\hline
\end{tabular}

mainly involve dry processes using $\mathrm{CaO}, \mathrm{Ca}(\mathrm{OH})_{2}$, $\mathrm{CaCO}_{3}$, or $\mathrm{NaHCO}_{3}$ as reagents, and provide very high efficiencies ( $>90 \%$ ), though they also require the installation of flue gas treatment systems and generate a new waste (Busani et al., 1995; Mallol et al., 2001). Primary or source reduction systems focus on raw materials and/or the process. Measures centering on raw materials include, for example, adding calcium compounds to the composition to encourage the HF present in the kiln atmosphere to form $\mathrm{CaF}_{2}$ in the products, thus retaining the fluorine. In regard to process-related measures, some authors (Hauck et al., 1992; Denisen and Vries, 1998) report that such reactions can be fostered in continuous kilns by increasing gas recirculation in the kiln preheating zone. However, ITC experience in relation to these approaches indicates that such measures remain largely ineffective when glazed or unglazed ceramic tiles are fired in fast cycles with peak temper-

Table 2

Chemical and mineralogical composition of the body compositions

\begin{tabular}{cllll}
\hline & & $\mathrm{A}$ & $\mathrm{G}$ & $\mathrm{P}$ \\
\hline Chemical & $\mathrm{SiO}_{2}$ & 57.5 & 64.0 & 65.8 \\
composition & $\mathrm{Al}_{2} \mathrm{O}_{3}$ & 15.6 & 17.5 & 20.6 \\
(wt.\%) & $\mathrm{Fe}_{2} \mathrm{O}_{3}$ & 5.26 & 6.01 & 0.66 \\
& $\mathbf{C a O}$ & $\mathbf{6 . 2 5} \pm \mathbf{0 . 1 0}$ & $\mathbf{1 . 2 1} \pm \mathbf{0 . 1 0}$ & $\mathbf{0 . 7 2} \pm \mathbf{0 . 1 0}$ \\
& $\mathrm{MgO}$ & 1.78 & 0.85 & 1.34 \\
& $\mathrm{Na}{ }_{2} \mathrm{O}$ & 0.41 & 0.47 & 4.48 \\
& $\mathrm{~K} 2 \mathrm{O}$ & 3.23 & 3.34 & 1.60 \\
Fluorine content & FOI & 9.18 & 5.93 & 3.91 \\
(mg/kg) & & $\mathbf{6 5 0} \pm \mathbf{2 0}$ & $\mathbf{6 2 0} \pm \mathbf{2 0}$ & $\mathbf{2 9 0} \pm \mathbf{1 5}$ \\
Mineralogical & Illite & 18 & 19 & 14 \\
composition & Kaolinite & 18 & 22 & 18 \\
(wt.\%) & Chlorite & 2 & - & 5 \\
& Quartz & 36 & 39 & 24 \\
& Albite & - & - & 38 \\
& Microcline & 6 & 6 & - \\
& Calcite & 10 & 3 & - \\
& Dolomite & 2 & 2 & \\
& Hematite & 5 & 6 & 0.5 \\
\hline
\end{tabular}

atures of 1100 to $1200{ }^{\circ} \mathrm{C}$ and firing times of about $50 \mathrm{~min}$.

As a first step to understanding why these approaches are ineffective, a previous lab study (García-Ten et al., 2006) addressed the thermal stability of fluorine compounds containing alkaline-earth elements. That study showed that the arising fluorine-containing crystalline species-fluorite $\left(\mathrm{CaF}_{2}\right)$ and cuspidine $\left(\mathrm{Ca}_{4} \mathrm{Si}_{2} \mathrm{O}_{7} \mathrm{~F}_{2}\right)$ were unstable in a ceramic matrix rich in silicon oxide $\left(\mathrm{SiO}_{2}\right)$ and aluminium oxide $\left(\mathrm{Al}_{2} \mathrm{O}_{3}\right)$ at temperatures above $1100{ }^{\circ} \mathrm{C}$.

The present paper examines the emission-adsorption phenomena of fluorine compounds during the firing of the most common types of ceramic tile body compositions used in the Castellón district (where $40 \%$ of the ceramic tiles made in the EU are manufactured). The heat treatments were performed in an electric laboratory batch kiln and in continuous fast-cycle industrial combustion kilns (roller kilns).

\section{Materials and experimental procedure}

\subsection{Materials}

Three typical industrial spray-dried powders used in manufacturing the main types of tile bodies made in the Spanish ceramic tile industry were selected, corresponding to a wall tile (A), glazed stoneware $(\mathrm{G})$, and porcelain tile $(\mathrm{P})$ composition. Tables 1 and 2 present the relevant characteristics of these products and the body compositions. The fluorine and calcium contents of the compositions are shown in bold type in Table 2, owing to their importance, as discussed further below.

The firing behaviour of the compositions differs as a function of the desired end properties (porosity, mechanical strength, etc.). Fig. 1 depicts the evolution of total and apparent porosity of the test compositions with temperature. Compositions $\mathrm{G}$ and $\mathrm{P}$ behave quite similarly. These types of compositions (used for producing stoneware and porcelain tiles) form liquid phase above $900{ }^{\circ} \mathrm{C}$ (Orts et al., 1993), which

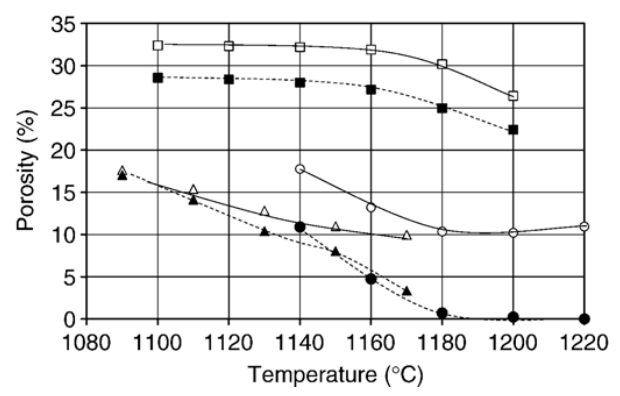

Fig. 1. Evolution of total porosity (-) and apparent (or open) porosity (---) with temperature of the compositions (squares: body A, triangles: body $\mathrm{G}$, circles: body $\mathrm{P}$ ) used in this study. 


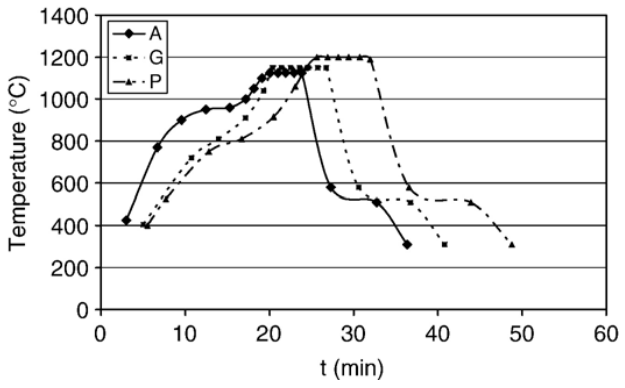

Fig. 2. Temperature-time curves in the roller kilns for the three studied compositions.

leads to a progressive reduction in body porosity with increasing temperature. In contrast, composition A displays quite a high, stable porosity in the temperature range analysed, owing to the crystallisation of calcium silicates and aluminosilicates (gehlenite, anorthite, and wollastonite) from the reaction of $\mathrm{CaO}$ obtained from calcite decomposition with $\mathrm{Al}_{2} \mathrm{O}_{3}$ and $\mathrm{SiO}_{2}$ from clay mineral dehydroxylation (Amorós et al., 1993).

\subsection{Heat treatments and sampling}

\subsubsection{Laboratory kiln}

The heat treatments in the laboratory kiln were conducted on cylindrical test pieces, $40 \mathrm{~mm}$ in diameter and $6 \mathrm{~mm}$ thick, formed by uniaxial pressing in a laboratory press. The mean dry bulk density of these pieces was $2.000 \pm 0.005 \mathrm{~g} / \mathrm{cm}^{3}$.

The laboratory heat treatments were performed in air atmosphere in an electric batch kiln. The firing cycle used was as follows:

O Heating: heating rate $25^{\circ} \mathrm{C} / \mathrm{min}$.

O Maximum temperatures: $400,600,800$, and $1000{ }^{\circ} \mathrm{C}$, in addition to peak firing temperatures of 1125,1150 , and $1200^{\circ} \mathrm{C}$, depending on the type of composition (A, G, or P). The residence time at these temperatures was $30 \mathrm{~min}$.
Cooling: forced convection, except in the range between 600 and $500{ }^{\circ} \mathrm{C}$, in which cooling was by natural convection.

\subsubsection{Industrial kilns}

To determine tile fluorine content in the roller kilns a significant number of (unglazed) tile samples were taken from the production line. The dry bulk densities were $1.95 \pm 0.03 \mathrm{~g} / \mathrm{cm}^{3}$ for composition P and $2.00 \pm 0.02 \mathrm{~g} / \mathrm{cm}^{3}$ for compositions A and $\mathrm{G}$.

Firing trials were conducted in three roller kilns fuelled by natural gas - each corresponding to a type of product. These are the kilns customarily used for ceramic tile production. The tiles were subjected to the standard thermal cycles used at the companies where the tests were carried out, with total firing times (cold to cold) between 40 and $55 \mathrm{~min}$, and peak temperatures of about 1125,1150 , and $1200^{\circ} \mathrm{C}$ for compositions $\mathrm{A}, \mathrm{G}$, and $\mathrm{P}$, respectively. The complete temperature-time curves are shown in Fig. 2.

Fig. 3 schematically illustrates one of these kilns. The most significant difference with respect to the laboratory kiln, besides the fuel used, is the movement of the combustion gases, which in industrial kilns circulate countercurrent to the tiles.

To study the fluorine emissions in these kilns, tile fluorine content was determined in different firing stages by taking tile samples from different parts of the kiln. In order to withdraw the tiles, rollers were removed in the relevant kiln areas and the tiles were allowed to fall onto the kiln floor. These were then collected manually and rapidly cooled to arrest the emission process. Knowing the sampling point and the firing cycle allowed determination of the maximum temperature to which each tile had been subjected.

Gas samples were extracted for analysis at different points in the roller kilns through the burner control openings (peepholes). This test procedure, based on American and European standards and fine-tuned at ITC (Monfort et al., 2003), has proved to provide good results. Certain basic precautions were taken in sampling, such as avoiding entry of outside air at points of the kiln in depression, using alumina probes, and using cooled probes in high-temperature zones $\left(T>1000^{\circ} \mathrm{C}\right)$.

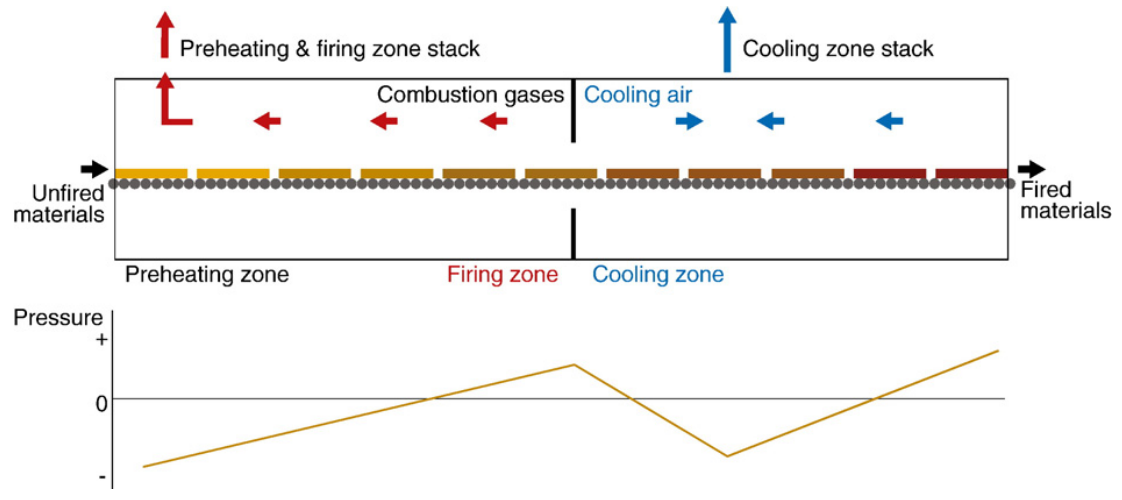

Fig. 3. Schematic illustration of the roller kiln with gas flow and static pressure curve. 


\subsection{Chemical analysis of fluorine content}

\subsubsection{In solid samples}

Tile fluorine content of the tile pieces was determined before and after heat treatment to establish the fluorine emissions during the firing stage. Sample preparation for the analytical determination of the fluorine content was performed by alkaline fusion of the samples with sodium carbonate followed by dissolution in water, elimination of the $\mathrm{Al}$ and $\mathrm{Fe}$ interferences, $\mathrm{pH}$ adjustment with a buffer (TISAB) and, finally, determination of the dissolved fluorine with an ion-selective electrode. The method is based on standard ASTM: D 1179 and was used because it has a lower detection limit than the X-ray fluorescence spectrophotometry method (Gazulla et al., 2003).

In order to obtain results of the unfired and heat-treated pieces that could be compared, a correction was made, taking into account the loss on ignition at each test temperature (Gonzalez et al., 2006). The corrected values were then used to calculate fluorine emission during heat treatment based on the difference between the initial fluorine content (unfired piece) and final fluorine content (pieces heat-treated at the test temperatures).

\subsubsection{In gaseous samples}

The fluorine compounds in the gas samples were determined by capturing a known volume of gas with an appropriate probe, asset out above, and determining the fluorine present in the capturing solution with an ion-selective electrode. The fluorine concentration in the gas stream was then calculated (Monfort et al., 2003).

\section{Results and discussion}

3.1. Firing in the electric laboratory kiln. Evolution of fluorine content in the test pieces

The results obtained in the study of the fluorine content of the ceramic test pieces fired at different temperatures in the electric laboratory kiln are sum-

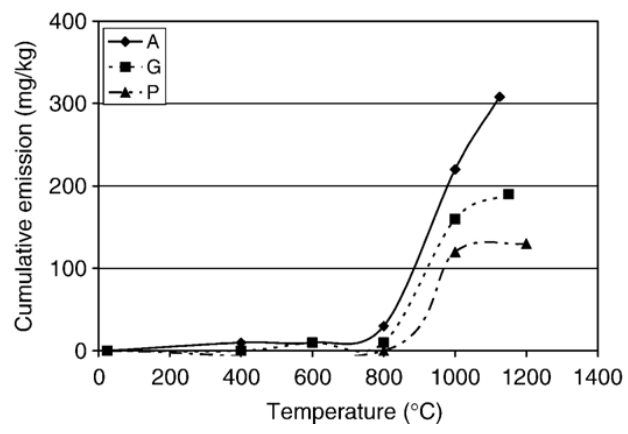

Fig. 4. Cumulative fluorine emissions in the electric laboratory kiln.

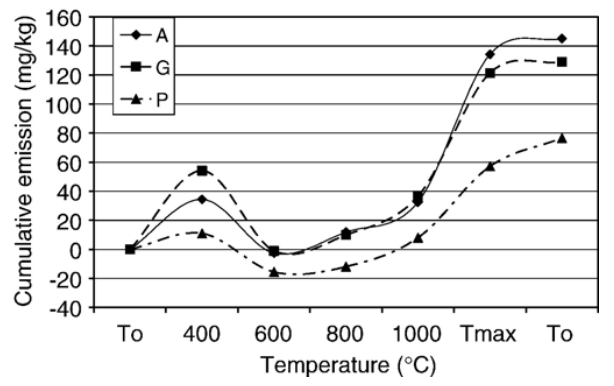

Fig. 5. Cumulative fluorine emissions $(\mathrm{mg} / \mathrm{kg})$ in the roller kilns (where $T_{0}$ is ambient temperature).

marised in Fig. 4, expressed as the cumulative fluorine emission at each temperature in absolute value.

Fig. 4 shows that the fluorine emission in air atmosphere of the three studied tile compositions only becomes significant above $800{ }^{\circ} \mathrm{C}$. Above this temperature the emissions increase progressively up to peak firing temperature. However, the respective increases differ, depending on the composition. Thus, while the composition A fluorine emission increases continually, that of compositions $G$ and $P$ displays a certain stabilisation above $1000{ }^{\circ} \mathrm{C}$. This difference in behaviour might be related to the larger quantity of liquid phase that forms in compositions $\mathrm{G}$ and $\mathrm{P}$ compared with that in composition $\mathrm{A}$, which reduces gas permeability, making fluorine emission more difficult. Although there are some differences in the chemical and mineralogical composition of the test compositions, the main difference in regard to fluorine retention is the greater calcium content of composition A in comparison with that of the other compositions; however, this characteristic does not appear to have a significant effect on fluorine retention. This might be explained by the results obtained in previous studies (García-Ten et al., 2006), and is discussed in detail below (Section 3.2.3).

\subsection{Firing in the roller kilns}

\subsubsection{Evolution of fluorine content in the tiles}

The results obtained in the study of the evolution of fluorine content in the tiles during firing in the roller kilns are plotted in Figs. 5-8.

The cumulative fluorine emission is respectively plotted in absolute $(\mathrm{mg} / \mathrm{kg})$ and relative (\%) values in Figs. 5 and 6. It may be observed, first, that the three compositions display similarly shaped curves, indicating that the emission mechanism is also similar. However, unlike the evolution observed in the experiments conducted in air atmosphere in the batch process 


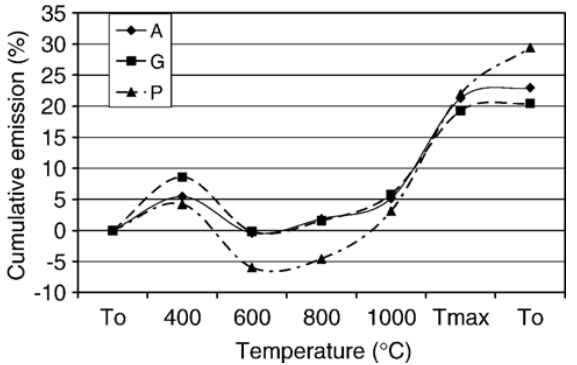

Fig. 6. Cumulative fluorine emissions (\%) in the roller kilns (where $T_{0}$ is ambient temperature).

(laboratory kiln), the emission begins at lower temperatures and there is no progressive rise in the emission values; instead, in some kiln zones the cumulative emission even decreases. This last effect indicates that there are kiln zones in which tiles adsorb rather than emit fluorine. Moreover, the absolute emission values are notably lower than the values recorded in the laboratory batch kiln (Fig. 4), particularly in composition A.

During the cooling stage there is no significant fluorine emission. Only composition P displays a slight fluorine emission, which is probably due to the higher firing temperature of this material.

In order to observe more clearly what occurs in each kiln zone, the differential emission of fluorine is respectively plotted in absolute $(\mathrm{mg} / \mathrm{kg})$ and relative $(\%)$ values in Figs. 7 and 8.

The following may be observed in Figs. 7 and 8:

- The temperatures at which emission and adsorption occur coincide in the three studied compositions, though the magnitude of these phenomena differs, owing to the differences in composition, heat treatment, and porosity indicated above.

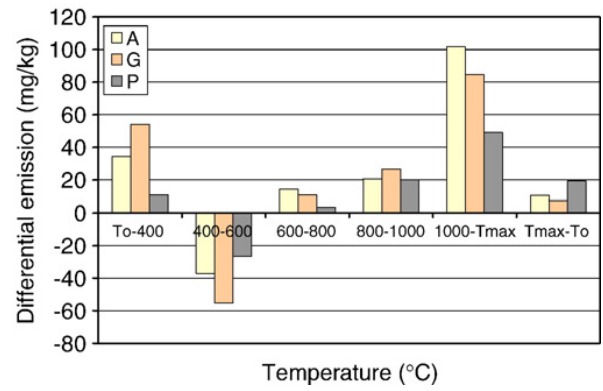

Fig. 7. Differential emissions of fluorine $(\mathrm{mg} / \mathrm{kg})$ in the roller kilns, in absolute values.
- A first fluorine emission occurs at low temperature, between ambient temperature $\left(T_{0}\right)$ and $400{ }^{\circ} \mathrm{C}$. This emission was not detected in the electric kiln with air atmosphere. According to the literature (Reymer and Jong, 1993) this difference is due to the absence of water vapour in the electric kiln atmosphere, and evidences the influence of the chemical composition of the kiln atmosphere.

- In the temperature range between 400 and $600{ }^{\circ} \mathrm{C}$, fluorine is adsorbed by the tiles, and the fluorine content in the tile increases in every case. The adsorbed fluorine comes from the gases that circulate countercurrent to the tiles from the peak temperature area towards the kiln entrance, an effect that also occurs when firing takes place in tunnel kilns (Hauck et al., 1992).

- Fluorine is released again above $600{ }^{\circ} \mathrm{C}$, up to peak firing temperature. The emission in this kiln zone increases notably with the rise in temperature, and maximises between $1000{ }^{\circ} \mathrm{C}$ and peak firing temperature. This behaviour differs from that observed in the laboratory kiln for compositions $\mathrm{G}$ and $\mathrm{P}$, in which a certain stabilisation of the fluorine emission was noted at high temperatures.

- As it was noted previously in the cumulative emissions, during cooling from peak temperature $\left(T_{\max }\right)$ to ambient temperature $\left(T_{0}\right)$ there is a slight fluorine emission, attributable to the high tile temperature in the first cooling zone. The emission is more significant in composition $\mathrm{P}$, particularly in relative terms, probably because this composition is subjected to a higher firing temperature $\left(1200^{\circ} \mathrm{C}\right)$.

These results in the fast firing roller kilns match the findings reported in the literature for other ceramic products (Hauck et al., 1992; Denisen and Vries, 1998), such as bricks and roof tiles, which are typically fired in tunnel kilns. Those studies describe the enormous

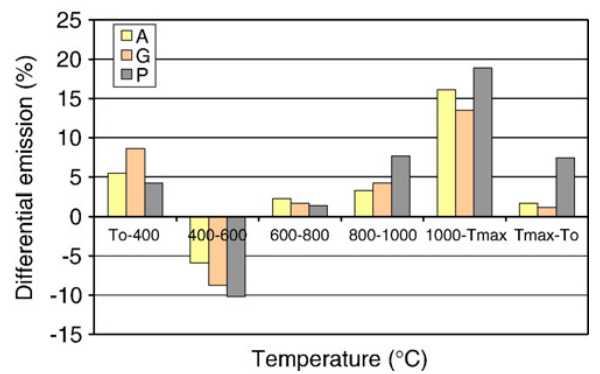

Fig. 8. Differential emissions of fluorine (\%) in the roller kilns, in relative values. 
influence of water vapour from combustion on fluorine emission at low temperature $\left(T<400{ }^{\circ} \mathrm{C}\right)$, as well as the existence of adsorption during preheating $\left(400-600^{\circ} \mathrm{C}\right)$ in continuous combustion tunnel kilns. However, in contrast to the predictions made in the foregoing studies for other ceramic products fired at lower peak temperatures $\left(800-1000{ }^{\circ} \mathrm{C}\right)$, comparison of compositions $\mathrm{A}$ and $\mathrm{G}$, whose fundamental difference is their calcium content, reveals no important differences in their overall fluorine compound emissions.

3.2.2. Evolution of HF content in the gaseous samples

As already mentioned, the literature (Reymer and Jong, 1993) indicates that the presence of water vapour in the kiln atmosphere plays an important role in HF emission during the firing of ceramic products, since the water in the atmosphere reacts with the fluorine in the raw materials to form HF. In the roller kilns involved in this study, most of the water in the atmosphere (over $80 \%$ ) comes from the water that forms in natural gas combustion. In order to study this phenomenon in greater detail a further series of tests were conducted on the roller kiln gases. Figs. 9 and 10 depict, respectively, the evolution of water and HF content in the roller kiln in which composition A was fired. For these calculations (water content and HF mass flow) the gas flow rate throughout the kiln was calculated theoretically from the experimental values of the combustion air and natural gas flow rates in the different burner groups (12 groups), taking into account the natural gas composition, the chemical combustion reactions, and the gas flow inside the kiln illustrated in Fig. 3.

The following may be noted in Figs. 9 and 10:

- The water content $\left(\mathrm{H}_{2} \mathrm{O}\right)$ that develops inside the kiln during natural gas combustion is plotted in Fig. 9. The graph shows that the water vapour produced in

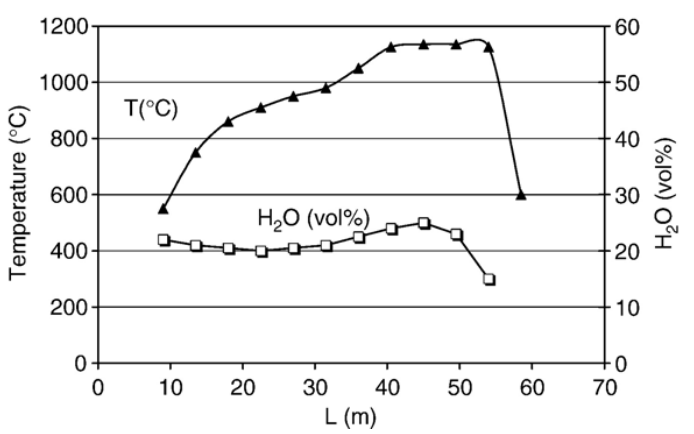

Fig. 9. Temperature and water vapour profiles in the roller kiln used for firing composition $\mathrm{A}$.

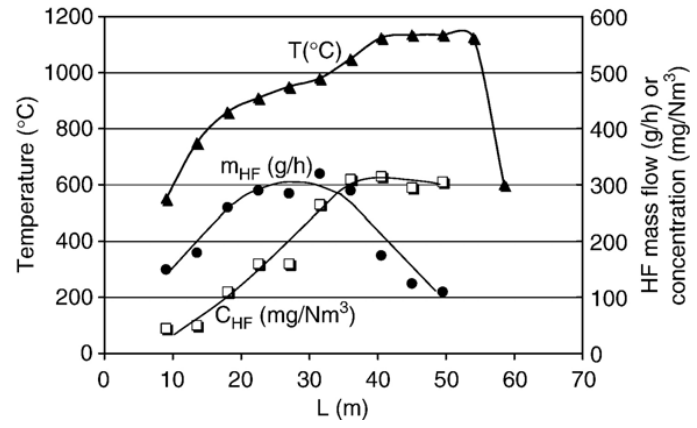

Fig. 10. Evolution of HF content in the roller kiln used for firing composition A.

combustion accounts for 15 to $25 \%$ of the gas volume circulating inside the kiln.

- The HF concentration values $\left(C_{\mathrm{HF}}\right)$ plotted in Fig. 10 have been experimentally determined from gas samples taken in different kiln zones. These values have been used to calculate HF mass flow $\left(m_{\mathrm{HF}}\right)$ throughout the kiln, while the combustion gas flow rates in the different burner groups have been calculated from the natural gas and air flow rates, taking into account the combustion reactions and the gas circulation direction (Fig. 3).

- The HF mass flow $\left(m_{\mathrm{HF}}\right)$ curve displays a maximum. Since the gases in the kiln circulate countercurrent to tile advance through the kiln, it may be inferred that there is a region in the preheating zone in which tiles adsorb fluorine from the kiln atmosphere, as it was noted above in the tests on tile fluorine content. In the roller kiln, however, the adsorption region in which fluorine mass flow decreases (Fig. 10, obtained from gas analysis) shifts towards slightly hotter areas, compared with the findings for tile fluorine content (Figs. 7 and 8), which might be due to the experimental difficulties involved in the sampling procedure.

\subsubsection{Thermal stability of the fluorine adsorbed in preheating}

The results obtained in the determination of the fluorine content in industrial tiles and of the fluorine concentration in the roller kiln atmosphere evidence the existence of a temperature range between 400 and $600{ }^{\circ} \mathrm{C}$ in which fluorine is captured by the tiles.

To verify this finding a series of experiments were conducted in which unfired industrial tiles of compositions $A$ and $G$ were held in the bottom part (under the rollers) of the preheating chamber of an industrial kiln for different times. The kiln zone chosen was the $600{ }^{\circ} \mathrm{C}$ region, in which the tiles might capture fluorine. As a 
panel of the kiln wall had to be removed to introduce and take out the test pieces, this test was only conducted with industrial tiles made from compositions A and G. The results obtained are shown in Fig. 11 (hollow symbols).

The figure shows that the fluorine content of body A increases progressively with tile residence time in the roller kiln. In contrast, body $\mathrm{G}$ only displays a rise in fluorine content with short times. At longer times, fluorine content is observed to stabilise with residence time.

These results demonstrate the capacity of unfired tiles - especially of composition A, which contains more calcite - to capture fluorine during the preheating stage in an industrial kiln. This is particularly the case when the tiles are subjected to slow firing cycles (tunnel kilns) with hour-long soaks at these temperatures (Hauck et al., 1992). When firing takes place in fast cycles (roller kilns), however, owing to the high heating rate, tile residence time in the adsorption area $\left(400-600{ }^{\circ} \mathrm{C}\right)$ is very short (2-4 $\mathrm{min})$, which limits the magnitude of the adsorption process.

This effect, described by other authors in calcareous compositions used in the manufacture of clay products fired in tunnel kilns at lower peak temperatures, has been used to diminish the emission of fluorine compounds during firing. The same procedure might also be used to reduce fluorine compound emissions during the firing of ceramic tiles in fast cycles, if the fluorine captured in preheating were to remain totally or partly in the pieces in the high temperature zone by suitably modifying the firing curves or kiln design. In this case, encouraging fluorine capture in preheating might reduce stack emissions of fluorine compounds.

In order to study the thermal stability of the fluorine captured in preheating, compositions $\mathrm{A}$ and $\mathrm{G}$ were held at $600{ }^{\circ} \mathrm{C}$ for different times inside the industrial kiln and then heat-treated at maximum temperatures of about

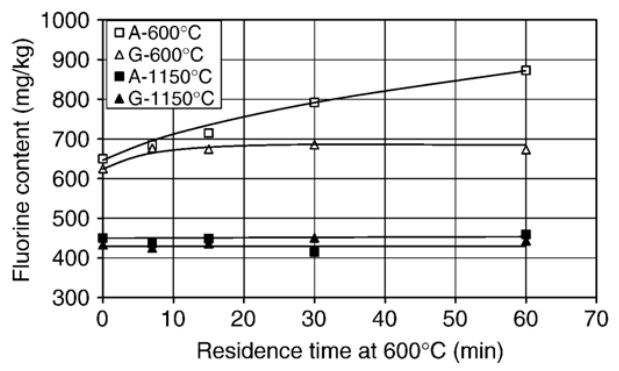

Fig. 11. Fluorine content of bodies A and $\mathrm{G}$ held for different times at $600{ }^{\circ} \mathrm{C}$ (hollow symbols) and subsequently treated at $1150{ }^{\circ} \mathrm{C}$ for 6 min (solid symbols).
Table 3

Stability of fluorine adsorption in the fired tile compositions

\begin{tabular}{lllll}
\hline Samples & $\begin{array}{l}\text { Fluorine } \\
\text { content } \\
(\mathrm{mg} / \mathrm{kg})\end{array}$ & Emission & $\mathrm{mg} / \mathrm{kg}$ & $\%$ \\
\cline { 3 - 5 } & Fired at $1125{ }^{\circ} \mathrm{C}$ & $500 \pm 20$ & - & - \\
& Refired at $1125{ }^{\circ} \mathrm{C}(6 \mathrm{~min})$ & $360 \pm 20$ & 140 & 28 \\
$\mathrm{G}$ & Refired at $300^{\circ} \mathrm{C}(30 \mathrm{~min})$ & $490 \pm 20$ & 0 & 0 \\
& Fired at $1150{ }^{\circ} \mathrm{C}$ & $490 \pm 20$ & - & - \\
& Refired at $1150{ }^{\circ} \mathrm{C}(6 \mathrm{~min})$ & $440 \pm 20$ & 50 & 10 \\
& Refired at $300^{\circ} \mathrm{C}(30 \mathrm{~min})$ & $500 \pm 20$ & 0 & 0 \\
\hline
\end{tabular}

$1150{ }^{\circ} \mathrm{C}$ for $6 \mathrm{~min}$ in an electric laboratory kiln. Their fluorine content was then determined. This heat treatment was intended to simulate the time that the pieces remained at high temperature during the industrial firing stage (Fig. 2) and to monitor the thermal stability of the fluorine compounds that formed during preheating adsorption.

The results are presented as solid symbols in Fig. 11. They show that the fluorine content of compositions A and $\mathrm{G}$, heat-treated at $1150^{\circ} \mathrm{C}$, is practically independent of tile residence time at $600{ }^{\circ} \mathrm{C}$. This indicates that all the fluorine captured by compositions A and $\mathrm{G}$ during preheating is subsequently emitted when the pieces reach the peak temperature zone of the roller kiln.

This behaviour may be interpreted on the basis of the results reported elsewhere (García-Ten et al., 2006), which demonstrated the low thermal stability of the fluorine crystalline compounds that formed in the preheating stage-fluorite $\left(\mathrm{CaF}_{2}\right)$ and cuspidine $\left(\mathrm{Ca}_{4} \mathrm{Si}_{2} \mathrm{O}_{7} \mathrm{~F}_{2}\right)$ - in a ceramic matrix rich in $\mathrm{SiO}_{2}$ and $\mathrm{Al}_{2} \mathrm{O}_{3}$ at temperatures above $1100{ }^{\circ} \mathrm{C}$. Note that the formation of anorthite $\left(\mathrm{CaAl}_{2} \mathrm{Si}_{2} \mathrm{O}_{8}\right)$ at the expense of fluorite is favoured thermodynamically $\left(\Delta G_{f, 1300 \mathrm{~K}}=\right.$ $-3259 \mathrm{~kJ} / \mathrm{mol}$ for anorthite and $\Delta G_{f, 1300 \mathrm{~K}}=$ $-1012 \mathrm{~kJ} / \mathrm{mol}$ for fluorite), which explains the low stability of the above compounds in these matrices at temperatures about $1000{ }^{\circ} \mathrm{C}$. Thus, fostering fluorine capture in preheating as a way of reducing fluorine emissions (as suggested for other ceramic materials fired in slow cycles and subjected to maximum temperatures of about $1000^{\circ} \mathrm{C}$ ) is ineffective in the studied compositions - even in the composition richer in calcium - because these compositions are subjected to peak firing temperatures exceeding $1100{ }^{\circ} \mathrm{C}$.

\subsubsection{Fluorine emission in a second heat treatment}

The results show that tiles fired in fast industrial firing cycles contain significant amounts of residual fluorine. To determine whether the fired tiles could emit fluorine during a second heat treatment (for example in a 
double-firing or even a third-fire process, or in drying after a polishing process), these tiles were refired in an electric kiln under different conditions.

First, to simulate a double-firing process, fired pieces of compositions $A$ and $\mathrm{G}$ were refired in a laboratory kiln at peak firing temperatures, respectively, of $1125^{\circ} \mathrm{C}$ for composition A (rich in calcium, with high fired porosity) and $1150{ }^{\circ} \mathrm{C}$ for composition $\mathrm{G}$ (poor in calcium, with low fired porosity), each piece being held for $6 \mathrm{~min}$ at the corresponding peak temperature.

Secondly, to simulate a drying process after possible machining operations (cutting, polishing, etc.), fired pieces of compositions $\mathrm{A}$ and $\mathrm{B}$ were refired at $300^{\circ} \mathrm{C}$ for $30 \mathrm{~min}$.

The results are summarised in Table 3 . They show that the studied materials are able to emit fluorine compounds in a second high-temperature firing, especially composition A. As observed previously, the composition richest in calcium produces the greatest emissions, probably owing to its greater fired porosity (and ensuing permeability) and the instability of the fluorine crystalline phases at peak firing temperature. The main limitation associated with the results in Table 3 is that they have been obtained in an electric batch kiln, in which the emission process is favoured for the reasons noted in Section 3.2.3; therefore, the emissions obtained in these experiments might be higher than in continuous industrial kilns. Nevertheless, these results explain qualitatively the behaviour observed in industrial practice and reported by other authors (Palmonari and Timellini, 1982; Dogeroglu and Kara, 2002) in relation to double-firing processes in which fluorine emission is observed in the second firing, even though fluorine-free glazes are customarily used.

On the other hand, in low-temperature thermal processes (such as drying of machined tiles) at temperatures of about $300{ }^{\circ} \mathrm{C}$, no fluorine emissions are observed, as was to be expected.

The low fluorine content and the detection limits of fluorine crystalline compounds by X-ray diffraction have not allowed a more detailed study of the form in which the fluorine compounds are retained in the fired samples, and of the emission mechanisms.

\section{Conclusions}

In this study, the fluorine emissions produced during the firing of different ceramic tile compositions in an electric laboratory batch kiln and in continuous fastcycle industrial combustion kilns (roller kilns) have been determined. The following conclusions may be drawn:

- The fluorine emissions of the studied wall tile (A), glazed stoneware $(\mathrm{G})$, and porcelain tile (P) compositions during firing in air atmosphere in a laboratory batch kiln did not become significant until temperatures above $800{ }^{\circ} \mathrm{C}$ were reached. Beyond this temperature there was a progressive increase in fluorine emission up to each respective peak firing temperature. However, this increase differed quantitatively as a function of the type of composition involved.

- The firing of these compositions in the roller kilns did not lead to a continuous, progressive rise in emissions; instead, the cumulative emission even decreased in some kiln zones. This last effect indicates that there are regions in the kilns in which fluorine is adsorbed rather than emitted by the material being processed. The temperatures at which emission and adsorption occurred coincided in the three studied compositions, though the magnitude of these phenomena was different. These results, observed in the fluorine analysis of both the tiles and the kiln gases, are qualitatively consistent with those reported in the literature for other types of clay compositions fired in tunnel kilns.

- The tests showed that practically all the fluorine adsorbed during preheating was subsequently released when the tiles reached peak temperature $\left(T>1100^{\circ} \mathrm{C}\right)$. These results demonstrate the ineffectiveness of the measures (raising calcium content and favouring gas-tile contact) aimed at encouraging fluorine adsorption in preheating, as a way of reducing fluorine emissions, when ceramic products are fired at peak temperatures exceeding $1100{ }^{\circ} \mathrm{C}$. There is a thermodynamic reason for this behaviour and it makes these measures ineffective for preventing fluorine emissions under these conditions. These findings are in accordance with practical experience in the ceramic tile industry.

- Finally, the study shows that tiles fired in fast industrial cycles (40-60 min) are able to emit fluorine when they are subjected to a second firing at high temperature. This was particularly the case with composition A (wall tiles), probably due to the resulting high fired porosity. The foregoing explains why ceramic tile manufactured by fast single-firing cycles gives rise to lower fluorine compound emissions than slow firing and/or double-firing processes.

\section{Acknowledgements}

This study has been funded by the Spanish Ministry of Science and Technology in the frame of the National Plan for Scientific Research, Development, and Technological Innovation 2000-2003, reference PPQ200300869. 


\section{References}

Amorós, J.L., Escardino, A., Sánchez, E., Zaera, F., 1993. Stabilità delle dimensioninelle piastrelle porose monocotte. Ceram. Inf. 324, 56-67 (in Italian).

Brosnan, D.A., 1992. Technology and regulatory consequences of fluorine emissions in ceramic manufacturing. Am. Ceram. Soc. Bull. 71 (12), 1798-1802.

Brosnan, D.A., 1994. Monitoring for hydrogen fluoride emissions. Ceram. Ind. 143 (1), 38-40.

Busani, G., Palmonari, C., Timellini, G., 1995. Ceramic tiles and the environment: air and water emissions, solid waste and noise. Ed. Edic. Cer. (in Italian).

Dehne, G., 1987. Relationship between fluorine emission during firing of ceramic products and the firing temperature and composition of raw material. Appl. Clay Sci. 2, 1-9.

Denisen, J.A.M., Vries, A.H., 1998. Reduction of fluoride emission from clay materials. ZI Int. 51 (1-2), 19-26.

Dogeroglu, T., Kara, S., 2002. Fluoride emission factors for ceramic wall-tile kilns. Am. Ceram. Soc. Bull. 81 (7), 52-56.

Galán, E., Gonzalez, I., Fabbri, B., 2002. Estimation of fluorine and chlorine emissions from Spanish structural ceramic industries. The case study of the Bailén area. Southern Spain. Atmos. Environ. 36, 5289-5298.

García-Ten, J., Monfort, E., Gómez, P., Gomar, S., 2006. Influence of calcite content on fluorine compound emissions during ceramic tile firing. J. Ceram. Process. Res. 7 (1), 675-682.

Gazulla, M.F., Gómez, P., Barba, A., Monfort, E., Orduña, M., 2003. A methodology for characterising ceramic wastes. Manag. Environ. Qual. Int. J. 14 (3), 333-343.

Gonzalez, I., Aparicio, P., Galán, E., Fabbri, B., 2002. A proposal for reducing $\mathrm{F}$ and $\mathrm{Cl}$ emission in the brick industry using new formulations. Appl. Clay Sci. 22, 1-7.

Gonzalez, I., Galán, E., Miras, A., 2006. Fluorine, chlorine and sulphur emissions from the Andalusian ceramic industry (Spain). Proposal for their reduction and estimation of threshold emission values. Appl. Clay Sci. 32, 153-171.
Hauck, D., Ruppik, M., Hilker, R., 1992. Reduction of fluorine emission by re-bonding in the preheating zone - final evaluation. ZI-Jahrbuch/bearbeitet Von Christina Kokot. Bauverlag, Wiesbad, pp. $47-73$.

IPTS. European Commission, December 2006. Reference Document on Best Available Techniques in the Ceramic Manufacturing Industry. http://eippcb.jrc.es. December 2006. 258 pp.

Mallol, G., Monfort, E., Busani, G., Lezaun, J., 2001. Combustion gas cleaning in the ceramic tile industry, In: ITC-AICE (Ed.), Technical Guide, 2nd edition. ISBN: 84-923176-5-5 (in Spanish).

Mazzali, P., Fogliani, G., Orlandi, L., Busani, G., 1980. Effetto della temperatura e del contenuto di calcio e magnesio sulla cessione di fluoronella cottura di piastrelle ceramiche. La Ceramica 33, 1-6 (in Italian).

Monfort, E., Gazulla, Mª.F., Celades, I., Gómez, P., Bigi, M., Tonelli, M., 2003. Ceramic kiln fluorine gas emission measurement. Am. Ceram. Soc. Bull. 82 (2), 31-35.

Monfort, E., Celades, I., Gomar, S., Gazulla, M.F., Adams, H., Tulip, J., 2004. Application of an on-line measurement system for HF emission control. Proceedings of the VIII World Congress on Ceramic Tile Quality. Castellón. Cámara Oficial de Comercio, Industria y Navegación, vol. II, pp. 401-413.

Nelms, L., Pretorius, F., Ranney, J.Q., Stoffa, G.M., 1995. Study rates HF measurement methods. Am. Ceram. Soc. Bull. 74 (2), 42-47.

Orts, Ma.J., Escardino, A., Amorós, J.L., Negre, F., 1993. Microstructural changes during the firing of stoneware floor tiles. Appl. Clay Sci. 8 (2/3), 193-205.

Palmonari, C., Timellini, G., 1982. Pollutant emission factors for the ceramic floor and wall tile industry. APCA J. 32 (10), 1095-1100.

Reymer, A., Jong, J., 1993. Fluoride emission of ceramic products. In: Durán, P., Fernández, J.F. (Eds.), Third Euro-Ceramics, vol. II. Faenza Editrice Ibérica, Castellón, pp. 1071-1076.

Strohmenger, W., 1983. Zur Fluorproblematik in der Ziegelindustrie (Problems associated with fluorine in the German brick and tile industry). ZI Int. 36 (2), 67-72. 



\section{ARTÍCULO № 4}

MONFORT, E.; GARCÍA-TEN, J.; CELADES, I.; GOMAR, S.

\section{Monitoring and possible reduction of HF in stack flue gases from ceramic tiles.}

J. Fluorine Chem., 131, 6-12, 2010.

Publicado en: enero de 2010

Número de citas (fuente: SCOPUS el 30 de junio de 2015): 6

Factor de impacto de la revista (2010): 1,719

Factor de impacto de la revista en cinco años (2010): 1,868 

Review

\title{
Monitoring and possible reduction of HF in stack flue gases from ceramic tiles
}

\author{
E. Monfort*, J. García-Ten, I. Celades, S. Gomar
}

Instituto de Tecnología Cerámica, Asociación de Investigación de las Industrias Cerámicas, Universitat Jaume I, Castellón, Spain

\section{A R T I C L E I N F O}

\section{Article history:}

Received 22 June 2009

Received in revised form 1 September 2009

Accepted 16 September 2009

Available online 3 October 2009

\section{Keywords:}

Ceramic tiles

Firing

Emission monitoring

HF stack emission

\begin{abstract}
A B S T R A C T
HF (hydrogen fluoride) emission control is one of the critical environmental parameters in the firing of ceramic materials at peak temperatures higher than $1000^{\circ} \mathrm{C}$. In this study, in-stack concentrations of $\mathrm{HF}$ were monitored on-line with laser-based equipment during the fast firing of ceramic tiles in continuous industrial roller hearth kilns under standard kiln operating conditions.

Three different ceramic tile compositions: porous red-body wall tiles, red-body stoneware tiles, and porcelain tiles were fired in industrial kilns customarily used to manufacture these types of tiles, modifying the heating rate and tile dry bulk density. The in-stack concentrations of HF can be explained on the basis of tile HF adsorption and emission processes in the kiln preheating and firing zones, analysed in previous studies.

The methodology used in this study has significant advantages for industrial studies compared with previous methodologies based primarily on laboratory-scale studies and analysis of solid material. The main advantages are: (a) rapid response, allowing abrupt changes in the HF emission to be studied; and (b) direct measurement of the in-stack concentration of HF, which is the most common parameter used as a legal limit for industrial emission control.

The study shows that tile HF adsorption in the preheating zone is very important. It also shows that HF stack emissions can vary significantly in continuous kilns depending on whether glazed or unglazed tiles are produced, or important changes occur in production (such as gaps in the kiln feed). The results indicate, furthermore, that HF stack emissions do not decrease significantly when realistic changes are made in industrial operating conditions if these industrial kilns are run at peak temperatures above $1100{ }^{\circ} \mathrm{C}$. The most important reduction in in-stack concentrations of HF is observed when glazed ceramic tiles are fired, so further research in this field can be made in order to reduce HF emissions.

(c) 2009 Elsevier B.V. All rights reserved.
\end{abstract}

\section{Contents}

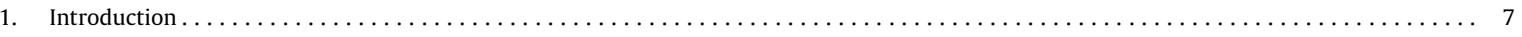

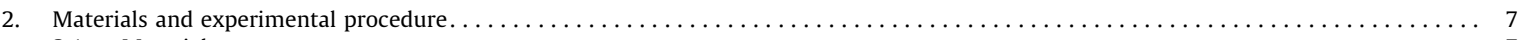

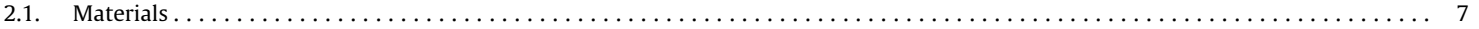

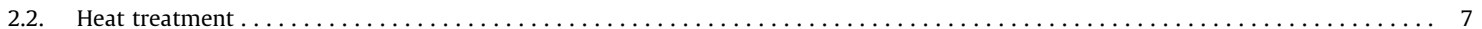

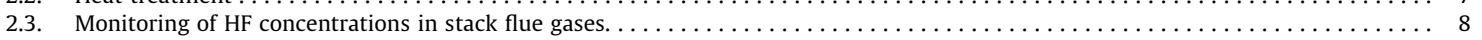

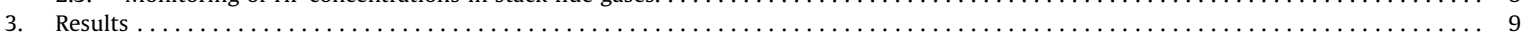

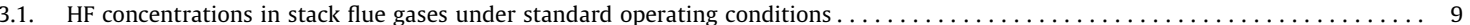

3.2. HF concentrations in stack flue gases under modified operating conditions $\ldots \ldots \ldots \ldots$

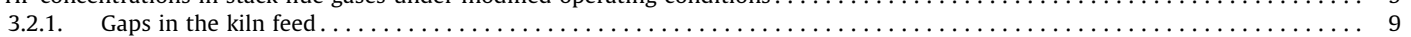

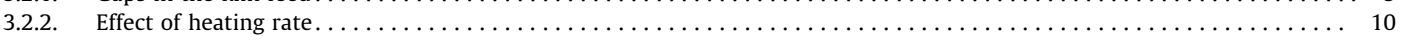

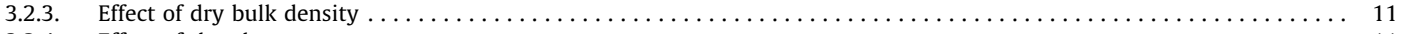

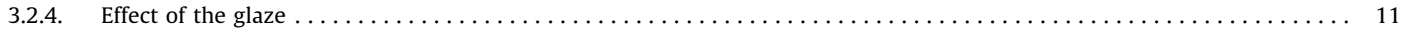

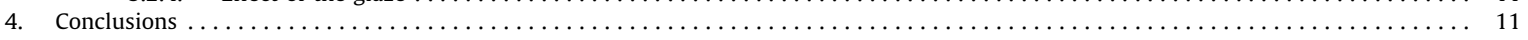

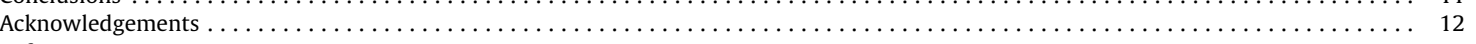

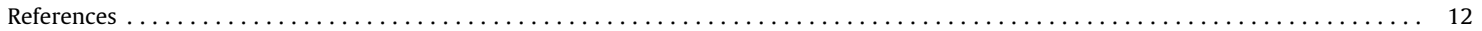

* Corresponding author at: ITC Campus Riu Sec 12006 Castellón, Spain. Tel.: +34 9643424 24; fax: +34 964342425.

E-mail address: emonfort@itc.uji.es (E. Monfort). 


\section{Introduction}

Industrial emission control has drawn growing attention in recent years, with increasingly stringent emission requirements aimed at achieving high productivity in an environmentally friendly manner. The development of the 1990 Clean Air Act and its amendments, and Directive 96/61/EC on Integrated Pollution Prevention and Control are key regulations in the heightened concern over environmental protection in the USA and $\mathrm{EU}$, respectively.

A major environmental issue for the ceramic industry, particularly for ceramic tile manufacture, is the assurance of appropriate control of fluorine emissions in the firing stage [1-9], exhausted mainly as HF in continuous combustion kilns $[10,11]$. Legal limits are usually based on HF concentrations in stack flue gases (in the EU Member States, typically around $5-10 \mathrm{mg} \mathrm{m}^{-3}$ ), measured during a set time under representative operating conditions [12].

The environmental legislation has imposed increasingly stringent emission limits of $\mathrm{HF}$ from ceramic factories in response to available evidence that such emissions have harmful effects on plants and animals $[13,14]$. On the other hand, in recent studies on air quality [15] significant concentrations of fluorine in particulate matter $\left(0.2 \mu \mathrm{g} \mathrm{m}^{-3}\right.$ on an annual mean basis) have been found in the Castellón ceramic cluster, which has a high concentration of ceramic tile manufacturing companies.

In foregoing ITC studies, a laser-based, on-line HF measurement system was adapted to the specific conditions of stacks in ceramic tile-firing kilns $[10,11]$. This very useful tool enables in-stack concentrations of $\mathrm{HF}$ to be characterised and rapid variations in $\mathrm{HF}$ concentrations to be monitored. The mechanisms involved in HF emissions have also been analysed in previous studies [15-17]. These studies have shown that the final HF stack emission is not only highly influenced by the fluorine content and chemical composition of the raw materials, but also by peak firing temperature and the HF emission and adsorption processes inside the kiln between the kiln feed and the gases. Important variations in $\mathrm{HF}$ concentrations in flue gas emissions may therefore ensue when changes occur in the firing process $[10,11]$. These can affect the environmental impact and the response of the end-of-pipe cleaning systems typically used to minimise HF emissions; the most popular being based on dry neutralisation processes with the addition of reagents such as $\mathrm{CaO}$, $\mathrm{Ca}(\mathrm{OH})_{2}, \mathrm{CaCO}_{3}$, or $\mathrm{NaHCO}_{3}[2,8,12,18-20]$.

When basic primary measures have been applied, such as reducing the input of fluorine in the raw materials and optimising the calcium content in the body composition, the only way to minimise the fluorine emission by applying primary measures in products fired at peak temperatures higher than $1000^{\circ} \mathrm{C}$, is to optimise the process [12]. Previous laboratory-scale studies performed at ITC have shown that the main process variables affecting $\mathrm{HF}$ emissions are dry bulk tile density and firing rate. Dry bulk density determines the gas permeability of the tile during the emission process, while the firing rate controls tile residence time in every firing phase. These studies have shown that other variables, such as the degree of milling (that is, particle size distribution), only slightly affect the HF emission.

The present study has been undertaken to analyse on-line, on an industrial scale, the HF concentrations in stack flue gases before they enter the HF removal systems, under standard and modified firing conditions. The study was conducted at industrial kilns where the different types of ceramic tiles were fired under standard conditions, modifying the heating rate and dry bulk tile density. The performance of the study on an industrial level enables realistic, practical modifications to be implemented, though the changes that can be made are obviously much more limited than on a laboratory scale.

\section{Materials and experimental procedure}

\subsection{Materials}

The study was carried out on three standard tile body compositions used in the Castellón ceramic cluster (Spain), where about $40 \%$ of the ceramic tiles made in the $\mathrm{EU}$ are produced. The studied compositions were referenced as follows: A (porous redbody wall tiles), G (red-body stoneware tiles), and $\mathrm{P}$ (porcelain tiles). Tables 1 and 2 summarise the main characteristics of these compositions.

\subsection{Heat treatment}

The three types of ceramic tiles were fired in different continuous roller hearth kilns, fuelled by natural gas, used,

Table 1

Characteristics of the types of tiles studied.

\begin{tabular}{lllllll}
\hline Ref. & \multicolumn{2}{l}{ Type of product } & & & \multicolumn{2}{l}{ Body characteristics } \\
\cline { 2 - 3 } & Industrial & Finish & $\begin{array}{l}\text { Group ISO } \\
\text { name }\end{array}$ & & $\begin{array}{l}\text { Fired } \\
\text { colour }\end{array}$ & $\begin{array}{l}\text { Open } \\
\text { porosity (\%) }\end{array}$ \\
\hline A & Wall tile & Glazed (GL) & BIII & & Red & 28.0 \\
G & Floor tile & Glazed (GL) & BIIa & & Red & 8.0 \\
P & Porcelain tile & Glazed (GL) & Bla & & White & 0.2 \\
\hline
\end{tabular}

Table 2

Chemical and mineralogical composition of the bodies.

\begin{tabular}{llccc}
\hline & & $\mathrm{A}$ & $\mathrm{G}$ & $\mathrm{P}$ \\
\hline Chemical composition & $\mathrm{SiO}_{2}$ & 57.5 & 64.0 & 65.8 \\
(wt\%) & $\mathrm{Al}_{2} \mathrm{O}_{3}$ & 15.6 & 17.5 & 20.6 \\
& $\mathrm{Fe}_{2} \mathrm{O}_{3}$ & 5.26 & 6.01 & 0.66 \\
& $\mathrm{CaO}$ & 6.25 & 1.21 & 0.72 \\
& $\mathrm{MgO}$ & 1.78 & 0.85 & 1.34 \\
& $\mathrm{Na}_{2} \mathrm{O}$ & 0.41 & 0.47 & 4.48 \\
& $\mathrm{~K}_{2} \mathrm{O}$ & 3.23 & 3.34 & 1.60 \\
& $\mathrm{LOI}$ & 9.18 & 5.93 & 3.91 \\
Fluorine content & $\mathrm{F}$ & $650 \pm 20$ & $620 \pm 20$ & $290 \pm 15$ \\
(mg kg-1) & & & & \\
Mineralogical & & & & \\
composition (wt\%) & Kaolinite & 18 & 22 & 14 \\
& Chlorite & 2 & - & 5 \\
& Quartz & 36 & 39 & 24 \\
& Albite & - & - & 38 \\
& Microcline & 6 & 6 & - \\
& Calcite & 10 & 3 & - \\
& Dolomite & 2 & 2 & \\
& Hematite & 5 & 6 & 0.5 \\
\hline
\end{tabular}

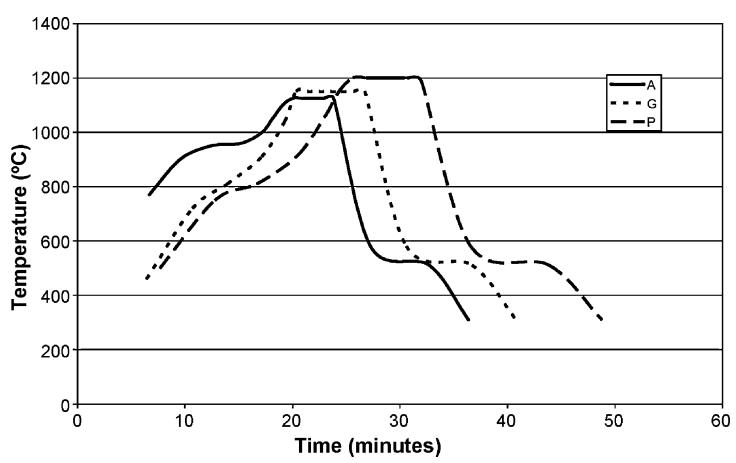

Fig. 1. Temperature-time curves in the industrial kilns used for the three studied compositions. 


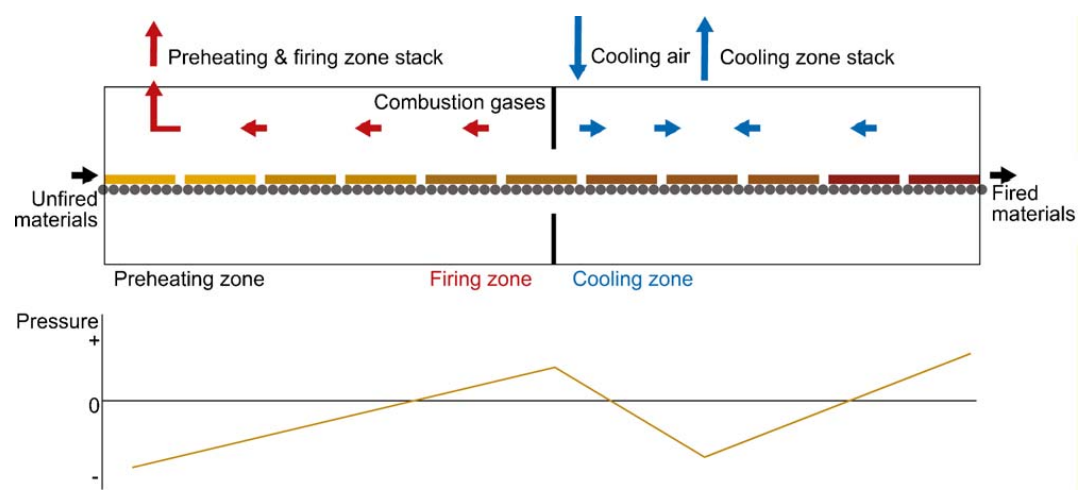

Fig. 2. Schematic illustration of the roller kiln with gas flow and static pressure curve.

respectively in industrial practice to manufacture these types of tiles.

The tiles were subjected to the standard thermal cycles used at the companies where the tests were carried out, with total firing times (cold to cold) of 40-55 min, and peak firing temperatures of about 1125,1150 , and $1200{ }^{\circ} \mathrm{C}$ for compositions $\mathrm{A}, \mathrm{G}$, and $\mathrm{P}$, respectively. The complete temperature-time curves are shown in Fig. 1.

Fig. 2 schematically illustrates one of these kilns. The most significant operating feature in relation to HF concentrations in the kilns is the movement of the combustion gases, which circulate counter current to the tiles in the preheating and firing zones according to the static pressure curve (see Fig. 2 below).

\subsection{Monitoring of HF concentrations in stack flue gases}

The in-stack concentrations of HF in the studied kilns were monitored on-line, thus allowing variations in the concentrations to be observed in real time, and enabling their relation to the manufacturing process and/or emission treatment variables to be studied.

The HF emissions were always monitored in the common stack exhausting the preheating and firing zone flue gases, since recent studies [17] have shown that no significant fluorine emissions occur during the cooling stage. The use of the in-stack concentrations of $\mathrm{HF}$ as a parameter is of particular interest, because it usually enables almost direct comparison with legal limits to be made, conversion only being needed to comply with legally required conditions. Thus, in this study, in accordance with the European recommendations for firing ceramics [10], all in-stack concentrations of $\mathrm{HF}$ are always referred to the following conditions: $273.15 \mathrm{~K}, 101.3 \mathrm{kPa}, 18 \%$ oxygen content by volume, and dry basis.

The HF measuring system used was a commercial apparatus (supplied by Boreal Laser Inc.) adapted for measuring $\mathrm{HF}$ concentrations in flue gases during ceramic tile firing, validated elsewhere [10,11]. Fig. 3 schematically shows the equipment and the probe designed for in-stack sampling. In this instrument, a TDL (tuned diode laser) selects the HF absorption band that displays no interferences with any other gases, which makes these instruments with infrared spectrometry and tuned lasers highly selective.

One of the instrument's basic features is its continuous calibration system, in which a fraction of the generated laser radiation passes through a reference cell with known HF content. The fact that the analyser has a self-calibrating system is of

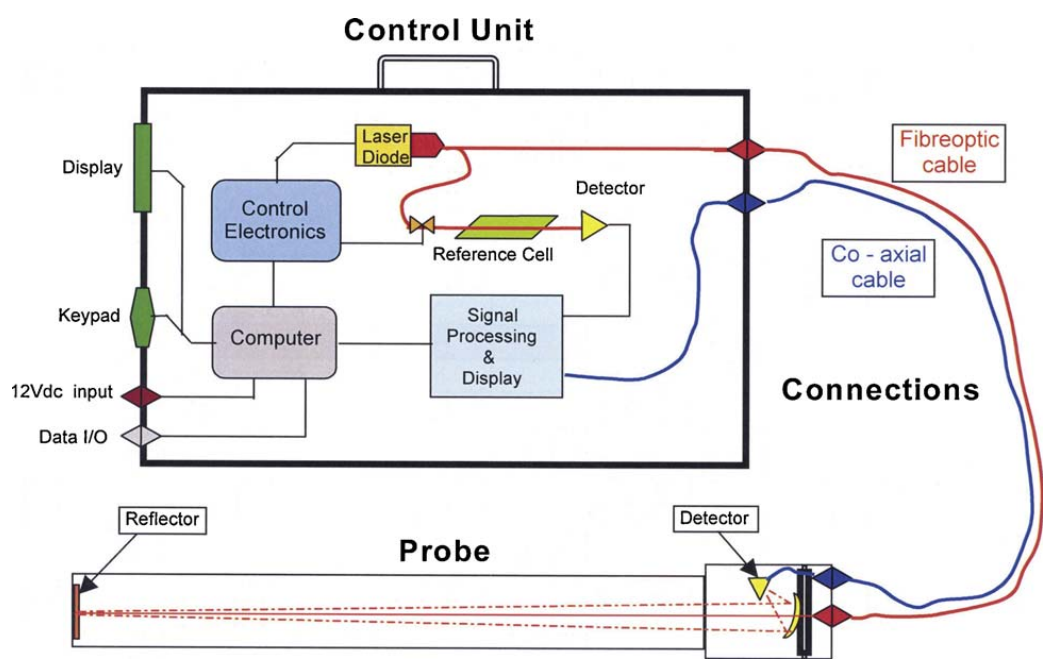

Fig. 3. Schematic illustration of the equipment used and probe designed for in-stack sampling.Source: Boreal Laser Inc. 

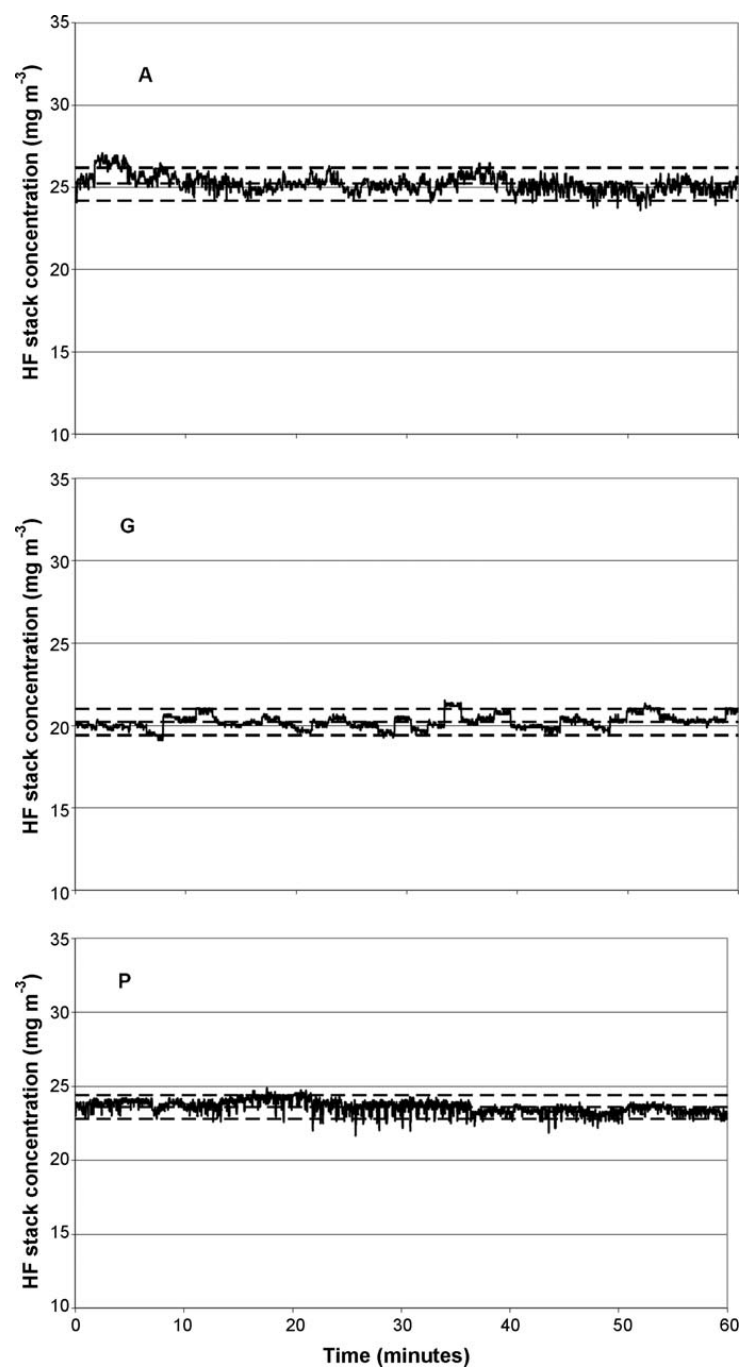

Fig. 4. Evolution of in-stack concentrations of HF under standard kiln operating conditions with bodies A, G, and P.

enormous practical importance since no standard gases need be used, thus simplifying the fieldwork.

\section{Results}

3.1. HF concentrations in stack flue gases under standard operating conditions

A series of assays were performed, related to the evolution of $\mathrm{HF}$ in-stack concentrations under standard kiln operating conditions in the three studied body compositions (A, G, and P), shown in

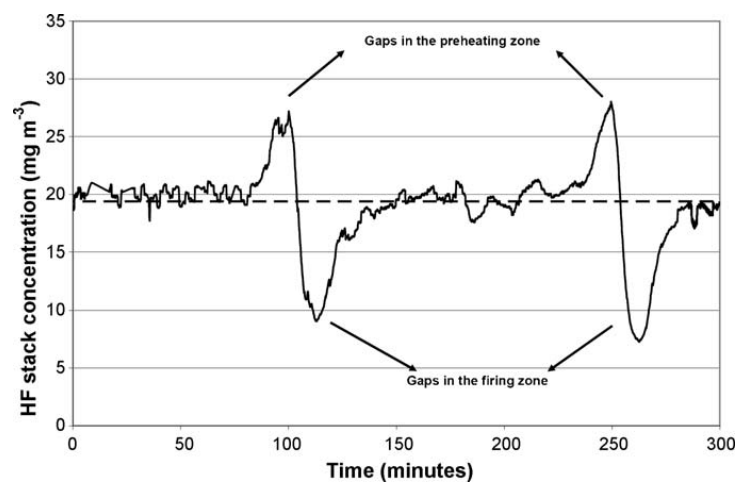

Fig. 5. Evolution of the in-stack concentration of HF with 15-min gaps in the tile feed (body P).

Fig. 4. In all cases, the variation in HF concentrations is observed to fluctuate in a relatively narrow margin with only slight swings around a mean value that, to all practical purposes, may be considered constant. The absolute values of the in-stack concentrations of HF obviously varied, depending on body composition, production throughput, and firing schedule.

The results indicate that the batch sampling procedure, sampling gas for a relatively short period of time (20-40 min), allows adequate determination of the HF concentrations in a kiln running under standard conditions [21], since the in-stack concentrations of HF do not vary significantly with time and can be appropriately characterised as a mean concentration, provided no changes occur during sampling (i.e. constant production throughput, body composition, etc.).

Table 3 shows the mean in-stack concentrations of HF during the period of time analysed, together with a 95\% confidence range $\left(C_{\mathrm{HF}} \pm 2 \sigma\right)$. The parameter $\left(2 \sigma / C_{\mathrm{HF}}\right)$ has a value of $3-4 \%$ for the three studied body compositions, confirming that the HF concentrations are quite constant in this process under standard operating conditions.

\subsection{HF concentrations in stack flue gases under modified operating} conditions

\subsubsection{Gaps in the kiln feed}

The kiln feed is quite often interrupted for several reasons (maintenance, model changeovers, etc.), leading to tile feed gaps. In order to study the effect of tile feed gaps on HF concentration in the end stream, the evolution of the fluorine concentration was monitored in the three kilns after the kiln feed was stopped for periods of 5 and $15 \mathrm{~min}$. In these experiments, the operating conditions (type of processed material, temperature profile, etc.) were kept constant.

The results obtained in the different studied tile compositions (A, G, and P) were qualitatively similar. For the sake of simplicity, only the results for porcelain tiles $(P)$ are therefore presented graphically.

The evolution of the in-stack concentrations of HF during a period of time in which two 15-min breaks occurred is shown in Fig. 5. This shows that an abrupt change takes place in the in-stack

Table 3

In-stack concentrations of HF under standard kiln operating conditions.

\begin{tabular}{lllll}
\hline Ref. & Mean HF concentration $C_{\mathrm{HF}}\left(\mathrm{mg} \mathrm{m}^{-3}\right)$ & Standard deviation $\sigma\left(\mathrm{mg} \mathrm{m}^{-3}\right)$ & $2 \sigma\left(\mathrm{mg} \mathrm{m}^{-3}\right)$ & $C_{\mathrm{HF}} \pm 2 \sigma\left(\mathrm{mg} \mathrm{m}^{-3}\right)$ \\
\hline A & 25.2 & 0.5 & 1.0 & $25.2 \pm 1.0$ \\
G & 20.2 & 0.4 & 0.8 & $20.2 \pm 0.8$ \\
P & 23.6 & 0.4 & 0.8 & $23.6 \pm 0.8$ \\
\hline
\end{tabular}


Table 4

Changes in in-stack concentrations of HF with gaps in the tile feed.

\begin{tabular}{lll}
\hline Body & $\begin{array}{l}\text { Increase in HF concentration } \\
\text { (\%) (gaps in preheating) }\end{array}$ & $\begin{array}{l}\text { Decrease in HF concentration } \\
\text { (\%) (gaps in firing) }\end{array}$ \\
\hline A & 80 & 50 \\
G & 60 & 70 \\
P & 40 & 55 \\
\hline
\end{tabular}

concentration of $\mathrm{HF}$, with an initial increase followed by a decrease stage. This can be explained by tile HF adsorption and emission processes during preheating and firing, respectively, in continuous kilns [17]. The initial increase is caused by the absence of tiles in the preheating zone. The HF in the gases flowing through this area is therefore not adsorbed and the stack HF concentration peaks at a value that is $40 \%$ higher than the HF concentration under standard conditions. Under these modified conditions, almost all the emitted HF goes to the stack, without any adsorption in the preheating zone, as occurs in batch kilns.

When the gap reaches the peak temperature zone, the HF concentration in the stack decreases significantly, minimising at a value that is approximately $55 \%$ lower than the initial value (under standard operating conditions), as a result of two simultaneous effects. On the one hand, the gap reaches the firing zone minimising the HF emissions, that is, the emission at peak temperature is very low, and as a result, the gases entering the stack from this area have a very low HF content. On the other hand, the presence of unfired material in the adsorption zone (preheating) adsorbs HF from the flue gases. As a result, the in-stack concentration of HF plunges, which may explain why the second peak (gap in the firing zone) is larger than the first (gap in the preheating zone).

These experiments were replicated in the different kilns used for bodies A and G, respectively, which yielded similar results. Table 4 shows the increase and decrease in in-stack concentrations of $\mathrm{HF}$, expressed as a percentage of the mean value under standard conditions for the three body compositions. For the $\mathrm{G}$ and $\mathrm{P}$ bodies, the decrease in in-stack concentrations of HF is larger when the tile gap reaches the firing zone than the increase in HF concentrations when the gap reaches the preheating zone, as set out above. However, body A displays the opposite behaviour: the increase in in-stack concentration of HF is larger than its decrease. Previous studies [16] suggest that this difference could be due to the higher calcite content in body $\mathrm{A}$ (6.25\% $\mathrm{CaO}$ compared with 1.21 and $0.72 \%$ $\mathrm{CaO}$ for compositions $\mathrm{G}$ and $\mathrm{P}$, respectively), which improves $\mathrm{HF}$ adsorption in the preheating zone. As a result, when the gap in the calcite-rich composition reaches the preheating zone, the absence of adsorption causes the in-stack concentration of HF to rise much more (80\%) than when the tile gap is related to compositions with a lower calcite content (40 and 60\%).

These outcomes are consistent with those obtained in previous studies, in which the fluorine content was monitored in solid material and in gas samples throughout the kiln [16,17], and can be explained by tile HF emission and adsorption processes during preheating and firing.

\subsubsection{Effect of heating rate}

Firing time was lengthened by $10 \%$ in the kiln that produced glazed porcelain tiles $(\mathrm{P})$ in order to reduce production throughput by a similar percentage. This was done by reducing tile speed through the kiln, extending cycle time (cold to cold) from 40 to $44 \mathrm{~min}$, decreasing production throughput from 1.25 to $1.15 \mathrm{~kg} / \mathrm{s}$ (thus meaning a reduction of $8 \%$ ).

The results obtained in monitoring the evolution of HF during this change are shown in Fig. 6 and Table 5. Though no great changes could be made in this test owing to industrial constraints,

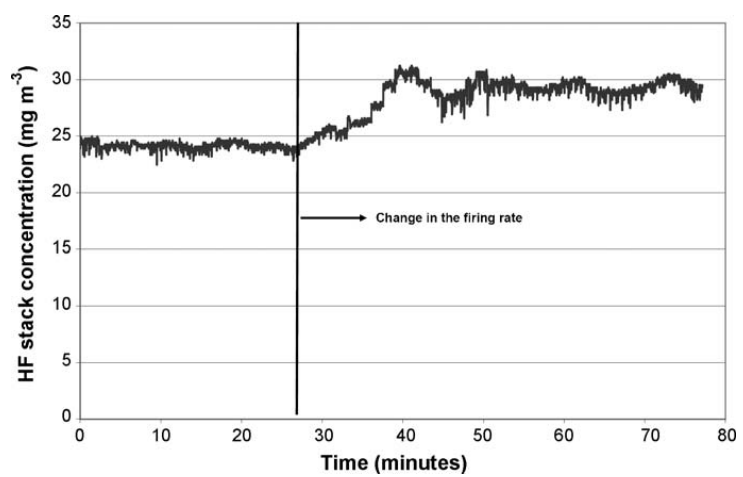

Fig. 6. Evolution of the in-stack concentration of HF during the change in firing rate (body P).

Table 5

Effect of heating rate on in-stack concentrations of HF (body composition P).

\begin{tabular}{llll}
\hline $\begin{array}{l}\text { Cold to cold } \\
\text { cycle }(\mathrm{min})\end{array}$ & $\begin{array}{l}\text { Production } \\
\text { throughput }\left(\mathrm{kg} \mathrm{s}^{-1}\right)\end{array}$ & \multicolumn{2}{l}{$\begin{array}{l}\mathrm{HF} \text { concentration } \\
\left(\mathrm{mg} \mathrm{m}^{-3}\right)\end{array}$} \\
\cline { 2 - 4 } & & Mean & $\sigma$ \\
\hline 40 & 1.25 & 22.2 & 3.4 \\
44 & 1.15 & 24.1 & 2.1 \\
\hline
\end{tabular}

the graph shows that when the heating rate decreased (equivalent to an increase in residence time in the kiln and a drop in production throughput), the in-stack concentration of HF rose slightly. These findings match those of previous laboratory-scale studies in which it was possible to make greater changes [17]. In fast-cycle processes, not all the initial HF content is released at peak firing temperature: $\mathrm{HF}$ is released progressively, so that longer residence times at temperatures at which $\mathrm{HF}$ is released raise HF emissions. This is because at temperatures above $1000^{\circ} \mathrm{C}$, the crystalline phases in which the fluorine might be retained - fluorite $\left(\mathrm{CaF}_{2}\right)$ and cuspidine $\left(\mathrm{Ca}_{4} \mathrm{Si}_{2} \mathrm{O}_{7} \mathrm{~F}_{2}\right)$ - are unstable [16]

These findings match industrial experience and are consistent with the results reported by other authors [22-24] in relation to firing cycles, which show that, for a given body composition, the resulting emission factors decrease when faster firing cycles are used. Moreover, the foregoing explains why ceramic tile manufacture by fast single-firing cycles leads to lower fluorine compound emissions than double-firing processes.

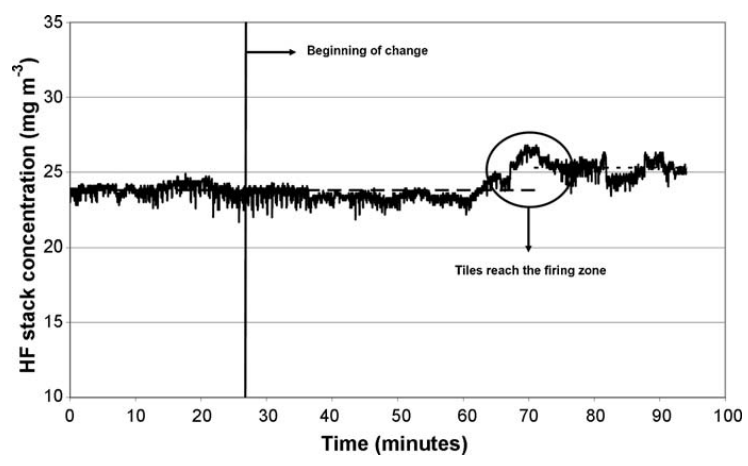

Fig. 7. Evolution of the in-stack concentration of HF during the change in dry bulk density (body P). 
Table 6

Effect of dry bulk density on in-stack concentrations of HF (body composition P).

\begin{tabular}{lll}
\hline Dry bulk density $\left(\mathrm{kg} \mathrm{m}^{-3}\right)$ & \multicolumn{2}{l}{ HF concentration $\left(\mathrm{mg} \mathrm{m}^{-3}\right)$} \\
\cline { 2 - 3 } & Mean & $\sigma$ \\
\hline 2030 & 23.8 & 0.7 \\
1945 & 25.3 & 0.6 \\
\hline
\end{tabular}

Table 7

Evolution of in-stack concentrations of HF with the introduction of unglazed tiles (body composition $\mathrm{A}$ )

\begin{tabular}{lc}
\hline Parameter & Value \\
\hline Mean HF concentration $\left(\mathrm{mg} \mathrm{m}^{-3}\right)$ & 26.3 \\
Standard deviation $(\sigma)\left(\mathrm{mg} \mathrm{m}^{-3}\right)$ & 0.3 \\
Decrease in HF concentration (\%) & 25 \\
Increase in HF concentration (\%) & 45 \\
\hline
\end{tabular}

\subsubsection{Effect of dry bulk density}

An important process variable that can affect HF emissions according to previous laboratory-scale studies is dry bulk tile density, which is directly related to tile porosity. Several experiments were performed on an industrial level to verify these results.

The results obtained in the stack of the kiln producing glazed porcelain tile (P), whose dry bulk density was changed from 2030 to $1945 \mathrm{~kg} / \mathrm{m}^{3}$ (thus involving a reduction of about $4 \%$ ) by reducing the pressing pressure are presented in Fig. 7 and Table 6. As in previous trials, in order to keep end-product quality steady, no large changes were made. The outcomes indicate that the HF concentrations in the stack rose when tiles with low bulk density reached the kiln firing zone. No changes were detected in HF emissions when the low-density tiles reached the preheating zone. This behaviour is related to the effect of the pressing stage on body microstructure: lower pressing pressure raises body porosity and pore size, while it also reduces pore tortuousness [25]. These effects lead to increased gas permeability of the body, facilitating the movement of $\mathrm{HF}$ from within the body to the gaseous phase (kiln environment). Therefore, despite the small change made in tile bulk density, it may be inferred that the overall effect of reducing bulk density raises $\mathrm{HF}$ emissions in the firing stage.

\subsubsection{Effect of the glaze}

Industrial trials were conducted in the three kilns to establish the effect of the presence of a glaze coating on the tile body. In these trials, kilns firing standard glazed tiles were partly fed with unglazed tiles (i.e. tile bodies), the number of unfired tiles being

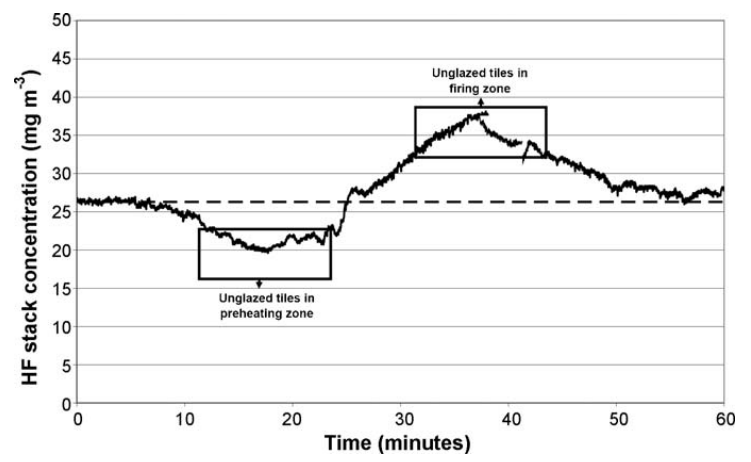

Fig. 8. Evolution of the in-stack concentration of HF with the introduction of unglazed tiles (body A).
Table 8

Effect of the glaze coating.

\begin{tabular}{|c|c|c|c|c|c|c|}
\hline \multirow[t]{3}{*}{ Body } & \multicolumn{6}{|c|}{$\mathrm{F}$ content $\left(\mathrm{mg} \mathrm{kg}^{-1}\right)$} \\
\hline & \multicolumn{3}{|c|}{ Glazed tiles } & \multicolumn{3}{|c|}{ Unglazed tiles } \\
\hline & Unfired & Fired & Emission & Unfired & Fired & Emission \\
\hline A & 660 & 560 & 100 & 660 & 470 & 160 \\
\hline G & 630 & 530 & 120 & 630 & 440 & 190 \\
\hline
\end{tabular}

about $10-15 \%$ of kiln throughput. The evolution of the HF concentration was monitored in the flue gas emissions (stack) in the three studied kilns, before and after unglazed tiles were fed into the kilns.

The experiments were conducted for A, G, and P bodies. Since the results were qualitatively similar, only the wall tile (A) data, whose variation was the most significant, are presented.

The findings are shown in Fig. 8 and Table 7. The dotted line in Fig. 8 indicates the HF emission when glazed wall tiles are being produced under standard operating conditions. An examination of the figure allows the following to be inferred:

- When unglazed tiles reach the preheating zone, the HF concentration recorded in the stack decreases progressively. This reduction may be assigned to the absence of a glaze coating on the tile face, which increases the contact area between the gases and the ceramic body. The HF-rich, counter-current gas stream circulates from the peak temperature zone to the stack. The adsorption process is therefore favoured and the HF content in the gases drops. These results also indicate that HF adsorption by the glaze layer may be considered almost negligible.

- When unglazed tiles reach the peak temperature zone, the HF emission is higher than when glazed tiles are fired. This could be due to two effects. First, glazed tiles release less HF at high temperatures because of two possible mechanisms: the glaze can fuse and seal the body, preventing HF emission through the tile's top surface, and/or some HF may dissolve in the glassy phase at high temperature. Secondly, unglazed tiles contain more fluorine (caused by fluorine enrichment in the preheating zone), leading to higher HF emission as a result of the low thermal stability of the fluorine crystalline compounds $\left(\mathrm{CaF}_{2}\right.$ and $\left.\mathrm{Ca}_{4} \mathrm{Si}_{2} \mathrm{O}_{7} \mathrm{~F}_{2}\right)$ that form in preheating [16].

A number of further experiments were conducted, varying the type of glaze, but no significant differences were found amongst the different glazes. The glazes tested were always of the industrial type, and no changes were made to heighten HF absorption.

In order to confirm the effect of the glaze, fluorine was analysed in unglazed and glazed ceramic tile bodies ( $A$ and $G$ bodies) before and after heat treatment, according to the procedure described elsewhere $[16,17]$. The results are presented in Table 8 . They show that the glazed tiles have a higher fluorine content compared with that of the unglazed tiles. This corroborates the results obtained by monitoring the in-stack concentrations of HF: that is, glazed tiles release significantly less HF (approximately 35\% less in recorded experiments). Further research needs to be carried out in order to study the mechanisms involved in this emission reduction process.

\section{Conclusions}

In this study, $\mathrm{HF}$ concentrations were measured in the stack flue gases of industrial roller kilns firing different types of ceramic tiles. The following conclusions may be drawn:

- The methodology used in this study with a laser-based, on-line HF analyser allows HF emission behaviour in continuous kilns to 
be efficiently monitored, because it allows rapid HF measurement when changes are made in the kiln.

- Under standard kiln operating conditions, the HF emissions in industrial ceramic tile kilns fabricating different types of tiles remained very steady with time, only slight fluctuations occurring around a practically constant mean value.

- When the standard firing conditions were modified, the variation in HF emissions was qualitatively similar for the three types of studied tiles (porous red-body wall tiles, red-body stoneware tiles and porcelain tiles).

- Interrupting the tile feed into the kilns produced two effects, depending on the location of the feed gap in the kiln: a feed gap in the preheating zone led to a significant rise in HF emissions as a result of decreased tile HF adsorption; in contrast, a feed gap in the firing zone caused the HF emissions to drop notably, owing to the absence of tiles in the kiln high-temperature zone.

- The study shows that realistic adjustments of certain industrial process variables (dry bulk tile density and heating rate) only lead to a very limited reduction in HF emissions.

- The results indicate, further, that glazing is an effective way of reducing $\mathrm{HF}$ emission, probably because of the formation of an impermeable coat by the fusion of glaze components at temperatures above the sealing temperature and/or dissolution at high temperature of some fluorine in the glassy phase. The glazes tested in this study were always of the industrial type, and no modified or special glazes were used. The outcomes encourage further research into the enhancement of the glaze fluorine retention capacity, as a way of reducing the environmental impact of the ceramic process in order to avoid or minimise the use of the end-of-pipe cleaning systems. Therefore, it opens up very interesting new possibilities, since the glazes may be used not only to improve the aesthetic and technical properties of ceramic tiles (or ceramic materials in general), but also to reduce the environmental impact in the firing stage.

\section{Acknowledgements}

This study has been funded by the Spanish Ministry of Science and Technology in the National Plan for Scientific Research,
Development, and Technological Innovation 2000-2003, reference PPQ2003-00869, and by the Spanish Ministry of Environment, National Plan for Research, Technological Development and Innovation 2004-2007, reference A571/2007/3-11.1.

\section{References}

[1] D.A. Brosnan, Am. Ceram. Soc. Bull. 71 (1992) 1798-1802.

[2] G. Bonvicini, A. Fregni, C. Palmonari, in: A. Tressaud (Ed.), Fluorine and the Environment, Vol. 1: Atmospheric Chemistry, Emissions \& Lithosphere, Elsevier, Amsterdam, 2006, pp. 225-249.

[3] G. Busani, C. Palmonari, G. Timellini, Ceramic Tiles and the Environment: Air and Water Emissions, Solid Waste and Noise, Edi. Cer, Sassuolo, Italy, 2005(in Italian). 4] G. Dehne, Appl. Clay Sci. 2 (1987) 1-9.

[5] E. Galán, I. Gonzalez, B. B. Fabbri, Atmos. Environ. 36 (2002) 5289-5298.

[6] M.F. Gazulla, P. Gómez, A. Barba, E. Monfort, M. Orduña, Manage. Environ. Qual. Int. J. 14 (2003) 333-343.

[7] I. González, P. Aparicio, E. Galán, B. Fabbri, Appl. Clay Sci. 22 (2002) 1-7.

[8] I. Gonzalez, E. Galán, A. Miras, Appl. Clay Sci. 32 (2006) 153-171.

[9] G. Mallol, E. Monfort, G. Busani, J. Lezaun, Technical Guide, second ed., ITC-AICE, Castellón, Spain, 2001 (in Spanish).

10] E. Monfort, I. Celades, S. Gomar, M.F. Gazulla, H. Adams, J. Tulip, J. Ind. Céram. Ver. 997 (2004) 50-56.

[11] E. Monfort, I. Celades, S. Gomar, M.F. Gazulla, H. Adams, J. Tulip, J. Ind. Céram. Ver. 998 (2005) $30-36$.

12] Reference Document on Best Available Techniques in the ceramic manufacturing industry, European commission, European IPPC Bureau, Sevilla, 2007, http:// ftp.jrc.es/eippcb/doc/cer_bref_0807.pdf (visited: 2009-06-25).

[13] L.H. Weinstein, A.W. Davison, Fluoride in the Environment: Effects on Plants and Animals, CABI, Cambridge, USA, 2004.

[14] A.W. Davison, L.H. Weinstein, in: A. Tressaud (Ed.), Fluorine and the Environment, Vol. 1: Atmospheric Chemistry, Emissions \& Lithosphere, Elsevier, Amsterdam, 2006, pp. 251-298.

[15] A. Escrig, E. Monfort, I. Celades, X. Querol, F. Amato, M.C. Minguillón, P.K. Hopke, J. Air Waste Manage. Assoc. (2009) 59.

[16] J. García-Ten, E. Monfort, P. Gómez, S. Gomar, J. Ceram. Process. Res. 7 (2006) 75-82.

[17] E. Monfort, J. García-Ten, I. Celades, S. Gomar, Appl. Clay Sci. 38 (2008) 250-258.

[18] D.A. Brosnan, Am. Ceram. Soc. Bull. 77 (1998) 47-50.

19] D.A. Brosnan

[20] E. Monfort, I. Celades, S. Mestre, R. Bono, H. Llop, J.M. de la Hoz, Key Eng. Mater. 206-213 (2001) 855-858.

[21] E. Monfort, M.F. Gazulla, I. Celades, P. Gómez, M. Bigi, M. Tonelli, Am. Ceram. Soc. Bull. 82 (2003) 31-35.

. 143 (1994) 38-40

[23] T. Dogeroglu, S. Kara, Am. Ceram. Soc. Bull. 81 (2002) 52-56.

24] A. Reymer, J. Jong, in: P. Durán, J.F. Fernández (Eds.), Third Euro-Ceramics, Faenza Editrice Ibérica, Castellón, Spain, 1993, pp. 1071-1076.

[25] A. Escardino, J.L. Amorós, M.J. Orts, V. Beltrán, in: W.M. Carty, C.W. Sinton (Eds.), Science of Whitewares II, Acers, Westerville, USA, 2000, pp. 309-318. 

Capítulo 8. Glosario. 

Para facilitar la lectura de la memoria se incluyen en este apéndice algunos de los términos de ingeniería ambiental y tecnología cerámica que aparecen con frecuencia en el texto o que se considera que pueden ser de utilidad para el lector.

Atomización (secaderos por atomización): Este tipo de secaderos se utilizan en el proceso de fabricación de baldosas cerámicas para el secado de la suspensión de materias primas del soporte obtenida tras la molienda vía húmeda. El secado se realiza pulverizando la suspensión en una cámara en la que se introduce una corriente de gases a temperaturas del orden de $550-650^{\circ} \mathrm{C}$, para dar lugar a un material granulado adecuado para su prensado.

Autorización Ambiental Integrada (AAI): Documento que agrupa los permisos medioambientales de una instalación industrial en uno solo. Es la resolución del órgano competente de la Comunidad Autónoma en la que se ubique la instalación industrial. El permiso incluirá todas las medidas necesarias para conseguir un alto nivel de protección del medio ambiente en su conjunto y para asegurar que la explotación de la instalación se efectúe de acuerdo con los principios generales aplicables a las obligaciones fundamentales del titular. El permiso también incluirá valores límite de emisión para las sustancias contaminantes, o parámetros equivalentes o medidas técnicas, requisitos adecuados para la protección del suelo y las aguas subterráneas y requisitos para el control. Las condiciones del permiso se fijarán basándose en las mejores técnicas disponibles publicadas en los Documentos de Conclusiones.

Azulejo (A): Es la denominación tradicional de las baldosas cerámicas con elevada porosidad (absorción de agua superior al 10\% en peso), normalmente vidriada, y cuyas características las hacen particularmente adecuadas para revestimiento de paredes interiores. En función de la coloración en cocido del soporte se clasifican en azulejo rojo (AR) y azulejo blanco (AB).

Baldosas cerámicas (pavimentos y revestimientos): Son placas de poco grosor generalmente utilizadas para revestimiento de suelos y paredes, fabricadas a partir de composiciones de arcillas y otras materias primas inorgánicas, que se someten a molienda y/o amasado, se moldean y seguidamente son secadas y cocidas a temperatura suficiente para que adquieran establemente las propiedades requeridas.

Barbotina: En el lenguaje industrial se utiliza este término para referirse a la suspensión en agua de las materias primas utilizadas para la fabricación del soporte o del esmalte.

BI - BII - BIII. Representa la propiedad de las baldosas cerámicas referente a la absorción de agua. Es un parámetro utilizado para la clasificación de las mismas. 
BREF (BAT Reference Document): Documento elaborado para determinadas actividades en el que se describen, en particular, las técnicas aplicadas, las emisiones actuales, los niveles de consumo, las consideraciones que se tienen en cuenta para determinar las MTD, así como las conclusiones sobre las MTD y las técnicas emergentes, tomando especialmente en consideración los criterios que se enumeran en el anexo III de la Directiva 2010/75/UE.

Concentración de contaminante: Expresada como masa por unidad de volumen $\left(\mathrm{mg} / \mathrm{m}^{3}\right.$, $\mathrm{mg} / \mathrm{l})$ o volumen por unidad de volumen (ppm). Este parámetro se utiliza para establecer el NEA - MTD, indicado en unidades de $\mathrm{mg} / \mathrm{Nm}^{3}$, y si se acompaña de un tiempo de promedio (valores por hora o diarios), puede ser utilizado como VLE para verificar la adecuada eficacia de un proceso o una tecnología de depuración prescrita en la autorización administrativa.

Condiciones normales: Condiciones de temperatura y presión utilizadas para expresar un volumen de gas. Estas condiciones son cero grados centígrados $\left(0{ }^{\circ} \mathrm{C} ; 273 \mathrm{~K}\right)$ y mil trece milibares de presión (1013 mbar).

Contaminación atmosférica: La introducción directa o indirecta, mediante la actividad humana, de sustancias, vibraciones, calor o ruido en la atmósfera, que puedan tener efectos perjudiciales para la salud humana o la calidad del medio ambiente, o que puedan causar daños a los bienes materiales o deteriorar o perjudicar el disfrute $u$ otras utilizaciones legítimas del medio ambiente.

Contaminantes primarios: Son aquellas sustancias que son vertidas directamente a la atmósfera por fuentes emisoras tales como chimeneas, procesos industriales, quema de combustibles fósiles, etc.

Contaminantes secundarios: Son los que se producen en la atmósfera a partir de precursores primarios.

DEI: Siglas de la Directiva 2010/75/EU sobre emisiones industriales. Esta Directiva actualiza la Directiva 1996/61/CE también conocida como Directiva IPPC.

Emisión absoluta (g/h): Utilizado habitualmente para caracterizar la emisión de los procesos con operación en continuo y para la elaboración periódica de informes medioambientales (PRTR). La emisión absoluta depende directamente de la producción másica de los procesos estudiados, por lo que es necesario tener en cuenta esta consideración a la hora de interpretar los datos obtenidos.

Emisión canalizada: Corriente vertida a la atmósfera a través de una conducción, bien sea fija o móvil.

Emisión difusa o fugitiva: Emisión no canalizada vertida a la atmósfera desde una superficie o volumen. 
Emisión: La expulsión a la atmósfera, al agua o al suelo de sustancias, vibraciones, calor o ruido procedentes de forma directa o indirecta de fuentes canalizadas o difusas de la instalación.

Factor de emisión específico (mg/kg producto): Usado para comparar procesos diferentes entre ellos, independientemente de la producción real de cada uno.

Factores de emisión: Son de gran utilidad para realizar registros o inventarios ambientales. Se distinguen dos tipos de factores de emisión: emisión absoluta $(\mathrm{g} / \mathrm{h})$ y factor de emisión específico ( $\mathrm{mg} / \mathrm{kg}$ producto).

Flúor - Fluoruro. En ocasiones la utilización del término flúor (Fluorine en inglés) y del término fluoruro (Fluoride en inglés) es indistinta, aunque estrictamente hablando, el flúor representa al elemento $F$ y a la molécula gaseosa diatómica $F_{2}$, mientras que fluoruro representa al ion $\mathrm{F}^{-}$(WHO, 1980; Tressaud, 2006).

Granulado: Producto obtenido en la etapa de secado por atomización en forma de aglomerados esféricos huecos de partículas con una humedad controlada que resultan muy adecuados para el prensado.

Gres esmaltado o gres (G): Es la denominación más frecuente de las baldosas cerámicas con baja porosidad (habitualmente con una absorción de agua inferior al 6\% en peso), normalmente vidriada, y cuyas características las hacen particularmente adecuadas para revestimiento de suelos interiores (residenciales y comerciales), por lo que en ocasiones se denominan pavimentos gresificados. En función de la coloración en cocido del soporte se clasifican en gres rojo (GR) y gres blanco (GB).

Gres porcelánico (P): Es la denominación de las baldosas cerámicas con muy baja porosidad (absorción de agua inferior al $0,5 \%$ en peso). Sus características permiten, además de los usos interiores en locales comerciales e incluso industriales, el uso en exteriores (pavimentos, fachadas, etc.). En función de si están vidriadas o no se clasifican en dos tipos básicos: gres porcelánico no esmaltado (también denominado gres técnico) y gres porcelánico esmaltado.

Inmisión o calidad de aire: Nivel de contaminación en el ambiente gaseoso, en puntos suficientemente alejados de las fuentes, como para no poder discernir cuál de ellas es la causante de los niveles de contaminación alcanzados a los que van a estar expuestos los receptores.

IPPC: Siglas en inglés de Prevención y Control Integrados de la Contaminación (Integrated Prevention Pollution Control), término que se aplica a la Directiva 1996/61/CE y a las leyes nacionales de transposición de dicha Directiva.

MTD: Mejor Técnica Disponible, término utilizado en inglés como BAT: Best Available Technique. Se entiende por la técnica más eficaz para proteger al medio ambiente en su 
conjunto, donde la tecnología empleada incluye el diseño, la construcción, el mantenimiento y la explotación, y debe ser viable técnica y económicamente.

NEA - MTD. Nivel de Emisión Asociado a una Mejor Tecnología Disponible, es un valor técnico. Según la legislación europea no es directamente un VLE, aunque es un valor de referencia utilizado para establecer los VLE prescritos en la legislación, y que en algunos casos sus valores pueden coincidir.

Partículas totales en suspensión (PST): Acumulación de gotas de un sólido o líquido en la atmósfera ambiental generada a partir de alguna actividad antropogénica o natural.

VLE. Valor límite de emisión, es un valor legal. Es el nivel de emisión prescrito por la administración y que no puede ser superado por un foco o instalación determinado. 


Capítulo 9. Anexos. 



\subsection{Anexo I. Ejercicio de cálculo teórico de la humedad presente en un horno continuo de combustión}

Para la realización de este ejercicio se ha partido de datos habituales en hornos industriales de cocción de baldosas cerámicas y de la información de la Tabla 4.3.

Base de cálculo: horno industrial de $5000 \mathrm{~m}^{2} /$ día de producción de baldosas cerámicas con un peso específico en crudo de $20 \mathrm{~kg} / \mathrm{m}^{2}$ y un consumo térmico de $0,7 \mathrm{kWh} / \mathrm{kg}$.

$$
\begin{gathered}
1 \text { horno de } 5000 \mathrm{~m}^{2} / \mathrm{d} \approx 208 \mathrm{~m}^{2} / \mathrm{h} \\
208 \mathrm{~m}^{2} / \mathrm{h} \cdot 20 \mathrm{~kg} / \mathrm{m}^{2}=4160 \mathrm{~kg} / \mathrm{h} \text { de producción }
\end{gathered}
$$

Humedad de las piezas: se supone una humedad del 0,005 kg agua/ $\mathrm{kg}$ sólido seco

$$
4160 \mathrm{~kg} / \mathrm{h} \cdot 0,005 \frac{\mathrm{kg} \text { de agua }}{\mathrm{kg} \text { de producto }} \approx 21 \frac{\mathrm{kg} \text { de agua }}{\mathrm{h}}
$$

Agua estructural de las materias primas: se supone una cantidad de agua estructural de las piezas de un $3 \%$ (kg agua/ kg sólido seco)

$$
4160 \mathrm{~kg} / \mathrm{h} \cdot 0,03 \frac{\mathrm{kg} \text { de agua }}{\mathrm{kg} \text { de producto }}=138 \frac{\mathrm{kg} \text { de agua }}{\mathrm{h}}
$$

Agua generada en la combustión:

$$
\begin{gathered}
4160 \mathrm{~kg} / \mathrm{h} \cdot 0,7 \frac{\mathrm{kWh}}{\mathrm{kg}} \cdot \frac{1 \mathrm{Nm}^{3} \text { gas natural }}{10,83 \frac{\mathrm{kWh}}{\mathrm{Nm}^{3}}} \cdot \frac{2,1 \mathrm{Nm}^{3} \text { agua }}{1 \mathrm{Nm}^{3} \text { gas natural }} \cdot \frac{0,8 \mathrm{~kg} \mathrm{H}_{2} \mathrm{O}}{1 \mathrm{Nm}^{3} \mathrm{H}_{2} \mathrm{O}}= \\
\approx 452 \frac{\mathrm{kg} \text { de agua }}{\mathrm{h}}
\end{gathered}
$$

Agua introducida en el aire de combustión:

1,3 exceso de aire $\cdot 274 \frac{\mathrm{Nm}^{3} \text { gas natural }}{\mathrm{h}} \cdot \frac{10,4 \mathrm{Nm}^{3} \text { aire }}{1 \mathrm{Nm}^{3} \text { gas natural }} \cdot 1,29 \frac{\mathrm{kg} \text { aire } \sec \mathrm{o}}{\mathrm{Nm}^{3} \text { aire }} \cdot 0,01 \frac{\mathrm{kg} \text { agua }}{\mathrm{kg} \text { aire } \sec \mathrm{o}} \approx$

$$
48 \frac{\mathrm{kg} \text { de agua }}{\mathrm{h}}
$$




\subsection{Anexo II. Concentración y emisión de flúor en determinadas materias primas utilizadas en composiciones cerámicas}

Se han analizado arcillas rojas y blancas, caolines y feldespatos. A continuación, se muestran los resultados correspondientes a cada una de las materias primas en forma de tabla.

Tabla 9.1. Arcillas rojas de bajo contenido de carbonatos.

\begin{tabular}{ccccc}
\hline \multirow{2}{*}{ Muestras de arcilla } & \multicolumn{2}{c}{$\begin{array}{c}\text { Concentración de flúor } \\
(\mathbf{m g} / \mathbf{k g})\end{array}$} & \multicolumn{2}{c}{ Emisión } \\
\cline { 2 - 5 } & Cruda & Cocida & $\mathbf{~ m g / k g}$ & $\%$ \\
\hline Moró & 470 & 315 & 155 & 33 \\
Villar & 550 & 351 & 199 & 36 \\
Galve & 611 & 505 & 106 & 17 \\
Morella & 635 & 533 & 102 & 16 \\
La Yesa & 760 & 453 & 307 & 40 \\
Rubielos & 546 & -- & -- & -- \\
Villar & 719 & -- & -- & -- \\
Moro bou & 476 & -- & -- & -- \\
Máximo & 760 & 533 & 307 & 40 \\
Mínimo & 470 & 315 & 102 & 16 \\
Mediana & 580,5 & 453 & 155 & 33 \\
№ muestras & 8 & 5 & 5 & 5 \\
\hline
\end{tabular}

Tabla 9.2. Arcillas rojas calcáreas.

\begin{tabular}{ccccc}
\hline \multirow{2}{*}{ Muestras de arcilla } & \multicolumn{2}{c}{$\begin{array}{c}\text { Concentración de flúor } \\
(\mathbf{m g} / \mathbf{k g})\end{array}$} & \multicolumn{2}{c}{ Emisión } \\
\cline { 2 - 5 } & Cruda & Cocida & $\mathbf{~ m g / k g}$ & $\%$ \\
\hline Mas Vell & 603 & 505 & 98 & 16 \\
Chulilla & 691 & 465 & 226 & 33 \\
Mas Vell & 744 & -- & -- & -- \\
Carbonática & 550 & -- & -- & -- \\
Máximo & 744 & 505 & 226 & 33 \\
Mínimo & 550 & 465 & 98 & 16 \\
Mediana & 647 & 485 & 162 & 24,5 \\
№ muestras & 4 & 2 & 2 & 2 \\
\hline
\end{tabular}


Tabla 9.3. Arcillas blancas.

\begin{tabular}{ccccc}
\hline \multirow{2}{*}{ Muestras de arcilla } & \multicolumn{2}{c}{$\begin{array}{c}\text { Concentración de flúor } \\
\text { ( } \mathbf{~ g / k g )}\end{array}$} & \multicolumn{2}{c}{ Emisión } \\
\cline { 2 - 5 } & Cruda & Cocida & $\mathbf{~ m g / k g}$ & $\%$ \\
\hline Teruel & 362 & 211 & 151 & 42 \\
Ucrania & 365 & 261 & 104 & 29 \\
Inglesa & 416 & 295 & 121 & 29 \\
Arcilla blanca 1 & 514 & 207 & 307 & 60 \\
Arcilla blanca 2 & 588 & 200 & 388 & 66 \\
Arcilla blanca 3 & 471 & 306 & 165 & 35 \\
Arcilla blanca 4 & 465 & 358 & 107 & 23 \\
Arcilla blanca 5 & 492 & 386 & 106 & 22 \\
Arcilla blanca 6 & 468 & 343 & 125 & 27 \\
Arcilla blanca 7 & 448 & 323 & 125 & 28 \\
Arcilla blanca 8 & 456 & 270 & 186 & 41 \\
Arcilla blanca 9 & 552 & 246 & 306 & 55 \\
Arcilla blanca 10 & 523 & -- & -- & -- \\
Arcilla blanca 11 & 459 & -- & -- & -- \\
Arcilla blanca 12 & 493 & -- & -- & -- \\
Arcilla blanca 13 & 289 & -- & -- & -- \\
Arcilla blanca 14 & 565 & -- & -- & -- \\
\hline Máximo & 588 & 386 & 388 & 66 \\
Mínimo & 289 & 200 & 104 & 22 \\
Mediana & 468 & 282,5 & 138 & 32 \\
No muestras & 17 & 12 & 12 & 12 \\
\hline
\end{tabular}


Tabla 9.4. Caolines.

\begin{tabular}{ccccc}
\hline \multirow{2}{*}{ Muestras de caolín } & \multicolumn{2}{c}{$\begin{array}{c}\text { Concentración de flúor } \\
(\mathbf{m g} / \mathbf{k g})\end{array}$} & \multicolumn{2}{c}{ Emisión } \\
\cline { 2 - 5 } & Cruda & Cocida & $\mathbf{m g} / \mathbf{k g}$ & $\%$ \\
\hline Caolín 1 & 170 & 50 & 120 & 71 \\
Caolín 2 & 721 & 303 & 418 & 58 \\
Caolín 3 & 361 & 230 & 131 & 36 \\
Caolín 4 & 347 & 178 & 169 & 49 \\
Caolín 5 & 446 & 210 & 236 & 53 \\
Máximo & 5 & 5 & 5 & 5 \\
Mínimo & 721 & 303 & 418 & 71 \\
Mediana & 170 & 50 & 120 & 36 \\
№ muestras & 361 & 210 & 169 & 53 \\
\hline
\end{tabular}

Tabla 9.5. Feldespatos.

\begin{tabular}{ccccc}
\hline \multirow{2}{*}{ Muestras de feldespato } & \multicolumn{2}{c}{$\begin{array}{c}\text { Concentración de flúor } \\
\text { ( } \mathbf{m g} / \mathbf{k g})\end{array}$} & \multicolumn{2}{c}{ Emisión } \\
\cline { 2 - 5 } & Cruda & Cocida & $\mathbf{m g} / \mathbf{k g}$ & $\%$ \\
\hline Potásico 1 (Segovia) & 50 & - & - & - \\
Potásico 2 (Segovia) & 100 & $<50$ & $>50$ & $>50$ \\
Potásico 3 (Alemania) & 240 & $<50$ & $>190$ & $>80$ \\
Sódico 1 & 60 & $<50$ & $>10$ & $<50$ \\
Sódico 2 & 397 & 186 & 211 & 55 \\
Sódico 3 (Turquía) & 308 & 177 & 131 & 42 \\
Magnésico 1 & 391 & 178 & 213 & 54 \\
Magnésico 2 & 231 & 67 & 164 & 71 \\
Magnésico 3 & 199 & 89 & 110 & 55 \\
Sódico-potásico (Francia) & 368 & 138 & 230 & 63 \\
Mixto (Cerdeña) & 253 & 138 & 115 & $<50$ \\
\hline Máximo & 397 & 186 & 230 & 80 \\
Mínimo & $<50$ & $<50$ & $>10$ & $<50$ \\
Mediana & 240 & 113,5 & 147,5 & 54,5 \\
№ muestras & 11 & 10 & 10 & 10 \\
\hline
\end{tabular}




Capítulo 10. Bibliografía. 

Ahmad, M.N., van den Berg, L.J.L., Shah, H.U., Masood, T., Büker, P., Emberson, L., Ashmore, M., 2012. Hydrogen fluoride damage to vegetation from peri-urban brick kilns in Asia: a growing but unrecognised problem? Environ. Pollut. 162, 319-24. doi:10.1016/j.envpol.2011.11.017

Amorós, J., Escardino, A., Sánchez, E., Zaera, F., 1993. Stabilità delle dimensioni nelle piastrelle porose monocotte. Ceramica Informazione, 324, 56-67.

An, D., He, G., Wang, Q., 1995. Indoor pollution by coal smoke containing sulfur dioxide, arsenic and fluorine and their influence on human's health. J. Environ. Heal.

ANFFECC, 2014. www.anffecc.com. Consultada en septiembre de 2015.

ASCER, 2014. www.ascer.es. Consultada en septiembre de 2015.

Aucejo, A., Ferrer, J., Gabaldón, C., Marzal, P., Seco, A., 1997. Diagnosis of boron, fluorine, lead, nickel and zinc toxicity in citrus plantations in Villarreal, Spain. Water, Air, Soil Pollut. 94, 349-360. doi:10.1007/BF02406067

Baron, P., Willeke, K., 2005. Aerosol Measurement: Principles, Techniques, and Applications. Wiley-Interscience.

Beltrán, V., Sánchez, E., García-Ten, J., Ginés, F., 1996. Materias primas empleadas en la fabricación de baldosas de pasta blanca en España. Téc. Cerám. 241, 114-128.

Blasco, A., 1992. Tratamiento de emisiones gaseosas, efluentes líquidos y residuos sólidos de la industria cerámica.

Bogue, R., 2015. Detecting gases with light: a review of optical gas sensor technologies. Sens. Rev. 35, 133-140. doi:10.1108/SR-09-2014-696

Bonvicini, G., Fregni, A., Palmonari, C., 2006. Fluorine compounds in gaseous emissions from industrial sources: the case of ceramic industries. Adv. Fluor. Sci., Advances in Fluorine Science 1, 225-249. doi:10.1016/S1872-0358(06)01007-4

Brindley, G., Nakahira, M., 1957. Kinetics of dehydroxylation of kaolinite and halloysite. J. Am. Ceram. 40 (10), 346-350. doi:10.1111/j.1151-2916.1957.tb12549.x

Brosnan, D., 1992. Technology and regulatory consequences of fluorine emissions in ceramic manufacturing. Am. Ceram. Soc. Bull. , 71 (12), 1798-1802.

Brosnan, D., 1994. Monitoring for hydrogen fluoride emissions. Ceram. Ind. 143 (1), 38-40.

Brosnan, D.A., Sanders, J.P., 1998. La normativa medioambiental y sus efectos sobre la industria cerámica en Norteamérica. En: Qualicer 98: V Congreso Mundial de la Calidad del Azulejo y del pavimento Cerámico. Castellón: Cámara Oficial de Comercio, Industria y Navegación, Vol.I, 215-223. 
Busani, G., Palmonari, C., Timellini, G., 1995. Piastrelle ceramiche \& ambiente. Emissioni gassose, acque, fanghi, rumore. Ed. EDI. CER, Sassuolo.

Celades López, I., 2013. Caracterización física, química, mineralógica y morfológica del material particulado emitido por focos canalizados de la industria de baldosas y fritas cerámicas. [Tesis Doctoral].

Chipera, S.J., Bish, D.L., 2002. Thermal Evolution of Fluorine from Smectite and Kaolinite. Clays Clay Miner. 50, 38-46. doi:10.1346/000986002761002658

Dai, S., Li, W., Tang, Y., Zhang, Y., Feng, P., 2007. The sources, pathway, and preventive measures for fluorosis in Zhijin County, Guizhou, China. Appl. Geochemistry 22, 1017-1024. doi:10.1016/j.apgeochem.2007.02.011

Dai, S., Ren, D., Ma, S., 2004. The cause of endemic fluorosis in western Guizhou Province, Southwest China. Fuel 83, 2095-2098. doi:10.1016/j.fuel.2004.03.016

DaiShe, W., BaoShan, Z., AiMin, W., 2004. A new estimation of fluoride source in coalburning endemic fluorosis areas of Guizhou Province. Chinese J. Endem. 23, 135137.

Dehne, G., 1987. Relationship between fluorine emission during firing of ceramic products and the firing temperature and composition of raw material. Appl. Clay Sci. 2, 1-9. doi:10.1016/0169-1317(87)90010-X

Denissen, J., Vries, A.H., 1998. Reduction of fluoride emission from clay materials. ZI Int. 51 (1-2), 19-26.

DETR, 1999. Department of Environment, Transportation and the Regions. Reducing fluoride emissions in brick, tile and pipe manufacture. Environmental Technology Best Practice Programme GG166, United Kingdom.

Dogeroglu, T., Kara, S., 2002a. Fluoride emission factors for ceramic wall-tile kilns. Am. Ceram. Soc. Bull. 81, 52-56.

Dogeroglu, T., Kara, S., 2002b. Fluoride emission factors. Am. Ceram. Soc. Bull. 81, 50-52.

Dogeroglu, T., Kara, S., 2004. Fluoride in ceramic materials. Am. Ceram. Soc. Bull. 83. 9101-9110.

DTI, 2004. Emission Monitoring Technologies for Combustion and Gasification Plant, DTI Technology Status Report, Cleaner Fossil Fuels Programme, TSR021.

EN 14411. 2012. Ceramic tiles - Definitions, classification, characteristics, evaluation of conformity and marking.

EN 14791. 2005. Stationary source emissions - Determination of mass concentration of sulphur dioxide - Reference method. 
EN 14792. 2005. Stationary source emissions - Determination of mass concentration of nitrogen oxides (NOx) - Reference method: Chemiluminescence.

EN 1911. 2010. Stationary source emissions - Determination of mass concentration of gaseous chlorides expressed as $\mathrm{HCl}$ - Standard reference method.

EPA Met. 13B. Determination of Total Fluoride Emissions from Stationary Sources (Specific Ion Electrode Method).

EPA Met. 26. Determination of Hydrogen Halide and Halogen Emissions from Stationary Sources Non-Isokinetic Method.

EPA Met. 6. Determination of Sulfur Dioxide Emissions from Stationary Sources.

EPAQS, 2006. Department for Environment, Food and Rural Affairs, Scottish Executive, National Assembly of Wales, Department of the Environment in Northern Ireland Expert Panel on Air Quality Standards. Guidelines for Halogens and Hydrogen Halides in Ambient Air for Protecting Human Health against Acute Irritancy Effects.

Escardino, A., Amorós, J.L., Orts, M.J., Beltrán, V., 1998. Influence of pressing variables on air permeability of fired floor tile bodies. Sci. Whitewares II 309-318.

Escrig, A., Monfort, E., Celades, I., Querol, X., Amato, F., Minguillón, M.C., Hopke, P.K., 2009. Application of Optimally Scaled Target Factor Analysis for Assessing Source Contribution of Ambient PM 10. J. Air Waste Manage. Assoc. 59, 1296-1307. doi:10.3155/1047-3289.59.11.1296

Fabbri, B., 1992. Flúor en las arcillas: contenidos y mecanismos de emisión. Cerám. Inf., Espec. Tecnargilla, 33-36.

Ferrer, S., Mezquita, A., Gomez-Tena, M., Machi, C., Monfort, E. 2015. Estimation of the heat of reaction in traditional ceramic compositions. Appl. Clay Science, 108, 28-39. doi:10.1016/j.clay.2015.02.019

Finkelman, R.B., Belkin, H.E., Zheng, B., 1999. Health impacts of domestic coal use in China. Proc. Natl. Acad. Sci. 96, 3427-3431. doi:10.1073/pnas.96.7.3427

Franzaring, J., Hrenn, H., Schumm, C., Klumpp, A., Fangmeier, A., 2006. Environmental monitoring of fluoride emissions using precipitation, dust, plant and soil samples. Environ. Pollut. 144, 158-165. doi:10.1016/j.envpol.2005.12.033

Freni, S.C., 1994. Exposure to high fluoride concentrations in drinking water is associated with decreased birth rates. J. Toxicol. Environ. Health 42, 109-21. doi:10.1080/15287399409531866

Fu, L., Liu, C., Wu, F., 1993. Main airborne fluoride sources and their treatment in Hangjiahu sericulture district. Rural Eco-environ. 4, pp. 26-28 
Fukuyama, H., Tabata, H., Nagata, K., 2003. Determination of gibbs energy of formation of cuspidine $\left(3 \mathrm{CaO} \cdot 2 \mathrm{SiO}_{2} \cdot \mathrm{CaF}_{2}\right)$ from the electromotive force method using $\mathrm{CaF} 2$ as the solid electrolyte. Metall. Mater. Trans. B 34, 307-311. doi:10.1007/s11663-0030076-z

Funk, J., 1982. Designing the optimum firing curve for porcelains. Ceram. Bull. 61 (6), 632635.

Galán, E., González, I., Fabbri, B., 2002. Estimation of fluorine and chlorine emissions from Spanish structural ceramic industries. The case study of the Bailén area, Southern Spain. Atmos. Environ. 36, 5289-5298. doi:10.1016/S1352-2310(02)00645-3

García Ten, J., Monfort, E., Gazulla, M.F., 2003, XLIII Congreso de la Sociedad Española de Cerámica y Vidrio, 2003 (Sociedad Española de Cerámica y Vidrio).

Gazulla, M., Gómez, M., Cabrera, M., Monfort, E., 1996. Determinación de flúor en las arcillas utilizadas en la fabricación de baldosas cerámicas. Téc. Cerám., 243, 298302.

Gazulla, M.F., Gómez, M.P., Barba, A., Monfort, E., Orduña, M., 2003. A methodology for characterising ceramic wastes. Manag. Environ. Qual. An Int. J. 14, 333-343. doi: $10.1108 / 14777830310479423$

Gazulla, M.F., Gómez, M.P., Orduña, M., Silva, G., 2005. Caracterización química, mineralógica y térmica de boratos naturales y sintéticos. Bol. Soc. Esp. Ceram. Vidr. 44, 21-31.

Gazulla, M.F., Rodrigo, M., Orduña, M., Ventura, M.J., 2015. Fluorine determination in glasses and glazes by WD-XRF. Glass Technology - European Journal of Glass Science and Technology Part A, Volume 56, Number 3, 95-101 (7).

Gómez, M.P., Gazulla, M.F., Zumaquero, E., Orduña, M., 2007. Utilización de técnicas acopladas de análisis térmico TG-DSC-QMSFTIR en la caracterización de arcillas y composiciones cerámicas utilizadas en la fabricación de baldosas cerámicas. Cuantificación de compuestos de carbono. Bol. Soc. Esp. Ceram. Vidr. doi:10.3989/cyv.2007.v46.i5.228

González, I., Aparicio, P., Galán, E., Fabbri, B., 2002. A proposal for reducing $\mathrm{F}$ and $\mathrm{Cl}$ emission in the brick industry using new formulations. Appl. Clay Sci. 22, 1-7. doi:10.1016/S0169-1317(02)00094-7

González, I., Galán, E., Miras, a., 2006. Fluorine, chlorine and sulphur emissions from the Andalusian ceramic industry (Spain)-Proposal for their reduction and estimation of threshold emission values. Appl. Clay Sci. 32, 153-171. doi:10.1016/j.clay.2005.07.005 
Grandjean P., Horder M., Thomassen Y., 1990. Fluoride, aluminum, and phosphate kinetics in cryolite workers. J Occup Med 32 (1):58-63. doi:10.1097/00043764-19900100000015

Grandjean, P., Olsen, J.H., 2004. Extended Follow-up of Cancer Incidence in FluorideExposed Workers. JNCI J. Natl. Cancer Inst. 96, 802-803. doi:10.1093/jnci/djh155

Grandjean, P., Olsen, J.H., Jensen, O.M., Juel, K., 1992. Cancer Incidence and Mortality in Workers Exposed to Fluoride. JNCl J. Natl. Cancer Inst. 84, 1903-1909. doi:10.1093/jnci/84.24.1903

Gribble, G., 2002. Naturally occurring organofluorines. Organofluorines. Springer-Verlag, Berlin/Heidelberg. doi:10.1007/10721878

Grigoriev, G.Y., Malyugin, S.L., Nabiev, S.S., Sukhanova, M.A., Ponurovskii, Y.Y., Nadezhdinskii, A.I., Shapovalov, Y.P., 2010. Remote detection of HF molecules in open atmosphere with the use of tunable diode lasers. Appl. Phys. B Lasers Opt. 101, 683-688. doi:10.1007/s00340-010-4273-6

Grim, R.E., Bradley, W.F., 1940. Investigation of the effect of heat on the clay minerals illite and montmorillonite. J. Am. Ceram. Soc. 23, 242-248. doi:10.1111/j.11512916.1940.tb14263.x

Hauck, D., Hilker, E., 1986. Possibilities for the reduction of fluorine emission in the firing of bricks and tiles. Ziegelindustrie Int. 7-8, 376-385.

Hauck, D., Ruppik, M., Hilker, R., 1992. Reduction of fluorine emission by re-bonding in the preheating zone-final evaluation. Zl-Jahrbuch/bearbeitet Von Christina Kokot. Bauverlag, Wiesbad, 47-73.

Heikens, A., Sumarti, S., Van Bergen, M., Widianarko, B., Fokkert, L., Van Leeuwen, K., Seinen, W., 2005. The impact of the hyperacid ljen Crater Lake: Risks of excess fluoride to human health. Sci. Total Environ. 346, 56-69. doi:10.1016/j.scitotenv.2004.12.007

Hill, J., 1995. Detection, measurement and control of gaseous hydrogen fluoride emissions produced when firing traditional ceramics. [Tesis Doctoral].

Hinds, W.C., 1999. Aerosol Technology: Properties, Behavior, and Measurement of Airborne Particles.

India, T., 2012. Flue gas analysis in industry: Practical guide for emission and process measurements.

IPCC, 2014. Climate Change 2013: The Physical Science Basis: Working Group I Contribution to the Fifth Assessment Report of the Intergovernmental Panel on Climate Change. 
IPTS, 2006. European Comission. Reference Document on Best Available Techniques on Emissions from Storage of bulk or dangerous materials. (http://eippcb.jrc.es)

IPTS, 2007. European Comission. Reference Document on Best Available Techniques in the Ceramic Manufacturing Industry. (http://eippcb.jrc.es)

ISO 15713. 2006. Stationary source emissions - Sampling and determination of gaseous fluoride content.

ITC, 2001. Curso de gestión medioambiental en la industria cerámica, 18 - 20 de diciembre de 2001. Castellón: Instituto de Tecnología Cerámica (ITC).

ITC, 2009. Instituto de Tecnología Cerámica y Comisión de Trabajo. Guía de Mejores Técnicas Disponibles para el sector de fabricación de baldosas cerámicas en la Comunitat Valenciana. Ed. Centro de Tecnologías Limpias. Conselleria de Medi Ambient, Aigua, Urbanisme i Habitatge. Generalitat Valenciana. Valencia, Spain.

IVE, 2011. Guía de la baldosa cerámica. 6 $6^{\underline{a}}$ ed. Valencia: Instituto Valenciano de la Edificación.

Jarque Fonfria, J.C., 2001. Estudio del comportamiento mecánico de soportes cerámicos crudos: mejora de sus propiedades mecánicas. [Tesis Doctoral].

Jayarathne, T., Stockwell, C.E., Yokelson, R.J., Nakao, S., Stone, E. a., 2014. Emissions of Fine Particle Fluoride from Biomass Burning. Environ. Sci. Technol. 48, 1263612644. doi:10.1021/es502933j

Junge, K.; Hauck, D, 2000. Los aditivos en el sector del ladrillo cerámico. Cerám. Inf. (Esp), 267, 116-147.

Kane, P.F., Larrabee, G.B., 2013. Characterization of Solid Surfaces.

Kolkmeier, H., 1986. Emission control in the brick and tile industry. ZI Int., 39 (10), 516-530.

Kolkmeier, H., 1991. Emissionen. ZI Int. 44, 544-548.

Kother, W.; Pauls, N., 1982. Determination of a production firing curve for optimum fluorine bonding in brick firing. ZI Int., 35 (3), 167-173.

Lund, K., Ekstrand, J., Boe, J., Søstrand, P., Kongerud, J., 1997. Exposure to hydrogen fluoride: an experimental study in humans of concentrations of fluoride in plasma, symptoms, and lung function. Occup. Environ. Med. 54, 32-37. doi:10.1136/oem.54.1.32

Mackenzie, R., 1957. The Differential Thermal Investigation Of Clays.

Mallol, G., Monfort, E., Busani, G., Lezaun, J., 2001. Depuración de los gases de combustión en la Industria Cerámica: guía técnica.

Manahan, S.E., 2007. Introducción a la química ambiental. UNAM, Mexico D.F. 
Masters, K., 1991. Spray drying handbook. $5^{\text {th }}$ ed. Harlow: Longman Scientific \& Technical.

Mazzali, P.,1989. La rilevazione di inquinanti non tradizionali nelle emissioni gassose dei processi di cottura di piastrelle ceramiche. En: Presidio Multizonale di Prevenzione, USL N. 16, Modena.

Mazzali, R., Fogliani, G., Orlandi, L., Busani, G., 1980. Effetto della temperatura e del contenuto di calcio e magnesio sulla cessione di fluoro nella cottura di piastrelle ceramiche. La Ceram.

McKenna, J.D., Turner, J.H., McKenna, J.P., Jr., 2008. Fine Particle (2.5 microns) Emissions: Regulations, Measurement, and Control. John Wiley \& Sons.

Mackenzie, R.C., 1957. The Differential Thermal Invetigation Clay. Mineral. Soc. London, 456 p. 456.

Mészáros, E., 1999. Fundamentals of atmospheric aerosol chemistry. Acad. Kiado, Budapest.

Mezhericher, M., Levy, A., Borde, I., 2010. Spray drying modelling based on advanced droplet drying kinetics. Chem. Eng. Process. Process Intensif. 49, 1205-1213. doi:10.1016/j.cep.2010.09.002

Minguillón Bengochea, M.C., 2007. Composición y fuentes del material particulado atmosférico en la zona cerámica de Castellón. Impacto de la introducción de las Mejores Técnicas Disponibles. [Tesis Doctoral].

Monfort, E., Celades, I., Gomar, S., Gazulla, M.F., Adams, H., Tulip, J., 2004. Application D'un Système de Mesure en Ligne pour le Contrôle des Émissions de Fluor (Première partie). Ind. Ceram. Verriere.

Monfort, E., Celades, I., Gomar, S., Gazulla, M.F., Adams, H., Tulipe, J., 2005. Application d'un système de mesure en ligne pour le contrôle des émissions de fluor (seconde partie). Ind. Ceram. Verriere.

Monfort, E., Celades, I., Mestre, S., Bono, R., Llop, H., de la Hoz, J.M., 2002. IndustrialScale Study of $\mathrm{NaHCO}_{3}$ Chemical Reactions with $\mathrm{HF}, \mathrm{HCl}$ and $\mathrm{SO}_{2}$ in Kiln Flue Gases, in: Key Engineering Materials. 855-858. doi:10.4028/www.scientific.net/KEM.206-213.855

Monfort, E., Gazulla, M.F., Celades, I., Gomez, P., Bigi, M., Tonelli, M., 2003. Ceramic kiln fluorine-gas emission measurement. Am. Ceram. Soc. Bull. 82, 31-35.

Monfort, E., Gomar, S., Celades, I., Gomez, P., Moro, E., Márquez, E., 2010a. Reducción de las emisiones de azufre de un horno túnel. Bol. Soc. Esp. Ceram. Vidr. 49, 343-350. 
Monfort, E., Mezquita, A., Granel, R., Vaquer, E., Escrig, A., Miralles, A., Zaera, V., 2010. Análisis de consumos energéticos y emisiones de dióxido de carbono en la fabricación de baldosas cerámicas. Bol. Soc. Esp. Ceram. Vidr. 49, 303-310.

Moreno, A., 2000. Adecuación de las propiedades de tintas y esmaltes a los nuevos sistemas de aplicación y técnicas decorativas. En: Actas del VI Congreso Mundial de la Calidad del Azulejo y del Pavimento Cerámico. Castellón: Cámara Oficial de Comercio, Industria y Navegación. Vol.I, Con-55-76.

Moro, E., Monfort, E., Gomar, S., Celades, I., Martínez, J., Márquez, E., 2008. Depuración de emisiones ácidas en un horno de ladrillos que usa coque de petróleo como combustible. Téc. Cerám., 362, 2-10.

Orts Tarí, M.J., 1991. Sinterización de piezas de pavimento gresificado. [Tesis Doctoral].

Orts, M.J., Escardino, A., Amorós, J.L., Negre, F., 1993. Microstructural changes during the firing of stoneware floor tiles. Appl. Clay Sci. 8, 193-205. doi:10.1016/01691317(93)90037-2

Ozsvath, D.L., 2009. Fluoride and environmental health: A review. Rev. Environ. Sci. Biotechnol. 8, 59-79. doi:10.1007/s11157-008-9136-9

Palmonari, C., Timellini, G., 1982. Pollutant Emission Factors for the Ceramic Floor and Wall Tile Industry. J. Air Pollut. Control Assoc. 32, 1095-1100. doi:10.1080/00022470.1982.10465517

Palmonari, C., Timellini, G., 1992. The ceramic tile industry and air pollution: control experiences in a ceramic district. Tile brick Int. 8, 161-165.

Pickering, W.F., 1985. The mobility of soluble fluoride in soils. Environ. Pollut. Ser. B Chem. Phys. 9, 281-308. doi:10.1016/0143-148X(85)90004-7

Querol, X., Pey, J., Pandolfi, M., Alastuey, A., Cusack, M., Pérez, N., Moreno, T., Viana, M., Mihalopoulos, N., Kallos, G., Kleanthous, S., 2009. African dust contributions to mean ambient PM10 mass-levels across the Mediterranean Basin. Atmos. Environ. 43, 4266-4277. doi:10.1016/j.atmosenv.2009.06.013

Reymer, A., Denissen, J., 2001. Roller Kiln with very low Fluoride Emission. Klei Glas Keramiek-Including Keramisch Jaarboek, 22 (9), 9-11.

Reymer, A., Jong, J., 1993. Fluoride emission of ceramic products, in: P. Durán, J.F. Fernández (Eds.), Third Euro-Ceramics, vol. II Faenza Editrice Ibérica, Castellón, 1071-1076.

Roche, K.J., Stanton, K.T., 2014. Measurement of fluoride substitution in precipitated fluorhydroxyapatite nanoparticles. J. Fluor. Chem. 161, 102-109. doi:10.1016/j.jluchem.2014.02.007 
Routschka, C.; Majdic, A., 1978. Studies on the behaviour of fluoride in the firing of refractory clays. ZI Int., 31 (2), 76-86.

SACMI 2015. Cooperativa Meccanici Imola Societá Cooperativa. A Radiating Heating Module for Continuous-Cycle Firing Kilns Of Ceramic Products. WO/2015/015263.

Sánchez, E.; García, J.; Ginés, F.; Negre, F., 1996. Aspectos a mejorar en las características y homogeneidad de las arcillas rojas empleadas en la fabricación de baldosas cerámicas. Téc. Cerám., 240, 16-29.

Sánchez, E.; García, J.; Sanz, V.; Ochandio, E., 1990. Raw Material Selection Criteria for the Production of Floor and Wall Tiles. Tile Brick Int., 6 (4), 15-21.

Sawyer, G.M., Oppenheimer, C., 2006. Chapter 5: Volcanic Fluorine Emissions: Observations by Fourier Transform Infrared Spectroscopy. Adv. Fluor. Sci. 1, 165185. doi:10.1016/S1872-0358(06)01005-0

Schiff, H.I., Nadler, S.D., Pisano, J.T., Mackay, G.I., 1996. Application of near-infrared TDLAS systems to HF measurements in aluminum smelters, in: Fried, A. (Ed.), Proceedings of the SPIE. 198-204. doi:10.1117/12.255326

Semrau, K.T., 1957. Emission of Fluorides from Industrial Processes-A Review. J. Air Pollut. Control Assoc. 7, 92-108. doi:10.1080/00966665.1957.10467795

Smith, A., 1955. Investigations on the moisture expansion of porous ceramic bodies. Trans. Br. Ceram. Soc. 54.5, 300-318.

Stevens, D.P., Mclaughlin, M.J., Randall, P.J., Keerthisinghe, G., 2000. Effect of fluoride supply on fluoride concentrations in five pasture species: Levels required to reach phytotoxic or potentially zootoxic concentrations in plant tissue. Plant Soil 227, 223233. doi:10.1023/A:1026523031815

Strohmenger, W., 1983. Problems associated with fluorine. ZI INT. ZI Int.

Tavener, S.J., Clark, J.H., 2006. Chapter 5 Fluorine: Friend or Foe? A Green Chemist's Perspective. Adv. Fluor. Sci. 2, 177-202. doi:10.1016/S1872-0358(06)02005-7

Todor, D., 1976. Thermal analysis of minerals. Tunbridge Wells: Abacus Press.

Tong, Z., 1988. An approach to several aspects of silkworm toxicosis caused by fluoride pollution in the air in Hangzhow. Agro-environ. Prot., 7 (5), p. 48

Tressaud, A., 2006. (ed.). Fluorine and the Environment: Atmospheric Chemistry, Emissions \& Lithosphere: Atmospheric Chemistry, Emissions \& Lithosphere. Elsevier.

Tsiros, J.X., Haidouti, C., Chronopoulou, A., 1998. Airborne fluoride contamination of soils and olive trees near an aluminum plant. Measurements and simulations. J. Environ. Sci. Heal. Part A 33, 1309-1324. doi:10.1080/10934529809376790 
Tulip, J. 2000. Gas detector with reference cell. US 6121627

Tunker, G.; Schmidt, H., 1981. Solution to a fluorine emission problem in stoneware production. CFI, Ceram. forum int., 58 (6), 388-393.

UNE 77-041. 2002. Calidad del agua. Determinación de cloruros. Método argentométrico.

UNE 77-216. 1995. Emisiones de fuentes estacionarias. Determinación de la concentración másica de dióxido de azufre. Método del peróxido de hidrógeno/perclorato de bario/torina.

UNICHIM 10787. 1999. Determinazione dei composti inorganici del fluoro.

VDI 2462. 1985. Measurement of gaseous emissions; measurement of the sulfur-trioxide concentration; 2-propanol method.

Warshaw, S.I., Seider, R., 1967. Comparison of Strength of Triaxial Porcelains Containing Alumina and Silica. J. Am. Ceram. Soc. 50, 337-343. doi:10.1111/j.11512916.1967.tb15128.x

Wei-hong, W.U., Zheng-miao, X. I. E., Jian-ming, X.U., Chao, L.I.U., 2001. Characteristics of fluoride emission from five clay minerals as affected by temperature, heating time and addition of calcium compounds. J. Zhejiang, 973, 284-288.

Weinstein, L.H., Davison, A.W., 2004. Fluorides in the environment: effects on plants and animals. CABI, Wallingford.

Wen, D., Kuang, Y., Liu, S., Zhang, D., Lu, Y., Li, J., 2006. Evidences and implications of vegetation damage from ceramic industrial emission on a rural site in the Pearl River Delta of China. J. For. Res. 17, 7-12. doi:10.1007/s11676-006-0002-8

WHO, 1980. Glossary on air pollution. WHO Regional Publications, Eur. Series No. 9. World Health Organization, Regional Office for Europe, Copenhagen.

WHO; 2002. Fluorides - Environmental Health Criteria 227. Ginebra.

Wu, D.S., 2004. Study on Environmental Geochemistry of Fluorine in Chinese Coals. Guiyang Institute of Geochemistry, Chinese Academy Sciences, 12-23, 49-50.

Xie, Z., Wu, W., Xu, J., 2003. Study on fluoride emission from soils at high temperature related to brick-making process. Chemosphere 50, 763-769. doi:10.1016/S0045-6535(02)00217-5

Zhang, B., Mei, H., Zhao, Y., Lin, X., Zhang, X., Dong, J., 2003. Distribution and risk assessment of fluoride in drinking water in the west plain region of Jilin Province, China. Environ. Geochem. Health 25, 421-431. doi:10.1023/B:EGAH.0000004560.47697.91 
Zhang, Y., Cao, S.R., 1996. Coal burning induced endemic fluorosis in China. Fluoride 29, 207-211.

Zheng, B., Ding, Z., Huang, R., Zhu, J., Yu, X., Wang, A., Zhou, D., Mao, D., Su, H., 1999. Issues of health and disease relating to coal use in southwestern China. Int. J. Coal Geol. 40, 119-132. doi:10.1016/S0166-5162(98)00064-0

Zheng, B.S., Huang, R.G., 1989. Human fluorosis and environmental geochemistry in southwest China. Developments in Geoscience, Contributions to 28th International Geology Congress, Washington, DC. Beijing, China. Science Press, pp. 171-176. 


